KURT ANDRÉ PEREIRA AMANN

\title{
METODOLOGIA SEMIEMPÍRICA UNIFICADA \\ PARA A ESTIMATIVA DA \\ CAPACIDADE DE CARGA DE ESTACAS
}

v.1

São Paulo

2010 
KURT ANDRÉ PEREIRA AMANN

\section{METODOLOGIA SEMIEMPÍRICA UNIFICADA \\ PARA A ESTIMATIVA DA \\ CAPACIDADE DE CARGA DE ESTACAS}

Tese apresentada à Escola Politécnica da Universidade de São Paulo para obtenção do título de Doutor em Engenharia

v.1

São Paulo

2010 
KURT ANDRÉ PEREIRA AMANN

\section{METODOLOGIA SEMIEMPÍRICA UNIFICADA \\ PARA A ESTIMATIVA DA \\ CAPACIDADE DE CARGA DE ESTACAS}

Tese apresentada à Escola Politécnica da Universidade de São Paulo para obtenção do título de Doutor em Engenharia

Área de Concentração:

Engenharia Geotécnica

Orientador: Prof. Doutor

Faiçal Massad

v.1

São Paulo

2010 

FICHA CATALOGRÁFICA

Amann, Kurt André Pereira

Metodologia semiempírica unificada para a estimativa da capacidade de carga de estacas / K.A.P. Amann. -- São Paulo, 2010. $2 \mathrm{v}$.

Tese (Doutorado ) - Escola Politécnica da Universidade de São Paulo. Departamento de Engenharia de Estruturas e Geotecnica.

1. Fundações por estacas 2. Métodos empíricos 3. Sondagem

dos solos I. Universidade de São Paulo. Escola Politécnica. Departamento de Engenharia de Estruturas e Geotécnica II. t. 


\section{DEDICATÓRIA}

À minha esposa, Fábia, e filhos, Olívia e Otávio, pelo carinho, compreensão e paciência, mesmo na minha ausência. 


\section{AGRADECIMENTOS}

Ao professor Dr. Faiçal Massad, pelo apoio e incentivo à autonomia na pesquisa, bem como pela confiança no trabalho desenvolvido.

Ao professor Dr. Paulo Albuquerque, pela atenção concedida sobre as provas de carga por ele executadas.

Aos professores do departamento de Matemática do Centro Universitário da FEl, Fábio Gerab, Rubener Freitas, Custódio Martins, Adilson Novazzi e Ayrton Novazzi, pelas valiosas sugestões de bibliografia e da forma de encaminhamento e apresentação das deduções matemáticas deste trabalho.

Aos alunos de iniciação científica e monitoria, Alberto Alvarez e Adriana Pedraja, pela colaboração no preparo da tabela-resumo da revisão bibliográfica dos eventos técnico-científicos, e pela digitalização de diversas figuras e tabelas de dados.

À Presidência da Fundação Educacional Inaciana Pe. Roberto Sabóia de Medeiros e à Reitoria do Centro Universitário da FEI, por todo o apoio oferecido durante o processo de preparação desta pesquisa.

Ao professor Dr. Marcio Rillo (in memorian), pelas atribuições conferidas e pela confiança depositada.

Às secretárias da Coordenadoria Departamental do Centro Universitário da FEl, pelo cuidado e atenção zelosa a todos os compromissos do Departamento de Engenharia Civil, ao longo destes anos de pesquisa, entre outras colaborações diversas.

Aos amigos da Pastoral Universitária da FEl, Carla Araújo, Marli Pirozelli, Raul Fernandes, Rafael Marcoccia, Pe. Paulo D'Elboux e todos os alunos participantes, por me ajudarem a lembrar que a vida não é determinada pelas circunstâncias.

À minha esposa Fábia e aos meus filhos, Olívia e Otávio, pelos sacrifícios suportados, por vezes, sem terem o meu reconhecimento e a minha gratidão explícitos.

A todos que direta ou indiretamente colaboraram para a conclusão deste trabalho e que não estão aqui citados nominalmente: os meus mais sinceros agradecimentos. 
A Verdade é una.

(citada por Mons. Luigi Giussani) 


\section{RESUMO}

A pesquisa parte do fato de que os métodos semiempíricos de estimativa da capacidade de carga de estacas não devem ser empregados indiscriminadamente em qualquer região do país sem as devidas adequações às características do solo local. Constata-se, com isso, que não existem metodologias específicas para proceder tais adequações e que o meio técnico acaba por realizar a mera classificação dos métodos em "conservador" ou "contra a segurança", o que se constitui num certo paradigma. Assim, o presente trabalho propõe uma Metodologia Semiempírica Unificada (MSU), em três etapas. Na primeira delas, o projetista estima a capacidade de carga a partir da otimização das melhores práticas adotadas pelos diversos métodos semiempíricos utilizados no Brasil. Discutem-se ainda o embutimento da ponta e a criação de novos métodos semiempíricos. Na segunda etapa, realiza-se a verificação de desempenho com base nos critérios de ruptura aplicados à curva carga-recalque de provas de carga. Nessa etapa, as imprecisões do dito paradigma são apontadas e faz-se uma nova proposta de aplicação dos critérios de ruptura. $\mathrm{Na}$ terceira etapa, faz-se uma retroanálise para aferição da estimativa semiempírica unificada da primeira etapa. Propõe-se, assim, o uso da separação das parcelas de atrito e ponta por meio de métodos de transferência de carga, bem como pela proposta de ajustes polinomiais, no caso de ensaios instrumentados. A análise crítica desse processo gerou a proposta de uma nova abordagem matemática da transferência de carga. A correção dos valores adotados para os coeficientes semiempíricos de cada camada, individualmente, é feita pela proposta de aplicação do conceito de Hierarquia dos Solos (AMANN, 2000). Os resultados de correção dos métodos semiempíricos, contudo, são específicos para o solo de cada local em estudo. Assim, são utilizados, como exemplo, ensaios em diversas regiões do país, o que permite a verificação da aplicabilidade da metodologia proposta.

Palavras-chave: Fundações por estacas. Critérios de ruptura. Carga de ruptura. Capacidade de carga. Transferência de carga. Métodos semiempíricos. 


\begin{abstract}
The research starts from the fact that the semiempirical methods for estimating the pile load capacity shouldn't be used indiscriminately in any country's region without making proper adjustments to the local soil characteristics. It is verified, from this, that there are no specific methodologies to make such adjustments and the geotechnical engineers find themselves forced to perform a simple classification of the methods in "conservative" or "against the safety", which constitutes a form of paradigm. In this context, this paper proposes a Unified Semiempirical Methodology (MSU) in three steps. In the first, the designer estimates the foundation load capacity from the optimization of best practices adopted by different semiempirical methods used in Brazil. A discussion is also made the toe embedment and the creation of new semiempirical methods. In the second step, the verification of the foundation performance is carried out, based on the failure criteria applied to the load-settlement curve of load tests. At this step, the inaccuracies from that paradigm are outlined and a new proposal is made for applying the failure criteria. In the third step, a backanalysis is accomplished to admeasure the unified semiempirical estimative from the first step. It is, thus, proposed to separate both shaft friction and toe resistance from the total load, by means of load transfer methods, and by the proposal of polynomial adjustments in the case of instrumented piles. With the critical analysis of this process, a new mathematical approach to load transfer is presented. The correction of the coefficients of the semiempirical methods is made by the application of the Soils's Hierarchy concept (AMANN, 2000). The results of semiempirical methods correction, however, are specific to the soils of each particular site. The applicability, of the proposed methodology, is illustrated using pile load tests from various parts of the country.
\end{abstract}

Keywords: Pile foundation. Failure criteria. Failure load. Bearing capacity. Load transfer. Semiempirical methods. 


\section{LISTA DE FIGURAS}

Figura 1 - Fluxograma do processo de projeto e execução de fundações por estacas (parte 1).....

Figura 2 - Modelo (ou critério) de Mohr-Coulomb para ruptura do solo do fuste por atrito lateral (adaptado de KÉZDI, 1964). .59

Figura 3 - Variação do fator de capacidade de carga $N_{q}$ conforme as considerações dos diversos autores (apud Vésic, 1967, citado por CINTRA e AOKI, 1999) .... .61

Figura 4 - Valores de KLAv em função do tipo de solo (AMANN, 2000). .77

Figura 5 - Valores de K KAv em função do tipo de solo (AMANN, 2000). .78

Figura 6 - Comparação gráfica entre os fatores de ponta do método de Alonso (AL) e dos métodos Décourt-Quaresma (DQ), Antunes-Cabral (AC) e Kárez-Rocha (KR) apud AMANN (20004) .81

Figura 7 - Variação do coeficiente $\mathrm{k}_{\mathrm{t}}$ para diversos métodos $\left(B 0=\beta_{0}\right)$. .88

Figura 8 - Interpretação do embutimento dos métodos semiempíricos a partir dos métodos teóricos de: a) Terzaghi (1943); b) De Beer (1945) e Meyerhof (1953); c) Berezantzev (1961), d) Skempton e Yassin (1953); adaptado de VELLOSO e LOPES, 2002.

Figura 9 - Curva carga-recalque da prova de carga da estaca E013 - Alemoa (MASSAD, 1994)

Figura 10 - Método das Leis de Cambefort Modificadas por Massad (1992), apud Amann (2008a). 102

Figura 11- Tentativa de aplicação do critério de Butler e Hoy à estaca E013, a qual não atinge a rigidez tangente limite e $7 \mathrm{kN} / \mathrm{mm}$. 107

Figura 12 - Curva exponencial de Van der Veen na forma fundamental e na forma parametrizada em relação aos parâmetros " $a=a_{v d v}$ " e "b=bvd", apud Amann (2008a).

Figura 13 - Curvas de Van der Veen ajustadas à curva de ensaio simulada, considerando diversas cargas máximas de ensaio $\left(P_{\max }\right)$.....

Figura 14 - Curvas de Chin (1972) ajustadas à curva de Referência, considerando diversas cargas máximas de ensaio $\left(P_{\max }\right)$.

Figura 15 - Comparação das previsões (estimativas) semiempíricas com os critérios de ruptura. 
Figura 16 - Esforços $(N)$, tensões de cisalhamento $(\tau)$ e deslocamentos $(y)$ em uma estaca apud Amann (2008c)

Figura 17- Diagramas típicos de $N(z)$ e curvas $\tau(z) \equiv f(z)$ correspondentes (VÉSIC, 1970)

Figura 18 - Indicação da força norma $\mathrm{N}(\mathrm{z})$, do atrito parcialmente mobilizado ao longo do fuste e da condição de solo homogêneo (simplificação) comparada a de solo heterogêneo.

Figura 19- Pontos delimitantes dos trechos da curva carga-recalque teórica (adaptado de FONSECA, et al.2007). 135

Figura 20- Diagrama Kr-Alr com as curvas hiperbólicas de cada trecho. 138

Figura 21 - Solução gráfica do sistema para a estaca metálica cravada da Penha 150 Figura 22 - Variação de C com $\mu$ reb/ $\mu$ para a estaca metálica cravada da Penha 150 Figura 23 - Domínios de ponta (curva) e atrito lateral (reta) (MELO, 2008) 154

Figura 24 - Forma de obtenção do limite inferior do atrito $\left(Q_{\mathrm{SL}}=Q_{\mathrm{SI}}\right)(\mathrm{MELO}, 2008)$

Figura 25 - Trechos da curva carga recalque do método das Leis de Cambefort modificadas (LCM) lançados no diagrama de Rigidez para comparação.

Figura 26 - Estaca raiz G603: a) curvas de Rigidez com recalques acumulados e não acumulados; b) curva carga-recalque considerando a envoltória dos carregamentos. 158

Figura 27 - Curva carga-recalque da estaca G201 (Amann, 2000) com interpretação pela Rigidez. 161

Figura 28 - Curva de Rigidez da estaca G201 161

Figura 29 - Ajustes do trecho 3-4 usando o diagrama de Rigidez. 162

Figura 30 - Ajuste do trecho 0-3 no diagrama de Rigidez. 163

Figura 31 - Ajuste dos trechos no diagrama de Rigidez para estaca da Penha (MASSAD, 1992, 1993). 164

Figura 32 - Primeira (fuste) e Segunda (ponta) Leis de Cambefort modificadas (adaptado de MASSAD, 2008) 165

Figura 33 - Discretização da estaca para iteração no caso de solo heterogêneo ...170 Figura 34 - Taxa de transferência de carga para o solo em função do recalque para as profundidades genéricas 1, 2 e 3 (SEED e REESE, 1959 apud COYLE e REESE, 1966) 
Figura 35 - Ruptura progressiva da estaca ao longo do seu comprimento (adaptado de FLEMING et al., 1992)

Figura 36 - a)1 $1^{\text {a }}$ Lei de Cambefort (1964), apud Baguelin e Venon (1971); b) 1ㄹ Lei de Cambefort Modificada por Massad (1992) para o primeiro carregamento da estaca: $A c=0 ; c)$ consideração da tensão residual $f_{\text {res }}$ no segundo carregamento da estaca (Massad 1992).

Figura 37 - Diagrama esquemático de sobreposição das formas propostas por diversos autores para obtenção do parâmetro $B$.

Figura 38 - Modelo de De Gennaro e Frank (2002) para interface estaca-solo não coesivo.

Figura 39 - Vista da montagem do sistema de reação (ABEF, 1989).

Figura 40 - Foto da montagem dos defletômetros e macacos hidráulicos (ABEF, 1989) 180

Figura 41 - Esquema de montagem da instrumentação (ABEF, 1989). 180

Figura 42 - Sondagens representativas SPT e CPT da estaca Barrete (apud ABEF, 1989)

Figura 43 - Determinação do produto E.S. 182

Figura 44 - Diagrama de transferência de carga em profundidade. 183

Figura 45 - Distribuição de atrito lateral em profundidade pelo método usual de linearização 184

Figura 46 - Diagrama de deslocamentos em profundidade para cada estágio de carga 185

Figura 47 - Relação $\tau(\mathrm{z})=\mathrm{f}[\mathrm{y}(\mathrm{z})]$ para cada estágio de carga 185

Figura 48 - Detalhe da curva $\tau(z)-y(z)$ obtida para o estágio de carga 3000 kN.....186 Figura 49 - Verificação da dependência de z e Po nas funções $\tau$ e y. 187

Figura 50 - Detalhe ampliado para o estágio de 2500 kN 188

Figura 51 - Curvas usuais de transferência de carga para cada profundidade 190

Figura 52 - Representações tridimensionais $\tau-y-z$ das funções $\tau\left(z, P_{0}\right)$ e y $\left(z, P_{0}\right)$ para a estaca Barrete 1 - campo experimental da USP-ABEF $\left({ }^{*} \tau\right.$ é representado aqui pela letra t).a) curvas t-z variando em y; b) curvas t-y variando em z; c) sobreposição dos gráficos a e b; d) gráfico c visto de outro ângulo. 191

Figura 53 - Representações tridimensionais $\tau-y-P_{0}$ das funções $\tau\left(z, P_{0}\right)$ e y $\left(z, P_{0}\right)$ para a estaca Barrete 1 - campo experimental da USP-ABEF. $\tau$ é representado aqui 
pela letra t.a) curva t-Po variando em y; b) curvas t-y variando em Po; c) sobreposição dos gráficos a e b;d) gráfico c visto de outro ângulo. ........................192 Figura 54 - Detalhe da variação da relação $\tau(z)-y(z)$ para $\mathrm{Po}=3000$ kN . ...............192 Figura 55 - Projeções das curvas de transferência de carga nos planos a) $\tau-P_{0}$, b) $\tau$ y e c) y- $P_{0}$ e sobreposição dos espaços y- $\tau-z$ e $\tau-y-P_{0}$ 193

Figura 56 - Projeções das curvas de transferência de carga nos planos $\tau$ - $P_{\circ}$ (similar à Figura 55a). 194

Figura 57 - Projeções das curvas de transferência de carga nos planos y- $P_{\circ}$ (similar à Figura 55c). 194

Figura 58 - Projeções das curvas de transferência de carga nos planos y-Po.......195

Figura 59 - Polinômios N(z) ajustados aos dados de instrumentação dy/dz. 197

Figura 60 - Polinômios $\tau(z)$ ajustados aos valores usuais de $\tau$ nos pontos médios dos trechos.

Figura 61 - Comparação entre os polinômios $\tau(z)$ ajustados e o método usual ( $\tau$ constante por camadas).

Figura 62 - Valores dos polinômios y(z) ajustados 199

Figura 63 - Ampliação em detalhe da forma da relação $\tau$-y para o estágio de carga de 2000 kN 200

Figura 64 - Comparação entre as curvas de transferência de carga obtidas a partir dos polinômios ajustados e pelo método usual.

Figura 65 - Superfícies t-y-z e y-t-Po para comparação entre: a) polinômios e b) usual; notar que a escala do eixo t (atrito) é diferente nas duas figuras. 201

Figura 66 - Superfície t-y-z vista por outro ângulo 202

Figura 67 - Projeção t-y das curvas de transferência de carga. 202

Figura 68 - Curvas $\tau\left(\mathrm{P}_{\mathrm{o}}\right)$ para trechos $\Delta \mathrm{Z}=\mathrm{L} / 10$. 203

Figura 69 - Curvas y $\left(\mathrm{P}_{\mathrm{o}}\right)$ para trechos $\Delta \mathrm{z}=\mathrm{L} / 10$. 204

Figura 70 - Polinômio ajustados para a relação $\tau$ - $P_{0}$ a $z=1,7 m$ 204

Figura 71 - Polinômio ajustados para a relação y- $P_{0}$ a $z=1,7 m$ 205

Figura 72 - Comparação das curvas $\tau\left(P_{0}\right)-y\left(P_{0}\right), \tau(z)-y(z)$ e os obtidos usualmente para as profundidades médias dos trechos instrumentados 206

Figura 73 - Gráfico do quociente dos polinômios $\tau\left(P_{\circ}\right) / y\left(P_{0}\right)$ e comparação com os valores usuais 208

Figura 74 - Sondagem de referência para a estaca G202 (AMANN, 2000) .... .213 
Figura 75 - Comparação das previsões (estimativas) semiempíricas com os critérios de ruptura

Figura 76 - Resumo da aplicação das Leis de Cambefort e da Rigidez para separação da parcela de atrito 220

Figura 77 - Aplicação dos ajustes polinomiais para obtenção da 1a․ lei e Cambefort em profundidades distintas dos pontos da instrumentação. 223

Figura 78 - Curvas $N(z)$ versus $y(z)$ com indicação da rigidez $b_{2}$ nos pontos instrumentados. 225

Figura 79 - Aplicação das Hierarquias dos Solos de atrito e ponta para definição das relações de resistência entre camadas de solo.

Figura 80 - Forma de apresentação dos resultados da Metodologia Semiempírica Unificada aplicada a solos de diversas regiões do país. 240

Figura 81 - Comparação gráfica entre os coeficientes de cisalhamento lateral $\left(\mathrm{K}_{\mathrm{Lg}}\right)$ do método de Alonso (AL) e Décourt-Quaresma (DQ) apud Amann (2004). 284 Figura 82 - Comparação gráfica entre os fatores de ponta do método de Alonso $(A L)$ e dos métodos Décourt-Quaresma (DQ), Antunes-Cabral (AC) e Karez-Rocha (KR) apud AMANN (20004) 288

Figura 83 - Correlações entre os coeficientes empíricos do método David Cabral e dos métodos Décourt-Quaresma e Aoki-Velloso, para estacas raiz e para estacas escavadas de grande diâmetro, apud Amann (2002) 302

Figura 84 - Comparação gráfica dos fatores de atrito lateral $\left(\mathrm{K}_{\mathrm{Lg}}=\beta_{1}\right)$ e de ponta $\left(K_{P g}=\beta_{2}\right)$ do método de Cabral et al $(C A)$ entre estacas Ômega (Ô) e Raiz $(R)$ e Escavadas de Grande Diâmetro (EGD) apud Amann (2004). 302

Figura 85 - Regressão linear, passando pela origem, para determinação da tendência do valor do produto K. $\alpha_{A V}$, dos métodos Aoki-Velloso (AV), MonteiroFranki (FK), David Cabral (CA), Cabral et al (CB) (AMANN, 2006). 309 Figura 86 - Comparação entre os valores atribuídos ao recalque da ponta dos critérios de Davisson (1972) e da NBR 6122 (2005) 315

Figura 87 - Critério da NBR6122 aplicado a estaca E013 - Alemoa. 317

Figura 88 - Critério de Fuller e Hoy aplicado a estaca E013 - Alemoa 320

Figura 89 - Critério de Butler e Hoy aplicado a estaca E013 - Alemoa.. 323

Figura 90 - Critério de De Beer e Wallays aplicado a estaca E013 - Alemoa 324

Figura 91 - Critério de Rigidez de Décourt aplicado à estaca E013 - Alemoa. 327 
Figura 92 - Critério de Chin aplicado à estaca E013 - Alemoa ...............................329

Figura 93 - Critério de Brinch Hansen 80\% aplicado à estaca E013 - Alemoa......331

Figura 94 - Critério de Van der Veen aplicado à estaca E013 - Alemoa

Figura 95 - Transformações matemáticas desde a função exponencial até a expressão de Van der Veen .338

Figura 96 - Curvas exponenciais com diferentes valores do parâmetro 'b': a) com estágios de carga constantes; b) com recalques equiespaçados .339

Figura 97 - Gráfico da hipérbole de Chin na sua forma fundamental. 341

Figura 98 - Gráfico da hipérbole de Chin parametrizada em duas escalas diferentes.

Figura 99 - Curva de Chin parametrizada. 342

Figura 100 - Variação dos valores dos interceptos do eixo $\tau$ dados pelo polinômio $\mathrm{A}_{\mathrm{C}}=\mathrm{a}_{\mathrm{C}}+\mathrm{b}_{\mathrm{C}} \cdot \mathrm{z}$, para cada profundidade $\mathrm{z}$, com $\mathrm{B}_{\mathrm{C}}=$ constante. 349

Figura 101 - Ajustes polinomiais para: a) relação $\tau-P_{0}$ a $z=1,7 \mathrm{~m}$; b) relação y- $P_{0} a$ $z=1,7 \mathrm{~m}$; c) relação $\tau-P_{\circ}$ a $\left.z=4,6 m ; d\right)$ a relação $y-P_{\circ}$ a $z=4,6 m$; e) relação y- $P_{\circ} a$ $z=6,3 \mathrm{~m} ; \mathrm{f}$ ) relação $y-P_{0}$ a $z=6,3 \mathrm{~m}$. .373

Figura 102 - Exemplo de curva ajustada e formas de apresentação da função $\tau(z)$ correspondente em função do comprimento $L$ da estaca.

Figura 103 - Distribuição da força normal para atrito constante com determinação de C. . 382 


\section{LISTA DE TABELAS}

Tabela 1 - Valores de $K_{A V}$ e $\alpha_{A V}$ sugeridos por Aoki \& Velloso (1975). .68

Tabela 2 - Coeficientes $F_{1}$ e $F_{2}$ em função do tipo de estaca (VELLOSO e ALONSO, 2000)

Tabela 3 - Valores dos fatores de correção $\alpha_{D Q}$ e $\beta_{D Q}$ (adaptada de DÉCOURT, 1996a)

Tabela 4 - Valores do coeficiente $C_{P}$ em função do solo junto à ponta (DÉCOURT, 1996a)

Tabela 5 - Expressões dos coeficientes característicos de atrito lateral $\mathrm{K}_{\mathrm{Lg}(i)}$ e de ponta $\mathrm{K}_{\mathrm{Pg}}[\mathrm{KPa}]$ para os vários métodos semi-empíricos estudados (VELLOSO e ALONSO, 2000, AMANN e MASSAD, 2000, KAREZ e ROCHA, 2000 e MONTEIRO, 2000 ) apud Amann (2006).

Tabela 6 - Metodologia aplicada ao cisalhamento lateral e à ponta (embutimento) em cada método.

Tabela 7 - Hierarquia dos solos (identificados por códigos) para os coeficientes de cisalhamento lateral $\left(\mathrm{K}_{\mathrm{Lg}}\right)$ em $\mathrm{kN} / \mathrm{m}^{2}$ das estacas de referência dos métodos semiempíricos (AMANN, 2006).....

Tabela 8 - Hierarquia dos solos (identificados por códigos) para os coeficientes de resistência de ponta $\left(\mathrm{K}_{\mathrm{Pg}}\right)$ em $\mathrm{kN} / \mathrm{m}^{2}$ das estacas de referência dos métodos semiempíricos (AMANN, 2006).

Tabela 9 - Exemplos de decomposição dos coeficientes semiempíricos em coeficientes parciais

Tabela 10 - Valores médios e desvios do coeficiente parcial de tipo de solo $\left(k_{t s}\right)$ para os diversos métodos semiempíricos

Tabela 11 - Valores médios e desvios do coeficiente parcial de tipo de ensaio $\left(k_{\mathrm{te}}\right)$ para os diversos métodos semiempíricos

Tabela 12 - Valores médios de $\mathrm{k}_{\mathrm{tE}}$ do fuste ( $\mathrm{L}$ ) e da ponta (P) a partir dos métodos semiempíricos analisados, relativos à estaca prémoldada cravada (de referência)..86 Tabela 13 - Aplicação dos métodos Mediado e Expedito de teste à estaca G202 (AMANN, 2000)

Tabela 14 - Valores do coeficiente característico $\mathrm{K}_{\mathrm{Lg}}$ para o fuste e respectivo SPT (N) médio para cada condição de embutimento 
Tabela 15 - Valores das tensões e carga no fuste para cada condição de embutimento e modelo de consideração das camadas no método Mediado ............92 Tabela 16 - Valores das tensões e carga na ponta para cada condição de embutimento e modelo de consideração das camadas no método Mediado..... .93 Tabela 17 - Cargas de ruptura estimadas pelos diversos modelos de consideração do atrito lateral e do embutimento da ponta par os métodos de teste. .93 Tabela 18 - Critérios de Ruptura para a Curva Carga-Recalque (P- $\delta$ ) de Estacas, adaptada de AMANN (2008b)

Tabela 19 - Pontos obtidos no ensaio de prova de carga da estaca E013 - Alemoa (MASSAD, 1994)

Tabela 20 - Coeficientes do método das Leis de Cambefort modificadas por Massad (1992) 103

Tabela 21 - Extrato das expressões definidas para cálculo das coordenadas dos pontos notáveis 4 e 5, apud Amann (2008b). 104

Tabela 22 - Valores da curva exponencial fundamental de Van der Veen. 112

Tabela 23 - Leituras obtidas na instrumentação e cargas calculadas 182

Tabela 24 - Coeficientes do polinômios $\tau(z)$ derivados de $N(z)$ 198

Tabela 25 - Comparação dos valores de B para $z=6,3 \mathrm{~m}$ pelas três formulações.207 Tabela 26 - Resumo da sondagem da estaca G202 para o fuste e para a ponta ...212 Tabela 27 - Valores dos coeficientes parciais empíricos do Método Mediado. 213

Tabela 28 - Cargas de ruptura estimadas pelos diversos modelos de consideração do atrito lateral e do embutimento da ponta par os métodos de teste. 214 Tabela 29 - Critérios mais próximos dos valores das estimativas semiempíricas ..216 Tabela 30 - Valores dos coeficientes característicos de cada camada corrigidos e adotados anteriormente das tabelas do método 228

Tabela 31 - Valores corrigidos do coeficiente parcial de tipo de estaca $\mathrm{k}_{\mathrm{tEL}}$ 230

Tabela 32 - Correção provisória dos coeficientes de tipo de ensaio $\mathrm{k}_{\mathrm{te}}$ 231 Tabela 33 - Valores do coeficiente característico de ponta para cada condição de embutimento. 232

Tabela 34 - Correção simultânea para as estacas G201 e G202 instaladas no Guarujá-SP. 237

Tabela 35 - Resumo dos artigos técnico-científicos para demonstração do paradigma de classificação dos métodos semiempíricos 
Tabela 36 - Coeficientes empíricos dos métodos para estacas raiz, em função do solo (AMANN, 2002) e valores dos coeficientes empíricos do Método de Cabral et al. para estacas Ômega, Raiz e da Fundesp para Escavada de Grande Diâmetro, e Brasfond para estacas Raiz (AMANN, 2004) 278 Tabela 37 - Valores dos coeficientes empíricos dos métodos semiempíricos para estacas Hélice-Contínua e comparação com Décourt-Quaresma (AMANN, 2004)279 Tabela 38 - Valores de $K_{F K}$ e $\alpha_{F K}$ sugeridos por Monteiro [g=FK] (2000) e Laprovitera(1988) [g=LP] apud Velloso e Lopes (2002).

Tabela 39 - Fatores $F_{1 g}$ e $F_{2 g}$ em função do tipo de estaca (MONTEIRO [FK], $2000 \mathrm{e}$ BENEGAS [BN], 1993, apud VELLOSO e LOPES, 2002)

Tabela 40- Coeficientes de cisalhamento lateral e ponta do método de Teixeira (1996) para diversos tipos de estaca (VELLOSO e ALONSO, 2000). 280

Tabela 41 - Coeficientes de cisalhamento lateral e ponta do método de PPC Velloso (1981) para diversos tipos de estaca (VELLOSO e ALONSO, 2000). 280

Tabela 42 - Valores dos coeficientes de tipo de ensaio $\left(K_{D V}\right.$ ou $K_{A L} \equiv K_{t e}$ ) e tipo de solo $\left(\alpha_{\mathrm{AL}}=\mathrm{k}_{\mathrm{ts}}\right)$ obtidos por Danziger e Velloso (1985) e Alonso (1980), apud Décourt (1996a) 281

Tabela 43 - Hierarquia dos solos e coeficientes $\mathrm{K}_{\mathrm{Lg}}$ dos Métodos Aoki-Velloso (AV), David Cabral (CA) e Brasfond (BR) para o cisalhamento lateral de estacas raiz (AMANN, 2002). 282

Tabela 44 - Hierarquia dos solos e fatores $K_{P g}$ dos Métodos Décourt-Quaresma (DQ), Aoki-Velloso (AV), David Cabral (CA) e Brasfond (BR) para o solo da ponta de estacas raiz (AMANN, 2002) 283

Tabela 45 - Correlações lineares $(y=a . x+b)$ entre os coeficientes dos métodos semiempíricos para estacas raiz, com indicação do coeficiente de determinação estatístico $\left(R^{2}\right)$ e seus valores críticos para 95\% de confiança, apud Amann (2002) 287

Tabela 46 - Regressões entre os coeficientes característicos de ponta $(\mathrm{KPg})$ do método de Alonso ( $A L)$ e dos métodos Décourt-Quaresma (DQ) , Antunes-Cabral (AC) e Karez-Rocha (KR) AMANN (2004)... 287

Tabela 47 - Comparação entre as hierarquias dos coeficientes $k_{t s}$ para os métodos de David Cabral ( $\left.\alpha_{C A}\right)$ e Aoki- Velloso ( $\left.\alpha_{A V}\right)$, apud Amann (2000) 295 
Tabela 48 - Ajustes estatísticos entre as estacas dos métodos de Cabral, apud Amann(2006) e $\mathrm{R}^{2}$ crítico para $95 \%$ de confiança.

Tabela 49 - Regressões lineares entre os coeficientes de atrito lateral $\left(K_{\mathrm{Lg}}=\beta_{1}\right)$ e de ponta $\left(K_{\mathrm{Pg}}=\beta_{2}\right)$ do método de Cabral et al $(C A)$, entre estacas Ômega (Ô) e Raiz (R) e Escavadas de Grande Diâmetro (EGD), e método Antunes-Cabral para estacas Hélice -Contínua ( $B_{1}$ e $B_{2}$ ), apud Amann (2004).

Tabela 50 - Regressões entre $K_{g}$ e $1 / \alpha_{g}$ e $R^{2}$ crítico com $95 \%$ de confiança (AMANN, 2006) 309

Tabela 51 - Valores críticos dos coeficientes de correlação e determinação das regressões

Tabela 52 - Valores dos coeficientes da expressão B.8 em função do tipo de estaca

Tabela 53 - Valores dos critérios de ruptura aplicados à estaca E013-Alemoa . 335

Tabela 54 - Valores da hipérbole de Chin parametrizada 341

Tabela 55 - Parâmetros, simbologia e expressões dos métodos de Massad(1992) e Randolph e Wroth (1978) 359

Tabela 56 - Atrito lateral unitário $\tau\left[\mathrm{kN} / \mathrm{m}^{2}\right]$ para ca,da trecho $\Delta z$ em cada estágio de carga $P_{0}[k N]$. .365

Tabela 57 - Valores de carga calculados considerando trecho linear na ponta. .....365 Tabela 58 - Valores da integral (N.dz) em [kN.m] para cada trecho de estaca .......365 Tabela 59 - Valores de encurtamento por trecho em [m] ….................................366

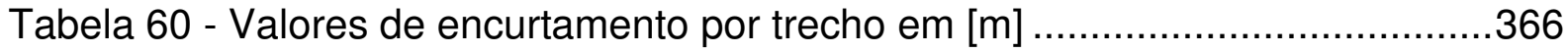
Tabela 61 - Deslocamentos y em $\mathrm{mm}$ para os pontos médios dos trechos da estaca.

Tabela 62 - Valores dos coeficientes dos polinômios integrados de $N(z)$, com y em [mm] 368

Tabela 63 - Linearização das inclinações $[\tau(z) . U]$ no trecho $\Delta z=6,8-5,8 m$ para estimativa da inclinação para $P_{0}=500 \mathrm{kN}$. 369

Tabela 64 - Coeficientes dos polinômios $\tau(z)$ derivados de $N(z)$ com $P_{o}=500 \mathrm{kN}$ corrigido.

Tabela 65 - Coeficientes dos polinômios $y(z)$ integrados de $N(z), P_{0}=500 \mathrm{kN}$ corrigido (y em [mm] ) 370

Tabela 66 - Valores de $\tau\left[\mathrm{kN} / \mathrm{m}^{2}\right]$ calculados por derivação dos polinômios $\mathrm{N}(\mathrm{z})$....371 
Tabela 67 - Valores de y[mm] calculados por integração dos polinômios $\mathrm{N}(\mathrm{z})$........371

Tabela 68 - Valores dos coeficientes das regressões polinomiais $\tau\left(P_{0}\right) \mathrm{kN} / \mathrm{m}^{2}$........374

Tabela 69 - Valores dos coeficientes das regressões polinomiais $y\left(P_{0}\right) \mathrm{mm}$..........374

Tabela 70 - Estacas escolhidas para exemplo de aplicação da MSU ......................383 


\section{LISTA DE SÍMBOLOS}

$\left(\mathrm{k}_{\mathrm{te}}\right)_{\text {Pcrit }}$ : coeficiente parcial de tipo de ensaio, para a ponta, dado pelo critério de ruptura 233

A: tensão inicial de ponta no comportamento bilinear da segunda Lei de Cambefort modificada 136

A e B: coeficientes da solução da EDO conforme Randolph e Wroth (1978)..... 346

$A_{L}$ : área da superfície do fuste da estaca. .58

$A_{c}$ : parâmetro inicial de transferência de carga nos métodos de Cambefort e Baguelin e Venon. 130

AC: sigla para o método Antunes-Cabral (1996) para estacas Hélice Contínua .......74

$A_{\text {Conc: }}$ área da seção de concreto

$a_{D}$ : constante do coeficiente parcial de dimensão da estaca em relação ao CPT .....87

AL: sigla para o método de Alonso (1996) para estacas Hélice contínua ................74

Alr: atrito lateral na ruptura para o método das Leis de Cambefort modificadas .....102

$\mathrm{Alr}_{1}$ : carga transferida por atrito lateral à camada superior do solo da estaca

$\mathrm{Alr}_{2}$ : carga transferida por atrito lateral à camada inferior do solo da estaca

Alr $r_{G}$ : somatória dos atritos laterais das estacas instaladas no mesmo local 237

$A_{P}$ : área da ponta da estaca. .58

$a_{\mathrm{rL}}$ : coeficiente de inclinação da reta de regressão do domínio do atrito no método da Rigidez de Décourt. 154

As: área da seção de aço 120

AV: sigla para o método Aoki-Velloso (1975) .74

$a_{v d v}$ : inclinação da reta de ajuste do critério de ruptura de Van der Veen 111

B: parâmetro de transferência de carga ou módulo de resistência do solo por atrito lateral

$B(z)$ : valor do parâmetro $B$ em função da profundiade $z$ 185

$B\left(z, P_{0}\right)$ : parâmetro $B$ como função da profunidade $z$ e do estágio de carga $P_{0}$ 190

$b_{1}$ : coeficiente de intercepção da reta de regressão linear da curva carga-recalque no trecho 2-3

$\mathrm{B}_{1}$ : coeficiente empírico de resistência de ponta para o método Antunes-Cabral ...284

$b_{1 r}: b_{1}$ para o descarregamento na prova de carga 136 
$b_{2}$ : coeficiente de inclinação da reta de regressão linear da curva carga-recalque no trecho 0-3

$\mathrm{B}_{2}$ : coeficiente empírico de resistência da ponta para o método Antunes-Cabral...302 $b_{21}$ : valor de $b_{2}$ para o solo da camada superior (1) do fuste no método das Leis de Cambefort modificadas 169

$b_{2 r}: b_{2}$ para o descarregamento na prova de carga 136

$B_{c}$ : parâmetro $B$ de transferência de carga nos métodos de Cambefort e Baguelin e Venon 130

$b_{\mathrm{D}}$ : constante do coeficiente parcial de dimensão da estaca em relação ao CPT .....87

BH: sigla para o critério de ruptura de Brinch Hansen 80\% (1963) .........................97

BR: sigla para o método da Brasfond (1991) para estacas raiz .74

$\mathrm{b}_{\mathrm{rL}}$ : coeficiente de intercepção da reta de regressão do domínio do atrito no método da Rigidez de Décourt 154

BT: sigla para o critério de ruptura de Butler e Hoy (1977). .97

$b_{v d v}$ : intercepto do ajuste do critério de ruptura de Van der Veen. 111

BW: sigla para o critério de ruptura de DeBeer e Walays (1972) .............................97

c: coesão do solo .59

C: coeficiente de desenvolvimento do atrito ao longo do fuste 137

$c_{1}$ : coeficiente de intercepção da reta de regressão linear da curva carga-recalque no trecho parabólico 3-M-4 136

$\mathrm{C}_{1}$ : coeficeinte de inclinação da reta de regressão linear do critério da Rigidez de Décourt 153

$C_{1 C}$ : coeficientes de inclinação da reta de regressão linear do critério de Chin .......153

$c_{11}: c_{1}$ para o descarregamento na prova de carga. 136

$\mathrm{C}_{2}$ : coeficiente de $\mathrm{P}_{0}{ }^{2}$ da reta de regressão linear da curva carga-recalque no trecho parabólico 3-M-4 136

$\mathrm{C}_{2}$ : coeficiente de intercepção da reta de regressão linear do critério da Rigidez de Décourt 153

$\mathrm{C}_{2 \mathrm{r}}: \mathrm{C}_{2}$ para o descarregamento na prova de carga 136 $c_{a}$ : adesão inicial entre o fuste e o solo .

CA: sigla par ao método David Cabral (1986), para estacas raiz, escavadas e ômega

CB: sigla para o método de Cabral et al. (2000) para estacas ômega .... .74 
$\mathrm{C}_{\text {het34: }}$ coeficiente de equivalência para o caso heterogêneo no trecho 3-4 da curva carga-recalque

$\mathrm{C}_{\text {het45: }}$ coeficiente de equivalência para o caso heterogêneo no trecho 4-5 da curva carga recalque

$\mathrm{C}_{\text {het78: }}$ coeficiente de equivalência para o caso heterogêneo no trecho 7-8 da curva carga recalque

$\mathrm{C}_{\text {het89: }}$ coeficiente de equivalência para o caso heterogêneo no trecho 8-9 da curva carga recalque

coc: coeficiente de intercepção da reta de regressão linear do critério de Chin 153

$\mathrm{C}_{\mathrm{P}}$ : coeficiente empírico de tipo de solo da ponta no método Décourt-Quaresma ....71

CV: sigla par ao método de P.P.C.Velloso (1981).......................................... 74

D: diâmetro ou menor dimensão da estaca.

$d_{1}$ : coeficiente de intercepção da reta de regressão linear da curva carga-recalque no trecho 4-5

$d_{1}: d_{1}$ para o descarregamento na prova de carga 136

$\mathrm{d}_{2}$ : coeficiente de inclinação da reta de regressão linear da curva carga-recalque no trecho 4-5

$d_{2 r}: d_{2}$ para o descarregamento na prova de carga 136

$\mathrm{d}_{\mathrm{c}}$ : diâmetro da ponteiro do cone do ensaio CPT .87

Dp: diâmetro da ponta em Amann (2008b) 104

DQ: sigla para o método Décourt-Quaresma (1978), Décourt (1996a) .74

DRM: sigla do sistema de ajuste da curva carga-recalque sem os trechos $7-8$ e 3-4 ...

DRM-C: sigla do sistema de ajuste da curva carga recalque sem o descarregamento 384

$\mathrm{dz}$ : elemento infinitesimal de estaca na profundidade $\mathrm{z}$ 127

E: módulo de elasticidade (Young) da estaca .97

EDO: Equação Diferencial Ordinária....

EDO2: Equação Diferencial de 2a. Ordem

EDP: Equação Diferencial Parcial

Ef: módulo de elasticidade do solo do fuste em Amann (2008b). 104

EGD: sigla para Estaca Escavada de Grande Diâmetro

$\mathrm{E}_{\mathrm{m}}$ : módulo pressiométrico para o método de transferência de carga de Frank e Zhao 
Ep: módulo de elasticidade do solo da ponta em Amann (2008b) 104

ESOPT: European Symposium On Penetration Tests

$F_{1}$ : inverso do coeficiente de tipo de estaca para a ponta no método Aoki-Velloso ..68

$\mathrm{F}_{2}$ : inverso do coeficiente de tipo de estaca para o fuste no método Aoki-Velloso ...68

fck: resistência característica do concreto.......................................................120

FH: sigla para o critério de ruptura de Fuller e Hoy (1970) ...................................97

FK: sigla para o método de Monteiro (2000), pela empresa Franki.........................74

$f_{\max }$ : resistência ao cisalhamento máximo do solo do fuste....................................68

$\mathrm{f}_{\mathrm{S}}$ : resistência do solo na luva de atrito do ensaio CPT ......................................67

$\mathrm{f}_{\mathrm{SAL}}$ : atrito dado pelo torque do ensaio SPT-T no método de Alonso (1996)............283

$\mathrm{FS}_{\mathrm{L}}$ : fator de segurança da tensão admissível por atrito lateral ...............................65

FS : fator de segurança da tensão admissível de ponta .........................................65

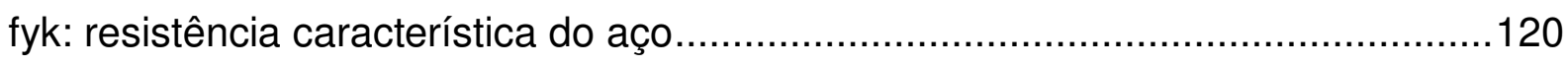

$\mathrm{G}_{\mathrm{b}}$ : módulo de cisalhamento do solo da ponta nos métodos de transferência de carga

GL: módulo de cisalhamento do solo do fuste nos métodos de tranferência de carga ..

GT: sigla para o métodos de Gotlieb et al (2000) para estacas Hélice-contínua.......74 $h$ : o menor inteiro positivo que elimine os termos em comum na solução da EDO

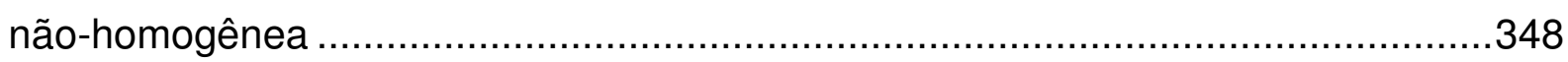

h': trecho do fuste com atrito parcialmente mobilizado para as Leis de Cambefort modificadas

h $_{\mathrm{SPT}}$ : comprimento de cravação do amostrador padrão do ensaio SPT para o método de Alonso 283

k: rigidez relativa estaca (fuste)-solo para as Leis de Cambefort modificadas ........103 $\mathrm{k}_{1}$ : coeficiente de rigidez relativa estaca (fuste)-solo no trecho 1 , camada superior136 $\mathrm{k}_{2}$ : coeficiente $\mathrm{k}$ para camada inferior do solo do fuste nas Leis de Cambefort modificadas

$\mathrm{K}_{\mathrm{AV}}$ : coeficiente de relação entre a resistência de ponta do ensaio CPT e o $\mathrm{N}$ do ensaio SPT no método Aoki-Velloso

$k_{c}$ : coeficiente de rigidez relativa entre o solo do fuste e a estaca até a profundidade $\mathrm{z}_{\mathrm{c}}$

$\mathrm{K}_{\mathrm{ef}}$ : coeficientes de tipo de estaca para o fuste em Amann (2008b) .......................104

$\mathrm{K}_{\mathrm{ep}}$ : coeficientes de tipo de estaca para a ponta em Amann (2008b).....................104 
KL: coeficiente característico de atrito lateral em Amann (2008b) 104

$\mathrm{K}_{\mathrm{Lg}}$ : coeficiente característico de resistência da estaca por atrito lateral...................72 $\mathrm{K}_{\mathrm{LG}}$ : coeficiente característico de resistência por atrito lateral global, para mais de uma estaca no local .237

$\mathrm{K}_{\mathrm{Lg}(\mathrm{i})}$ : coeficiente característico de resistência da camada (i) por atrito lateral. .73 $\mathrm{K}_{\mathrm{Lméd}}$ : coeficiente característico de resistência por cisalhamento lateral calculado com o SPT médio ao longo do fuste .92

$\mathrm{Kp}$ : coeficiente característico de atrito lateral em Amann (2008b) 104 $\mathrm{K}_{\mathrm{P} 3 \mathrm{D}(\mathrm{i})}$ : valor do coeficiente característico de ponta para cada camada no embutimento 3D abaixo da ponta. .76

$\mathrm{K}_{\mathrm{P} 8 \mathrm{D}(\mathrm{i})}$ : valor do coeficiente característico de ponta para cada camada no

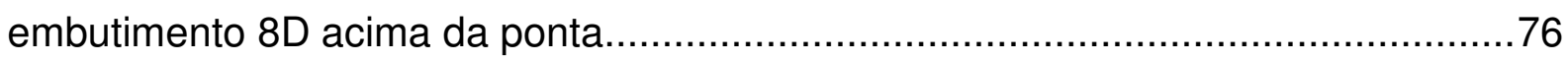

$\mathrm{K}_{\mathrm{Pg}}$ : coeficiente característico de resistência da estaca pela ponta ........................72 $K_{\text {pméd: }}$ coeficiente característico de resistência pela ponta calculado com a média de 3 SPT's em torno da ponta .92

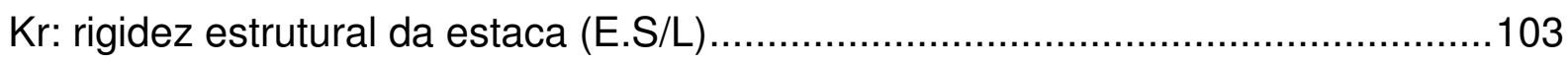
KR: sigla para o método dKárez-Rocha (2000) para estacas Hélice Contínua .........74 $\mathrm{Kr}_{1}$ : rigidez estrutural da estaca no trecho superior (camada mais fraca) ..............136 $\mathrm{Kr}_{2}$ : rigidez estrutural da estaca no trecho inferior (camada mais resistente)..........136 $\mathrm{Kr}_{\text {adot }}$ : rigidez estrutural da estaca adotada inicialmente para iteração....................142 $\mathrm{Kr}_{\mathrm{aj}}$ : rigidez estrutural da estaca ajustada por iterações ao sistema de equações dos trechos da curva carga-recalque .....................................................................143

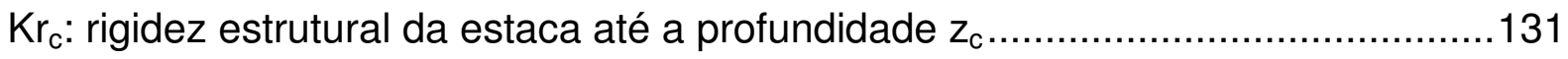

$\mathrm{k}_{\text {reb}}$ : coeficiente $\mathrm{k}$ para o descarregamento nas Leis de Cambefort Modificadas ....166

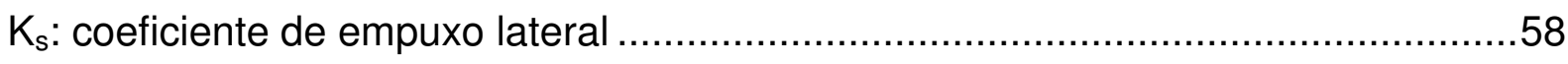

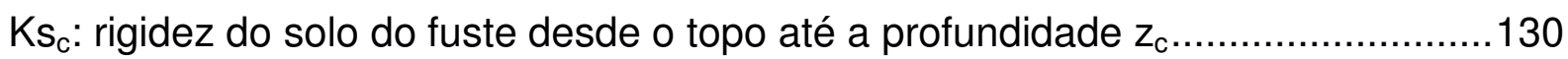
$\mathrm{k}_{\text {solo }}$ : coeficiente de tipo de solo no método de transferência de carga de Frank e Zhao 176

Ksr: rigidez equivalente do sistema solo (do fuste) - estaca

$\mathrm{k}_{\mathrm{tc}}$ : coeficiente parcial da ponta devido ao critério de ruptura adotado....................233

$\mathrm{k}_{\mathrm{tD}}$ : coeficiente parcial de de influência de dimensão ou do diâmetro ........................65

$k_{\text {te: }}$ : coeficiente parcial de influência de tipo de ensaio de campo ou sondagem .......65

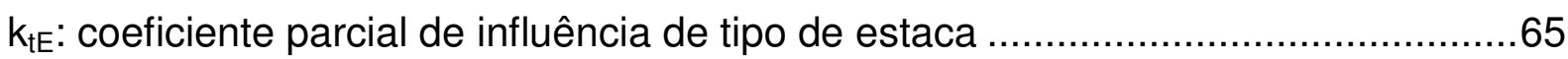

$\mathrm{k}_{\mathrm{tEL} L \mathrm{corm}}$ : coeficiente parcial de tipo de estaca, corrigido pela médio.........................230 
$\mathrm{k}_{\mathrm{t}}$ : coeficiente parcial empírico de tipo de ensaio e solo $\left(\mathrm{k}_{\mathrm{te}} \cdot \mathrm{k}_{\mathrm{ts}}\right) \ldots \ldots \ldots \ldots \ldots \ldots \ldots \ldots \ldots . .226$

$\mathrm{K}_{\text {tlim: }}$ : rigidez tangente limite do critério de Butler e Hoy .......................................97

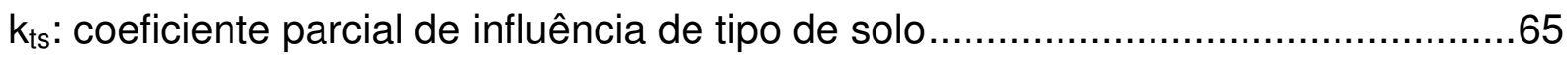

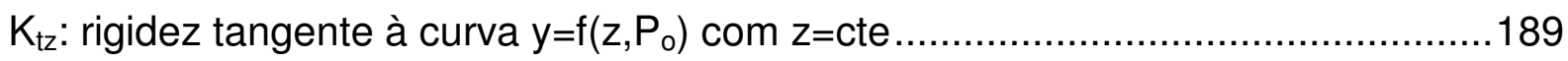

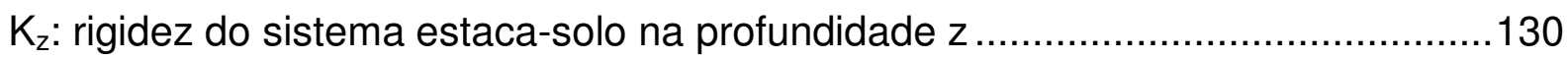

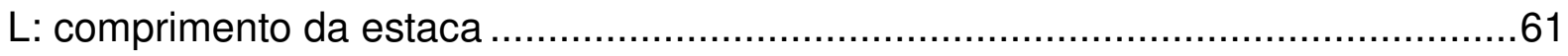

LCM: sigla do método das Leis de Cambefort Modificadas ..................................134

m: grau da função r(z) na EDO não-homogênea ..............................................349

M e N: coeficientes da solução da EDO conforme Massad (1985) ........................345

MDR: sigla do Método das Duas Retas de Massad e Lazo .................................134

MDRM: sigla para o Método das Duas Retas Modificado de Marques e Massad...134

MPE: sigla do Método da Parábola-Exponencial de Massad ................................135

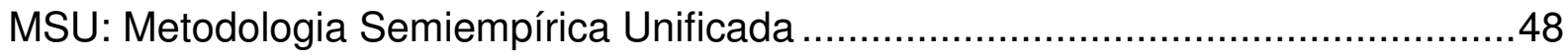

$\mathrm{N}$ : número de golpes nos últimos $30 \mathrm{~cm}$ do amostrador do ensaio SPT ..................67

$\mathrm{N}(\mathrm{z})$ : solicitação ou carga normal atuante na seção da estaca na profundidade z..127 $\mathrm{n}_{3}$ : número de valores SPT consideradas no embutimento 3D abaixo da ponta........76

$\mathrm{n}_{8}$

NBR: sigla para o critério de ruptura da norma brasileira NBR 6122 (1996) ............97

$\mathrm{N}_{\mathrm{c}}$ : fator de capacidade de carga relativo à coesão .............................................60

$\mathrm{N}_{\text {eq: }}$ relação entre SPT e índice de torque SPT-T .............................................66

Nf: sondagem SPT média do fuste em Amann (2008b) .....................................104

Nk: resistência estrutural da estaca ..........................................................120

$\mathrm{N}_{\text {medG: }}$ média dos SPT's para mais de uma prova de carga no mesmo local..........237

Np: sondagem SPT na ponta em Amann (2008b)...............................................104

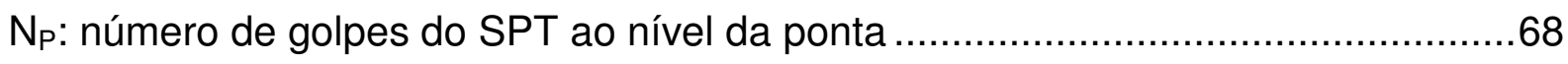

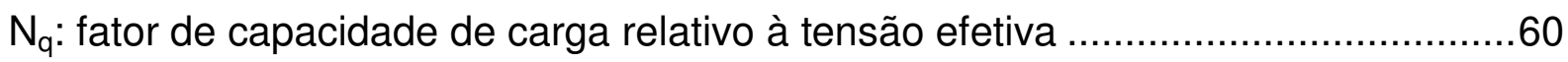

$\mathrm{N}_{\gamma}$ fator de capacidade de carga relativo à massa específica do solo .......................60

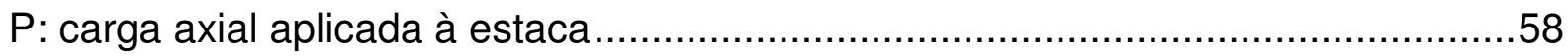

$P_{\mathrm{b}}$ : carga na ponta pelo fuste no método Randolph e Wroth.................................360

$P_{h}$ : carga residual na ponta da estaca para as Leis de Cambefort modificadas......103

$P_{\mathrm{L}}$ : atrito lateral desenvolvido entre fuste e solo58; carga transferida por atrito lateral na ruptura estimada por somatória das camadas .................................................

$\mathrm{P}_{\mathrm{L3D}}$ : carga transferida por atrito lateral na ruptura estimada por somatória das camadas sem o trecho de 3D acima da ponta ...................................................93 
$\mathrm{P}_{\mathrm{L8D}}$ : carga transferida por atrito lateral na ruptura estimada por somatória das camadas sem o trecho de 8D acima da ponta

$\mathrm{P}_{\mathrm{LN}}$ : carga transferida por atrito lateral na ruptura estimada pelo média do SPT do fuste

$\mathrm{P}_{\mathrm{LN} 3 \mathrm{D}}$ : carga transferida por atrito lateral na ruptura estimada pelo média do SPT do fuste sem o trecho 3D

$P_{\mathrm{LN} 8 \mathrm{D}}$ : carga transferida por atrito lateral na ruptura estimada pela média do SPT do fuste sem o trecho 8D

$P_{\text {max }}$ : carga máxima aplicada na prova de carga .112

$P_{\text {min }}$ : carga mínima a ser aplicada no ensaio de prova de carga 115

$\mathrm{P}_{\mathrm{o}}$ : carga aplicada no topo da estaca para as Leis de Cambefort modificadas..... 103 $\mathrm{P}_{03}$ : carga calculada para o ponto 3 da curva carga-recalque nas Leis de Cambefort modificadas 168

$\mathrm{P}_{\text {034: }}$ cargas teóricas calculadas para o trecho parabólico 3-4 da curva carga recalque para as Leis de Cambefort modificadas

$\mathrm{P}_{04}$ : carga correspondente ao ponto 4 da curva carga-recalque no método das Leis de Cambefort modificadas. 106

$\mathrm{P}_{\text {o5}}$ : carga máxima aplicada no ensaio ou carga de ruptura física da estaca para as Leis de Cambefort modificadas

$\mathrm{P}_{\mathrm{P}}$ : carga estimada transferida pela ponta apoiada (OD) no SPT da camada inferior 93; reação do solo sob a ponta da estaca

$\mathrm{P}_{\mathrm{p} 3}$ : carga estimada transferida pela ponta calculada pela média de 3 SPT's em torno da ponta

$\mathrm{P}_{\mathrm{P} 3 \mathrm{D}}$ : carga estimada transferida pela ponta embutida 3D acima e 3D abaixo da ponta .93

$\mathrm{P}_{\mathrm{P} 8 \mathrm{D}}$ : carga estimada transferida pela ponta embutida 8D acima e 3D abaixo da ponta

$\mathrm{P}_{\mathrm{R}}$ : carga de ruptura estimada por somatória das camadas e 1 SPT na ponta......212; Carga de ruptura estimada por somatória das camadas e 1 SPT na ponta93; carga de ruptura física do sistema estaca-solo.

$\mathrm{P}_{\mathrm{R} 3 \mathrm{D}}$ : carga de ruptura estimada por somatória das camadas e com 3D acima de embutimento da ponta. .93

$\mathrm{P}_{\mathrm{R} 8 \mathrm{D}}$ : carga de ruptura estimada por somatória das camadas e com 8D acima de embutimento da ponta. 
$P_{\mathrm{Rc}}$ : carga de ruptura convencional.

$\mathrm{P}_{\mathrm{RN}}$ : carga de ruptura estimada por média dos SPT's das camadas e 1 SPT na ponta

$\mathrm{P}_{\mathrm{RN} 3 \mathrm{D}}$ : carga de ruptura estimada pela média dos SPT's do fuste e $3 \mathrm{D}$ de embutimento da ponta. .93

$\mathrm{P}_{\mathrm{RN} 3 \mathrm{P}}$ : carga de ruptura estimada pela média dos SPT's do fuste e por 3 SPT's no entorno da ponta .93

$\mathrm{P}_{\mathrm{RN8D}}$ : carga de ruptura estimada pela média dos SPT's do fuste e $3 \mathrm{D}$ de embutimento da ponta .93

$\mathrm{P}_{\text {rvdv }}$ : carga de ruptura do critério de Van der Veen. 110

$P_{s}$ : carga de atrito mobilizado pelo fuste no método Randolph e Wroth. 360

$P_{t}$ : carga no topo da estaca para o método de Randolph e Wroth 134

$\mathrm{q}_{\mathrm{c}}$ : resistência de ponta do ensaio CPT 64

qL: tensão de atrito estático máxima no contato fuste-solo .58

$\mathrm{q}_{\mathrm{p}}$ : tensão de ruptura da ponta da estaca. .58

$Q_{s}$ : parcela de atrito lateral separada pelo método da Rigidez de Décourt incluindo cargas residuais 155

$\mathrm{Q}_{\mathrm{SL}}$ : valor limite inferior do atrito lateral no método da Rigidez de Décourt 155 $Q_{\text {su }}$ : valor limite superior para o atrito lateral no método da Rigidez de Décourt.....154 $Q_{u c}$ : carga de ruptura convencional pelo critério da Rigidez de Décourt 153

r: recalque obtido pelo ajuste dos critérios de ruptura

R: coeficiente de rigidez do solo da ponta para as Leis de Cambefort modificadas 103 $R$ ': coeficiente inicial de rigidez da ponta para comportamento bilinear na segunda Lei de Cambefort modificada. 166

$\mathrm{R}_{1}$ : valor de $\mathrm{R}$ para o solo da camada superior do fuste no método das Leis de Cambefort modificadas 169

$R^{2}$ : coeficiente de determinação ou explicação estatístca da regressão linear 113

$\mathrm{R}_{\mathrm{f}}$ : razão de atrito $\left(\mathrm{f}_{\mathrm{s}} / \mathrm{q}_{\mathrm{c}}\right)$ do ensaio $\mathrm{CPT}$ .78

Rig: sigla para o critério de ruptura da Rigidez de Décourt (1999). .97

$\mathrm{R}_{\mathrm{L}}$ : atrito estático máximo entre fuste e solo (resistência por atrito lateral)..... .58

$r_{0}$ : raio da estaca circular no método de Randolph e Wroth 362

$R_{P}$ : máxima carga suportada pelo solo da ponta (resistência de ponta) .58 $\mathrm{R}_{\text {reb }}$ : coeficiente de rigidez da ponta para o descarregamento na segunda Lei de Cambefort modificada 166 
S: área da seção transversal da estaca

$S_{p}$ : área da seção da ponta

t: parâmetro de deformabilidade do sistema estaca-solo na transferência de carga.....

$T(z)$ : carga transferida ao solo por atrito lateral até a profundidade z

$\mathrm{T}_{\text {máx: }}$ valor de máximo torque obtido no ensaio SPT-T..... .283

TX: sigla para o método de Teixeira (1996) .74

TZ: sigla para o critério de ruptura de Terzaghi (1943) .97

U: perímetro da seção transversal de estaca

VdV: sigla para o critério de ruptura de Van der Veen (1953 modificado por Aoki (1976))

W: peso próprio da estaca.

$\mathrm{w}_{2}$ : fator de recalque inicial de ponta.

$\mathrm{w}_{\mathrm{b}}$ : recalque da ponta no método Randolph e Wroth

$\mathrm{w}_{\mathrm{s}}$ : recalque do fuste no método Randolph e Wroth

$\mathrm{w}_{\mathrm{t}}$ : recalque no topo da estaca para o método de Randolph e Wroth

$\mathrm{x}_{\mathrm{vdv}}$ : parâmetro da curva exponencial fundamental deVan der Veen em Amann (2008a)

$y\left(P_{\circ}\right)$ : deslocamentos (recalques) em função do estágio de carga $P_{o}$ aplicado ......188

$y(z)$ : deslocamentos (recalques) da estaca em função da profundiade $z$. 173 $y\left(z, P_{0}\right)$ : deslocamentos (recalques) y como função da profunidade $z$ e do estágio de carga $P_{0}$

$\mathrm{y}_{0,1 \mathrm{D}}$ : recalque de ruptura convencional correspondente a $10 \%$ do diâmetro. 153 $\mathrm{y}_{1}$ : recalque do topo na mobilização plena do atrito no topo da estaca para as Leis de Cambefort modificadas 103 $\mathrm{y}_{11}$ : recalque de plena mobilização do atrito $\left(\mathrm{y}_{1}\right)$ na camada superior (1) de solo do fuste no método das Leis de Cambefort modificadas. 168 $\mathrm{y}_{12}$ : recalque de plena mobilização do atrito $\left(\mathrm{y}_{1}\right)$ na camada inferior (2) de solo do fuste no método das Leis de Cambefort modificadas 168 $\mathrm{y}_{1 \mathrm{r}}$ : recalque no fuste correspondente à reversão plena do atrito lateral no descarregamento para as Leis de Cambefort modificadas 166 $\mathrm{y}_{2}$ : recalque de ruptura da ponta para as Leis de Cambefort modificadas 103 $\mathrm{y}_{3}$ : recalque da ponta correspondente à mudança de rigidez para comportamento bilinear na segunda Lei de Cambefort modificada 
$\mathrm{y}_{0}$ : recalque no topo da estaca para as Leis de Cambefort modificadas 103

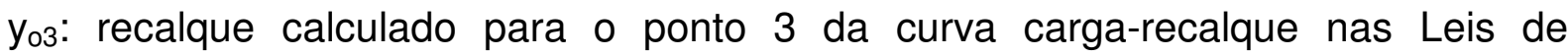
Cambefort modificadas 168

Уо34: recalques teóricos calculados para o trecho parabólico 3-4 da curva cargarecalque para as Leis de Cambefort modificadas 167 yo4: recalque do topo na mobilização plena do atrito à cota da ponta da estaca para as Leis de Cambefort modificadas 103 $y_{05}$ : recalque do topo na ruptura da ponta para as Leis de Cambefort modificadas 103 $\mathrm{y}_{\mathrm{p}}$ : recalque na ponta da estaca na análise da expressão do coeficiente $\mathrm{C}$ 381 $z$ : profundidade do elemento de estaca analisado nos métodos de transferência de carga 127

z': profundidade em que o atrito (cisalhamento) lateral atinge o valor máximo 132 $z_{c}$ : profundidade em que conhecidos os valores de deformação, carga ou cisalhamento na estaca 132

$\mathrm{z}_{\mathrm{k}}$ : raiz quadrada do coeficiente $\mathrm{k}$ de rigidez relativa solo (fuste)-estaca 142 $z_{k 1}$ : valor de $z_{k}$ para o solo da camada superior do solo do fuste nas Leis de Cambefort modificadas 169 $z_{\mathrm{k} 2}$ : valor de $z_{\mathrm{k}}$ para o solo da camada inferior do solo do fuste nas Leis de Cambefort modificadas 169

$z_{\text {kadot: }}$ raiz do coeficiente $\mathrm{k}$ adotado inicialmente para iterações. 142 $Z_{\text {kreb}}$ : raiz quadrada do coeficiente $\mathrm{k}$ no descarregamento 143

$Z_{\text {krebadot }}$ : valor de $Z_{\text {kreb }}$ adotado inicialmente para as iterações 143 $\Delta \mathrm{P}_{\mathrm{o}}$ : diferença entre a carga máxima do ensaio e as cargas do descarregamento nas provas de carga 136

$\Delta \mathrm{y}_{\mathrm{o}}$ : diferença entre $\mathrm{o}$ recalque máximo do ensaio $e$ os recalques do descarregamento nas provas de carga 136 $\alpha_{A v}$ : coeficiente de razão entre resistência de atrito e de ponta do método AokiVelloso

$\alpha_{C A}$ : coeficiente de razão entre resistência de atrito e de ponta do método David Cabral 295

$\alpha_{C V}$ : coeficiente empírico de tipo de estaca para o método P.P.C. Velloso 280 $\alpha_{D Q}$ : coeficiente empírico de tipo de estaca e solo para a ponta no método DécourtQuaresma 
$\alpha:$ coeficiente de relação entre a resistência de ponta da estaca e do ensaio CPT ...64 $\beta$ ': coeficiente de influência da ponta na transferência de carga do fuste para as Leis

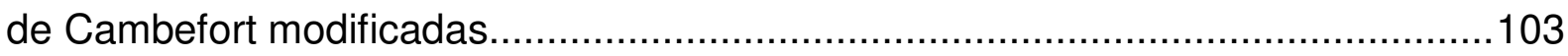
$\beta_{0}$ : coeficiente empírico de dimensão e pressão de injeção para o método David Cabral

$\beta_{1}$ : coeficiente empírico de cisalhamento lateral para o método David Cabral........295

$\beta_{2}$ : coeficiente empírico de ponta para o método David Cabral..............................295

$\beta_{31}$ : valor de $\beta_{3}$ ' para o solo da camada superior do fuste no método das Leis de Cambefort modificadas 169

$\beta_{32}$ : valor de $\beta_{3}$ ' para o solo da camada inferior do fuste no método das Leis de Cambefort modificadas 169

$\beta_{\mathrm{CV}}$ : coeficiente de dimensão da estaca para o método P.P.C.Velloso 280

$\beta_{\mathrm{DQ}}$ : coeficiente empírico de tipo de estaca e solo para o fuste no método DécourtQuaresma .71

$\beta_{3}^{\prime}$ : valor de $\beta$ ' para mobilização plena do atrito no topo da estaca. 103

$\beta$ :coeficiente de relação entre o atrito da estaca e da luva do ensaio CPT .64

$\delta_{\mathrm{b}}$ : recalque atribuído à ponta no critério de ruptura da NBR6122/96 315 $\delta$ :recalque da curva carga-recalque nos critérios de ruptura .97

$\phi_{a}:$ ângulo de atrito fuste-solo .58

$\phi$ : ângulo de atrito interno do solo .59

$\gamma_{c}$ : coeficiente de minoração da resistência do concreto 120

$\gamma_{\mathrm{f}}$ : coeficiente majorador das solicitações. 120

$\gamma_{s}$ : coeficiente de minoração da resistência do aço 120 $\gamma$ :massa específica do solo

$\lambda_{1}$ : valor de $\lambda$ para o solo da camada superior do fuste no método das Leis de Cambefort modificadas 169

$\lambda_{2}$ : valor de $\lambda$ para o solo da camada inferior do fuste no método das Leis de Cambefort modificadas 169

$\lambda_{c}$ : coeficiente de rigidez relativa entre o solo (fuste e ponta) e a estaca até a profundidade $\mathrm{z}_{\mathrm{c}}$ 131

$\lambda_{\mathrm{CV}}$ : coeficiente empírico de tipo de carregamento para o método P.P.C.Velloso ..280 $\lambda_{\text {reb }}$ : valor de $\lambda$ para o descarregamento 
$\lambda$ :coeficiente de rigidez relativa solo (fuste e ponta) - estaca para o método das Leis

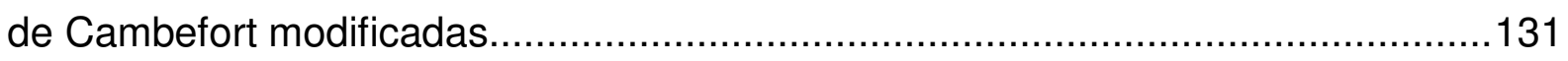

$\mu_{1}$ : coeficiente de carga residual da camada superior do solo da estaca...............137 $\mu_{1 r e b}$ : coeficiente de carga residual no descarregamento para a camada superior de solo do fuste

$\mu_{2}$ : coeficiente de carga residual da camada inferior do solo da estaca..................137 $\mu_{2 \text { reb }}$ : coeficiente de carga residual no descarregamento para a camada inferior de solo do fuste 139

$\mu$ Alr: atrito desenvolvido no ensaio de prova de carga ou atrito majorado das cargas residuais para o método das Leis de Cambefort modificadas .................................106 $\mu_{\mathrm{r}}$ : símbolo do parâmetro t no método de Randolph e Wroth ..................................129 $\mu_{\text {reb: }}$ coeficiente de carga residual para o descarregamento da curva carga-recalque..

$\mu$ :coeficiente de carga residual para as Leis de Cambefort modificadas.................103 vp: coeficiente de Poisson do solo da ponta em Amann (2008b)...........................104

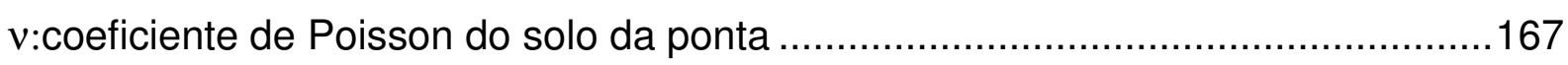

$\sigma_{\mathrm{h}}$ : tensão horizontal aplicada pelo solo no fuste ………..................................58

$\sigma_{\mathrm{v}}$ : tensão vertical de peso próprio do solo............................................................

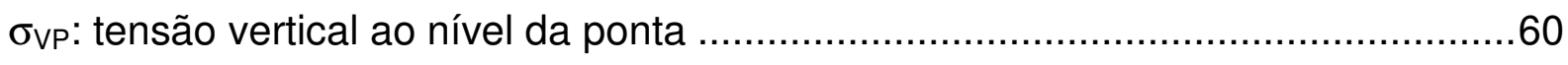
$\tau\left(P_{o}\right)$ : tensão de atrito ou cisalhamento em função do estágio de carga $P_{\circ}$ aplicado... 188 $\tau(z)$ : tensão de atrito ou cisalhamento em função da profundiade z173; tensão de

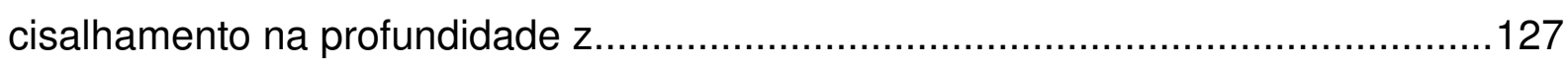
$\tau\left(z, P_{\circ}\right)$ : cisalhamento $t$ como função da profunidade $z$ e do estágio de carga $P_{0} \ldots .190$ $\tau$ :tensão de resistência ao cisalhamento nos métodos de transferência de carga..126 


\section{SUMÁRIO}

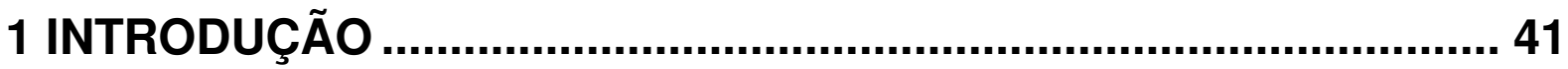

1.1 O PROJETO DE FUNDAÇÕES POR ESTACAS.................................. 42

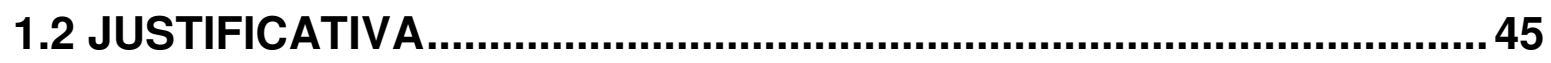

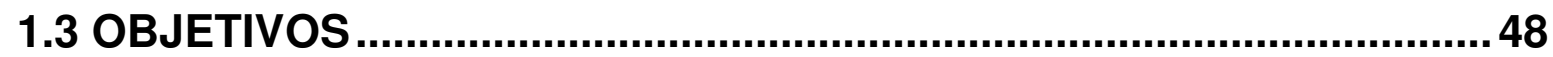

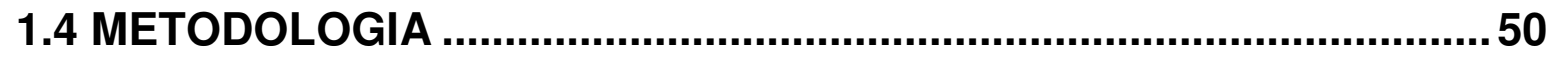

1.5 ESTRUTURA E ORGANIZAÇÃO DO TRABALHO .............................53

2 PREVISÃO DA CAPACIDADE DE CARGA ................................. 57

2.1 CAPACIDADE DE CARGA DE ESTACAS .....................................57

2.2 MÉTODOS TEÓRICOS .................................................................58

2.3 MÉTODOS EMPÍRICOS ................................................................62

2.4 MÉTODOS SEMIEMPÍRICOS ..........................................................63 63

2.4.1 A semelhança entre a estaca e o ensaio CPT ....................................64

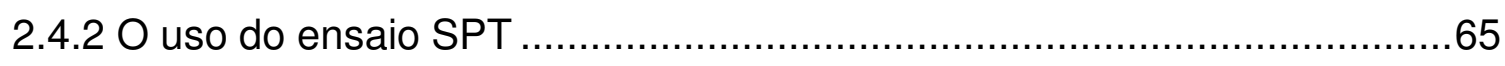

2.4.2. 10 uso dos valores de torque SPT-T e a correção da sondagem pelo $N_{\text {eq }} . . . .66$

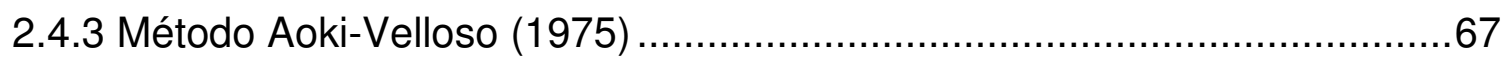

2.4.4 Método Décourt-Quaresma (1978) e Décourt (1996a).............................70

2.5 GENERALIZAÇÃO DOS MÉTODOS SEMIEMPÍRICOS (AMANN 2000)

2.6 APRESENTAÇÃO DOS MÉTODOS SEMIEMPÍRICOS ANALISADOS

2.7 CONCEITUAÇÃO DAS HIERARQUIAS DOS SOLOS (AMANN, 2000)

2.8 EXEMPLO DE APLICAÇÃO DO CONCEITO DE HIERARQUIAS DOS SOLOS E DA GENERALIZAÇÃO DOS MÉTODOS SEMIEMPÍRICOS..... 80

2.9 DISCUSSÃO DOS COEFICIENTES PARCIAIS DE INFLUÊNCIA .......82

2.9.1 Consideração do coeficiente parcial de tipo de solo $\left(\mathrm{k}_{\mathrm{ts}}\right)$. .83

2.9.2 Consideração do coeficiente parcial de tipo de ensaio de campo ou

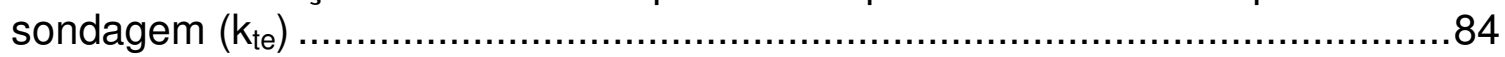

2.9.3 Consideração dos coeficientes parciais de tipo de estaca $\left(\mathrm{k}_{\mathrm{tE}}\right) \ldots \ldots \ldots \ldots \ldots . . . . .66$

2.9.4 Consideração do coeficiente parcial de dimensões ou diâmetro $\left(\mathrm{k}_{\mathrm{tD}}\right) \ldots \ldots . .87$

2.10 DISCUSSÃO DAS CONDIÇÕES DE EMBUTIMENTO DA PONTA... 88 2.11 PROPOSTA DE MÉTODOS DE TESTE PARA EXEMPLIFICAR A APLICAÇÃO DA METODOLOGIA SEMIEMPIRICA UNIFICADA (MSU).. 89 
2.11.1 Método Mediado de teste .90

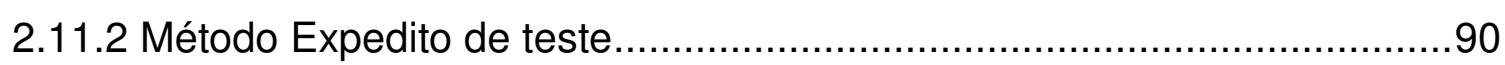

2.12 EXEMPLO DE APLICAÇÃO DOS MÉTODOS DE TESTE..................91

3 VERIFICAÇÃO DO DESEMPENHO DE ESTACAS.......................... 95

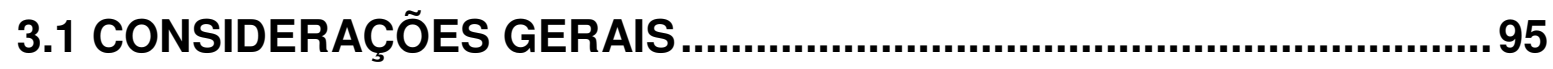

3.2 CRITÉRIOS DE RUPTURA ANALISADOS ........................................96

3.3 APLICAÇÃO DOS CRITÉRIOS A UM CASO DE OBRA .....................98

3.4 DISCUSSÃO DA FORMA DE APLICAÇÃO DOS CRITÉRIOS.............99

3.5 DISCUSSÃO DO PARADIGMA DE VERIFICAÇÃO DA APLICABILIDADE DOS MÉTODOS SEMIEMPÍRICOOS. 100

3.6 COMPARAÇÃO ENTRE OS CRITÉRIOS DE RUPTURA E OS MÉTODOS DAS LEIS DE CAMBEFORT MODIFICADAS POR MASSAD (1992) E DAS DUAS RETAS DE MASSAD E LAZO (1998) 102

3.6.1 Breve descrição do método das Leis de Cambefort modificadas por Massad (1992) e das Duas Retas (MASSAD e LAZO, 1998) .........................102

3.6.2 Discussão da comparação com os critérios de recalque limite ...............105

3.6.3 Discussão da comparação com os critérios de rigidez tangente limite e

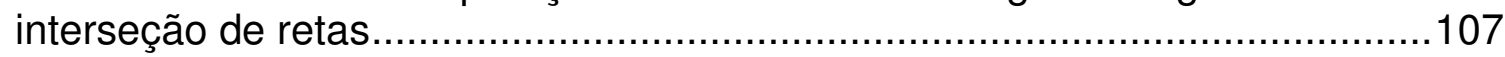

3.6.4 Discussão da comparação com os critérios de ajuste matemático ..........109

3.7 PROPOSTA DE NOVA FORMA DE CONSIDERAÇÃO DOS CRITÉRIOS DE RUPTURA

3.7.1 Exemplo de comparação entre métodos semimpíricos e critérios de ruptura.

3.7.2 Proposta de consideração dos critérios

3.7.3 Correção dos coeficientes empíricos dos métodos semiempíricos a partir

de provas de carga e dos critérios de ruptura

\section{AFERIÇÃO DA PARCELA DE ATRITO LATERAL PELOS} MÉTODOS DE TRANSFERÊNCIA DE CARGA E DA RIGIDEZ DE DÉCOURT (2008)

4.1 DEDUÇÃO GERAL DA EQUAÇÃO DIFERENCIAL DA TRANSFERÊNCIA DE CARGA DE ESTACAS AO SOLO (AMANN, 2008C)

4.1.1 Função $\tau(z)$ incógnita: solução pela Equação Diferencial Ordinária de 2ª .

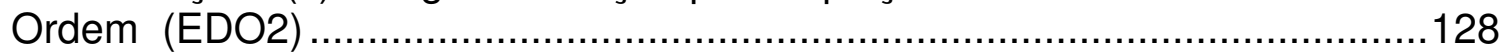

4.1.1.1 Coeficientes de Rigidez do Sistema Estaca- Solo (AMANN, 2008c)........... 130

4.1.2 Expressão Geral da Transferência de Carga de Estacas (AMANN, 2008c) 


\subsection{MÉTODO DAS LEIS DE CAMBERFORT MODIFICADAS POR}

MASSAD.

4.3 PROPOSTA PARA DETERMINAÇÃO SIMULTÂNEA DE Kr E Alr COM AJUSTE OTIMIZADO DA CURVA CARGA-RECALQUE 137

4.3.1 Análise do caso de solo heterogêneo . 139

4.3.2 Solução do sistema para a curva completa (estaca compressível). 140

4.3.3 Solução para curva com trecho 7-8 (descarregamento) pouco desenvolvido (estaca intermediária).

4.3.4 Solução para curva com trechos 7-8 e 3-4 (parabólicos) pouco desenvolvidos (estaca curta).

4.3.5 Solução para curva sem descarregamento

4.4 EXEMPLO DE APLICAÇÃO DA SOLUÇÃO DO SISTEMA A UMA ESTACA METÁLICA CRAVADA COMPRESSÍVEL (LONGA).

4.5 SEPARAÇÃO DAS PARCELAS DE ATRITO E PONTA PELO MÉTODO DA RIGIDEZ DE DÉCOURT (2008).

4.5.1 Proposta de interpretação do diagrama de Rigidez para definição dos trechos da curva no método das Leis de Cambefort modificadas.

4.6 EXEMPLO DE APLICAÇÃO DA COMPARAÇÃO ENTRE O MÉTODO DA RIGIDEZ E O MÉTODO DAS LEIS DE CAMBEFORT MODIFICADAS 160

4.7 OBTENÇÃO DOS DEMAIS PARÂMETROS DO MÉTODO DAS LEIS DE CAMBEFORT MODIFICADAS 165

4.8 PROPOSTA DE ITERAÇÃO PARA SEPARAÇÃO DA CONTRIBUIÇÃO DAS CAMADAS DE SOLO HETEROGÊNEO NO ATRITO LATERAL

5 A AFERIÇÃO DO ATRITO DAS CAMADAS POR AJUSTES POLINOMIAIS DE ENSAIOS INSTRUMENTADOS E A NOVA ABORDAGEM MATEMÁTICA DA TRANSFERÊNCIA DE CARGA.. 172

5.1 DISCUSSÃO CONCEITUAL DO PARÂMETRO B $=\tau(z) / y(z) \ldots \ldots . . . .173$

5.1.1 Formas matemáticas usuais do parâmetro $\mathrm{B}=\tau(\mathrm{z}) / \mathrm{y}(\mathrm{z}) \ldots \ldots \ldots \ldots \ldots \ldots \ldots . . .174$

5.2 APRESENTAÇÃO DA PROVA DE CARGA DE EXEMPLO ...............178 5.3 RESULTADOS DA INSTRUMENTAÇÃO E APLICAÇÃO DA FORMA DE ANÁLISE USUAL ...................................................................182

5.4 NOVA ABORDAGEM MATEMÁTICA DA TRANSFERÊNCIA DE CARGA 187

5.5 PROPOSTA DE AJUSTES POLINOMIAIS $\tau(z)$ e y(z) PARA ANÁLISE DOS DADOS DA INSTRUMENTAÇÃO 196

5.6 PROPOSTA DE AJUSTES POLINOMIAIS $\tau\left(P_{0}\right)$ e y(Po) PARA ANÁLISE DA VARIAÇÃO DE $\tau$ E y COM Po 
5.7 DETERMINAÇÃO DA EQUAÇÃO DO PARÂMETRO $B\left(P_{o}\right)=\tau\left(P_{o}\right) / y\left(P_{o}\right)$

5.8 APLICAÇÃO DA NOVA ABORDAGEM E DOS AJUSTES

POLINOMIAIS

6 PROPOSIÇÃO DA METODOLOGIA SEMIEMPÍRICA UNIFICADA PARA CORREÇÃO DOS COEFICIENTES EMPÍRICOS

6.1 PRIMEIRA ETAPA: PREVISÃO (ESTIMATIVA) DA CAPACIDADE DE CARGA

6.1.1 Exemplo de aplicação da previsão.................................................212

6.2 SEGUNDA ETAPA: VERIFICAÇÃO DO DESEMPENHO ...................214

6.2.1 Escolha do critério de ruptura adequado ao método semiempírico e ao sistema solo-estaca em estudo.

6.2.2 Escolha do critério de ruptura para correção do método semiempírico no

local em estudo

6.3 TERCEIRA ETAPA: AFERIÇÃO E CORREÇÃO DOS MÉTODOS SEMIEMPÍRICOS

6.3.1 Aferição pela separação das parcelas de atrito e ponta.

6.3.2 Aferição por ajustes polinomiais da instrumentação .222

6.3.3 Correção dos coeficientes empíricos dos métodos empregando a Hierarquia dos Solos (AMANN, 2000).....

6.3.3.1 Correção do coeficiente característico $K_{L g}$

6.3.3.2 Correção dos coeficientes característicos $K_{L g(i)}$ de cada camada pela Hierarquia dos Solos.....

6.3.3.3 Correção dos coeficientes parciais $k_{t(i)}$ dos métodos

6.4 CORREÇ̃̃O DOS MÉTODOS PARA MAIS DE UMA ESTACA ENSAIADA NO SOLO LOCAL

6.5 EXEMPLOS DE APLICAÇÃO DA METODOLOGIA SEMIEMPÍRICA UNIFICADA A ESTACAS DE DIVERSAS REGIÕES. 239

7 CONCLUSÕES E CONSIDERAÇÕES FINAIS 241

7.1 SOBRE OS OBJETIVOS ESPECÍFICOS. 242

7.2 SOBRE O OBJETIVO GERAL: A PROPOSIÇÃO DA MSU PARA CORREÇÃO DOS MÉTODOS SEMIEMPÍRICOS 248

7.3 CONSIDERAÇÕES FINAIS 250

7.4 SUGESTÕES PARA TRABALHOS FUTUROS 251 APÊNDICE A - REVISÃO BIBLIOGRÁFICA DOS EVENTOS TÉCNICO-CIENTÍFICOS DA DÉCADA (2000-2010) 274 APÊNDICE B - SOBRE A GENERALIZAÇÃO DOS MÉTODOS E AS HIERARQUIAS DOS SOLOS 


\section{B.1 VALORES DOS COEFICIENTES EMPÍRICOS DE CADA MÉTODO}

B.1.1 Valores atribuídos por outros autores 280

B.2 HIERARQUIAS DOS SOLOS (AMANN, 2002, 2004 e 2006)............. 281

B.2.1 Definição dos grupos de solos (Amann, 2000) 281

B.2.2 Valores dos coeficientes característicos de resistência e as hierarquias282 B.3 CORRELAÇÕES ENTRE OS COEFICIENTES EMPÍRICOS PARA COMPARAÇÃO DIRETA ENTRE OS DIVERSOS MÉTODOS

B.4 DISCUSSÃO DAS CONDIÇÕES DE EMBUTIMENTO DA PONTA.. 289

B.5 EXEMPLO DE APLICAÇÃO DA GENERALIZAÇÃO DOS MÉTODOS E DAS HIERARQUIAS DOS SOLOS 291

B.6 ANÁLISE DO COEFICIENTE DE TIPO DE SOLO $\left(\mathbf{k}_{\mathrm{ts}}\right)$. 294

B.7 ANÁLISE DO COEFICIENTE PARCIAL DE TIPO DE ENSAIO $\left(\mathbf{k}_{\mathrm{te}}\right) 296$ B.8 ESTIMATIVA DOS VALORES DO COEFICIENTE PARCIAL DE TIPO DE ESTACA $\left(k_{\mathrm{tE}}\right)$ 298

B.9 COEFICIENTE DE DIMENSÃO OU DIÂMETRO $\left(\mathrm{k}_{\mathrm{tD}}\right)$ 305

B.10 DISCUSSÃO SOBRE USO DA MÉDIA AO LONGO DO FUSTE OU DA SOMATÓRIA DAS CAMADAS PARA CÁLCULO DO CISALHAMENTO LATERAL (AMANN, 2000 e 2006) E PROPOSTA DO MÉTODO EXPEDITO DE TESTE 308

B.11 DISCUSSÃO ESTATÍSTICA DA VALIDADE DAS REGRESSÕES 311

B.12 GENERALIZAÇÃO DE MÉTODOS ESTATíSTICOS 312 APÊNDICE C - CONSIDERAÇÕES SOBRE OS CRITÉRIOS DE RUPTURA

C.1 ANÁLISE, DISCUSSÃO E APLICAÇÃO DOS CRITÉRIOS DE RUPTURA A UM CASO REAL...........................................................314

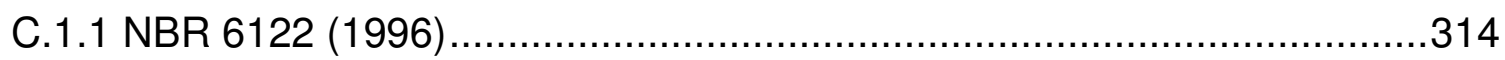

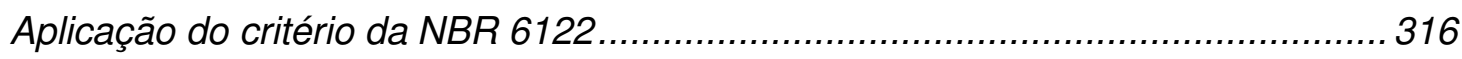

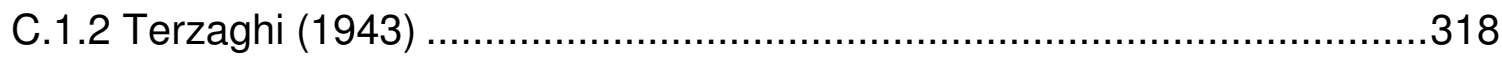

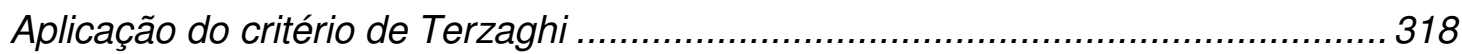

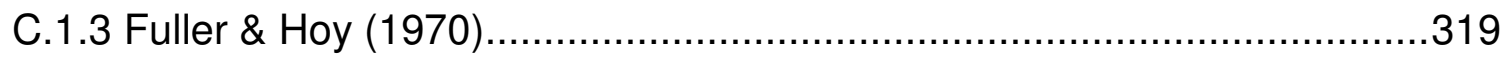

Aplicação do critério de Fuller e Hoy .................................................................. 320

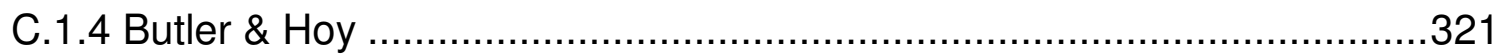

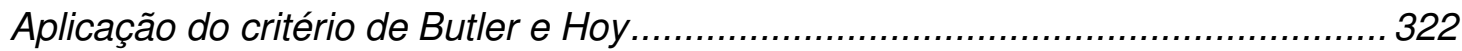

C.1.5 De Beer (1968) e De Beer \& Wallays (1972) ....................................323

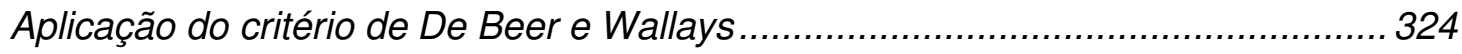

Comparação com o critério de Housel (Creep).................................................. 325 
C.1.6 Rigidez de Décourt (1999). 326

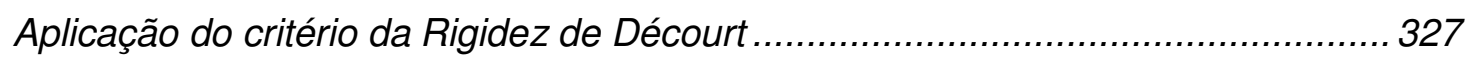

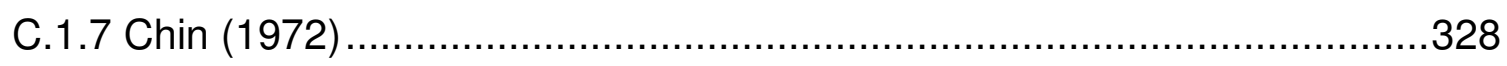

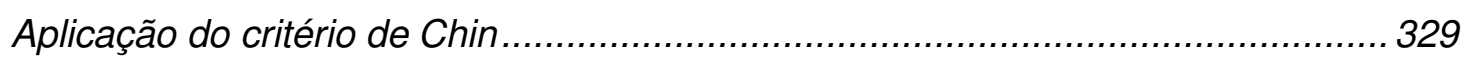

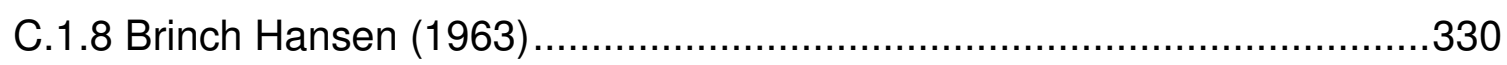

Aplicação do critério de Brinch Hansen 80\%................................................... 331

C.1.9 Van der Veen (1953) e a generalização de Aoki (1976) .........................332

Aplicação do critério de Van der Veen generalizado ............................................. 333

Comparação com o critério de Mazurkiewicz (1970) ……................................. 333

C.2 CONSIDERAÇÕES SOBRE OS CRITÉRIOS DE RUPTURA ............334

C.3 ANÁLISE CRÍTICA DOS CRITÉRIOS DE VAN DER VEEN (1953) E

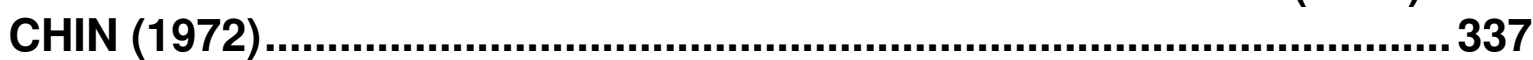

C.3.1 PARAMETRIZAÇÃO DO CRITÉRIO DE VAN DER VEEN (AMANN, 2008a). 337

C.3.2 PARAMETRIZAÇÃO DO CRITÉRIO DE CHIN (AMANN, 2008a). 340 APÊNDICE D - DEDUÇÃO DA EXPRESSÃO GERAL DE TRANSFERÊNCIA DE CARGA

D.1 A SOLUÇÃO DA EDO DE 2ª ORDEM HOMOGÊNEA COM COEFICIENTES CONSTANTES 343

D.2 SOLUÇÃO DA EDO DE 2a ORDEM NÃO-HOMOGÊNEA COM COEFICIENTES CONSTANTES 347

D.3 DEFINIÇÃO DOS COEFICIENTES DE RIGIDEZ DO SISTEMA SOLOESTACA (AMANN, 2008C). 351

D.4 EXPRESSÃO GERAL DA TRANSFERÊNCIA DE CARGA DE ESTACAS (AMANN, 2008C). 357

D.5 EXPRESSÕES DE MASSAD (1992) E RANDOLPH E WROTH (1978) A PARTIR DA EXPRESSÃO GERAL (AMANN, 2008c) 358

D.6 MODIFICAÇÃO DOS MÉTODOS COM BASE NA CORRESPONDÊNCIA ENTRE AMBOS (AMANN, 2008c) 361

D.7 COMPARAÇÃO COM O MÉTODO DE FLEMING (1992), APUD AMANN (2008c) 363

APÊNDICE E - ANÁLISE DE ENSAIOS INSTRUMENTADOS.......... 365

E.1 TABELAS DE APLICAÇÃO DA ANÁLISE USUAL .........................365

E.2 COMENTÁRIOS SOBRE AS FIGURAS TRIDIMENSIONAIS DE REPRESENTAÇÃODA RELAÇÃO t-y-z-Po 367

E.3 TABELAS DOS POLINÔMIOS AJUSTADOS AOS PONTOS DE ENSAIO 
E.4 PROPOSTA DE AJUSTES POLINOMIAIS $\tau\left(\mathbf{P}_{0}\right)$ e $\mathbf{y}\left(\mathbf{P}_{0}\right)$ PARA ANÁLISE DA VARIAÇÃO DE $\tau$ E y COM Po

E.4.1 Ajuste das cargas na ponta para o estágio de carga $P_{0}=500 \mathrm{kN}$.

E.5 PROPOSTA DE AJUSTE POLINOMIAL PARA A FUNÇÃO DE CISALHAMENTO $\tau(z)$

E.6 PROPOSTA DE AJUSTE POLINOMIAL PARA A FUNÇÃO DE DESLOCAMENTO y(z)

E.7 FÓRMULAS GERAIS PARA AS FUNÇÕES PARTINDO DO VALOR INICIAL DA PONTA DA ESTACA $(z=L)$

E.8 PROPOSTA DE AJUSTE POLINOMIAL DE SUPERFÍCIE PARA AS

EXPRESSÕES $\tau\left(z ; P_{0}\right)$ E y(z;Po) 379

E.9 DEDUÇÃO DA EXPRESSÃO DO COEFICIENTE C DE DISTRIBUIÇÃO DO ATRITO LATERAL AO LONGO DO FUSTE 380 APÊNDICE F - RESULTADOS DA APLICAÇÃO DA MSU A DIVERSOS TIPOS DE ESTACA E SOLOS 383 


\section{INTRODUÇÃO}

Os métodos semiempíricos, usados largamente no Brasil para a previsão da capacidade de carga de fundações por estacas, foram criados a partir de ensaios em solos específicos das regiões de experiência de seus autores e, sendo assim, não são universais, conforme alertam Velloso e Alonso (2000), os quais recomendam sua aplicação cautelosa e com ressalvas a solos de regiões distintas das originais. A própria norma brasileira de Projeto e Execução de Fundações NBR 6122 (1996), em revisão desde 2006 - recomenda que o método (ou processo) empírico usado seja "consagrado" pela literatura técnica e pela prática de projeto, além da demonstração de sua aplicabilidade ao solo do local da obra.

Nas últimas décadas, tal verificação de aplicabilidade tem se dado por meio de comparações das previsões semiempíricas com os critérios de ruptura aplicados às curvas carga-recalque de ensaios de prova de carga, classificando-se os métodos em "conservadores" ou "contra a segurança" e na grande maioria das vezes sem propor qualquer correção que permita sua aplicação de forma mais adequada ao solo local.

Buscando-se a otimização desse processo e a ampliação da aplicabilidade dos métodos semiempíricos, o presente trabalho propõe uma metodologia de adequação dos valores dos coeficientes empíricos aos solos de regiões não pesquisadas originalmente pelos autores dos métodos analisados. Tal metodologia inclui a aferição das previsões semiempíricas usando-se, além dos critérios de ruptura, a separação das parcelas de resistência por atrito lateral e pela ponta por meio dos métodos de análise de transferência de carga e da Rigidez de Décourt (1999). Adicionalmente, para a atribuição de valores corrigidos aos coeficientes empíricos dos métodos semiempíricos, propõe-se a aplicação do conceito de Hierarquia dos Solos, proposto por Amann (2000).

Para introduzir esse tema de ampla complexidade, este trabalho se inicia com a apresentação do processo de elaboração de um projeto de fundações por estacas, permitindo a contextualização do escopo da tese. 


\subsection{O PROJETO DE FUNDAÇÕES POR ESTACAS}

Toda a estrutura de engenharia deve transferir as cargas de peso próprio e de utilização para o solo do local em que for construída. O "elemento isolado de fundação" (CINTRA e AOKI, 1999) é a parte da estrutura que transfere carga ao maciço de solo, o qual é normalmente o elo fraco. Sendo o solo um material natural, seu comportamento e resistência apresentam grande variabilidade, o que torna o projeto de fundações peculiar como mostrado no fluxograma da Figura 1, elaborado para ilustrar o escopo do presente trabalho (notem-se os blocos sombreados), conforme as etapas de projeto comumente adotadas no Brasil.

Considerando que já se tenham as informações sobre a obra e os resultados das sondagens (ensaios de campo), elabora-se um projeto preliminar (anteprojeto) estimando-se um diâmetro e comprimento inicial, os quais são avaliados e revisados pela previsão da capacidade de carga via métodos semiempíricos, até se chegar ao valor necessário para suportar a estrutura.

Definidas as suas dimensões, executam-se as estacas da obra e uma quantidade amostral destas é ensaiada à prova de carga para verificação do seu desempenho quanto ao comportamento carga-recalque. Esses ensaios não destrutivos (nos quais se aplicam apenas 1,6 vezes a carga de trabalho da estaca - apud MARZIONNA, 2008) permitem avaliar a qualidade do estaqueamento (CINTRA e AOKI, 1999) e o fator de segurança estatístico da obra (NIYAMA et al, 1996 e AOKI, 2008) para eventuais reforços em caso de resultados insatisfatórios, porém não indicam a margem de segurança contra o estado limite de ruptura.

Embora a norma permita a extrapolação da curva carga-recalque, estabelecendo-se assim um critério de ruptura, há nisso sérias limitações como já discutido por Massad (1994) e Décourt e Niyama (1994). Portanto, não é plenamente confiável aferir-se a precisão e acurácia dos métodos semiempíricos com tais extrapolações, além não permitirem a otimização do projeto, que poderia, muitas vezes, ser mais econômico.

Destaca-se que a NBR 6122 (1996) permite reduzir o fator de segurança mediante realização de provas de carga em estacas-teste, favorecendo o ajuste e a melhoria do projeto. 


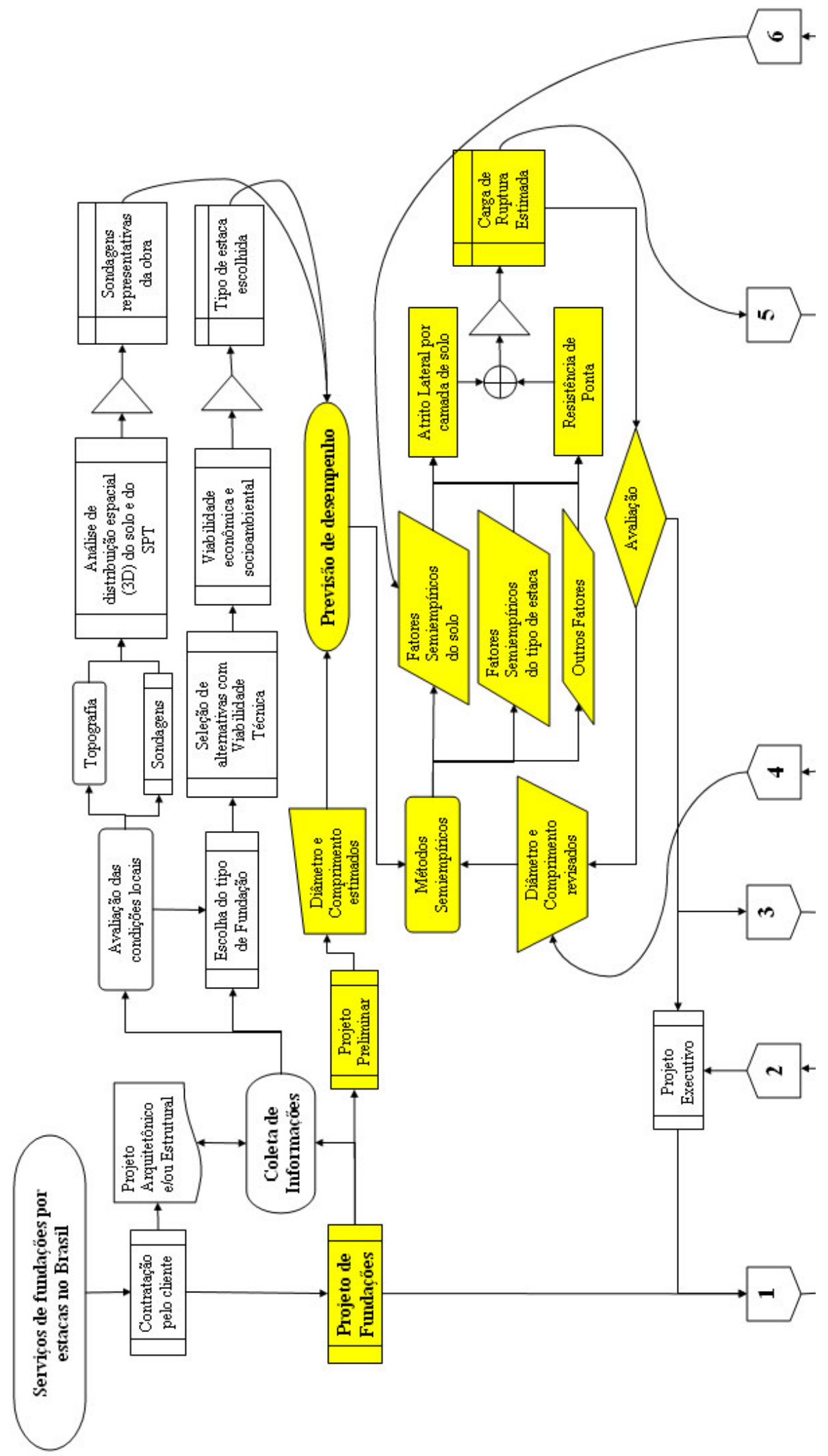

Figura 1 - Fluxograma do processo de projeto e execução de fundações por estacas (parte 1). 


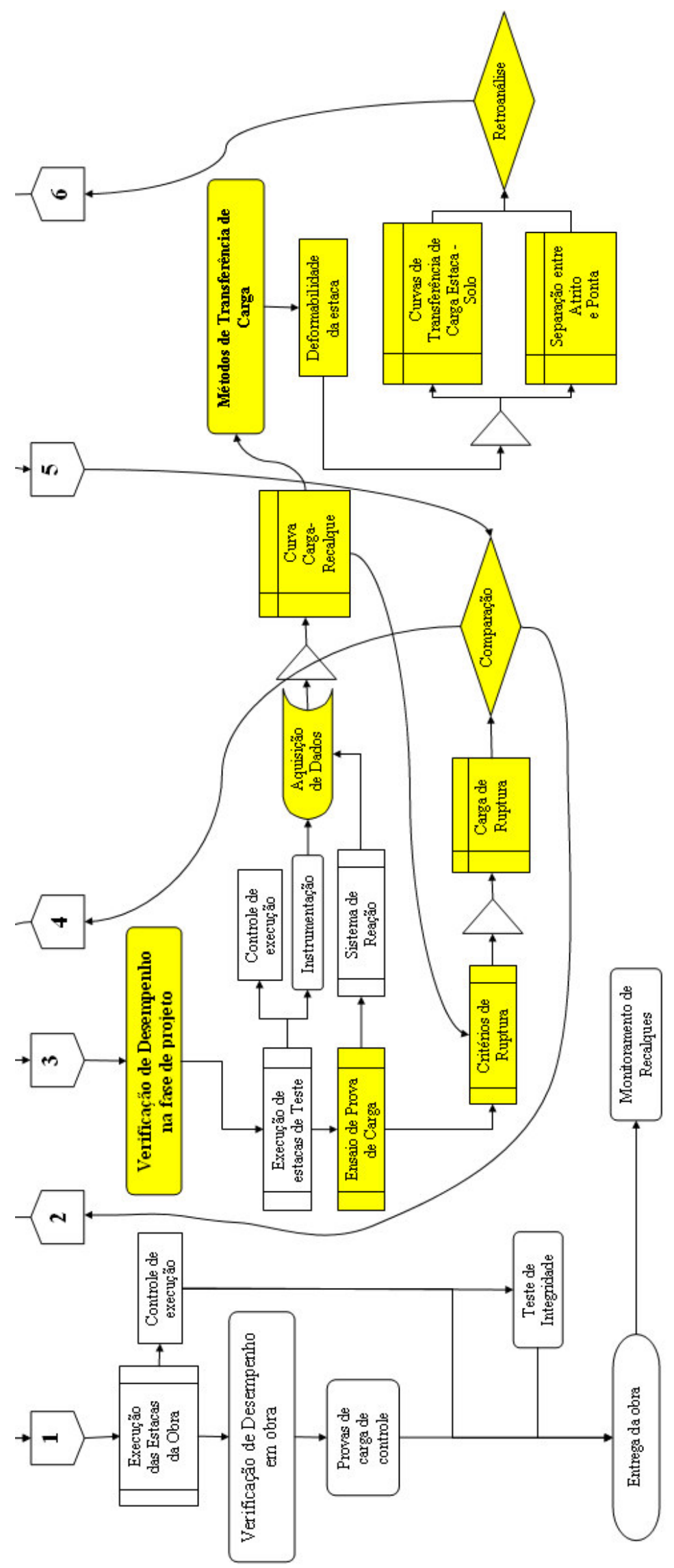

Figura 1(cont.) - Fluxograma do processo de projeto e execução de fundações por estacas (parte 2). 
Cintra e Aoki (1999) indicam que estacas-teste raramente são usadas e Aoki (2008) discute a validade dessa redução, dado que a segurança da obra não pode ser estabelecida a priori, mas somente após a verificação do desempenho das estacas amostradas, avaliando-se conjuntamente a sua probabilidade de ruína. Ainda assim, pode-se ponderar que os resultados de ruptura obtidos a partir de ensaios em estaca-teste na fase de projeto são mais adequados do que as estimativas puramente semiempíricas sem correções, sobretudo se forem executadas outras obras na mesma região que possam se favorecer desta experiência anterior.

Considerados procedimentos mais elaborados, os Métodos de Transferência de Carga têm sido empregados em artigos científicos, permitindo a separação das parcelas de carga referentes ao fuste e à ponta. Considera-se que, se aplicados a estacas-teste na fase de projeto, eles permitem realizar retroanálise e aferição das parcelas de atrito e ponta consideradas nos métodos semiempíricos e a partir disto corrigi-las, conforme a proposta aqui colocada.

Esta introdução pretendeu contextualizar o presente trabalho no panorama da metodologia brasileira de projeto. Em seguida, será apresentada a organização estrutural do trabalho, bem como seus objetivos, justificativa e metodologia.

\subsection{JUSTIFICATIVA}

O já mencionado alerta de Velloso e Alonso (2000) e a recomendação da NBR 6122 (1996), bem com a quantidade de trabalhos publicados em eventos técnicocientíficos brasileiros na última década (sobre os quais se apresenta uma tabela resumo no Apêndice $A$ ), justificam o interesse e a importância do tema aqui tratado para a engenharia brasileira.

$\mathrm{Na}$ literatura internacional, contudo, a atenção voltou-se para o estudo de estacas lateralmente carregadas, sendo poucos os trabalhos relativos à capacidade de carga de estacas axialmente carregadas no mesmo período. Essa alteração de foco internacional pode ter alguma relação com a idéia expressa numa frase de Alonso (2004, p. 22), o qual considera que "[...] este problema da previsão da capacidade de carga geotécnica de uma estaca já se encontra praticamente resolvido [...]”.

Apesar dessa consideração, quando analisados os resultados do "Concurso para previsão do comportamento de estacas raiz" (CARVALHO et. al., 2004) promovido 
por ocasião do Seminário de Fundações Especiais e Geotecnia - SEFE V (2004) -, no qual onze participantes aplicaram diversos métodos semiempíricos para duas estacas raiz ensaiadas à compressão, constata-se para a relação carga $_{\text {estimada }} /$ carga $_{\text {real }}$ uma média de 0,76, com desvio padrão de 0,25 e amplitude desde 0,45 até 1,52. Isso demonstra que, na média, se subestima a resistência em cerca de $25 \%$, o que está a favor da segurança, porém contra a economia de recursos. Deve-se considerar, contudo, que, no concurso, o objetivo não era projetar as estacas com segurança, mas sim estimar-se o melhor possível a carga de ruptura de ambas. Considerando-se tal observação, ao se analisar o intervalo de $\pm 20 \%$ da cargareal, adotado como critério de premiação, apenas 7 das 22 previsões $(31,8 \%)$, relativas aos ensaios de compressão, estavam dentro do mesmo. Assim, pode-se dizer que o problema está equacionado, mas não plenamente resolvido. É proposta do presente trabalho oferecer subsídios para que esta marca seja melhorada.

Por outro lado, Alonso (2004, p. 22) observa que pouca atenção se dá à transferência de carga e à previsão da curva carga-recalque: "[...] está na hora de nossas universidades, em seus cursos de mestrado e doutorado, se dedicarem mais profundamente a este assunto, deixando de lado, um pouco, os já inúmeros estudos dos métodos de previsão de capacidade de carga".

Fazendo uma releitura dessa observação, constata-se, pela análise das mencionadas publicações nacionais, que o meio geotécnico brasileiro tem se restringido à simples classificação dos métodos semiempíricos em "conservadores" ou "contra a segurança" quando comparados aos critérios de ruptura da curva cargarecalque. São raras as propostas de adequação dos métodos a solos de regiões específicas, constituindo-se tal forma de classificação numa espécie de paradigma. Portanto, considera-se aqui que a questão não é deixar de lado os estudos de métodos de previsão da capacidade de carga em prol dos métodos de transferência de carga, mas sim incorporar esses últimos aos primeiros e mudar o paradigma com o qual tais estudos são comumente conduzidos. Dessa forma, poder-se-iam propor correções ou modificações dos métodos semiempíricos que conduzissem a previsões mais próximas dos resultados obtidos em provas de carga.

Como exemplos de raras propostas de correção dos métodos citam-se: Albiero (1990) que propôs aplicar coeficientes globais de correção para os métodos; Amann (2000), que propôs o uso de um coeficiente de correção local (e não geral) dos 
resultados. Estas correções, porém, não correspondem a uma modificação dos métodos para o tipo de solo local, pois tratam apenas de corrigir o valor final de carga de ruptura semiempírica, sem maior aprofundamento sobre suas formas de aplicação.

Considera-se aqui que o mais indicado seria a modificação dos valores dos coeficientes empíricos dos solos e tipo de estaca, de modo que não mais se falaria em avaliação de aplicabilidade "do método", mas sim "da metodologia" de previsão da capacidade de carga de estacas com a qual o método foi criado, tendo em vista que os valores dos coeficientes do método original já não seriam os mesmos. A partir do entendimento desta metodologia, a sua aplicabilidade poderia ser determinada de forma mais adequada para o solo em estudo do que empregando diretamente o método original, que se aplica apenas a algumas regiões específicas.

Nesta linha, pode-se citar Corrêa (1988), Araújo e Wolle (2006) e Benegas (1993), apud Velloso e Lopes (2002), que propuseram, por meio de tentativas, novos valores dos coeficientes de tipo de estaca que reduzissem a dispersão dos resultados, sem contudo desenvolver uma metodologia mais elaborada e direta para este procedimento de correção.

Por outro lado, Alonso (1980), Danziger e Velloso (1986), Monteiro (2000) e Laprovitera (1988) apud Velloso e Lopes (2002) apresentaram valores dos coeficientes empíricos de tipo de solo a partir de metodologia estatística de correlação entre o ensaio de penetração de cone (CPT de Begeman) e a sondagem à percussão (SPT). Esta forma de análise, embora adequada, atende a correção da "Metodologia" Aoki-Velloso, mas não é adequada para outras metodologias que não são diretamente baseados no CPT, como, por exemplo, a do método DécourtQuaresma ou dos métodos baseados em outros ensaios de campo.

Para o caso específico do método Décourt-Quaresma, Décourt (2008) sugere o uso do conceito de SPT equivalente, obtido de ensaios SPT com determinação do torque (SPT-T), para sua aplicação em solos de outras regiões distintas da Bacia Sedimentar Terciária de São Paulo. Contudo essa metodologia corrige os valores da sondagem e não o método em si, e se tal correção for aplicada aos demais métodos semiempíricos as dispersões relativas entre eles se mantém, não sendo, portanto, uma metodologia de aplicação geral. 
Verifica-se, assim, que a metodologia de correção dos coeficientes semi-empíricos dos solos e de tipo de estaca não foi, até então, estabelecida de forma unificada, sendo em alguns casos realizada por meio de correlações entre ensaios de campo e, em outros, por tentativas até a obtenção de um melhor ajuste.

Justifica-se, assim, o objeto desta pesquisa, que se traduz justamente no estabelecimento de uma metodologia unificada e bem definida para a correção dos coeficientes empíricos de solos distintos dos originalmente estudados pelos autores dos métodos semiempíricos, permitindo a adequação de aplicabilidade de qualquer método a qualquer tipo de estaca e tipo de solo.

A partir do estabelecimento desta metodologia unificada, obter-se-á um ganho de conhecimento sobre os métodos e a possibilidade de otimização do projeto com economia de recursos e aumento da segurança.

Tendo-se, assim, justificado o trabalho, já é possível apresentar seus objetivos, como segue.

\subsection{OBJETIVOS}

O presente trabalho pretende discutir o mencionado paradigma de análise de aplicabilidade dos métodos semiempíricos possibilitando um avanço na forma como são aplicados. Assim, pode-se enunciar o que segue:

- Objetivo geral: estabelecer uma Metodologia Semiempírica Unificada (MSU) para atribuição de valores aos coeficientes dos solos nos diversos métodos semiempíricos, considerando as condicionantes ao longo do processo, tais como os ensaios de campo, ensaios de prova de carga, critérios de extrapolação da carga de ruptura e separação das parcelas de atrito e ponta, à luz do conceito de Hierarquia dos Solos, proposto por Amann (2000).

Considerando-se as condicionantes supra, cada etapa do processo será analisada e discutida conceitualmente, revelando-se uma série de objetivos específicos, elencados como seguem:

- Estabelecer a relação conceitual entre os métodos semiempíricos, os métodos teóricos e os puramente empíricos; 
- Analisar criticamente os métodos, buscando estabelecer a metodologia utilizada na criação de cada um, a fim de se chegar à proposta da Metodologia Semiempírica Unificada;

- Discutir a consideração do tipo de ensaio de campo nos métodos semiempíricos;

- Discutir o paradigma atual de análise de aplicabilidade dos métodos e propor uma nova forma de análise;

- Aproveitar a vasta experiência brasileira na aplicação de tais métodos, de modo a valorizar o conhecimento adquirido pelo meio técnico nacional;

- Determinar as relações dos critérios de ruptura da curva carga-recalque entre si e com os métodos de transferência de carga, permitindo sua melhor interpretação e aplicação, bem como a determinação do critério mais adequado a cada metodologia semiempírica;

- Deduzir, a partir da base conceitual dos métodos de transferência de carga, uma nova abordagem matemática para o problema de transferência de carga, de forma a permitir análises mais amplas, quando disponíveis ensaios de prova de carga instrumentados;

- Determinar a relação dos diversos métodos de transferência de carga entre si, bem como com o da Rigidez, propondo-se uma forma única de análise e separação das parcelas de atrito e ponta, aplicados às provas de carga nãoinstrumentadas;

- Propor nova forma de solução para o método de transferência de carga das Leis de Cambefort modificadas por Massad (1992, 1993, 1996, 2004, 2007), na sua forma mais geral, de modo a se obter, simultaneamente, os parâmetros de rigidez estrutural da estaca $(\mathrm{Kr})$ e o atrito lateral (Alr) na ruptura;

- Determinar, a partir da separação da parcela de atrito e do conceito de Hierarquia dos Solos (AMANN, 2000), valores corrigidos para os coeficientes empíricos de cada camada de solo para cada local estudado;

- Discutir as condições de embutimento da ponta da estaca e sua consideração nos diversos métodos semiempíricos; 
- Determinar os valores corrigidos dos coeficientes empíricos para os solos da ponta;

- Separar os coeficientes empíricos de tipo de estaca dos coeficientes empíricos de tipo de solo nos métodos semiempíricos;

- Propor, com a Metodologia Semiempírica Unificada, a forma de criação de novos métodos semiempíricos.

Apesar de extensa, esta lista de objetivos específicos deve ser plenamente contemplada para se alcançar o objetivo geral de forma direta e inequívoca, além de permitir um ganho de conhecimento amplo sobre a forma de aplicação mais eficiente dos diversos métodos envolvidos em cada etapa da análise.

Tendo-se apresentado os objetivos gerais e específicos, pode-se, enfim, passar ao detalhamento metodológico do trabalho.

\subsection{METODOLOGIA}

Para alcançar os objetivos elencados, respeitando-se as etapas consideradas no projeto e execução de fundações já apresentado, o desenvolvimento da metodologia de pesquisa se fará da seguinte forma:

A) Etapa de Previsão de Comportamento:

1) Análise crítica e conceitual dos métodos semiempíricos de modo a obter sua forma generalizada, a qual permite, além da comparação entre métodos desenvolvidos com metodologias distintas, obtenção dos diversos fatores de influência considerados nos métodos (de tipo de estaca, de tipo de ensaio de campo, de tipo de solo e de dimensões);

2) Conceituação e demonstração da forma de aplicação das Hierarquias dos Solos (AMANN, 2000), considerando a experiência brasileira de uso dos métodos semiempíricos para atribuição dos valores dos coeficientes empíricos de cada camada de solo e da separação entre os coeficientes de tipo de estaca e tipo de solo; 
3) Identificação das duas metodologias de consideração do atrito lateral e das três metodologias de consideração do embutimento da ponta mais empregadas pelos métodos semiempíricos, gerando seis formas distintas de previsão a serem comparadas com os critérios de ruptura da etapa de verificação de desempenho;

4) Proposta de um método semiempírico de teste para demonstração da aplicação da Metodologia Semiempírica Unificada;

B) Etapa de Verificação de Desempenho:

1) Análise crítica e conceitual dos diversos critérios de ruptura da curva carga-recalque, buscando as inter-relações entre eles, a melhor interpretação dos seus resultados e da sua forma de aplicação;

2) Comparação dos critérios com os métodos de transferência de carga, sobretudo com as Leis de Cambefort modificadas por Massad (1993), de modo a melhor compreender sua interpretação e aplicação;

3) Discussão do paradigma atual de classificação dos métodos semiempíricos em conservadores ou contra a segurança e proposta de nova forma de análise da aplicabilidade dos métodos;

C) Etapa de Aferição e Correção dos métodos semiempíricos:

1) Antes da aplicação dos métodos de transferência de carga, procede-se sua análise crítica e conceitual, a partir da dedução e proposta de uma nova abordagem matemática, considerando ainda a inter-relação entre esses métodos;

2) Com a aplicação dessa nova abordagem matemática da transferência de carga, propõe-se uma nova forma de análise de ensaios de prova de carga instrumentados;

3) Com a análise conceitual dos métodos de transferência de carga e a definição da interrelação entre eles, pode-se estabelecer uma metodologia única para a separação das parcelas de atrito e de ponta em ensaios não instrumentados, considerando ainda a interrelação destes com o método da Rigidez de Décourt (1999); 
4) Definida essa metodologia única de separação entre atrito e ponta, propõe-se, ao mesmo tempo, nova forma de obtenção simultânea dos valores de rigidez estrutural da estaca $(\mathrm{Kr})$ e do atrito lateral na ruptura (Alr) com base no método de transferência de carga das Leis de Cambefort modificadas por Massad (1992, 1993);

5) Tomando-se o método semiempírico de teste proposto na primeira etapa, faz-se um exemplo de aplicação da metodologia e determinação da parcela de atrito lateral separadamente, usando-se o conceito de Hierarquia dos Solos (AMANN, 2000) para se separar os valores dos coeficientes de tipo de estaca dos valores dos de tipo de solo, bem como os valores correspondentes a cada camada de solo individualmente;

6) Adotando-se a nova forma de análise da aplicabilidade dos métodos, conforme resultado da discussão do mencionado paradigma na etapa anterior, adota-se o critério de ruptura adequado ao caso em estudo e atribui-se o valor da parcela de ponta na ruptura; a partir daí aplica-se a Hierarquia dos Solos para determinação dos valores individuais dos solos, no trecho de embutimento da ponta;

7) Finalmente, tem-se, assim, os valores corrigidos dos coeficientes empíricos do método de teste proposto, os quais valem exclusivamente para o solo do local em estudo. Esses coeficientes corrigidos devem resultar na melhor aproximação possível do valor previsto semiempiricamente ao valor obtido pelo critério de ruptura adotado para o solo e tipo de estaca em questão.

Após todo o desenvolvimento dessas análises, a Metodologia Semiempírica Unificada pode ser enunciada e suas etapas de aplicação podem ser definidas a partir das conclusões obtidas. Partindo do exemplo de aplicação da correção ao método de teste proposto, pode-se empregar a mesma metodologia de correção a qualquer outro método semiempírico e inclusive demonstrar-se a forma de criação de novos métodos. Por fim, apresentam-se exemplos de aplicação a ensaios executados em campos experimentais e obras de diversas regiões do país. 
Importante é entender que a proposta aqui feita é a de criação de uma "Metodologia" e não de uma nova "Teoria" ou "Método", pois os valores obtidos para os coeficientes empíricos de tipo de solo não são fixados: eles variarão de acordo com o solo estudado. $O$ que se pretende é que tais valores sejam determinados por uma metodologia única e otimizada, cuja definição, enunciação e aplicação estão nos objetivos da pesquisa. Observa-se, ainda, que a Metodologia Semiempírica Unificada (MSU) não pretende substituir ou invalidar os métodos existentes; pelo contrário, valoriza a experiência brasileira à medida em que parte dos próprios métodos para o desenvolvimento da metodologia de correção proposta.

Isso posto, apresenta-se a forma de organização do presente trabalho.

\subsection{ESTRUTURA E ORGANIZAÇÃO DO TRABALHO}

Após a Introdução do Capítulo 1, a estrutura do trabalho segue de perto as etapas apresentadas no item referente à metodologia. Dada a complexidade e abrangência do tema, optou-se por apresentar em cada capítulo um item referente à Revisão Bibliográfica específica, imediatamente seguido de um item de discussão e análise conceitual, no qual são analisadas as referências sobre o tema do capítulo e apresentadas as novas propostas para seu uso e aplicação no corpo da Metodologia Semiempírica Unificada (MSU). Ao fim de cada capítulo, um item com exemplos de aplicação é apresentado para ilustração das propostas.

Considerou-se, portanto, que a opção convencional de um extenso capítulo de Revisão Bibliográfica, seguido por outro extenso capítulo de discussões e análises da bibliografia e por fim os capítulos de aplicações, análises de resultados e conclusões, tornaria 0 texto disperso e imprimiria certa dificuldade de acompanhamento do desenvolvimento do raciocínio proposto. Assim, a distribuição de temas dos capítulos se apresenta como segue.

O Capítulo 2 refere-se à etapa de Previsão de Comportamento, abordando-se os doze métodos semiempíricos mais empregados no Brasil, escolhidos a partir da revisão bibliográfica dos eventos técnico-científicos brasileiros da última década (2000-2010), resumidos no Apêndice A, que subsidia a definição do paradigma atual de análise de aplicabilidade dos métodos. Apresenta-se o conceito de Hierarquia dos Solos e também a generalização dos métodos semiempíricos, que permitirá a 
proposta da metodologia unificada. São definidas as relações desses métodos com os métodos teóricos e empíricos, bem como as metodologias de consideração do atrito e do embutimento da ponta, a serem empregadas na metodologia unificada. Dois novos métodos semiempíricos de teste são propostos para representarem os demais métodos analisados e para exemplificar a aplicação da correção dos coeficientes empíricos à luz das Hierarquias dos Solos.

O Capítulo 3 trata da etapa de Verificação de Desempenho por meio de ensaios de prova de carga analisados pelos nove critérios de ruptura mais empregados no mundo e analisados por Fellenius $(1980,2006)$. São determinadas suas interrelações e são comparados com o método de transferência de carga das Leis de Cambefort modificadas por Massad (1992, 1993, 2001), o que permite um melhor entendimento e uma melhor interpretação de seus resultados. Discute-se o paradigma atual de análise de aplicabilidade dos métodos semiempíricos e propõese a nova forma de análise para a questão, com demonstração de um exemplo de aplicação.

No Capítulo 4 iniciam-se as análises dos métodos de transferência de carga que permitirão a aferição e correção dos coeficientes empíricos dos métodos semiempíricos. Desenvolve-se então a dedução da expressão geral de transferência de carga e a análise da inter-relação entre esses diversos métodos. Propõe-se, assim, uma metodologia unificada para separação das parcelas de atrito e ponta, considerando-se a relação dos métodos de transferência de carga com o método da Rigidez de Décourt (2008). Propõe-se também nova forma de solução do método das Leis de Cambefort modificadas por Massad (1992, 1993), Massad e Lazo (1998), Marques e Massad (2004), Fonseca et al. (2007) para obtenção simultânea da rigidez da estaca e do atrito lateral que melhor ajustem os trechos da curva carga-recalque, com exemplo de aplicação.

O Capítulo 5 desenvolve primeiramente a análise da distribuição do atrito nas camadas de solo do fuste pela determinação do parâmetro "B" de transferência de carga (que define as comumente chamadas curvas "t-z"). A partir disso é desenvolvida a dedução de uma nova abordagem matemática do fenômeno do atrtio latera, que será aplicada numa, também nova, proposta de análise por ajuste polinomial dos resultados de provas de carga instrumentadas. 
No Capítulo 6, finalmente enuncia-se a Metodologia Semiempírica Unificada (MSU) de forma completa a partir das conclusões extraídas dos capítulos precedentes, que visaram determinar a forma mais eficiente de aplicação e desenvolvimento de cada etapa. Detalha-se a proposta de emprego das Hierarquias dos Solos e a da generalização dos métodos semiempíricos para determinação da distribuição do atrito entre as camadas de solo do fuste para ensaios não instrumentados. Apresentam-se exemplos de suas diversas possibilidades e de sua aplicação.

No capítulo 7 são tecidas as conclusões e considerações finais, bem como as propostas de pesquisas futuras.

Os capítulos até aqui comentados constam do volume 1 da tese, sendo que o volume 2 concentra os apêndices do trabalho, os quais apresentam os desenvolvimentos matemáticos, de raciocínio e aplicação de exemplos de forma mais detalhada, considerando que o texto deve ter certa agilidade para permitir o bom entendimento da metodologia proposta.

Assim, no Apêndice A apresentam-se comentários que subsidiam a definição do paradigma atual de análise de aplicabilidade dos métodos semiempíricos e uma tabela-resumo com os artigos consultados, pertencentes aos eventos técnicocientíficos mais significativos do cenário nacional na última década.

O Apêndice B apresenta mais detalhadamente considerações acerca das Hierarquias dos Solos, da generalização dos métodos semiempíricos, da separação dos coeficientes de tipo de estaca do tipo de solo e da atribuição de valores dos coeficientes parciais de tipo de solo para cada camada.

No Apêndice C apresentam-se alguns exemplos de aplicação e detalhes da comparação entre os critérios de ruptura, o método da Rigidez e as Leis de Cambefort modificadas por Massad (1992, 1993) e Massad e Lazo (1998).

No Apêndice D são detalhadas as deduções da expressão geral e da nova abordagem matemática da transferência de carga aqui proposta, bem como a interrelação entre os métodos concernentes, demonstrando a possibilidade de aplicação de apenas um dos métodos na separação das parcelas de atrito e ponta.

O Apêndice E apresenta as tabelas dos resultados de aplicação da forma usual e da nova proposta de análise das provas de carga instrumentadas, de forma a detalhar os valores empregados na confecção dos gráficos do Capítulo 5. Apresenta ainda 
detalhes da obtenção da expressão do parâmetro matemático "B" de transferência de carga e dos polinômios aqui utilizados para ajuste dos dados de instrumentação, conforme a nova forma de análise de ensaios instrumentados proposta.

O Apêndice $F$ apresenta a aplicação da Metodologia Semiempírica Unificada, enunciada no Capítulo 6, a estacas ensaiadas em diversas regiões e tipos de solo do país, para demonstrar sua aplicabilidade praticamente irrestrita.

Enfim, a expectativa é que a presente tese seja um instrumento útil e de referência para projetistas e pesquisadores da área de fundações por estacas, permitindo o avanço da pesquisa em fundações do ponto de vista científico aliado à prática, com economia de recursos obtida pela otimização do projeto. 


\section{PREVISÃO DA CAPACIDADE DE CARGA}

Aborda-se aqui a etapa de Previsão de Comportamento, apresentando-se os doze métodos semiempíricos mais empregados no Brasil a serem analisados, bem como a generalização destes métodos e o conceito de Hierarquia dos Solos que abrem caminho para a unificação pretendida. Conceituam-se ainda os métodos teóricos e empíricos e sua relação com os semiempíricos, determinando-se e discutindo-se suas metodologias de consideração do atrito e de embutimento da ponta. Ao final propõe-se dois métodos semiempíricos de teste, que servirão como exemplo de aplicação da correção proposta, à luz das Hierarquias dos Solos.

É importante mencionar que aqui se considera o emprego do termo "estimativa" mais adequado do que "previsão" da capacidade de carga (que se tornou de uso corrente), pois esse último estaria mais ligado a um evento, como por exemplo a ocorrência ou não de ruptura, do que com a determinação do valor de carga com que, probabilisticamente, se dá este evento. Assim sendo, o termo "estimativa" passará a ser empregado quando referir-se à determinação de valores de capacidade de carga e o termo "previsão", quando referir-se à ocorrência do evento de ruptura.

\subsection{CAPACIDADE DE CARGA DE ESTACAS}

Para se projetar uma fundação, deve-se verificar se a estrutura suporta as deformações (recalques) na sua condição de trabalho (estado limite de utilização, definido pela estrutura), bem como verificar a adequação do fator de segurança da carga admissível adotada em relação à sua ruptura geotécnica (estado limite último definido pelo solo, apud HACHICH et al, 1996). Como observado por Alonso (2004) no capítulo anterior, a estimativa de recalques não é o método de projeto mais empregado no Brasil. Isso leva à exigência de se estimar do melhor modo possível a condição de estado limite último, para que se possa estabelecer a carga admissível para a fundação, a partir da adoção de fatores de segurança ponderados (minoração das resistências e majoração dos esforços) que conduzam a uma condição de trabalho aceitável para a estrutura. 
Com relação a esta condição de estado limite último, emprega-se aqui o termo "capacidade de carga" na sua forma generalista (CINTRA e AOKI,1999), discriminando-se, quando for o caso, a condição de "ruptura convencional" (carga limite para um recalque limite arbitrado, apud NIYAMA et al., 1996), sendo que a omissão desta referência remete ao conceito de ruptura física (carga última, conforme CINTRA,1998 apud CINTRA e AOKI,1999).

Os métodos utilizados para determinação desta capacidade de carga podem ser teóricos, empíricos ou semiempíricos e a interrelação entre eles é fundamental para que se interprete melhor estes últimos, objetos centrais dessa pesquisa.

\subsection{MÉTODOS TEÓRICOS}

Um método teórico pode ser definido como aquele que se origina exclusivamente do intelecto humano quando se propõe a investigar um fenômeno observado e avaliar quais as variáveis a serem consideradas na sua explicação (NIELSEN NETO, 1991). No caso de uma estaca, raciocina-se que o equilíbrio de forças que a estabilizam quando submetida a uma carga axial $(P)$ se estabelece pela ação do atrito desenvolvido entre o fuste e o solo $\left(P_{\mathrm{L}}\right)$, adicionada da reação de apoio oferecida pelo solo da ponta $\left(P_{P}\right)$, sendo o comportamento de cada uma destas parcelas bastante distinto. Assim, a carga de ruptura física $\left(P_{R}\right)$ se dá quando atingida a máxima capacidade portante do solo da ponta $\left(R_{P}\right)$, após ter-se alcançado o máximo atrito estático entre fuste e solo $\left(\mathrm{R}_{\mathrm{L}}\right)$. Essas duas parcelas podem ser definidas como tensões atuantes nas respectivas superfícies, ficando a expressão matemática da capacidade de carga da estaca definida pela soma do produto das tensões máximas de atrito $\left(q_{L}\right)$ e ponta $\left(q_{p}\right)$ pelas respectivas áreas superficiais do fuste $\left(A_{L}\right)$ e da ponta $\left(A_{P}\right)$ :

$$
P_{R}=R_{L}+R_{P}=q_{L} \cdot A_{L}+q_{P} \cdot A_{P}
$$

O modelo de ruptura geralmente adotado para o solo do fuste é o de Mohr-Coulomb, representado na Figura 2, no qual a tensão de atrito máxima $\left(q_{\mathrm{L}}\right)$ no contato entre fuste e solo depende do ângulo de atrito fuste-solo $\left(\phi_{a}\right)$, da adesão inicial entre fuste e solo ( $\left.\mathrm{C}_{\mathrm{a}}\right)$ e da tensão horizontal (ou normal) aplicada pelo solo no fuste $\left(\sigma_{\mathrm{h}}\right)$, a qual se relaciona com a tensão vertical $\left(\sigma_{\mathrm{v}}\right)$ através do coeficiente de empuxo lateral $\left(\mathrm{K}_{\mathrm{s}}\right)$. 
Sendo a tensão vertical efetiva variável ao longo da profundidade devido ao peso próprio do solo, o atrito lateral também deve acompanhar tal variação. Em solos sedimentares homogêneos essa variação pode ser linearmente crescente, contudo, em solos residuais, outros efeitos podem modificar essa condição. Kézdi (1964) discute a influência da instalação da estaca e do coeficiente $K_{s}$ nessa variação. Em areias, por exemplo, Aoki e Cintra (1999) citam Moretto (1972) para o qual, por efeito de arqueamento, o atrito máximo atinge um valor limite a uma profundidade média de 15 diâmetros, mantendo-se constante no restante do comprimento da estaca. Desta forma, dependendo das características do solo, alguns autores tratam 0 problema em termos de tensões efetivas (o chamado método $\beta$ : $\beta=q_{L} / \sigma_{v}$ ) ou em função da coesão (método $\alpha: \alpha=q_{\llcorner} / c$ ).

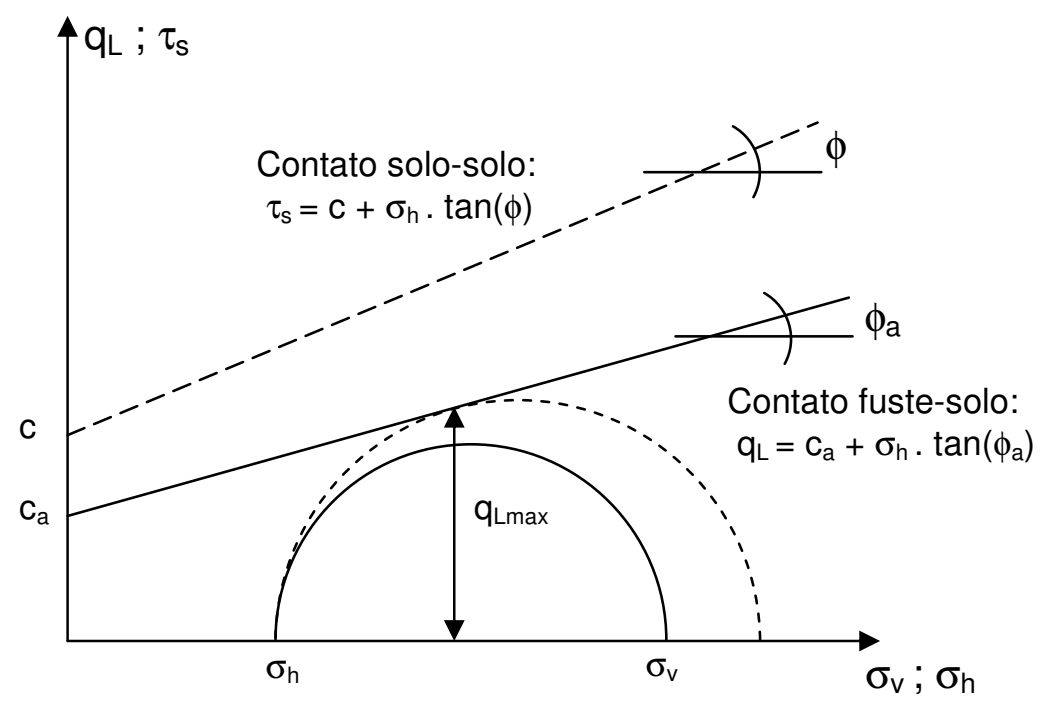

Figura 2 - Modelo (ou critério) de Mohr-Coulomb para ruptura do solo do fuste por atrito lateral (adaptado de KEZDI, 1964)

É interessante observar na Figura 2 que o solo apresenta uma condição de ruptura própria, ocasionada por efeito de cisalhamento no contato entre suas partículas (ângulo de atrito $\phi$ e coesão c), que na figura é representada como sendo maior do que a do contato fuste-solo, o que nem sempre ocorre. Fleming et al. (1992) apontam que dada a rugosidade do fuste de estacas escavadas é mais coerente assumir-se que a ruptura se dê no solo ao redor da estaca do que na sua interface.

Discute-se, portanto, que embora o termo "ruptura por atrito lateral" esteja consagrado no meio técnico, não se deve entender o fenômeno de ruptura do solo do fuste simplesmente como o deslizamento entre estaca e solo (ruptura física por 
atrito). Isso pode ocorrer junto ao topo de estacas cravadas, em solos não-coesivos para um nível de deslocamento (recalque) elevado, raramente alcançado em ensaios de prova de carga, mas não necessariamente nos demais casos correntes.

Diante disso, sugere-se aqui o uso do termo "cisalhamento lateral" (genericamente aplicado ao cisalhamento do solo ao redor da estaca ou no contato fuste-solo), em substituição ao termo "atrito lateral", quando ele se referir à ruptura do solo do fuste, mantendo-se o termo "atrito lateral" quando for relativo à forma de transferência de carga da estaca para o solo ao longo do fuste. Atende-se, dessa maneira, à tradição da engenharia de fundações usando o significado da palavra adequado ao fenômeno observado.

Para a ponta, a ruptura (plastificação) se dá no solo abaixo dela, que, excessivamente comprimido, desloca-se em direção à superfície. Esse modelo da Teoria da Plasticidade foi aplicado por Prandtl (1920) na punção de metais e adaptado por Terzaghi (1943) para o caso de fundações apoiadas no solo (apud VELLOSO e LOPES, 2004). A tensão de ponta na ruptura $\left(q_{p}\right)$ é então expressa por:

$$
q_{p}=c \cdot N_{C}+\sigma_{v p} \cdot N_{q}+0,5 \cdot \gamma \cdot D \cdot N_{\gamma}
$$

onde:

$$
\begin{array}{ll}
\sigma_{\mathrm{VP}} & : \text { tensão vertical do solo ao nível da ponta; } \\
\gamma & : \text { massa específica do solo; } \\
\mathrm{N}_{\mathrm{c}}, \mathrm{N}_{\mathrm{q}}, \mathrm{N}_{\gamma} & : \text { fatores de capacidade de carga; } \\
\mathrm{D} & \text { : diâmetro ou menor dimensão da ponta da estaca. }
\end{array}
$$

Valores de $N_{c}, N_{q}$ e $N_{\gamma}$ e outras contribuições ao estudo de capacidade de carga da ponta foram propostos por diversos autores entre os quais se pode citar entre outros Meyerhof (1951, 1956, 1976), Berezantzev et al.(1961), Vésic (1972), conforme apresentado na Figura 3. Os parâmetros do solo (c, $\delta$ e $\gamma$ ) a serem empregados devem observar sempre o tipo de solo (argilas ou areias) e suas condições, drenada ou não-drenada, devendo, preferencialmente, ser obtidos por ensaios de laboratório. Portanto a expressão teórica completa da capacidade de carga de estacas pode ser escrita como apresentam Poulos e Davis (1980): 


$$
P_{R}=U \cdot \int_{0}^{L}\left(C_{a}+K s \cdot \sigma_{V} \cdot \tan \phi_{a}\right) \cdot d z+A P \cdot\left(c \cdot N_{C}+\sigma_{V P} \cdot N_{q}+0,5 \cdot \gamma \cdot D \cdot N_{\gamma}\right)-W
$$

sendo:

$$
\begin{array}{ll}
\text { U } & \text { : perímetro da estaca; } \\
\text { L } & \text { : comprimento da estaca; } \\
\text { W } & \text { : peso próprio da estaca. }
\end{array}
$$

Ao se desconsiderar a sobrepressão ao nível da ponta em análises não-drenadas, pode-se também desprezar o peso próprio (W) da estaca no cálculo da carga de ruptura (apud POULOS e DAVIS, 1980, e COYLE e REESE, 1966).

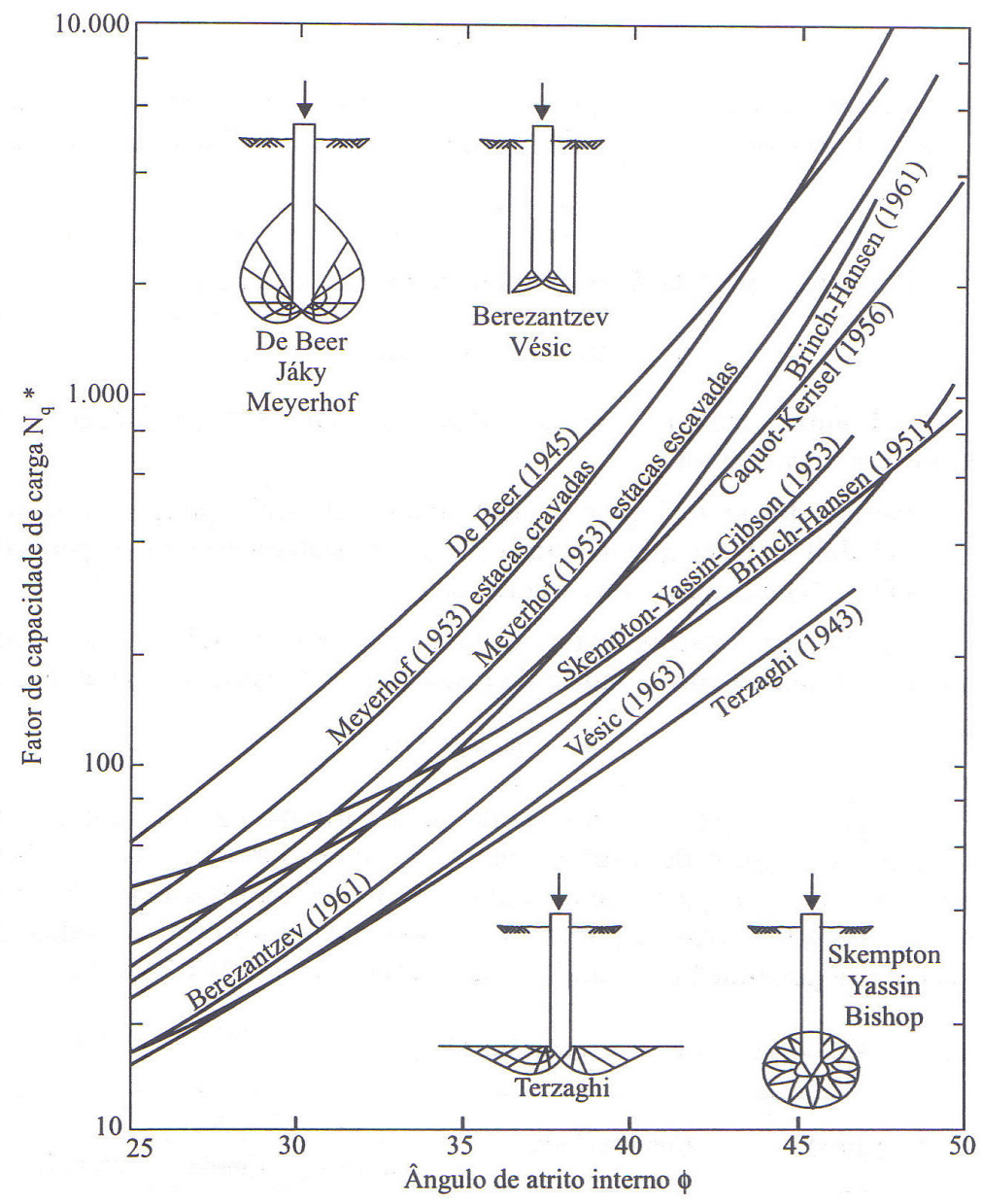

Figura 3 - Variação do fator de capacidade de carga $N_{q}$ conforme as considerações dos diversos autores (apud Vésic, 1967, citado por CINTRA e AOKI, 1999) .

Essa formulação teórica ainda hoje é objeto de análise de pesquisadores (FLEMING et al., 1992) que buscam melhorar a forma de estimativa do ângulo de atrito a ser utilizado. Pode-se exemplificar (sem mais detalhes, visto não ser escopo desta 
pesquisa) com os trabalhos de Nguyen e Hanna (2003), Yang e Mu (2008) e O'Kelly e Gavin (2007), que podem ser obtidas junto ao "Journal of American Society of Civil Engineers" (ASCE) e à Revista Geothecnique.

Décourt (1996a) critica esse método teórico baseado na Teoria da Plasticidade, exemplificando que, para uma variação de $30^{\circ}$ para $35^{\circ}$ no ângulo de atrito, a capacidade de carga pode aumentar em $100 \%$, além de o fator $\mathrm{N}_{\mathrm{q}}$ apresentar uma variação de 5 a 10 vezes para o seu valor máximo, como se observa na Figura 3.

Devido à necessidade de ensaios de laboratório e às dificuldades de se trabalhar com as incertezas dessas formulações, no Brasil adotou-se o uso de correlações empíricas com ensaios de campo - sondagens SPT (principalmente) e CPT (complementarmente) - como meio mais prático de se estimar as resistências de cisalhamento lateral e de ponta. Ainda assim, tais formulações teóricas influenciaram as metodologias semiempíricas, como se discutirá mais adiante.

\subsection{MÉTODOS EMPÍRICOS}

Um método puramente empírico é aquele que não busca qualquer raciocínio intelectual prévio, mas privilegia a observação do fenômeno para dela extrair informações que permitirão executar novos experimentos, controladamente modificados para a constatação e enumeração das variáveis que o influenciam (NIELSEN NETO, 1991).

Esse tipo de metodologia empírica foi muito utilizado em estudos de cravabilidade, como, por exemplo, as fórmulas usadas nas empresas Franki, Christiani-Nielsen e Scac (VELLOSO e LOPES, 2002), pois, para estacas cravadas, já no processo de instalação se pode avaliar a resistência do solo à penetração pela variação da altura de queda, peso do martelo, etc. Esses métodos também são comumente chamados de "fórmulas dinâmicas", justamente pelo uso da análise das condições de cravação. Até o ano de 1975, era muito conhecido o critério de definição de comprimento de estacas cravadas pela somatória do SPT igual a 30 golpes (TEIXEIRA, 2000).

Outro exemplo é apresentado por Mello (1975), segundo o qual o comprimento é definido pela somatória do SPT igual a 15 vezes a tensão de trabalho (MPa) do concreto da estaca. 
Um exemplo de método empírico para estabelecimento da nega de cravação é obtido a partir das recomendações de Vargas (1979, p 35):

$$
\begin{aligned}
& \text { O IPT [Instituto de Pesquisas Tecnológicas] de São Paulo tem } \\
& \text { observado que a penetração dos tubos das estacas Franki, com } 40 \\
& \text { a } 50 \mathrm{~cm} \text { de diâmetro, é de uns poucos milímetros por golpe, de } \\
& \text { martelo de } 2 \text { a } 3 \text { t [toneladas], caindo de } 1 \mathrm{~m} \text { de altura, nas camadas } \\
& \text { de resistência à penetração [do amostrador] IPT da ordem de } 15 \\
& \text { golpes } / 30 \mathrm{~cm} \text {. O mesmo acontece com as estacas pré-moldadas de } \\
& \text { concreto, com } 500 \text { a } 1.000 \mathrm{~cm}^{2} \text { de secção nas camadas de } \\
& \text { resistência à penetração IPT de } 10 \text { a } 15 \text { golpes/30cm. [...] } \\
& \text { Evidentemente [...] em camadas de resistência a penetração } \\
& \text { maiores do que 25, a cravação é quase impossível. }
\end{aligned}
$$

Para estacas escavadas, contudo, considerando os custos elevados envolvidos na execução de ensaios de prova de carga em verdadeira grandeza e a grande variabilidade da resistência dos solos em comparação às suas propriedades físicas, o procedimento puramente empírico torna-se praticamente inviável. Algumas adaptações com base nas estacas cravadas podem eventualmente ser feitas, como a indicação de Mello (1975) do valor de 4,0 MPa de tensão do concreto de estacas Strauss contra 5,0 MPa para as pré-moldadas. Atualmente, o uso de ensaios de prova de carga dinâmica permite reduzir tais custos, porém, não se trata de um método propriamente empírico, visto que suas análises são baseadas nas formulações de propagação de ondas.

\subsection{MÉTODOS SEMIEMPÍRICOS}

Diante das dificuldades de aplicação dos métodos puramente teóricos e dos puramente empíricos expostas anteriormente, a engenharia de fundações recorre frequentemente ao uso de métodos intermediários, ou seja, os chamados semiempíricos, que alguns autores denominam por "fórmulas estáticas" devido ao fato de se basearem na análise do equilíbrio de forças (teoria da estática) e por contraposição às chamadas "fórmulas dinâmicas". Os métodos semiempíricos podem ser definidos como os que partem das formulações teóricas já apresentadas complementando-as com o estabelecimento das tensões máximas de atrito e ponta obtidas a partir de correlações empíricas com ensaios de campo (que eliminam a influência das variáveis relativas à retirada e transporte de amostras do solo ao 
laboratório, entre outras). Assim, os ensaios de campo, ou sondagens, são parte essencial dos métodos semiempíricos e serão comentados adiante.

A partir dessa definição, são apresentados alguns aspectos conceituais dos métodos semiempíricos de forma geral (correlações com as sondagens, aspectos teóricos considerados, etc.), destacando-se, em seguida, os doze métodos mais utilizados no Brasil e que serão analisados na sequência.

\subsubsection{A semelhança entre a estaca e o ensaio CPT}

Dos ensaios de campo, o de penetração estática de cone (NBR 12069), ou CPT, com sua ponteira e luva de atrito (tipo Begemann), é considerado o que mais se aproxima do comportamento de uma estaca penetrando estaticamente no solo (VÉSIC, 1963, 1965, apud VELLOSO e LOPES, 2002). A semelhança física entre o modelo (cone) e o protótipo (estaca) foi analisada por Weber (1971), apud Velloso e Lopes (2002), entre outros. Dessa análise, verificaram-se diversos efeitos a serem considerados na transposição dos valores obtidos desse ensaio para a estaca, em geral equacionados como uma série de coeficientes multiplicativos.

Albiero (1990) comenta que nos anais do European Symposium On Penetration Tests - ESOPT I (1978) - apresentou-se um levantamento mundial das expressões empíricas para estimativa da carga admissível de estacas com base em resultados de resistência de ponta $\left(q_{c}\right)$ dos ensaios CPT, dentre elas: Tassos e Agnostopoulos (1978), Desan et al. (1978), Senneset (1970), Rodin et al. (1970) e o método Philliponnat et al (1978), conhecido como Soletanche, muito usado no Brasil, todos apud Albiero (1990). Essas diferentes expressões matemáticas foram colocadas numa forma genérica para permitir a comparação entre si, como se observa na expressão (4), apresentada por Albiero (1990):

$$
P_{a d m}=\frac{\beta \cdot \overline{q_{c}} \cdot A_{L}}{F S_{L}}+\frac{\alpha \cdot \overline{q_{c P}} \cdot A_{P}}{F S_{P}}
$$

Nessa expressão identificam-se: o coeficiente que correlaciona o cisalhamento (atrito) lateral $(\beta)$ da luva de atrito do cone com o do fuste da estaca; o mesmo para a ponta $(\alpha)$, bem como os fatores de segurança parciais respectivamente em cada 
caso, $F S_{L}$ e $F S_{P}$, e o uso de valores médios de $q_{c}\left(\overline{q_{c}}\right)$ ao longo do fuste e na região de embutimento da ponta $\left(\overline{q_{\mathrm{cP}}}\right)$.

Albiero (1990) considera que os coeficientes $\alpha$ e $\beta$ incorporam intrinsecamente outros coeficientes aqui chamados de "parciais" que levam em conta a influência: a) do tipo de solo (aqui simbolizado por $\mathrm{k}_{\mathrm{ts}}$ ); b) do tipo de estaca (aqui, $\mathrm{k}_{\mathrm{tE}}$ ); c) das dimensões da estaca $\left(\mathrm{k}_{\mathrm{tD}}\right)$. Poucos métodos separam a influência do tipo de estaca da influência do tipo de solo, considerando em geral a ponta das estacas escavadas em torno de $40 \%$ do valor obtido para as cravadas. Mais detalhes sobre estes coeficientes parciais e como eles se incorporam à metodologia proposta serão discutidos mais adiante.

\subsubsection{O uso do ensaio SPT}

No Brasil, o ensaio de campo mais utilizado é o SPT (Standard Penetration Test) ou Sondagem de Simples Reconhecimento, regido pela norma NBR 6484 (Décourt 1996a). Ele é considerado por uma série de autores internacionais como de finalidade exclusiva para reconhecimento do perfil do solo mediante a amostragem para fins de caracterização tátil-visual e cujos resultados se prestam unicamente à classificação de consistência ou compacidade do solo. Já o CPT, como anteriormente comentado, é o que de fato se considera apropriado para indicar a resistência do solo solicitado pelas ações da estaca.

De qualquer forma, diversos autores propuseram correlações entre os resultados desses dois ensaios, demonstrando que o SPT também pode ser um indicador da resistência esperada para o solo, embora com maior dispersão. Isso permitiu o desenvolvimento de métodos semiempíricos com base no SPT ou ainda adaptações dos métodos com base no CPT, bastando para isso incluir na sua formulação um coeficiente parcial de tipo de ensaio, aqui simbolizado por $\mathrm{k}_{\mathrm{te}}$.

Os primeiros métodos brasileiros publicados com uso do SPT foram os de AokiVelloso (1975) e Décourt-Quaresma (1978), sendo o último mais difundido a partir do ano de 1982. Esses dois métodos serão apresentados detalhadamente, enquanto os demais serão expostos resumidamente na forma generalizada proposta por Amann (2000). 
Antes, porém, convém neste item apresentar uma variação do ensaios SPT, o SPT$\mathrm{T}$, com medida de torque, e suas potencialidades.

\subsubsection{O uso dos valores de torque SPT-T e a correção da sondagem pelo $N_{\text {eq }}$}

A inclusão de medidas de torque no ensaio SPT foi sugerida por Ranzini (1988) ao observar que os operadores do ensaio realizavam um movimento de rotação nas hastes para descolar o amostrador aderido ao solo e facilitar sua extração ao término da cravação.

Com este ensaio, Décourt (1993) sugeriu o chamado índice de torque (T/N), ou seja, a relação entre o torque medido e o SPT, como um classificador da estrutura dos solos. Este índice permitiria aplicar correlações com o SPT, obtidas num solo particular, a solos de outros locais, através do conceito de SPT equivalente $\left(\mathrm{N}_{\text {eq }}\right)$. Assim, conhecendo-se o índice de torque dos solos de São Paulo (BSTSP-Bacia Sedimentar Terciária da cidade de São Paulo), cujo valor é da ordem de 1,2, podese calcular para outro solo qualquer o seu valor $\mathrm{N}_{\text {eq }}=\mathrm{T} / 1,2$, permitindo então a aplicação das inúmeras correlações já pesquisadas para São Paulo. Sendo uma proposta bastante prática e que tem se demonstrado pertinente a um grande número de casos, poder-se-ia considerar que o problema de aplicação dos métodos semiempíricos a outros solos distintos dos originais estaria resolvido com a correção da sondagem pelo $\mathrm{N}_{\text {eq. }}$

De fato, se o interesse é a obtenção de um resultado comparativo para aplicação em projeto, do ponto de vista empírico, pode-se dizer que o procedimento atende bem. Contudo, ao se considerar que, após corrigidas as sondagens pelo valor do índice de torque constante de 1,2, as diferenças relativas entre os diversos métodos continuam as mesmas, pode-se dizer que ele não é uma forma de correção global para os demais métodos semiempíricos. Nesse sentido, não atende à proposta de metodologia unificada aqui pesquisada.

Ainda assim, esse ensaio apresenta boas perspectivas de aplicação à estimativa de capacidade de carga, sendo que Alonso (1994) apresentou comparações diretas entre as medidas de torque e do atrito lateral de estacas, desenvolvendo 
posteriormente um método semiempírico para estacas Hélice-Contínua (ALONSO, 1996) com seus resultados.

\subsubsection{Método Aoki-Velloso (1975)}

Aoki (2007) revelou que elaborou juntamente com o engenheiro Dirceu Velloso este método a partir de sua prática com os métodos empíricos utilizados na empresa Franki S.A (na década de 1960) que empregavam a somatória de golpes do SPT para definir a cota de parada da ponta de estacas tipo Franki.

Aoki e Velloso (1975) basearam seu método nos ensaios de penetração estática de cone (CPT) com luva de atrito (de Begemann). Assim, para determinar o atrito lateral, ou, como aqui se prefere chamar, o cisalhamento lateral de ruptura, esse método utiliza a razão de atrito ( $\left.\alpha_{\mathrm{AV}}\right)$ existente entre a resistência por atrito lateral local da luva de atrito $\left(f_{s}\right)$ e a resistência de ponta $\left(q_{c}\right)$, relação esta que assume um determinado valor médio para cada tipo de solo.

Para permitir o uso com o ensaio SPT, estes autores estabeleceram uma correlação linear passando pela origem entre os ensaios SPT e CPT para cada tipo de solo. Com isso pode-se estimar o valor da resistência de ponta do cone, multiplicando-se os resultados (N) do SPT por este coeficiente empírico de tipo de ensaio denominado $\mathrm{K}_{\mathrm{AV}}$, o qual também apresenta diferentes valores para cada tipo de solo. Assim, esse método depende, em grande escala, da precisa caracterização do tipo de solo quando realizada a sondagem.

É importante atentar para o fato de que os valores de ruptura usados para verificar o desempenho desse método foram obtidos através de ensaios de provas de carga pelo critério de Van der Veen (1953), que será discutido mais adiante.

O cisalhamento lateral é, nesse caso, calculado pela somatória do atrito lateral em diversos trechos (i) do comprimento da estaca. Dessa forma, considera-se o seguinte:

$$
\mathrm{q}_{\mathrm{L}}=\frac{1}{\mathrm{~L}} \cdot \sum_{\mathrm{i}=1}^{\mathrm{i}=\mathrm{n}} \mathrm{f}_{\max (\mathrm{i})} \cdot \Delta \mathrm{L}_{(\mathrm{i})}
$$




$$
\begin{gathered}
f_{\max (i)}=\frac{f_{S(i)}}{F_{2}}=\frac{q_{C(i)} \cdot \alpha_{A V(i)}}{F_{2}}=\frac{N_{(i)} \cdot K_{A V(i)} \cdot \alpha_{A V(i)}}{F_{2}} \\
q_{P}=\frac{q_{C}}{F_{1}}=\frac{N_{P} \cdot K_{A V P}}{F_{1}}
\end{gathered}
$$

onde: $f_{\max }$ : resistência ao cisalhamento máximo do solo do fuste;

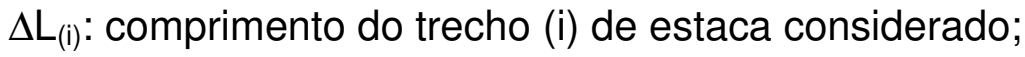

$\mathrm{N}_{P}$ : número de golpes do SPT ao nível da ponta;

$\mathrm{K}_{\mathrm{AVP}}$ : coeficiente de tipo de ensaio $\left(\mathrm{K}_{\mathrm{AV}}\right)$ do solo da ponta;

$F_{1}$ e $F_{2}$ : coeficientes empíricos de escala entre o cone e o tipo de estaca, respectivamente para ponta e fuste;

Os valores destes coeficientes são tabelados para cada tipo de solo e estaca, como segue (Tabela 1 e Tabela 2).

Tabela 1 - Valores de $\mathrm{K}_{\mathrm{AV}}$ e $\alpha_{\mathrm{AV}}$ sugeridos por Aoki \& Velloso (1975).

\begin{tabular}{lcc}
\hline \multicolumn{1}{c}{ Solos } & $\mathrm{K}_{\mathrm{AV}}\left(\mathrm{kN} / \mathrm{m}^{2}\right)$ & $\alpha_{\mathrm{AV}}(\%)$ \\
\hline Areia & 1000 & 1,4 \\
Areia siltosa & 800 & 2,0 \\
Areia silto argilosa & 700 & 2,4 \\
Areia argilosa & 600 & 3,0 \\
Areia argilo siltosa & 500 & 2,8 \\
Silte & 400 & 3,0 \\
Silte arenoso & 550 & 2,2 \\
Silte areno argiloso & 450 & 2,8 \\
Silte argiloso & 230 & 3,4 \\
Silte argilo arenoso & 250 & 3,0 \\
Argila & 200 & 6,0 \\
Argila arenosa & 350 & 2,4 \\
Argila areno siltosa & 300 & 2,8 \\
Argila siltosa & 220 & 4,0 \\
Argila silto arenosa & 330 & 3,0 \\
\hline
\end{tabular}

Outros autores pesquisaram a correlação entre CPT e SPT, como por exemplo, Danziger \& Velloso (1986) para os solos da cidade do Rio de Janeiro, Alonso (1980) para os solos da cidade de São Paulo. Velloso e Lopes (2002) citam também o trabalho de Laprovitera (1988), que utilizou valores modificados e interpolados a partir dos sugeridos por Danziger (1982), os quais são apresentados no Anexo B.

AMANN (2000) fez uma série de análises identificando tendências do valor de $K_{A V}$ em relação às concentrações de areia, silte e argila em cada tipo de solo: 
- a presença de areia em qualquer dos demais tipos de solo (silte, argila, silte argiloso ou argila siltosa) conduz a um aumento no valor de $\mathrm{K}_{\mathrm{AV}}$;

- a presença de silte, por outro lado, diminui o $\mathrm{K}_{\mathrm{AV}}$, exceto na argila pura;

- a presença de argila diminui $\mathrm{K}_{\mathrm{AV}}$ para qualquer outro tipo de solo considerado.

Essas análises constituem a base da elaboração do conceito de Hierarquia dos Solos (AMANN, 2000), que será discutido detalhadamente mais adiante.

Tabela 2 - Coeficientes $F_{1}$ e $F_{2}$ em função do tipo de estaca (VELLOSO e ALONSO, 2000)

\begin{tabular}{ccc}
\hline Tipo de estaca & $\mathrm{F}_{1}$ & $\mathrm{~F}_{2}$ \\
\hline Franki & 2,50 & 5,00 \\
de Aço cravada & 1,75 & 3,50 \\
Pré-moldada de & $1+\frac{\mathrm{D}(\mathrm{cm})}{80}$ & $2 .\left(1+\frac{\mathrm{D}(\mathrm{cm})}{80}\right)$ \\
concreto & 3,00 & 6,00 \\
Escavadas & 3,50 & 7,00 \\
Esc. Gde. Diâmetro & &
\end{tabular}

Quanto aos coeficientes $F_{1}$ e $F_{2}$, em geral guardam entre si uma relação de 1 para 2 devido à real área da luva de atrito que está em contato com o solo após o deslocamento da ponta do cone. Velloso e Lopes (2002) comentam que essa proporção foi adotada como forma de separar esses dois coeficientes, pois, pelas retroanálises, obtém-se apenas um único valor global.

Para alguns tipos de estacas, a relação 1 para 2 pode não ser a mais adequada. Corrêa (1988) utilizou inicialmente em seus estudos com estacas raiz os fatores relativos a estacas escavadas dados na Tabela 2, não conseguindo boa correlação. Por fim, chegou aos valores $F_{1}=3,0$ e $F_{2}=2,0$ como os que melhor se ajustaram aos ensaios de prova de carga. $O$ fato de $F_{2}$ resultar menor do que $F_{1}$ se explica pela estaca raiz desenvolver maior atrito lateral enquanto que a ponta se comporta como a de uma estaca escavada.

Velloso e Lopes (2002) citam ainda os trabalhos de Laprovitera (1988) e Benegas (1993) que propuseram novos valores para $F_{1}$ e $F_{2}$, considerando os melhores ajustes estatísticos obtidos para 200 provas de carga do banco de dados da COPPE-UFRJ, porém utilizando para a ponta não apenas $o$ valor de $q_{c}$ à profundidade da mesma, mas sim numa região de embutimento de 1,0 diâmetro $(1,0 . D)$ acima e o mesmo abaixo da ponta. Também Monteiro (2000) modificou os valores de $K_{A V}$ e $\alpha_{A V}$ bem como os de $F_{1}$ e $F_{2}$, incluindo outros tipos de estacas, além de considerar para a ponta a região de embutimento de 7,0.D acima e 3,5.D 
abaixo da ponta. A análise dessas considerações de embutimento também serão discutidas adiante.

Note-se que estas propostas de novos valores e trecho de embutimento não representam uma correção do método para um solo específico em estudo como é a proposta desta pesquisa, pois os valores propostos foram tomados como revisão ou modificação do método original sem indicação de restrição do uso. Também não se tratou nesses trabalhos de se estruturar uma metodologia de correção para quaisquer tipos de métodos, ou seja, uma metodologia unificada como aqui é proposta.

\subsubsection{Método Décourt-Quaresma (1978) e Décourt (1996a)}

Décourt (2007) informou que a origem do método Décourt-Quaresma para estacas cravadas (considerada estaca de referência) veio do desejo de tornar práticas as proposições teóricas e conceituais de Vésic, pesquisador que o incentivou à publicação do método após anos de aplicação e constante verificação. É um método contemporâneo ao de Aoki-Velloso, sendo ambos amplamente difundidos e aplicados na engenharia brasileira. Recebeu reconhecimento internacional devido ao prêmio recebido em 1982, num concurso de previsão de capacidade de carga de estacas cravadas, por ocasião do ESOPT II.

Em princípio, esse método foi desenvolvido para estacas do tipo pré-moldadas de concreto cravadas, o qual foi considerado como estaca de referência. Velloso e Alonso (2000) comentam que esse método sofreu diversas modificações para incluir outros tipos de estacas e ajustes dos coeficientes de tipo de solo. Apresenta-se aqui a versão de Décourt (1996a), que sugeriu coeficientes de tipo de estaca e de solo $\alpha_{D Q}$ e $\beta_{D Q}$. Assim, por exemplo, as estacas escavadas em geral deveriam sofrer uma redução no cisalhamento lateral para considerar o desconfinamento do solo e também na ponta, devido à deficiência de limpeza do fundo de escavação durante o processo construtivo. Décourt (1996a) ressalva que os valores tabelados desses coeficientes só devem ser usados na ausência de experiência local, coerentemente com o alerta de Velloso e Alonso (2000), mas sem proposta para sua correção.

Nesse método, as tensões q e qp ficam assim definidas: 


$$
\begin{gathered}
q_{L}=10 \cdot\left(\frac{\overline{N_{S P T}}}{3}+1\right) \cdot \beta_{D Q} \\
q_{P}=\overline{N_{P}} \cdot C_{P} \cdot \alpha_{D Q}
\end{gathered}
$$

onde: $\quad \overline{\mathrm{N}}_{\mathrm{SPT}}$ : número de golpes médio ao longo do fuste da estaca $3 \leq \mathrm{N} \leq 50$; $\overline{\mathrm{N}_{\mathrm{P}}}$ : é a média dos três valores de SPT em torno (embutimento) da ponta (1,0 m acima, na ponta e 1,0 $\mathrm{m}$ abaixo desta);

$\mathrm{C}_{\mathrm{P}}$ : é o coeficiente empírico do solo da ponta.

$\alpha_{D Q}$ e $\beta_{D Q}$ : coeficientes empíricos de tipo da estaca e solo, respectivamente para a ponta e atrito lateral.

Os valores dos coeficientes empíricos originalmente propostos encontram-se na Tabela 3 e na Tabela 4.

Tabela 3 - Valores dos fatores de correção $\alpha_{D Q}$ e $\beta_{D Q}$ (adaptada de DÉCOURT, 1996a)

\begin{tabular}{cccccc}
\hline \multirow{2}{*}{ Tipo de Solo } & $\begin{array}{c}\text { Estacas } \\
\text { Escavadas } \\
\text { (em geral) }\end{array}$ & $\begin{array}{c}\text { Estacas } \\
\text { escavadas } \\
\text { (bentonita) }\end{array}$ & $\begin{array}{c}\text { Estaca } \\
\text { hélice } \\
\text { contínua }\end{array}$ & $\begin{array}{c}\text { Estacas } \\
\text { raiz }\end{array}$ & $\begin{array}{c}\text { Injetadas } \\
\text { sob alta } \\
\text { pressão }\end{array}$ \\
\hline \multirow{2}{*}{ Argilas } & $\alpha_{\mathrm{DQ}}=0,85$ & 0,85 & 0,30 & 0,85 & 1,00 \\
& $\beta_{\mathrm{DQ}}=0,80$ & 0,90 & 1,00 & 1,50 & 3,00 \\
\multirow{3}{*}{ Solos intermediários } & $\alpha_{\mathrm{DQ}}=0,60$ & 0,60 & 0,30 & 0,60 & 1,00 \\
& $\beta_{\mathrm{DQ}}=0,65$ & 0,75 & 1,00 & 1,50 & 3,00 \\
Areias & $\alpha_{\mathrm{DQ}}=0,50$ & 0,50 & 0,30 & 0,50 & 1,00 \\
& $\beta_{\mathrm{DQ}}=0,50$ & 0,60 & 1,00 & 1,50 & 3,00 \\
\hline
\end{tabular}

Tabela 4 - Valores do coeficiente $C_{P}$ em função do solo junto à ponta (DÉCOURT, 1996a)

\begin{tabular}{cc}
\hline Tipo de solo & $\mathrm{C}_{\mathrm{P}}\left(\mathrm{kN} / \mathrm{m}^{2}\right)$ \\
\hline Argila & 120 \\
Silte argiloso (residual) & 200 \\
Silte arenoso & 250 \\
Areia & 400 \\
\hline
\end{tabular}

É importante ressaltar que esse método apresenta forma de consideração do cisalhamento lateral pela média dos SPT's, diferentemente de Aoki-Velloso que considera a somatória camada a camada (trecho a trecho da estaca) e para a ponta considera a média num trecho de embutimento de até 1,0 $\mathrm{m}$ acima e 1,0 $\mathrm{m}$ abaixo da ponta (3 valores de SPT). Também privilegia o comportamento do solo (arenoso, argiloso ou intermediário) e não sua classificação específica.

Décourt (2007), informa ainda que este método foi verificado com provas de carga cujo critério de ruptura foi o de recalque limite das estacas cravadas, considerado como sendo $10 \%$ do diâmetro (0,1.D), o que remete ao conceito de carga de ruptura 
convencional, diferentemente do utilizado por Aoki e Velloso (1975) quando da aplicação do critério de extrapolação exponencial de Van der Veen (1953). A importância desse detalhe será discutida no item referente à verificação de desempenho.

\subsection{GENERALIZAÇÃO DOS MÉTODOS SEMIEMPÍRICOS (AMANN 2000)}

Antes da apresentação de outros métodos semiempíricos, torna-se importante para a abordagem aqui pretendida discutir-se a sua generalização (AMANN, 2000, 2002, 2004 e 2006).

AMANN (2000) analisou as expressões matemáticas dos métodos em função do SPT e concluiu que as tensões $q_{L}$ e $q_{P}$ podem ser apresentadas generalizadamente sob a seguinte forma simplificada:

$$
q=K_{g} \cdot N
$$

definindo-se o chamado "coeficiente característico de resistência $\mathrm{K}_{\mathrm{g}}$ (generalizado)", que multiplica o número de golpes $(\mathrm{N})$ da sondagem SPT (ou eventualmente o resultado de outro tipo de ensaio de campo), resultando na tensão de ruptura do solo, podendo aplicá-lo ao fuste ou à ponta.

A partir disto, AMANN (2000) propõe a definição do coeficiente característico para o atrito lateral $\left(\mathrm{K}_{\mathrm{Lg}}\right)$ e o correspondente para a ponta $\left(\mathrm{K}_{\mathrm{Pg}}\right)$. O termo "característico" vem do fato desse coeficiente incluir todos os coeficientes parciais, de tipo de solo, de estaca, de ensaio e dimensão, sendo, portanto, característico do caso particular estudado. O índice " $g$ " indica a sigla do método semiempírico que é empregado em seu cálculo, a saber: Décourt-Quaresma (DQ), Aoki-Velloso (AV), etc., como se verá adiante.

Assim, são definidas a tensão de cisalhamento lateral $\left(q_{L}\right)$ e a tensão de ponta $\left(q_{p}\right)$, ambas na ruptura, como sendo dadas pela forma geral das expressões (11) e (12):

$$
\begin{gathered}
q_{L g}=K_{L g} \cdot \overline{N_{S P T}} \\
q_{P g}=K_{P g} \cdot \overline{N_{P}}
\end{gathered}
$$


É importante verificar que a metodologia que emprega $\overline{\mathrm{N}_{\mathrm{SPT}}}$ e $\overline{\mathrm{N}_{\mathrm{P}}}$ (médias) é a do método Décourt-Quaresma ( $g=D Q)$. Para aplicar esta generalização à metodologia de Aoki-Velloso, $\overline{N_{P}}$ deve ser substituído pelo valor do SPT da camada da ponta $\left(\mathrm{N}_{\mathrm{P}}\right)$ diretamente. Analogamente, para outros métodos, $\overline{\mathrm{N}_{\mathrm{P}}}$ deve representar a média das resistências nas regiões de embutimento da ponta, conforme a consideração do método em análise. Com relação ao atrito lateral, Aoki-Velloso adota a somatória dos valores individuais de cisalhamento lateral máximo $\left(f_{\max (i)}\right)$ estimados com base no SPT $\left(\mathrm{N}_{(\mathrm{i})}\right)$ de cada camada (i) do subsolo, com espessura $\Delta \mathrm{L}_{(i)}$, [ver expressões (5) e (6)]. Assim, de forma generalizada, a tensão de cisalhamento lateral na ruptura $\left(q_{L}\right)$ ficaria definida como ilustra matematicamente a expressão (13):

$$
\mathrm{f}_{\max (\mathrm{i})}=\mathrm{K}_{\mathrm{Lg}(\mathrm{i})} \cdot \mathrm{N}_{(\mathrm{i})} \quad ; \text { donde: } \quad \mathrm{q}_{\mathrm{Lg}}=\frac{1}{\mathrm{~L}} \cdot \sum_{\mathrm{i}=1}^{\mathrm{n}} \mathrm{K}_{\mathrm{Lg}(\mathrm{i})} \cdot \mathrm{N}_{(\mathrm{i})} \cdot \Delta \mathrm{L}_{(\mathrm{i})}
$$

A partir disso, define-se um novo coeficiente característico, que AMANN (2000) denominou de "coeficiente característico de resistência da camada por atrito lateral $\left(K_{\mathrm{Lg}(\mathrm{i})}\right)$ ", que nada mais é do que a relação entre o atrito unitário máximo $\left(\mathrm{f}_{\max (\mathrm{i})}\right)$ da camada de solo e o seu respectivo número de golpes do ensaio $\mathrm{SPT}\left(\mathrm{N}_{(\mathrm{i})}\right)$.

Dessa forma, a comparação entre métodos semi-empíricos com diferentes metodologias de cálculo (média dos SPT ou somatória dos valores individuais de cada camada) pode ser realizada de forma conceitualmente simples, igualando-se as expressões (11) e (13):

$$
\mathrm{K}_{\mathrm{Lg}}=\frac{1}{\mathrm{~L} \cdot \overline{\mathrm{N}_{\mathrm{SPT}}}} \cdot \sum_{\mathrm{i}=1}^{\mathrm{i}=\mathrm{n}} \mathrm{K}_{\mathrm{Lg}(\mathrm{i})} \cdot \mathrm{N}_{(\mathrm{i})} \cdot \Delta \mathrm{L}_{(\mathrm{i})}
$$

De forma análoga, a comparação para a resistência de ponta dessas diferentes metodologias pode ser realizada com o emprego da expressão (3.21):

$$
\mathrm{K}_{\mathrm{Pg}}=\frac{1}{\overline{\mathrm{N}_{\mathrm{P}}}} \cdot \mathrm{K}_{\mathrm{Pg}(\mathrm{P})} \cdot \mathrm{N}_{\mathrm{P}}
$$

É interessante notar que, salvo nos casos em que há variação brusca de resistência do solo na ponta, os valores de $\overline{N_{P}}$ e $N_{P}$ são muito próximos $\left(K_{P g(P)} \cong K_{P g}\right)$. De qualquer forma, especial atenção deve ser dada à consideração do trecho de 
embutimento na camada portante da ponta, como se discutirá adiante. Isso feito, o atrito lateral deve ser considerado somente até esse limite, não avançando na região da ponta.

Com tais considerações sobre a generalização para comparação dos métodos semiempíricos, apresentam-se a seguir os doze métodos aqui analisados.

\subsection{APRESENTAÇÃO DOS MÉTODOS SEMIEMPÍRICOS ANALISADOS}

Velloso e Alonso (2000) apresentaram uma coletânea de diversos métodos semiempíricos desenvolvidos por autores brasileiros, os quais serão aqui comentados mais do ponto de vista da metodologia adotada em cada um, do que da sua aplicação propriamente dita. Os doze métodos aqui analisados são: AokiVelloso (1975) - sigla aqui adotada: [AV]; Décourt-Quaresma (1996) - [DQ]; Monteiro (2000), pela empresa Franki - [FK]; Teixeira (1996) - [TX]; P.P.C. Velloso (1981) - [CV]; David Cabral (1986) - [CA]; Brasfond (1991) - [BR]; Alonso (1996) [AL]; Antunes-Cabral (1996) - [AC]; Kárez-Rocha (2000) - [KR]; Gotlieb et al. (2000) - [GT]; Cabral et al. (2000) - [CB]. Como citam Velloso e Alonso (2000), muitos desses métodos são baseados na metodologia proposta por Aoki e Velloso, contudo outros podem ser aproximados a metodologia de Décourt-Quaresma.

Nessa linha, faz-se aqui referência aos trabalhos de Amann (2002, 2004 e 2006) que demonstrou as correlações existentes entre os diversos métodos semiempíricos, sendo que AMANN (2006), apresenta uma análise geral de doze métodos semiempíricos brasileiros para diferentes tipos de estacas (Tabela 5), abordando suas semelhanças e distinções, além da discussão das Hierarquias dos Solos, que serão abordadas logo mais, abrindo caminho para a proposta da Metodologia Semiempírica Unificada.

A Tabela 5 apresenta a forma generalizada dos doze métodos semiempíricos avaliados com as respectivas siglas (g) adotadas e indicação das estacas para as quais foram elaborados, bem como as expressões de cálculo dos coeficientes característicos de resistência da estaca, que permitem, como já exposto, as comparações diretas entre os mesmos. A rigor, a unidade destes coeficientes deveria ser $\left[\mathrm{kN} / \mathrm{m}^{2} .30 \mathrm{~cm} /\right.$ golpe], visto que a unidade do SPT é o número de golpes 
para cravação dos últimos $30 \mathrm{~cm}$ do amostrador padrão. Contudo, por simplificação, adota-se apenas $\left[\mathrm{kN} / \mathrm{m}^{2}\right]$.

Tabela 5 - Expressões dos coeficientes característicos de atrito lateral $\mathrm{K}_{\mathrm{Lg}(\mathrm{i})}$ e de ponta $\mathrm{K}_{\mathrm{Pg}}$ [kPa] para os vários métodos semi-empíricos estudados (VELLOSO e ALONSO, 2000, AMANN e MASSAD, 2000, KAREZ e ROCHA, 2000 e MONTEIRO, 2000 ) apud Amann (2006).

\begin{tabular}{|c|c|c|c|}
\hline Método $(\mathrm{g})$ & $\mathrm{K}_{\mathrm{Lg}(\mathrm{i})}$ & $\mathrm{K}_{\mathrm{Pg}}$ & Estacas \\
\hline Aoki -Velloso (AV) & $\frac{\mathrm{K}_{\mathrm{AV}(\mathrm{i})} \cdot \alpha_{\mathrm{AV}(\mathrm{i})}}{\mathrm{F}_{2}}$ & $\frac{\mathrm{K}_{\mathrm{AV}}}{\mathrm{F}_{1}}$ & $\begin{array}{l}\text { Franki, Pré-mold., } \\
\text { Metálica, Escav. c/ } \\
\text { Lama* Raiz* }\end{array}$ \\
\hline $\begin{array}{l}\text { Monteiro - Franki, } \\
\text { (FK) }\end{array}$ & $\frac{\mathrm{K}_{\mathrm{FK}(\mathrm{i})} \cdot \alpha_{\mathrm{FK}(\mathrm{i})}}{\mathrm{F}_{2 \mathrm{FK}}}$ & $\frac{\mathrm{K}_{\mathrm{FK}}}{\mathrm{F}_{1 \mathrm{FK}}}$ & $\begin{array}{l}\text { Franki, Pré-mold., } \\
\text { Metálica, Escav. c/ } \\
\text { Lama, HLC, Ômega, } \\
\text { Raiz, Strauss }\end{array}$ \\
\hline $\begin{array}{c}\text { Décourt - } \\
\text { Quaresma (DQ) }\end{array}$ & $\frac{10 \cdot \beta_{\mathrm{DQ}}}{\overline{\mathrm{N}_{\mathrm{SPT}}}} \cdot\left(\frac{\overline{\mathrm{N}_{\mathrm{SPT}}}}{3}+1\right)=10 \cdot \beta_{\mathrm{DQ}} \cdot\left(\frac{1}{3}+\frac{1}{\overline{\mathrm{N}_{\mathrm{SPT}}}}\right)$ & $C_{P} \cdot \alpha_{D Q}$ & $\begin{array}{l}\text { Pré-mold., Franki, } \\
\text { Strauss, Escav. c/ e } \\
\text { s/ Lama, HLC, Raiz, } \\
\text { Microestaca }\end{array}$ \\
\hline Teixeira (TX) & $\beta_{\text {TX }}$ & $\alpha_{T X}$ & $\begin{array}{l}\text { Pré-mold., Franki, } \\
\text { Metálica, Escav. s/ } \\
\text { Lama, Raiz }\end{array}$ \\
\hline P.P.C.Velloso (CV) & $\alpha \cdot \lambda \cdot a^{\prime} \cdot \frac{\mathrm{N}^{\mathrm{b}^{\prime}}}{\mathrm{N}} \cong \alpha \cdot \lambda \cdot \mathrm{a}^{\prime}$ & $\alpha . \beta . a \cdot \frac{\mathrm{N}^{\mathrm{b}}}{\mathrm{N}} \cong \alpha . \beta . \mathrm{a}$ & $\begin{array}{l}\text { Cravadas e } \\
\text { Escavadas }\end{array}$ \\
\hline $\begin{array}{l}\text { David Cabral (CA) } \\
\text { Brasfond (BR) }\end{array}$ & ${ }^{100 \cdot \beta_{1} \cdot \beta_{0}}{ }_{\beta_{B}} ; \beta_{0}=f(D)$ & 100. $\beta_{2} \cdot \beta_{0} ; \beta_{0}=f(D)$ & $\begin{array}{l}\text { Raiz, Esc. c/ Lama } \\
\text { Raiz }\end{array}$ \\
\hline Alonso (AL) & $\alpha_{\mathrm{AL}} \cdot \mathrm{f}_{\mathrm{SAL}}=\alpha_{\mathrm{AL}} \cdot \frac{100}{0,41 \cdot \mathrm{h}_{\mathrm{SPT}}-0,032} \cdot \frac{\overline{\mathrm{T}_{\text {max }}}}{\overline{\mathrm{N}_{\mathrm{SPT}}}}$ & $\beta_{A L} \cdot \overline{\overline{T_{\min }}}$ & $\begin{array}{l}\text { Hélice Contínua } \\
\text { (HLC) }\end{array}$ \\
\hline $\begin{array}{l}\text { Antunes-Cabral } \\
\text { (AC) }\end{array}$ & $\mathrm{B}_{1}$ & $\mathrm{~B}_{2}$ & HLC \\
\hline $\begin{array}{c}\text { Karez - Rocha } \\
(\mathrm{KR})\end{array}$ & $\mathrm{K}_{\mathrm{LKR}}$ & $\mathrm{K}_{\mathrm{PKR}}$ & HLC \\
\hline $\begin{array}{l}\text { Gotlieb et al. (GT) } \\
\text { Cabral et al. (CB) }\end{array}$ & $\begin{array}{c}\beta_{\mathrm{GT}}=2 \\
\beta_{1}\end{array}$ & $\begin{array}{c}\alpha_{\mathrm{GT}}=60 \\
\beta_{2}\end{array}$ & $\begin{array}{c}\text { HLC } \\
\text { Ômega }\end{array}$ \\
\hline
\end{tabular}

Tabela 6 - Metodologia aplicada ao cisalhamento lateral e à ponta (embutimento) em cada método

\begin{tabular}{|c|c|c|}
\hline Método $(\mathrm{g})$ & Modelo aplicado ao cisalhamento lateral & Modelo aplicado à ponta \\
\hline DQ; BR; TX & $\mathrm{N}_{\mathrm{SPT}}$ médio ao longo do fuste & Média de 3 SPT em torno da ponta \\
\hline GT & $\mathrm{N}_{\mathrm{SPT}}$ médio ao longo do fuste & $\begin{array}{l}\text { Média do SPT entre o trecho 8.D } \\
\text { acima e 3.D abaixo da ponta }\end{array}$ \\
\hline AL & Torque máximo médio ao longo do fuste & $\begin{array}{l}\text { Torque mínimo médio no trecho } 8 . D \\
\text { acima e } 3 . D \text { abaixo da ponta }\end{array}$ \\
\hline FK & $\mathrm{N}_{\mathrm{SPT}}$ de cada camada individual & $\begin{array}{l}\text { Média do SPT entre o trecho 7,5.D } \\
\text { acima e 3,5.D abaixo da ponta }\end{array}$ \\
\hline CV & $\mathrm{N}_{\mathrm{SPT}}$ de cada camada individual & $\begin{array}{l}\text { Média do SPT entre o trecho 8.D } \\
\text { acima e 3,5.D abaixo da ponta }\end{array}$ \\
\hline $\begin{array}{l}\text { AV; AC; CB } \\
\text { KR; CA }\end{array}$ & $\begin{array}{l}\mathrm{N}_{\mathrm{SPT}} \text { de cada camada individual } \\
\mathrm{N}_{\mathrm{SPT}} \text { médio ao longo do fuste }\end{array}$ & $\begin{array}{l}N_{\text {SPT }} \text { ao nível da ponta } \\
N_{\text {SPT }} \text { ao nível da ponta }\end{array}$ \\
\hline
\end{tabular}

Os valores de $\beta_{0}$ do método David Cabral, bem como seus congêneres, serão discutidos no item sobre o coeficiente parcial de diâmetro, no Apêndice B. Convém notar que os métodos de Décourt-Quaresma (DQ) e Alonso (AL) variam com o valor 
do SPT no cálculo de $\mathrm{K}_{\mathrm{Lg}}$, o que os torna semelhantes e peculiares em relação aos demais.

A Tabela 6 apresenta a metodologia aplicada para a ponta e para o cisalhamento lateral em cada método. As diversas regiões de consideração do embutimento serão melhor discutidas adiante.

Para os métodos que utilizam consideração do embutimento 8D (ou 7,5D) acima da ponta, a tensão de ponta é calculada como segue:

$$
\mathrm{q}_{P}=\frac{\frac{\sum_{\mathrm{i}=1}^{\mathrm{n}_{8}} \mathrm{~N}_{(\mathrm{i})} \cdot \mathrm{K}_{\mathrm{P} 8 \mathrm{D}(\mathrm{i})}}{\mathrm{n}_{8}}+\frac{\sum_{\mathrm{j}=1}^{\mathrm{n}_{3}} \mathrm{~N}_{(\mathrm{j})} \cdot \mathrm{K}_{\mathrm{P} 3 \mathrm{D}(\mathrm{j})}}{\mathrm{n}_{3}}}{2}
$$

sendo: $\quad \mathrm{K}_{\mathrm{P} 8 \mathrm{D}(\mathrm{i})}$ : valor do coeficiente característico de ponta para cada camada no embutimento 8D acima da ponta;

$\mathrm{K}_{\mathrm{P} 3 \mathrm{D}(\mathrm{i})}$ : valor do coeficiente característico de ponta para cada camada no embutimento 3D abaixo da ponta;

$\mathrm{n}_{8}$ : número de valores SPT consideradas no embutimento 8D acima da ponta;

$\mathrm{n}_{3}$ : número de camadas consideradas no embutimento 3D abaixo da ponta;

Observa-se, assim, que no trecho acima da ponta o peso de cada camada é menor do que embaixo.

$\mathrm{Na}$ aplicação de alguns métodos é também importante se observar os valores limites do SPT (em geral $3 \leq N \leq 50$, ou eventualmente $N \leq 20$, para algumas estacas) considerados pelos autores (VELLOSO e ALONSO, 2000).

Os valores indicados para os coeficientes desses métodos, pelos seus autores, são apresentados no Apêndice B.

Há ainda outros métodos brasileiros que não foram aqui abordados, como o de Vorcaro e Velloso (2000), apud Velloso e Lopes (2002), classificado como método estatístico pelo uso desse princípio em sua proposição, mas também poderia ser tomado como empírico. Apesar de não considerado nessas análises pode ser também generalizado através do conceito de Hierarquia dos Solos (mais adiante discutido), como também apresentado no Apêndice B. 


\subsection{CONCEITUAÇÃO DAS HIERARQUIAS DOS SOLOS (AMANN, 2000)}

Amann (2000) propôs as chamadas Hierarquias dos Solos como uma forma de relacionar as resistências dos diferentes tipos de solos para um mesmo valor de SPT. Em suas análises, identificou que quando os valores dos coeficientes característicos de resistência, acima introduzidos, eram colocados em ordem decrescente nas tabelas de solos, a posição relativa da maioria dos tipos de solo era mantida nos diversos métodos. Desta constatação surgiu o conceito das hierarquias, notadamente referindo-se aos valores dos coeficientes característicos propostos.

A Figura 4 mostra a hierarquia que está implícita no método Aoki-Velloso para o coeficiente característico de resistência por cisalhamento lateral e a Figura 5 mostra a hierarquia para o coeficiente da ponta.

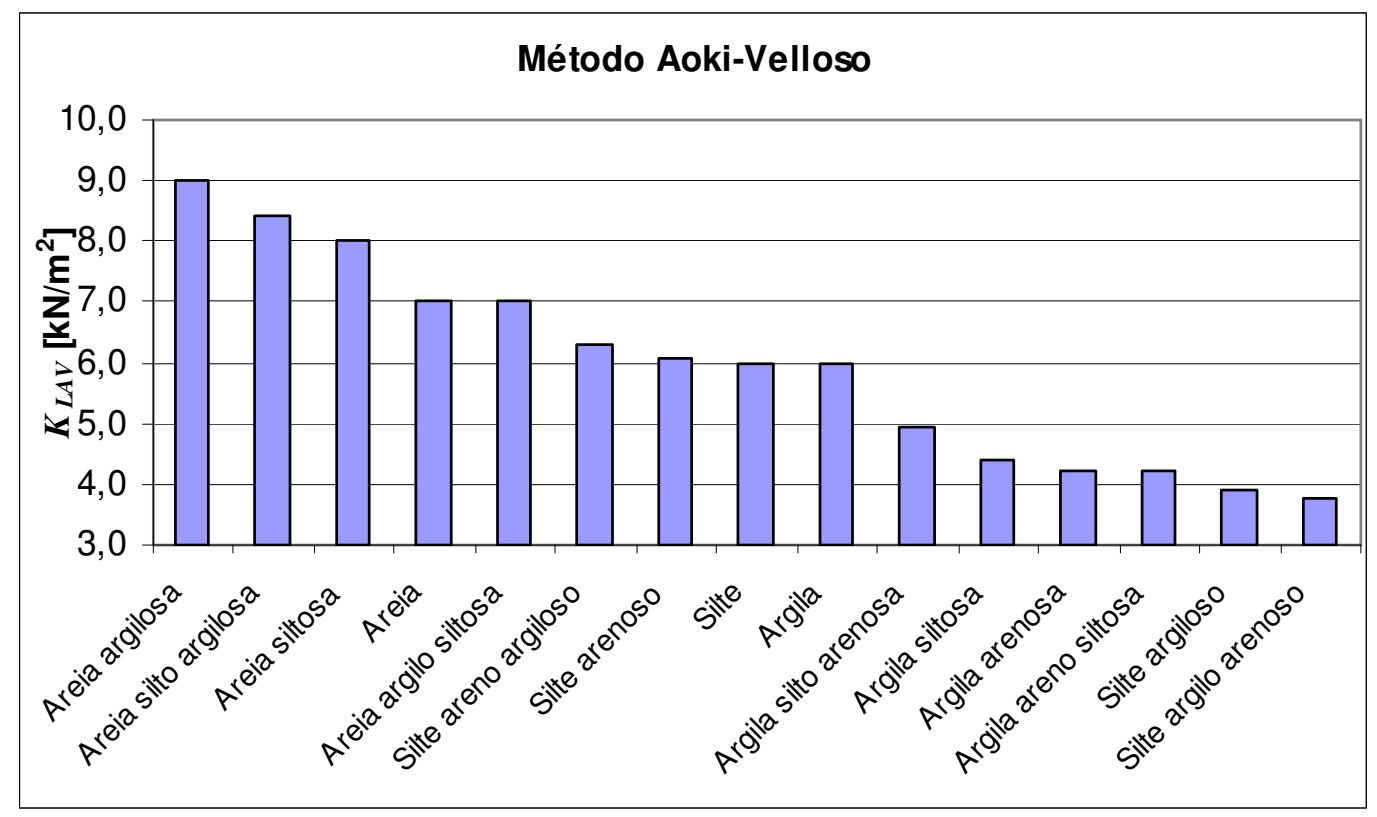

Figura 4 - Valores de $\mathrm{K}_{\mathrm{LAV}}$ em função do tipo de solo (AMANN, 2000).

A constatação destas hierarquias permite, por exemplo, dizer que a resistência por cisalhamento lateral do solo do fuste de uma camada de areia argilosa é cerca de $29 \%$ maior que a resistência de uma camada de areia com o mesmo SPT. Em contrapartida, a resistência de ponta, da camada de areia argilosa, chega a apenas $60 \%$ da resistência da camada de areia.

Para o fuste, verifica-se ainda que a resistência por cisalhamento lateral de uma camada de argila é $51 \%$ maior que a resistência de uma camada de silte argiloarenoso com o mesmo SPT. 


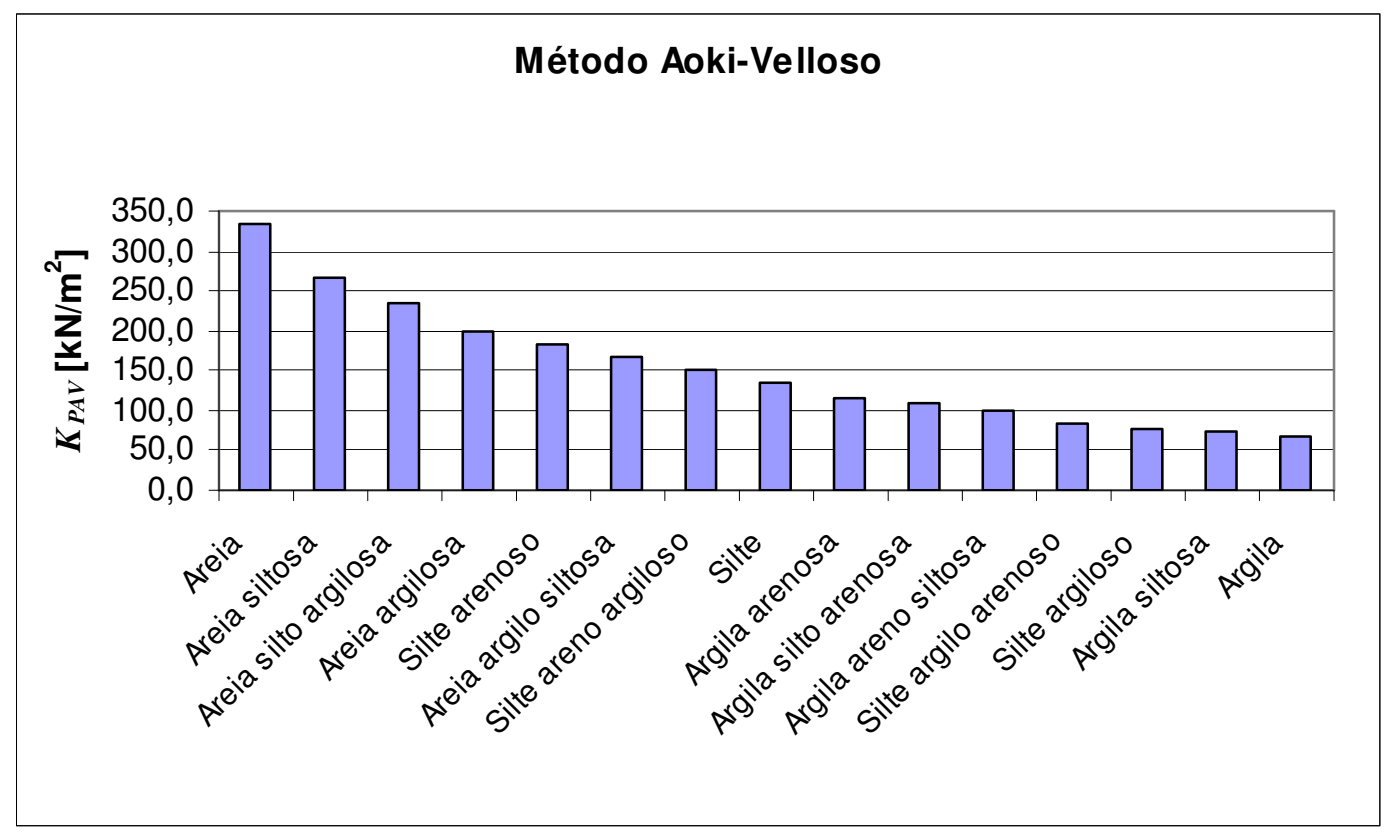

Figura 5 - Valores de $\mathrm{K}_{\mathrm{PAV}}$ em função do tipo de solo (AMANN, 2000).

Já para a resistência de ponta, uma camada de argila alcança apenas $80 \%$ da resistência da camada de silte argilo-arenoso. Esse conceito será utilizado na formulação da Metodologia Semiempírica Unificada para atribuição de valores corrigidos aos coeficientes semiempíricos de cada camada de solo, após separada a resistência do solo do fuste.

É evidente que esses valores variam de método para método, mas o interessante é que a posição relativa da maioria dos solos se mantém; daí a denominação de hierarquias. Uma visão dessa assertiva é apresentada para as estacas de referência adotadas em cada método semiempírico, conforme a Tabela 7 e a Tabela 8.

Assim, verifica-se uma ordem preferencial (mais provável) de resistência, uma hierarquia própria para os solos com mesmo SPT, solicitados por cisalhamento ao longo do fuste, que é indicada pela Tabela 7. Similarmente, apresenta-se a Tabela 8 para os solos da ponta, sendo a hierarquia distinta daquela do cisalhamento lateral.

Essas chamadas hierarquias podem ser explicadas pela relação entre a resistência ponta $\left(q_{c}\right)$ do cone (CPT) tipo Begemann e a razão de atrito $\left(R_{f}=f_{s} / q_{c}\right)$, com a qual se classifica o comportamento dos solos em arenoso, argiloso ou intermediário, com algumas subdivisões (ROBERTSON e CAMPANELLA, 1983, apud SCHNAID, 2000). É fato, então, a existência das hierarquias embasadas nessas observações e na 
experiência mundialmente adquirida de classificação do solo com o ensaio de cone (CPT).

Tabela 7 - Hierarquia dos solos (identificados por códigos) para os coeficientes de cisalhamento lateral $\left(K_{\mathrm{Lg}}\right)$ em kN/m² das estacas de referência dos métodos semiempíricos (AMANN, 2006)

\begin{tabular}{|c|c|c|c|c|c|c|c|c|c|c|}
\hline Solo & $\begin{array}{l}\text { cód. } \\
\text { solo }\end{array}$ & $\begin{array}{c}\mathrm{K}_{\mathrm{LCB}} \\
\text { ômega }\end{array}$ & $\begin{array}{l}\text { cód. } \\
\text { solo }\end{array}$ & $\begin{array}{l}\mathrm{K}_{\mathrm{LAV}} \\
\text { pré }\end{array}$ & $\begin{array}{l}\text { cód. } \\
\text { solo }\end{array}$ & $\begin{array}{l}\mathrm{K}_{\mathrm{LCA}} \\
\text { lama }\end{array}$ & $\begin{array}{l}\text { cód. } \\
\text { solo }\end{array}$ & $\begin{array}{l}\mathrm{K}_{\mathrm{LCA}} \\
\text { raiz }\end{array}$ & $\begin{array}{l}\text { cód. } \\
\text { solo }\end{array}$ & $\begin{array}{l}\mathrm{K}_{\mathrm{LFK}} \\
\text { pré }\end{array}$ \\
\hline & & & 130 & 5,14 & 130 & 3,50 & 130 & 8,00 & & \\
\hline Areia & 100 & 5,40 & & & & & & & & \\
\hline Areia siltosa & 120 & 5,00 & 120 & 4,57 & 120 & 3,30 & 120 & 8,00 & 120 & 4,47 \\
\hline \multirow[t]{6}{*}{ Areia argilosa } & 130 & 4,70 & & & & & & & 200 & 4,39 \\
\hline & & & 100 & 4,00 & 100 & 3,00 & 100 & 7,00 & 100 & 4,38 \\
\hline & & & & & & & & & 130 & 4,32 \\
\hline & & & 210 & 3,46 & 210 & 3,50 & 210 & 6,00 & 210 & 4,29 \\
\hline & & & & & 310 & 2,50 & 310 & 5,00 & 310 & 4,02 \\
\hline & & & 300 & 3,43 & 300 & 2,40 & 300 & 5,00 & 300 & 3,93 \\
\hline Silte & 200 & 4,20 & 200 & 3,43 & 200 & 2,30 & 200 & 5,00 & & \\
\hline Argila siltosa & 320 & 3,90 & 320 & 2,51 & 320 & 2,00 & 320 & 4,00 & 320 & 3,34 \\
\hline Argila & 300 & 3,20 & & & & & & & & \\
\hline Silte arenoso & 210 & 3,00 & & & & & & & & \\
\hline Argila arenosa & 310 & 3,00 & 310 & 2,40 & & & & & & \\
\hline Silte argiloso & 230 & 2,50 & 230 & 2,23 & 230 & 2,00 & 230 & 3,50 & 230 & 3,29 \\
\hline
\end{tabular}

Tabela 8 - Hierarquia dos solos (identificados por códigos) para os coeficientes de resistência de ponta $\left(\mathrm{K}_{\mathrm{Pg}}\right)$ em $\mathrm{kN} / \mathrm{m}^{2}$ das estacas de referência dos métodos semiempíricos (AMANN, 2006)

\begin{tabular}{|c|c|c|c|c|c|c|c|c|c|c|c|}
\hline Solo & $\begin{array}{l}\mathrm{K}_{\mathrm{PFK}} \\
\text { pré }\end{array}$ & $\begin{array}{l}\text { cód. } \\
\text { solo }\end{array}$ & $\begin{array}{c}\mathrm{K}_{\mathrm{PCA}} \\
\text { raiz }\end{array}$ & $\begin{array}{l}\text { cód. } \\
\text { solo }\end{array}$ & $\begin{array}{c}\mathrm{K}_{\mathrm{PCA}} \\
\text { escav. }\end{array}$ & $\begin{array}{l}\text { cód. } \\
\text { solo }\end{array}$ & $\begin{array}{c}\mathrm{K}_{\mathrm{PBR}} \\
\text { raiz }\end{array}$ & $\begin{array}{l}\text { cód. } \\
\text { solo }\end{array}$ & $\begin{array}{l}\mathrm{K}_{\mathrm{PTX}} \\
\text { pré }\end{array}$ & $\begin{array}{l}\text { cód. } \\
\text { solo }\end{array}$ & $\begin{array}{c}\mathrm{K}_{\mathrm{PCB}} \\
\text { ômega }\end{array}$ \\
\hline Areia & 292 & 100 & 300 & 100 & 250 & 100 & 270 & 100 & 400 & 100 & 320 \\
\hline Areia siltosa & 272 & 120 & 280 & 120 & 200 & 120 & 210 & 120 & 360 & 120 & 280 \\
\hline Areia argilosa & 216 & 130 & 230 & 130 & 200 & 130 & 180 & 130 & 300 & 130 & 260 \\
\hline Argila siltosa & 200 & 320 & 200 & 320 & 150 & 320 & 150 & 320 & 260 & 320 & 250 \\
\hline \multirow[t]{2}{*}{ Silte } & 192 & 200 & 180 & & & & & & & & \\
\hline & & & & & & & & & & 300 & 180 \\
\hline \multirow[t]{2}{*}{$\begin{array}{c}\text { Argila } \\
\text { arenosa }\end{array}$} & 176 & 310 & 150 & 310 & 140 & 310 & 120 & 310 & 210 & 310 & 175 \\
\hline & & & & 200 & 120 & & & & & $\begin{array}{r}210 \\
-200\end{array}$ & $\begin{array}{l}156 \\
120\end{array}$ \\
\hline Argila & 128 & 300 & 100 & 300 & 110 & 300 & 100 & 300 & 160 & & \\
\hline Silte argiloso & 104 & 230 & 100 & 230 & 110 & 230 & 80 & 230 & 110 & 110 & 120 \\
\hline Silte arenoso & 100 & 210 & 100 & 210 & 100 & & & & & & \\
\hline
\end{tabular}

No Apêndice B são apresentados os valores calculados para os coeficientes característicos de resistência da estaca e outras análises de Amann (2006), referentes às hierarquias dos solos. 


\subsection{EXEMPLO DE APLICAÇÃO DO CONCEITO DE HIERARQUIAS DOS SOLOS E DA GENERALIZAÇÃO DOS MÉTODOS SEMIEMPÍRICOS}

No Apêndice B, item B.5, apresenta-se um exemplo de como aplicar as análises de verificação da hierarquia dos solos à antecipação dos resultados comparativos entre os diversos métodos. Evidentemente, não se pode com isso prever de fato a carga de ruptura (pois não se prescinde do ensaio de prova de carga para isso), mas é possível verificar-se quais os métodos com tendência a menores ou maiores resultados, relativamente entre si.

Como exemplo foram escolhidos os trabalhos de Alledi et al. (2006) e Alledi e Polido (2008), cuja análise completa pode ser acompanhada no referido apêndice. Aqui será apresentado um resumo das considerações efetuadas para a ponta das estacas pesquisadas por esses autores, como segue.

As estacas pesquisadas eram do tipo Hélice-contínua, EH1 (L=8,0m) e EH2 ( $L=12,0 \mathrm{~m})$, de 0,4m de diâmetro instrumentadas, e o solo, o litorâneo de Vitória-ES com camadas alternadas de argila e areia. Sobre as curvas carga-recalque, foram aplicados diversos critérios de ruptura baseados em recalque limite e em interseção de retas, não sendo usados os critérios de Van der Veen, Chin ou Rigidez (o que se discutirá no próximo capítulo). Como o ensaio foi levado a um bom nível de deformação (>10\%.D), os resultados dos critérios usados foram semelhantes, adotando-se respectivamente para cada estaca os valores de $700 \mathrm{kN}$ e $1000 \mathrm{kN}$.

A forma de aplicação da generalização dos métodos e das hierarquias se faz, para o caso de análise da ponta, por exemplo, a partir da Figura 82, aqui reproduzida como Figura 6, por se aplicar aos métodos de estaca Hélice. São utilizados também a Tabela 5 e a Tabela 6 para avaliar particularmente o método de Gotlieb.

Nessa figura vê-se que os valores do coeficiente característico $K_{P D Q}$ do método Décourt Quaresma são mais conservadores que os demais, inclusive mais que o método de Alonso. Como para os três tipos de solos os valores são proporcionais em todos os métodos, pode-se calcular a relação média entre os valores de ponta de cada método e do Décourt-Quaresma. Esta relação será proporcional ao resultado final da resistência de ponta se o valor de SPT da ponta for igual para cada método. Assim, conclui-se que caso Décourt-Quaresma se aproxime do valor 
obtido em ensaios para a ponta, os demais a terão superestimado; caso um dos demais se aproxime do valor de ensaio, então Décourt-Quaresma a terá subestimado.

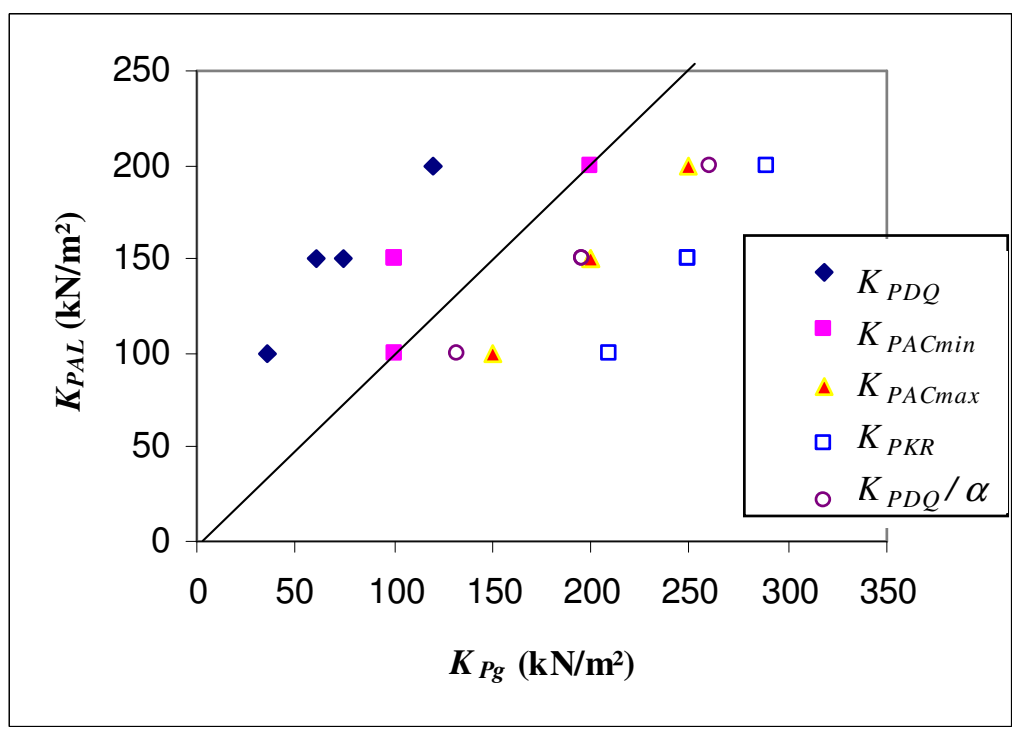

Figura 6 - Comparação gráfica entre os fatores de ponta do método de Alonso ( $A L)$ e dos métodos Décourt-Quaresma (DQ), Antunes-Cabral (AC) e Kárez-Rocha (KR) apud AMANN (20004)

Para o método de Gotlieb, pode-se ver, na Tabela 5, que seu coeficiente característico é $\mathrm{K}_{\mathrm{PGT}}=60 \mathrm{kN} / \mathrm{m}^{2}$ para qualquer tipo de solo, o que resulta em valores próximos à média de Décourt-Quaresma, conforme a Figura 6. Dessa forma, para o mesmo valor de SPT, esses dois métodos devem resultar em valores próximos de resistência da ponta. A análise da Tabela 6 , contudo, mostra que as considerações de embutimento da ponta são diferentes para esses métodos. Portanto, a diferença entre eles agora passa a ser dada pela relação entre a média de 3 SPT's em torno da ponta e a média do trecho 8D acima e 3D abaixo da ponta.

Desse modo, sem que se apliquem plenamente os métodos, pode-se prever a relação entre seus resultados a partir da metodologia proposta. Obviamente, ao se aplicar um deles que, por ventura, se aproxime dos valores de ensaio, os demais já terão seu comportamento identificado sem a necessidade de aplicação.

Analisando agora os resultados do artigo: para a estaca EH1, o método de AntunesCabral (AC) foi o que mais se aproximou do valor experimental, enquanto que o de Décourt-Quaresma (DQ) subestimou seu valor, coerentemente com a análise 
proposta acima. Os valores de Décourt-Quaresma corrigidos pelo torque SPT-T resultou valores ligeiramente superiores aos obtidos nos ensaios.

Para esse caso, o método de Gotlieb et al (GT) superestimou em 4,5 vezes o valor da ponta, o que aparentemente não está coerente com a análise feita anteriormente, na qual seu valor estaria próximo ao de Décourt-Quaresma, e, portanto, deveria também subestimá-la. Contudo, isso fica explicado ao se observar que as sondagens (não reproduzidas aqui) constantes do artigo de Alledi et al. (2006), na região de $8 \mathrm{D}$ acima da ponta a sondagem associada a esta estaca $\mathrm{EH} 1$, apresentam grande heterogeneidade. Visto que DQ utiliza valores no entorno de apenas 1,0m (acima e abaixo) da ponta, seu valor não sofreu tal influência, demonstrando a importância de se analisar a sondagem e as condições de embutimento, sendo que nem sempre as indicadas pelo método utilizado são adequadas ao caso em estudo.

Para a estaca EH2, os métodos de Décourt-Quaresma (DQ) e Gotlieb et al (GT) foram os que mais se aproximaram dos valores experimentais da ponta, observando-se que, para essa estaca não havia tamanha variação dos valores de SPT na região 8D acima da ponta. Conclui-se, assim, a coerência com a análise acima apresentada.

Deixa-se aqui de apresentar outros exemplos, ressaltando-se, porém, que com a aplicação da generalização e do conceito de hierarquias, pode-se interpretar de forma mais sólida os resultados dos métodos semiempíricos, reconhecendo-se as características que levam cada um a ser bem ajustado em alguns casos e não tão bem sucedido em outros. Trata-se de uma forma de análise mais interessante do que a mera classificação dos métodos em "conservadores" ou "contra a segurança" e será de grande valia na elaboração da metodologia Semiempírica Unificada aqui proposta.

\subsection{DISCUSSÃO DOS COEFICIENTES PARCIAIS DE INFLUÊNCIA}

Nesse ponto torna-se conveniente abrir um parêntesis na Revisão Bibliográfica até aqui apresentada e discutir-se a consideração dos coeficientes de influência parciais que constituem os coeficientes característicos apresentados.

A partir do identificado no trabalho de Albiero (1990) e da generalização apresentada acima, pode-se expressar que: 


$$
\begin{gathered}
\mathrm{K}_{\mathrm{Lg}(\mathrm{i})}=\left(\mathrm{k}_{\mathrm{ts} L} \cdot \mathrm{k}_{\mathrm{te}} \cdot \mathrm{k}_{\mathrm{tEL}} \cdot \mathrm{k}_{\mathrm{tD}}\right)_{(\mathrm{i})} \\
\mathrm{K}_{\mathrm{Pg}}=\mathrm{k}_{\mathrm{tsP}} \cdot \mathrm{k}_{\mathrm{te}} \cdot \mathrm{k}_{\mathrm{tEP}} \cdot \mathrm{k}_{\mathrm{tD}}
\end{gathered}
$$

O significado de cada um pode ser recuperado dos itens 2.4.1 e 2.4.2 acima:

- $\quad \mathrm{k}_{\mathrm{ts}}$ :coeficiente parcial de influência do tipo de solo;

- $\mathrm{k}_{\mathrm{tE}}$ : coeficiente parcial de influência do tipo de estaca;

- $\mathrm{k}_{\mathrm{tD}}$ : coeficiente parcial de influência das dimensões da estaca;

- $\mathrm{k}_{\mathrm{te}}$ : coeficiente parcial de influência do tipo de sondagem;

Nas expressões (17) e (18), o índice "L" representa o solo do fuste (lateral) da estaca e "P" o solo da ponta, sendo que o "i" representa o solo da camada considerada.

Quando considerados os métodos semiempíricos estudados, pode-se correlacionar seus coeficientes empíricos com estes coeficientes parciais obtendo-se conclusões como as exemplificadas na Tabela 9:

Tabela 9 - Exemplos de decomposição dos coeficientes semiempíricos em coeficientes parciais

\begin{tabular}{ccl}
\hline $\begin{array}{c}\text { Coeficientes } \\
\text { semiempíricos }\end{array}$ & $\begin{array}{c}\text { Coeficientes } \\
\text { parciais }\end{array}$ & \multicolumn{1}{c}{ Significado incorporado } \\
\hline$\alpha_{A V}$ & $\mathrm{k}_{\mathrm{tsL}}$ & tipo de solo do fuste \\
$\mathrm{K}_{\mathrm{AV}}$ & $\mathrm{k}_{\mathrm{ts}} \cdot \mathrm{k}_{\mathrm{te}}$ & tipo de solo e tipo de ensaio (fuste ou ponta) \\
$\mathrm{C}_{\mathrm{PDQ}}$ & $\mathrm{k}_{\mathrm{tsP}}$ & tipo de solo da ponta \\
$\alpha_{\mathrm{DQ}}$ & $\mathrm{k}_{\mathrm{tsP}} \cdot \mathrm{k}_{\mathrm{tEP}}$ & tipo de solo e de estaca para a ponta \\
$\beta_{\mathrm{DQ}}$ & $\mathrm{k}_{\mathrm{tsL}} \cdot \mathrm{k}_{\mathrm{tEL}}$ & tipo de solo e de estaca para o fuste \\
$\beta_{1 \mathrm{CA}}$ & $\mathrm{k}_{\mathrm{ts}} \cdot \mathrm{k}_{\mathrm{tEL}} \cdot \mathrm{k}_{\mathrm{te}}$ & tipo de solo, de estaca e de ensaio para o fuste \\
$\beta_{2 \mathrm{CA}}$ & $\mathrm{k}_{\mathrm{tsP}} \cdot \mathrm{k}_{\mathrm{tEP}} \cdot \mathrm{k}_{\mathrm{te}}$ & tipo de solo, de estaca e de ensaio para a ponta \\
$\beta_{\mathrm{OCA}}$ & $\mathrm{k}_{\mathrm{tD}}$ & de dimensão ou diâmetro \\
\hline
\end{tabular}

Seguem-se as discussões acerca de como são considerados esses coeficientes parciais nos métodos semiempíricos, conforme as análises aqui tecidas.

\subsubsection{Consideração do coeficiente parcial de tipo de solo $\left(\mathrm{k}_{\mathrm{ts}}\right)$}

Amann (2000) considera que dentre os coeficientes parciais aqui descritos o único que se pode considerar que tenha influência exclusiva do tipo de solo é o $\mathrm{k}_{\mathrm{ts}}$, ou seja, a razão de atrito, que correlaciona a resistência de cisalhamento lateral com a resistência da ponta do solo, conforme apresentado em detalhes no Apêndice $B$. 
Resumindo o referido apêndice, Amann (2000) separou esse coeficiente dos de tipo de estaca nos métodos de David Cabral (entre outros), desenvolvidos para estacas específicas, utilizando a relação entre os coeficientes característicos de resistência por cisalhamento lateral e pela ponta. Obteve, assim, valores de $\mathrm{k}_{\mathrm{ts}(\mathrm{CA})}$ próximos aos propostos originalmente no método Aoki-Velloso $\left(k_{\mathrm{ts}(\mathrm{AV})}=\alpha_{\mathrm{AV}}\right)$, sendo o mesmo procedimento aplicável a outros métodos (AMANN, 2004 e 2006), o que demonstrou a validade da generalização proposta.

Incluiram-se nas análises aqui desenvolvidas também os valores obtidos em ensaios realizados por outros autores em diversos tipos de solos e regiões, dentre os quais citam-se: Alonso (1980), Danziger e Velloso (1986), Laprovitera (1988) e Benegas (1993) apud Velloso e Lopes (2002). A partir disso, pode-se aqui propor os seguintes valores médios com seus respectivos desvios para esse coeficiente (Tabela 10):

Tabela 10 - Valores médios e desvios do coeficiente parcial de tipo de solo $\left(\mathrm{k}_{\mathrm{ts}}\right)$ para os diversos métodos semiempíricos

\begin{tabular}{lcc}
\hline \multirow{2}{*}{ Solos } & \multicolumn{2}{c}{$\mathrm{k}_{\mathrm{ts}}(\%)$} \\
\cline { 2 - 3 } & média & desvio padrão \\
\hline Areia & 1,90 & 0,47 \\
Areia siltosa & 2,44 & 0,54 \\
Areia silto argilosa & 2,62 & 0,43 \\
Areia argilosa & 3,12 & 0,52 \\
Areia argilo siltosa & 3,06 & 0,68 \\
Silte & 3,12 & 0,33 \\
Silte arenoso & 2,87 & 0,73 \\
Silte areno argiloso & 3,13 & 0,27 \\
Silte argiloso & 3,47 & 0,08 \\
Silte argilo arenoso & 3,04 & 0,16 \\
Argila & 5,41 & 0,63 \\
Argila arenosa & 3,27 & 0,53 \\
Argila areno siltosa & 3,54 & 0,76 \\
Argila siltosa & 4,29 & 0,95 \\
Argila silto arenosa & 3,92 & 1,02 \\
\hline
\end{tabular}

\subsubsection{Consideração do coeficiente parcial de tipo de ensaio de campo ou sondagem $\left(k_{\mathrm{te}}\right)$}

Esse coeficiente se presta a considerar outros tipos de ensaio de campo (sondagens) executados, correlacionando-os com o ensaio CPT, aqui considerado como de ensaio de referência. No caso geral dos métodos brasileiros, o ensaio mais 
empregado é o SPT, para o qual diversos autores, já citados no item anterior, pesquisaram seus valores em diversas regiões, como apresentado no Apêndice B.

Albiero (1990), após experimentar diversos tipos de correção dos valores de sondagem SPT e da sua correlação com o CPT, concluiu que, mais importante do que considerar tais correções, é estabelecer as correlações específicas para ao local em estudo, pois, desta forma, os métodos semiempíricos apresentaram melhor desempenho de estimativa com menor dispersão. A partir disso, Amann (2000) propôs utilizar coeficientes de correção dos métodos semiempíricos exclusivamente para a obra ou solo da região estudada (não global), obtendo assim redução significativa do desvio padrão dos resultados.

Essa constatação vai de encontro à proposta da metodologia unificada de correção dos métodos para um local especifico.

Por fim, embora a correção rigorosa desse coeficiente deva ser feita por meio de correlação local entre os dois ensaios (SPT e CPT), considerando-se que a proposta seja corrigir os valores dos coeficientes empíricos a partir da experiência semiempírica brasileira, sua correção se fará de maneira provisória com base nas Hierarquias dos Solos.

A Tabela 11 apresenta os valores de $k_{\text {te }}$ médios e seus desvios, considerando os valores propostos pelos diversos autores apresentados no Apêndice B.

Tabela 11 - Valores médios e desvios do coeficiente parcial de tipo de ensaio $\left(k_{\text {te }}\right)$ para os diversos métodos semiempíricos

\begin{tabular}{lcc}
\hline \multirow{2}{*}{ Solos } & \multicolumn{2}{c}{$\mathrm{k}_{\mathrm{te}}\left(\mathrm{kN} / \mathrm{m}^{2}\right)$} \\
\cline { 2 - 3 } & media & desvio padrão \\
\hline Areia & 777 & 189 \\
Areia siltosa & 670 & 131 \\
Areia silto argilosa & 620 & 83 \\
Areia argilosa & 557 & 29 \\
Areia argilo siltosa & 533 & 51 \\
Silte & 453 & 40 \\
Silte arenoso & 510 & 29 \\
Silte areno argiloso & 427 & 59 \\
Silte argiloso & 283 & 39 \\
Silte argilo arenoso & 343 & 70 \\
Argila & 233 & 25 \\
Argila arenosa & 423 & 92 \\
Argila areno siltosa & 300 & 0 \\
Argila siltosa & 243 & 17 \\
Argila silto arenosa & 320 & 29 \\
\hline
\end{tabular}




\subsubsection{Consideração dos coeficientes parciais de tipo de estaca $\left(k_{\mathrm{tE}}\right)$}

Esse coeficiente busca adaptar os métodos às diversas estacas, pois, em geral, cada autor inicia o estudo para um tipo de estaca, considerada como referência. Amann (2002, 2004 e 2006) procurou isolar esse coeficiente dos demais nos diversos métodos, procedimento que pode ser visto em detalhes no Apêndice $B$, sendo aqui apresentadas suas conclusões.

Verificou-se que o método Décourt-Quaresma considera o coeficiente de tipo de estaca $\left(\mathrm{k}_{\mathrm{tE}}\right)$ variável com o tipo de solo, tanto para a ponta quanto para o fuste, enquanto é possível admitir que todos os demais consideram-no constante e independente do tipo de solo. Isso também é discutido no Apêndice B.

Para atender aos objetivos propostos de definição da Metodologia Semiempírica Unificada, propõe-se aqui valorizar a experiência brasileira, a qual indica, para a maioria dos métodos, que o coeficiente de tipo de estaca pode ser considerado constante e independente do tipo de solo. Interpreta-se, assim, que os valores adotados pelos diversos autores se referem às médias ajustada dos valores individuais de cada tipo de solo. $\mathrm{Na}$ etapa de aferição e correção dos coeficientes, contudo, as duas formas de análise serão consideradas para atender à proposta de metodologia unificada.

Como conclusão, considerando-se as análises aqui descritas, a fim de se sugerirem valores desse coeficiente para ponta e fuste, a Tabela 12 apresenta os valores médios com respectivo desvio padrão, tomando-se todos os métodos semiempíricos e relacionando-os à estaca pré-moldada cravada, aqui considerada como estaca de referência geral.

Tabela 12 - Valores médios de $\mathrm{k}_{\mathrm{tE}}$ do fuste $(\mathrm{L})$ e da ponta $(\mathrm{P})$ a partir dos métodos semiempíricos analisados, relativos à estaca prémoldada cravada (de referência)

\begin{tabular}{ccccc}
\hline \multirow{2}{*}{ Estaca } & \multicolumn{2}{c}{$\begin{array}{c}\mathrm{k}_{\mathrm{tEL}} \text { relativo ao fuste da } \\
\text { estaca cravada }\end{array}$} & $\begin{array}{c}\mathrm{k}_{\mathrm{tEP}} \text { relativo à ponta da } \\
\text { estaca cravada }\end{array}$ \\
\cline { 2 - 5 } & média & desvio padrão & média & desvio padrão \\
\hline Franki & 0,31 & 0,25 & 0,46 & 0,20 \\
Metálica & 0,29 & 0,02 & 0,61 & 0,25 \\
Prémoldada cravada & 0,29 & 0,00 & 0,57 & 0,00 \\
Strauss & 0,20 & 0,18 & 0,37 & 0,13 \\
Raiz & 0,44 & 0,11 & 0,47 & 0,22 \\
Hélice contínua & 0,26 & 0,12 & 0,32 & 0,28 \\
Esc. Gde. Diâm. & 0,21 & 0,19 & 0,35 & 0,16 \\
Ômega & 0,27 & 0,15 & 0,47 & 0,27 \\
\hline
\end{tabular}




\subsubsection{Consideração do coeficiente parcial de dimensões ou diâmetro $\left(\mathbf{k}_{\mathrm{tD}}\right)$}

Décourt (1996a) comenta que a influência da forma (circular, quadrada, etc.) da estaca ainda é controversa e, portanto, não será aqui abordada. Porém alguns autores sugerem correções de resistência por efeito das dimensões da estaca comparadas às do cone CPT, devendo isso eventualmente ser levada em conta. No Apêndice B apresentam-se as expressões consideradas por alguns autores pesquisados por Albiero (1990), as consideradas por David Cabral $\left(\beta_{0}\right)$ em seus métodos e as que constam nos métodos Aoki-Velloso e PPC Velloso (1981) para estacas cravadas (Tabela 2). Da análise destas chega-se aqui à proposta de uma expressão unificada dada por:

$$
k_{t D}=1+\frac{a_{D}}{100} \cdot\left(b_{D}-\frac{D}{d_{c}}\right)
$$

sendo: $\quad a_{D}$ : constante que depende do tipo de estaca;

$b_{D}$ : constante que depende do tipo de estaca;

D: diâmetro da estaca em [cm];

$\mathrm{d}_{\mathrm{c}}$ : diâmetro da ponteira do cone igual $3,568 \mathrm{~cm}$;

Em geral os valores de $a_{D}$ e $b_{D}$ são adotados como iguais a 1,0 pelos autores internacionais (DeBeer ou Holeyman, apud VELLOSO e LOPES, 2002), o que pode ser considerado praticamente uma média em relação às considerações dos métodos brasileiros para estacas escavadas de grande diâmetro (EGD), raiz, e prémoldada cravada, conforme se vê na Figura 7 , cujos comentários podem ser vistos no Apêndice B.

Como em geral não se tem muitos subsídios para a correção desse coeficiente, pois seria preciso uma série de avaliações em estacas de diferentes diâmetros, sugerese considerar seu valor igual a 1,0 na metodologia a ser desenvolvida, só modificando-o quando houver mais de um diâmetro sendo analisado no mesmo local. 


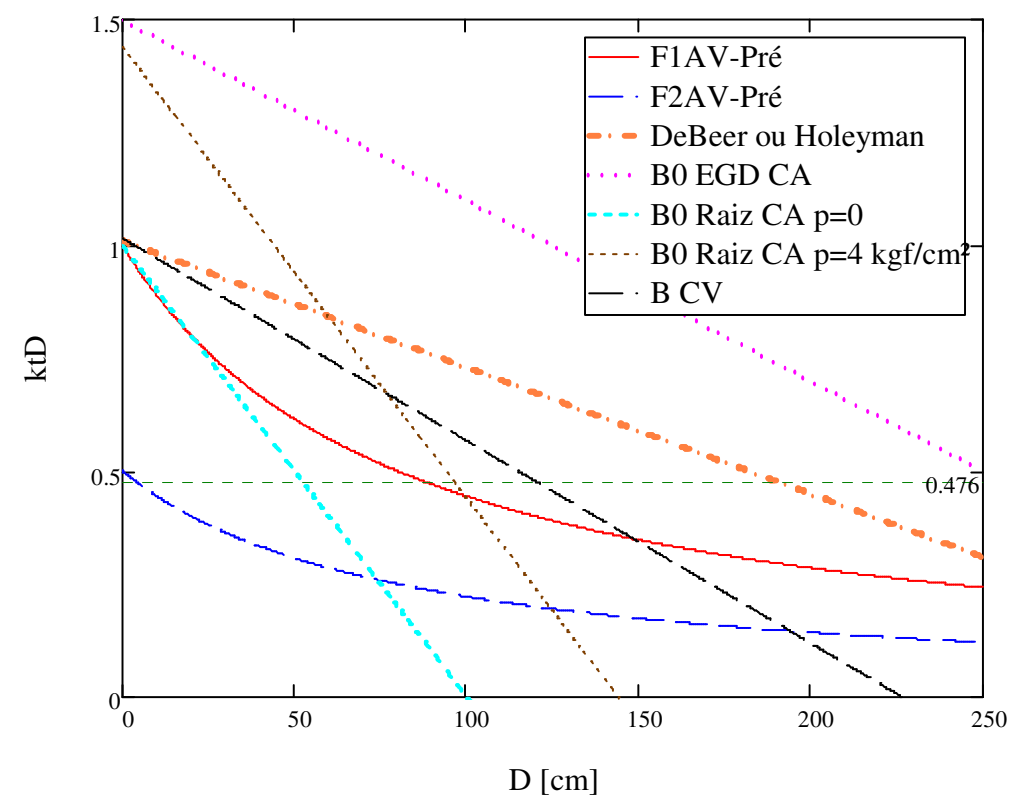

Figura 7 - Variação do coeficiente $\mathrm{k}_{\mathrm{t} D}$ para diversos métodos $\left(\mathrm{B} 0=\beta_{0}\right)$.

\subsection{DISCUSSÃO DAS CONDIÇÕES DE EMBUTIMENTO DA PONTA}

As considerações de embutimento da ponta constantes da Tabela 6 para cada método semiempírico estudado são aqui interpretadas como oriundas dos métodos teóricos (ver Figura 3). Reconhece-se assim mais uma ligação conceitual entre os métodos teóricos e semiempíricos, como se apresenta na Figura 8:

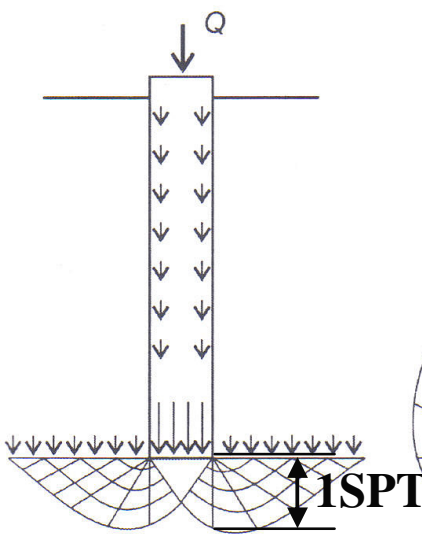

(a)

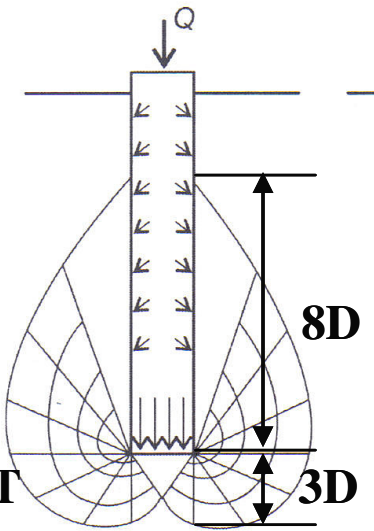

(b)

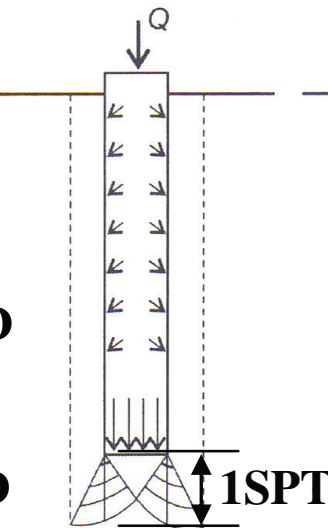

(c)

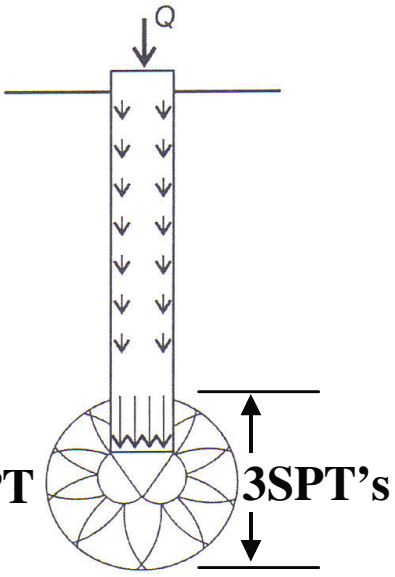

(d)

Figura 8 - Interpretação do embutimento dos métodos semiempíricos a partir dos métodos teóricos de: a) Terzaghi (1943); b) De Beer (1945) e Meyerhof (1953); c) Berezantzev (1961), d) Skempton e Yassin (1953); adaptado de VELLOSO e LOPES, 2002. 
Alguns métodos na Tabela 6 apresentam valores de 7,5D e 3,5D para 0 embutimento, o que pode ser considerado certo preciosismo, podendo-se aproximálos a 8D e 3D para fins práticos. Nada impede, porém, que sejam adicionalmente considerados na aplicação da Metodologia Semiempírica Unificada para comparação e verificação de adequação dos valores ao solo local.

Assim, os casos (a) e (c) da Figura 8 podem ser associados aos métodos que consideram apenas o valor de SPT na cota da ponta estaca. O caso (d) pode ser associado aos métodos que utilizam 3 valores de SPT em torno da ponta. Deve-se considerar que para o caso de Décourt-Quaresma, por exemplo, considerar o embutimento fixo em 1,0m acima e 1,0m abaixo, para um intervalo de diâmetros de $10 \mathrm{~cm}$ (raiz) a $250 \mathrm{~cm}$ (EGD), representa a variação da consideração do embutimento desde 10D até 0,4D.

Cada um desses tipos de embutimento da Figura 8 serão considerados no desenvolvimento da metodologia unificada, de forma a permitir que se verifique qual deles melhor corresponde ao caso em estudo.

De forma geral, recomenda-se aqui que o embutimento seja analisado juntamente com a sondagem e não apenas considerado o indicado pelo método empregado, pois, em alguns casos, isso pode levar a resultados superestimados, como já exemplificado no item 2.8. Trata-se portanto de outra forma de correção e modificação dos métodos semiempíricos, a qual será avaliada neste estudo.

\subsection{PROPOSTA DE MÉTODOS DE TESTE PARA EXEMPLIFICAR A APLICAÇÃO DA METODOLOGIA SEMIEMPIRICA UNIFICADA (MSU)}

Diante de todo o exposto até este ponto, explorando conceitualmente os métodos semiempíricos, pode-se sugerir que os exemplos de utilização da Metodologia Semiempírica Unificada a ser desenvolvida se façam não pela sua aplicação a todos os métodos, mas a um ou dois métodos de teste que representem os métodos estudados, para evitar sua aplicação repetidas vezes no texto. A partir dos exemplos aplicados e comentados a estes métodos de teste, a aplicação aos demais fica imediata. 
Deve-se considerar que estes métodos serão corrigidos pela aplicação da Metodologia Semiempírica Unificada a ser desenvolvida e, portanto, ao final, os valores obtidos serão idênticos àqueles obtidos da correção de qualquer outro método, pois a MSU deve convergir necessariamente para o valor otimizado. Neste sentido, ela permitirá corrigir os métodos, mas também utilizar quaisquer tabelas de coeficientes de que se disponha.

Assim sendo, dois são os métodos de teste a serem aplicados.

\subsubsection{Método Mediado de teste}

Este método é sugerido para representar os métodos que adotam a somatória das resistências, camada a camada de solo, ao longo do fuste e apenas o solo imediatamente abaixo da ponta. A fórmula de cálculo é dada pelas expressões (17) e (18) e os coeficientes desse método podem ser vistos na Tabela $10\left(k_{t s}\right)$, Tabela $11\left(k_{t e}\right)$, Tabela $12\left(k_{t E}\right)$ e $k_{t D}=1,0$.

A denominação "Mediado" vem do fato de seus coeficientes corresponderem à media de todos os demais métodos.

A aplicação desse método de teste permitirá a exemplificação de como corrigir os métodos que correspondam a essa consideração, conforme a Tabela 6.

A consideração apenas do solo da ponta se deve ao fato de não ser prática a correção dos métodos no caso de mais de uma estaca instalada no mesmo terreno, com variação nas condições de embutimento. Isso gera uma tal variedade de condições de ponta que não é possível corrigir nem ponta nem atrito lateral de forma adequada. A simplificação da condição de embutimento, por outro lado, permite que a correção seja feita de forma facilitada. Contudo, serão efetuados exemplos de correção para os casos de estaca isolada em que a ponta seja considerada com embutimento diferenciado, conforme o discutido no item 2.10.

\subsubsection{Método Expedito de teste}

A partir da discussão apresentada no item B.10 do Apêndice B, sobre a validade de se adotar um coeficiente único constante para o cisalhamento lateral sem considerar a influência do solo, como fazem alguns dos métodos estudados, sugere-se a 
proposição de um método de teste que considere o coeficiente de tipo de solo e de tipo de ensaio um único valor médio constante. O nome "expedito" é devido à simplificação da etapa de avaliação da resistência de cada camada de solo do fuste. Este valor deve ser aplicado à média dos SPT's ao longo do fuste.

Assim, ao invés de se utilizarem os coeficientes $k_{t s}$ e $k_{t e}$, estes são substituídos pelo coeficiente característico $\mathrm{k}_{\mathrm{tse}}=\mathrm{k}_{\mathrm{ts}} \cdot \mathrm{k}_{\mathrm{te}}=14 \mathrm{kN} / \mathrm{m}^{2}$, com base no valor médio arredondado dos produtos da Tabela 10 pela Tabela 11. A Tabela $12\left(\mathrm{k}_{\mathrm{tE}}\right)$ deve ser usada normalmente para considerar o tipo de estaca e recomenda-se usar ainda a Tabela 11 para o solo da ponta pois o uso de um único valor médio neste caso traz dispersões muito grandes. Esse valor deve ser multiplicado pela média de três SPT's em torno da ponta.

Este método representa vários métodos analisados e permitirá exemplificar suas aplicações.

\subsection{EXEMPLO DE APLICAÇÃO DOS MÉTODOS DE TESTE}

Para exemplificar a aplicação destes métodos de teste escolheu-se a estaca denominada G202 (AMANN, 2000), tipo raiz, constante do trabalho de Corrêa (1988), que apresenta as seguintes características: $D=250 \mathrm{~mm} ; \mathrm{L}=20,92 \mathrm{~m} ; \mathrm{Kr}=63$ kN/mm, solo do Guarujá (litoral - SP) e cuja aplicação do exposto neste capítulo, com as tabelas do item 2.9, resulta no condensado de informações da Tabela 13 e seguintes:

Tabela 13 - Aplicação dos métodos Mediado e Expedito de teste à estaca G202 (AMANN, 2000)

\begin{tabular}{ccccc}
\hline Solo & $\begin{array}{c}\text { Argila silto } \\
\text { arenosa }\end{array}$ & $\begin{array}{c}\text { Areia } \\
\text { siltosa }\end{array}$ & $\begin{array}{c}\text { Argila } \\
\text { siltosa }\end{array}$ & $\begin{array}{c}\text { Silte } \\
\text { arenoso }\end{array}$ \\
\hline $\mathrm{N}_{\text {méd (i) }}$ & 3,0 & 8,0 & 3,4 & 15,0 \\
$\Delta \mathrm{L}^{\prime} \mathrm{L}_{(\mathrm{i})}$ & 0,043 & 0,712 & 0,239 & 0,006 \\
$\Delta \mathrm{L} / \mathrm{L}_{(\mathrm{i})}(3 \mathrm{D})$ & 0,045 & 0,707 & 0,248 & - \\
$\Delta \mathrm{L} / \mathrm{L}_{(\mathrm{i})}(8 \mathrm{D})$ & 0,048 & 0,688 & 0,264 & - \\
$\mathrm{k}_{\mathrm{ts}}(\%)$ & 3,918 & 2,438 & 4,291 & 2,873 \\
$\mathrm{k}_{\mathrm{te}}\left(\mathrm{kN} / \mathrm{m}^{2}\right)$ & 320,0 & 670,0 & 243,3 & 510,0 \\
$\mathrm{k}_{\mathrm{tEL}}$ & 0,439 & 0,439 & 0,439 & 0,439 \\
$\mathrm{k}_{\mathrm{tEP}}$ & 0,474 & 0,474 & 0,474 & 0,474 \\
$\mathrm{~K}_{\mathrm{tD}}$ & 1,0 & 1,0 & 1,0 & 1,0 \\
$\mathrm{~K}_{\mathrm{Lg}(\mathrm{i}) \mathrm{kN} / \mathrm{m}^{2}}$ & 5,51 & 7,18 & 4,59 & 6,44 \\
$\mathrm{~K}_{\mathrm{Pg}(\mathrm{i})} \mathrm{kN} / \mathrm{m}^{2}$ & 151,6 & 317,3 & 115,3 & 241,6 \\
$\mathrm{q}_{\mathrm{L}(\mathrm{i})}\left(\mathrm{kN} / \mathrm{m}^{2}\right)$ & 16,52 & 57,13 & 15,60 & 96,56 \\
\hline
\end{tabular}


Nessa tabela a simbologia dada por (3D) indica os valores obtidos caso se adote o embutimento de 3D acima e 3D abaixo da ponta, e a dada por (8D) representa os valores caso se adotasse o embutimento 8D acima e 3D abaixo da ponta, conforme apresentado no item 2.10. A omissão dessa referência indica a adoção de consideração apenas do SPT do solo da ponta, que nesse exemplo ocorre para o silte arenoso, situação que pode também ser representada pelo símbolo "0D”.

Tabela 14 - Valores do coeficiente característico $\mathrm{K}_{\mathrm{Lg}}$ para o fuste e respectivo SPT $(\mathrm{N})$ médio para cada condição de embutimento

\begin{tabular}{ccc}
\hline Embutimento & $\mathrm{K}_{\mathrm{Lg}}\left(\mathrm{kN} / \mathrm{m}^{2}\right)$ & $\mathrm{N}_{\text {med }}$ \\
\hline OD & 7,74 & 5,9 \\
3D & 7,63 & 5,9 \\
8D & 8,00 & 5,5 \\
\hline $\mathrm{K}_{\text {Lméd }}\left(\mathrm{kN} / \mathrm{m}^{2}\right)$ & 6,20 & 5,9 \\
$\mathrm{~K}_{\text {pméd }}\left(\mathrm{kN} / \mathrm{m}^{2}\right)$ & 211,35 & 26,0 \\
\hline
\end{tabular}

A Tabela 14 apresenta os valores do coeficiente característico de resistência por cisalhamento lateral $\left(\mathrm{K}_{\mathrm{Lg}}\right)$ para cada condição de embutimento considerada e o respectivo valor médio do SPT ao longo do fuste, descontado o trecho de embutimento, conforme o método Mediado de teste. $\mathrm{O}$ valor de $\mathrm{K}_{\mathrm{Lm} \text { éd }}$ representa $\mathrm{O}$ mesmo coeficiente calculado, considerando-se o SPT médio ao longo do fuste independentemente das camadas de solo, correspondendo, portanto, ao método Expedito de teste. $\mathrm{O}$ valor $\mathrm{K}_{\text {pméd }}$ representa o valor do coeficiente característico, considerando a média de 3 valores de SPT em torno da ponta para o mesmo método Expedito.

Tabela 15 - Valores das tensões e carga no fuste para cada condição de embutimento e modelo de consideração das camadas no método Mediado

\begin{tabular}{ccccc}
\hline Modelo & Tensão & $\left(\mathrm{kN} / \mathrm{m}^{2}\right)$ & Estimativa & $(\mathrm{kN})$ \\
\hline somatória & $\mathrm{q}_{\mathrm{Lg}}$ & $=45,68$ & $\mathrm{P}_{\mathrm{L}}$ & $=750,54$ \\
das & $\mathrm{q}_{\mathrm{L} 3 \mathrm{D}}$ & $=45,02$ & $\mathrm{P}_{\mathrm{L} 3 \mathrm{D}}$ & $=713,18$ \\
camadas & $\mathrm{q}_{\mathrm{L} 8 \mathrm{D}}$ & $=44,22$ & $\mathrm{P}_{\mathrm{L} 8 \mathrm{D}}$ & $=657,09$ \\
\hline \multirow{4}{*}{ média } & $\mathrm{q}_{\mathrm{Lmed}}$ & $=36,60$ & $\mathrm{P}_{\mathrm{LN}}$ & $=601,43$ \\
& $\mathrm{q}_{\mathrm{Lmed} 3 \mathrm{D}}$ & $=36,60$ & $\mathrm{P}_{\mathrm{LN} 3 \mathrm{D}}$ & $=579,87$ \\
& $\mathrm{q}_{\mathrm{Lmed8D}}$ & $=34,29$ & $\mathrm{P}_{\mathrm{LN} 8 \mathrm{D}}$ & $=509,48$ \\
\hline
\end{tabular}

A Tabela 15 apresenta os valores calculados em cada modelo de consideração das camadas de solo para o método Mediado. O valor correspondente ao cisalhamento lateral para o método Expedito é igual ao qLmed3D.

O significado de cada carga estimada pode ser definido como: 
a) carga transferida por atrito lateral na ruptura estimada por somatória das camadas $\left(\mathrm{P}_{\mathrm{L}}\right)$;

b) idem, sem o trecho de 3D acima da ponta $\left(P_{L 3 D}\right)$;

c) idem, sem o trecho 8D acima da ponta $\left(P_{\mathrm{L} 8 \mathrm{D}}\right)$;

d) idem, calculada pela média do SPT do fuste $\left(P_{L N}\right)$;

e) idem, sem o trecho de 3D $\left(P_{L N 3 D}\right)$;

f) idem, sem o trecho 8D $\left(P_{L N 8 D}\right)$.

Tabela 16 - Valores das tensões e carga na ponta para cada condição de embutimento e modelo de consideração das camadas no método Mediado

\begin{tabular}{cccc}
\hline Tensão & $\mathrm{kN} / \mathrm{m}^{2}$ & Estimativa & $\mathrm{kN}$ \\
\hline $\mathrm{q}_{\mathrm{Pg}}$ & $=3623$ & $\mathrm{P}_{\mathrm{P}}$ & $=177,86$ \\
$\mathrm{q}_{\mathrm{Pg} 3 \mathrm{D}}$ & $=6280$ & $\mathrm{P}_{\mathrm{P} 3 \mathrm{D}}$ & $=308,29$ \\
$\mathrm{q}_{\mathrm{Pg} 8 \mathrm{D}}$ & $=5863$ & $\mathrm{P}_{\mathrm{P} 8 \mathrm{D}}$ & $=287,78$ \\
\hline $\mathrm{q}_{\mathrm{P} 3}$ & $=5495$ & $\mathrm{P}_{\mathrm{P} 3}$ & $=269,74$ \\
\hline
\end{tabular}

$\mathrm{Na}$ Tabela 16, apresentam-se os valores das tensões de ponta para cada caso de embutimento e o valor $\mathrm{q}_{\mathrm{p} 3}$ refere-se à ponta do método Expedito.

O significado de cada carga de ponta estimada pode ser definido como:

a) ponta apoiada (OD) no SPT da camada inferior $\left(\mathrm{P}_{\mathrm{P}}\right)$;

b) embutida 3D acima e 3D abaixo da ponta $\left(\mathrm{P}_{\mathrm{P} 3 \mathrm{D}}\right)$;

c) embutida 8D acima e 3D abaixo da ponta $\left(\mathrm{P}_{\mathrm{P} 8 \mathrm{D}}\right)$.

d) média de 3 SPT's em torno da ponta $\left(\mathrm{P}_{\mathrm{p} 3}\right)$

Tabela 17 - Cargas de ruptura estimadas pelos diversos modelos de consideração do atrito lateral e do embutimento da ponta par os métodos de teste.

\begin{tabular}{ccll}
\hline Modelo & Estimativa & \multicolumn{1}{c}{ Cálculo } & \multicolumn{1}{c}{$(\mathrm{kN})$} \\
\hline Somatória & $\mathrm{P}_{\mathrm{R}}$ & $=\mathrm{P}_{\mathrm{L}}+\mathrm{P}_{\mathrm{P}}$ & $=928,41$ \\
das & $\mathrm{P}_{\mathrm{R} 3 \mathrm{D}}$ & $=\mathrm{P}_{\mathrm{L} 3 \mathrm{D}}+\mathrm{P}_{\mathrm{P} 3 \mathrm{D}}$ & $=1021,47$ \\
camadas & $\mathrm{P}_{\mathrm{R} 8 \mathrm{D}}$ & $=\mathrm{P}_{\mathrm{L} 8 \mathrm{D}}+\mathrm{P}_{\mathrm{P} 8 \mathrm{D}}$ & $=944,87$ \\
\hline \multirow{3}{*}{ Média } & $\mathrm{P}_{\mathrm{RN}}$ & $=\mathrm{P}_{\mathrm{LN}}+\mathrm{P}_{\mathrm{P}}$ & $=779,30$ \\
& $\mathrm{P}_{\mathrm{RN} 3 \mathrm{D}}$ & $=\mathrm{P}_{\mathrm{LN} 3 \mathrm{D}}+\mathrm{P}_{\mathrm{P} 3 \mathrm{D}}$ & $=888,16$ \\
& $\mathrm{P}_{\mathrm{RN} 8 \mathrm{D}}$ & $=\mathrm{P}_{\mathrm{LN} 8 \mathrm{D}}+\mathrm{P}_{\mathrm{P} 8 \mathrm{D}}$ & $=797,26$ \\
\hline Expedito & $\mathrm{P}_{\mathrm{RN} 3 \mathrm{P}}$ & $=\mathrm{P}_{\mathrm{LN} 3 \mathrm{D}}+\mathrm{P}_{\mathrm{P} 3}$ & $=849,61$ \\
\hline
\end{tabular}

Finalmente, na Tabela 17 apresentam-se as cargas de ruptura utilizando o método Mediado, fazendo-se a combinação dos diversos resultados referentes aos modelos de consideração do cisalhamento lateral e do embutimento da ponta, a saber: pelo método Mediado: $P_{R}, P_{R 3 D}, P_{R 8 D}, P_{R N}, P_{R N 3 D}, P_{R N 8 D}$, e mais uma pelo Expedito: $P_{\text {RN3P. }}$ 
Considerando-se todos esses valores, é possível interpretar todos os tipos de métodos semiempíricos e, ao mesmo tempo, é dada a abertura para se identificar qual dos modelos de consideração do cisalhamento lateral e de embutimento da ponta é o mais adequado ao solo e estaca em questão. Desta forma, a Metodologia Semiempírica Unificada não pretende estabelecer de antemão a forma de embutimento ou de consideração do fuste, mas permitir que os resultados demonstrem qual é o modelo mais adequado ao solo em questão.

Estss resultados referem-se, portanto, à primeira etapa de Previsão (estimativa) da Capacidade de Carga da estaca, devendo tais valores serem confrontados com os critérios de ruptura da curva carga-recalque, mas não da forma como se faz com o atual paradigma de análise. 


\section{VERIFICAÇÃO DO DESEMPENHO DE ESTACAS}

Neste capítulo, abordam-se os diversos critérios de ruptura sobre as curvas cargarecalque de ensaios de prova de carga. São analisadas as considerações de Fellenius $(1980,2006)$, entre outros autores, sobre tais critérios e alguns trabalhos de Amann (2008a, b e c) para definição de parada do ensaio. Buscando melhor interpretá-los, propõe-se uma comparação com o método de transferência de carga baseado nas Leis de Cambefort modificadas por Massad (1992, 1993).

Por fim, apresentam-se resultados de aplicação dos critérios a casos práticos de estacas e discute-se o paradigma de classificação dos métodos semiempíricos, definindo-se nova proposta a ser empregada na Metodologia Semiempírica Unificada

\subsection{CONSIDERAÇÕES GERAIS}

A verificação do desempenho de um elemento isolado de fundação por estacas é feita pelo chamado ensaio de prova de carga em verdadeira grandeza (dimensões da estaca de teste similares às da obra). A entrada de energia no sistema se faz pela aplicação das cargas no topo da estaca e os resultados obtidos são os recalques (deslocamentos verticais). Apresentados num gráfico, a curva cargarecalque permite definir, em geral, três fases distintas: a primeira reflete uma certa proporcionalidade entre cargas e recalques; a segunda corresponde a uma deformação viscoplástica em que a velocidade de carregamento influi muito sobre os recalques; e a terceira corresponde à definição da carga de ruptura (NIYAMA et al. 1996). A forma da curva, contudo, varia com a rigidez do sistema e com a velocidade do ensaio, que pode ser lenta $(S M L)$, rápida $(Q M L)$, mista (lenta+rápida), cíclica (carga e descarga alternadas), todas regidas pela NBR12131; há ainda o ensaio com penetração constante (CRP), praticamente não utilizado no Brasil.

O ensaio de prova de carga é comumente utilizado para controle da uniformidade de desempenho (comportamento) carga-recalque das estacas de uma obra, sendo especificado, nesse caso, como ensaio não destrutivo (em geral com carga máxima 
de 1,5 vezes a carga de trabalho, ou 1,6 conforme a revisão da norma, apud MARZIONNA, 2008).

Com essa curva de ensaio, é possível verificar o valor de carga admissível da fundação, que deve atender a dois diferentes critérios, segundo a norma brasileira NBR-6122: a) um relacionado ao recalque, segundo o qual a carga admissível deve ser menor do que 1/1,5 vezes a carga que provoca o recalque admissível da estrutura; b) o outro em relação à carga de ruptura $\left(P_{R}\right)$, considerando que a carga admissível não pode superar a metade $\left(\mathrm{P}_{\mathrm{R}} / 2\right)$ de seu valor. Ocorre que nas condições de ensaios não destrutivos, ou quando ocorrem problemas com a estabilidade ou capacidade de carga do equipamento, pode-se não atingir as condições limite, sendo necessário empregar critérios que definam um valor considerado como o de ruptura, com base na curva carga-recalque "interrompida prematuramente" que se obteve.

Para estacas de teste, por outro lado, deve-se necessariamente chegar ao menos a uma carga que atenda aos critérios de ruptura convencional (deslocamento ou recalque limite de 0,1.D a 0,3.D, este último para estacas escavadas). A ruptura física é raramente alcançada, devido ao nível elevado de recalques que exige. Assim, tanto no caso de recalque-limite quanto no de interrupção prematura do ensaio é necessário adotar-se um critério de ruptura para a curva obtida.

Analisando vários desses critérios, Fellenius (1980) afirma que a definição da carga de ruptura deve ser baseada em uma interpretação matemática da curva cargarecalque, a fim de que não haja influência da escala do desenho ou da interpretação pessoal, como ocorre em muitos dos métodos desenvolvidos. Em seu livro eletrônico, Fellenius (2006) apresenta e discute alguns novos métodos e abandona outros anteriormente mencionados. No Apêndice C apresentam-se as considerações desse autor, entre outros, quanto aos diversos critérios aqui abordados para constituição da Metodologia Semiempírica Unificada.

\subsection{CRITÉRIOS DE RUPTURA ANALISADOS}

No presente trabalho, optou-se por enfatizar os métodos mais utilizados no Brasil e aqueles indicados por Fellenius (1980), cujo célebre artigo têm sido referência frequente quando se trata de interpretar provas de carga. Considerando-se o mérito 
deste autor, publicações recentes de sua autoria (FELLENIUS, 2001 e 2006) também são apresentadas como forma de atualização de sua visão do problema. Incluem-se ainda comentários de outros autores a respeito dos métodos selecionados.

Partindo-se do trabalho de Fellenius (1980), dentre os métodos por ele recomendados os nove aqui analisados são apresentados na Tabela 18, organizada por Amann (2008b) na forma de um resumo condensado.

Tabela 18 - Critérios de Ruptura para a Curva Carga-Recalque (P- $\delta$ ) de Estacas, adaptada de AMANN (2008b)

\begin{tabular}{|c|c|c|c|}
\hline Grupo & Autor & Critério & Aplicação \\
\hline \multirow{4}{*}{ Recalque Limite $\delta_{\text {lim }}$} & & interseção da curva $\delta$-P & \\
\hline & NBR6122 (1996) [NBR] & $\begin{array}{c}\text { com a reta } \\
\delta=P .(E . S / L)+(D / 30)\end{array}$ & SML \\
\hline & Terzaghi (1943) [TZ\} & $\delta_{\lim }=\mathrm{D} / 10$ & SML e CRP \\
\hline & $\begin{array}{c}\text { Brinch Hansen (80\%) } \\
\text { (1963) }[\mathrm{BH}]\end{array}$ & $\begin{array}{c}\delta^{1 / 2}=\mathrm{P} .(\mathrm{a} . \delta+\mathrm{b}) \\
\delta_{\lim }=\mathrm{b} / \mathrm{a}\end{array}$ & CRP \\
\hline Rigidez Tangente Limite & Fuller \& Hoy (1970) [FH] & $\mathrm{Kt}_{\text {lim }}=7,0 \mathrm{kN} / \mathrm{mm}$ & $\begin{array}{c}\text { Estacas } \\
\text { Curtas }\end{array}$ \\
\hline \multirow{2}{*}{$\begin{array}{l}\text { Interseção das retas } \\
\text { pseudoelástica e } \\
\text { pseudoplástica }\end{array}$} & Butler \& Hoy (1977) [BT] & $\begin{array}{c}\text { interseção da reta } \\
\text { pseudoelástica com a } \\
\text { pseudoplástica de } \\
\text { inclinação igual a Kt } \mathrm{K}_{\text {lim }}\end{array}$ & 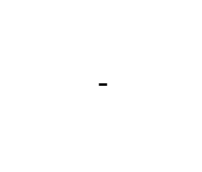 \\
\hline & $\begin{array}{l}\text { De Beer e Wallays } \\
\text { (1972) [BW] }\end{array}$ & $\begin{array}{l}\text { interseção das retas no } \\
\text { diagrama } \log (\delta)-\log (P)\end{array}$ & SML \\
\hline \multirow{3}{*}{ Ajuste matemático } & Chin-Kondner (1970) & $\begin{array}{c}\delta=P \cdot(a \cdot \delta+b) \\
\operatorname{Pr}=1 / a\end{array}$ & - \\
\hline & $\begin{array}{c}\text { Décourt (Rigidez) (1999) } \\
\text { [Rig] }\end{array}$ & $\begin{array}{c}\mathrm{P} / \delta=a \cdot P+b \\
P / \delta=0\end{array}$ & - \\
\hline & $\begin{array}{l}\text { Van der Veen por Aoki } \\
\text { (1976) [VdV] }\end{array}$ & a. $\delta+b=-\ln (1-P / P r)$ & - \\
\hline
\end{tabular}

Legenda da Tabela 18: $\delta$ : recalque $[\mathrm{mm}]$; P: carga $[\mathrm{kN}]$; Pr: carga de ruptura; E: módulo de elasticidade da estaca; $S$ : área da seção transversal da estaca; L: comprimento da estaca; $D$ : diâmetro da estaca; $\mathrm{K}_{\text {tlimm }}$ : rigidez tangente da curva; "a" e "b": parâmetros das expressões matemáticas dos diversos critérios.

Desses, os mais usados no Brasil são os de ajuste matemático, os quais permitem extrapolações da curva de ensaio. Os demais serão considerados para se construir uma visão mais ampla dos critérios, mesmo porque eventualmente também são utilizados nas análises da curva carga-recalque.

A revisão da literatura e a aplicação destes critérios a um caso de obra podem ser vistos no Apêndice $C$, sendo que no capítulo atual se tratará mais da discussão de sua aplicação, sobretudo em relação ao paradigma atual de classificação dos 
métodos semiempíricos. Buscar-se-á, nessa discussão, colherem-se subsídios para a melhor aplicação desses critérios e a proposta de uma nova forma de verificação da aplicabilidade dos métodos com base na Metodologia Semiempírica Unificada.

\subsection{APLICAÇÃO DOS CRITÉRIOS A UM CASO DE OBRA}

No Apêndice C, apresenta-se um exemplo ilustrativo aplicado a uma estaca, sendo aqui discutidos alguns aspectos relevantes quanto à interpretação dessa aplicação, sobretudo à luz do método de transferência de carga das Leis de Cambefort modificadas por Massad (1992), o que fornece subsídios para um melhor entendimento e utilização desses critérios.

O exemplo escolhido foi a estaca E013 dos tanques da Alemoa, em Santos-SP, já analisada por Massad (1994). É uma estaca tipo tubo metálico preenchido com concreto, de comprimento 45,0 m, diâmetro 0,46 m; e rigidez estrutural de 197 $\mathrm{kN} / \mathrm{mm}$, instalada num solo quaternário marinho da Baixada Santista.

Tabela 19 - Pontos obtidos no ensaio de prova de carga da estaca E013 - Alemoa (MASSAD, 1994)

\begin{tabular}{cc}
\hline $\mathrm{P}(\mathrm{kN})$ & $\delta(\mathrm{mm})$ \\
\hline 0 & 0 \\
314 & 0.93 \\
628 & 1.96 \\
943 & 3.53 \\
1257 & 5.61 \\
1571 & 8.48 \\
1885 & 11.76 \\
2199 & 14.70 \\
2513 & 18.55 \\
2827 & 24.97 \\
3104 & 41.97 \\
\hline
\end{tabular}

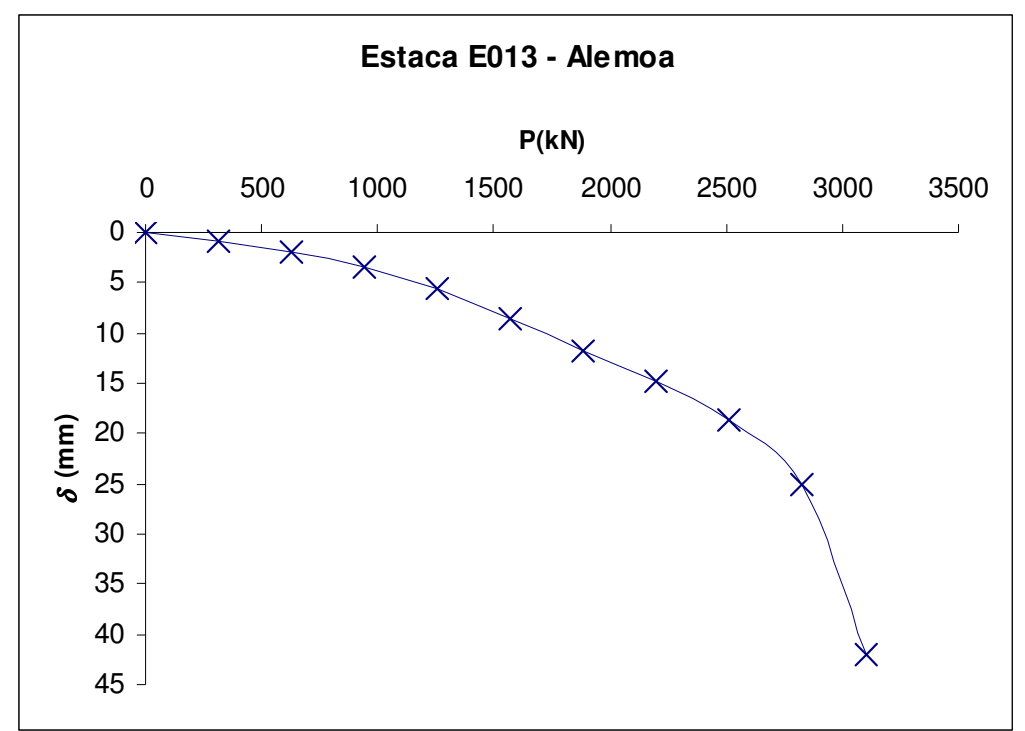

Figura 9 - Curva carga-recalque da prova de carga da estaca E013 - Alemoa (MASSAD, 1994)

A Tabela 19 apresenta os dados de prova de carga, do tipo "carregamento lento", no primeiro ciclo de carga (com cargas residuais de instalação), omitidos os dados do descarregamento. O gráfico obtido dessa tabela de dados é mostrado na Figura 9. 
Nas análises de Massad (1994), usando as Leis de Cambefort modificadas, cerca de 2578 kN correspondem ao aqui chamado "atrito lateral desenvolvido no ensaio". Ao se descontar o efeito das cargas residuais devidas à sua cravação no terreno, obtém-se cerca de 1600 kN como a resistência de atrito (cisalhamento) efetivamente oferecida pelo solo. Essas considerações serão discutidas mais adiante.

\subsection{DISCUSSÃO DA FORMA DE APLICAÇÃO DOS CRITÉRIOS}

É importante destacar que a interpretação dos trabalhos de Fellenius $(1980,2006)$ permite extrair muito mais do que a demonstração de aplicação desses diversos critérios. Pode-se dizer que tais critérios são muito mais indicados por Fellenius (1980, 2006) como de uso prático para estabelecer o ponto de finalização (parada) do ensaio de prova de carga, do que para se estabelecer a carga de ruptura sobre uma curva carga-recalque já executada. Contudo, a interpretação e uso que se tem feito de seus trabalhos é muito mais no segundo sentido do que no primeiro.

De fato, Fellenius (2006, p. 8-10 e 8-11) faz diversas menções ao emprego dos critérios, incluindo os de ajuste matemático, durante (e não depois) a execução do ensaio e alerta que "é fácil enganar-se e acreditar que o trecho extrapolado da curva corresponde a medidas reais". E encerra dizendo que "a capacidade de carga adotada em projeto [...] não deve ser superior à máxima carga aplicada à estaca no ensaio".

$\mathrm{Na}$ realidade brasileira, boa parte das provas de carga não é levada ao nível de recalque desejável, e com isso aplicam-se esses critérios para extrapolações da curva e definição da carga de ruptura pretensamente "física", a qual raramente ocorre. Acrescente-se a isso que os critérios de extrapolação da curva cargarecalque necessariamente resultarão em valores maiores do que a máxima carga aplicada no ensaio. E é justamente esse valor extrapolado que tem sido usado correntemente para classificação dos métodos semiempíricos, segundo o paradigma atual de verificação da aplicabilidade destes, aqui discutido. Os exemplos podem ser vistos no Apêndice $A$, que traz o resumo dos trabalhos apresentados em eventos técnico-científicos brasileiros na última década. 
Portanto, é essencial que, ao se adotar um critério de ruptura para tal verificação de aplicabilidade, isto seja feito de maneira mais consciente, como será proposto mais adiante.

\subsection{DISCUSSÃO DO PARADIGMA DE VERIFICAÇÃO DA APLICABILIDADE DOS MÉTODOS SEMIEMPÍRICOS}

Como já mencionado na justificativa desta pesquisa, os métodos semiempíricos devem passar por uma verificação de sua aplicabilidade quando aplicados a solos distintos dos originalmente estudados por seus autores. Pela análise dos eventos técnico-científicos brasileiros, resumidos no Apêndice $A$, verifica-se que 0 procedimento corrente, aqui chamado de "paradigma atual", tem sido a comparação dos resultados das estimativas semiempíricas a valores dos critérios de ruptura, sobretudo dos que empregam extrapolação da curva carga-recalque. De acordo com o resultado dessa comparação, os métodos são geralmente classificados como "contra a segurança" ou "conservadores", sendo que os que mais se aproximam do valor do critério empregado podem ser considerados "adequados", gerando o que se pode chamar de um ranqueamento.

A partir do apresentado no item anterior, a consideração da adequação de aplicabilidade com base nos critérios de ruptura pode ser questionada. Ainda assim, outros aspectos devem ser levados em conta para discussão da inadequação desse paradigma.

Embora os trabalhos mencionados no Apêndice $A$ sejam concernentes à realidade brasileira, escolheu-se para exemplificar e discutir tal inadequação o trabalho de Titi e Abu-Farsakh (2004), que avaliaram os métodos semiempíricos baseados no CPT propostos por Schmertmann (1978), De Ruiter e Beringen (1979), Bustamante e Gianeselli (1982), Tumay e Fakhroo (1982), Aoki e Velloso (1975), Price e Wardle (1982), Philiponnat (1982) e Clisby et al (1978), aplicados a 35 estacas de concreto com seção quadrada, cravadas em solos argiloso e estratificados. Os autores fazem uma série de avaliações estatísticas para identificarem o desempenho dos métodos em relação ao critério de ruptura de Butler e Hoy (1977). Comentando as conclusões do trabalho, os autores atribuem ao método brasileiro a "qualidade" de subestimar a capacidade de carga das estacas. 
Considerando um exemplo do que usualmente se faz no Brasil, critica-se aqui o trabalho de Titi e Abu-Farsakh (2004) principalmente pela adoção genérica do critério de ruptura de Butler e Hoy (1977), apesar deste nada ter a ver, por exemplo, com o método Aoki-Velloso (1975), que empregou em suas análises o critério de Van der Veen (1953). É importante considerar, com certa ênfase, que ao se empregar um critério de ruptura na concepção de um método semiempírico, tal critério passa a fazer parte inerente do mesmo método e, assim, compará-lo com outros critérios não tem sentido para avaliar o método em si. O que se avalia, nesse caso, é apenas a adequação do método semiempírico ao critério de ruptura escolhido e nada mais.

O mesmo ocorre toda vez que se compara o método Décourt-Quaresma com o critério de Van der Veen, visto que seus autores empregaram originalmente o critério de recalque limite de $10 \%$ do diâmetro (D/10).

Em outras palavras, para se avaliar de fato a aplicabilidade de um método semiempírico deve-se comparar sua estimativa de capacidade de carga com 0 critério de ruptura utilizado pelo seu autor durante sua concepção.

Diante dessa colocação, os trabalhos que ranqueiam os métodos semiempíricos sem aprofundar o conhecimento sobre tais considerações configuram-se num desperdício de recursos, por não serem capazes de atribuir causas aos resultados "contra a segurança" ou "a favor da segurança", como aqui se pretende com a Metodologia Semiempírica Unificada. Se acrescentada a essas assertivas a consideração da dispersão dos valores obtidos nos ensaios de campo mais a dispersão dos critérios de ruptura, pode-se dizer que qualquer pretenso ranqueamento dos métodos semiempíricos se torna na verdade um "jogo de dados".

Mais adiante será proposta uma nova forma de consideração dos critérios de ruptura para verificação da aplicabilidade dos métodos semiempíricos, dentro da proposta da Metodologia Semiempírica Unificada.

Para a melhor interpretação desses critérios, apresentam-se agora algumas considerações dos trabalhos de Amann (2008a, b) sobre sua comparação com od métodos de transferência de carga das Leis de Cambefort modificadas por Massad (1992). 


\subsection{COMPARAÇÃO ENTRE OS CRITÉRIOS DE RUPTURA E OS MÉTODOS DAS LEIS DE CAMBEFORT MODIFICADAS POR MASSAD (1992) E DAS DUAS RETAS DE MASSAD E LAZO (1998)}

Com o intuito de ampliar o conhecimento acerca destes critérios, Amann (2008a) verificou a possibilidade de analisá-los à luz das Leis de Cambefort modificadas por Massad (1992) e do método das Duas Retas de Massad e Lazo (1998), considerados métodos mais refinados de análise da curva carga-recalque. Apresenta-se, a seguir, os conceitos gerais desses métodos para subsidiar as discussões e comparações com os critérios que se seguirão.

\subsubsection{Breve descrição do método das Leis de Cambefort modificadas por Massad (1992) e das Duas Retas (MASSAD e LAZO, 1998)}

O Método das Leis de Cambefort Modificadas e o método das Duas Retas (MASSAD e LAZO, 1998) buscam avaliar a ação do atrito lateral isoladamente sobre a estaca, analisando o valor do recalque elástico da estaca, sob ação exclusivamente da carga de atrito lateral.

A Figura 10 apresenta as expressões matemáticas de cada trecho da curva cargarecalque e a obtenção gráfica da parcela de atrito lateral (Alr) nestes métodos.

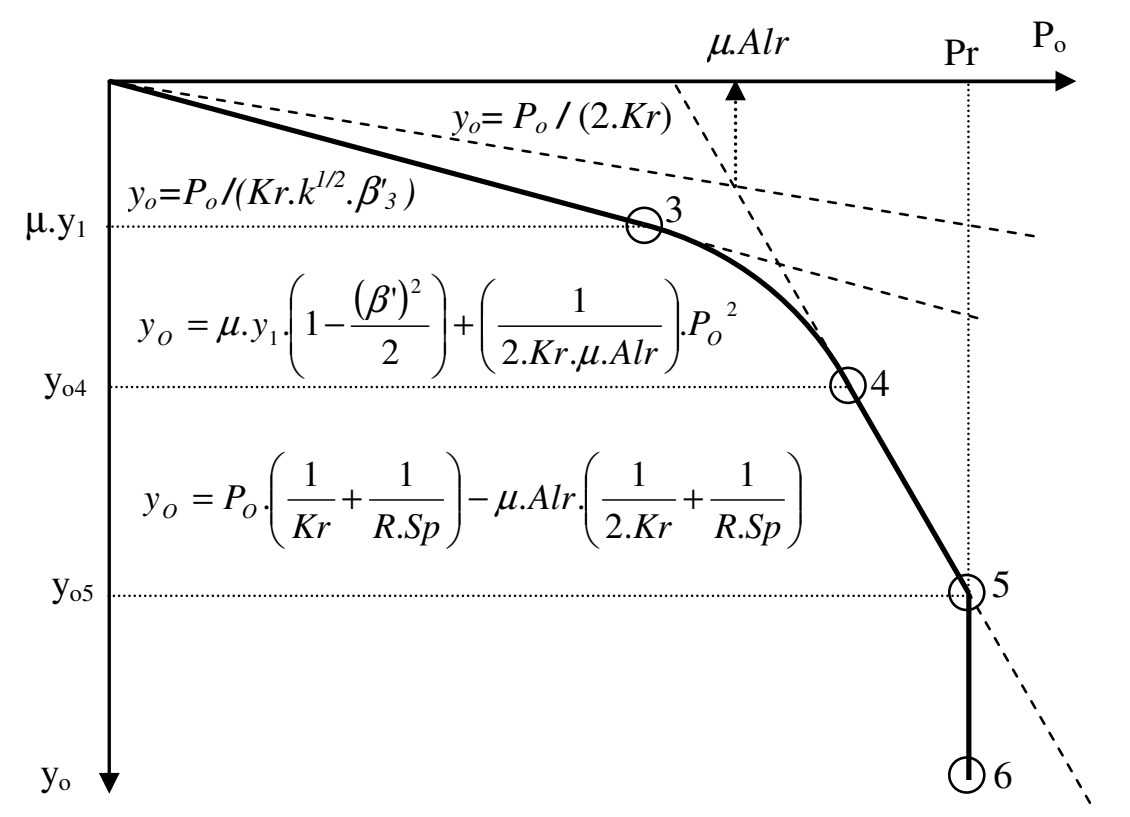

Figura 10 - Método das Leis de Cambefort Modificadas por Massad (1992), apud Amann (2008a) 
Na Figura 10 distinguem-se os seguintes parâmetros:

$\mathrm{y}_{0}$ : recalque no topo da estaca;

$\mathrm{P}_{\mathrm{o}}$ : carga aplicada ao topo da estaca;

Kr: rigidez estrutural da estaca;

k: rigidez relativa estaca (fuste)-solo;

$\beta$ ': coeficiente de influência da ponta na transferência de carga do fuste;

$\beta_{3}{ }^{\prime}$ : valor de $\beta$ ' para mobilização plena do atrito no topo da estaca;

$\mu$ : coeficiente de carga residual;

$\mathrm{y}_{1}$ : recalque do topo na mobilização plena do atrito no topo da estaca; estaca;

$\mathrm{y}_{04}$ : recalque do topo na mobilização plena do atrito à cota da ponta da

$\mathrm{y}_{05}$ : recalque do topo na ruptura da ponta;

$\mathrm{R}$ : coeficiente de rigidez do solo da ponta;

$\mathrm{S}_{\mathrm{p}}$ : área da seção da ponta.

Tabela 20 - Coeficientes do método das Leis de Cambefort modificadas por Massad (1992)

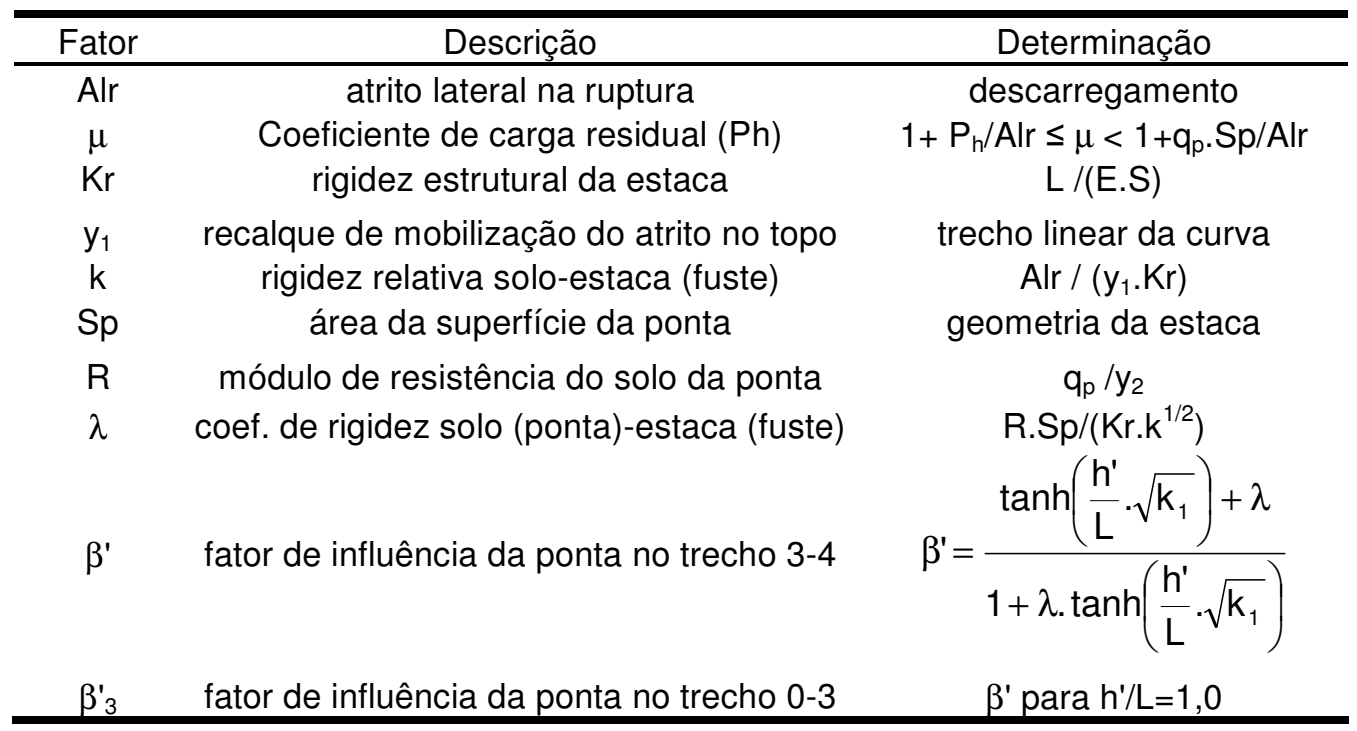

Legenda: $P_{h}$ : carga residual na ponta; $q_{p}$ : tensão de ruptura do solo na ponta; $y_{2}$ : recalque de ruptura da ponta; $h$ ': trecho do fuste com atrito parcialmente mobilizado.

A Tabela 20 complementa as informações do método. Assim, observam-se na figura: o trecho 0-3, pseudoelástico; o trecho 3-4 viscoplástico, em que o cisalhamento lateral é mobilizado progressivamente ao longo do fuste, sob influência da velocidade de carregamento na forma da curva; e o trecho 4-5, que define a mobilização da resistência de ponta até a ruptura no ponto 5.

Para auxiliar na compreensão da relação entre as Leis de Cambefort e os critérios de ruptura, Amann (2008b) desenvolveu uma metodologia para se estimar a curva 
carga-recalque da estaca a partir dos valores dos coeficientes característicos propostos por Amann (2000) e já apresentados e discutidos no item 2.5.

Do trabalho de Amann (2008b), extraiu-se a Tabela 21 com as expressões obtidas para determinação dos pontos notáveis 4 e 5 (Figura 10) do método das Duas Retas (MASSAD e LAZO, 1998), a partir dos coeficientes característicos de cisalhamento lateral $\left(\mathrm{K}_{\mathrm{Lg}}\right)$ e de ponta $\left(\mathrm{K}_{\mathrm{Pg}}\right)$ [AMANN, 2000, já apresentados], aqui notados como "KL"e "Kp", respectivamente.

Note-se que estas expressões indicam que o recalque de ruptura $\left(\mathrm{y}_{05}\right)$ pode ser diretamente relacionado com o diâmetro, como sugere Décourt (1996a) para definição da ruptura convencional. O recalque referente à mobilização plena do atrito lateral também o pode, porém com uma relação do tipo linear ( $\left.\mathrm{y}_{04}=\mathrm{b}+\mathrm{a} . \mathrm{D}\right)$, que de certa forma é compatível com a proposição do critério de ruptura da NBR 6122 (ver detalhes no Apêndice $\mathrm{C}$ ), porém aqui considerando-se também a rigidez do solo e não só a da estaca.

Tabela 21 - Extrato das expressões definidas para cálculo das coordenadas dos pontos notáveis $4 \mathrm{e}$ 5, apud Amann (2008b)

\begin{tabular}{|c|c|c|}
\hline Fator & Expressão do Método & Expressão em função dos parâmetros do sistema \\
\hline$P_{04}$ & $=\mu \cdot A l r+\mu \cdot y_{1} \cdot R \cdot S p$ & $=\mu \cdot \mathrm{KL} \cdot \mathrm{Nf} \cdot\left[\pi \cdot \mathrm{D}^{2} \cdot\left(\frac{\mathrm{L}}{\mathrm{D}}\right)+\frac{\mathrm{D}}{\left(1-v \mathrm{p}^{2}\right)} \cdot \frac{\mathrm{Ep}}{2 \cdot \mathrm{Ef}} \cdot \frac{\mathrm{Dp}}{\mathrm{D}}\right]$ \\
\hline $\mathrm{Y}_{04}$ & $=\mu \cdot \mathrm{y}_{1}+\frac{\mu \cdot \mathrm{Alr}}{2 \cdot \mathrm{Kr}}+\frac{\mathrm{R} \cdot \mathrm{Sp}}{\mathrm{Kr}} \cdot \mu \cdot \mathrm{y}_{1}$ & $=\mu \cdot \frac{K L}{2 \cdot K_{e f}} \cdot\left[1+4\left[m^{-1}\right] \cdot \frac{E f}{E} \cdot D \cdot\left(\frac{L}{D}\right)^{2}+\frac{4}{\pi \cdot\left(1-v p^{2}\right)} \cdot \frac{E p}{E} \cdot\left(\frac{L}{D}\right) \cdot \frac{D p}{D}\right.$ \\
\hline $\mathrm{P}_{05}$ & $=\mu \cdot A l r+\mu \cdot y_{2} \cdot R \cdot S p$ & $=\pi \cdot \mathrm{D}^{2} \cdot\left[\left(\frac{\mathrm{L}}{\mathrm{D}}\right) \cdot \mathrm{KL} \cdot \mathrm{Nf}+\frac{1}{4} \cdot \mathrm{Kp} \cdot \mathrm{Np} \cdot\left(\frac{\mathrm{Dp}}{\mathrm{D}}\right)^{2}\right]$ \\
\hline $\mathrm{Y}_{05}$ & $=\mu \cdot y_{2}+\frac{\mu \cdot A l r}{2 \cdot K r}+\frac{R \cdot S p}{K r} \cdot \mu \cdot y_{2}$ & $\begin{array}{l}=\mathrm{D} \cdot\left[\left(\frac{\pi \cdot\left(1-v \mathrm{p}^{2}\right)}{\mathrm{Ep} \cdot 4[\mathrm{~m}]}+\frac{1}{\mathrm{E}} \cdot\left(\frac{\mathrm{L}}{\mathrm{D}}\right)\right)\right. \\
\left.\left(\frac{\mathrm{Dp}}{\mathrm{D}}\right) \cdot[\mathrm{Kp} \cdot \mathrm{Np}-\mathrm{KL} \cdot \mathrm{Nf} \cdot(\mu-1)]+2 \cdot \mu \cdot\left(\frac{\mathrm{L}}{\mathrm{D}}\right)^{2} \cdot \frac{\mathrm{KL} \cdot \mathrm{Nf}}{\mathrm{E}}\right]\end{array}$ \\
\hline
\end{tabular}

Legenda: diâmetro do fuste da estaca (D); relação comprimento/diâmetro (L/D); relação entre diâmetro da ponta e do fuste $(\mathrm{Dp} / \mathrm{D})$; módulo de elasticidade da estaca $(E)$; módulo de elasticidade do solo do fuste (Ef) e da ponta (Ep); coeficiente de Poisson do solo da ponta (vp); coeficiente característico de atrito lateral (KL); coeficiente característico de atrito lateral $(\mathrm{Kp})$; sondagem SPT média do fuste (Nf); sondagem SPT na ponta (Np); coeficientes de tipo de estaca para fuste e ponta $\left(\mathrm{K}_{\mathrm{ef}}\right.$ e $\left.\mathrm{K}_{\mathrm{ep}}\right)$;coeficiente de carga residual $(\mu)$.

Para ter uma ideia mais específica de qual a carga de ruptura que seria obtida pelos critérios de Van der Veen e de Chin, Amann (2008b) simulou uma prova de carga a partir das expressões da Tabela 21 com valores de coeficientes característicos 
médios, a saber: estaca escavada; $D=500 \mathrm{~mm} ; \mathrm{L} / \mathrm{D}=25 ; \mathrm{E}=25 \mathrm{GPa} ; \mathrm{Dp} / \mathrm{D}=1,0 ; \mathrm{Nf}=$ 20 golpes; $\mathrm{Np}=20$ goles, para solo areia. Para estes valores, a simulação resulta carga de ruptura $\operatorname{Pr}$ no ponto 5 resulta $3141,6 \mathrm{kN}$ com recalque de $62 \mathrm{~mm}$, pouco maior do que $10 \%$ do diâmetro. Esta carga é considerada, para efeito dessa análise, como a hipoteticamente "real".

Assim, tomando-se a curva teórica da estaca de referência simulada e determinando-se incrementos de carga de $10 \%$ da carga de ruptura, simulam-se os pontos da curva de ensaio que permitem compará-la com a curva dos critérios de Van der Veen e de Chin. Com isso busca-se entender como se apresentam os ajustes desses critérios quando aplicados à curva teórica do método das Leis de Cambefort modificadas por Massad (1992).

\subsubsection{Discussão da comparação com os critérios de recalque limite}

Para os critérios de estabelecimento do recalque limite a partir de um valor em relação do diâmetro da estaca, como é caso de Terzaghi (1943), é interessante a opinião de Fellenius (1980, p. 22): "Estas definições não consideram o encurtamento elástico da estaca, que pode ser substancial para estacas longas, enquanto é desprezível para estacas curtas".

Contudo, ao se considerar a expressão de cálculo de $y_{05}$ (recalque de ruptura) na Tabela 21, verifica-se que é possível, a partir de parâmetros da estaca e do solo, calcular-se um valor desta relação para definição do recalque na ruptura na forma $y_{0} / D$. Com isso, lança-se novas possibilidades de análise, podendo-se a partir disto explicar os valores empíricos usualmente admitidos de 0,1D para ruptura de estacas cravadas e 0,3D para ruptura de estacas escavadas, ao mesmo tempo em que isso permitiria o estabelecimento do recalque limite a partir da análise dos parâmetros do sistema estaca-solo, como apresentado naquela tabela.

Se aplicado ao caso de exemplo (Apêndice $C$ ), vê-se que o recalque máximo de ensaio é inferior a 0,1D e, portanto, este é um exemplo de prova de carga em que este não foi utilizado como critério de parada de ensaio, como é a recomendação de Fellenius $(1980,2006)$ e sua aplicação perde o sentido.

Também Fellenius (1994) pondera sobre critérios como o da NBR 6122, o qual deriva do critério de Davisson (1972), e considera que estes não levam em conta 
realmente a forma da curva carga-recalque nem a real transferência de carga aplicada ao solo. No entanto, Fellenius $(1980,2001)$ indica este tipo de método por ser de fácil aplicação e ter o mérito de permitir ao engenheiro, durante a execução do ensaio, determinar o máximo deslocamento para uma determinada carga admissível, considerando as dimensões da estaca.

Dos comentários de Fellenius (2006), extrai-se que o método de Davisson (e da NBR6122), é muito influenciado pela precisão dos dados de ensaio, incluindo o módulo de elasticidade da estaca, que é, na maioria das vezes, simplesmente estimado. Fica aqui a recomendação para os cuidados devidos em sua aplicação.

Destaca-se aqui, contudo, que a reta considerada pelo critério da NBR 6122 pode ser correlacionada com a relação linear $\mathrm{y}_{04}=\mathrm{b}+\mathrm{a} . \mathrm{D}$ e à carga $\mathrm{P}_{04}$ da Tabela 21 , de tal modo que se poderia admitir que o critério da norma pode resultar valores de ruptura próximos muito próximos a $\mathrm{P}_{04}$, que, pela Figura 10, resultaria num valor apenas um pouco superior a $\mu$ Alr, ou seja, ao atrito lateral mais a carga residual, aqui chamado de "atrito desenvolvido no ensaio" para diferenciá-lo do atrito (ou cisalhamento) máximo desenvolvido pelo solo.

Quando se analisa o resultado de aplicação ao exemplo (Apêndice $C$ ), a ruptura dada pela norma é de 2927,5 kN, sendo que das observações de Massad (1994), comentadas no item 3.3, tem-se $\mu \mathrm{Alr}=2594,0 \mathrm{kN}$, apenas $333,5 \mathrm{kN}$ de diferença. Pode-se dizer, portanto, que os resultados do critério de ruptura convencional da NBR 6122 indiquem valores próximos ao ponto 4 da curva carga-recalque, na concepção das Leis de Cambefort modificadas por Massad (1992). A partir disso, pode-se interpretar melhor os resultados desse critério e, a partir da Tabela 21, calcular o valor da constante $\mathrm{y}_{\mathrm{b}}=\mathrm{D} / 30$ que resulte na interseção com a curva, exatamente no ponto 4.

O critério de Brinch Hansen (1963), apesar de ser de recalque limite, estabelece seu valor pelo ajuste matemático da curva, sendo abordado com os critérios desse tipo.

Assim, esses são apenas dois exemplos de como se interpretar os critérios de ruptura, à luz das Leis de Cambefort Modificadas, sendo para esta pesquisa fundamental que os critérios não sejam aplicados para comparação com os métodos semiempiricos sem este pleno entendimento, a fim de se evitarem os equívocos já consagrados pelo paradigma atual. 


\subsubsection{Discussão da comparação com os critérios de rigidez tangente limite e interseção de retas}

O critério de Fuller e Hoy (1970) arbitra a ruptura para uma rigidez tangente limite de $7,0 \mathrm{kN} / \mathrm{mm}$, a qual, em geral, só é obtida na região de desenvolvimento da resistência de ponta, trecho 4-5 (Figura 10). Ocorre, contudo, que nem todas as estacas possuem condições de atingir tal rigidez no trecho 4-5, dependendo dos parâmetros do sistema estaca-solo, conforme a Tabela 21, não sendo possível aplicar este critério.

O exemplo demonstrado no Apêndice $C$ resultou mínima rigidez tangente do trecho 4-5 igual a $16,29 \mathrm{kN} / \mathrm{mm}$ e não se pode garantir que, levando o ensaio a níveis de carga e recalque maiores, ela seria alcançada. Assim, pode-se sugerir que o valor de rigidez tangente limite seja calculado pelos parâmetros do sistema estaca-solo, conforme a Tabela 21 e não simplesmente arbitrado, o que permitiria melhor interpretação desse critério do que a simples adoção do valor empírico de $7 \mathrm{kN} / \mathrm{mm}$. De fato, com a Tabela 21, pode-se, inclusive, identificar as condições em que tal valor pode ou não ser alcançado.

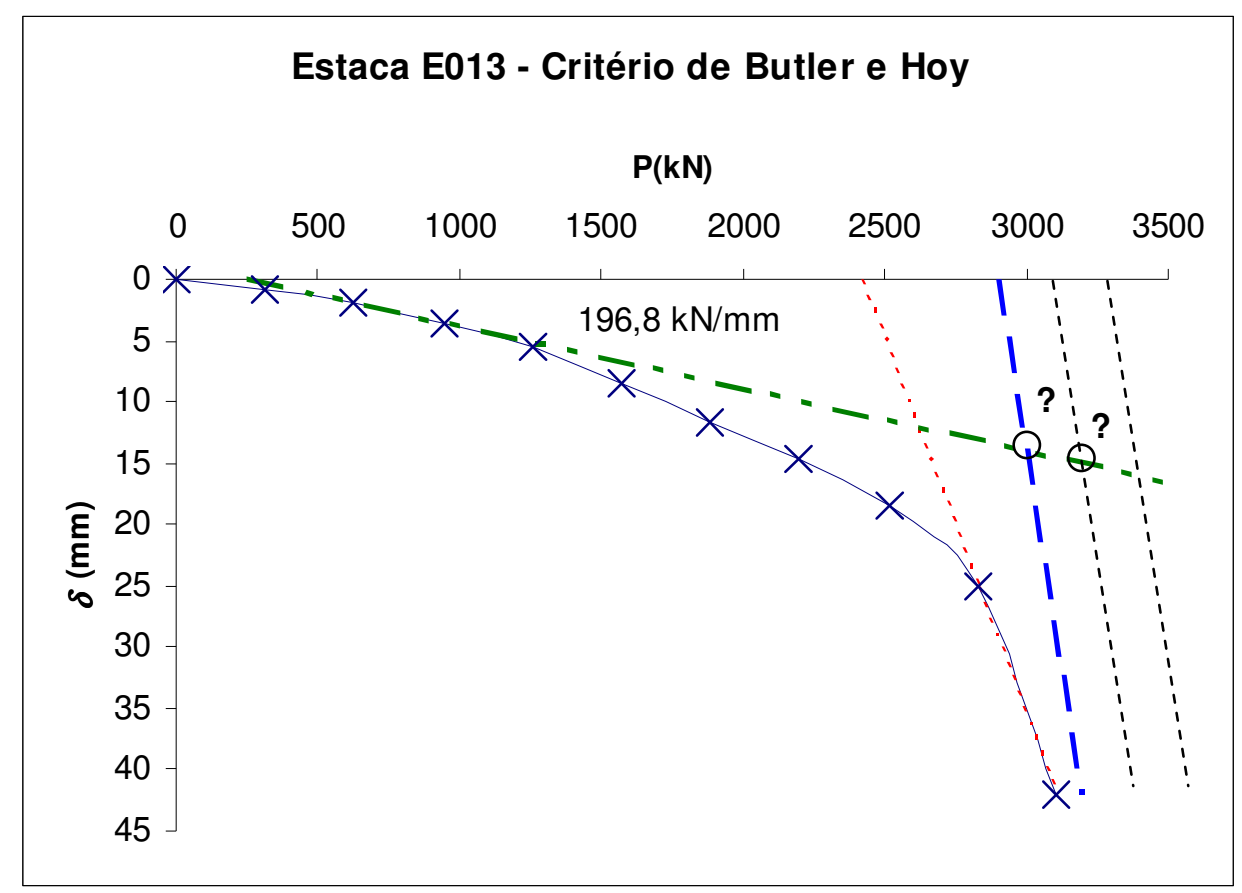

Figura 11- Tentativa de aplicação do critério de Butler e Hoy à estaca E013, a qual não atinge a rigidez tangente limite e $7 \mathrm{kN} / \mathrm{mm}$.

O critério de Butler e Hoy (1977) depende da reta tangente de Fuller e Hoy (1970), pois a ruptura convencional é definida pela interseção entre esta e a reta do trecho 
inicial pseudoelástico da curva (que pode ser definida pela mesma inclinação da reta da NBR6122, porém passando pela origem do diagrama), conforme a Figura 11.

Comparando-se com a Figura 10, pode-se dizer que, se fosse adotada a rigidez tangente igual à rigidez (ou inclinação da reta) do trecho 4-5, o resultado seria um valor entre o ponto 3 e o ponto 4, novamente apenas um pouco acima de $\mu$ Alr. É importante observar, que segundo o método das Duas Retas de Massad e Lazo (1998), o valor de $\mu$ Alr é dado pela interseção entre a reta do trecho 4-5 e a reta de rigidez com inclinação de $2 \mathrm{Kr}$, sendo $\mathrm{Kr}$ a rigidez estrutural da estaca. Dá-se assim, uma interpretação do resultado deste critério em que, caso a rigidez tangente da reta 4-5 chegue a ser menor que os $7 \mathrm{kN} / \mathrm{mm}$ de Fuller e Hoy, essa reta tangencia um ponto da curva entre os pontos 3 e 4 , e seu resultado fica entre $\mu$ Alr e $P_{04}$. Caso a reta 4-5 não atinja tal rigidez, o critério fica indefinido.

Poder-se-ia pensar que este critério indicaria, portanto, a resistência de cisalhamento lateral e não a ruptura da estaca, contudo, é importante lembrar que esse valor de atrito lateral desenvolvido no ensaio $\mu$ Alr não é o valor de resistência do solo por cisalhamento lateral (indicado por MASSAD, 1994, como da ordem de $1600 \mathrm{kN}$, neste caso), pois nele está incorporado o efeito das cargas residuais devidas à instalação da estaca.

Então pode-se dizer que os critérios de Fuller e Hoy e Butler e Hoy indicam o valor de carga de ruptura convencional próximo ao valor do atrito lateral desenvolvido no ensaio ( $\mu \mathrm{Alr}$ ), que é superior à resistência por cisalhamento lateral $\left(P_{L}=A l r\right)$ e inferior à resistência de ponta. Com isso, ao se adotar esse valor de ruptura convencional, tem-se uma "reserva de carga de ponta", cujo valor é indefinido e com a qual a rigor não se pode contar (devido à sua incerteza).

A implicação disto é que a comparação entre os resultados desses critérios e as cargas de ruptura semiempíricas estimadas na primeira etapa da Metodologia Semiempírica Unificada conduzem, necessariamente, a uma subestimativa da carga de ruptura da estaca, impactando a estimativa de fuste e de ponta dos métodos semiempíricos. Assim, se um dos métodos semiempíricos viesse a resultar a carga de ruptura estimada maior do que a ruptura convencional destes critérios, certamente estaria ele mais próximo (embora não se saiba o quanto) da ruptura real do que um outro que tenha acertado "na mosca" o valor deste critério de ruptura. 
Assim, retomando as críticas ao trabalho de Titi e Abu-Farsakh (2004) (que adotaram este critério em suas análises) e ao paradigma atual de verificação da aplicabilidade dos métodos semiempíricos, o que se está verificando atualmente não é se o método semiempírico é aplicável ou não ao solo local, mas sim se ele resulta estimativas próximas ou não do critério de ruptura adotado. Sendo assim, comparar os métodos semiempíricos com outros critérios, diferentes do originalmente empregado pelo seu autor, perde o sentido.

Antes de encerrar este item, comenta-se o critério de De Beer e Wallays (1972), o qual busca num diagrama bilogarítmico $(\log \delta \times \log P)$ definir a ruptura convencional na interseção de duas retas, ou no ponto de mudança da inclinação, também chamada "carga de fluência" (NIYAMA, 1996 e FRANK, 1999).

Como esse critério busca um ponto de mudança de comportamento da curva, este ponto resulta próximo do ponto 4 da Figura 10 . O seu resultado está também próximo à mobilização plena do cisalhamento lateral ao longo do fuste da estaca, com eventual acréscimo de cargas residuais, sendo que, a partir daí, a reta 4-5 define a mobilização da ponta. Portanto, recai-se próxima à consideração já feita para os outros métodos discutidos neste item.

\subsubsection{Discussão da comparação com os critérios de ajuste matemático}

Dentre os critérios de ajuste matemático, os mais utilizados no Brasil são o de Van der Veen (1953) modificado por Aoki (1979) (de agora em diante, simplesmente denominado Van der Veen), o de Chin (1972) e, atualmente o da Rigidez de Décourt (1999), que começa a ser popularizado, sobretudo com a proposta de Décourt (2008) de utilizá-lo para separação da parcela de atrito lateral, como se verá oportunamente. Deve-se considerar, contudo, que o fato desses critérios extrapolarem a ruptura, e, portanto, saírem da região do ponto 4 , isto não significa que seus valores são mais adequados do que os anteriores, mesmo que o ajuste da curva seja muito bom, como se verá.

É importante destacar que a recomendação de Fellenius (2006) para estes critérios é a de realização do ajuste no trecho final da curva, tendo-se portanto ultrapassado o trecho pseudolinear inicial, considerando, assim, que o final da curva indicaria de forma mais adequada (melhor ajuste linear) o valor da carga de ruptura. 
Apresentam-se a seguir algumas considerações dos trabalhos de Amann (2008a e b) sobre a comparação dos métodos de Van der Veen e de Chin aos métodos de transferência de carga das Leis de Cambefort modificadas por Massad (1992) e de Massad e Lazo (1998), como forma de se obterem mais subsídios para interpretar o significado do resultado dos critérios, evitando-se confundí-lo com a carga de ruptura pretensamente real. Outros detalhes desta comparação podem ser vistos no Apêndice C. O critério da Rigidez será discutido no item sobre separação das parcelas de atrito e ponta.

O método de Van der Veen (1953) foi modificado por Aoki (1976) que propôs liberar o modelo matemático da passagem obrigatória pela origem do diagrama de ajuste, ou seja, incluindo o intercepto ( $\left.b_{v d v}\right)$.

$$
P=P_{r d v} \cdot\left(1-e^{-a_{v d v} \cdot \delta}\right) \Rightarrow P=P_{r d v} \cdot\left(1-e^{-a_{v d v} \cdot \delta+b_{v d v}}\right)
$$

Note-se que, para os ajustes dos critérios, os recalques são aqui simbolizados por " $\delta$ ". A solução da carga de ruptura $P_{\text {rvdv }}$ se faz por tentativas, até que se obtenha 0 ajuste linear dado pela expressão:

$$
a_{v d v} \cdot \delta+b_{v d v}=-\ln \left(1-\frac{P}{P_{r v d v}}\right) \Rightarrow \delta=-\frac{1}{a_{v d v}} \cdot\left[\ln \left(1-\frac{P}{P_{r d v}}\right)+b_{v d v}\right]
$$

A forma de apresentação da segunda expressão (21) não é a usual, pois, em geral, se faz o ajuste dos parâmetros considerando-se que as entradas do sistema são os recalques, quando, na realidade do ensaio, o que se faz é entrar com a carga para obter-se a resposta do sistema em forma da leitura do recalque. O método dos mínimos quadrados, geralmente utilizado para obtenção do resultado, possui direção de análise definida, ou seja, deve-se entrar com os valores de carga para obteremse os de recalque, resultando valores sensivelmente diferentes para os parâmetros quando isso é invertido. Da mesma forma, quando se gera a curva calculada, os valores de entrada devem ser as cargas de ensaio e não os recalques obtidos; por isso a apresentação da expressão na forma sugerida. 

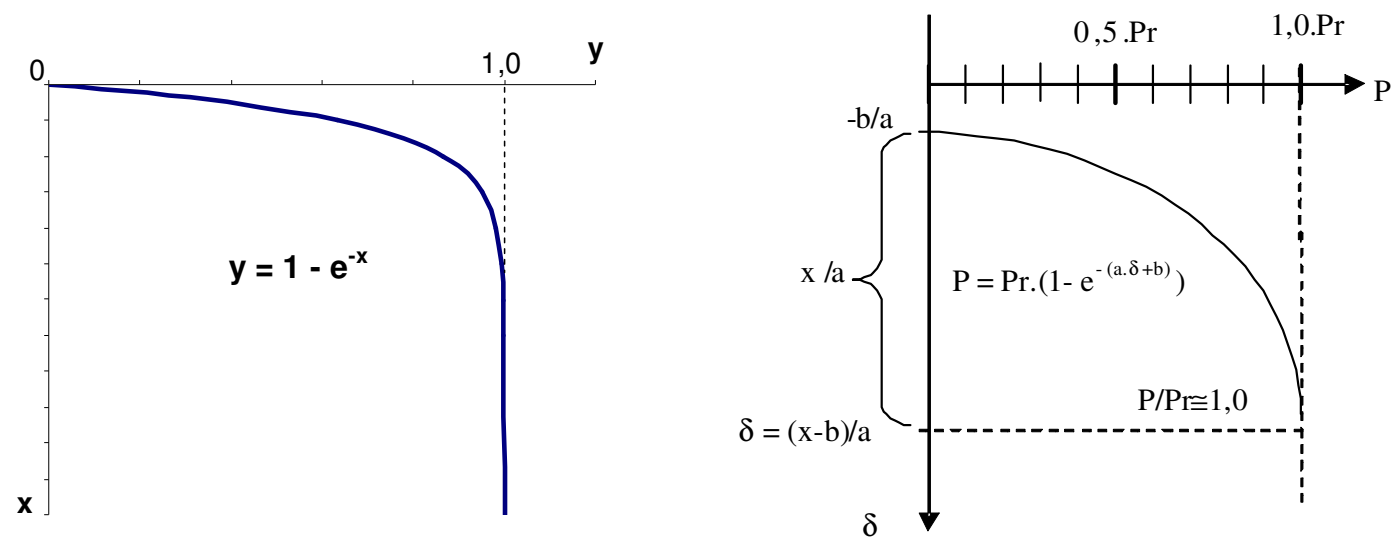

Figura 12 - Curva exponencial de Van der Veen na forma fundamental e na forma parametrizada em

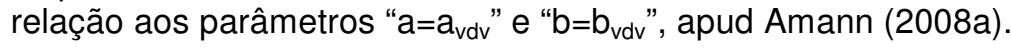

O trabalho de Amann (2008a) identifica a influência matemática dos parâmetros $\mathrm{a}_{\mathrm{v} d v}$ e $b_{v d v}$ e propõe a análise deste critério a partir da parametrização da curva, conforme se apresenta na Figura 12.

Portanto, ao parametrizar a curva exponencial de Van der Veen modificado, tem-se:

$$
y_{v d v}=\frac{P}{P_{r d v}} \Rightarrow x_{v d v}=-\ln \left(1-\frac{P}{P_{r d v}}\right)=a_{v d v} \delta+b_{v d v}
$$

A partir da curva exponencial fundamental da Figura 12, definem-se valores de $\mathrm{x}_{\mathrm{vdv}}$ únicos para cada valor de $\mathrm{P} / \mathrm{P}_{\text {rvdv }}$, (Tabela 22) permitindo interpretar-se melhor a curva carga recalque calculada em relação à ensaiada.

Algo semelhante pode ser obtido para o critério de Chin, como apresentado no Apêndice C. A aplicação da parametrização se faz no sentido de permitir localizar quão próximo da ruptura ajustada está um determinado valor de recalque, podendo ser este o valor limite (convencional) ou um valor da própria curva durante o ensaio. Em geral, tendo-se os valores dos parâmetros $a_{v d v}$ e $b_{v d v}$, para estacas com ruptura da ordem de $1000 \mathrm{kN}$, uma precisão excelente é alcançada ao adotar-se $x_{v d v}=4,6$, pois alcançado o recalque $\delta$ correspondente, se está a $99 \%$ da carga de ruptura do critério, o que permite uma interpretação diferenciada do mesmo.

Assim, tendo-se os recalques simulados com base na Tabela 21, e gerada a curva simulada, pode-se calcular os parâmetros da Tabela 22 e definir a comparação entre as duas formas de análise. 
Tabela 22 - Valores da curva exponencial fundamental de Van der Veen

\begin{tabular}{cccc}
\hline $\mathbf{x}_{\mathbf{v d v}}=\mathbf{a}_{\mathbf{v d v}} \mathbf{\delta}+\mathbf{b}_{\mathbf{v d v}}$ & $\mathbf{y}_{\mathbf{v d v}}=\mathbf{P} / \mathbf{P}_{\mathbf{r v d v}}$ & $\mathbf{x}_{\mathrm{vdv}}=\mathbf{a}_{\mathbf{v d v}} \cdot \boldsymbol{\delta}+\mathbf{b}_{\mathbf{v d v}}$ & $\mathbf{y}_{\mathbf{v d v}}=\mathbf{P} / \mathbf{P}_{\mathbf{r v d v}}$ \\
0 & 0 & 2,303 & 0,9 \\
0,105 & 0,1 & 3,219 & 0,96 \\
0,223 & 0,2 & 4,605 & 0,99 \\
0,357 & 0,3 & 5,809 & 0,997 \\
0,511 & 0,4 & 6,908 & 0,999 \\
0,693 & 0,5 & 8,112 & 0,9997 \\
0,916 & 0,6 & 9,210 & 0,9999 \\
1,204 & 0,7 & 9,903 & 0,99995 \\
1,609 & 0,8 & 11,513 & 0,99999 \\
\hline
\end{tabular}

A partir disto, na Figura 13 e na Figura 14 pode-se verificar que as curvas ajustadas de Van der Veen e de Chin são muito influenciadas pela carga máxima do ensaio, $P_{\max }$. Faz-se, a seguir, primeiramente uma análise do critério de Van der Veen e, em seguida, algumas rápidas comparações entre este e o de Chin.

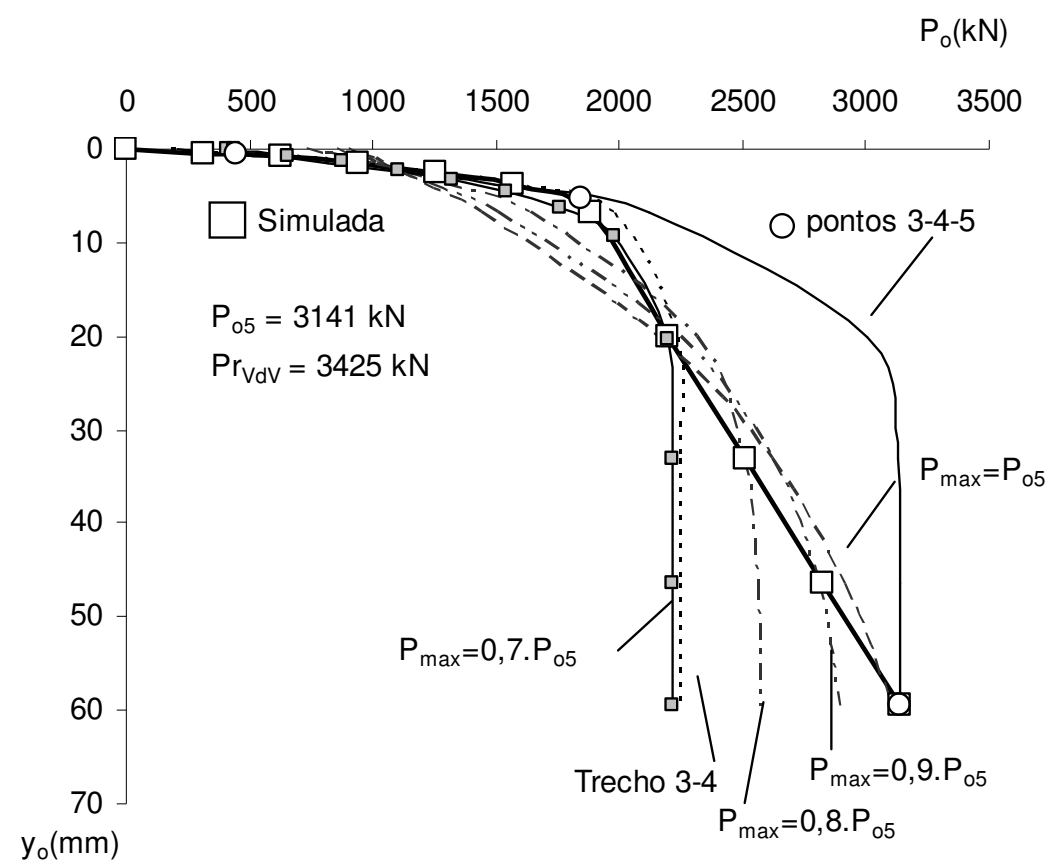

Figura 13 - Curvas de Van der Veen ajustadas à curva de ensaio simulada, considerando diversas cargas máximas de ensaio $\left(P_{\max }\right)$.

$\mathrm{Na}$ Figura 13, ao ajustar-se a exponencial de Van der Veen generalizado a todos os pontos da curva de ensaio simulada (veja-se indicação da curva tracejada " $P_{\max }=P_{05}$ " na figura), notam-se alguns eventos interessantes: a carga inicial para o recalque zero resulta 904,6 kN, e não zero, iniciando-se, portanto, a curva ajustada já perto do terceiro ponto do ensaio; passa então próxima ao quarto ponto do ensaio, afastase, em seguida, para baixo, em direção ao sétimo ponto do ensaio e, após afastar- 
se novamente, agora para cima, passa enfim próxima à carga de ruptura $(3099,6$ $\mathrm{kN}$ ), tendendo, enfim, para a carga de ruptura do critério, que resultou $3424,9 \mathrm{kN}$, para recalque infinito. A carga de ruptura "real" $\left(P_{05}\right)$ está a 0,9173. $P_{r v d v}$, resultando um $x_{v d v}=2,4922$, com um coeficiente de determinação $R^{2}=0,9557$. Assim, no caso deste tipo de curva apresentado pela estaca, o critério de Van der Veen estaria 9\% contra a segurança, superestimando a verdadeira carga de ruptura.

Continuando a pesquisa, considerando que o ensaio de prova de carga raramente chega ao ponto de ruptura, Amann (2008b) eliminou sequencialmente o último ponto a cada nova análise, ou seja, $P_{\max }=0,9 . P_{05} ; P_{\max }=0,8 . P_{05}$,etc., e recalculou os incrementos de carga, obtendo-se, assim, as curvas indicadas na Figura 13, com comportamentos muito semelhantes ao anterior em termos de afastamento e aproximação da curva exponencial ajustada em relação ao terceiro, quarto, sétimo e último pontos.

O procedimento adotado nesta análise foi o seguinte: a) recalculam-se as novas cargas correspondentes aos estágios, com incrementos de 10\% da carga máxima simulada (por exemplo, $10 \%$ de $P_{\max }=0,9 . P_{05}$ ) e calculam-se os recalques pelas expressões da Tabela 21; b) aplica-se o critério de Van der Veen e acha-se a carga de ruptura $\mathrm{P}_{\mathrm{rvdv}}$; c) calculam-se os recalques ajustados pela curva exponencial com a expressão (22); d) para se achar a carga de recalque zero e os pontos da curva acima de $0,9 . \mathrm{P}_{05}$ ou 0,8.P $\mathrm{P}_{05}$, etc., deve-se usar a expressão (22), porém, utilizando como entrada os recalques dos pontos da curva simulada completa.

Assim, para $P_{\max }=0,7 . P_{05}=2199,5 \mathrm{kN}$, a melhora do ajuste foi expressiva, passando para $R^{2}=0,9825$ e a carga inicial para recalque zero foi de $410,1 \mathrm{kN}$, sendo que, antes disso, estava muito elevada. Observa-se na Figura 12 que, nesse caso, a exponencial ajustada passa próximo a todos os sete pontos do ensaio simulado, e muito mais próximo ao último ponto $\left(0,9993.0,7 . P_{\max }\right)$ do que nos demais casos. Assim, a carga máxima de ensaio resultou em 0,9904. $P_{r v d v}$, com $x_{v d v}=4,644$. Embora a carga de ruptura extrapolada pelo critério esteja a $70,68 \%$ da ruptura "real" $\left(P_{05}\right)$, o último ponto neste caso dá a "aparência" de que a estaca está muito próxima $\left(0,9904 \mathrm{P}_{\mathrm{rvdv}}\right)$ da ruptura extrapolada.

Foi feito também um ajuste passando pelos os pontos 3 e 4 das Leis de Cambefort (Figura 10) cujo resultado foi muito próximo do ajuste para 0,7.P omax. Outra tentativa de análise, tomando-se unicamente as coordenadas dos pontos notáveis 3,4 e 5 
das Leis de Cambefort, levou à curva indicada no gráfico que, após o ponto 4, abre um grande arco afastado da curva simulada e mergulha a assíntota sobre o valor de $\mathrm{P}_{05}$.

Assim, considerando que a curva de ensaio da estaca se aproxime da curva da teórica das Leis de Cambefort Modificadas, pode-se resumir as seguintes análises:

a) o critério de Van der Veen é muito influenciado pelo valor do último ponto medido;

b) aparentemente, por menos que a curva ajustada se aproxime da ensaiada, esta passará muito próximo do último ponto medido o qual representará cerca de 1,0 a $10 \%$ da ruptura do critério, sendo mais próxima deste quanto menos próxima do valor real de ruptura estiver a carga máxima;

c) se o ensaio alcançar cerca de $70 \%$ da carga de ruptura (valor que permite o início da definição do trecho de ponta, e que é apenas ligeiramente superior ao sugerido por Décourt e Niyama, 1994, parar aceitação do critério) o melhor ajuste da curva se aproxima de $\mathrm{R}^{2}=0,9800$, sendo que este valor melhora se o último ponto é inferior ao ponto 4 de mobilização de recalques (o que significa que bons ajustes indicariam uma curva pouco definida e com carga de ruptura muito próxima do último ponto medido);

d) o valor do $x_{v d v}$ que definiria a ruptura do critério deve aumentar quanto menor for o desenvolvimento da curva;

e) o valor de $x_{v d v}=4,64$ para o último ponto do ensaio indica que a curva provavelmente se desenvolveu apenas até $70 \%$ da ruptura real, enquanto que valores da ordem de 2,50 indicariam que se pode estar próximo a $90 \%$ da ruptura real.

Conclusões semelhantes podem ser extraídas da análise da Figura 14 aplicada ao critério de Chin. Fazendo uma comparação, a condição que melhor ajusta a curva simulada de referência em ambos os casos é aquela em que o ensaio vai apenas até $70 \%$ da carga de ruptura $\mathrm{P}_{05}$, mesmo que com menos pontos o $\mathrm{R}^{2}$ estatístico seja maior, pois neste caso tem-se o desenvolvimento do início do trecho de mobilização de ponta. Alcançando $80 \%$ de $\mathrm{P}_{05}$ a curva ajustada deixa de aproximar os pontos iniciais da curva de referência para tentar ajustar melhor os pontos da reta 4-5 da ponta, no caso de Van der Veen (1953), afastando-se também dos pontos 
intermediários. No caso de Chin (1972), o ajuste é melhor no trecho 3-4, afastandose no trecho 4-5.

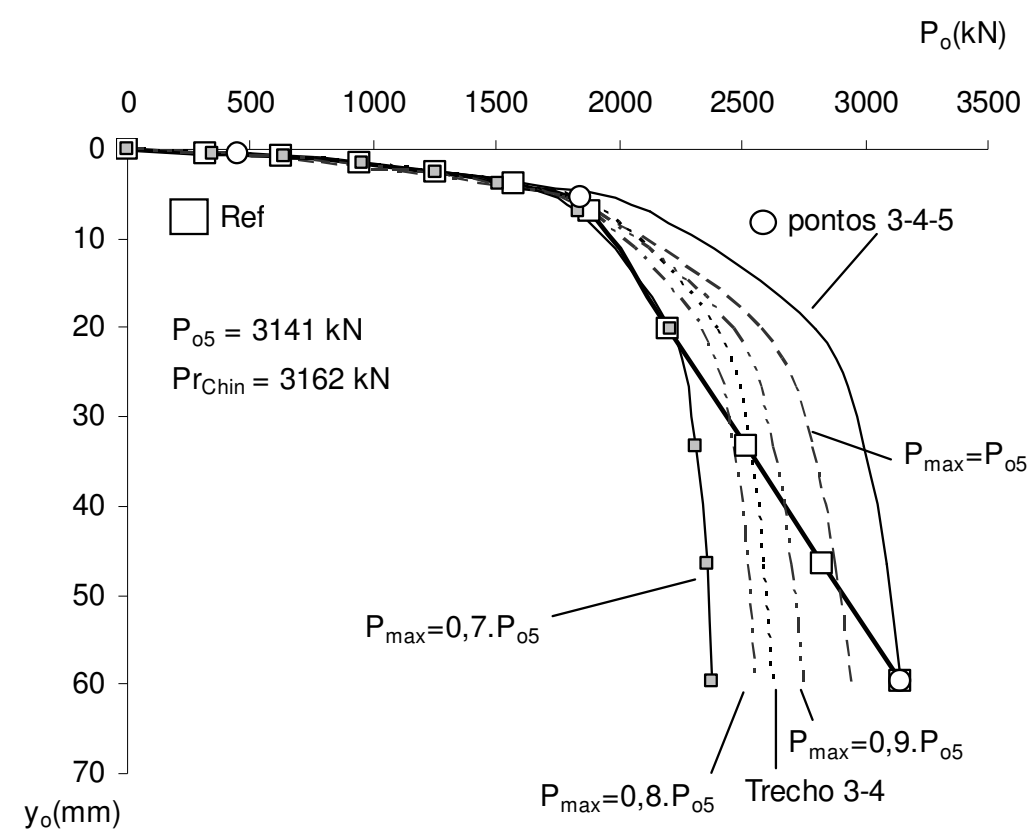

Figura 14 - Curvas de Chin (1972) ajustadas à curva de Referência, considerando diversas cargas máximas de ensaio $\left(P_{\max }\right)$.

Note-se que embora o ajuste da exponencial de Van der Veen (1953) à curva simulada não seja dos melhores $\left(R^{2}=0,950\right)$ a carga de ruptura extrapolada é apenas $9,0 \%$ superior à $P_{05}$ no caso de Van der Veen (1953) e praticamente igual a $P_{05}$ no caso de Chin (1972).

Pode-se ainda concluir que a carga máxima de ensaio, considerada para teste igual a 0,7.P $P_{05}$, é coincidentemente a carga mínima exigida por norma no ensaio: da carga de ruptura estimada em projeto adota-se, em geral, coeficiente de segurança 2,0, definindo-se a carga de trabalho. Então se deve levar a estaca até pelo menos 1,5 vezes este valor, ou seja: $P_{\min }=1,5 \cdot P_{05} / 2=0,75 \cdot P_{05} \cong 0,7 \cdot P_{05}$. Isto explica porque em geral a curva de Van der Veen (1953) ajusta bem a curva de ensaio: se esta fosse levada a cargas maiores, com maior definição da reta 4-5 de ponta, a curva passaria a não ajustar tão bem o ensaio (algo diferente ocorre para estacas cravadas com dois ou mais carregamentos). Isto está de acordo com o observado por Décourt e Niyama (1994). Para Chin (1972), a observação também é válida (Figura 14).

A Figura 13 mostra ainda que o ajuste de Van der Veen (1953) aos pontos da curva contidos no trecho 3-4 (Figura 10), como sugerida por Massad (1994b), é bastante 
próxima à curva ajustada com $P_{\max }=0,7 \cdot P_{05}$. Vê-se que, de fato, a carga de ruptura indicada pela assíntota da exponencial de Van der Veen não é a ruptura real $\left(\mathrm{P}_{05}\right)$, mas sim uma indicação bastante a favor da segurança. Isto não ocorre para a hipérbole de Chin.

O ajuste da curva exclusivamente passando pelos pontos notáveis 3, 4 e 5 (Figura 13 e Figura 14) resulta numa curva que ajusta o trecho $3-4$, descola da reta $4-5$ e finalmente passa pelo ponto 5, para ambos os critérios.

Desta forma, pode-se entender melhor como é a relação entre os valores obtidos por estes dois critérios e o método das leis modificadas de Cambefort, permitindo reduzir equívocos de interpretação. Esclarece-se aqui que, portanto, é um equívoco considerar que o melhor ajuste da curva leva à carga de ruptura mais confiável, pois comprova-se nessa análise que, quando a curva se ajusta muito bem aos pontos do ensaio há grande chance de a ruptura extrapolada ser da ordem de $70 \%$ da "real", considerando o comportamento do solo similar ao das Leis de Cambefort modificadas.

O critério de Brinch Hansen $80 \%$ poderia também ser avaliado dessa maneira, contudo, deixa-se de fazê-lo por não agregar maiores informações ao que já se discutiu.

O critério da Rigidez de DÉCOURT (1999), modificado por Décourt (2008), pode, da mesma forma, ser confrontado com as Leis de Cambefort modificadas para extraírem-se conclusões semelhantes. Nesse sentido, seguindo outra linha de dedução, Massad (2008) estabelece tal comparação de forma matemática, a ser discutida por ocasião da apresentação da separação entre as parcelas de atrito e ponta.

Dada a constatação de que os métodos de transferência de carga, como o das Leis de Cambefort Modificadas, são de fundamental importância para a análise e a separação das parcelas de atrito e ponta, como já ilustrado acima, o próximo capítulo se ocupará de apresentá-los com as respectivas análises críticas. 


\subsection{PROPOSTA DE NOVA FORMA DE CONSIDERAÇÃO DOS CRITÉRIOS DE RUPTURA}

Após ter-se demonstrado, à luz dos métodos das Leis de Cambefort modificadas, interpretações mais elaboradas sobre os resultados dos critérios de ruptura e esclarecido que o paradigma de análise da aplicabilidade dos métodos semiempíricos pela comparação indiscriminada entre os seus resultados não é adequado, propõe-se agora uma nova forma de se verificar o desempenho dos métodos semiempíricos.

Considerando que a premissa de desenvolvimento da Metodologia Semiempírica Unificada deve ser aberta para incorporar a diversidade de métodos e critérios, buscando, contudo, o resultado otimizado para ocaso em estudo, a proposta é que se comparem os resultados dos diversos métodos semiempíricos com os critérios aqui apresentados para identificarem-se quais estão próximos uns dos outros, o que deve indicar quais critérios são mais adequados para cada método semiempírico no caso em estudo. Para isso, propõe-se um exemplo a seguir.

\subsubsection{Exemplo de comparação entre métodos semimpíricos e critérios de ruptura}

Para exemplificar a proposta, tomaram-se os resultados da estaca raiz G202, apresentada no item 2.12, analisando-se o gráfico da Figura 15, o qual apresenta todas as estimativa semiempíricas e todas as cargas de ruptura dos critérios.

A proposta de análise deste gráfico se faz em faixas horizontais com amplitude de $100 \mathrm{kN}$, neste caso, conforme apresentado pelas elipses que circundam os resultados mais próximos entre si dentro desta amplitude.

Pode-se ver que, de acordo com o paradigma atual, comparando-se, por exemplo, o método Expedito ( $P_{\mathrm{RN} 3 \mathrm{P}}$ na coluna 7$)$ com o critério de ruptura de Chin (coluna 2 ) ou da Rigidez (por ajuste linear, da coluna 3), este seria conservador. Contudo, quando comparado com o de Butler e Hoy (BT na coluna 9), como sugeriram Titi e AbuFarsakh (2004), ele seria bastante contra a segurança. Já se comparado ao critério de Terzaghi (0,1D, na coluna 6), ele estaria apenas um pouco a favor da segurança, sendo considerado adequado. Ou ainda, em relação a Brinch Hansen $(\mathrm{BH}$, coluna 
5), ele estaria apenas um pouco contra a segurança, podendo em alguns casos ser considerado adequado.

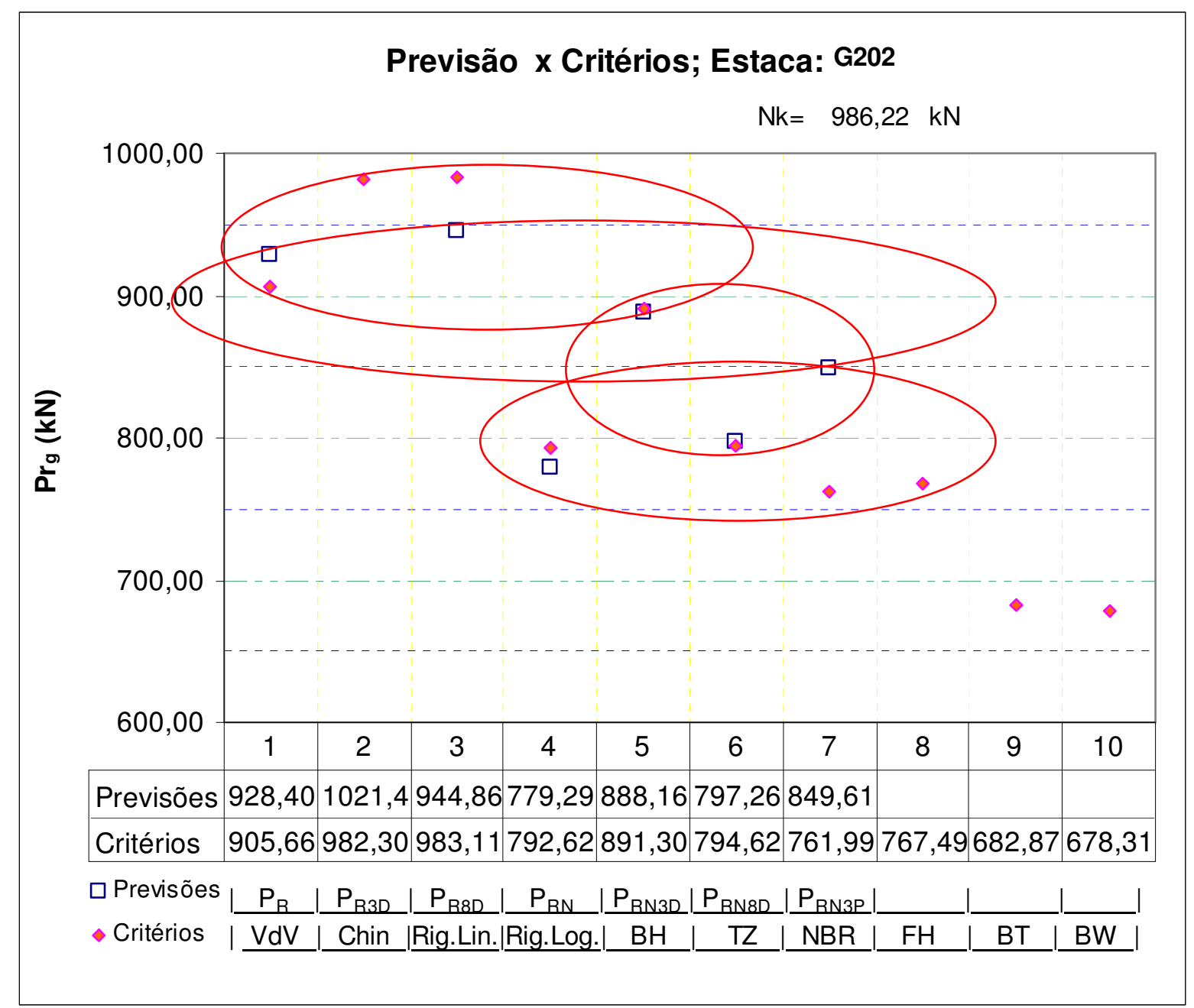

Legenda: VdV = Van der Veen; Chin= Chin; Rig.Lin.= Rigidez por ajuste linear; Rig.Log.= Rigidez por ajuste logarítmico; $\mathrm{BH}=$ Brinch Hansen; TZ = Terzaghi $(0,1 \mathrm{D}) ; \mathrm{NBR}=\mathrm{NBR} 6122 ; \mathrm{FH}$ = Fuller e Hoy; $\mathrm{BT}=$ Butler e Hoy; $\mathrm{BW}=$ De Beer e Wallays

Figura 15 - Comparação das previsões (estimativas) semiempíricas com os critérios de ruptura.

Por outro lado, se o critério escolhido fosse o de Terzaghi, o método "vencedor" do ranque seria o Mediado considerando a média dos SPT's do fuste e com embutimento de 8D acima e 3D abaixo da ponta ( $P_{\mathrm{RN} 8 \mathrm{D}}$, coluna 6$)$, pois os resultados praticamente coincidiram (estimativa $0,3 \%$ acima do critério). $O$ segundo método do ranque para este critério seria o Mediado, considerando-se a média dos SPT's do fuste e com apenas 1 SPT abaixo da ponta $\left(P_{\mathrm{RN}}\right.$, coluna 4$)$.

De outro modo, se o critério escolhido fosse o de Brinch Hansen ( $\mathrm{BH}$ coluna 5), o vencedor seria o Mediado considerando a média dos SPT' do fuste e embutimento de 3D acima e 3D abaixo da ponta ( $P_{\text {RN3D }}$, coluna 5). 
Mas se o critério adotado fosse o de Van der Veen ( $\mathrm{dV}$, coluna 1), o melhor resultado seria do método Mediado, considerando a média dos SPT's do fuste e o embutimento de 3D acima e 3D abaixo da ponta ( $P_{\mathrm{RN} 3 \mathrm{D}}$, coluna 5), com subestimativa de apenas $2 \%$ da ruptura do critério. Ainda para este critério, o método Mediado com uso da somatória das camadas do fuste e apenas um SPT na ponta $\left(P_{R}\right.$, coluna 1$)$ estaria contra a segurança. $O$ mesmo se daria para o método Mediado com somatória das camadas do fuste e com embutimento 8D acima e 3D abaixo ( $P_{\text {R8D }}$, coluna 4), ficando todos os demais classificados como conservadores.

O que se busca demonstrar novamente com estas observações é que atestar a aplicabilidade de um método semiempírico, classificá-lo como contra a segurança ou conservador, ou mesmo ranquear seus resultados, baseando-se apenas na proximidade de seus resultados com o do critério de ruptura adotado, não tem sentido algum se a pretensão é verificar se o método é bom estimador da carga de ruptura da estaca. Conclui-se, mais uma vez, que todas essas análises apenas comparam os métodos ao critério adotado, o que não garante nada em termos de aplicabilidade ou segurança, pois modificando-se o critério adotado, mudam-se as conclusões acerca do método.

O fato de se ter aplicado este exemplo para os métodos de teste, e não para os semiempíricos de fato, não muda o caráter geral das conclusões acima obtidas, visto que as dispersões apresentadas são muito semelhantes e que os métodos de teste (Mediado e Expedito), aplicados no exemplo, são oriundos dos valores médios dos coeficientes empíricos dos métodos semiempíricos usuais, de acordo com a experiência brasileira, podendo perfeitamente constituírem-se em métodos de uso corrente. O que muda é o fato dos métodos semiempíricos usuais já possuírem um critério de ruptura preferencial a ser adotado, como já discutido no item 3.5, o que os métodos de teste aqui propostos ainda não possuem.

Sendo assim, para o caso da criação de novos métodos semiempíricos, ou mesmo na hipótese de se testar a aplicabilidade de outros critérios aos métodos usuais, verifica-se que é necessário estabelecer-se alguma forma conceitualmente coerente de escolha do critério de ruptura a ser adotado. 


\subsubsection{Proposta de consideração dos critérios}

Diante do fato de que não há como escapar à necessidade de escolher um critério de ruptura para a análise dos métodos semiempíricos, propõe-se aqui sugestões de como realizar tal escolha de forma conceitualmente consistente.

A primeira forma de escolha que se pode sugerir é a adoção do critério mais próximo da carga máxima alcançada no ensaio, atendendo assim à consideração de Fellenius (2006) supra citado. Desta forma, não se menospreza nem se superestima a carga de ruptura de forma ostensiva, como aparentemente ocorre com a adoção de um critério qualquer de forma indiscriminada (ver item 3.6).

Outra indicação que deve ser observada encontra-se na parte superior direita da Figura 15 , onde se verifica a anotação da carga $\mathrm{Nk}=986 \mathrm{kN}$, que indica a carga de ruptura estrutural da estaca, calculada pela sua taxa de armadura e pela resistência característica do concreto (fck, o qual deve a rigor ser determinado por controle tecnológico). Em nenhum caso, nem para os métodos semiempíricos, nem para os critérios de ruptura, deve-se considerar válidos resultados acima desse limite, a menos que se confirme uma subestimativa da resistência do concreto.

A fórmula de cálculo de Nk pode ser obtida de Velloso e Alonso (2000):

$$
\mathrm{Nk}=\frac{1}{\gamma_{\mathrm{f}}} \cdot\left(\frac{0,85 \cdot \mathrm{A}_{\text {conc }} \cdot \mathrm{fck}}{\gamma_{c}}+\frac{\text { As.fyk }}{\gamma_{s}}\right)
$$

onde: $\gamma_{f}$ é coeficiente majorador das solicitações; $\gamma_{\mathrm{c}}$ : coeficiente de minoração da resistência do concreto; $\gamma_{s}$ : coeficiente de minoração da resistência do aço; $A_{\text {conc }}$ : área da seção de concreto; As: área da seção de aço; fyk: resistência característica do aço; fck: resistência característica do concreto.

No cálculo da carga máxima de ruptura estrutural, se determinados fck e fyk por meio de controle tecnológico, devem ser adotados os coeficientes de majoração e minoração iguais a 1,0 .

Por outro lado, em se tratando da análise de métodos cujo critério de ruptura utilizado em sua concepção tenha sido divulgado, este deve ser preferencialmente utilizado. Evidentemente, ao se analisarem diversos métodos ao mesmo tempo, como é comum, sugere-se que sejam considerados os respectivos critérios e 
montado um gráfico como o da Figura 15 para sua interpretação. $O$ ideal seria que os autores publicassem os dados estatísticos de dispersão dos resultados, quando da concepção dos métodos, para uma melhor análise. Na falta destes, porém, podese considerar um peso maior quando ocorre a proximidade entre métodos e critérios afins, se a pretensão for verificar a adequação do critério ao método para o solo em questão.

Se os valores forem muito díspares, ou ainda, se os métodos em análise não apresentam informação em relação ao critério empregado, os resultados próximos entre si, obtidos para o solo local e estaca em questão, podem indicar um novo critério a ser adotado para o caso especifico estudado. É importante, nesse caso, que todas as demais análises (com mesmo solo da região e mesmo tipo de estaca) sejam efetuadas com base neste novo critério adotado.

No exemplo acima, supondo-se que o método dado na coluna $5\left(\mathrm{P}_{\mathrm{RN} 3 \mathrm{D}}\right)$ tivesse sido elaborado com base em comparações com o critério de Van der Veen, teria mais peso sua proximidade com este do que o fato de ter se aproximado mais (quase "na mosca") do critério de Brinch Hansen (BH, coluna 5).

Por outro lado, se o método da coluna $4\left(\mathrm{P}_{\mathrm{RN}}\right)$ fosse elaborado com base no critério de Chin, pode-se dizer que ele não estaria adequado para ser empregado no caso em questão, visto apresentar-se muito conservador em relação a este. Como alternativa, dever-se-ia examinar outros casos na região e verificar se esse método $\left(P_{\mathrm{RN}}\right)$ se aproxima sistematicamente dos critérios da Rigidez com ajuste logarítmico, de Terzaghi, da NBR 6122 ou de Fuller e Hoy, pois eles aparecem ali próximos, dentro da elipse.

Já se o interesse for por determinar qual o melhor método semiempírico e o respectivo critério ótimo a ser adotado, para a estaca e solo da região, poder-se-ia sugerir que se utilizasse no local do exemplo o critério da Rigidez com o método $\mathrm{P}_{\mathrm{R} 8 \mathrm{D}}$, desde que estes resultem valores próximos entre si num número significativo de provas de carga na região.

Dessa forma, a Metodologia Semiempírica Unificada possui flexibilidade para utilização de qualquer critério e sempre aponta para os melhores resultados (otimizados), especificamente para o caso em análise, demonstrando claramente 0 motivo da adoção do par método-critério. Como em todo e qualquer processo com 
base empírica, a experiência com seu uso e aplicação local indicará valores cada vez mais adequados ao longo do tempo.

Observe-se que essa proposta de consideração dos critérios pode ser também usada para se identificar qual o melhor critério a ser usado na comparação com um novo método semiempírico, ou um que nunca tenha sido usado na região para aquele tipo de estaca. Porém, isso ainda não se constitui em uma forma de correção dos métodos para se melhorar as estimativas em relação a um dado critério, como faz parte da proposta da MSU.

Neste sentido, mais alguns passos devem ser dados, conforme se discute a seguir.

\subsubsection{Correção dos coeficientes empíricos dos métodos semiempíricos a partir de provas de carga e dos critérios de ruptura}

Considerando-se que a proposta da MSU não é apenas o estabelecimento do critério de ruptura mais adequado, mas sim a adequação do método semiempírico para que ele se aproxime mais de um dado critério adotado, torna-se importante considerar outros aspectos.

Se boa parte dos autores dos métodos basearam-se nos ensaios de CPT e depois os correlacionaram com os resultados do SPT, sua base de análise deve ser a resistência de ponta do cone $\left(q_{c}\right)$, para a qual diversos autores internacionais pesquisaram correlações com parâmetros do solo, como coesão e ângulo de atrito, etc. Nesses casos, os coeficientes empíricos devem ter sido estabelecidos primeiramente para a ponta, com base nos ensaios de cone, e, assim, o atrito lateral é colocado num plano secundário. Se não houver a luva de atrito no ensaio, seu valor acaba sendo, por vezes, estimado pela razão de atrito, a partir da classificação do solo, ou mesmo sendo admitido para ele um valor médio único independemente do tipo de solo.

Contudo, quando se analisam as provas de carga com a pretensão de aproximaremse os resultados dos métodos semiempíricos aos de um dado critério de ruptura, observa-se que a carga de ruptura da ponta da estaca quase nunca é alcançada, diferentemente do que ocorre com o cone. Sendo assim, num ensaio de prova de carga em geral, o que se consegue obter, com alguma garantia mínima, é a carga limite transferida por atrito lateral, mais eventuais cargas residuais. A ponta, porém, 
sofre uma breve mobilização, suficiente apenas para se vislumbrar sua rigidez, raramente sua ruptura.

Diante disto, para se efetivar tal correção com a Metodologia Semiempírica Unificada, pode-se no máximo tentar separar a parcela transferida por atrito daquela que mobilizou parcialmente a ponta. Tendo-se adotado um critério de ruptura (qualquer que seja), a carga na ponta, ao final do ensaio, é dada pela diferença de valores entre a parcela separada de atrito e o resultado do critério (descontando-se ainda eventuais cargas residuais).

Dessa forma, a parcela de atrito lateral se constitui aqui a de maior confiança em termos de obtenção de seu valor, sendo a parcela de ponta atribuída por diferença, sem se poder atestar, de fato, o seu valor de ruptura. Com essa constatação, a correção dos coeficientes empíricos do fuste terá maior confiabilidade do que a correção dos de ponta, ao contrário do que ocorre quando tais análises partem dos resultados do ensaio de cone. Essa é outra dificuldade de compatibilização entre os métodos semiempíricos e os critérios de ruptura que o paradigma atual não tem ferramentas para resolver. A adoção de coeficientes de segurança da ponta maiores do que os do atrito, só é eficiente para atribuição da carga admissível, em nada favorecendo a estimativa da carga de ruptura, objeto principal dos métodos.

Evidentemente, a partir de tais considerações, o critério de ruptura escolhido deve resultar sempre em valores maiores do que a parcela de atrito lateral, caso contrário isto representaria carga de ponta negativa (o que em geral não ocorre) quando comparado à carga máxima do ensaio. Isto indica mais um item a se considerar na escolha do critério de ruptura a ser adotado.

Este tema será melhor detalhado quando da proposição final da correção pela MSU, sendo que para desenvolvê-lo se faz necessário justamente discutir a forma de separação das parcelas de atrito e ponta, a partir dos métodos de transferência de carga e da Rigidez de Décourt (2008), como segue. 


\section{AFERIÇÃO DA PARCELA DE ATRITO LATERAL PELOS MÉTODOS DE TRANSFERÊNCIA DE CARGA E DA RIGIDEZ DE DÉCOURT (2008)}

O interesse nos métodos de transferência de carga se dá como ferramenta de separação das parcelas de atrito e de ponta, de modo que se possa aferir os valores dos coeficientes característicos estimados inicialmente pelos métodos semiempíricos. Seu uso constitui-se, assim, na primeira parte da terceira etapa: Aferição e Corrreção (ou Adequação) dos métodos semiempíricos. Tal separação entre as parcelas de atrito e ponta pode também ser feita pelo método da Rigidez de Décourt (2008), o qual será discutido mais adiante no item 4.5, também à luz da transferência de carga.

Esses métodos consideram a deformação elástica do material da estaca, a qual, durante o processo de carga e descarga, interage por atrito com o solo ao longo do comprimento do fuste, fenômeno este chamado de transferência de carga.

Da literatura técnica, os métodos de maior interesse são:

a) Cambefort (1964), cuja formulação permite considerar a evolução da função de transferência de carga em profundidade, com os carregamentos sucessivos, até da ruptura;

b) Coyle e Reese (1966), que, a partir da estimativa de um deslocamento na ponta, aplicam um processo de integração numérica para achar o deslocamento no topo da estaca;

c) Baguelin e Venon (1971), que, a partir do modelo de Cambefort (1964), estabeleceram coeficientes de rigidez para o sistema soloestaca, para o fuste e para a ponta;

d) Randolph e Wroth (1978), cuja formulação leva em consideração a variação do módulo de cisalhamento do solo, e Randolph (1994) que introduziu no modelo coeficientes para considerar efeitos de instalação da estaca e da interação em grupos de estacas; 
e) Frank e Zhao (1982), que propuseram uma aplicação prática dos resultados de ensaios pressiométricos para obtenção dos parâmetros de Baguelin e Venon (1971), considerando um modelo de transferência de carga $(y-\tau)$ bi-linear;

f) Massad (1992), que propôs uma metodologia para a separação das parcelas de ponta e de atrito, a partir do modelo de Baguelin e Venon (1971), e ainda considera as eventuais cargas residuais; Massad (1993), que ampliou a aplicação do modelo para solos com duas camadas de comportamentos (rigidezes) diferentes; Massad e LAZO (1998), que apresentaram o método da Duas Retas, com aplicação do modelo a estacas rígidas; Massad (2002), que explicita a forma de separação entre atrito e ponta utilizando-se a análise do descarregamento da estaca, incluindo a análise de provas de carga cíclicas; Marques e Massad (2004), que apresentam o método das Duas Retas Modificado para aplicação a estacas com bulbos e estacas rígidas com atuação inicial da ponta;

g) Fleming (1992), que propôs o uso de relações hiperbólicas para a transferência de carga no método de Randolph e Wroth (1978) e elaborou, a partir disso, simplificações matemáticas;

h) Fonseca, et. al. (2007), Amann (2008c) e Massad (2008), que apresentam as relações entre os modelos de Randolph e Wroth (1978) e Massad (1992).

Esses métodos e modelos de análise são também chamados na literatura internacional como modelos "t-z", referindo-se à forma de solução do problema que é baseada na relação entre os deslocamentos (o ' $z$ ' é aqui simbolizado por ' $y$ ', embora internacionalmente ' $y$ ' se refira aos deslocamentos laterais) da estaca e a tensão de cisalhamento mobilizada ( $t$, aqui simbolizado como $\tau$ ) no solo, e têm sido empregados extensamente na literatura internacional. Como exemplos, citam-se: Haldar e Babu (2008), que aplicam essa metodologia para determinarem fatores de resistência de projeto, a partir dos coeficientes parciais de análise estatística de segurança, conforme as normas FHwA (2001) e AS-2159 (1995), respectivamente americana e australiana; Zhu e Chang (2002), que utilizam a metodologia para 
analisar a chamada "degradação" do módulo de cisalhamento, que é a sua redução com o incremento de deformação; Mylonakis (2001), que utiliza o modelo para determinação do coeficiente de mola de Winkler, aplicável a estacas comprimidas.

Dada a grande quantidade de métodos e suas diferentes nuances, optou-se no presente trabalho por apresentar a dedução matemática geral da transferência de carga de estacas, como apresentado por Amann (2008c) e, a partir dela, demonstrar os casos particulares referentes a cada um dos métodos citados.

\subsection{DEDUÇÃO GERAL DA EQUAÇÃO DIFERENCIAL DA TRANSFERÊNCIA DE CARGA DE ESTACAS AO SOLO (AMANN, 2008C)}

A dedução aqui demonstrada pretende ser a mais generalizada possível, permitindo sua aplicação a estacas de qualquer seção transversal, material ou perfil de solo. Dessa forma, poder-se-á verificar que os métodos de Randolph e Wroth (1978) e das Leis de Cambefort Modificadas por Massad (1992), entre outros, podem ser todos deduzidos a partir dela, podendo-se considerá-los casos particulares em função das simplificações e condições de contorno que cada autor levou em conta em suas deduções particulares.

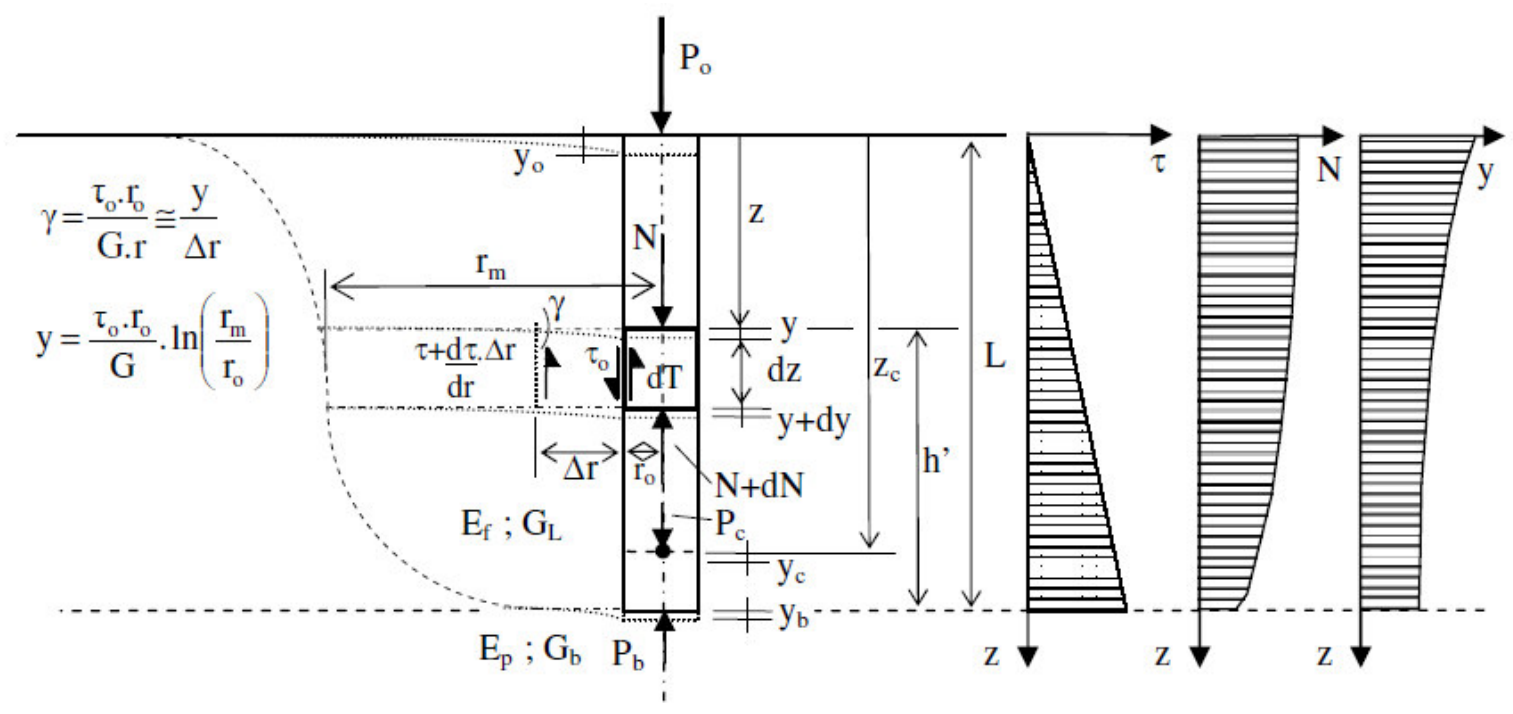

Figura 16 - Esforços $(\mathrm{N})$, tensões de cisalhamento $(\tau)$ e deslocamentos $(\mathrm{y})$ em uma estaca apud Amann (2008c)

Inicialmente, observe-se a Figura 16, que apresenta uma estaca com perímetro $U$, comprimento L, módulo de elasticidade $\mathrm{E}$ e área da seção transversal $\mathrm{S}$, instalada num solo com tensão de resistência ao cisalhamento $\tau$ variável com a profundidade 
$z$, tensão de resistência de ponta $q_{p}$, módulos de elasticidade e de cisalhamento ao longo do fuste $E_{f}$ e $G_{L}$ respectivamente, e abaixo da ponta $E_{p}$ e $G_{b}$, sob ação de uma carga $P_{0}$ aplicada no topo.

Sendo $N(z)$ a força normal que atua no eixo da estaca numa profundidade $z$ qualquer e $\mathrm{T}(\mathrm{z})$ a carga transferida ao solo por atrito lateral, pelo diagrama de corpo livre (Figura 16) de um elemento infinitesimal de altura $d z$, localizado nesta profundidade, pode-se estabelecer a equação de equilíbrio estático em função da tensão mobilizada de atrito lateral $\tau(z)$ :

$$
\begin{aligned}
\mathrm{N}(\mathrm{z})=[\mathrm{N}(\mathrm{z})+\mathrm{dN}(\mathrm{z})]+\mathrm{dT}(\mathrm{z}) & \Rightarrow \mathrm{dN}(\mathrm{z})=-\mathrm{dT}(\mathrm{z})=-\mathrm{U} \cdot \mathrm{T}(\mathrm{z}) \cdot \mathrm{dz} \Rightarrow \\
& \Rightarrow \mathrm{dN}(\mathrm{z})=-\mathrm{U} \cdot \tau(\mathrm{z}) \cdot \mathrm{dz}
\end{aligned}
$$

Ao mesmo tempo, a carga $\mathrm{N}(\mathrm{z})$ ao longo do eixo da estaca gera uma expressão de encurtamento elástico $\mathrm{y}(\mathrm{z})$ devida à Lei de Hooke. Derivando-a e substituindo na expressão (24) tem-se:

$$
\begin{gathered}
E=\frac{N(z) / S}{[-d y(z)] / d z} \Rightarrow \frac{d y(z)}{d z}=-\frac{N(z)}{E \cdot S} \Rightarrow \frac{d^{2} y(z)}{d z^{2}}=-\frac{1}{E \cdot S} \cdot \frac{d N(z)}{d z} \Rightarrow \\
\Rightarrow \frac{d^{2} y(z)}{d z^{2}}=\frac{U}{E \cdot S} \cdot \tau(z)
\end{gathered}
$$
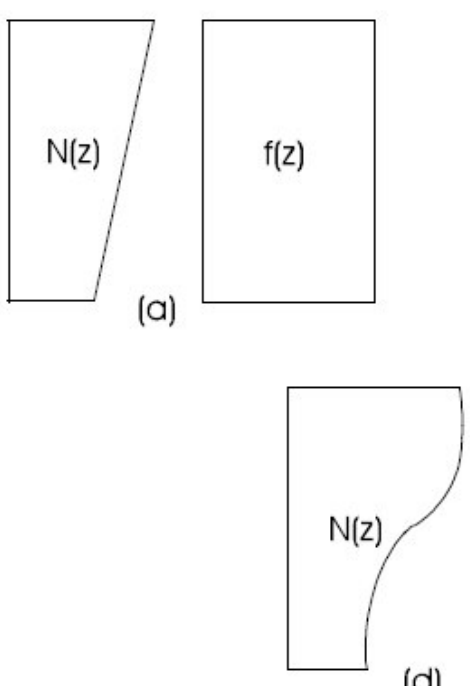

(d)

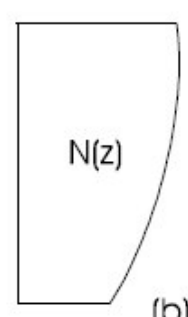

(b)
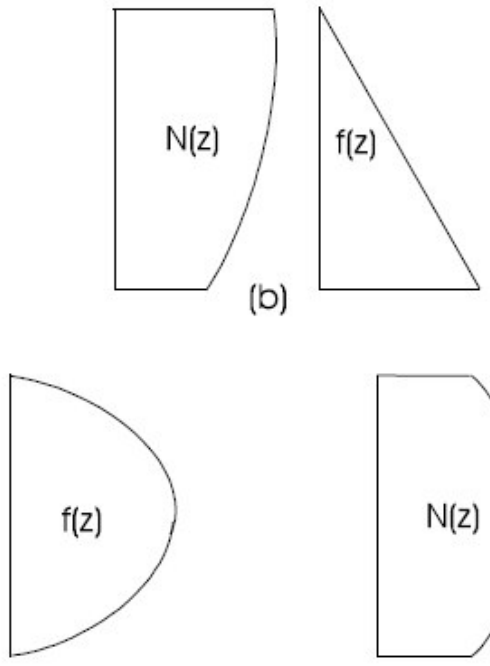

Figura 17- Diagramas típicos de $N(z)$ e curvas $\tau(z) \equiv f(z)$ correspondentes (VÉSIC, 1970) 
Essa expressão (25) é a equação diferencial da transferência de carga de estacas. Dessa forma, identificam-se as relações existentes entre as funções $y(z), N(z)$ e $\tau(z)$ $\equiv \mathrm{f}(\mathrm{z})$, conforme apresentadas por Vésic (1970), na Figura 17. As relações gerais entre essas funções matemáticas, considerando uma condição inicial para a profundidade $z_{c}$ (profundidade para a qual são conhecidos os valores de deformação, carga ou tensão de cisalhamento solicitada ao solo), são assim dadas por:

$$
\begin{gathered}
\tau(z)=-\frac{1}{U} \cdot \frac{d N(z)}{d z} \Rightarrow \tau(z)=\frac{E \cdot S}{U} \cdot \frac{d^{2} y(z)}{d z^{2}} \\
N(z)=-U \cdot \int_{z_{c}}^{z} \tau(z) \cdot d z+N\left(z_{c}\right) \Rightarrow N(z)=-E \cdot S \cdot \frac{d y(z)}{d z} \\
y(z)=-\frac{1}{E \cdot S} \cdot \int_{z_{c}}^{z} N(z) \cdot d z+y\left(z_{c}\right) \Rightarrow \\
\Rightarrow y(z)=-\frac{1}{E \cdot S} \cdot \int\left(-U \cdot \int_{z_{c}}^{z} \tau(z) \cdot d z+N\left(z_{c}\right)\right) \cdot d z+y\left(z_{c}\right)
\end{gathered}
$$

A partir de qualquer uma dessas funções, quer sejam conhecidas ou estimadas, pode-se encontrar as demais.

\subsubsection{Função $\tau(z)$ incógnita: solução pela Equação Diferencial Ordinária de 2a. Ordem (EDO2)}

Para a solução, parte-se do conceito de mobilização da tensão de atrito lateral em função do deslocamento devido ao encurtamento do elemento da estaca, ou seja:

$$
\tau(z)=B \cdot y(z)
$$

Substituindo-se a expressão (29) em (25), tem-se:

$$
\frac{d^{2} y(z)}{d z^{2}}=\frac{U}{E \cdot S} \cdot \tau(z) \Rightarrow \frac{d^{2} y(z)}{d z^{2}}=\frac{U}{E . S} \cdot B \cdot y(z) \Rightarrow y^{\prime \prime}-\frac{U}{E . S} \cdot B \cdot y=0
$$

No Apêndice D, detalham-se as formas de solução da Equação Diferencial (30) com comentários sobre as interessantes possibilidades de variação destas. Aqui são condensadas as conclusões do referido apêndice. 
A expressão (30) é uma Equação Diferencial de Segunda Ordem (EDO2), dita homogênea quando se considera o coeficiente B constante, o que é admitido por Massad (1992). Sua solução é dada pelas funções hiperbólicas:

$$
y(z)=y_{c} \cdot \cosh \left[t \cdot\left(z_{c}-z\right)\right]+\frac{P_{c}}{E \cdot S \cdot t} \cdot \sinh \left[t \cdot\left(z_{c}-z\right)\right]
$$

Assim, a expressão das cargas (força normal no eixo da estaca) fica então:

$$
N(z)=y_{c} \cdot E \cdot S \cdot t \cdot \sinh \left[t \cdot\left(z_{c}-z\right)\right]+P_{c} \cdot \cosh \left[t \cdot\left(z_{c}-z\right)\right]
$$

e a expressão do cisalhamento fica dada por:

$$
\tau(z)=\frac{t}{U} \cdot\left\{y_{c} \cdot E \cdot S \cdot t \cdot \cosh \left[t \cdot\left(z_{c}-z\right)\right]+P_{c} \cdot \sinh \left[t \cdot\left(z_{c}-z\right)\right]\right\}
$$

sendo o parâmetro t dado por:

$$
t=\sqrt{\frac{U \cdot B}{E \cdot S}} \Rightarrow t^{2}=\frac{U \cdot B}{E \cdot S}
$$

O índice "c", que surge nessas expressões, indica que esses valores são conhecidos para um determinado ponto ao longo do fuste da estaca, podendo ser considerado um valor inicial, ou condição de contorno. $O$ parâmetro $t$ define fisicamente a característica de deformação da estaca em relação ao solo do fuste, via o parâmetro $B$, o que será discutido mais adiante. Apenas para comparação, na notação de Randolph e Wroth (1978), o parâmetro t é simbolizado por " $\mu$ ", e que aqui será denominado por $\mu_{r}$. Mais adiante serão discutidos o parâmetro t e a sua relação com a rigidez do sistema solo-estaca.

A expressão (33) pode ser considerada a função que ajusta os pontos experimentais de medidas da resistência por cisalhamento, a qual trará subsídios para aferição na terceira etapa da Metodologia Unificada.

Caso a relação entre $\tau(z)$ e $y(z)$ não seja constante, mas linear, como admitida por Cambefort (1964) e Baguelin e Venon (1971), tem-se, no lugar da expressão (29): 


$$
\tau(z)=B_{c} \cdot y(z)+A_{c}
$$

A substituição de (35) em (25) resulta na solução, que pode ser comparada com a expressão (31):

$$
y(z)=y_{c} \cdot \cosh \left[t \cdot\left(z_{c}-z\right)\right]+\frac{P_{c}}{E \cdot S \cdot t} \cdot \sinh \left[t \cdot\left(z_{c}-z\right)\right]-\frac{A_{c}}{B_{c}}
$$

Observa-se que, qualquer que seja o polinômio ou função em " $z$ " adotado para $A_{c}$ da expressão (36), a solução geral será sempre a solução da EDO2 homogênea subtraída do quociente desse polinômio pelo parâmetro $B_{c}$ (que é considerado constante para cada profundidade $z$ ao longo do eixo da estaca).

Considerando-se a solução dada pela expressão (31) ou pela (36), a expressão geral pretendida deve considerar a rigidez do sistema, de forma a simplificar sua formulação. Nesse sentido, no Apêndice $D$, apresentam-se as análises das rigidezes do sistema, sendo, a seguir, apresentadas algumas delas que permitem a simplificação pretendida.

\subsubsection{Coeficientes de Rigidez do Sistema Estaca- Solo (AMANN, 2008c)}

No Apêndice D são definidas diversas rigidezes possíveis de serem avaliadas no sistema estaca-solo, bem como suas relações com aquelas utilizadas pelos diversos autores, das quais se extraem algumas que permitirão simplificar a formulação geral:

- rigidez do topo da estaca $\left(\mathrm{K}_{z 0}\right)$, para $\mathrm{z}=0$, é a rigidez (secante) de DÉCOURT (1999) que no trecho inicial é igual ao $b_{2}$ de Massad e Lazo (1998). Essa rigidez pode ser estendida para qualquer profundidade $z$, como sendo a do topo do elemento da estaca:

$$
K_{z}=\frac{N(z)}{y(z)} \Rightarrow K_{z 0}=\frac{N(0)}{y(0)}
$$

- rigidez (do solo) do fuste $\left(\mathrm{Ks}_{\mathrm{c}}\right)$, desde o topo da estaca até a profundidade $\mathrm{z}_{\mathrm{c}}$ : 


$$
\mathrm{Ks}_{\mathrm{c}}=\frac{\mathrm{T}\left(\mathrm{z}_{\mathrm{c}}\right)}{\mathrm{y}\left(\mathrm{z}_{\mathrm{c}}\right)}
$$

- rigidez (estrutural) da estaca $\left(\mathrm{Kr}_{\mathrm{c}}\right)$, como o $\mathrm{Kr}$ em Massad (1992), aqui aplicada ao ponto de valores conhecidos:

$$
\mathrm{Kr}_{\mathrm{c}}=\frac{\mathrm{E} \cdot \mathrm{S}}{\mathrm{z}_{\mathrm{c}}}
$$

- coeficiente de rigidez relativa (solo do) fuste - estaca ( $k_{c}$ ), como o k em Massad (1992), porém aqui vem desde o topo até a profundidade $z_{c}$ :

$$
\mathrm{k}_{\mathrm{c}}=\frac{\mathrm{Ks}_{\mathrm{c}}}{\mathrm{Kr}_{\mathrm{c}}}
$$

- rigidez equivalente do sistema (solo do) fuste-estaca (Ksr). É interessante notar que a rigidez equivalente do sistema é igual à média geométrica das rigidezes do solo e da estaca:

$$
\mathrm{Ksr}=\sqrt{\mathrm{Ks}_{\mathrm{c}} \cdot \mathrm{Kr}_{\mathrm{c}}}
$$

- coeficiente de rigidez relativa entre o solo (fuste e ponta)-estaca "abaixo de $z_{c}$ " e o solo (fuste)-estaca "acima de $z_{c}$ " $\left(\lambda_{c}\right)$; para o caso de $z_{c}=L$, torna-se 0 próprio coeficiente de rigidez relativa solo (ponta-fuste)-estaca, simbolizada como $\lambda$ por Massad (1993):

$$
\lambda_{\mathrm{c}}=\frac{\mathrm{Kp}}{\mathrm{Ksr}}
$$

Assim, para facilitar o processo de comparação entre os métodos de transferência de carga, segue-se a explicitação dessas rigidezes acima discutidas nas soluções da EDO, podendo-se reescrever a expressão (31) e, analogamente, a (32) como sendo:

$$
\begin{aligned}
& y(z)=y_{c} \cdot\left\{\cosh \left[t \cdot\left(z_{c}-z\right)\right]+\lambda_{c} \cdot \sinh \left[t \cdot\left(z_{c}-z\right)\right]\right\} \\
& N(z)=\frac{P_{c}}{\lambda_{c}} \cdot\left\{\sinh \left[t \cdot\left(z_{c}-z\right)\right]+\lambda_{c} \cdot \cosh \left[t \cdot\left(z_{c}-z\right)\right]\right\}
\end{aligned}
$$

Parte-se, finalmente, para a transformação da expressão (43) na expressão geral da transferência de carga de estacas. 


\subsubsection{Expressão Geral da Transferência de Carga de Estacas (AMANN, 2008c)}

Deduzida com mais detalhes no Apêndice $D$, apresenta-se a expressão geral de transferência de carga de estacas:

$$
\mathrm{N}(\mathrm{z})=\mathrm{y}(\mathrm{z}) \cdot \frac{\mathrm{Ks}_{\mathrm{c}}}{\sqrt{\mathrm{k}_{\mathrm{c}}}} \cdot\left(\frac{\tanh \left[\mathrm{t} \cdot\left(\mathrm{z}_{\mathrm{c}}-\mathrm{z}\right)\right]+\lambda_{\mathrm{c}}}{1+\lambda_{\mathrm{c}} \cdot \tanh \left[\mathrm{t} \cdot\left(\mathrm{z}_{\mathrm{c}}-\mathrm{z}\right)\right]}\right) \Rightarrow \mathrm{N}(\mathrm{z})=\mathrm{y}(\mathrm{z}) \cdot \mathrm{Kr} \mathrm{r}_{\mathrm{c}} \cdot \sqrt{\mathrm{k}_{\mathrm{c}}} \cdot \beta_{\mathrm{c}}
$$

Essa é a expressão geral da transferência de carga, obtida pela rigidez do sistema estaca-solo, que é dada pela razão entre as expressões (44) e (43), conforme o conceito de rigidez do topo do elemento de estaca na profundidade $z$, tratado no item anterior. Note-se a semelhança com a expressão deduzida por Massad (1992 e 1995), visto ter-se aqui adotado a mesma linha de dedução, porém, dando-se destaque para o conceito de rigidez do solo $\left(\mathrm{Ks}_{\mathrm{c}}\right)$ e para a possibilidade de se adotar uma profundidade qualquer $\left(\mathrm{z}_{\mathrm{c}}\right)$ como condição de contorno.

Se substituídas na expressão (45) as notações de Massad (1992), que considera um valor limite para o atrito lateral $\left(\mathrm{f}_{\max }\right)$ correspondente a um deslocamento $\mathrm{y}_{1}$ do fuste (relação elastoplástica) na profundidade $z^{\prime}=L-h^{\prime}$, e com a condição de contorno $\mathrm{Ks}_{\mathrm{c}}=\mathrm{Alr} / \mathrm{y}_{1}$ e $\mathrm{y}\left(\mathrm{L}-\mathrm{h}^{\prime}\right)=\mathrm{y}_{1}$ tem-se:

$$
\mathrm{P}^{\prime}=\frac{\operatorname{A} \operatorname{lr}}{\sqrt{\mathrm{k}}} \cdot\left(\frac{\tanh \left[\frac{\mathrm{h}^{\prime}}{\mathrm{L}} \cdot \sqrt{\mathrm{k}}\right]+\lambda}{1+\lambda \cdot \tanh \left[\frac{\mathrm{h}^{\prime}}{\mathrm{L}} \cdot \sqrt{\mathrm{k}}\right]}\right)=\frac{\text { Alr }}{\sqrt{\mathrm{k}}} \cdot \beta^{\prime}
$$

A expressão (46) é a mesma de Massad (1995) para a carga transferida ao solo na profundidade $z^{\prime}=L-h$ ', onde ocorre a mobilização plena do atrito lateral $f_{\max }$. Assim, o apóstrofo (') indica que se está na profundidade em que ao atrito lateral está plenamente mobilizado. Acima deste ponto o recalque do fuste já é maior que $\mathrm{y}_{1}$, porém o atrito está no limite $\tau\left[z<\left(L-h^{\prime}\right)\right]=f_{\max }$; abaixo tem-se $\tau\left[z>\left(L-h^{\prime}\right)\right]<f_{\max }$ e os recalques variam com a relação de rigidez $\mathrm{K}_{z}=\mathrm{N}(\mathrm{z}) / \mathrm{y}(\mathrm{z})$ dada pela expressão (45). A Figura 18 ilustra a mobilização parcial do atrito e as expressões para determinação da força normal $[\mathrm{N}(\mathrm{z})]$ ao longo do fuste: 


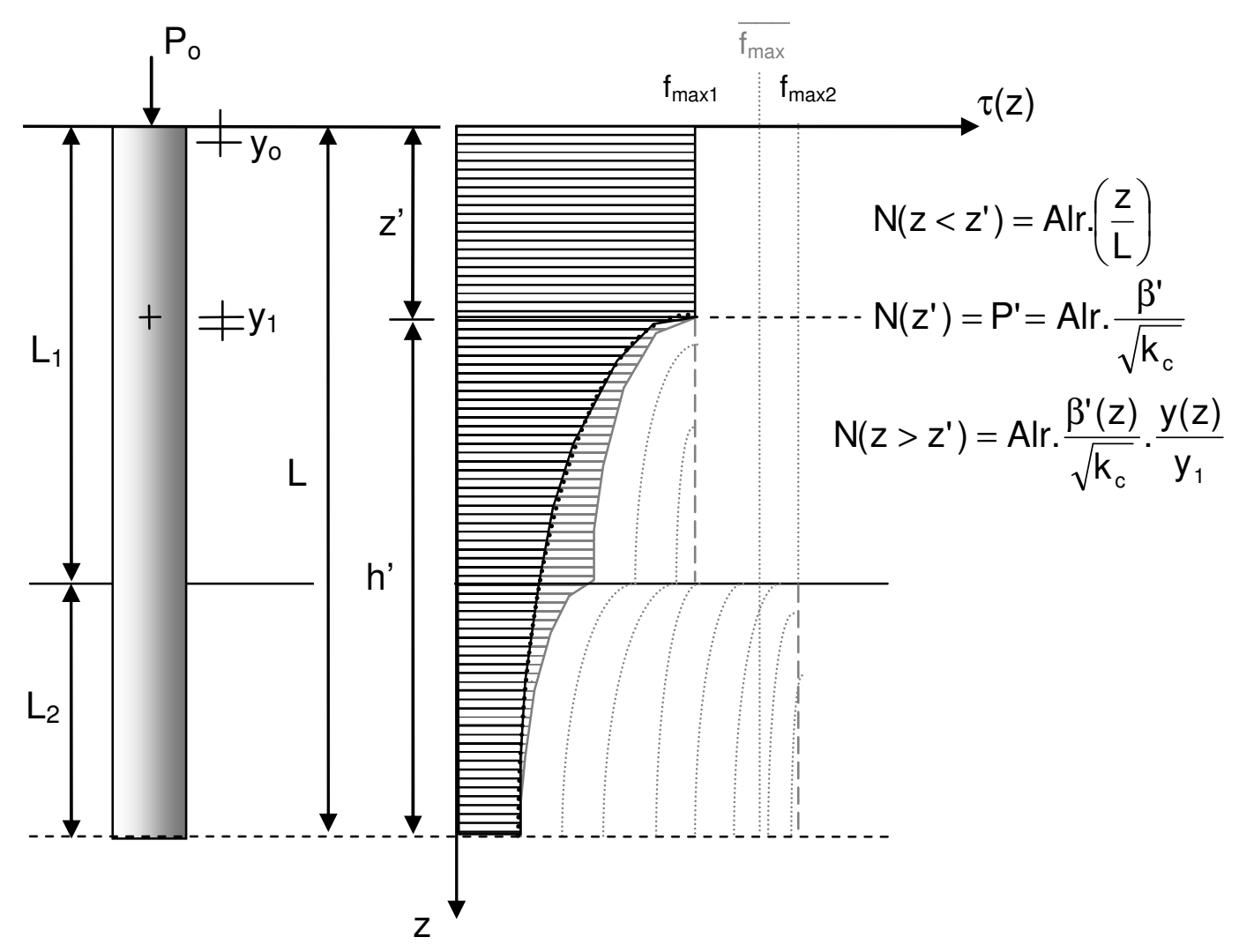

Figura 18 - Indicação da força norma N(z), do atrito parcialmente mobilizado ao longo do fuste e da condição de solo homogêneo (simplificação) comparada a de solo heterogêneo.

Para o caso da carga no topo da estaca, por substituição de $z=0$ na expressão (45) tem-se:

$$
\mathrm{N}(0)=\mathrm{P}_{\mathrm{o}}=\frac{\text { Alr }}{\mathrm{y}_{1}} \cdot \frac{\mathrm{y}_{\mathrm{o}}}{\sqrt{\mathrm{k}}} \cdot\left(\frac{\tanh (\sqrt{\mathrm{k}})+\lambda}{1+\lambda \cdot \tanh (\sqrt{\mathrm{k}})}\right)=\frac{\text { Alr }}{\sqrt{\mathrm{k}}} \cdot \frac{\mathrm{y}_{0}}{\mathrm{y}_{1}} \cdot \beta^{\prime}{ }_{3}
$$

Essa expressão (47) é a usada por Massad (1992 e 1995) para o trecho inicial da curva carga-recalque de mobilização do atrito lateral no topo da estaca.

Ainda para demonstrar a generalidade da expressão (45), substituindo-se nela as notações de Randolph e Wroth (1978), chega-se a:

$$
\mathrm{N}(\mathrm{z})=\frac{\mathrm{y}(\mathrm{z})}{\mu_{\mathrm{r}} \cdot \mathrm{L}} \cdot \frac{2 \cdot \pi}{\zeta} \cdot \frac{\mathrm{L}}{\mathrm{r}_{0}} \cdot r_{0} \cdot G \cdot\left(\frac{\tanh \left[\mu_{\mathrm{r}} \cdot(\mathrm{L}-\mathrm{z})\right]+\frac{4}{\eta \cdot(1-\mathrm{v})} \cdot \frac{\zeta}{2 \cdot \pi} \cdot \frac{r_{0}}{\mathrm{~L}} \cdot \mu_{\mathrm{r}} \cdot \mathrm{L}}{1+\frac{4}{\eta \cdot(1-\mathrm{v})} \cdot \frac{\mathrm{L}}{\pi \cdot \lambda_{\mathrm{r}} \cdot r_{0} \cdot} \cdot \frac{\tanh \left[\mu_{\mathrm{r}} \cdot(\mathrm{L}-\mathrm{z})\right]}{\mu_{\mathrm{r}} \cdot \mathrm{L}}}\right)
$$


Aplicando em (48) a distributiva e substituindo para a carga no topo: $\mathrm{z}=0 ; \mathrm{N}(0)=\mathrm{P}_{\mathrm{t}}$; $y(0)=w_{t}$, chega-se à expressão deduzida por Randolph e Wroth (1978) para estacas flexíveis em solos homogêneos:

$$
\frac{P_{t}}{G \cdot r_{0} \cdot w_{t}}=\frac{\frac{4}{\eta \cdot(1-v)}+\frac{2 \cdot \pi}{\zeta} \cdot \frac{L}{r_{o}} \cdot \frac{\tanh \left[\mu_{r} \cdot L\right]}{\mu_{r} \cdot L}}{1+\frac{4}{\eta \cdot(1-v)} \cdot \frac{1}{\pi \cdot \lambda_{r}} \cdot \frac{L}{r_{o}} \cdot \frac{\tanh \left[\mu_{r} \cdot L\right]}{\mu_{r} \cdot L}}
$$

As comparações com os demais métodos podem ser vistas no Apêndice D, comprovando-se a generalidade da dedução aqui demonstrada. No próximo capítulo será discutido o parâmetro B da expressão (29) e sua consideração em cada um desses métodos, pois basicamente é ele quem os diferencia.

Considerando-se assim que os métodos de transferência de carga são oriundos de uma única base conceitual e, portanto, são correlacionáveis, é possível escolher apenas um deles para aplicação à separação das parcelas de ponta e atrito, sugerindo-se aqui o método baseado nas Leis de Cambefort Modificadas por Massad [LCM] $(1992,1993)$ e seus derivados, quais sejam: o método das Duas Retas [MDR] (MASSAD e LAZO, 1998) e o das Duas Retas Modificado [MDRM] (MARQUES e MASSAD, 2007).

\subsection{MÉTODO DAS LEIS DE CAMBERFORT MODIFICADAS POR MASSAD}

Neste item faz-se uma análise do método das Leis de Cambefort modificadas por (MASSAD, 1992, 1993) com suas implementações mais recentes, propondo-se, a seguir, uma nova forma de análise e obtenção de resultados de separação das parcelas de atrito e ponta.

O diferencial do método baseado nas Leis de Cambefort Modificadas (LCM) por Massad (1991, 1992, 1993, 1994a, b e c, 1995), é a consideração das cargas residuais $\left(\mathrm{P}_{h}\right)$ resultantes de instalação por cravação ou de ensaios de carregamento prévio da estaca, bem como a separação das parcelas de atrito e ponta, a partir da análise direta da curva carga-recalque do ensaio de prova de carga.

A curva carga-recalque é, então, representada por trechos definidos como mostra a Figura 19, cada um correspondendo a uma determinada etapa da transferência de carga da estaca para o solo, conforme se alcançam as singularidades na função de 
transferência de carga. Cada trecho possui uma forma matemática definida, cujo ajuste à curva de ensaio permite realizar a determinação da parcela de atrito (Alr), mediante um valor de rigidez estrutural da estaca $(\mathrm{Kr})$ adequado.

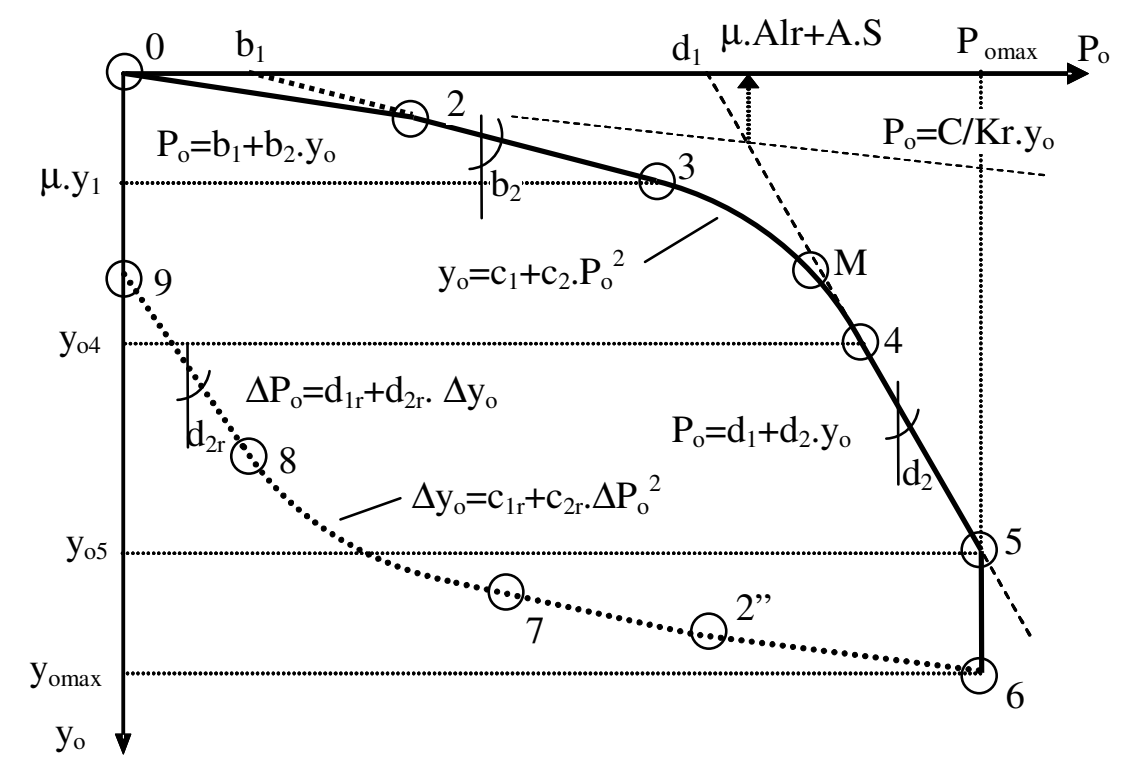

Figura 19- Pontos delimitantes dos trechos da curva carga-recalque teórica (adaptado de FONSECA, et al.2007)

Observe-se, na Figura 19, que o valor procurado para aplicação à Metodologia Semiempírica Unificada é o Alr, sendo que para determiná-lo uma série de análises devem ser consideradas.

Dependendo da rigidez relativa entre o solo do fuste e a estaca $\left[\mathrm{k}=\mathrm{Alr} /\left(\mathrm{y}_{1} \cdot \mathrm{Kr}\right)\right]$, podese ter alguns trechos mais ou menos desenvolvidos, como os trechos 0-2-3 e 3-M-4 mostrados na Figura 19. Em geral, estacas longas ou compressíveis $(k \geq 8)$ e algumas estacas intermediárias ( $2 \leq \mathrm{k} \leq 8$ ) possuem o trecho 3-M-4 bem desenvolvido, permitindo ajuste parabólico e exponencial do mesmo (Método da Parábola e da Exponencial [MPE] MASSAD, 1992, 1993). O ponto M representa o atrito lateral máximo desenvolvido, atingindo a interface entre camadas de diferentes resistências, ou o limite superior da camada mais resistente de embutimento da ponta da estaca. Para estacas curtas ou rígidas $(k \leq 2)$, esse trecho curvo é bastante reduzido, devendo-se recorrer às retas 0-3 e 4-5 (Método das Duas Retas [MDR] MASSAD e LAZO, 1998) para proceder a análise, ou às retas 2-3 e 4-5 para o caso em que a ponta reaja significativamente desde o início do ensaio, como ocorre nas 
estacas cravadas ou com bulbos (Método das Duas Retas Modificado [MDRM] MARQUES e MASSAD, 2004).

As expressões matemáticas do método original foram aqui generalizadas para condensar as diversas modificações propostas ao longo dos anos. Seguem as expressões gerais para cada trecho do carregamento:

- Trecho 2-3 ou, quando $A=0$, trecho 0-3:

$$
P_{o}=K r_{1} \cdot \sqrt{k_{1}} \cdot \beta_{3}^{\prime} \cdot y_{\circ}+A \cdot S \cdot w_{2}=b_{2} \cdot y_{0}+b_{1}
$$

- Trecho 3-M-4:

$$
\mathrm{y}_{\mathrm{o}}=\mu_{1} \mathrm{y}_{11} \cdot\left(1-\frac{\beta^{\prime 2}}{2}\right)+\frac{\mathrm{C}}{\mu_{1} A \mathrm{Ar}_{1} \cdot \mathrm{Kr} \mathrm{r}_{1}} \cdot \mathrm{P}_{0}^{2}=\mathrm{c}_{1}+\mathrm{C}_{2} \cdot \mathrm{P}_{\mathrm{o}}^{2}
$$

- Trecho 4-5:

$$
\begin{aligned}
& \mathrm{P}_{\mathrm{o}}=\left[(\mu \cdot \mathrm{Alr}+\mathrm{A} \cdot \mathrm{S})-\left(\mu_{1} \mathrm{Alr}_{1} \cdot \frac{\mathrm{C}}{\mathrm{Kr}_{1}}+\mu_{2} \mathrm{Alr}_{2} \cdot \frac{\mathrm{C}}{\mathrm{Kr}_{2}}+\frac{\mu_{2} \mathrm{Alr}_{2}}{\mathrm{Kr}_{1}}+\text {.2.A.S. } \frac{\mathrm{C}}{\mathrm{Kr}}\right) \cdot\left(\frac{1}{\frac{1}{\mathrm{Kr}}+\frac{1}{\mathrm{R} \cdot \mathrm{S}}}\right)\right]+ \\
& +y_{0} \cdot\left(\frac{1}{\frac{1}{K r}+\frac{1}{R \cdot S}}\right) \Rightarrow P_{0}=d_{1}+y_{0} \cdot d_{2}
\end{aligned}
$$

Onde: $\quad \mathrm{Kr}_{1}$ e $\mathrm{Kr}_{2}$ : rigidezes estruturais respectivamente no trecho 1 (camada superior de solo) e no trecho 2 (camada inferior de solo).

$\mathrm{k}_{1}$ : coeficiente de rigidez relativa estaca (fuste)-solo no trecho 1 ;

$\beta_{3}^{\prime}$ : parâmetro de influência da ponta na transferência de carga para o topo da estaca;

$\beta^{\prime}$ : parâmetro de influência da ponta na transferência de carga para o ponto de mobilização plena do atrito da estaca;

$\mathrm{w}_{2}=1 /\left[\cosh \left(z_{\mathrm{k}}\right)+\lambda \cdot \sinh \left(z_{\mathrm{k}}\right)\right]$

$b_{2}, b_{1}, c_{2}, c_{1}, d_{2}$ e $d_{1}$ : coeficientes de regressões lineares da curva carga-recalque.

C : coeficiente de desenvolvimento do atrito ao longo do fuste.

$\mathrm{O}$ descarregamento apresenta expressões análogas, substituindo-se $\mathrm{P}_{\mathrm{o}}$ por $\Delta P_{0}=\left(P_{\text {omax }}-P_{0}\right)$ e $y_{0}$ por $\Delta y_{0}=\left(y_{o m a x}-y_{0}\right)$, bem como acrescentando o índice " $r$ " (de "rebound") aos coeficientes das equações de ajuste $\left(b_{2 r}, b_{1 r}, c_{2 r}, c_{1 r}, d_{2 r}\right.$ e $\left.d_{1 r}\right)$ e ao fator de carga residual $\mu$. Os índices 1 e 2 aplicados a $\mu$, Alr, $y_{1}$ e $\mathrm{Kr}$ referem-se 
respectivamente à camada de solo superior (em geral menos resistente) e à do solo de embutimento da ponta. Quando o solo pode ser considerado homogêneo evidentemente tem-se $\mu_{1} \mathrm{Alr}_{1}=\mu \mathrm{Alr}, \mathrm{Kr}_{1}=\mathrm{Kr}$ e $\mu_{2} A \mathrm{Ar}_{2}=0$. O coeficiente $\mathrm{C}$ representa a forma de desenvolvimento ou distribuição do atrito lateral ao longo do fuste, sendo igual a 1/2 para atrito constante e 2/3 para atrito crescente com a profundidade (Massad, 2001). Outros valores de $C$ podem ser obtidos a partir dos ábacos de Leonards e Lowel (1979), apud Fellenius (1980), ou da integração da equação de distribuição do atrito com a profundidade, conforme aqui deduzida no Apêndice $E$, item E.9.

\subsection{PROPOSTA PARA DETERMINAÇÃO SIMULTÂNEA DE Kr E Alr COM AJUSTE OTIMIZADO DA CURVA CARGA-RECALQUE}

A aplicação do método das Leis de Cambefort Modificadas inicia-se ajustando, por regressão, cada trecho da curva carga recalque, para obterem-se os valores de $b_{2}$, $b_{1}, c_{2}, c_{1}, d_{2}, d_{1}$ e seus correspondentes no descarregamento. Em seguida, é feita a estimativa da rigidez estrutural $(\mathrm{Kr})$ da estaca para obtenção do valor de atrito lateral na ruptura (Alr).

Propõe-se aqui a possibilidade de um ajuste otimizado da curva experimental, encontrando-se, simultaneamente, o par de valores Alr e $\mathrm{Kr}$ que resultam no melhor ajuste das expressões teóricas de cada trecho à curva de ensaio, sendo que, evidentemente, a rigidez $\mathrm{Kr}$ obtida deve ser coerente com a estimativa do material da estaca (ver Apêndice D). Após obtidos os valores de Alr e Kr, parte-se para obtenção dos demais parâmetros $\left(R, \lambda\right.$ e $\left.\beta_{3}{ }^{\prime}\right)$ e, por iteração, os valores de $k$, $\beta$ ' e de $y_{1}$, conforme metodologia de Massad $(1992,1993)$. A estimativa de $\mu$ pode ser feita pelo descarregamento, avaliando-se conceitualmente a relação $\mu_{\mathrm{reb}} / \mu$.

As expressões matemáticas fundamentais que definem esta forma de solução, com $A=0$, são:

$$
\mu \mathrm{Alr}=\frac{\mathrm{C}}{\mathrm{C}_{2} \cdot \mathrm{Kr}} \quad[\text { trecho } 3-4]
$$




$$
\begin{gathered}
\mu \text { Alr }=\frac{d_{1}}{1-d_{2} \cdot \frac{C}{K r}} \quad \text { [trecho 4-5] } \\
\mu_{\text {reb }} \text { Alr }=\frac{C}{c_{2 r} \cdot K r} \quad \text { [trecho 7-8] } \\
\mu_{\text {reb } A l r ~}=\frac{d_{1 r}}{1-d_{2 r} \cdot \frac{C}{K r}} \quad[\text { trecho 8-9] }
\end{gathered}
$$

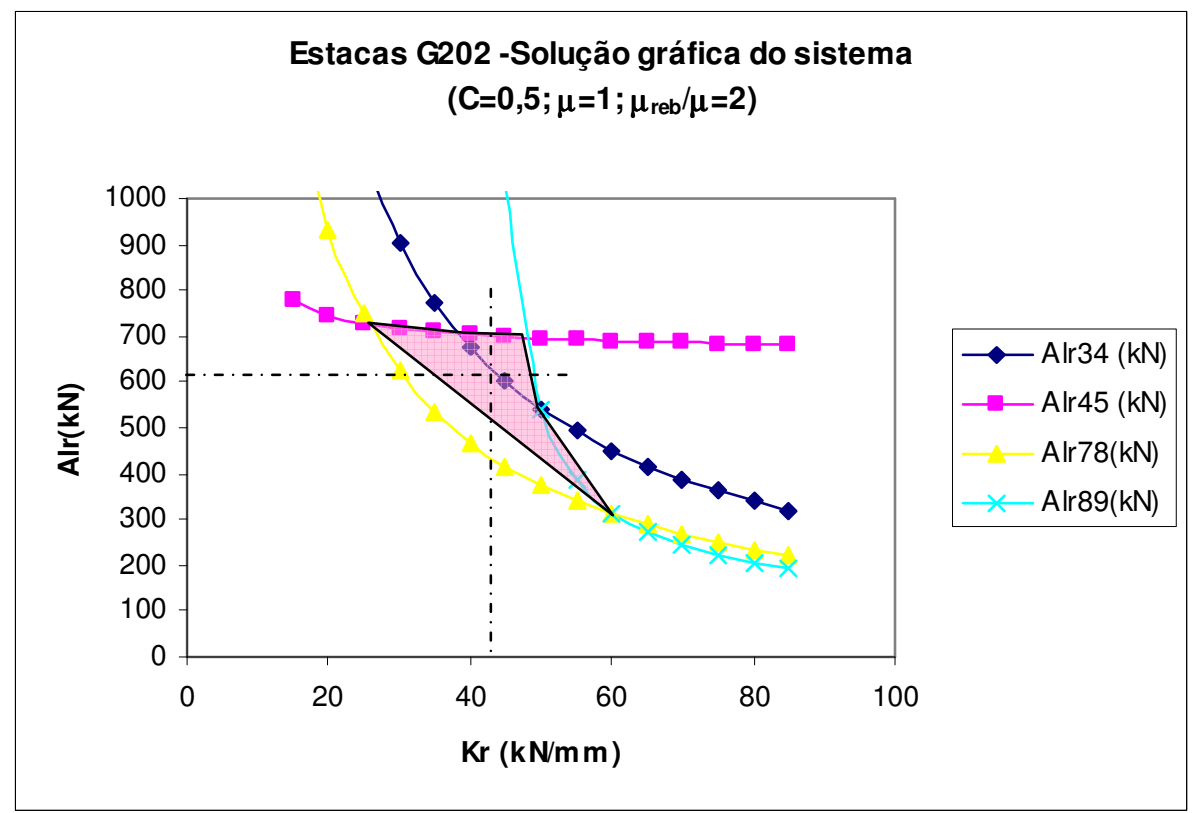

Figura 20- Diagrama Kr-Alr com as curvas hiperbólicas de cada trecho

Verifica-se que essas expressões indicam uma relação hiperbólica entre o atrito Alr e a rigidez estrutural $\mathrm{Kr}$ da estaca, as quais são ilustradas na Figura 20, aplicada à estaca tipo raiz denominada G202.

Pode-se perceber da Figura 20 que, tendo-se o trecho 4-5 bem desenvolvido, os valores de atrito pouco variam com a alteração de $\mathrm{Kr}$, indicando que a imprecisão de seu valor influi pouco no valor de $\mu$ Alr. A interseção entre estas hipérboles, ou seja, a solução do sistema, define o par de valores (Kr, Alr) que melhor ajusta a curva experimental. Para cada circunstância, duas equações apenas seriam suficientes para obtenção de uma solução, contudo verifica-se que, em alguns casos, o sistema assim fica indeterminado, e outros trechos da curva devem ser incluídos na análise. 
O polígono da Figura 20 representa a região onde deveria ser esperada a solução (Kr, Alr) aproximada. Constata-se que esta solução só pode ser fechada (interseção das hipérboles num único ponto) se o valor de $\mathrm{C}$ em cada trecho puder ser variável, o que vem a ser incoerente para a formulação em questão.

A seguir demonstra-se que, com alguma manipulação matemática, para o caso de solo heterogêneo, é possível substituir $C$ por coeficientes $C_{\text {het34, }}, C_{\text {het45, }} C_{\text {het78, }} C_{\text {het89 }}$ em cada trecho e, assim, obter-se uma solução para o sistema.

\subsubsection{Análise do caso de solo heterogêneo}

A dedução da solução do sistema completo para solo heterogêneo (camada 1, superior, menos resistente e camada 2, inferior, mais resistente, na Figura 19) pode ser feita considerando-se as expressões (53) a (56), aplicados ao caso de solo heterogêneo com $A \neq 0$, onde os índices 1 ou 2 indicam a respectiva camada de solo:

$$
\begin{aligned}
& \mu_{1} \mathrm{Alr}_{1}=\frac{\mathrm{C}}{\mathrm{C}_{2} \cdot \mathrm{Kr}_{1}} \quad \text { [trecho 3-M-4] } \\
& \mu_{1} A \mathrm{Ar}_{1}=\frac{\mathrm{d}_{1}-\mu_{2} \mathrm{Alr}_{2} \cdot\left[1-\mathrm{d}_{2} \cdot\left(\frac{1}{\mathrm{Kr}_{1}}+\frac{\mathrm{C}}{\mathrm{Kr}_{2}}\right)\right]-\mathrm{A} \cdot S \cdot\left(1-2 \cdot \mathrm{d}_{2} \cdot \frac{\mathrm{C}}{\mathrm{Kr}}\right)}{1-\mathrm{d}_{2} \cdot \frac{\mathrm{C}}{\mathrm{Kr}_{1}}} \quad \text { [trecho 4-5] } \\
& \mu_{\text {treb }} \mathrm{Alr}_{1}=\frac{\mathrm{C}}{\mathrm{C}_{2 \mathrm{r}} \cdot \mathrm{Kr}_{1}} \quad \text { [trecho 7-8] } \\
& \mu_{\text {treb }} A \mathrm{Ar}_{1}=\frac{\mathrm{d}_{1 \mathrm{r}}-\mu_{2 \mathrm{reb}} A \mathrm{Al}_{2} \cdot\left[1-\mathrm{d}_{2 r} \cdot\left(\frac{1}{\mathrm{Kr}_{1}}+\frac{\mathrm{C}}{\mathrm{Kr}_{2}}\right)\right]-\text { A.S. }\left(1-2 \cdot \mathrm{d}_{2 \mathrm{r}} \cdot \frac{\mathrm{C}}{\mathrm{Kr}}\right)}{1-\mathrm{d}_{2 r} \cdot \frac{\mathrm{C}}{\mathrm{Kr}_{1}}} \text { [trecho 4-5] }
\end{aligned}
$$

Devem-se deixar todas as expressões em função de $\mu \mathrm{Alr}$ e $\mathrm{Kr}$, substituindo-se todos os $\mu_{1} \mathrm{Alr}_{1}, \mu_{2} \mathrm{Alr}_{2}, \mu_{1 \mathrm{reb}} \mathrm{Alr} r_{1}, \mu_{2 r e b} \mathrm{Alr} \mathrm{r}_{2}, \mathrm{Kr}_{1}$ e $\mathrm{Kr}_{2}$ por expressões em função desses dois termos: 


$$
\begin{aligned}
& \mu \mathrm{Alr}=\frac{\mathrm{C}_{\mathrm{het} 34}}{\mathrm{C}_{2} \cdot \mathrm{Kr}} ; \operatorname{com} \mathrm{C}_{\mathrm{het} 34}=\frac{\mathrm{C}}{\frac{\mu_{1} \mathrm{Alr}}{\mu \mathrm{Alr}} \cdot \mathrm{a}_{\mathrm{Kr} 1}} \\
& \mu \text { Alr }=\frac{d_{1}-\text { A.S. }\left(1-2 \cdot d_{2} \cdot \frac{C}{K r}\right)}{1-d_{2} \cdot \frac{C_{\text {het } 45}}{K r}} \\
& \text { com } C_{\text {het } 45}=\frac{\mu_{1} A_{1}}{\mu \operatorname{Alr}} \cdot\left[C \cdot\left(\frac{1}{a_{\mathrm{kr} 1}}-\frac{1}{a_{\mathrm{kr} 2}}\right)-\frac{1}{a_{\mathrm{kr} 1}}\right]+\left(\frac{\mathrm{C}}{a_{\mathrm{kr} 2}}+\frac{1}{a_{\mathrm{kr} 1}}\right) \\
& \mu \mathrm{Alr}=\frac{\mathrm{C}_{\text {het78 }}}{\mathrm{C}_{2 \mathrm{r}} \cdot \mathrm{Kr}} ; \text { com } \mathrm{C}_{\text {het78 }}=\frac{1}{\frac{\mu_{\text {treb }}}{\mu_{1}}} \cdot \mathrm{C}_{\text {het34 }} \\
& \mu \text { Alr }=\frac{1}{\frac{\mu_{\text {reb }}}{\mu}} \cdot \frac{d_{1 r}-A_{r} \cdot S \cdot\left(1-2 \cdot d_{2 r} \cdot \frac{C}{K r}\right)}{1-d_{2 r} \cdot \frac{C_{\text {het89 }}}{K r}} \\
& \text { com } \quad C_{\text {het89 }}=\frac{\mu_{1} A_{1 r}}{\mu \text { Alr }} \cdot\left[\frac{\mu_{\text {treb }}}{\mu_{1}} \cdot \frac{1}{\frac{\mu_{\text {reb }}}{\mu}} C \cdot\left(\frac{1}{a_{\mathrm{kr} 1}}-\frac{1}{a_{\mathrm{kr} 2}}\right)-\frac{1}{a_{\mathrm{kr} 1}}\right]+\left(\frac{C}{a_{\mathrm{kr} 2}}+\frac{1}{a_{\mathrm{kr} 1}}\right)
\end{aligned}
$$

Os coeficientes serão discutidos no item seguinte. Dessa forma, verifica-se que os valores de $\mathrm{C}_{\text {het }}$ em cada trecho mudam para considerar a variação de rigidez de cada camada e portanto pode-se obter uma solução para o sistema. Essas expressões levam à solução pretendida de forma direta, como segue.

\subsubsection{Solução do sistema para a curva completa (estaca compressível)}

Do ponto de vista do modelo matemático, consideram-se como variáveis do problema nesta etapa $\mathrm{Kr}, \mu \mathrm{Alr}, \mu_{1} \mathrm{Alr} r_{1} / \mu \mathrm{Alr}, \mathrm{C}, \mu_{1 \mathrm{reb}} / \mu_{1}, \mu_{1 \mathrm{reb}} / \mu_{1}$ e A.S $=\mathrm{b}_{1} / \mathrm{w}_{2}$ sendo este último dependente de $\mathrm{Kr}$, devendo ser resolvido por iteração.

Matematicamente, para solução do problema, devem-se ter no máximo quatro variáveis, e, portanto, é preciso ter-se um juízo a respeito dos valores das outras duas, além do produto AS, o qual, em primeira análise, poderia ser considerado zero. Assim, em cada situação, deve-se considerar sobre quais variáveis se pode ter 
alguma idéia do valor conceitualmente mais adequado, ou de sua faixa de variação. Dependendo das variáveis cujos valores se podem atribuir, a sequência de substituição de expressões na solução do sistema pode mudar, considerando que, pelo método de substituição, partem-se das expressões com menos variáveis para as com mais variáveis (escalonamento).

Em geral, sugere-se adotar inicialmente $\mathrm{C}=0,5$ (atrito constante ao longo do fuste) e para $\mu_{1}$ Alr $r_{1} / \mu$ Alr avaliar a sondagem e a geometria da estaca através da expressão (65):

$$
\frac{\mu_{1} A_{1} r_{1}}{\mu A I r}=\left(1+\frac{L_{2}}{L_{1}} \cdot\left(\frac{U_{1}}{U_{2}} \cdot \frac{f_{\max 1}}{f_{\max 2}} \cdot \frac{\mu_{1}}{\mu_{2}}\right)^{-1}\right)^{-1}
$$

onde: $U$ representa o perímetro da estaca em cada camada de solo da estaca ( 1 ou 2). A relação $\mu_{1} / \mu_{2}$ pode ser adotada em princípio igual a 1 , podendo ser alterada posteriormente caso se conclua que a camada 2 não mobilizou plenamente $o$ atrito. Já $f_{\max 1} / f_{\max 2}$ pode ser estimado pela Hierarquia dos Solos em conjunto com a sondagem.

É importante verificar que a adoção de valores para $L_{1}$ e $L_{2}$ com base na sondagem ou características geométricas da estaca impacta nos valores das constantes físicogeométricas $\mathrm{a}_{\mathrm{kr} 1}=\mathrm{Kr}_{1} / \mathrm{Kr}$ e $\mathrm{a}_{\mathrm{kr} 2}=\mathrm{Kr}_{2} / \mathrm{Kr}$.

$$
a_{\mathrm{kr} 1}=\frac{\mathrm{Kr}_{1}}{\mathrm{Kr}}=\frac{\mathrm{E}_{1} \cdot \mathrm{S}_{1}}{\mathrm{E}_{2} \cdot \mathrm{S}_{2}} \cdot \frac{1}{\frac{\mathrm{L}_{1}}{\mathrm{~L}_{2}}}+1 ; \quad \text { e } \quad \mathrm{a}_{\mathrm{Kr} 2}=\frac{\mathrm{Kr}_{2}}{\mathrm{Kr}}=\frac{1}{\frac{\mathrm{E}_{1} \cdot \mathrm{S}_{1}}{\mathrm{E}_{2} \cdot \mathrm{S}_{2}}} \cdot \frac{\mathrm{L}_{1}}{\mathrm{~L}_{2}}+1
$$

Caso não se disponha de boas informações para atribuição desses valores (sobretudo de $f_{\max 1} / f_{\max 2}$ e $L_{2} / L_{1}$ que aqui se sugere fazer com base no embutimento e pela análise da sondagem) pode-se considerar o solo homogêneo assumindo $\mu_{1} A_{1} r_{1} / \mu$ Alr $=0,5$ e $L_{1}=L_{2}=L / 2$, que para estaca sem variação de diâmetro resulta $a_{k r 1}=a_{k r 2}=2$.

caminho de solução quando se dispõe de todos os trechos da curva bem desenvolvidos pode ser descrito como segue:

1) das expressões (61) e (63) calcula-se: 


$$
\frac{\mu_{1 r e b}}{\mu_{1}}=\frac{c_{2}}{c_{2 r}}
$$

Esse valor deve ser verificado, pois, se ultrapassado o ponto $\mathrm{M}$ de ensaio (Figura 19), então $\mu_{1 \mathrm{reb}}=2$ e pode-se determinar $\mu_{1}$. O valor de $\mu_{1}$ deve posteriormente ser analisado verificando se obedece às condições $1 \leq \mu_{1} \leq 2$ e $\mu_{2} \leq \mu \leq \mu_{1}$ (pois o trecho superior deve mobilizar o atrito em maior grau que o inferior);

2) substitui-se (61) em (62) e desenvolvendo-se os coeficientes $C_{\text {het34 }}$ e $C_{\text {het45, }}$, chega-se a expressão (68):

$$
\begin{aligned}
& \mathrm{d}_{1}=\mathrm{b}_{1} \cdot\left(\cosh \left(\mathrm{z}_{\mathrm{k}}\right)+\frac{1}{\mathrm{z}_{\mathrm{k}}} \cdot \frac{\mathrm{d}_{2}}{\mathrm{Kr}-\mathrm{d}_{2}} \cdot \sinh \left(\mathrm{z}_{\mathrm{k}}\right)\right) \cdot\left(1-\frac{2 \cdot \mathrm{d}_{2} \cdot \mathrm{C}}{\mathrm{Kr}}\right)+ \\
& +\frac{1}{\mathrm{Kr}} \cdot\left(\frac{1}{\mathrm{C}_{2}} \cdot \frac{\mathrm{C}}{\mathrm{a}_{\mathrm{kr} 1}}\right) \cdot\left\{\frac{1}{\frac{\mu_{1} \mathrm{Alr} 1}{\mu \mathrm{Alr}}}-\frac{\mathrm{d}_{2}}{\mathrm{Kr}} \cdot\left[\frac{1}{\frac{\mu_{1} A l r_{1}}{\mu \mathrm{Alr}}} \cdot\left(\frac{\mathrm{C}}{\mathrm{a}_{\mathrm{kr} 2}}+\frac{1}{\mathrm{a}_{\mathrm{kr} 1}}\right)+\mathrm{C} \cdot\left(\frac{1}{\mathrm{a}_{\mathrm{kr} 1}}-\frac{1}{\mathrm{a}_{\mathrm{kr} 2}}\right)-\frac{1}{\mathrm{a}_{\mathrm{kr} 1}}\right]\right)
\end{aligned}
$$

onde: $z_{k}=k^{1 / 2}$.

Se $b_{1}=0$ na expressão (68), pode-se isolar $\mathrm{Kr}$ e calcular seu valor analiticamente. Caso contrário, deve-se fazer uma iteração dupla (que pode ser programada facilmente com ferramentas "solver" de planilhas eletrônicas), pois o valor de $z_{k}=k^{1 / 2}$ depende de Kr. O processo iterativo sugerido é o descrito a seguir:

a) tendo-se ajustado todos os trechos da curva, adota-se um valor de $\mathrm{Kr}_{\text {adot }}$ que pode ser aproximadamente $80 \%$ do $\mathrm{Kr}$ estrutural calculado para a estaca pela estimativa de seu módulo de elasticidade;

b) calculam-se os produtos $\left(\beta_{3 .}^{\prime} z_{k}\right)=b_{2} / K_{\text {adot }}$ e $\quad\left(\lambda . z_{k}\right)=d_{2} /\left(K_{\text {adot }}-d_{2}\right)$;

c) adota-se, inicialmente, um valor baixo de $Z_{\text {kadot }}$, que pode ser $10^{-2}$ e com ele calcula-se a expressão $\left(\beta_{3}^{\prime}{ }_{3} z_{k}\right)_{\text {calc }}$ :

$$
\left(\beta^{\prime}{ }_{3} \cdot z_{k}\right)_{\text {calc }}=\frac{z_{\text {kadot }} \cdot \tanh \left(z_{\text {kadot }}\right)+\left(\lambda \cdot z_{k}\right)}{\frac{1}{z_{\text {kadot }}} \cdot\left(z_{\text {kadot }}+\tanh \left(z_{\text {kadot }}\right) \cdot\left(\lambda \cdot z_{k}\right)\right)}
$$

d) adotam-se novos valores de $z_{\text {kadot }}$, até o valor calculado $\left(\beta_{3}^{\prime} \cdot Z_{k}\right)_{\text {calc }}$ esteja próximo (com uma tolerância predefinida, por exemplo de $10^{-5}$ ) do produto $\left(\beta_{3 .}^{\prime} z_{k}\right)$ do passo (b) acima, achando-se o valor definitivo de $z_{k}$; 
e) substituem-se os valores de $z_{k}$ definitivo e de $K r_{\text {adot }}$ na expressão (68) e calcula-se o valor de $d_{1 \text { calc }}$, o qual deve ser comparado ao valor de $d_{1}$ ajustado no início;

f) caso $d_{1 \text { calc }}$ seja próximo de $d_{1}$, com precisão de $10^{-3}$, pode-se considerar $\mathrm{Kr}_{\text {adot }}$ como o $\mathrm{Kr}_{\text {aj }}$ de melhor ajuste da curva de carregamento, com seu respectivo $\mathrm{k}=\left(\mathrm{Z}_{\mathrm{k}}\right)^{2}$. Caso contrário, adota-se novo valor para $\mathrm{Kr}_{\text {adot }}$ (por exemplo $85 \%$ de $\mathrm{Kr}$ estrutural), repete-se desde o passo (a) até que essa precisão seja alcançada. $\mathrm{O}$ valor $\mathrm{Kr}_{\mathrm{aj}}$ deve ser coerente com o estrutural da estaca, caso contrário o ajuste da curva deve ser refeito.

3) Tendo-se o valor de $\mathrm{Kr}_{\mathrm{aj}}$, substitui-se em (61) e acha-se $\mu$ Alr:

$$
\mu \mathrm{Alr}=\frac{1}{\frac{\mu_{1} \mathrm{Alr}_{1}}{\mu \mathrm{Alr}}} \cdot \frac{\mathrm{C}}{\mathrm{C}_{2} \cdot \mathrm{Kr} \cdot \mathrm{a}_{\mathrm{Kr} 1}}
$$

4) Agora, calcula-se $z_{\text {kreb }}$ para o descarregamento pela iteração seguinte:

g) calculam-se os produtos $\left(\beta_{3 \text { reb }}^{\prime} \cdot Z_{\text {kreb }}\right)=b_{2 r} / K_{\text {aj }}$ e $\left(\lambda_{\text {reb }} \cdot Z_{\text {kreb }}\right)=d_{2 r} /\left(K_{r a j}-d_{2 r}\right)$;

h) adota-se, inicialmente, um valor baixo de $z_{\text {kreb}}$, que pode ser $10^{-2}$, e com ele calcula-se a expressão $\left(\beta^{\prime}{ }_{\text {rreb. }} Z_{\text {kreb }}\right)_{\text {calc }}$ :

$$
\left(\beta_{3 \text { reb }}^{\prime} \cdot z_{\text {kreb }}\right)_{\text {calc }}=\frac{z_{\text {krebadot }} \cdot \tanh \left(z_{\text {krebadot }}\right)+\left(\lambda_{\text {reb }} \cdot z_{\text {kreb }}\right)}{\frac{1}{z_{\text {krebadot }}} \cdot\left(z_{\text {krebadot }}+\tanh \left(z_{\text {krebadot }}\right) \cdot\left(\lambda_{\text {reb }} \cdot z_{\text {kreb }}\right)\right)}
$$

i) adotam-se novos valores de $z_{\text {krebadot, }}$, até que o valor calculado $\left(\beta^{\prime}{ }_{3 r e b} \cdot z_{k r e b}\right)_{\text {calc }}$ esteja próximo (com uma tolerância predefinida, por exemplo de $10^{-5}$ ) do $\left(\beta^{\prime}{ }_{\text {zreb. }} Z_{\mathrm{kreb}}\right)$ do passo $(\mathrm{g})$ acima, achando-se o valor definitivo de $z_{\mathrm{kreb}}$;

5) tendo-se $\mu$ Alr e $z_{k r e b}$, substituem-se todos os demais valores em (64) e achase $\mu_{\mathrm{reb}} / \mu$ que pode ser calculado pela expressão (72): 


$$
\begin{aligned}
& \frac{\mu_{\text {reb }}}{\mu}=\frac{1}{\mu \text { Alr } .\left(1-\frac{d_{2 r}}{\mathrm{Kr}} \cdot\left(\frac{\mathrm{C}}{\mathrm{a}_{\mathrm{kr} 2}}+\frac{1}{\mathrm{a}_{\mathrm{kr} 1}}\right)\right)} \mathrm{x}
\end{aligned}
$$

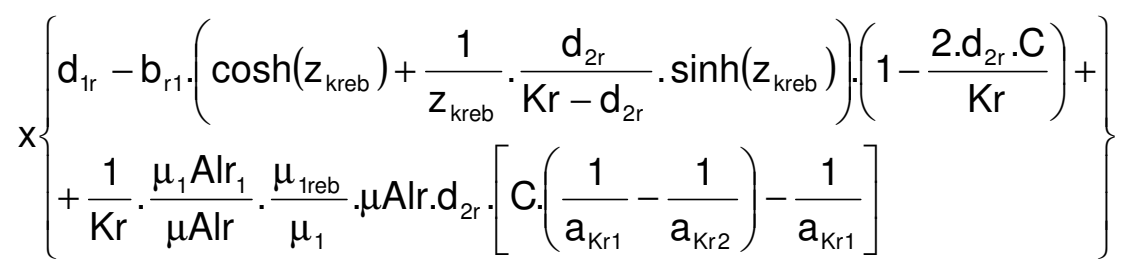

6) se for adotado $\mu_{1 \mathrm{reb}} / \mu_{1}=\mu_{\mathrm{reb}} / \mu$ então a expressão se torna (73):

$$
\frac{\mu_{\text {reb }}}{\mu}=\frac{K r \cdot\left[b_{r 1} \cdot\left(\cosh \left(z_{\mathrm{kreb}}\right)+\frac{1}{z_{\mathrm{kreb}}} \cdot \frac{\mathrm{d}_{2 \mathrm{r}}}{\mathrm{Kr}-\mathrm{d}_{2 \mathrm{r}}} \cdot \sinh \left(\mathrm{z}_{\mathrm{kreb}}\right)\right) \cdot\left(1-\frac{2 \cdot \mathrm{d}_{2 \mathrm{r}} \cdot \mathrm{C}}{\mathrm{Kr}}\right)-\mathrm{d}_{1 \mathrm{r}}\right]}{\mu \mathrm{Alr} \cdot\left\{\mathrm{d}_{2 \mathrm{r}} \cdot\left[\left(\frac{\mathrm{C}}{\mathrm{a}_{\mathrm{kr} 2}}+\frac{1}{\mathrm{a}_{\mathrm{kr} 1}}\right)+\frac{\mu_{1} \text { Alr }}{\mu \text { Alr }} \cdot\left(\mathrm{C} \cdot\left(\frac{1}{\mathrm{a}_{\mathrm{kr} 1}}-\frac{1}{\mathrm{a}_{\mathrm{kr} 2}}\right)-\frac{1}{\mathrm{a}_{\mathrm{kr} 1}}\right)\right]-\mathrm{Kr}\right\}}
$$

7) tendo-se $\mu_{\mathrm{reb}} / \mu$, deve-se atribuir o valor de $\mu_{\text {reb }}$ com base no conhecimento que se tem do caso em estudo. Em geral, se a curva de ensaio ultrapassou o ponto 4, a estaca mobilizou plenamente o atrito lateral e seu valor é igual a 2 , caso contrário, deve variar entre 1 e 2 . Calcula-se assim $\mu$, que deve estar entre 1 e 1+Qpr/Alr ou no máximo 2.

8) verifica-se o valor de $\mu_{2}$ :

$$
\mu_{2}=\frac{1-\frac{\mu_{1} \text { Alr }_{1}}{\mu \text { Alr }}}{\frac{1}{\mu}-\frac{1}{\mu_{1}} \cdot \frac{\mu_{1} \text { Alr }_{1}}{\mu \text { Alr }}}
$$

valor esse que deve atender à condição $\mu_{2} \leq \mu \leq \mu_{1}$, devido à forma de solicitação da estaca. É de fundamental importância essa verificação para se considerar a adequação ou não do ajuste realizado. Caso não atenda, pode-se considerar que o trecho 7-8 não esteja bem ajustado e, então, tenta-se igualar $\mu_{1 \mathrm{reb}} / \mu_{1}=\mu_{\mathrm{reb}} / \mu$, usando-se a expressão (73) e ignorando o valor obtido no passo 2. Caso ainda não atenda, o valor adotado para $\mu_{1} A \mid r_{1} / \mu$ Alr está inadequado e parte-se então para a análise sem o trecho 7-8, apresentada mais adiante;

9) Se as verificações foram adequadas, calcula-se finalmente Alr a partir do valor de $\mu$; 
10) O valor da carga máxima transferida pela ponta (Qp), que em geral ainda não é a carga de ruptura da ponta ( $Q p r)$, é obtida pela diferença $Q p=P_{\text {omax }}-A l r$;

Caso o trecho 7-8 não permita bom ajuste, segue-se para o próximo item.

\subsubsection{Solução para curva com trecho 7-8 (descarregamento) pouco desenvolvido (estaca intermediária)}

Neste caso o trecho curvo do descarregamento (7-8 na Figura 19) não se apresenta bem desenvolvido ou seu ajuste a uma parábola não apresenta resultados coerentes. Sendo assim, não se pode considerar o valor de $\mu_{1 \text { reb }} / \mu_{1}=c_{2} / c_{2 r}$. Sugerese adotar como condição de verificação $\mu_{1 \mathrm{reb}} / \mu_{1}=\mu_{\mathrm{reb}} / \mu$, que é o mesmo que se considerar $\mu=\mu_{1}=\mu_{2}$ e que representa justamente o ponto de transição da condição.

Sugere-se, inicialmente, adotar $C=0,5, L_{1}$ e $L_{2}$ (de acordo com o embutimento provável pela análise da sondagem, ou $\mathrm{L}_{1}=\mathrm{L}_{2}=\mathrm{L} / 2$, caso não haja) e $\mu_{\text {reb }} / \mu$ coerente ao caso em questão (2 para estacas escavadas no primeiro carregamento ou um valor entre 1 e 2 para estacas cravadas), deixando-se $\mu_{1} A_{1} r_{1} / \mu$ Alr como variável a ser obtida. Isso permite que a solução indique qual o valor de $\mu_{1} A{ }_{1} r_{1} / \mu A l r$ que leva à condição de $\mu_{\text {reeb }} / \mu_{1}=\mu_{\text {reb }} / \mu$.

Em relação à solução de substituição apresentada no item anterior, tem-se as seguintes alterações:

$$
\begin{aligned}
& d_{1 r}=b_{1 r} \cdot\left(\cosh \left(z_{\text {kreb }}\right)+\frac{1}{z_{\text {kreb }}} \cdot \frac{d_{2 r}}{K r-d_{2 r}} \cdot \sinh \left(z_{\text {kreb }}\right)\right) \cdot\left(1-2 \cdot d_{2 r} \cdot \frac{C}{K r}\right)+ \\
& +\frac{\mu_{\mathrm{reb}}}{\mu} \cdot\left\{\begin{array}{l}
\mathrm{d}_{1}-\mathrm{b}_{1} \cdot\left(\cosh \left(\mathrm{z}_{\mathrm{k}}\right)+\frac{1}{\mathrm{z}_{\mathrm{k}}} \cdot \frac{\mathrm{d}_{2}}{\mathrm{Kr}-\mathrm{d}_{2}} \cdot \sinh \left(\mathrm{z}_{\mathrm{k}}\right)\right) \cdot\left(1-2 \cdot \mathrm{d}_{2} \cdot \frac{\mathrm{C}}{\mathrm{Kr}}\right)+ \\
+\frac{\mathrm{d}_{2}}{\mathrm{Kr}^{2}} \cdot \frac{\mathrm{C}}{\mathrm{C}_{2} \cdot \mathrm{a}_{\mathrm{kr} 1}} \cdot\left[\mathrm{C} \cdot\left(\frac{1}{\mathrm{a}_{\mathrm{kr} 1}}-\frac{1}{\mathrm{a}_{\mathrm{kr} 2}}\right)-\frac{1}{\mathrm{a}_{\mathrm{kr} 1}}\right]
\end{array}\right\} \times \\
& \times \frac{1-\frac{d_{2 r}}{K r} \cdot\left(\frac{C}{a_{\mathrm{Kr} 2}}+\frac{1}{a_{\mathrm{Kr} 1}}\right)}{1-\frac{d_{2}}{K r} \cdot\left(\frac{C}{a_{\mathrm{kr} 2}}+\frac{1}{a_{\mathrm{Kr} 1}}\right)}-\frac{\mu_{\text {treb }}}{\mu_{1}} \cdot \frac{d_{2 r}}{\mathrm{Kr}^{2}} \cdot \frac{C}{c_{2} \cdot a_{\mathrm{kr} 1}} \cdot\left[C \cdot\left(\frac{1}{a_{\mathrm{Kr} 1}}-\frac{1}{a_{\mathrm{kr} 2}}\right)-\frac{1}{a_{\mathrm{kr} 1}}\right]
\end{aligned}
$$


- Ao invés de substituir a expressão (61) de $\mu$ Alr em (63), deve-se isolar $\mu_{1} A_{1} r_{1} / \mu$ Alr na expressão (61) e substituir nas expressões (62) do trecho 4-5 e (64) do trecho 8-9, dado que agora também é uma incógnita. Dessa forma, no lugar da expressão (72) do passo 5, deve-se fazer uma iteração tripla para obter $z_{k}$ [expressão (69)], $z_{\text {kreb }}$ [expressão (71)] e $K r$ usando a expressão (75) e compará-la com o valor de $\mathrm{d}_{1 \mathrm{r}}$ com precisão de $10^{-3} \mathrm{kN}$ :

- Substitui-se o valor de Kr na expressão (62) e acha-se $\mu$ Alr:

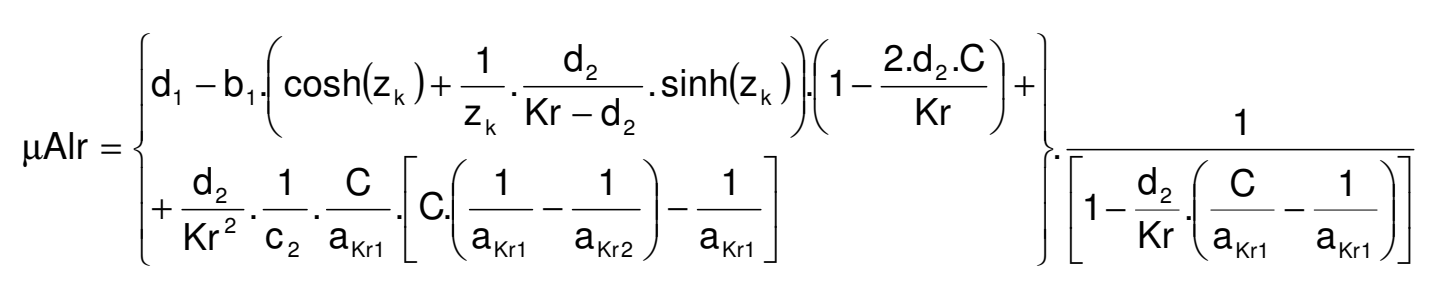

- Substituindo-se tudo na expressão (61), tem-se $\mu_{1} \mathrm{Alr}_{1} / \mu \mathrm{Alr}$

$$
\frac{\mu_{1} \mathrm{Alr}_{1}}{\mu \mathrm{Alr}}=\frac{1}{\mu \mathrm{Alr}} \cdot \frac{\mathrm{C}}{\mathrm{C}_{2} \cdot \mathrm{Kr} \cdot \mathrm{a}_{\mathrm{Kr} 1}}
$$

- Tendo-se $\mu_{1} A$ Alr $1 / \mu$ Alr, pela expressão (65) isola-se a relação $f_{\max } / f_{\max 2}$, sabendo-se que foi adotada a premissa de $\mu=\mu_{1}=\mu_{2}$;

- Adotando-se o valor de $\mu_{\mathrm{reb}}$ adequado, como já apresentado, acha-se $\mu$ (que deve atender aos critérios já discutidos) e em seguida Alr;

- Acham-se Alr $1, A l r_{2}, f_{\max }, f_{\max 1}$ e $f_{\max 2 .}$, com $f_{\max 2} \geq f_{\max 1}$;

Caso o valor de $\mathrm{Kr}$ não seja coerente com o estrutural calculado, verifica-se, então, se o trecho 3-4 está bem desenvolvido, podendo-se desconsiderá-lo, como segue.

\subsubsection{Solução para curva com trechos 7-8 e 3-4 (parabólicos) pouco desenvolvidos (estaca curta)}

Se o trecho 3-4 tem pequena extensão os ajustes parabólico e exponencial ficam prejudicados em confiabilidade e o método das Duas Retas (MDR) deve ser utilizado (Massad e Lazo, 1998).

Esse método utiliza apenas as retas 0-3 e 4-5 para ajuste da curva experimental. Poder-se-ia utilizar as expressões já apresentadas, contudo, nesse caso, não se 
dispõe de informação ou equações adicionais a respeito de $\mu_{1 \text { reb }} / \mu_{1} \mathrm{e}$, portanto, não tem sentido utilizar a formulação para solo heterogêneo. Isso também ocorre devido à grande rigidez da estaca em relação ao solo, fazendo com que as diferenças entre eventuais camadas sejam desprezíveis em relação à imposição de deslocamento da rigidez elevada da estaca. Portanto, adotam-se $\mu_{1} A_{1} r_{1} / \mu A l r=0,5, \quad L_{1}=L_{2}=L / 2 \quad$ (o embutimento passa a não ter tanta influência). Dessa forma, pode-se propor a solução por duas vias:

- A primeira, quando não se conhece $\mathrm{Kr}$ com alguma certeza, contudo é possível atribuir-se um valor confiável à $\mu_{\mathrm{reb}} / \mu=\mu_{1 \mathrm{reb}} / \mu_{1}$, como, por exemplo, no caso de estacas escavadas no primeiro carregamento, cujo valor seria 2,0. A substituição é análoga à do caso anterior, exigindo iteração tripla, com a expressão (78):

$$
\begin{aligned}
& d_{1 r}=b_{1 r} \cdot\left(\cosh \left(z_{\text {kreb }}\right)+\frac{1}{z_{\text {kreb }}} \cdot \frac{d_{2 r}}{K r-d_{2 r}} \cdot \sinh \left(z_{\text {kreb }}\right) \cdot\left(1-2 \cdot d_{2 r} \cdot \frac{C}{K r}\right)+\right. \\
& +\frac{\frac{\mu_{\mathrm{reb}}}{\mu} \cdot \operatorname{Kr} \cdot\left[b_{1} \cdot\left(\cosh \left(z_{\mathrm{k}}\right)+\frac{1}{z_{\mathrm{k}}} \cdot \frac{\mathrm{d}_{2}}{\mathrm{Kr}-\mathrm{d}_{2}} \cdot \sinh \left(z_{\mathrm{k}}\right)\right) \cdot\left(1-2 \cdot \mathrm{d}_{2} \cdot \frac{\mathrm{C}}{\mathrm{Kr}}\right)-\mathrm{d}_{1}\right]}{\mathrm{d}_{2} \cdot\left\{\left(\frac{\mathrm{C}}{\mathrm{a}_{\mathrm{kr} 2}}+\frac{1}{\mathrm{a}_{\mathrm{kr} 1}}\right)+\frac{\mu_{1} \mathrm{Alr}}{\mu \mathrm{Alr}} \cdot\left[\mathrm{C} \cdot\left(\frac{1}{\mathrm{a}_{\mathrm{kr} 1}}-\frac{1}{\mathrm{a}_{\mathrm{kr} 2}}\right)-\frac{1}{\mathrm{a}_{\mathrm{kr} 1}}\right]\right\}-\mathrm{Kr}} \times \\
& \times\left\{\left[1-\frac{\mathrm{d}_{2 \mathrm{r}}}{\mathrm{Kr}} \cdot\left(\frac{\mathrm{C}}{\mathrm{a}_{\mathrm{kr} 2}}+\frac{1}{\mathrm{a}_{\mathrm{kr} 1}}\right)\right]-\frac{\mathrm{d}_{2 \mathrm{r}}}{\mathrm{Kr}^{2}} \cdot \frac{\mu_{1} \mathrm{Alr}_{1}}{\mu \mathrm{Alr}} \cdot\left[\mathrm{C} \cdot\left(\frac{1}{\mathrm{a}_{\mathrm{kr} 1}}-\frac{1}{\mathrm{a}_{\mathrm{kr} 2}}\right)-\frac{1}{\mathrm{a}_{\mathrm{kr} 1}}\right]\right\}
\end{aligned}
$$

Para o atrito, tem-se:

$$
\mu \operatorname{Alr}=\frac{\mathrm{Kr} \cdot\left[d_{1}-b_{1} \cdot\left(\cosh \left(z_{k}\right)+\frac{1}{z_{k}} \cdot \frac{d_{2}}{K r-d_{2}} \cdot \sinh \left(z_{k}\right)\right) \cdot\left(1-\frac{2 \cdot d_{2} \cdot C}{K r}\right)\right]}{d_{2} \cdot\left[\left(\frac{C}{a_{k r 1}}+\frac{1}{a_{k r 1}}\right)+\frac{\mu_{1} A \operatorname{Al}_{1}}{\mu \operatorname{Alr}}\left[C \cdot\left(\frac{1}{a_{\mathrm{kr} 1}}-\frac{1}{a_{k r 2}}\right)-\frac{1}{a_{k r 1}}\right]\right]-K r}
$$

O procedimento para achar o Alr e demais informações segue o mesmo do caso anterior.

- A segunda forma é adequada para o caso de se conhecer o $\mathrm{Kr}$ da estaca com alguma certeza, por exemplo, para estacas pré-moldadas ou metálicas cravadas. Assim, adota-se o Kr estrutural da estaca, e fazem-se as iterações 
(69) e (71) apenas para obter $z_{k}$ e $z_{k r e b}$. Visto que agora $K r$ não é variável, pode-se optar por adotar $\mu_{\text {reb }} / \mu$ ou $C$ como variáveis:

$$
\begin{aligned}
& \frac{\mu_{\text {reb }}}{\mu}=\frac{\left[b_{1 r} \cdot\left(\cosh \left(z_{\text {kreb }}\right)+\frac{1}{z_{\text {kreb }}} \cdot \frac{d_{2 r}}{k r-d_{2 r}} \cdot \sinh \left(z_{\text {kreb }}\right) \cdot\left(1-2 \cdot d_{2 r} \cdot \frac{C}{K r}\right)-d_{1 r}\right]\right.}{K r \cdot\left[b_{1} \cdot\left(\cosh \left(z_{k}\right)+\frac{1}{z_{k}} \cdot \frac{d_{2}}{K r-d_{2}} \cdot \sinh \left(z_{k}\right)\right) \cdot\left(1-2 \cdot d_{2} \cdot \frac{C}{K r}\right)-d_{1}\right]} \times \\
& \times \frac{d_{2} \cdot\left\{\left(\frac{C}{a_{\mathrm{kr} 2}}+\frac{1}{a_{\mathrm{kr} 1}}\right)+\frac{\mu_{1} A \operatorname{Al} 1}{\mu \operatorname{Alr}} \cdot\left[C \cdot\left(\frac{1}{a_{\mathrm{kr} 1}}-\frac{1}{a_{\mathrm{kr} 2}}\right)-\frac{1}{a_{\mathrm{kr} 1}}\right]\right\}-\mathrm{Kr}}{\left[\frac{\mathrm{d}_{2 \mathrm{r}}}{\mathrm{Kr}} \cdot\left(\frac{\mathrm{C}}{\mathrm{a}_{\mathrm{kr} 2}}+\frac{1}{\mathrm{a}_{\mathrm{kr} 1}}\right)\right]+\frac{\mathrm{d}_{2 \mathrm{r}}}{\mathrm{Kr}^{2}} \cdot \frac{\mu_{1} \mathrm{Alr}}{\mu \mathrm{Alr}} \cdot\left[\mathrm{C} \cdot\left(\frac{1}{\mathrm{a}_{\mathrm{kr} 1}}-\frac{1}{a_{\mathrm{kr} 2}}\right)-\frac{1}{\mathrm{a}_{\mathrm{kr} 1}}\right]-1}
\end{aligned}
$$

Se $\circ \mu_{\text {reb }} / \mu$ encontrado pela expressão (80) resultar $\mu$ fora do intervalo de 1,0 a 2,0, resta apenas adotar $\mathrm{C}$ como variável, mantendo $\mu_{\text {reb }} / \mu$ como constante com valor conceitual coerente ao caso em estudo (2,0 para estacas escavadas no $1^{\text {o }}$ carregamento e entre 1,0 e 2,0 para cravadas). Para esse cálculo usa-se a expressão (78) com $C$ variando (iterações por solver) até se obter o valor de $d_{11}$. Em geral $C$ deve ser maior ou igual a 0,5 para solos com atrito minimamente crescente com a profundidade, devendo-se verificar se essa condição é coerente com a sondagem.

\subsubsection{Solução para curva sem descarregamento}

O ajuste, nesse caso, deve ser feito pelos trechos 3-4 e 4-5, podendo-se utilizar para eles as expressões do sistema completo, sem se ocupar com os valores de $\mu_{\text {reb }} / \mu$. Verifica-se, assim, que não se pode isolar o valor de Alr, exceto em duas situações: a) no caso em que a estaca seja escavada no primeiro carregamento, pois então $\mu=1$; b) quando a estaca já sofreu carregametno anterior com mobilização da ponta (ultrapassado o ponto 4 da Figura 19), quando então $\mu=2$. Nos demais casos, resulta apenas numa estimativa de $\mu A \mathrm{Al}$, ou seja, incluídas as cargas residuais.

Se a curva de ensaio não definiu o trecho 4-5, pode-se aplicar o método da Parábola-Exponencial [MPE], desde que a estaca seja intermediária ou compressível ( $k \geq 5$ ), ou, ainda, que $\lambda$ seja aproximadamente 1 (MASSAD, 1993). 


\subsection{EXEMPLO DE APLICAÇÃO DA SOLUÇÃO DO SISTEMA A UMA ESTACA METÁLICA CRAVADA COMPRESSÍVEL (LONGA)}

A estaca escolhida como exemplo é a da "Penha", analisada por MASSAD (1992, 1993), por ser intermediária com comportamento ligeiramente compressível $(k=5)$ e as seguintes características: estaca metálica tubada, $D_{\text {ext }}=343 \mathrm{~mm} ; D_{\text {int }}=323 \mathrm{~mm}, \mathrm{~L}=$ 20,6 m; Kr= $101 \mathrm{kN} / \mathrm{mm}$, calculada pelas dimensões e módulo de elasticidade do aço de $210 \mathrm{GPa}$.

Fazendo-se o ajuste dos trechos da prova de carga (ver Apêndice D), obtém-se:

$\mathrm{b}_{1}=0$;

$\mathrm{b}_{2}=219,28 \mathrm{kN} / \mathrm{mm}$;

$\mathrm{c}_{1}=3,222 \mathrm{~mm}$;

$\mathrm{C}_{2}=1,69215 \mathrm{E}-06 \mathrm{~mm} / \mathrm{kN}^{2}$;

$\mathrm{d}_{1}=2999,97 \mathrm{kN}$; $\mathrm{d}_{2}=1,41443 \mathrm{E}-03 \mathrm{kN} / \mathrm{mm}$;

$\mathrm{C}_{1} \mathrm{r}=1,067 \mathrm{~mm}$;

$\mathrm{C}_{2 \mathrm{r}}=1,56692 \mathrm{E}-06 \mathrm{~mm} / \mathrm{kN}^{2}$;

$\mathrm{d}_{1 \mathrm{r}}=508,31 \mathrm{kN}$;

$\mathrm{d}_{2 \mathrm{r}}=182,1 \mathrm{kN} / \mathrm{mm}$.

Considerando-se a curva completa e adotando-se $\mu_{1} A l r_{1} / \mu A l r=0,5, C=0,5, a_{\mathrm{kr} 1}=$ $a_{\mathrm{kr} 2}=2$ (caso de estaca com rigidez constante e solo homogêneo), obtém-se:

$\mathrm{Kr}=98,49 \mathrm{kN} / \mathrm{mm}$;

$\mu \mathrm{Alr}=3000,0 \mathrm{kN}$,

$\mu_{1 \text { reb }} / \mu_{1}=1,08$

$\mu_{\text {reb }} / \mu=0,853$.

É importante observar que o valor de $\mathrm{Kr}$ obtido é próximo do determinado pelas dimensões e módulo de elasticidade da estaca acima mencionado (97,5\%), o que é significativo visto que a geometria da estaca metálica praticamente não varia e o módulo de elasticidade do aço é conhecido, fatores esses que incutem erro em estacas escavadas. Isso indica que a proposta de solução do sistema otimiza o resultado e, se aplicado a estacas escavadas, resultará na rigidez provável apresentada pela estaca. O gráfico da Figura 21 apresenta as curvas hiperbólicas $\mu \mathrm{Alr}=f(\mathrm{Kr})$ obtidas.

Nesta figura percebe-se que o ponto de interseção das hipérboles dos trechos 3-4, 4-5 e 7-8 praticamente coincidem num ponto em torno de $3000 \mathrm{kN}$ para $\mu$ Alr e de $100 \mathrm{kN} / \mathrm{mm}$ para Kr. O ramo quase vertical da curva do trecho 8-9 representa sua assíntota e não deve ser considerado para efeito de interseção. Observe-se que a curva do trecho 7-8 apresenta-se deslocada para baixo e, de fato, para que ela coincida no ponto de interseção, o valor de $\mu_{\mathrm{reb}} / \mu$ deve ser exatamente igual a 1,0. Isso demonstra que o trecho 7-8 subsidia os cálculos, mas a precisão do ajuste do trecho não permite que se exija sua passagem na interseção das demais curvas. Em alguns casos, como já sugerido, deve-se até mesmo desconsiderá-lo. 


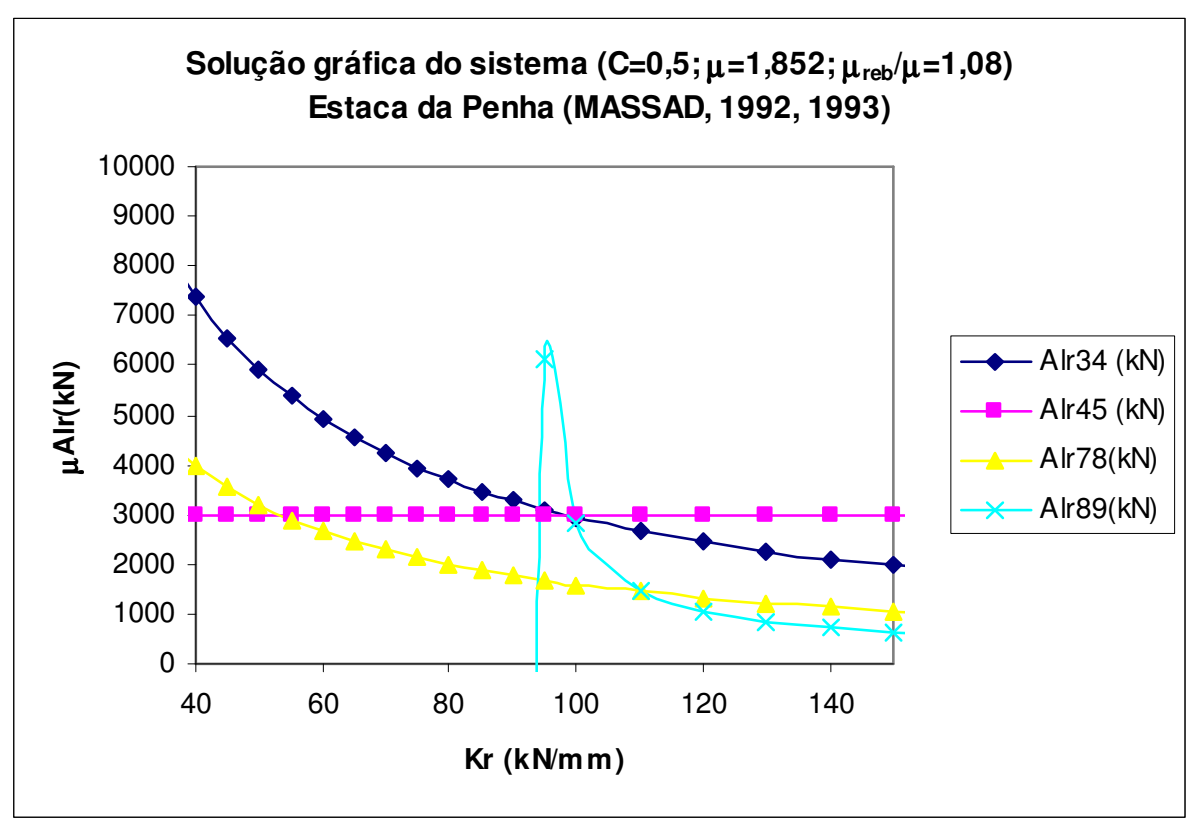

Figura 21 - Solução gráfica do sistema para a estaca metálica cravada da Penha

A Figura 22 ilustra a variação de $\mathrm{C}$ com $\mu_{\mathrm{reb}} / \mu$ para este caso, onde se vê que as interseções das curvas dos trechos 3-4 e 8-9 com a do trecho 7-8 ocorrem próximas a $\mathrm{C}=0,5$ e $\mu_{\mathrm{reb}} / \mu=1,0$. O trecho 4-5 não aparece por resultar em valores negativos, visto tratar-se de uma região próxima da assíntota da função, devendo ser desconsiderado por motivos de imprecisão. O cruzamento das curvas do trecho 3-4 e 8-9 ocorre acima de $\mu_{\mathrm{reb}} / \mu=2,0$, saindo fora do domínio, não sendo interessante. Quando os ajustes da curva de ensaio são perfeitos, as interseções neste tipo de gráfico ocorrem todas num único ponto. Daí o caráter aproximado do método.

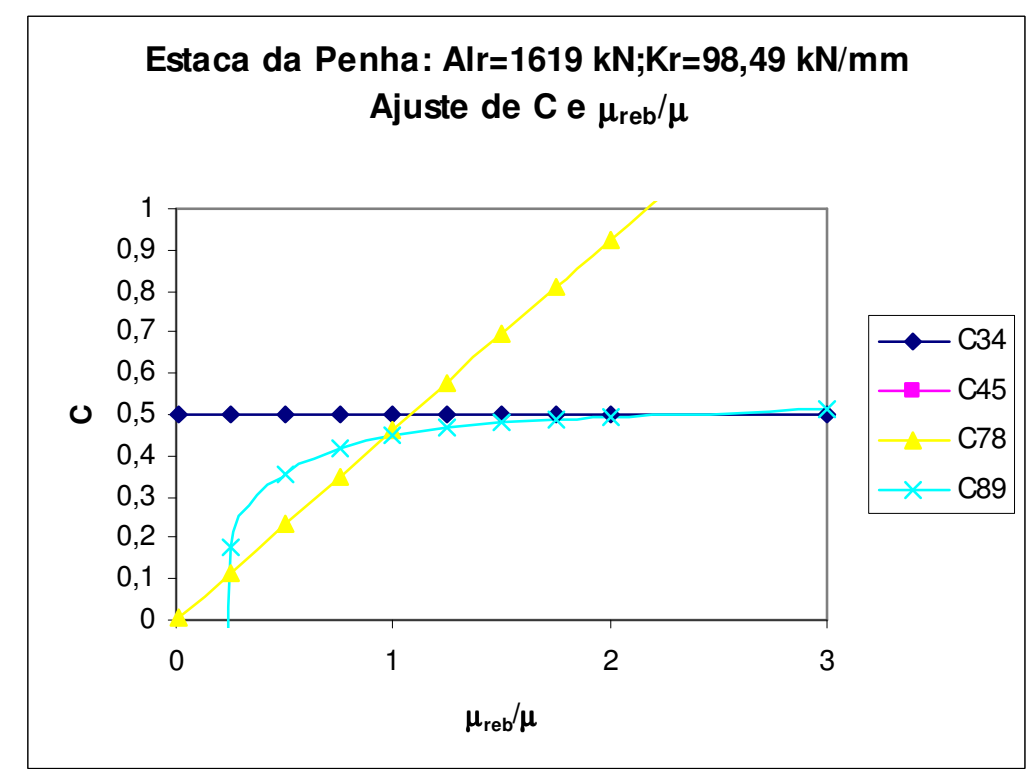

Figura 22 - Variação de $\mathrm{C} \operatorname{com} \mu_{\text {reb }} / \mu$ para a estaca metálica cravada da Penha 
Considerando-se que $\mu_{1 \text { reb }}=2,0$ (ultrapassado o ponto 4) obtém-se $\mu_{1}=1,852$, valor próximo ao 1,83, encontrado por Massad (1992) para $\mu$ no caso de solo homogêneo, demonstrando que o ajuste da curva de descarregamento corresponde à camada superior, conforme sugere Massad (1993).

Quando da análise, considerando o solo homogêneo, Massad (1992) adotou o Método da Parábola-Exponencial, para ajuste do trecho 3-4, obtendo $\mu \mathrm{Alr}=2740 \mathrm{kN}$, e pela parábola do trecho 7-8 no descarregamento, adotando $\mu_{\mathrm{reb}}=2,0$, encontrou Alr $=1496 \mathrm{kN}$, o que resulta em $\mu=1,83$. Em trabalho posterior, Massad (1993) aplicou o método do solo heterogêneo, fazendo as seguintes considerações: a estaca é de atrito, sem reação de ponta e portanto a ruptura corresponde ao atrito, resultando $\mu \mathrm{Alr}=3000 \mathrm{kN}$ (carga em que ocorreu a ruptura brusca); a estaca foi dividida ao meio para efeito de atribuição da camada superior e inferior (nesse caso, as duas camadas, de argila variegada e de areia variegada, possuíam a mesma média de SPT) em função da verificação de que havia embuchado $10 \mathrm{~m}$; para o descarregamento, como Massad (1993) não considera separação entre as camadas, o resultado do ajuste do trecho parabólico 7-8 resultou Alr=1496 kN, como no caso de solo homogêneo. Disto resulta $\mu=3000 / 1496=2,005$, que deve obviamente ser arredondado para 2,0. Para a separação dos atritos da camada superior e inferior, usou o ajuste exponencial do trecho 3-M, o qual resultou $\mu \mathrm{Alr}_{1}=1308 \mathrm{kN}$, restando $\mu \mathrm{Alr}_{2}=1692 \mathrm{kN}$. Isso indica uma distribuição de $43,7 \%\left(\mu_{1} \mathrm{Alr}_{1} / \mu \mathrm{Alr}=0,437\right)$ para a camada superior e 56,3\% para a camada inferior, a qual estava embuchada. Essa pequena diferença em relação a $50 \%\left(\mu_{1} \mathrm{Alr}_{1} / \mu \mathrm{Alr}=0,5\right)$, provavelmente, se deve muito mais à aproximação da curva exponencial do que ao solo embuchado e a escolha do ponto médio da estaca como interface entre as camadas, o que também é uma aproximação em relação à realidade. Convém comentar ainda que Massad (1993) não considerou distinção entre os coeficientes da carga residual, resultando $\mu=\mu_{1}=\mu_{2}=2,0$, ou seja, considerou que, durante a instalação da estaca, ocorreu a mobilização plena do atrito nas duas camadas.

Comparando com a solução pelo sistema, esta consideração seria o mesmo que adotar $\mu_{1 \mathrm{reb}} / \mu_{1}=\mu_{\mathrm{reb}} / \mu=\mathrm{c}_{2} / \mathrm{c}_{2 \mathrm{r}}$ e modificando o sistema para esta condição, tomando-se desta vez como incógnitas $\mu$ Alr, $\mathrm{Kr}$ e $\mu_{1} \mathrm{Alr} \mathrm{r}_{1} / \mu \mathrm{Alr}$, obtém-se:

$$
\mu \mathrm{Alr}=3000,38 \mathrm{kN} ; \quad \mathrm{Kr}=116,24 \mathrm{kN} / \mathrm{mm} ; \quad \mu_{1} \mathrm{Alr}_{1} / \mu \mathrm{Alr}=0,424
$$


Esses valores são bastante próximos aos obtidos por Massad (1993): $\mu \mathrm{Alr}=3000$ $\mathrm{kN}, \mathrm{Kr}=101 \mathrm{kN} / \mathrm{mm}$ [para solo homogêneo Massad (1992) obteve $107 \mathrm{kN} / \mathrm{mm}$ ] e $\mu_{1} A_{1} r_{1} / \mu$ Alr $=0,437$. Verifica-se, portanto, que, apesar da leve superestimativa de $16 \%$ sobre $\mathrm{Kr}$, é válida a aplicação do sistema proposto para a determinação desses parâmetros do modelo.

Com relação ao valor de $\mu_{\mathrm{reb}} / \mu=\mu_{1 \mathrm{reb}} / \mu_{1}=\mathrm{c}_{2} / \mathrm{c}_{2 \mathrm{r}}=1,08$, que resulta no sistema, deve-se considerar que ele depende diretamente do bom ajuste da parábola do trecho 7-8, como é feito para o caso de solo homogêneo, sendo que nem sempre o descarregamento permite tal qualidade de ajuste. Nesse caso, trata-se de um valor ajustado, bastante próximo de 1,0 . Caso fosse adotado 1,0 , ter-se-ia $\mu=\mu_{1}=\mu_{2}=2,0$, visto que se considera conceitualmente $\mu_{\text {reb }}=2,0$ quando a curva de ensaio demonstra ter desenvolvido bem a reta de ponta do trecho 4-5. Assim, o valor de $\mu_{1}=1,85$ seria uma aproximação do valor real, o qual seria 2,0 .

$\mathrm{Na}$ análise aqui procedida, pesa ainda para essa consideração o fato de que conceitualmente deve-se ter a condição $\mu_{2} \leq \mu \leq \mu_{1}$, pois o trecho superior da estaca deve mobilizar maior proporção do atrito máximo que o trecho inferior, caso não seja mobilizado totalmente $O$ atrito. Assim, sugere-se que sempre que a relação $c_{2} / c_{2 r}$ esteja próxima do valor conceitual (1,0 para estacas cravadas e 2,0 para estacas escavadas no primeiro carregamento), esta deve ser corrigida para ser preservada a relação $\mu_{2} \leq \mu \leq \mu_{1}$ (desde que se verifique a plena mobilização do atrito no carregamento). Caso o seu valor seja muito distante, deve-se rever o ajuste ou verificar se o trecho parabólico no carregamento (3-4) e no descarregamento (7-8) estão bem definidos, pois, caso contrário, deve-se adotar o ajuste exclusivamente pelas retas 4-5 e 8-9, que são o equivalente do sistema proposto ao Método das Duas Retas, como se apresentou no item 4.3.4.

Verificados os bons resultados da aplicação do sistema proposto, segue-se, após a apresentação da separação das parcelas de atrito e ponta pelo método da Rigidez de Décourt (1999), a apresentação de como obter os demais parâmetros do método, tendo-se definidos os valores de Kr e Alr para a estaca. 


\subsection{SEPARAÇÃO DAS PARCELAS DE ATRITO E PONTA PELO MÉTODO DA RIGIDEZ DE DÉCOURT (2008)}

Décourt (1999) propôs ajustar a curva carga-recalque a uma expressão hiperbólica do tipo:

$$
\text { Rig }=\frac{P_{0}}{y_{0}}=C_{2}+C_{1} \cdot P_{\circ}
$$

onde: $\mathrm{C}_{1}$ e $\mathrm{C}_{2}$ são os coeficientes da regressão linear.

Define-se, dessa forma, a rigidez (Rig), que quando é nula indica a ruptura no ensaio. Segundo Fellenius (2006), a expressão (81) é comparável ao critério de ruptura de Chin (1972), o que permite definir a carga de ruptura por $Q_{u}=C_{2} / C_{1}$ :

$$
\frac{y_{0}}{P_{0}}=c_{o C}+c_{1 C} \cdot y_{\circ}=\frac{1}{C_{2}}-\frac{C_{1}}{C_{2}} \cdot y_{\circ}
$$

onde: $c_{o c}$ e $c_{1 c}$ são coeficientes de regressão linear do critério de Chin (1972).

É importante destacar que o ajuste é feito para o trecho final da curva de Rigidez e que Décourt (2008) indica este ajuste linear para estacas de deslocamento, enquanto para estacas escavadas, cuja ruptura não fica definida no ensaio, sugere um ajuste bilogarítmico $\left[\log \left(P_{0}\right) x \log (R i g)\right]$, com definição da ruptura convencional $\left(Q_{u c}\right)$ para a rigidez correspondente ao recalque da ponta de $10 \%$ do diâmetro da estaca (0,1D). Melo (2008) apresenta as expressões de cálculo para este critério:

$$
\begin{gathered}
\log \left(P_{\mathrm{o}}\right)=b_{\mathrm{rP}}-a_{\mathrm{rP}} \cdot \log (\text { Rig }) \\
\mathrm{Q}_{\mathrm{uc}}=10^{\left[\mathrm{b}_{\mathrm{rp}}-\mathrm{a}_{\mathrm{rP}} \cdot \log \left(\operatorname{Rig}_{0,1 \mathrm{D}}\right)\right]}
\end{gathered}
$$

Sugere-se aqui, contudo, que seja usada a seguinte expressão (85), por ser de maior praticidade ao evitar calcular a Rigidez para $\mathrm{y}_{0}=\mathrm{y}_{0,1 \mathrm{D}}=0,1 \mathrm{D}$ :

$$
Q_{u c}=\left(y_{0,1 D} \cdot 10^{\frac{b_{\mathrm{rp}}}{a_{\mathrm{rp}}}}\right)\left(\frac{1}{\frac{1}{a_{\mathrm{rp}}}+1}\right)
$$

E para cálculo da curva carga-recalque teórica, é aqui sugerido a expressão (86): 


$$
y_{0}=P_{0}^{\left(\frac{1}{a_{\mathrm{rp}}+1}\right)} \cdot 10^{\frac{-\mathrm{b}_{\mathrm{rp}}}{\mathrm{a}_{\mathrm{rp}}}}
$$

Os índices "p" nos coeficientes da reta (83) foram aqui introduzidos para destacar que o trecho final da curva pertence ao assim chamado "domínio da ponta". Décourt (2008) estende com isso o método da Rigidez para permitir a separação do atrito lateral, especificando nesse caso o ajuste linear para o trecho correspondente ao "domínio do atrito". Assim, na expressão (87), o valor do intercepto $b_{\mathrm{rL}}$ (sendo $\mathrm{a}_{\mathrm{rL}} \mathrm{a}$ inclinação da reta de regressão) resulta diretamente no limite superior do valor de atrito lateral $\left(Q_{\mathrm{su}}\right)$ :

$$
P_{\mathrm{o}}=\mathrm{b}_{\mathrm{rL}}-\mathrm{a}_{\mathrm{rL}} \cdot \operatorname{Rig} \mathrm{AL}_{\mathrm{AL}}=\mathrm{Q}_{\mathrm{su}}-\mathrm{a}_{\mathrm{rL}} \cdot \operatorname{Rig}_{\mathrm{AL}}
$$

Os índices "L" ou "AL" indicam aqui o "domínio do atrito". A Figura 23 ilustra esta separação dos domínios.

Para definição do domínio de ponta, Décourt (2008) sugere regressões tomando-se, a cada nova regressão, um ponto a mais, desde o último até o primeiro ponto de ensaio. Quando se perde a linearidade da função bilogarítmica, define-se então o limite do domínio da ponta.

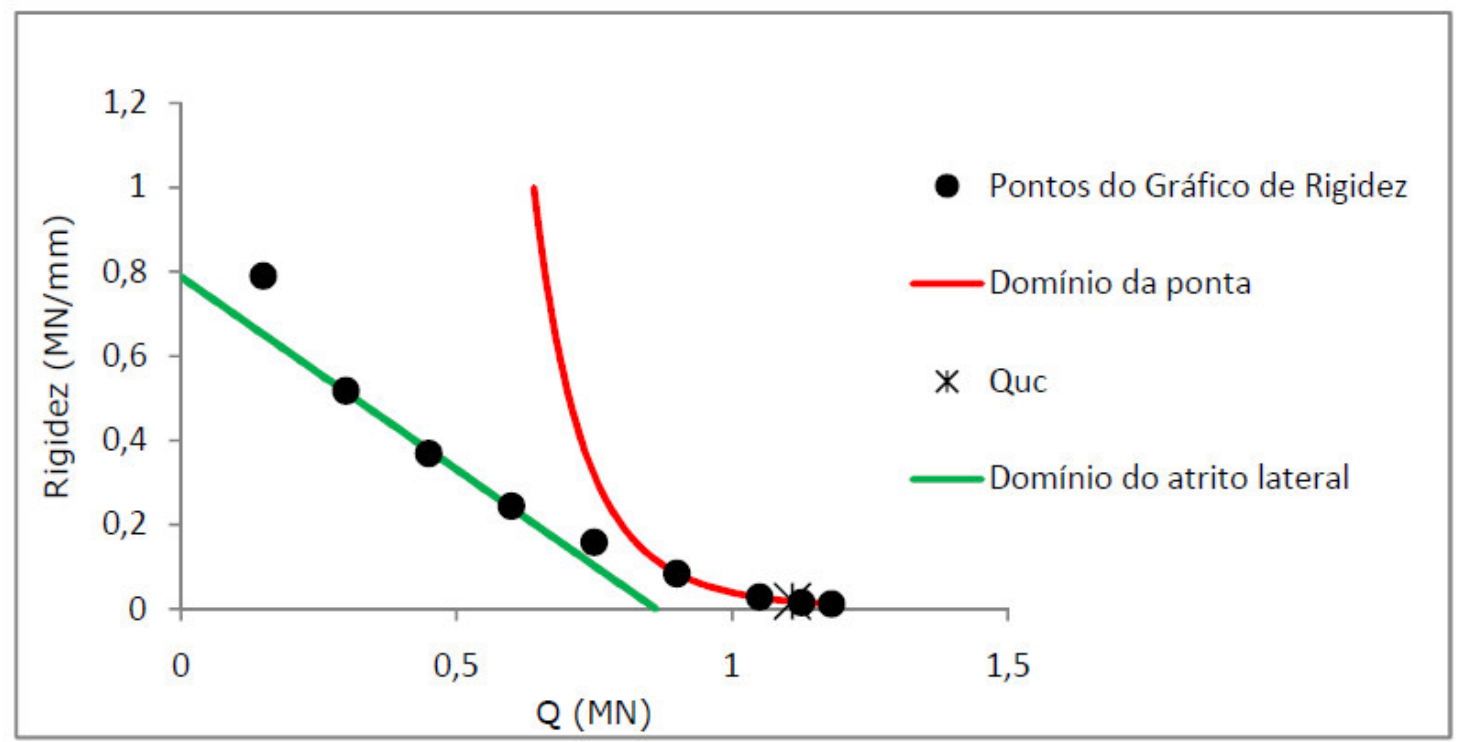

Figura 23 - Domínios de ponta (curva) e atrito lateral (reta) (MELO, 2008) 
O valor da parcela atrito lateral desenvolvida no ensaio $\left(Q_{s}\right)$ é calculado pela média entre $Q_{s u}$ e o limite inferior $\left(Q_{s L}\right)$. Este último é definido da seguinte maneira (MELO, 2008):

a) faz-se o ajuste linear entre os logaritmos da carga e do recalque [expressão(83)] no trecho final da curva carga-recalque, o que permite obter a carga de ruptura convencional $Q_{u c}$ para $y_{0}=0,1 D$;

b) o último ponto de ensaio $\left(\mathrm{P}_{0}, \mathrm{y}_{\mathrm{o}}\right)$ considerado neste ajuste é chamado de "ponto de regressão";

c) ajustando uma reta [expressão (87)], passando pelo ponto da curva correspondente a $Q_{u c}$ e pelo "ponto de regressão", obtém-se $Q_{\mathrm{sL}}$ como sendo a intercepção desta reta com o eixo das cargas.

A Figura 24 demonstra a obtenção de $Q_{s L}$.

Comparando-se com o método das Duas Retas de Massad e Lazo (1998), $\mathrm{Q}_{\mathrm{SL}}$ deve ser um valor próximo ao do coeficiente $d_{1}$ da reta do trecho 4-5 (Figura 19).

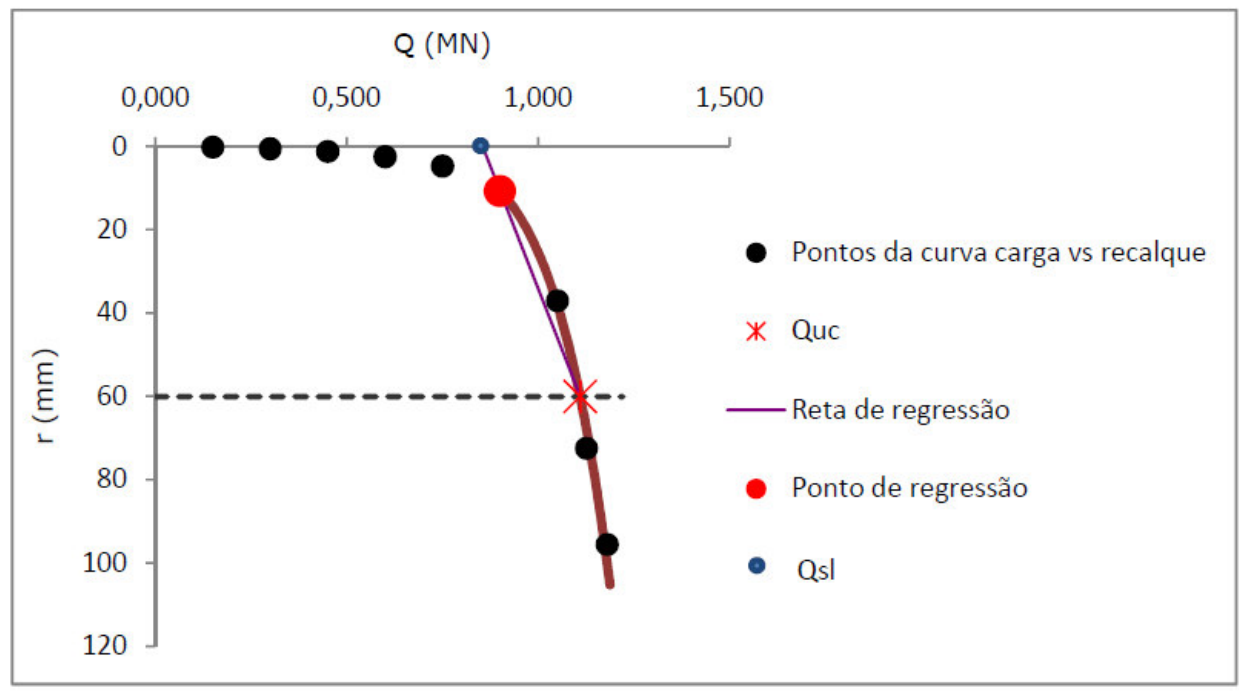

Figura 24 - Forma de obtenção do limite inferior do atrito $\left(Q_{\mathrm{sL}}=Q_{\mathrm{sl}}\right)(\mathrm{MELO}, 2008)$

Fazendo um paralelo com as Leis de Cambefort Modificadas, a adoção de $d_{1}$ e de $\mathrm{P}_{04}$ (ver item 3.6.1 e Figura 19) como sendo os limites inferior e superior do atrito, seriam muito mais práticos e resultariam valores bastante próximos. A partir dessa observação discute-se, no item seguinte, uma proposta de como empregar o diagrama de Rigidez de forma a aprimorar a determinação dos trechos da curva carga-recalque sob a ótica das Leis de Cambefort Modificadas. 
Décourt (2008), além de propor a separação das parcelas de atrito e ponta, propõe em seu método a estimativa da carga residual, a qual deve ser levada em conta na separação da parcela atrito, sob pena de se superestimá-lo. Propõe, assim, deslocar a curva do segundo carregamento para a origem do diagrama carga-recalque e calcular a diferença entre a carga do último ponto do primeiro carregamento e a carga obtida na curva do segundo carregamento para o recalque máximo do primeiro. Trata-se de uma aproximação, porém o raciocínio pode ser considerado semelhante à aplicação do coeficiente $\mu$ de carga residual nas Leis de Cambefort Modificadas, nas proximidades do valor Alr.

\subsubsection{Proposta de interpretação do diagrama de Rigidez para definição dos trechos da curva no método das Leis de Cambefort modificadas.}

Massad (2008) comparou o método da Rigidez com os métodos de transferência de carga de Fleming (1992) e com o das Leis de Cambefort Modificadas (LCM), obtendo interessantes conclusões sobre suas limitações de aplicabilidade, resumidas mais adiante.

Seguindo outra linha de raciocínio, traçando-se no diagrama de Rigidez as equações correspondentes aos trechos da curva carga-recalque, na visão das Leis Modificadas de Cambefort, obtém-se o apresentado na Figura 25.

Percebe-se, assim, que também é possível identificarem-se os trechos da curva, segundo as Leis de Cambefort Modificadas, no diagrama de Rigidez. De fato, uma virtude deste diagrama é permitir a evidência desses trechos, como intuiu Décourt (2008). Os diagramas de Chin e de Van der Veen praticamente anulam essa possibilidade devido à escala do gráfico, restando apenas a linearidade de seu ajuste a ser analisada.

$\mathrm{Na}$ Figura 25, pode-se ver que o trecho linear a que Décourt (2008) atribui o "domínio de atrito", na visão das Leis de Cambefort Modificadas (LCM) é, na verdade, um trecho de pouca curvatura da função $\operatorname{Rig}_{34}$, o qual corresponde de fato à mobilização do atrito ao longo do fuste. Note-se que essa função $\mathrm{Rig}_{34}$ possui um pico à esquerda, na região em que faz concordância com a curva $\operatorname{Rig}_{23}$ do trecho 2-3 das Leis de Cambefort. Na Figura 25 deve-se ainda verificar a curva Rig ${ }_{45}$ que corresponde ao trecho 4-5 das Leis de Cambefort. Esta, curva ajustada aos últimos 
pontos do carregamento, é tratada por Décourt (2008) como sendo uma curva $\log \left(P_{\circ}\right) \times \log (R i g)$, enquanto pelas Leis de Cambefort seria uma hipérbole, que tem o mesmo caráter assintótico procurado por Décourt em seu ajuste.

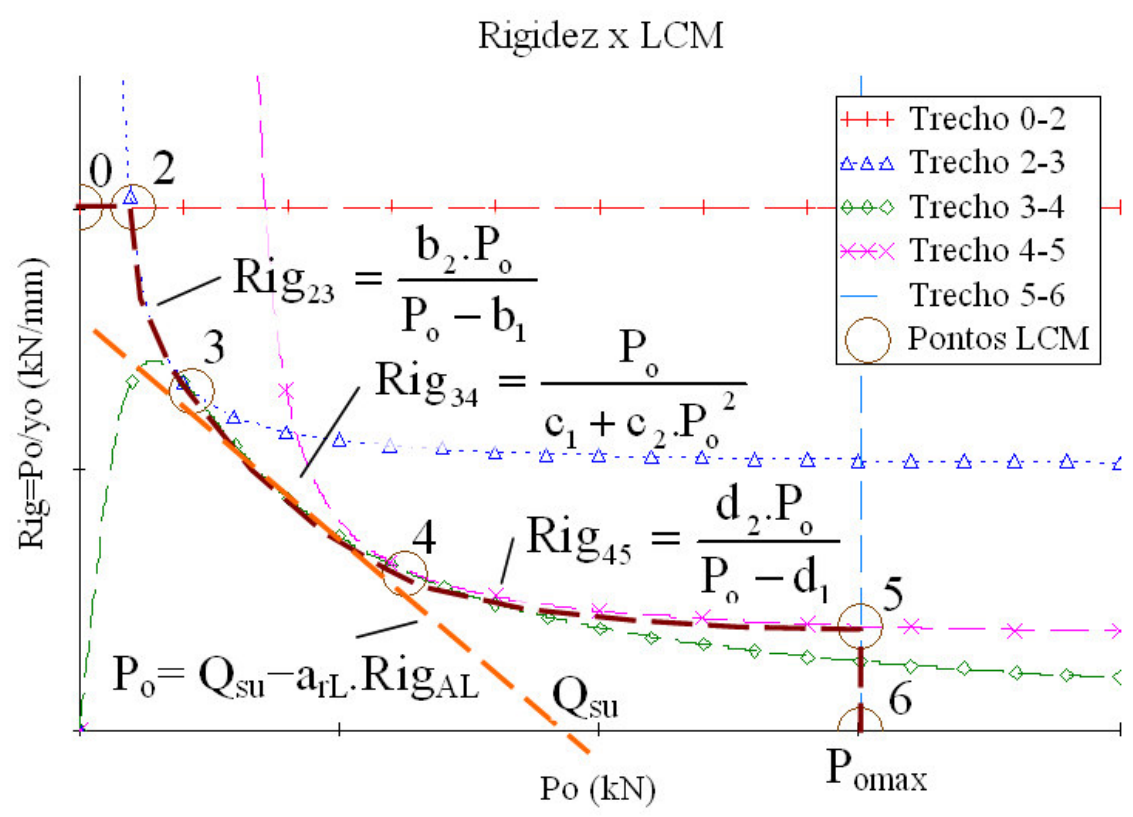

Figura 25 - Trechos da curva carga recalque do método das Leis de Cambefort modificadas (LCM) lançados no diagrama de Rigidez para comparação.

Com tais análises, podem-se fazer algumas observações sobre o exemplo da Estaca E9 do Porto, apresentado por Décourt (2008), onde a prova de carga apresenta cinco carregamentos. Nesse caso, Décourt (2008) considerou a aplicação do método da Rigidez com os recalques acumulados, o que, de acordo com a análise aqui feita, demonstra-se inadequado pois distorce o valor de Rigidez no início das curvas dos carregamentos subsequentes, já que para a mesma carga estes apresentam, então, recalques exagerados. O procedimento de se deslocar as curvas para a origem antes de calcular as rigidezes ("zerando" a escala de medidas de recalques a cada novo carregamento), por outro lado, reduz o valor dos recalques do trecho da ponta nos carregamentos subsequentes. Isso pode ser visto, na Figura 26a, onde se aplicaram os dois procedimentos à estaca raiz G603 (Amann, 2000), a qual foi submetida a três carregamentos.

Para se evitar tal distorção dos valores de recalques, seja no trecho inicial da curva, seja no trecho final relativo à ponta, o procedimento adotado no presente trabalho foi o de considerar a curva carga-recalque definida pela envoltória dos pontos de carregamento, como se vê na Figura 26b, resultando numa curva de Rigidez 
completa, sem distorções. Fazendo-se uma analogia com ensaios de encruamento em aço, essa curva envoltória representa aproximadamente o comportamento da estaca como se ela sofresse apenas um carregamento monotônico, ou seja, sem descarregamentos.

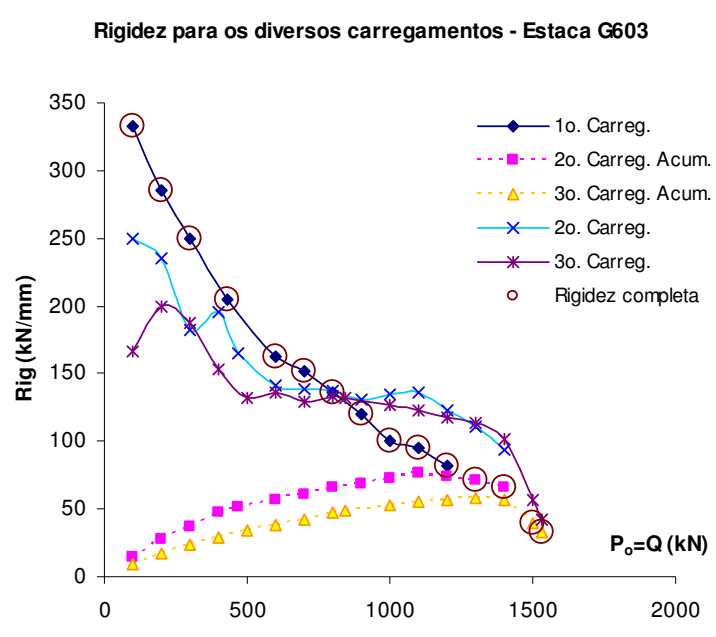

a)

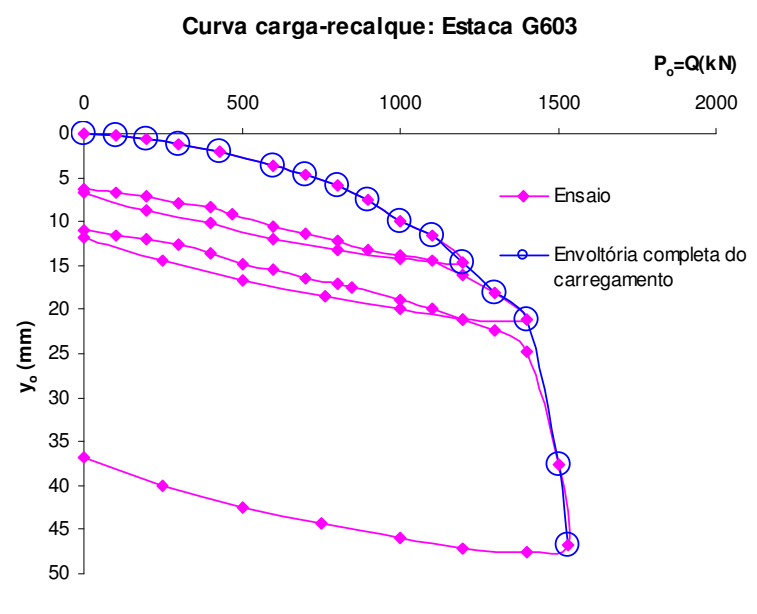

b)

Figura 26 - Estaca raiz G603: a) curvas de Rigidez com recalques acumulados e não acumulados; b) curva carga-recalque considerando a envoltória dos carregamentos.

É importante considerar ainda que, para estacas rígidas, o trecho 3-4 fica bastante reduzido e a reta (87) passa a ajustar, na verdade, uma parte da curva $\operatorname{Rig}_{45}$ e não mais da $\operatorname{Rig}_{34}$. Sobre isso se fará um paralelo com as conclusões de Massad (2008), mais adiante.

Buscando dar maior praticidade à obtenção do atrito desenvolvido no ensaio $Q_{s}$, que Décourt calcula como a média entre $Q_{s u}$ e $Q_{s L}$, da comparação aqui feita entre esses métodos pode-se sugerir adotar o critério de obtenção de $\mu$ Alr do método das Duas Retas, ou seja, a interseção entre a reta do trecho 4-5 e a reta de rigidez $\mathrm{Kr} / \mathrm{C}$. Para isso, no diagrama de Rigidez, basta marcar no eixo das rigidezes o valor de $\mathrm{Kr} / \mathrm{C}$ e traçar uma reta horizontal até encontrar a curva do domínio da ponta ajustada à hipérbole Rig $g_{45}$; a carga correspondente à interseção é 0 valor de $\mu$ Alr, o qual corresponde aproximadamente ao valor médio calculado por Décourt. É importante lembrar que esse valor possui influência das cargas residuais (quantificada por $\mu$ ) e, portanto, não é ainda o valor de Alr de fato. Se na curva carga recalque tem-se $b_{1} \neq 0$, então este valor tem ainda a influência do produto A.S, e ambos precisam ser descontados. 
Diante dessas novas interpretações da curva de Rigidez, pode-se verificar a coerência do aqui proposto com as conclusões de Massad (2008):

- Para estacas escavadas rígidas (com o trecho 3-4 reduzido e a reta (87) ajustando na verdade parte do trecho 4-5), se $A=0$ [expressão (50)], conforme demonstra, Massad (2008), $Q_{s u}$ tende a $P_{04}$ (limite superior) e $a_{r L}=-\mu y_{1}$, conforme sugerido. Se $A \neq 0$, então tem-se $a_{r L}=-$ $\mu y_{1}$ (1-A.S/Po $)$ e a ponta adiciona uma parcela de reação devida a $A S$, que afasta $Q_{\text {su }}$ de $P_{\text {o4 }}$, reduzindo a precisão do método da Rigidez;

- Para estacas de deslocamento rígidas, tem-se $Q_{\text {su }}=\mu A$ Ir se $A=0$, e afasta-se de $\mu$ Alr se for diferente, o que prejudica a precisão da estimativa;

- Para estacas compressíveis, Massad (2008) comenta que o cálculo é iterativo e praticamente impossível de se obter a estimativa de $\mu \mathrm{Alr}$, exceto para estacas flutuantes, pois, assim, fica definida a carga de ponta, caso em que: $Q_{\text {su }} \cong \mu$ Alr e $a_{r L}=-\mu y_{1}+\left(\mu A l r-P_{0}\right) /(4 K r)$.

Com relação a esta última conclusão de Massad (2008), pode-se sugerir aqui o seguinte caminho de solução, quando a estaca não for flutuante: a reta do domínio de atrito dada pela expressão (87) se apresenta como uma hipérbole semelhante à (82) de Chin, quando colocada num diagrama carga-recalque, e disto resulta que $\mathrm{C}_{2}=1 / \mathrm{c}_{\mathrm{oC}}=\mathrm{Q}_{\mathrm{su}} / \mathrm{a}_{\mathrm{rL}}$ e $\mathrm{C}_{1}=-\mathrm{c}_{1 \mathrm{C}} \cdot \mathrm{C}_{2}=-1 / \mathrm{a}_{\mathrm{rL}}$.

Isso significa que ao invés de ajustar a curva à Rigidez, pode-se ajustá-la diretamente à hipérbole (82), obtendo-se diretamente $Q_{s u}=b_{r L}=1 / c_{1 C}$ e $a_{r L}=c_{o c} / c_{1 C}$. No diagrama carga-recalque sua expressão fica:

$$
y_{o}=-\frac{a_{r L} \cdot P_{o}}{P_{o}-Q_{s u}}
$$

A partir disso, tomando-se outro trabalho de Massad (1994), em que se discutiu as diversas formas de ajuste do trecho curvo 3-4, a relação entre o ajuste parabólico e o hiperbólico permite deduzir a seguinte relação entre os dois métodos, desde que válida a condição de estaca compressível ( $k \geq 5$ ou $\lambda \cong 1)$ : 


$$
\mu \cdot A l r=\frac{0,141}{\mathrm{Kr} \cdot \mathrm{C}_{\mathrm{oc}} \cdot \mathrm{C}_{1 \mathrm{C}}} \cong \frac{0,141 \cdot \mathrm{Q}_{\mathrm{su}}{ }^{2}}{\mathrm{Kr} \cdot \mathrm{a}_{\mathrm{rL}}}
$$

Sem esta formulação (89), aqui recuperada de Massad (1994), de fato não é possível a determinação de $Q_{\text {su }}$ nem de $\mu$ Alr para o caso de estacas escavadas compressíveis. Já a obtenção de Alr (isolado das cargas residuais) depende da estimativa de $\mu$ pelo descarregamento, sem o qual não se pode retirar as cargas residuais do valor obtido.

Nesse contexto, considerando tal comparação entre os dois métodos, a aplicação que aqui se fará do método da Rigidez será no sentido de auxiliar a interpretação e definição dos trechos da curva carga-recalque, inclusive no descarregamento. Isso permitirá uma melhor definição dos ajustes na aplicação das Leis de Cambefort modificadas, método este que será o definidor da separação entre atrito e ponta na Metodologia Semiempírica Unificada, no caso geral de ensaios não instrumentados.

Apresenta-se a seguir um exemplo de aplicação dessa proposta.

\subsection{EXEMPLO DE APLICAÇÃO DA COMPARAÇÃO ENTRE O MÉTODO DA RIGIDEZ E O MÉTODO DAS LEIS DE CAMBEFORT MODIFICADAS}

Apresenta-se aqui um exemplo de aplicação da forma de comparação acima proposta para uma estaca raiz, desta vez a G201 (Amann, 2000), também instalada no Guarujá e constante do trabalho de Corrêa (1988). Possui L=20,92m; D=250 mm e $\mathrm{Kr}=40 \mathrm{kN} / \mathrm{mm}$ e perfil de solo semelhante ao da estaca G202.

A prova de carga da estaca G201 é apresentada na Figura 27 com os pontos de ensaio numerados para melhor entendimento do procedimento.

A Figura 27 mostra a interpretação pelo método da Rigidez, para o qual a capacidade de carga convencional (0,1D) seria $Q_{u c}=985,2 \mathrm{kN}, Q_{s L}=554,7 \mathrm{kN}$. As expressões das curvas teóricas de atrito e ponta são apresentadas e os valores dos seus coeficientes podem ser vistos na Figura 28.

A curva de Rigidez é apresentada na Figura 28, na qual percebe-se que sua ponta forma uma assíntota sub-horizontal, observada por Décourt (2008), visto ser a estaca escavada e, portanto, cabível o ajuste $\log \left(P_{0}\right) x \log (R i g)$. Verifica-se que 0 
domínio do atrito alcança praticamente a ruptura convencional, indicando que, nesse caso, ela poderia até ser da ordem de $0,3 \mathrm{D}$, dado que a estaca é escavada.

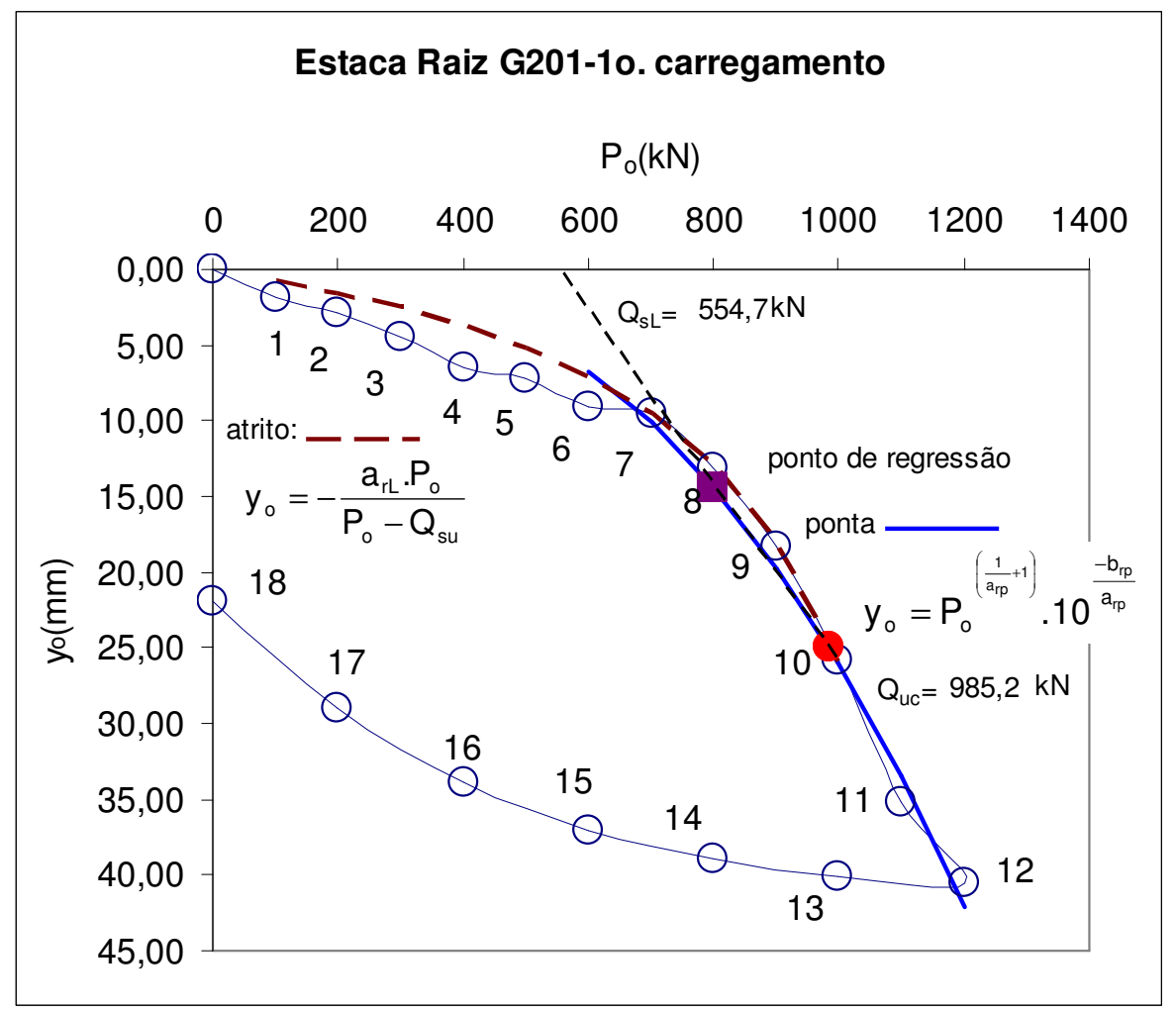

Figura 27 - Curva carga-recalque da estaca G201 (Amann, 2000) com interpretação pela Rigidez

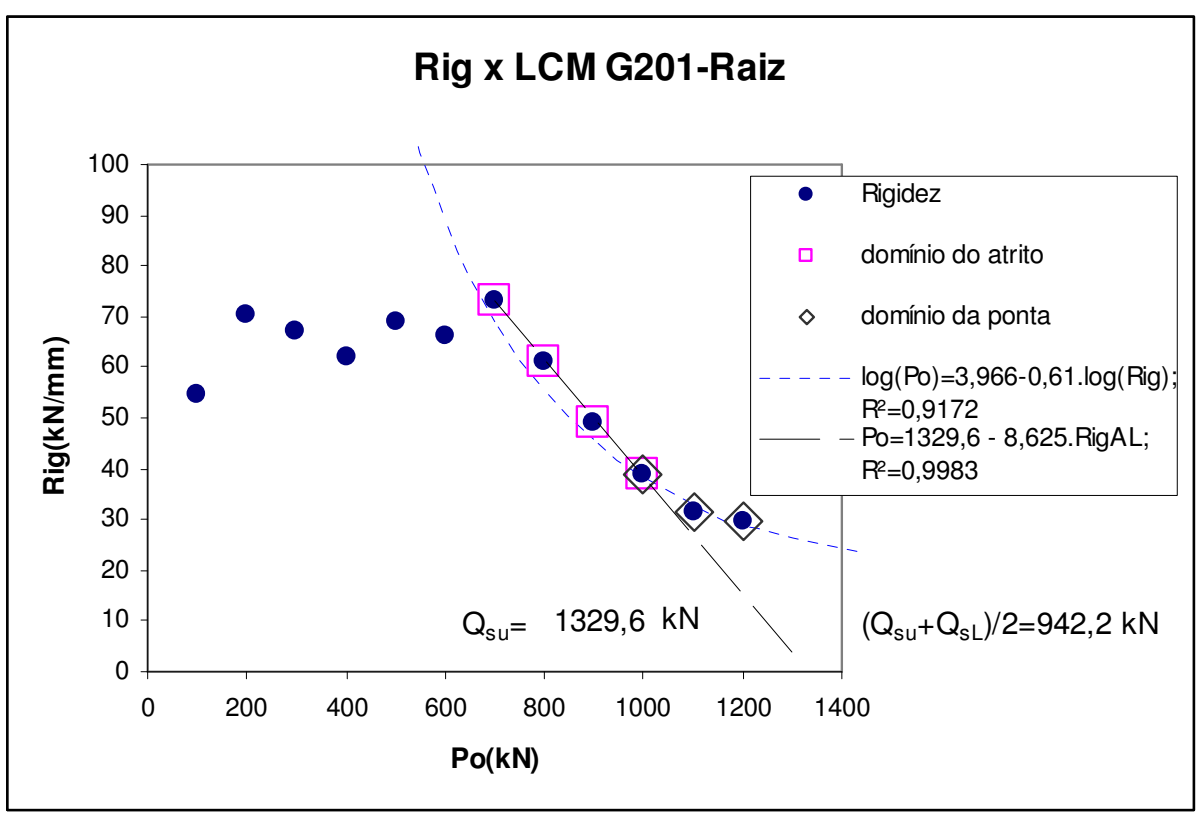

Figura 28 - Curva de Rigidez da estaca G201 
A Figura 28 apresenta a separação das parcelas de atrito e ponta, indicando os três últimos pontos como de ajuste do domínio de ponta e uma região extensa de ajuste linear, associado ao domínio do atrito. A intercepção com o eixo das cargas resulta em $Q_{s u}=1329,6 \mathrm{kN}$ e, assim, a média com $Q_{\mathrm{sL}}$ resulta em $Q_{\mathrm{L}}=942,2 \mathrm{kN}$.

Considerando se tratar do primeiro carregamento de uma estaca escavada, pode-se dizer que o efeito de carga residual não se aplica e portanto a parcela de atrito é 942,2 kN, restando para a ponta 257,8 kN de reação para a carga máxima do ensaio e apenas $43 \mathrm{kN}$ para a carga de ruptura convencional. Nesse caso, a correção do método semiempírico para a ponta ficaria prejudicada se adotado o valor de ruptura convencional.

Após essas considerações acerca do método da Rigidez, o exemplo de comparação com o método das Leis de Cambefort Modificadas (LCM) se inicia, atribuindo-se quais dos pontos de ensaio correspondem aos trechos da Figura 19.

Assim, assumindo que $b_{1}=0$ nesse caso, enquanto se mantém o ajuste da ponta $\left(\operatorname{Rig}_{45}\right)$ para os pontos 8 a 12, são feitos diversos ajustes para o atrito (Rig $\left.{ }_{34}\right)$, conforme se vê na Figura 29.

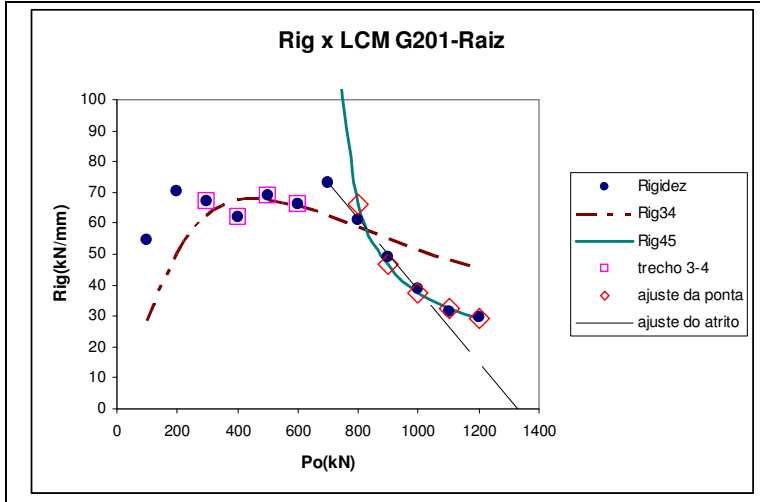

a)

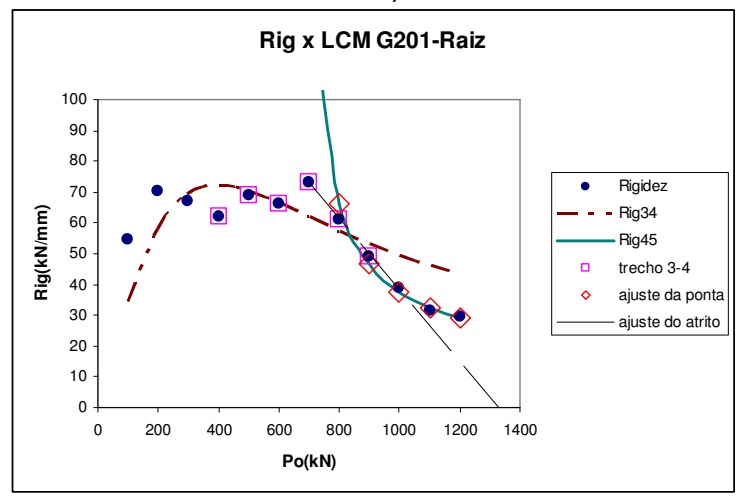

c)

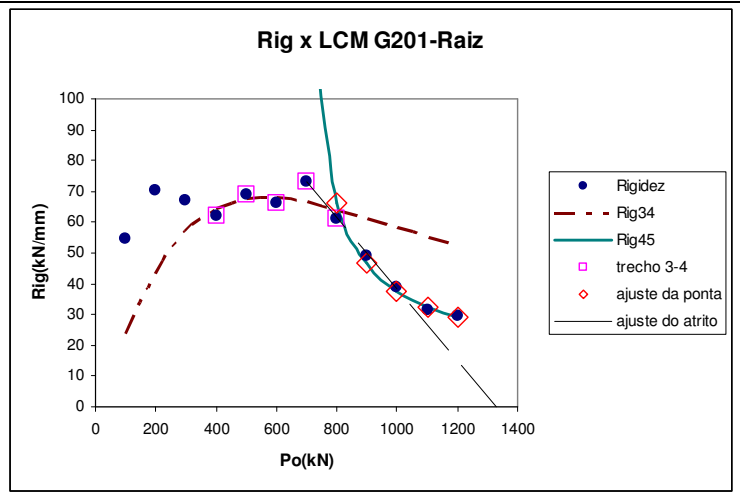

b)

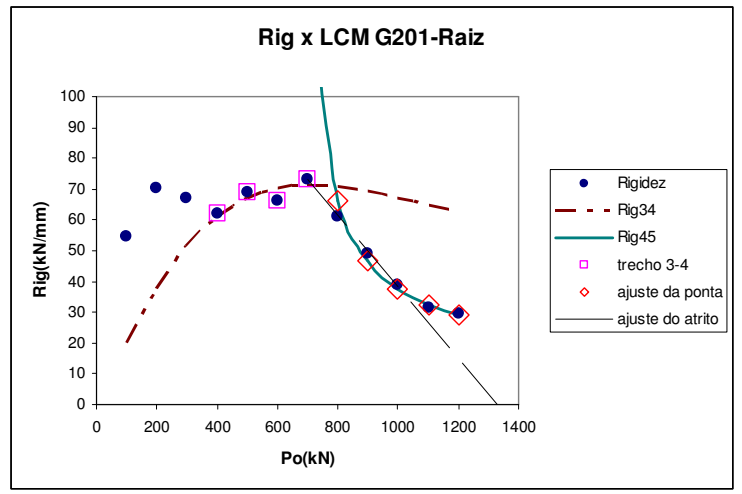

d)

Figura 29 - Ajustes do trecho 3-4 usando o diagrama de Rigidez. 
É importante verificar que por mais que se tente ajustar o trecho 3-4 para que ele coincida com a reta de domínio de atrito, segundo Décourt, isso não ocorre, pois a função $\operatorname{Rig}_{34}$ não se ajusta (lembrando que esse trecho deve ao mesmo tempo apresentar bom ajuste parabólico no diagrama carga-recalque). O que melhor se pode fazer é o ajuste "d)" onde se tomaram os pontos 4 a 7 . Isso ocorre porque esta estaca tem comportamento tendendo a rígido, segundo as Leis de Cambefort modificadas, e assim o trecho 3-4 não fica bem definido.

Como já havia concluído Massad (2008), aqui há certo prejuízo do método, pois o que se está ajustando linearmente, de fato, não é um trecho correspondente ao atrito, mas sim um trecho já do início de mobilização da ponta. Deve-se lembrar que a linearidade no diagrama da Rigidez reflete-se numa hipérbole na curva cargarecalque, indicando que, na prova de carga, os pontos iniciais tomados para a reta 4-5 podem ser razoavelmente ajustados a uma hipérbole, o que permitiria um ajuste pelo método de Fleming (1992), por exemplo. Para as Leis de Cambefort modificadas, contudo, aproxima-se esse trecho a uma reta (4-5).

Para atestar que a estaca é rígida, o que permitiria o seu tratamento pelo método das Duas Retas pelas Leis de Cambefort modificadas, basta verificar que o trecho 03 no diagrama carga-recalque possui inclinação constante, resultando numa reta horizontal no diagrama da Rigidez. Observe-se que, desde a origem até o ponto 8 no diagrama de Rigidez, os pontos oscilam em torno de 60 a 70 kN/mm.

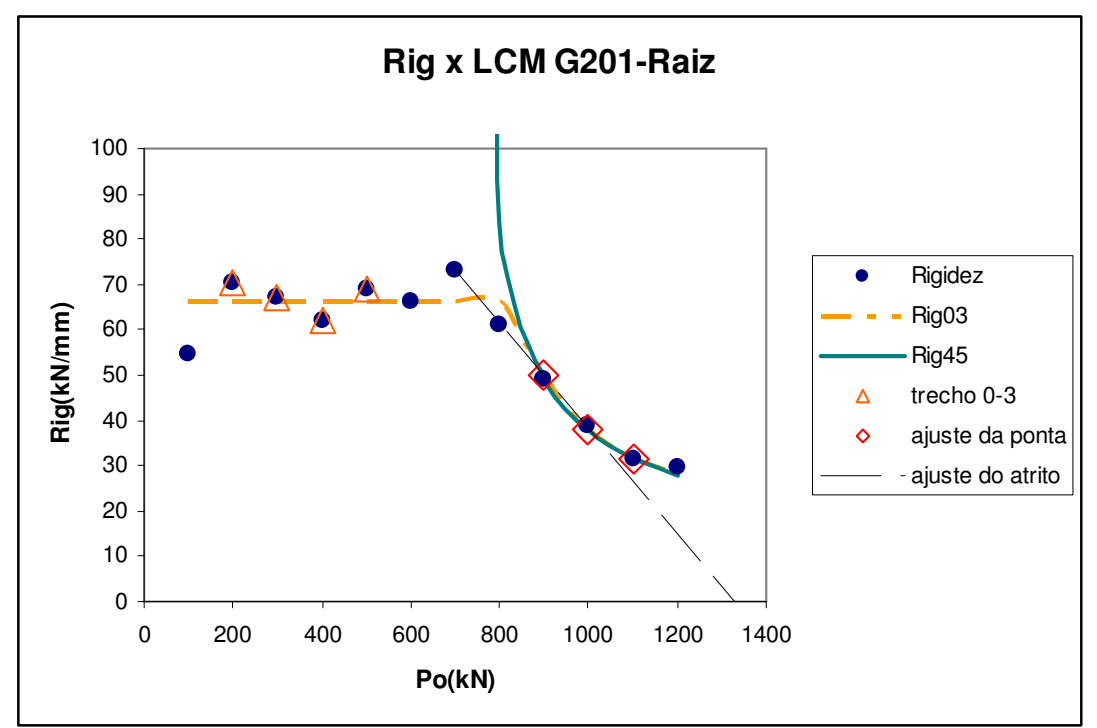

Figura 30 - Ajuste do trecho 0-3 no diagrama de Rigidez. 
Tomando-se os pontos de 1 a 5 (ver Figura 30) obtém-se uma média de $67 \mathrm{kN} / \mathrm{mm}$, enquanto com o ajuste linear pelas Leis de Cambefort modificadas no diagrama carga-recalque, obtém-se $66 \mathrm{kN} / \mathrm{mm}$. Após o ponto 7, a horizontal do trecho 0-3 encontra com a curva 4-5, praticamente sem transição, demonstrando o comportamento rígido dessa estaca, segundo as Leis de Cambefort modificadas.

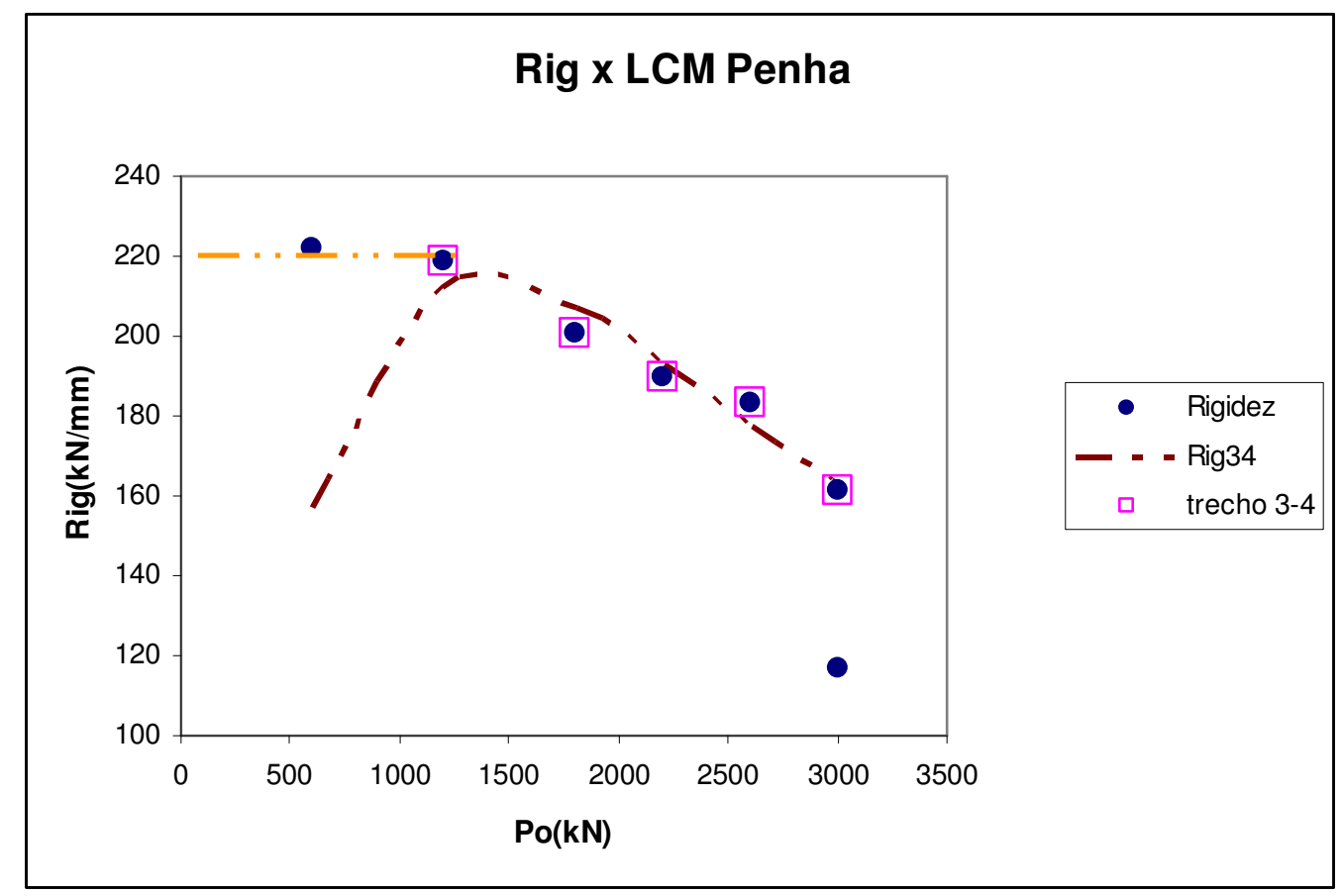

Figura 31 - Ajuste dos trechos no diagrama de Rigidez para estaca da Penha (MASSAD, 1992, 1993).

Aplicando-se para a estaca da Penha (MASSAD, 1992, 1993), observa-se na Figura 31 que, ao contrário do caso da estaca raiz G201, o ajuste da curva Rig 34 à região linear do diagrama de Rigidez se faz de forma adequada, pois, nesse caso, a função se ajusta aos dados, tanto no diagrama de Rigidez quanto no de carga-recalque.

Note-se que na Figura 31, apenas dois pontos definem a região do trecho inicial 0-3 e que o último ponto de Rigidez demonstra a ocorrência da ruptura (relativamente brusca), como apresentada conceitualmente na Figura 25. Não há definição de ponta $\left(\operatorname{Rig}_{45}\right)$, pois essa estaca da Penha é tubada e pode ser considerada no limite entre estaca flutuante e de ponta (Massad, 1993).

Demonstra-se, assim, a utilidade do diagrama de Rigidez para atribuição e interpretação dos trechos da curva carga-recalque admitidos pelas Leis de Cambefort modificadas. 


\subsection{OBTENÇÃO DOS DEMAIS PARÂMETROS DO MÉTODO DAS LEIS DE CAMBEFORT MODIFICADAS}

Após ter-se obtido os valores de $\mathrm{Kr}$ e $\mu$ Alr, pode-se facilmente calcular os valores dos demais parâmetros do método:

$$
\begin{gathered}
\mathrm{k}=\mathrm{z}_{\mathrm{k}}^{2} ; \quad \beta_{3}=\frac{\mathrm{b}_{2}}{\mathrm{Kr} \cdot \mathrm{z}_{\mathrm{k}}} ; \quad \lambda=\frac{\mathrm{d}_{2}}{\mathrm{Kr}-\mathrm{d}_{2}} \cdot \frac{1}{\mathrm{z}_{\mathrm{k}}} \\
\mathrm{A}=\frac{\mathrm{b}_{1}}{\mathrm{~S} \cdot \mathrm{w}_{2}}=\frac{\mathrm{b}_{1}}{\mathrm{~S}} \cdot \frac{1}{\cosh \left(\mathrm{z}_{\mathrm{k}}\right)+\sinh \left(\mathrm{z}_{\mathrm{k}}\right)}
\end{gathered}
$$

Com os valores de $\mathrm{k}$ pode-se classificar o comportamento da estaca, sendo: $\mathrm{k} \leq 2$ rígida (ajuste pelas retas 4-5 e 8-9), $(2<\mathrm{k}<8$ ) intermediária (ajuste pelos trechos 34, 4-5 e 8-9) ou $k \geq 8$ compressível (é possível ajuste por 3-4 e 7-8).

A Figura 32 apresenta as Leis de Cambefort modificadas por Massad (2008), as quais permitem a consideração das cargas residuais desenvolvidas na estaca após receber carregamento devido a ensaio ou cravação. Nesta figura e nas expressões seguintes identificam-se os demais parâmetros do método:

$$
\begin{aligned}
& \mathrm{y}_{1}=\frac{\text { Alr }}{\mathrm{Kr} \cdot \mathrm{k}} \\
& \mathrm{B}=\frac{\mathrm{f}_{\max }}{\mathrm{y}_{1}}
\end{aligned}
$$
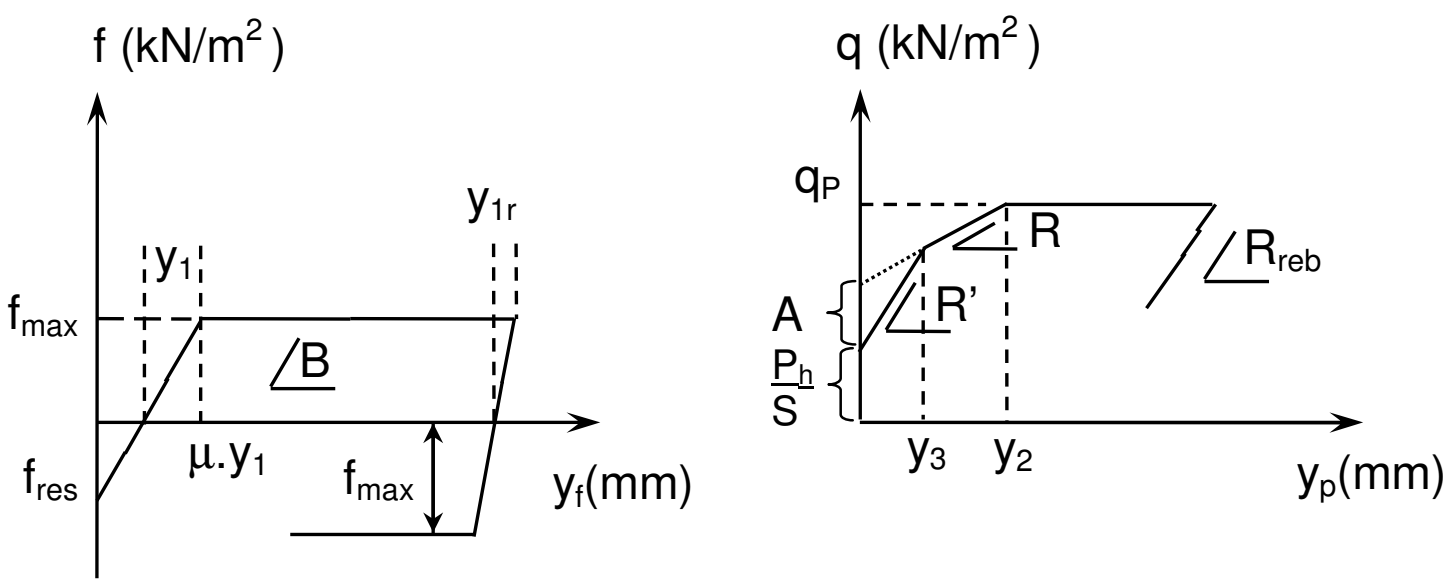

Figura 32 - Primeira (fuste) e Segunda (ponta) Leis de Cambefort modificadas (adaptado de MASSAD, 2008) 


$$
\begin{gathered}
\mathrm{y}_{1 \mathrm{r}}=\frac{\mathrm{Alr}}{\mathrm{Kr} \cdot \mathrm{k}_{\mathrm{reb}}} \\
\mathrm{R}=\frac{\lambda \cdot \mathrm{z}_{\mathrm{k}} \cdot \mathrm{Kr}}{\mathrm{S}} \\
\mathrm{R}^{\prime}=\frac{\mathrm{A}}{\mathrm{y}_{3}}+\mathrm{R} ; \mathrm{y}_{3} \cong \mu \mathrm{y}_{1} \\
\mathrm{R}_{\mathrm{reb}}=\frac{\lambda_{\text {reb }} \cdot \mathrm{z}_{\mathrm{kreb}} \cdot \mathrm{Kr}}{\mathrm{S}} \\
\mathrm{P}_{\mathrm{h}}=\text { Alr } \cdot(\mu-1)
\end{gathered}
$$

Onde: $\quad y_{1 r}$ : recalque no fuste correspondente à reversão plena do atrito lateral no descarregamento;

$\mathrm{k}_{\text {reb }}$ : coeficiente k para o descarregamento;

R': coeficiente inicial de rigidez da ponta para comportamento bilinear na segunda Lei de Cambefort modificada;

$\mathrm{y}_{3}$ : recalque da ponta correspondente à mudança de rigidez para comportamento bilinear na segunda Lei de Cambefort modificada;

$\mathrm{R}_{\text {reb: }}$ coeficiente de rigidez da ponta para o descarregamento na segunda Lei de Cambefort modificada;

$\lambda_{\text {reb: }}$ valor de $\lambda$ para o descarregamento;

B: coeficiente de resistência por atrito da primeira Lei de Cambefort;

Com esses parâmetros é possível caracterizar completamente a transferência de carga da estaca para o solo.

Sugere-se aqui ainda formas de cálculo para outros parâmetros, como a carga que chega na ponta $(Q p)$ e seu recalque $y_{p}$, bem como o recalque máximo do topo $\left(\mathrm{y}_{05}\right)$ :

$$
\begin{gathered}
Q p=P_{\text {omax }}-\text { Alr } \\
y_{p}=\frac{1}{\mu} \cdot \frac{Q p}{R \cdot S} \\
y_{05}=\mu y_{p}+\mu A l r \cdot \frac{C}{K r}+\frac{Q p}{K r}+A \cdot S \cdot w_{2}
\end{gathered}
$$

Para $\mathrm{y}_{2}$ pode-se adotar uma estimativa semiempírica de $\mathrm{q}_{\mathrm{p}}$ (ruptura da ponta) e calcular a deformação correspondente pela teoria da elasticidade [expressão (102)], adaptada de Massad (2008): 


$$
y_{2}=q_{p} \cdot \frac{(1-v) \cdot S}{2 \cdot D} \cdot \frac{8}{\pi D(1-v)} \cdot \frac{1}{\frac{A}{y_{3}}+R}
$$

Onde: $v$ : coeficiente de Poisson do solo da ponta.

Pode-se ainda sugerir, por simplicidade, adotar um valor convencional para $\mathrm{y}_{2} \mathrm{da}$ ordem de 0,1D para estacas cravadas e até 0,3D para escavadas.

Interessante também é calcular a curva teórica no trecho curvo 3-4, o que deve ser feito de forma parametrizada pelas expressões seguintes:

$$
\begin{gathered}
\mathrm{y}_{034}=\mu \mathrm{y}_{1}+\mu \operatorname{Alr} \cdot \frac{\mathrm{C}}{\mathrm{Kr}} \cdot\left(1-\frac{\mathrm{h}^{\prime}}{\mathrm{L}}\right)^{2}+\frac{\mu \mathrm{Alr}}{\mathrm{Kr}} \cdot \frac{\beta^{\prime}}{\mathrm{z}_{\mathrm{k}}} \cdot\left(1-\frac{\mathrm{h}^{\prime}}{\mathrm{L}}\right) \\
\mathrm{P}_{034}=\mu \operatorname{Alr} \cdot\left[\frac{\beta^{\prime}}{\mathrm{z}_{\mathrm{k}}}+\left(1-\frac{\mathrm{h}^{\prime}}{\mathrm{L}}\right)\right] \\
\beta^{\prime}=\frac{\tanh \left(\frac{\mathrm{h}^{\prime}}{\mathrm{L}} \cdot \mathrm{z}_{\mathrm{k}}\right)+\lambda}{1+\tanh \left(\frac{\mathrm{h}^{\prime}}{\mathrm{L}} \cdot \mathrm{z}_{\mathrm{k}}\right) \cdot \lambda}
\end{gathered}
$$

onde $h^{\prime} / L$ é a proporção do comprimento do fuste que ainda não mobilizou o atrito máximo. Assim, no ponto 3 da curva, a mobilização do atrito máximo se dá no topo da estaca e falta ainda todo o fuste, tendo-se, portanto, $h^{\prime} / L=1$. No ponto 4 , a mobilização do atrito máximo chega à ponta e então tem-se $h^{\prime} / L=0$. Para calcular o trecho curvo, basta adotar valores de h'/L entre zero e 1 e calcular os pares de valores $\left(\mathrm{P}_{034} ; \mathrm{y}_{034}\right)$.

Convém observar que no ponto 3 da curva carga-recalque (Figura 19) tem-se $\beta^{\prime}=\beta_{3}{ }_{3}$ e no ponto $4 \beta^{\prime}=\lambda$, e assim, podem-se calcular as coordenadas dos pontos 3 e 4 , as quais devem ser compatíveis com o cálculo pelas retas $0(2)-3$ e 4-5:

$$
\begin{gathered}
P_{03}=\mu A I r \cdot \frac{\beta_{3}^{\prime}}{z_{k}} \text { e } \quad y_{03}=\mu y_{1} \\
P_{04}=\mu A I r+R . S . \mu y_{1}+\text { A.S. }\left(1-2 \cdot d_{2} \cdot \frac{C}{K r}\right)
\end{gathered}
$$




$$
\mathrm{y}_{\mathrm{o} 4}=\mu \mathrm{y}_{1}+\mu \mathrm{Alr} \frac{\mathrm{C}}{\mathrm{Kr}}+\frac{\text { R.S. } \mu \mathrm{y}_{1}}{\mathrm{Kr}}+\text { A.S. }\left(\frac{1}{\mathrm{Kr}}-\frac{1}{\mathrm{R} . \mathrm{S}}\right)
$$

Tendo-se calculado as coordenadas $\mathrm{y}_{03}, \mathrm{P}_{03}, \mathrm{y}_{04}$ e $\mathrm{P}_{04}, \mathrm{y}_{05}$ e $\mathrm{P}_{05}=\mathrm{P}_{\text {omax }}$, tem-se a definição completa da curva carga-recalque teórica. Evidentemente, isso não é necessário para a separação das parcelas de atrito e ponta, que já foi demonstrada, contudo, permite a avaliação do bom ajuste do método ao caso estudado.

\subsection{PROPOSTA DE ITERAÇÃO PARA SEPARAÇÃO DA CONTRIBUIÇÃO DAS CAMADAS DE SOLO HETEROGÊNEO NO ATRITO LATERAL}

Depois de separada a parcela de atrito lateral, seu valor pode ser usado para correção dos valores dos coeficientes empíricos na Metodologia Semiempírica Unificada. Assim, pode-se obter o valor do coeficiente característico $\mathrm{K}_{\mathrm{Lg}}$ para correção do valor de atrito lateral do método Expedito e algumas variantes do método Mediado que utilizem a média ao longo do fuste. Contudo, para o caso do método Mediado por somatória de resistência das camadas, deve-se ainda atribuir a cada camada uma contribuição no valor do atrito lateral total, atribuindo-se os valores dos coeficientes $\mathrm{K}_{\mathrm{Lg}(\mathrm{i})}$.

Se o subsolo apresentar apenas duas camdas distintas, é possível aplicar a formulação de solo heterogêneo das Leis de Cambefort modificadas, obtendo-se os respectivos valores de atrito em cada uma. Proposta semelhante é também encontrada em Fleming et al. (1992). Com base nisso, apresenta-se uma proposta de iteração, aplicada ao método das Leis de Cambefort em solo heterogêneo, para obtenção dos parâmetros da primeira e segunda lei em duas camadas de solo.

Para a situação de solo heterogêneo, com duas camadas, Massad (1993) sugere a estimativa da reação de ponta por ensaio à tração ou pelos métodos semiempíricos. Sendo que aqui a transferência de carga é o método de apoio à aferição dos métodos semiempíricos, e não o contrário, sugere-se outro procedimento, qual seja a determinação dos valores de $\mathrm{y}_{11}, \mathrm{y}_{12}, \mathrm{z}_{\mathrm{k} 1}$, entre outros, por iteração com o seguinte roteiro:

1) atribui-se inicialmente valores aos recalques $y_{11}$ e $y_{12}$ que podem ser iguais a $\mathrm{y}_{1}$; 
2) calculam-se os valores de $k_{1}$ e $k_{2}$ e de $z_{k 1}$ e $z_{k 2}$ :

$$
\mathrm{k}_{1}=\frac{\mathrm{Alr}_{1}}{\mathrm{Kr}_{1} \cdot \mathrm{y}_{11}} \text { e } \quad \mathrm{k}_{2}=\frac{\mathrm{Alr}_{2}}{\mathrm{Kr}_{2} \cdot \mathrm{y}_{12}}
$$

3) calculam-se na sequência os produtos (R.S), ( $\left.\lambda_{2} \cdot Z_{k 2}\right),\left(\beta_{32} \cdot z_{k 2}\right),\left(R_{1} \cdot S\right),\left(\lambda_{1} \cdot z_{k 1}\right)$, $\left(\beta_{31} . Z_{k 1}\right)$ :

$$
\begin{aligned}
& \mathrm{R} . \mathrm{S}=\frac{1}{\frac{1}{\mathrm{~d}_{2}}-\frac{1}{\mathrm{Kr}}} \\
& \left(\lambda_{2} \cdot z_{\mathrm{k} 2}\right)=\frac{\mathrm{R} \cdot \mathrm{S}}{\mathrm{Kr}_{2}} \\
& \left(\beta_{32} \cdot z_{\mathrm{k} 2}\right)=\frac{\tanh \left(z_{\mathrm{k} 2}\right)+\left(\lambda_{2} \cdot z_{\mathrm{k} 2}\right)}{\frac{1}{z_{\mathrm{k} 2}}+\tanh \left(z_{\mathrm{k} 2}\right) \cdot\left(\lambda_{2} \cdot z_{\mathrm{k} 2}\right)} \\
& \mathrm{R}_{1} \cdot \mathrm{S}=\left(\beta_{32} \cdot \mathrm{z}_{\mathrm{k} 2}\right) \cdot \mathrm{z}_{\mathrm{k} 2} \cdot \mathrm{Kr}_{2} \\
& \left(\lambda_{1} \cdot z_{\mathrm{k} 1}\right)=\frac{\mathrm{R}_{1} \cdot \mathrm{S}}{\mathrm{Kr}_{1}} \\
& \left(\beta_{31} \cdot z_{\mathrm{k} 1}\right)=\frac{\tanh \left(\mathrm{z}_{\mathrm{k} 1}\right)+\left(\lambda_{1} \cdot \mathrm{z}_{\mathrm{k} 1}\right)}{\frac{1}{\mathrm{z}_{\mathrm{k} 1}}+\tanh \left(\mathrm{z}_{\mathrm{k} 1}\right) \cdot\left(\lambda_{1} \cdot \mathrm{z}_{\mathrm{k} 1}\right)}
\end{aligned}
$$

4) calcula-se então o coeficiente $b_{21}$ :

$$
\mathrm{b}_{21}=\left(\beta_{31} \cdot \mathrm{z}_{\mathrm{k} 21}\right) \cdot \mathrm{Kr} \mathrm{r}_{1}
$$

5) o valor de $b_{21}$ deve ser compatível com o de $b_{2}$ ajustado da curva, dentro de uma dada precisão. Para isso, variam-se os valores de $\mathrm{y}_{11}$ e $\mathrm{y}_{12}$ com uma ferramenta tipo "solver", até que $b_{21} \cong b_{2}$.

De posse desses valores, calculam-se os parâmetros para cada camada e podemse calcular as coordenadas dos pontos 3 e 4 da curva no topo: 


$$
\begin{aligned}
& P_{\text {o3h }}=\mu_{1} A_{1 r} \cdot \frac{\beta_{31}}{z_{k 1}} \quad \text { e } \quad y_{03 h}=\mu_{1} y_{11} \\
& \mathrm{P}_{\mathrm{ouh}}=\mu_{1} \mathrm{Alr}_{1}+\mu_{2} \mathrm{Alr}_{2}+\text { R.S. } \mu_{2} \mathrm{y}_{12}+\text { A.S. }\left(1-2 \cdot \mathrm{d}_{2} \cdot \frac{\mathrm{C}}{\mathrm{Kr}}\right) \\
& \mathrm{y}_{04 \mathrm{~h}}=\mu_{2} \mathrm{y}_{12}+\mu_{1} \mathrm{Alr}_{1} \frac{\mathrm{C}}{\mathrm{Kr}_{1}}+\frac{\mu_{2} \mathrm{Alr}_{2}}{\mathrm{Kr}_{1}}+\mu_{2} \mathrm{Alr}_{2} \frac{\mathrm{C}}{\mathrm{Kr}_{2}}+\frac{\text { R.S. } \mu_{2} \mathrm{y}_{12}}{\mathrm{Kr}_{2}}+\mathrm{A} . \mathrm{S} \cdot\left(\frac{1}{\mathrm{Kr}}-\frac{1}{\mathrm{R} . \mathrm{S}}\right)
\end{aligned}
$$

O raciocínio usado para a proposta dessa iteração pode ser visualizado na Figura 33, que guarda certa semelhança com o método de Coyle e Reese (1963).

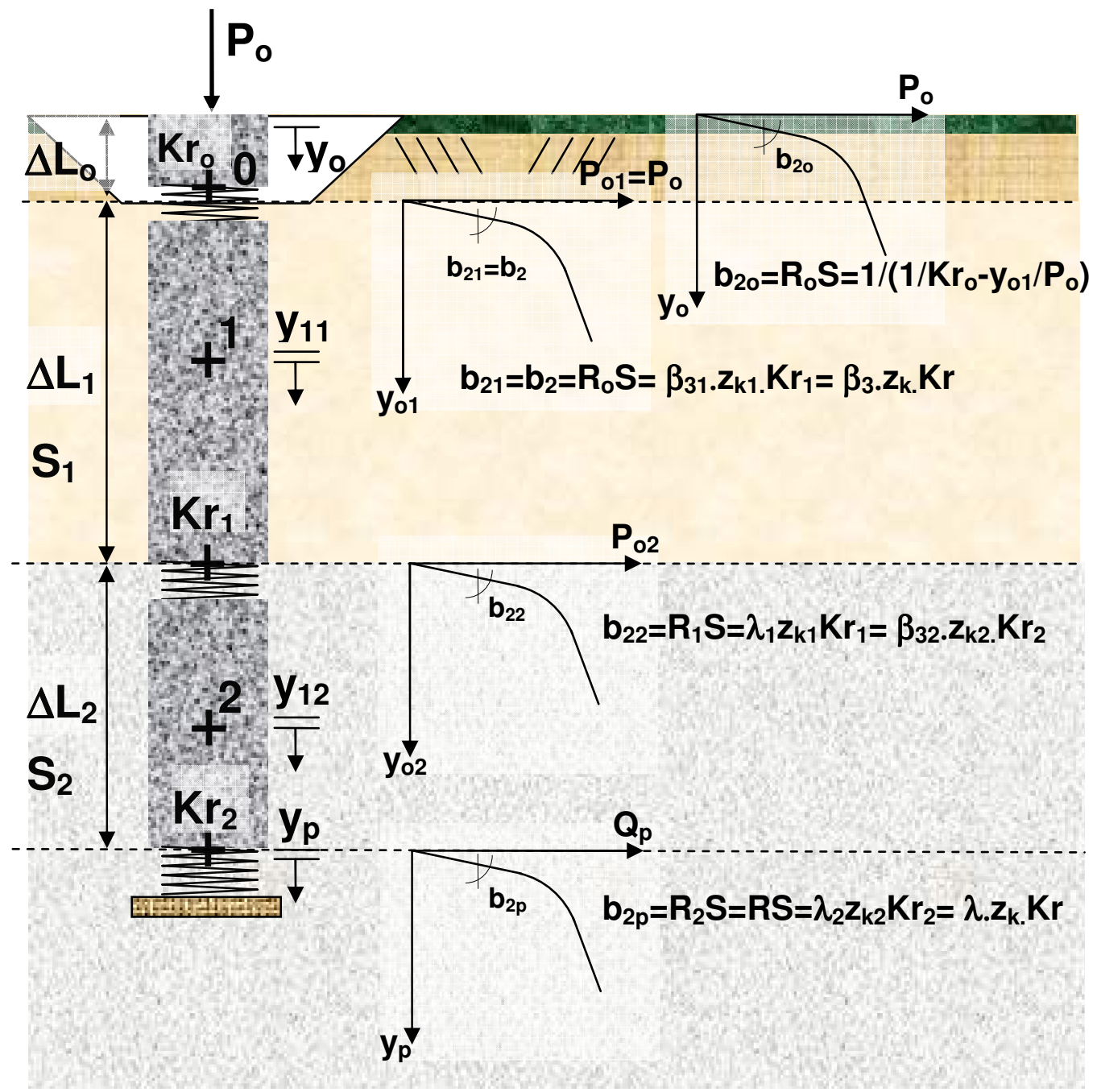

Figura 33 - Discretização da estaca para iteração no caso de solo heterogêneo

Nessa figura demonstra-se que a estaca pode ser dividida conforme as camadas de solo e, fazendo-se a compatibilidade de deslocamentos entre a "ponta fictícia" do trecho superior e o "topo fictício" do trecho inferior, pode-se realizar a iteração 
proposta e determinarem-se os parâmetros de Cambefort para cada camada. Convém notar que em geral as estacas ensaiadas possuem um trecho livre que é reforçado (maior rigidez) e, portanto, isso deve ser levado em conta, pois a formulação do método das Leis de Cambefort modificadas considera apenas o trecho de estaca imerso no solo.

No caso da camada de solo inferior ser considerada como a camada de embutimento da ponta da estaca (3D ou $8 D$ ), pode-se analisá-la pela rigidez $R_{1} S$ e, assim, apenas 0 atrito da camada superior $f_{\max 1}$ pode ser usado para corrigir os métodos semiempíricos que consideram tal embutimento. Caso se considere apenas o SPT da ponta (embutimento OD), o fuste pode ser dividido em duas camadas para a correção do atrito nos métodos semiempíricos.

Pode-se, por outro lado, adotar $\mathrm{R}_{2} \mathrm{~S}=\mathrm{R}_{1} \mathrm{~S}$, dividir a camada 1 em duas e reaplicar a análise como se o comprimento da estaca correspondesse apenas à camada 1. Isso resulta em algum erro, mas amplia as possibilidades de análise para três camadas.

Se aplicada a três camadas, devem-se considerar algumas reservas quanto à qualidade das estimativas, pois podem não convergir. Contudo, é possível obteremse valores confiáveis se o deslocamento de algum ponto intermediário da estaca for conhecido, como por exemplo, de um ponto de instrumentação. Assim, entre dois pontos conhecidos, é possível aplicar tal iteração e dividir o trecho em mais duas camadas, ampliando a quantidade de informação sobre a transferência de carga, mesmo nos ensaios instrumentados. Nesse caso, para facilitar a obtenção das rigidezes $b_{20}, b_{21}, b_{22}$ e $b_{2 p}$, uma nova forma de ajuste e análise dos resultados de instrumentação é apresentada no Capítulo 5.

Por outro lado, considerando que a grande maioria das provas de carga não é instrumentada, e que a quantidade de camadas de solos distintos pode ser bem maior do que três, os métodos que considerem a somatória das várias camadas para o atrito precisam de outra forma de análise, a fim de se inferir a contribuição do atrito de cada uma, para se corrigirem os coeficientes $\mathrm{K}_{\mathrm{Lgi}}$ de todas elas. Assim, no Capítulo 6 desenvolve-se a proposta de uso do conceito de Hierarquias dos Solos para se atribuir a contribuição de cada camada no atrito lateral em tais casos. 


\section{A AFERIÇÃO DO ATRITO DAS CAMADAS POR AJUSTES POLINOMIAIS DE ENSAIOS INSTRUMENTADOS E A NOVA ABORDAGEM MATEMÁTICA DA TRANSFERÊNCIA DE CARGA}

Como já apresentado, após ter-se separado as parcelas de atrito e ponta por meio dos métodos de transferência de carga, pode-se propor diretamente a correção dos coeficientes empíricos dos métodos semiempíricos que consideram a média do SPT ao longo do fuste. Para os métodos que consideram o atrito pela somatória das camadas, porém, é necessário atribuir-se a cada camada de solo a sua parcela individual de contribuição.

No caso de não se dispor de instrumentação na estaca ensaiada (caso mais comum), a proposta de iteração desenvolvida no item 4.8 permite que se atribuam os atritos individuais, de forma relativamente confiável, a até três camadas de solo. Para o caso de maior número de camadas, a proposta da Metodologia Semiempírica Unificada é empregar o conceito de Hierarquia dos Solos para atribuição dos valores individuais corrigidos, como se verá no Capítulo 6. Contudo é importante que se aqui contemple também a análise dos ensaios instrumentados, dada a maior quantidade de informação que estes disponibilizam.

A primeira vista, ao se dispor de instrumentação no ensaio, a proposta de discretização da estaca em elementos e posterior iteração por compatibilidade de rigidezes, apresentada no item 4.8, parece perder o sentido. Contudo deve-se considerar que, num terreno muito estratificado, é demasiado oneroso instalar um extensômetro para cada camada. Assim, o uso conjugado dos resultados da instrumentação e da iteração proposta, permite uma análise mais completa do sistema estaca-solo, e, consequentemente, melhor qualidade na atribuição do valor de atrito a cada camada de solo, sem maiores custos. Mesmo para o caso de falha de alguns instrumentos, eventualmente ocorrida durante o processo de confecção da estaca de teste, tal proposta se mostra interessante.

Ao obterem-se as rigidezes $b_{2}$, a partir dos resultados de carga e deslocamento do fuste nas interfaces das camadas, o problema fica resolvido de forma bastante viável. Para obterem-se tais informações de deslocamento e carga, contudo, 
esbarra-se na forma usual de análise dos ensaios instrumentados, a qual trata os resultados de forma discreta e não contínua com a profundidade. Com isso, algumas dificuldades podem surgir para se obterem os resultados nas profundidades mais convenientes para escolha das interfaces entre os elementos discretizados da estaca.

Dessa constatação surge a proposta de se analisarem os dados de instrumentação de forma contínua ao longo do fuste, utilizando-se para isso ajustes polinomiais dos resultados com a profundidade. Com isso, podem-se obter facilmente polinômios que representem as funções $\mathrm{N}(\mathrm{z})$, e, a partir deles, por derivação ou integração, obterem-se as funções polinomiais de $\tau(z)$ e de $y(z)$, conforme apresentado no item 4.1. As possibilidades dessa proposta são ainda mais amplas, pois ela permite obterem-se diretamente, embora com menor precisão, os parâmetros do modelo de transferência de carga, como por exemplo, o parâmetro B da expressão (29), dado pela razão $\tau(z) / y(z)$.

Assim, este capítulo trata da viabilidade de aplicação dos ajustes polinomiais aos ensaios instrumentados, bem como de seu uso para a obtenção direta do parâmetro B. Verifica-se, no decorrer dessa análise, a ocorrência de uma aparente inconsistência matemática e, com a solução desta, o surgimento da proposta de uma nova abordagem matemática da transferência de carga.

\subsection{DISCUSSÃO CONCEITUAL DO PARÂMETRO B $=\tau(z) / y(z)$}

O parâmetro B, coeficiente da Equação Diferencial de $2^{\mathrm{a}}$ Ordem da expressão (30), representa a função de relação entre a mobilização da tensão de cisalhamento $\tau(z)$ por atrito lateral no solo e os deslocamentos $y(z)$ do fuste da estaca. Como $\tau(z)$ e $\mathrm{y}(\mathrm{z})$ variam em $\mathrm{z}$, B também varia com a profundidade $[\mathrm{B}=f(\mathrm{z})]$, podendo-se considerar também que é uma função definida por uma curva a partir de três variáveis $[\mathrm{B}=f(\mathrm{z}, \tau, \mathrm{y})]$. Fisicamente, $\mathrm{B}$ depende da característica de deformação do solo do fuste dada pelos seus módulos de elasticidade $E_{f}$ ou de cisalhamento $G_{L}$. Matematicamente, B é uma função racional, como segue: 


$$
B=\frac{\tau(z)}{y(z)}
$$

Sendo o parâmetro B definido por um quociente, em que o numerador é a derivada segunda do denominador, como visto na expressão (26), toma-se essa definição matemática como ponto de apoio para o desenvolvimento das análises e discussões aqui tecidas. Assim, no caso de ajustes polinomiais dos resultados da intrumentação, esta relação deve ser obedecida, para que a proposta seja considerada válida.

\subsubsection{Formas matemáticas usuais do parâmetro $B=\tau(z) / y(z)$}

Algumas formas matemáticas foram propostas por diversos autores para a curva representativa da função $\tau=f(\mathrm{y})$, de modo que se pode compará-las aos polinômios ajustados desta proposta. Seed \& Reese (1957) apud Coyle e Reese (1966), por exemplo, relacionam a taxa de mobilização do atrito lateral $\left[\tau(z) / f_{\max }(z)\right.$ ou $\left.f / f_{\max }\right]$ com os respectivos deslocamentos $[\mathrm{y}(\mathrm{z})]$ produzidos no centro de cada trecho (elemento) da estaca, variando em profundidade. Tais curvas permitem determinar qual a parcela de atrito lateral desenvolvido pela estaca em determinado elemento, com base no seu deslocamento, sendo assim obtidas para diferentes profundidades (Figura 34 e Figura 35).

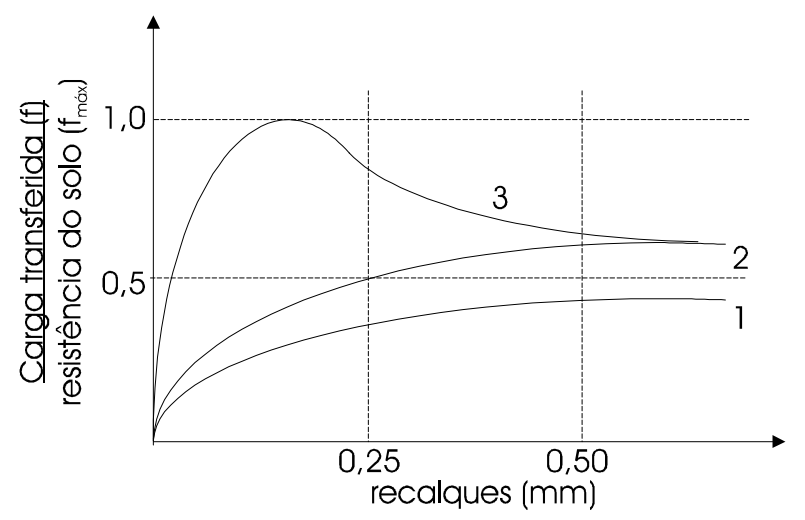

Figura 34 - Taxa de transferência de carga para o solo em função do recalque para as profundidades genéricas 1, 2 e 3 (SEED e REESE, 1959 apud COYLE e REESE, 1966)

Como a estaca em compressão é mobilizada do topo para a base, o solo na região superior apresenta deslocamentos maiores do que na ponta, na qual chega também uma carga menor. Essa redução se dá pela transferência de carga em profundidade, alterando a taxa de mobilização da tensão de cisalhamento ao longo do fuste. A 
Figura 35 ilustra esse fato, indicando as curvas $\tau-\mathrm{y}$ (o cisalhamento $\tau$ é indicado por f) e a taxa de mobilização, para cada profundidade, numa estaca submetida à carga axial $(\mathrm{P})$ no topo.
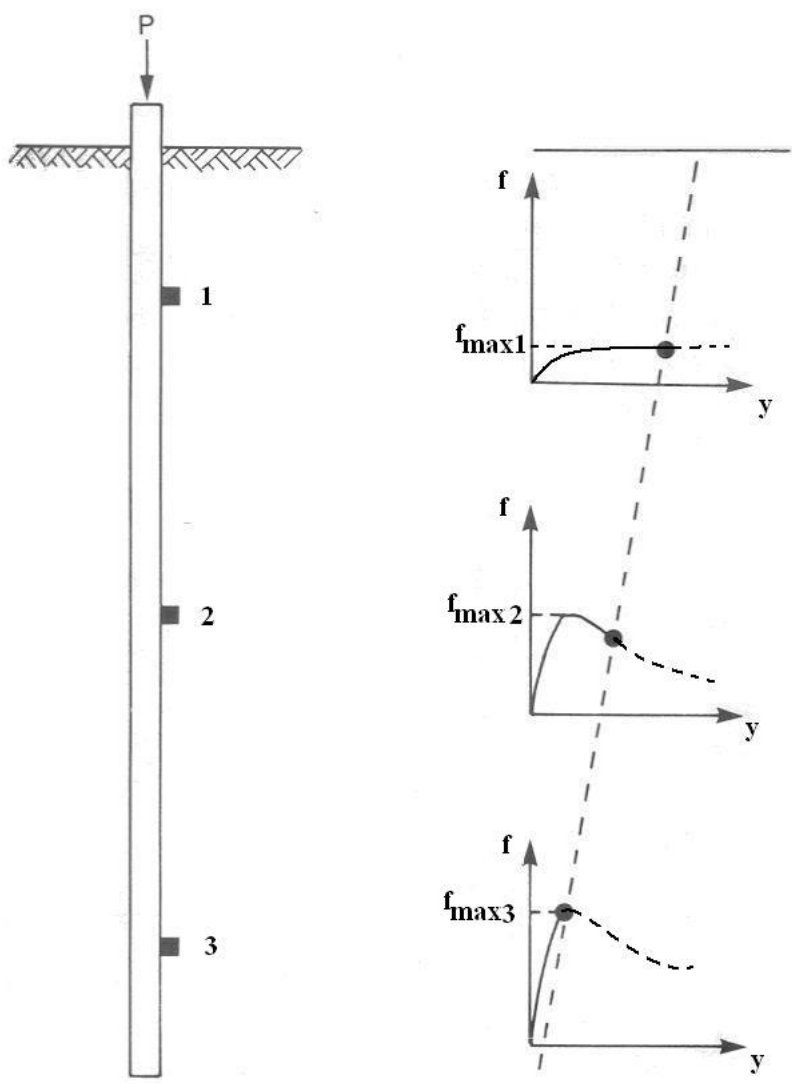

Figura 35 - Ruptura progressiva da estaca ao longo do seu comprimento (adaptado de FLEMING et al., 1992)

Assim, as curvas 1 e 2 da Figura 34 são comumente representadas como hipérboles, cuja assíntota indica o valor de atrito máximo na ruptura do solo na profundidade em que se encontra. A expressão típica é apresentada como:

$$
\frac{y}{\tau}=a_{1} \cdot y+a_{0} \Rightarrow \tau=\frac{y}{a_{1} \cdot y+a_{0}} \Rightarrow B=\frac{\tau}{y}=\frac{1}{a_{1} \cdot y+a_{0}}
$$

Já a curva 3 da Figura 34 possui representação algébrica com expoente 1/2 (raiz quadrada) para os deslocamentos y (REESE et al., 1969, apud POULOS e DAVIS, 1980), função esta semelhante à pesquisada por Kondner (1963), apud Burin (1989), que apresenta um pico de cisalhamento máximo e depois vai decaindo lentamente: 


$$
\begin{aligned}
& \frac{\sqrt{y}}{\tau}=a_{1} \cdot y+a_{0} \Rightarrow \tau=\frac{\sqrt{y}}{a_{1} \cdot y+a_{0}} \Rightarrow \\
& \Rightarrow B=\frac{\tau}{y}=\frac{1}{\sqrt{y} \cdot\left(a_{1} \cdot y+a_{0}\right)}=\frac{1}{a_{1} \cdot y^{2 / 3}+a_{0} \cdot y^{1 / 2}}
\end{aligned}
$$

Outros autores de diversos métodos de transferência de carga propuseram diferentes funções $B$ de mobilização do atrito para ajuste aos dados experimentais, como segue:

- Cambefort (1964) e Baguelin e Venon (1971):

$$
B=B_{c}+\frac{A_{c}}{y(z)}
$$

- Massad (1992):

$$
B=\frac{f_{\max }}{y_{1}}=c t e
$$

- Randolph e Wroth (1978), sendo $\mathrm{G}_{\mathrm{s}}=\mathrm{G}_{\llcorner} / 2$ :

$$
\mathrm{B}=\frac{\mathrm{G}_{\mathrm{s}}}{\zeta \cdot \mathrm{r}_{\mathrm{o}}}=\mathrm{cte}
$$

- Fleming (1992):

$$
B=\frac{1}{b \cdot y(z)+a}=\frac{1}{\frac{y(z)}{f_{\max }}+a}=\frac{1}{a} \cdot\left(1-\frac{\tau(z)}{f_{\max }}\right)
$$

- Frank e Zhao (1982):

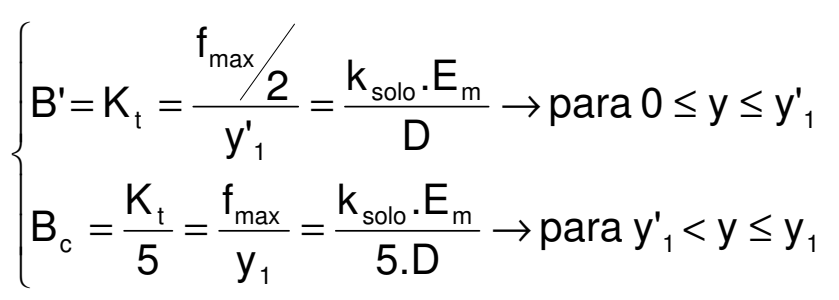

Os símbolos usados para Randolph e Wroth (1978) são esclarecidos no Apêndice D. Nas expressões (127), $E_{m}$ é o módulo pressiométrico (Ménard) do solo e $k_{\text {solo }} u m$ coeficiente que considera o tipo de solo. 
Verifica-se, portanto, que Cambefort (1964) propõe a linearização do trecho curvo por uma reta média, com inclinação $B_{c}$ e o intercepto $A_{c}$. Frank e Zhao (1982) sugerem um ajuste bi-linear, com a inclinação $B^{\prime}$ até a metade do valor do atrito máximo e com inclinação $B_{c}$ (obtido por ensaios pressiométricos) a partir daí. Massad (1992), por sua vez, adota um modelo linear simplificado (elastoplástico), passando pela origem do diagrama, como demonstrado na Figura 36:

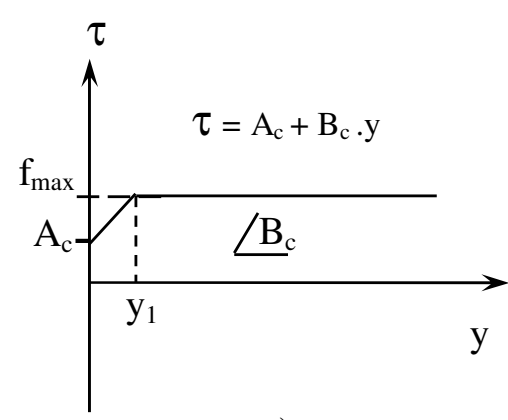

a)

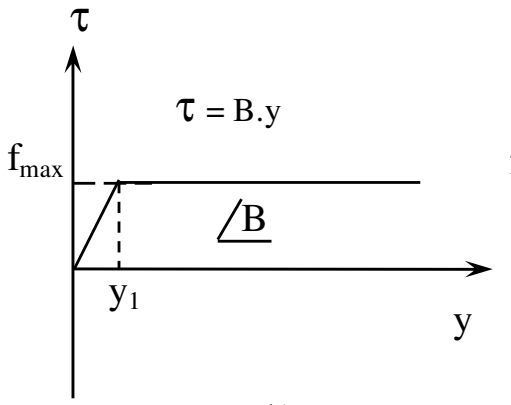

b)

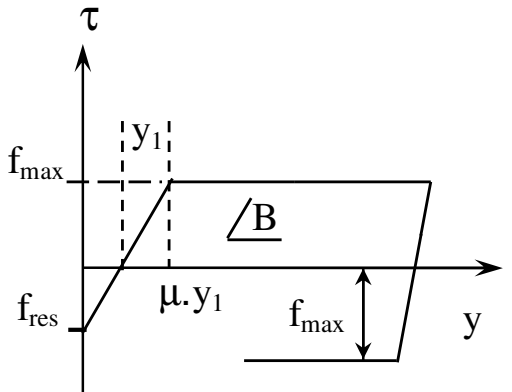

c)

Figura 36 - a)1a Lei de Cambefort (1964), apud Baguelin e Venon (1971); b) 1a Lei de Cambefort Modificada por Massad (1992) para o primeiro carregamento da estaca: $A c=0$; c) consideração da tensão residual $f_{\text {res }}$ no segundo carregamento da estaca (Massad 1992).

A Figura 37 é aqui proposta para mostrar uma representação do que seria a sobreposição dessas expressões num único diagrama y- $\tau$ :

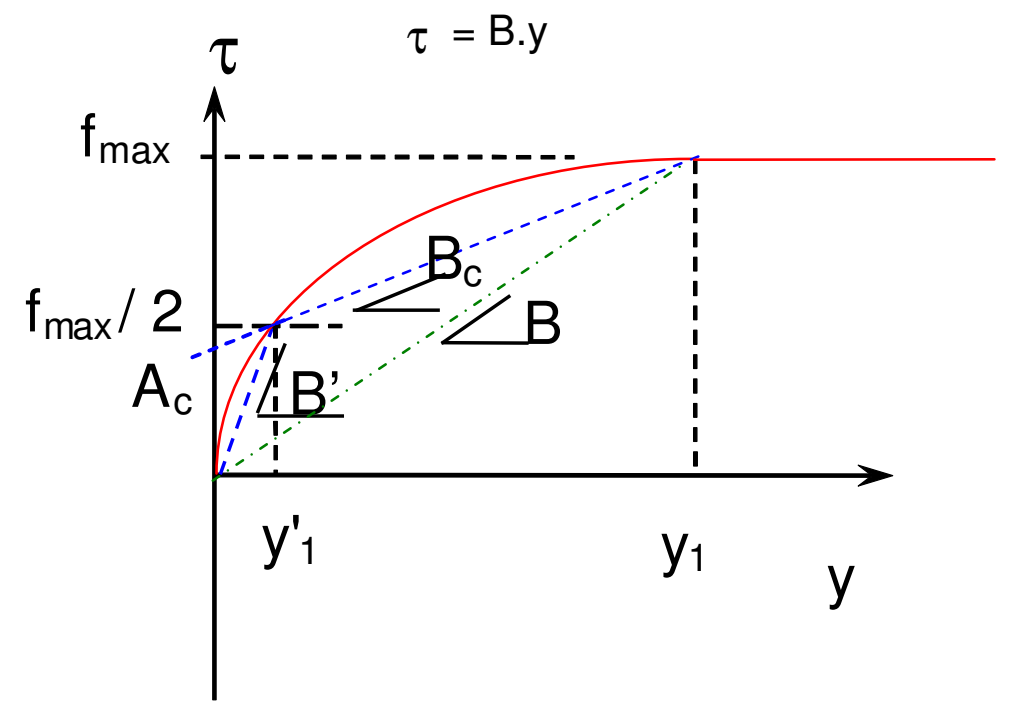

Figura 37 - Diagrama esquemático de sobreposição das formas propostas por diversos autores para obtenção do parâmetro B.

Na Figura 37, a curva assintótica representa a função "real", que é aproximada por Fleming (1992) a uma hipérbole, análoga à proposta por Coyle e Reese (1966). 


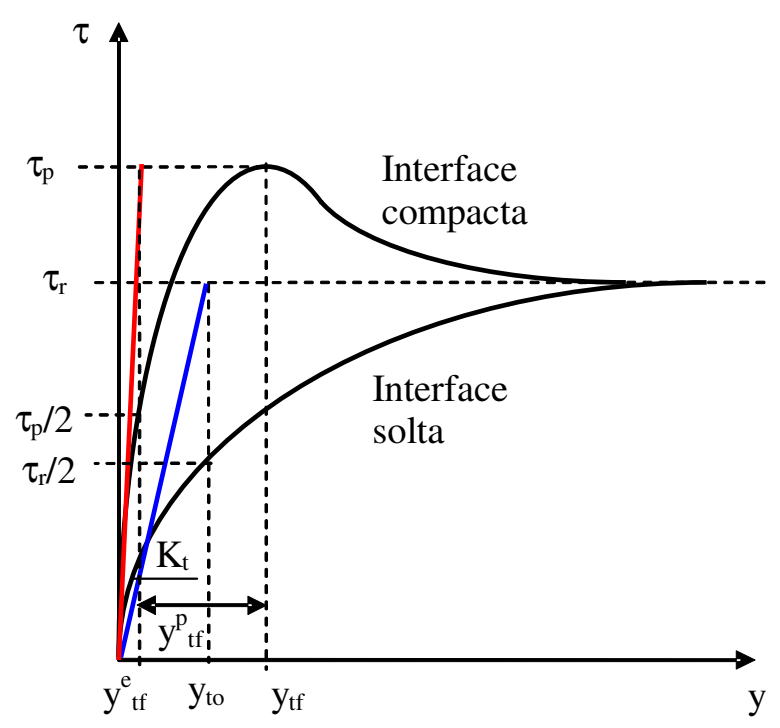

Figura 38 - Modelo de De Gennaro e Frank (2002) para interface estaca-solo não coesivo.

Deve-se, ainda, mencionar o trabalho de De Gennaro e Frank (2002), que propuseram um modelo de representação da interface de contato para solos nãocoesivos, a partir da consideração do coeficiente de atrito e do deslocamento tangencial plástico relativo $\left(\mathrm{u}_{\mathrm{t}}^{\mathrm{p}}\right)$, baseado no modelo Cam-Clay. A Figura 38 ilustra seu diagrama, cujas expressões matemáticas são de tipo misto (hiperbólicaexponencial), não contínuas.

Diante do exposto, é surpreendente observar uma completa inadequação de todas essas expressões em relação à definição matemática do parâmetro $\mathrm{B}$, dada no início do item 5.1, pois em nenhuma delas o numerador corresponde à derivada segunda do denominador.

Tal situação conduziu à necessidade de análise da forma experimental de obtenção da relação $\tau-y$, que define o parâmetro B. Assim, aplicando-a a uma prova de carga instrumentada, busca-se elucidar esta aparente inadequação, como segue.

\subsection{APRESENTAÇÃO DA PROVA DE CARGA DE EXEMPLO}

A metodologia matemática de análise do parâmetro B demonstrou uma aparente inadequação das expressões matemáticas propostas pelos autores dos diversos métodos de transferência de carga. Portanto, aplica-se aqui a metodologia 
experimental de obtenção da relação $\tau-y$ para avaliar e elucidar esse impasse matemático.

A estaca escolhida é a escavada, do tipo barrete (ABEF, 1989), instalada no campo experimental da USP-ABEF. Os dados da estaca e outros detalhes encontram-se listados no Apêndice $E$, sendo os aspectos essenciais resumidos nos próximos parágrafos.

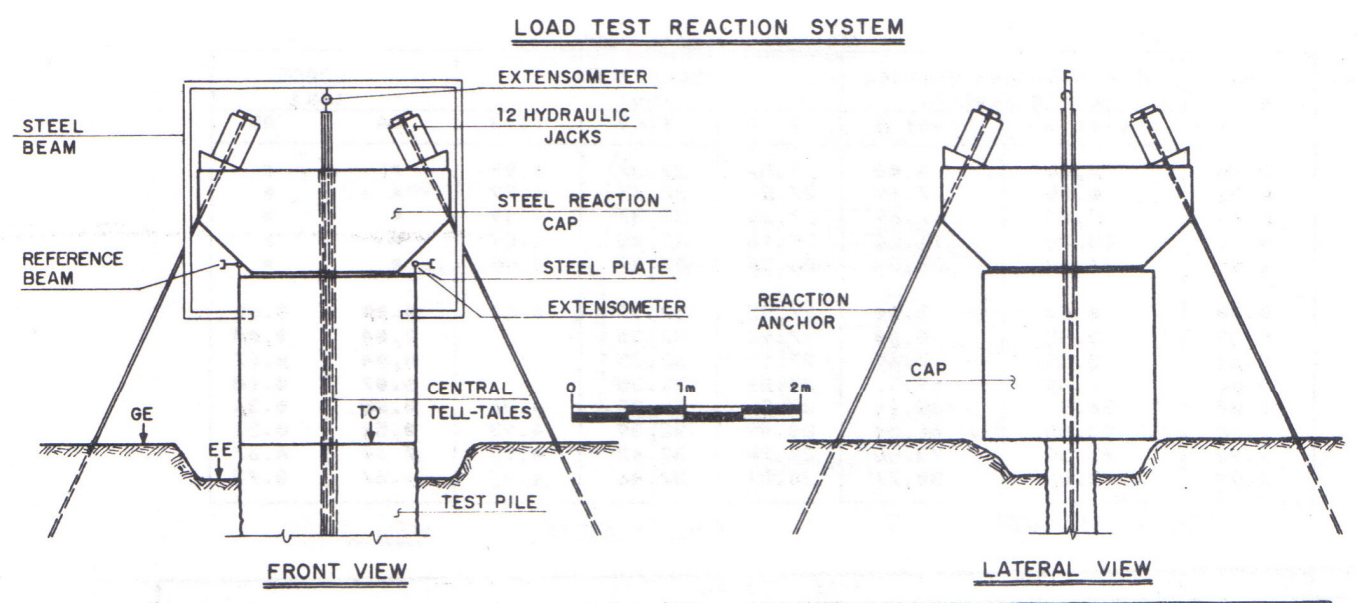

Figura 39 - Vista da montagem do sistema de reação (ABEF, 1989).

Essa estaca barrete é composta por um painel de parede diafragma, construído com a técnica convencional de trincheira, escavada com "clamshell", e preenchida com lama bentonítica. Possui seção retangular com dimensões: $1,65 \mathrm{~m} \times 0,40 \mathrm{~m} e$ comprimento de 7,50m. A resistência do concreto aos 28 dias resultou em 29,6 MPa. A armadura empregada consta de 40 barras de $12,5 \mathrm{~mm}$ de diâmetro nominal. Foi ensaiada à prova de carga com carregamento misto (lento+rápido).

O topo da estaca estava na cota $101,868 \mathrm{~m}$, enquanto o nível do terreno estava a $102,148 \mathrm{~m}$. Escavou-se o terreno até a cota $101,368 \mathrm{~m}$, tendo-se, portanto, um trecho livre da estaca de $0,5 \mathrm{~m}$, sem instrumentação.

A instrumentação, do tipo extensômetro elétrico ("strain-gage") e barras deslocáveis tipo "tell-tales", foi instalada em três níveis: C, na cota 97,968m; B, na cota 95,568m e A, na cota $94,568 \mathrm{~m}$, esta última a $0,2 \mathrm{~m}$ da ponta, a qual está na cota $94,368 \mathrm{~m}$. A estaca ficou então dividida da seguinte forma: $0,5 \mathrm{~m}$ de trecho livre (topo até 0 terreno) e 7,0m de trecho enterrado, sendo este subdividido, pela instrumentação, em três trechos subsequentes: $3,4 \mathrm{~m} ; 2,4 \mathrm{~m}, 1,0 \mathrm{~m}$ e, por fim, 0,2m, até a ponta. 


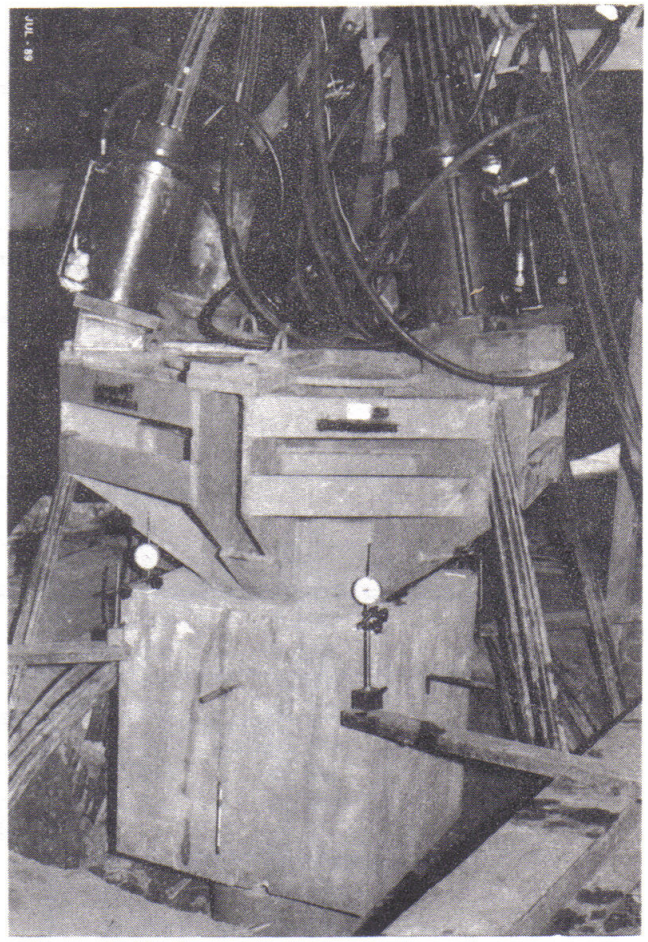

Figura 40 - Foto da montagem dos defletômetros e macacos hidráulicos (ABEF, 1989).

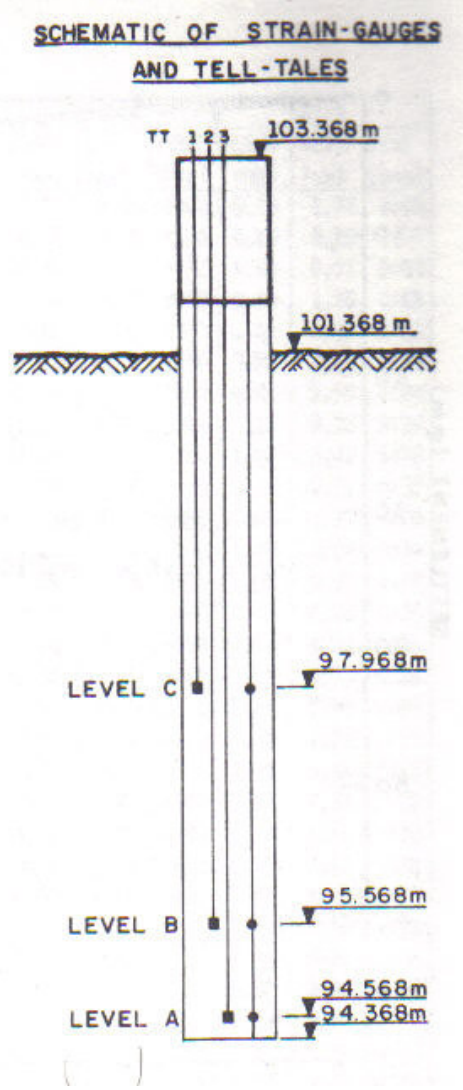

Figura 41 - Esquema de montagem da instrumentação (ABEF, 1989).

O solo representativo é o da sondagem SPT S1 1", na cota 102,160m, alinhada com os furos de sondagem S8 1", S6 1", e com os ensaios de cone CPT 1BGIl; 1DF; 1BGI, também realizados no local. A estratificação em função dos trechos instrumentados pode ser assim descrita: 3,4m de camadas alternadas de silte argilo arenoso, areia argilo-siltosa e caolinita, com SPT variando de 24 a 31 golpes; logo abaixo, tem-se silte arenoso, cobrindo os trechos instrumentados seguintes $(2,4 \mathrm{~m}$ e $1,0 \mathrm{~m})$ com 24 a 50 golpes; por fim, no trecho desde $0,2 \mathrm{~m}$ até a ponta, sua resistência chega a 45 golpes (ABEF, 1989). 


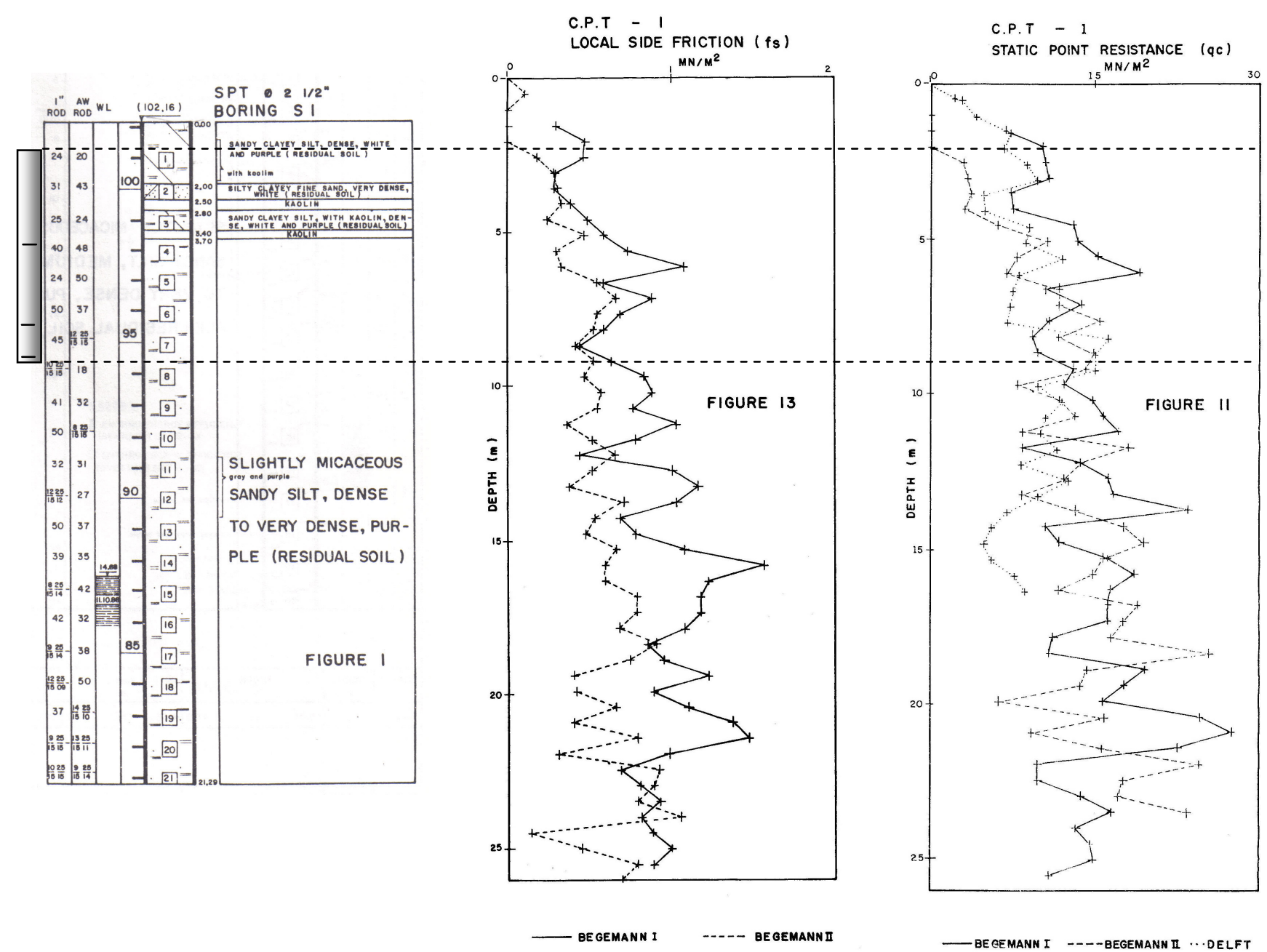

Figura 42 - Sondagens representativas SPT e CPT da estaca Barrete (apud ABEF, 1989) 


\subsection{RESULTADOS DA INSTRUMENTAÇÃO E APLICAÇÃO DA FORMA DE ANÁLISE USUAL}

Os resultados dos "strain-gages" da instrumentação dessa estaca são apresentados na Tabela 23, considerando-se o primeiro carregamento:

Tabela 23 - Leituras obtidas na instrumentação e cargas calculadas

\begin{tabular}{ccccccc}
\hline \multirow{2}{*}{ Carga $[\mathrm{kN}]$} & \multicolumn{3}{c}{ "Strain-Gages" $\varepsilon=\mathrm{dy} / \mathrm{dz} .10^{-6}$} & \multicolumn{3}{c}{ Cargas N $(\mathrm{z})[\mathrm{kN}]$} \\
\cline { 2 - 7 } & Nível A & Nível B & Nível C & $\mathrm{N}\left(\mathrm{z}_{\mathrm{A}}\right)$ & $\mathrm{N}\left(\mathrm{z}_{\mathrm{B}}\right)$ & $\mathrm{N}\left(\mathrm{z}_{\mathrm{C}}\right)$ \\
\hline 0 & 0.00 & 0.00 & 0.00 & 0 & 0 & 0 \\
500 & 0.00 & 3.80 & 7.70 & 0 & 60 & 110 \\
1000 & 5.80 & 20.20 & 26.90 & 80 & 290 & 390 \\
1500 & 21.20 & 42.30 & 49.00 & 300 & 610 & 710 \\
2000 & 38.50 & 63.50 & 70.20 & 550 & 910 & 1010 \\
2500 & 65.40 & 86.50 & 95.20 & 940 & 1250 & 1370 \\
3000 & 98.10 & 115.40 & 125.00 & 1410 & 1660 & 1800 \\
\hline
\end{tabular}

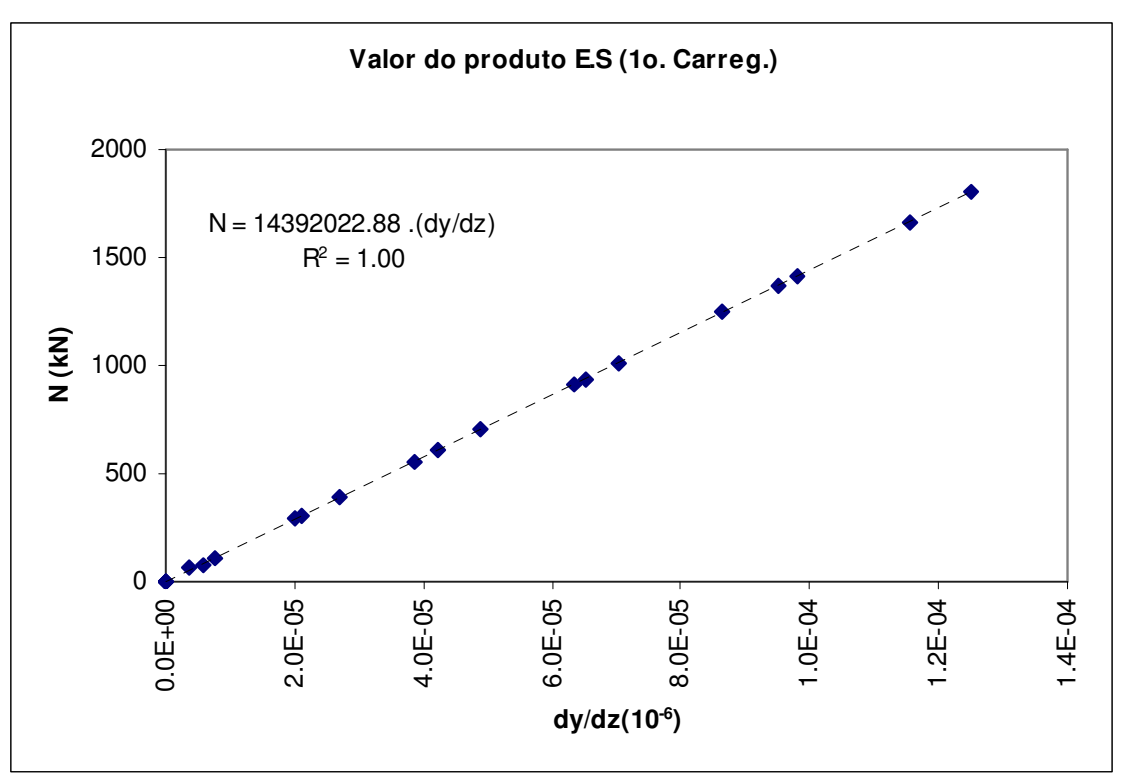

Figura 43 - Determinação do produto E.S.

Do produto E.S obtido pela inclinação da reta da Figura 43 e do cálculo da seção $S$, o módulo de elasticidade adotado para a estaca resulta aproximadamente 21,81 GPa. O diagrama da Figura 44 foi construído com os valores da Tabela 23 para as cargas $\mathrm{N}(\mathrm{z})$ em cada profundidade. 


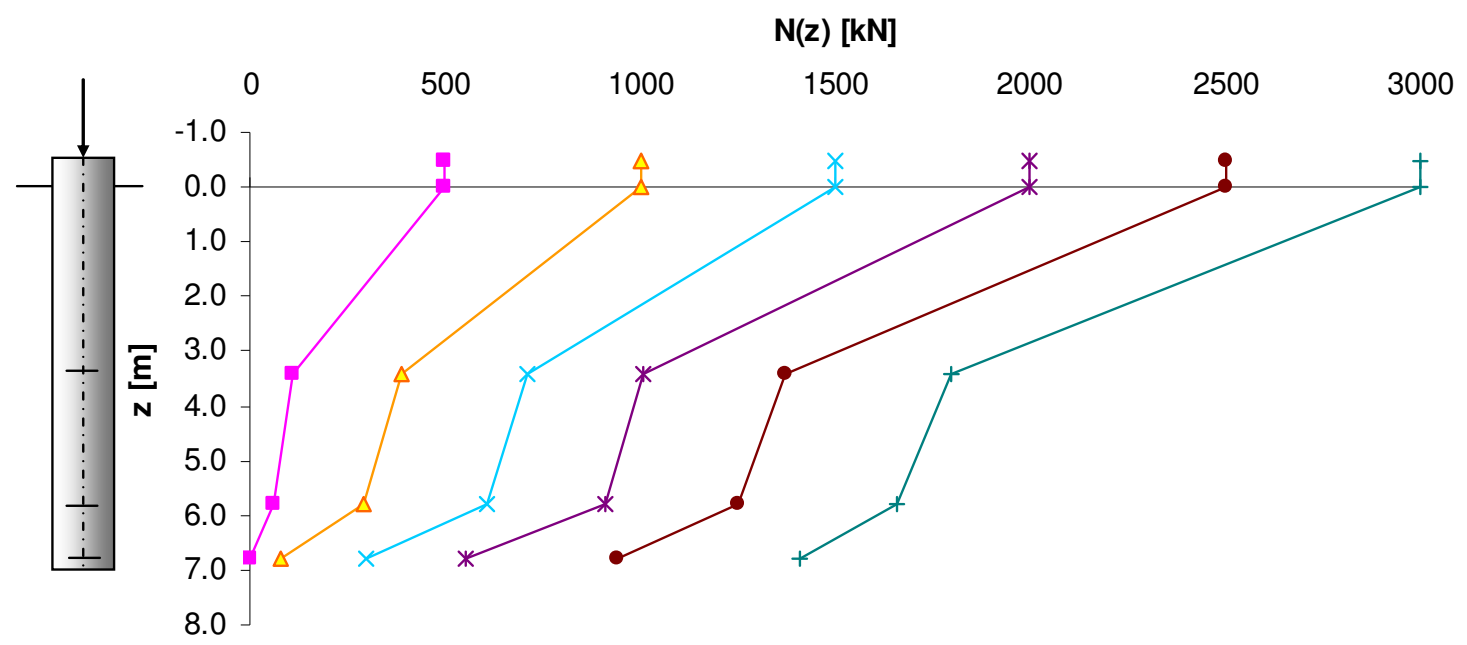

Figura 44 - Diagrama de transferência de carga em profundidade.

No método usual de análise dos instrumentos, esse diagrama é define o atrito lateral desenvolvido em cada trecho da estaca através da inclinação das retas, que é dada pela diferença entre as cargas em duas profundidades (carga transferida ao solo) dividida pelo perímetro e pelo comprimento do trecho, ou seja, pela distância entre os instrumentos $(\Delta z)$. Trata-se da aplicação da expressão (24), aqui reproduzida como (128):

$$
\tau(z)=-\frac{1}{U} \cdot \frac{d N(z)}{d z} \Rightarrow \tau(z) \cdot U=-\frac{d N(z)}{d z}
$$

Dessa forma, a inclinação de cada reta da Figura 44 resulta no produto $\tau$. $U$ em cada trecho, o que pode ser chamado de "carga transferida por metro linear de estaca", pois sua unidade é $[\mathrm{kN} / \mathrm{m}]$. Sabendo-se o perímetro $U$, acha-se o atrito unitário $\tau$ no trecho em $\left[\mathrm{kN} / \mathrm{m}^{2}\right]$.

A representação gráfica usual, nesse caso, é feita considerando o atrito unitário constante ao longo do trecho, conforme se apresenta na Figura 45. Percebe-se claramente nessa figura que o trecho $\Delta \mathrm{z}_{2}$ (Nível B) apresenta um baixo atrito mobilizado durante o carregamento. Como o SPT não apresenta redução proporcional nesse trecho, resta concluir que isso se deva a algum outro fator, como o descolamento entre fuste e solo, ou a mudança brusca do produto E.S (diâmetro ou módulo do concreto, área de aço) etc. 


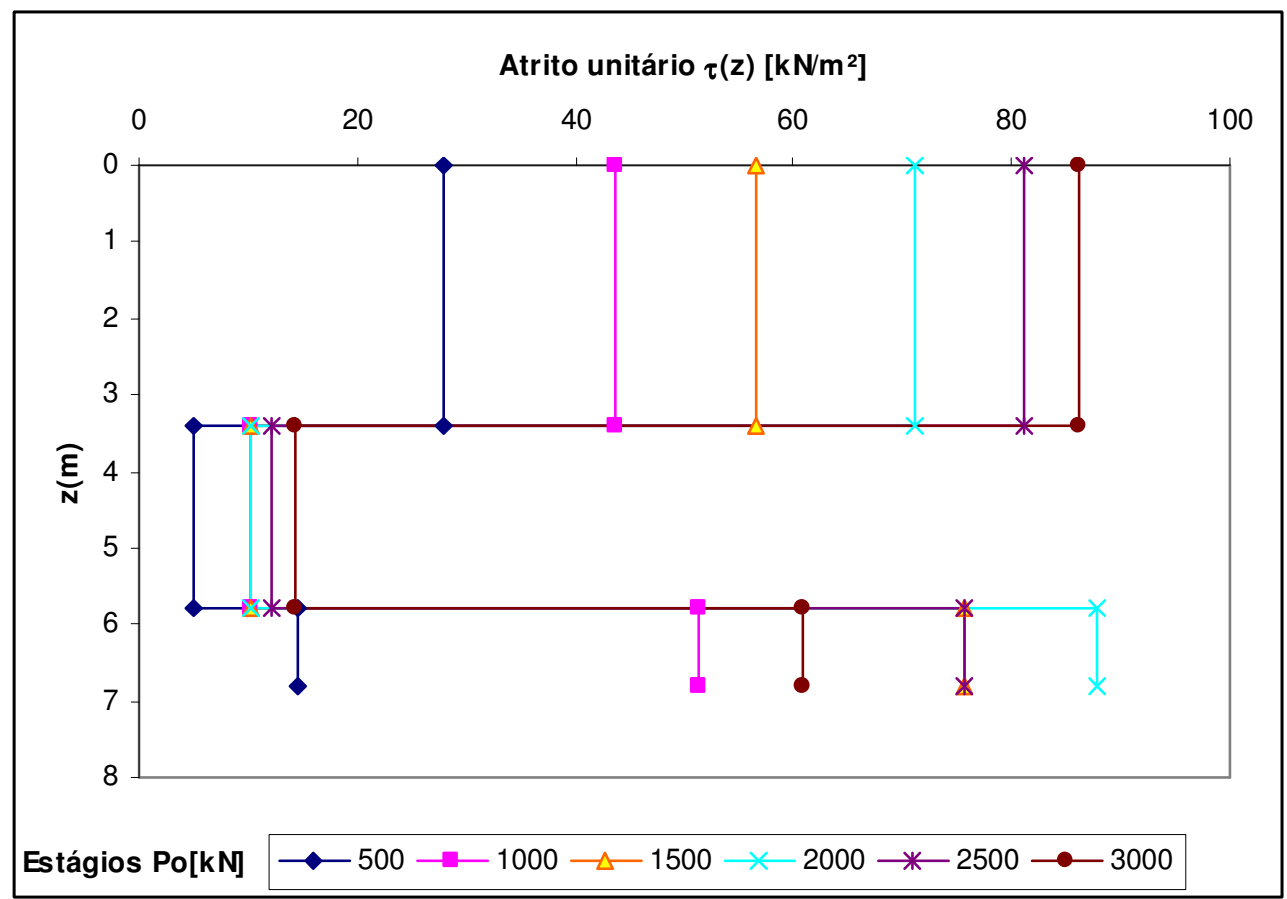

Figura 45 - Distribuição de atrito lateral em profundidade pelo método usual de linearização

Para se definir o parâmetro $B$, deve-se obter a relação $\tau$ / y e, para isso, determinamse os valores de y (deslocamentos) ao longo da profundidade $z$ por integração de $\mathrm{N}(\mathrm{z})$, conforme a expressão (28). Deve-se somar o resultado ao yo no topo, considerando o encurtamento do trecho livre, pois as medidas do topo da estaca são ligeiramente diferentes do ponto em que esta se encontra com o terreno (topo real para a transferência de carga). Tem-se assim:

$$
y_{0}-y(z)=\frac{1}{E . S} \cdot \int_{0}^{z} N(z) \cdot d z \Rightarrow\left[y_{0}-y(z)\right] E \cdot S=\int_{0}^{z} N(z) \cdot d z
$$

A expressão (129) indica que a área do gráfico das cargas resulta no produto do encurtamento elástico do trecho pela constante de rigidez, E.S. Conhecendo-se E.S e $y_{0}$ acha-se $y(z)$, resultando na Figura 46.

Apesar dos valores de deslocamento variarem pouco devido à elevada rigidez da estaca, os valores apresentados devem conceitualmente ajustar-se a polinômios do segundo grau e não a retas, como aparentemente intui-se à primeira vista, pois a expressão adotada usualmente para as cargas é linear. 


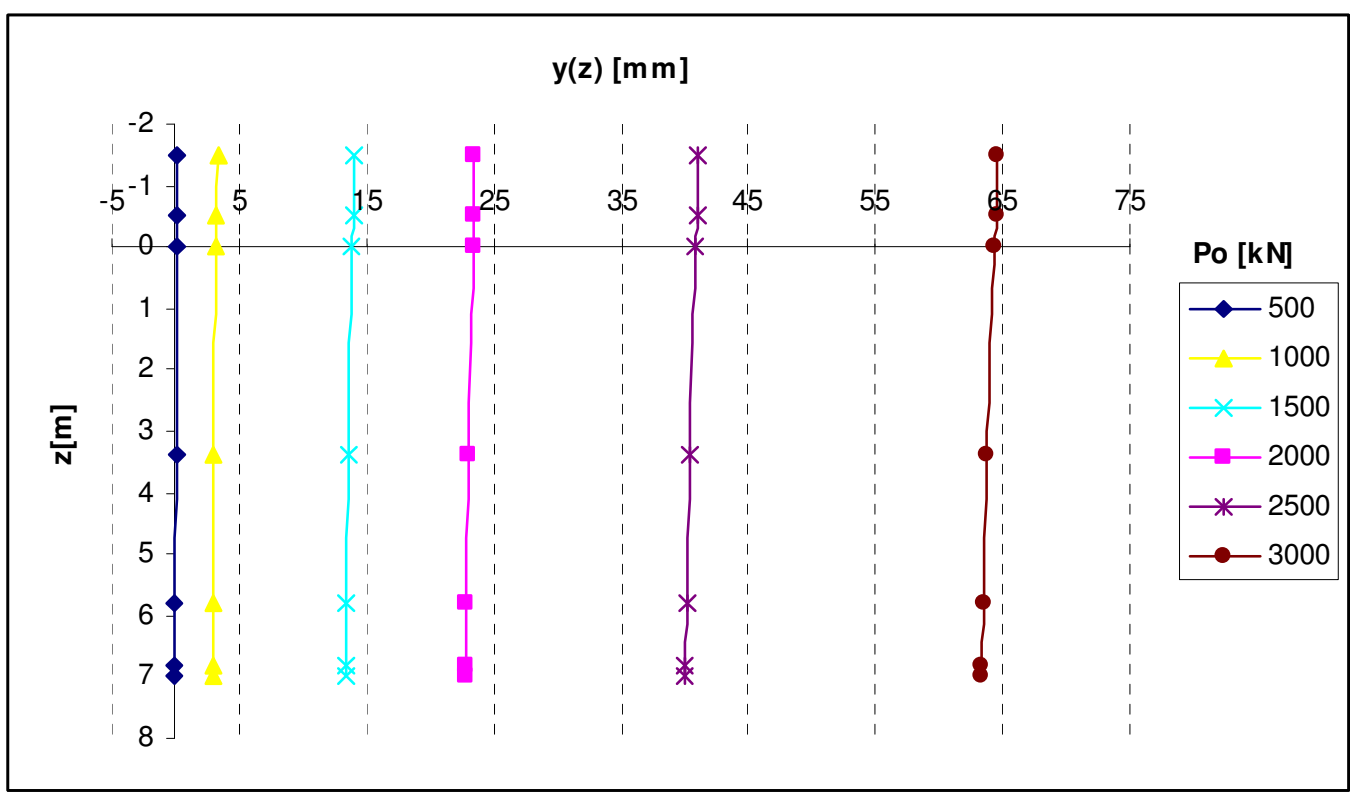

Figura 46 - Diagrama de deslocamentos em profundidade para cada estágio de carga

Agora, de posse dos valores de $\tau$ e y, pode-se fazer a relação entre os mesmos para se determinar a função $\tau(z)=f[y(z)]$, a qual pode ser definida como $\tau(z)=B(z) \cdot y(z)$. Deve-se atentar para que a dedução até aqui apresentada tem considerado sempre as funções $\tau$ e y como funções da profundidade z. Como descrito acima, nesse caso, é como se houvesse uma relação tridimensional, ou três variáveis influenciando o fenômeno de transferência de carga, a saber: $\tau$, y e z.

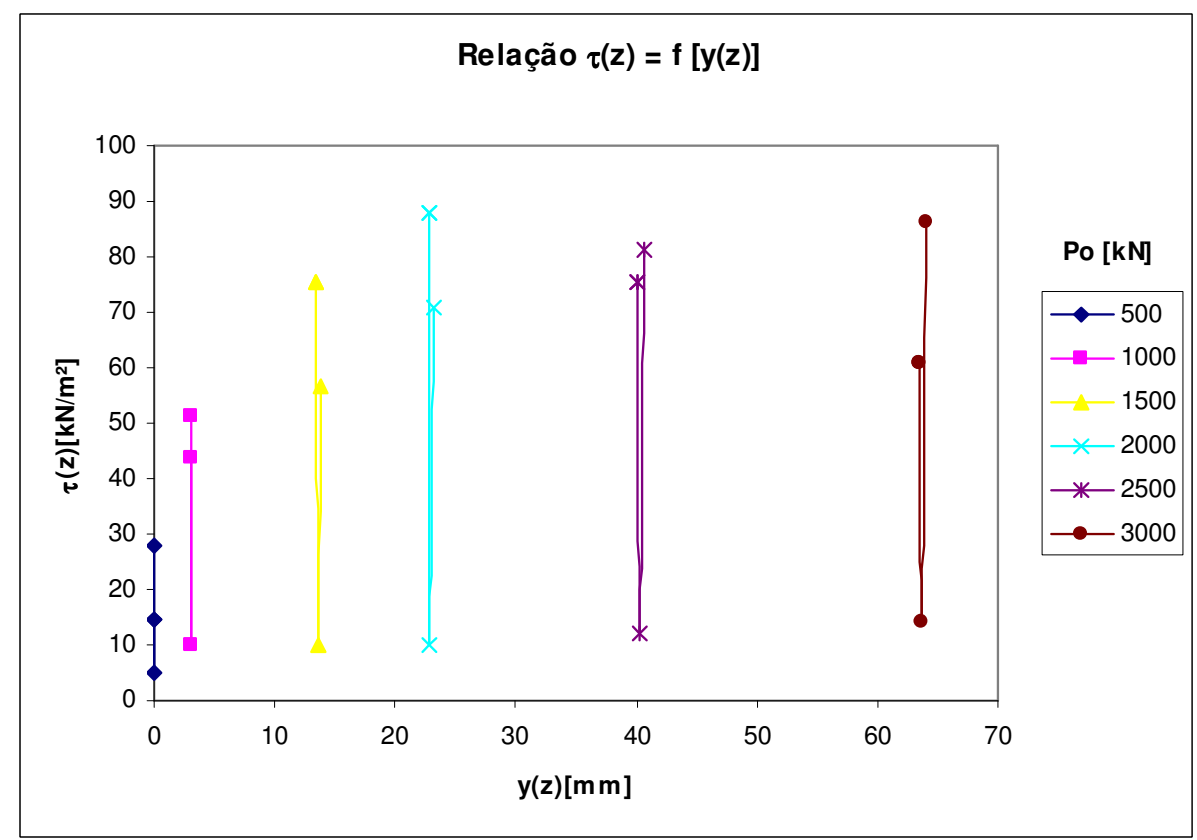

Figura 47 - Relação $\tau(z)=f[y(z)]$ para cada estágio de carga 
Como o atrito lateral é usualmente considerado constante em cada trecho, para se traçarem os gráficos representativos da relação entre $\tau(z)$ e $y(z)$ há a necessidade de se calcular o deslocamento dos pontos médios pela análise da deformação de cada trecho instrumentado da estaca. A Figura 47 mostra o resultado.

Note-se que as curvas obtidas deveriam ser as curvas de transferência de carga em profundidade, com o formato assintótico apresentado pelos diversos autores dos métodos de transferência de carga, porém são totalmente diferentes das hiperbólicas usualmente empregadas, como se vê na Figura 47.

Devido às diferentes magnitudes dos deslocamentos em cada estágio de carga, a escala não permite visualizar adequadamente a forma dessas curvas que de fato representam a relação $\tau(z)-y(z)$. Tomando-se um dos estágios de carga, por exemplo, $3000 \mathrm{kN}$, onde o atrito lateral deve estar mais próximo do plenamente mobilizado, pode-se ver o detalhe na Figura 48.

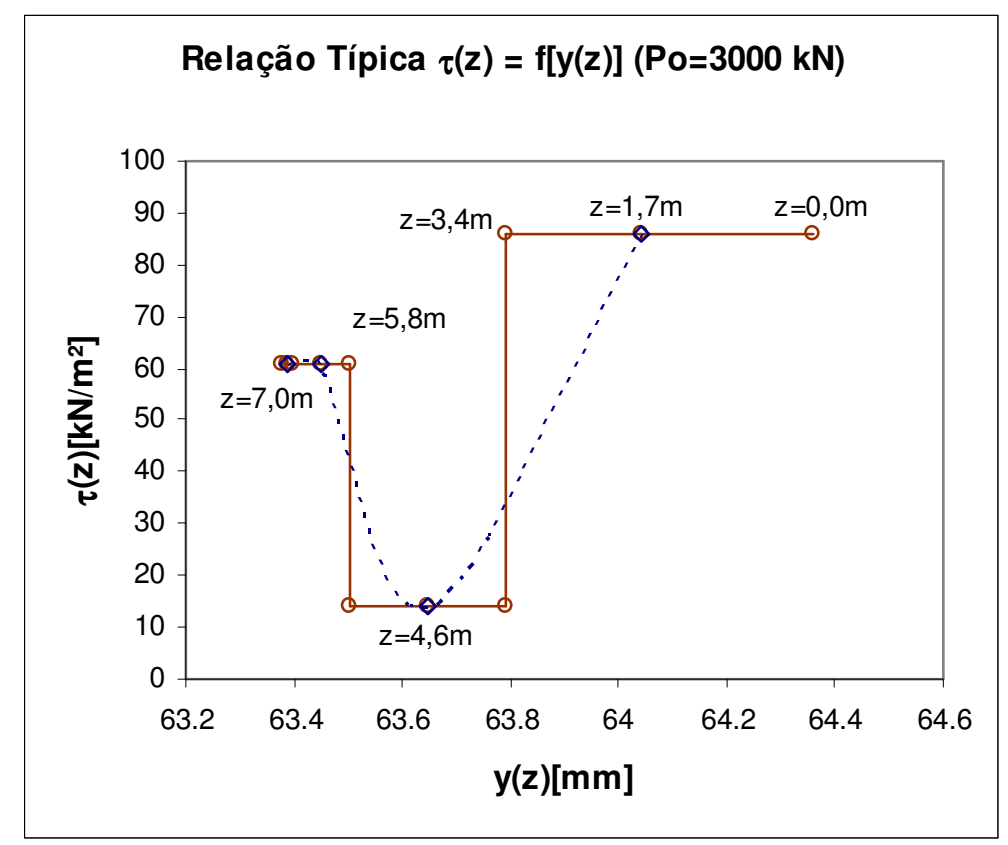

Figura 48 - Detalhe da curva $\tau(\mathrm{z})-\mathrm{y}(\mathrm{z})$ obtida para o estágio de carga $3000 \mathrm{kN}$

A forma da curva da Figura 48 é similar para todos os demais estágios de carga. A linha tracejada indica a forma da curva ao se considerar apenas o deslocamento médio do trecho, como uma função contínua. Observa-se na Figura 48 que, como ocorreu na dedução matemática, a relação $\tau(z) / y(z)$, obtida experimentalmente, também não resulta na forma hiperbólica usualmente apresentada. De fato, relacionando-se $\tau(z)$ com $y(z)$, obtém-se uma curva com elevado grau de 
complexidade, seja fixando valores de $z$ para sua solução, seja considerando $\tau(z)$ com $\mathrm{y}(\mathrm{z})$ como formas paramétricas de uma hipotética função $\tau=f(\mathrm{y})$.

Portanto, demonstra-se que além, da incoerência matemática, há também uma incoerência da análise usual dos dados instrumentados. Para a solução deste problema e para a proposta de uma abordagem matemática adequada, é necessário interpretar o processo de execução do ensaio, bem como da mobilização do atrito ao longo do carregamento, como é proposto a seguir.

\subsection{NOVA ABORDAGEM MATEMÁTICA DA TRANSFERÊNCIA DE CARGA}

Obtém-se a resposta à questão dessa aparente incoerência ao fixar-se uma profundidade $z$, anotando-se os pares de valores $(y, \tau)$ no mesmo diagrama, para cada estágio de carga $P_{0}$. Assim, conclui-se que as funções $\tau$ e y demonstram-se não apenas funções de $z$, mas também de $P_{0}$, que, sendo a entrada de energia do sistema, constitui-se na quarta variável (até então ignorada) a ser considerada no problema.

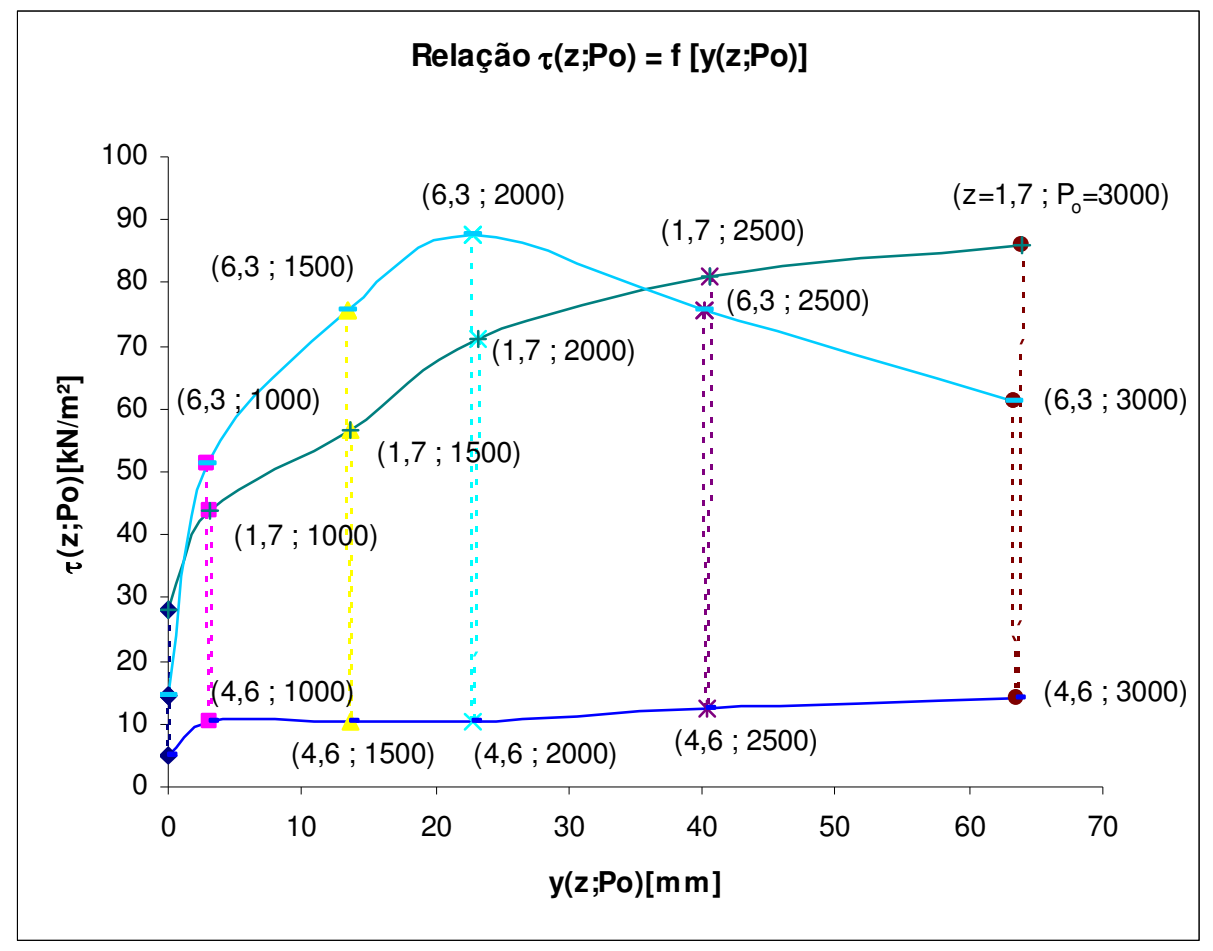

Figura 49 - Verificação da dependência de z e Po nas funções $\tau$ e y.

Isso pode ser aplicado na própria Figura 47 , anotando-se os pares de valores z e $\mathrm{P}_{\mathrm{o}}$ correspondentes a cada ponto $(y, \tau)$ do gráfico, e em seguida ligando-se os pontos 
de mesmo valor de z. O resultado, como se vê na Figura 49, na qual foram tracejadas as curvas (quase verticais) referentes a cada $\mathrm{P}_{\mathrm{o}}$ constante, é que ao ligar os pontos de mesma profundidade $z$, obtém-se as curvas de transferência de carga em profundidade com o aspecto semi-assintótico esperado. Vê-se, portanto, que as curvas praticamente verticais da Figura 47 (e seu detalhe da Figura 48) representam a solução $\tau(z)=B . y(z)$ para $P_{0}$ constante (Figura 50 ), enquanto a curva assintótica utilizada pelos diversos autores na solução (Figura 37) é, na verdade, definida por $\tau\left(P_{o}\right)=B \cdot y\left(P_{0}\right)$, para uma profundidade $z$ constante .

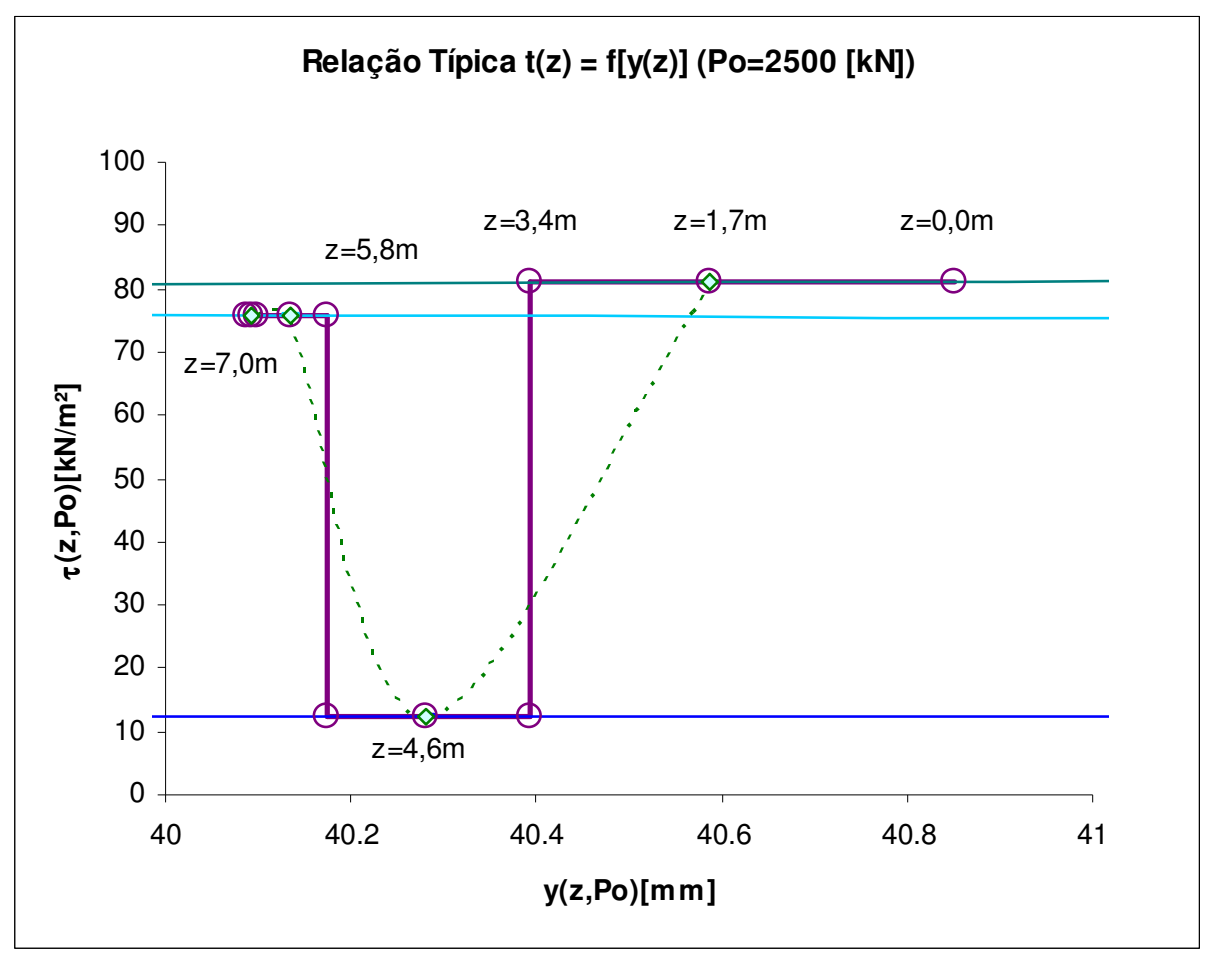

Figura 50 - Detalhe ampliado para o estágio de 2500 kN

Assim, a nova abordagem matemática que aqui se propõe é a consideração da transferência de carga como função de duas variáveis independentes: $z$ e $P_{0}$. Desta forma:

$$
\tau\left(z, P_{o}\right)=B \cdot y\left(z, P_{o}\right) \Rightarrow B=\frac{\tau\left(z, P_{o}\right)}{y\left(z, P_{o}\right)}
$$

e então $B$ também pode ser considerado uma função dessas duas variáveis $\left[\mathrm{B}=f\left(\mathrm{z}, \mathrm{P}_{\mathrm{o}}\right)\right]$. Sendo assim, tomando-se $\mathrm{y}\left(\mathrm{z} ; \mathrm{P}_{\mathrm{o}}\right)$, pode-se expressar matematicamente que seu diferencial é dado pelas derivadas parciais de $z$ e $P_{0}$ : 


$$
\mathrm{y}=f\left(z, \mathrm{P}_{\mathrm{o}}\right) \Rightarrow \mathrm{dy}=\frac{\partial \mathrm{y}}{\partial \mathrm{z}} \cdot \mathrm{dz}+\frac{\partial \mathrm{y}}{\partial \mathrm{P}_{\mathrm{o}}} \cdot d \mathrm{P}_{\mathrm{o}}
$$

Trata-se, portanto, de uma Equação Diferencial Parcial (EDP), com sua forma própria de solução e notação, e da qual a EDO2 da expressão (30) é um caso particular em que $P_{o}$ é constante.

Para verificar esta assertiva, basta observar que quando se fixa o valor de $P_{0}$ (estágio de carga aplicado), obtém-se $\mathrm{dP}_{0}=0$, e a função varia apenas em $\mathrm{z}$ :

$$
\begin{aligned}
& d y=\frac{\partial y}{\partial z} \cdot d z+\frac{\partial y}{\partial P_{o}} \cdot 0 \Rightarrow \frac{d y}{d z}=\frac{\partial y}{\partial z} \Rightarrow \frac{\partial^{2} y}{\partial z^{2}}=\frac{d^{2} y}{d z^{2}}=\frac{U}{E \cdot S} \cdot \tau\left(z, P_{o}\right)_{P_{o}=c t e} \Rightarrow \\
& \Rightarrow \frac{\partial^{2} y}{\partial z^{2}}=\frac{U}{E \cdot S} \cdot\left[B\left(z, P_{o}\right) \cdot y\left(z, P_{o}\right)\right]_{P_{o}=c t e} \Rightarrow B\left(z, P_{o}\right)_{P_{o}=c t e}=\frac{\tau(z)}{y(z)}
\end{aligned}
$$

Com isso, obtêm-se curvas $\tau(z)-y(z)$, que possuem o aspecto da Figura 50.

Quando se fixa o valor de $z$ (profundidade analisada), então dz=0 e a função varia apenas em $P_{0}$ :

$$
d y=\frac{\partial y}{\partial z} \cdot 0+\frac{\partial y}{\partial P_{o}} \cdot d P_{o} \Rightarrow \frac{d y}{d P_{o}}=\frac{\partial y}{\partial P_{o}} \equiv \frac{1}{K_{t z}} \Rightarrow B\left(z, P_{o}\right)_{z=c t e}=\frac{\tau\left(P_{o}\right)}{y\left(P_{o}\right)}
$$

São obtidas, assim, curvas $\tau\left(\mathrm{P}_{\mathrm{o}}\right)-\mathrm{y}\left(\mathrm{P}_{\mathrm{o}}\right)$ com o aspecto das curvas da Figura 51, similares às utilizadas pelos diversos autores (Figura 37). Na expressão (133), $\mathrm{K}_{\mathrm{tz}}$ representa a rigidez tangente à curva $\mathrm{y}=f\left(\mathrm{z}, \mathrm{P}_{\mathrm{o}}\right)_{\mathrm{z}=\mathrm{cte}}$.

Em outras palavras, matematicamente a Equação Diferencial de $2^{\underline{a}}$ Ordem (EDO2) para a deformação da estaca, dada em (30), é solucionada discretamente para cada profundidade $\mathrm{z}$, obtendo-se as relações matemáticas $\tau=f(\mathrm{y})$ a partir dos pares de valores $(\tau, y)$ de cada estágio de carga $P_{0}$. Na dificuldade de se obter experimentalmente o valor do parâmetro B pelas curvas $\tau(z)-y(z)$, os diversos autores fixam a profundidade $z$, simplificando a solução em forma de EDO2, e definem $B$ através das curvas $\tau\left(P_{0}\right)-y\left(P_{0}\right)$.

De fato, segundo McCallum et al. (1997), pela regra da cadeia para a solução de Equações Diferenciais Parciais, é possível avaliar uma das derivadas parciais a partir de outra mais fácil de se medir experimentalmente. É exatamente isso que se 
faz quando se avalia o parâmetro $B$, fixando a profundidade $z$, e variando o valor de $P_{0}$.

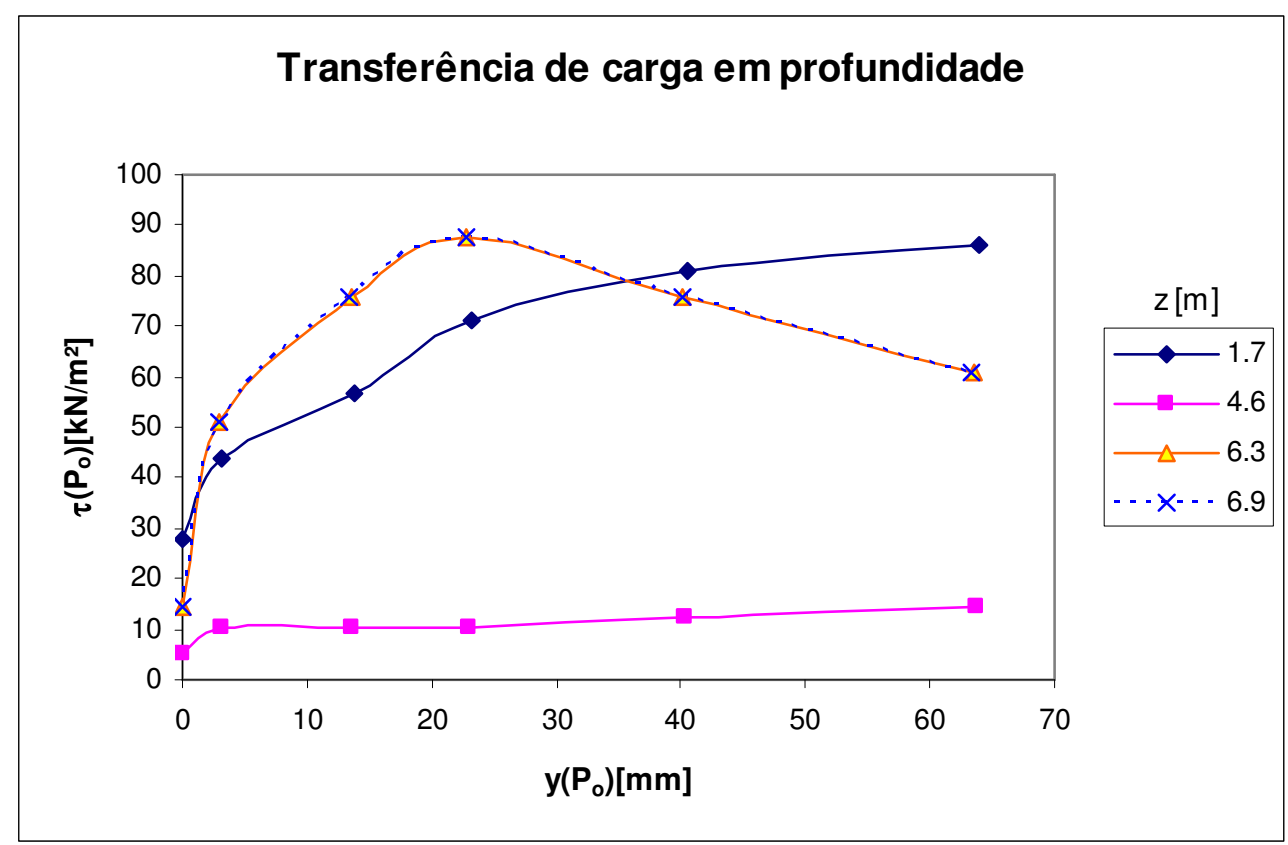

Figura 51 - Curvas usuais de transferência de carga para cada profundidade

Assim, para cada par de valores $\left(z, P_{0}\right)$, obtêm-se funções do tipo $\tau\left(z, P_{0}\right)=$ $B\left(z, P_{0}\right) \cdot y\left(z, P_{0}\right)$. Como a representação gráfica de funções envolvendo quatro variáveis (4 dimensões, $P_{0}, z, \tau, y$, sendo $z$ e $P_{0}$ as variáveis independentes) não é simples, usualmente se fixa uma das variáveis enquanto se analisa a variação das demais.

Ressalta-se que as simplificações feitas pelos autores dos métodos de transferência de carga buscam soluções para o caso de solo considerado homogêneo em profundidade, de forma que se possa adotar uma única relação $\tau$-y, e um único valor de $\mathrm{B}$, para representar o comportamento médio da estaca. Com isso, as curvas da Figura 51 passam ainda por uma simplificação, como demonstra a Figura 37.

Fica assim definida a nova abordagem matemática da transferência de carga, que permite acoplar a forma de determinação experimental do parâmetro $B$, a qual antes não ficava matematicamente clara, por estar descrita apenas em termos de z.

Apresentam-se aqui algumas figuras tridimensionais, comentadas no Apêndice $\mathrm{E}$, item E.2, de modo a facilitar a visualização e o entendimento dessa nova abordagem. 

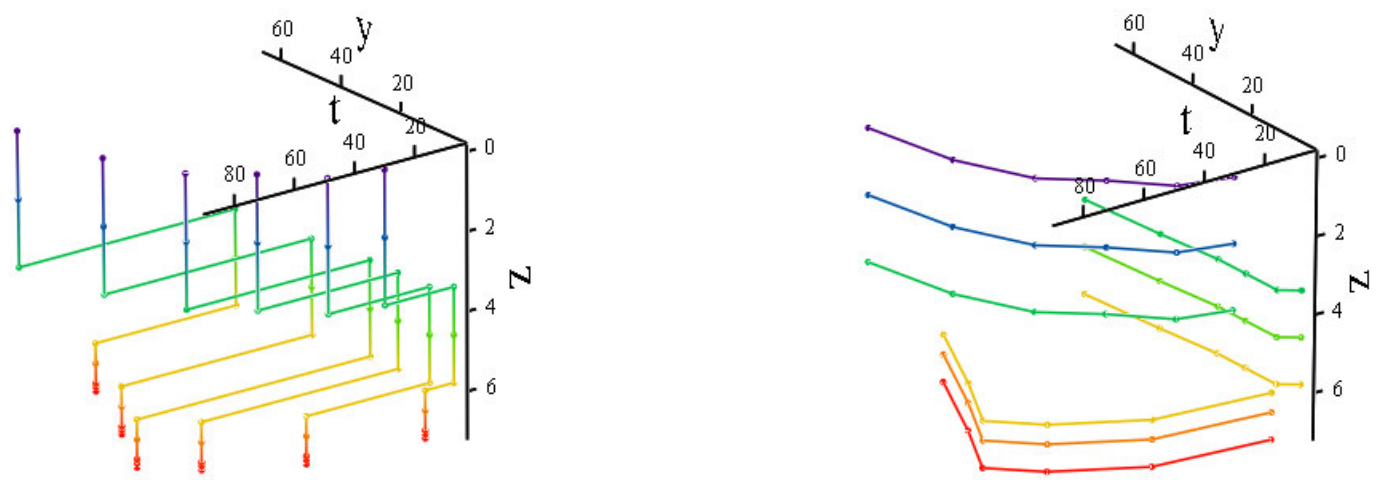

(a)

(b)
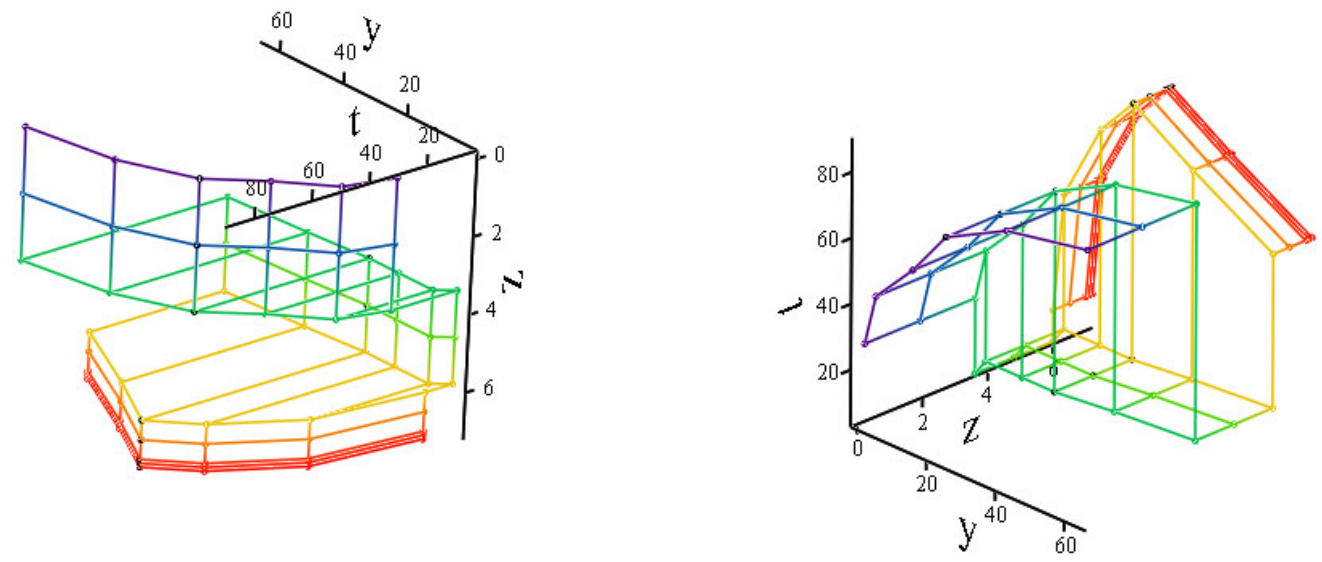

(c)

Figura 52 - Representações tridimensionais $\tau-y-z$ das funções $\tau\left(z, P_{0}\right)$ e $y\left(z, P_{0}\right)$ para a estaca Barrete 1 - campo experimental da USP-ABEF $\left({ }^{*} \tau\right.$ é representado aqui pela letra $\left.\left.t\right) . a\right)$ curvas $t-z$ variando em y; b) curvas t-y variando em z; c) sobreposição dos gráficos a e b; d) gráfico c visto de outro ângulo. 

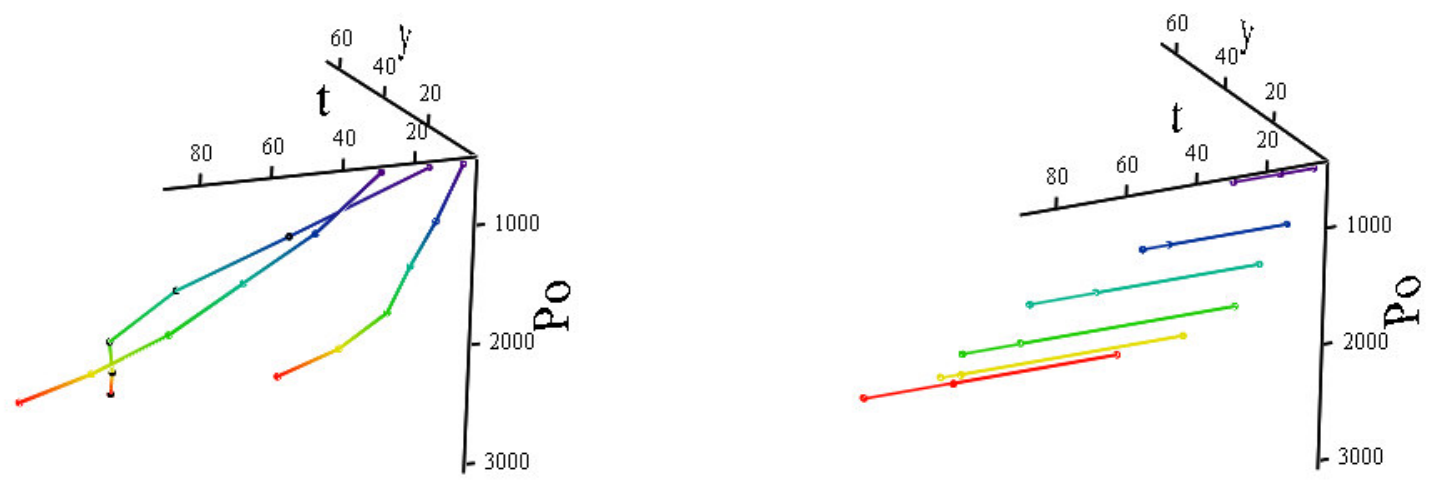

(a)

(b)
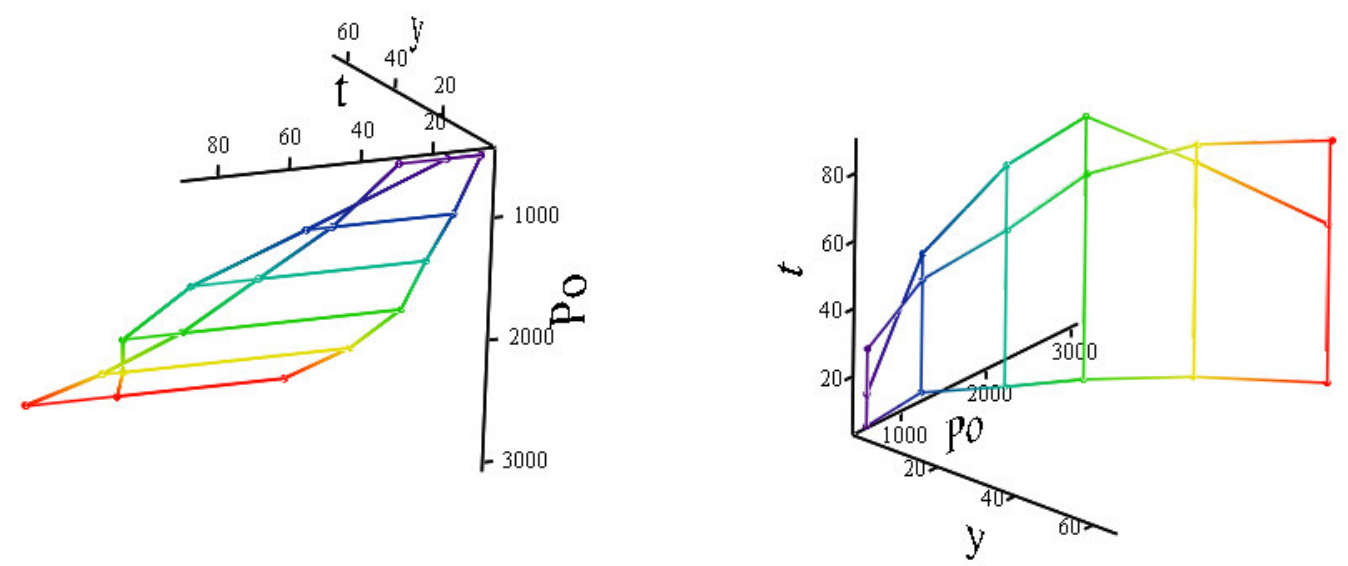

(c)

Figura 53 - Representações tridimensionais $\tau-y-P_{0}$ das funções $\tau\left(z, P_{0}\right)$ e y $\left(z, P_{0}\right)$ para a estaca

Barrete 1 - campo experimental da USP-ABEF. $\tau$ é representado aqui pela letra t.a) curva t-Po variando em y; b) curvas t-y variando em Po; c) sobreposição dos gráficos a e b;d) gráfico c visto de outro ângulo.

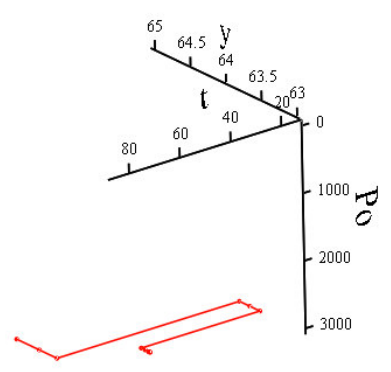

Figura 54 - Detalhe da variação da relação $\tau(z)$ $\mathrm{y}(\mathrm{z})$ para $\mathrm{Po}=3000 \mathrm{kN}$. 

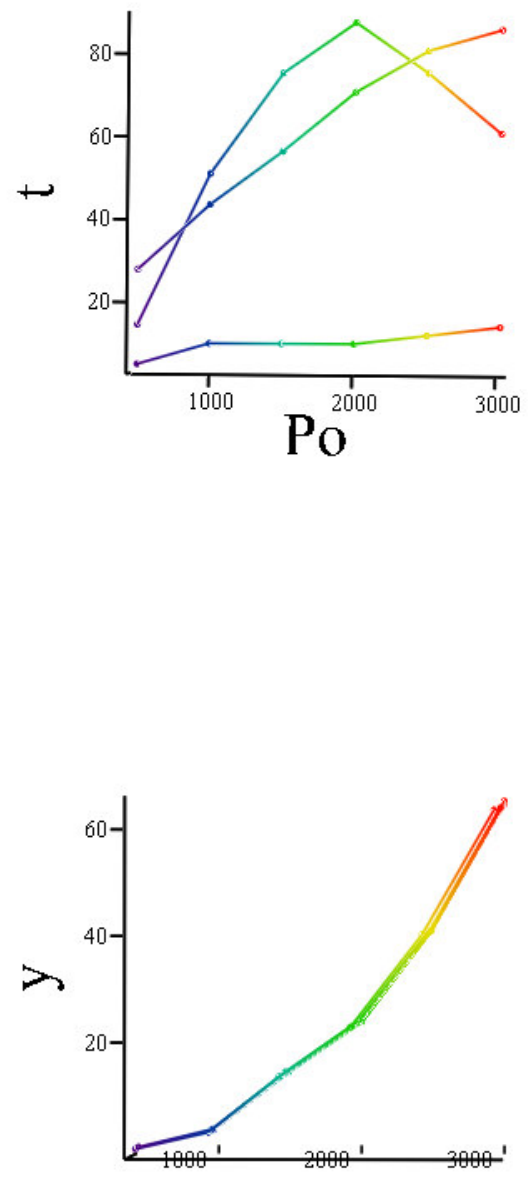

Po

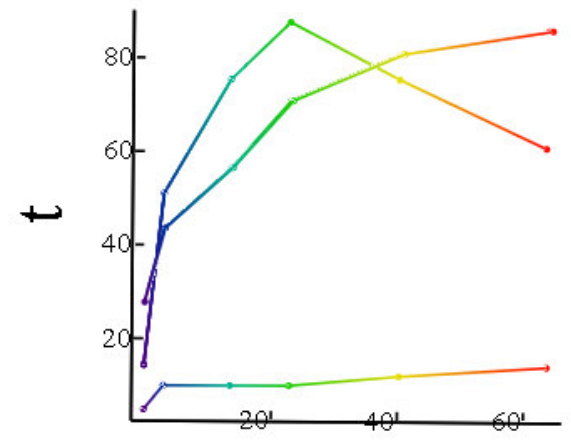

$\mathrm{y}$

(a)

(b)

(c)

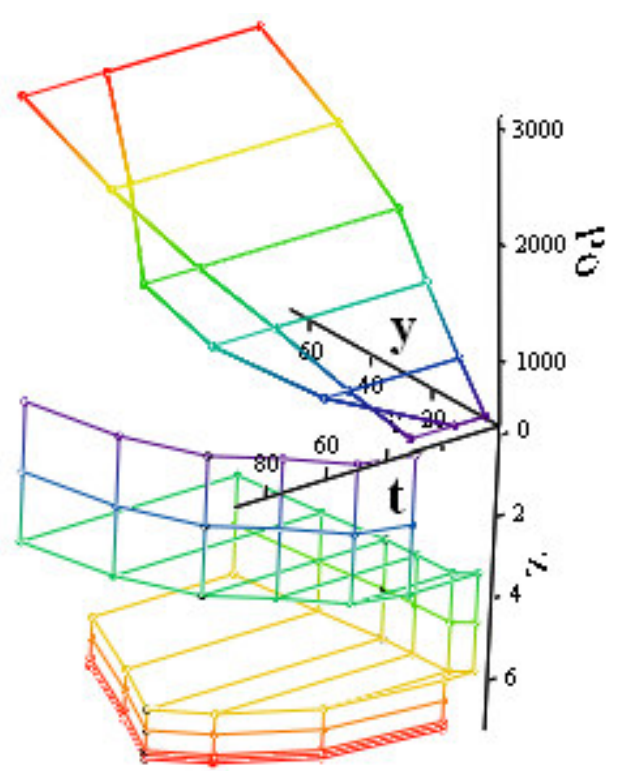

(d)

Figura 55 - Projeções das curvas de transferência de carga nos planos a) $\tau$-Po , b) $\tau$-y e c) y-Po $e$ sobreposição dos espaços $y-\tau-z$ e $\tau-y-P_{0}$.

Considerando esta abordagem, propõe-se identificar um meio de explicitar a função de transferência de carga e o parâmetro $B$ a partir das relações $\tau-P_{0}(a), y-P_{0}(c) d a$ Figura 55.

Em um primeiro momento, a sugestão é estudarem-se os diagramas $\tau-P_{0}$, de forma a se visualizar como varia o atrito unitário com a evolução dos estágios de carga, os quais são a entrada de energia do sistema $\left(P_{0}\right)$ : 


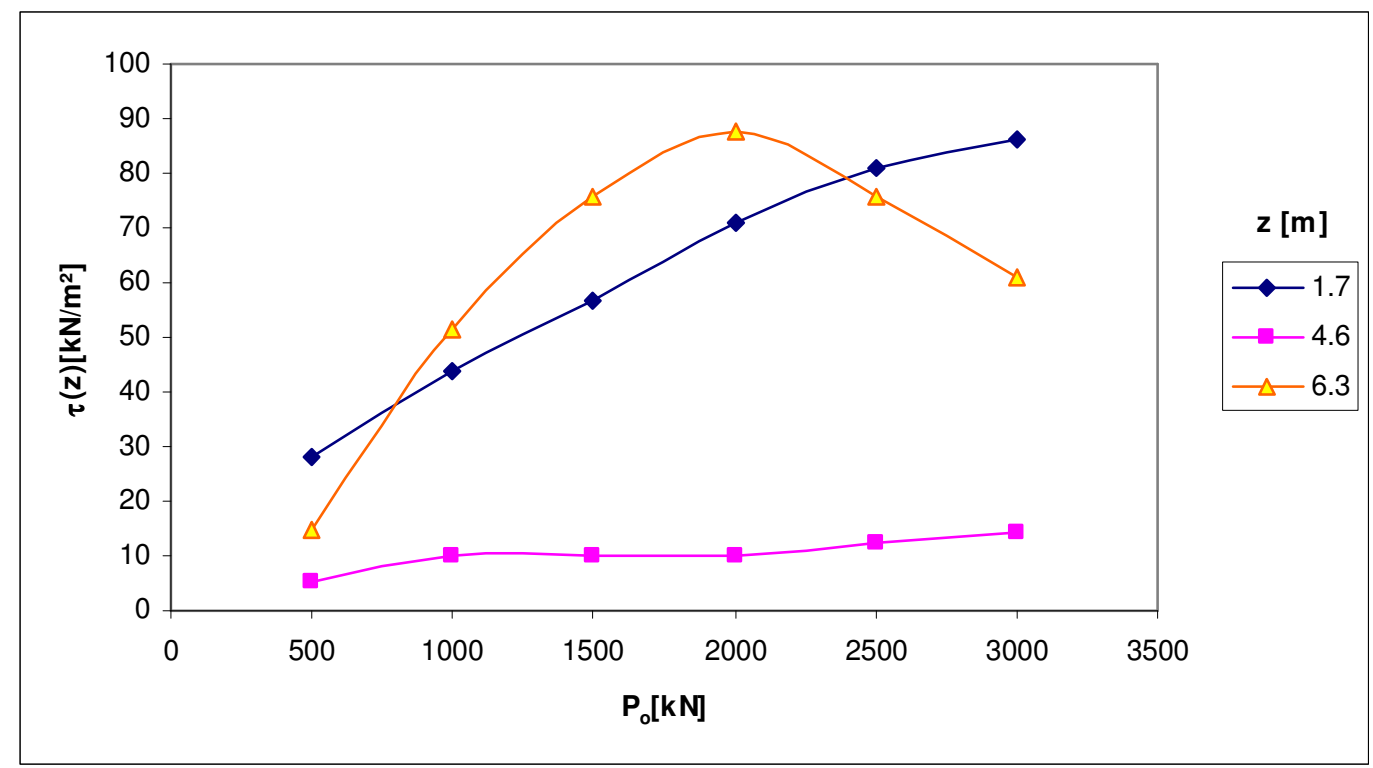

Figura 56 - Projeções das curvas de transferência de carga nos planos $\tau-P_{\circ}$ (similar à Figura 55a).

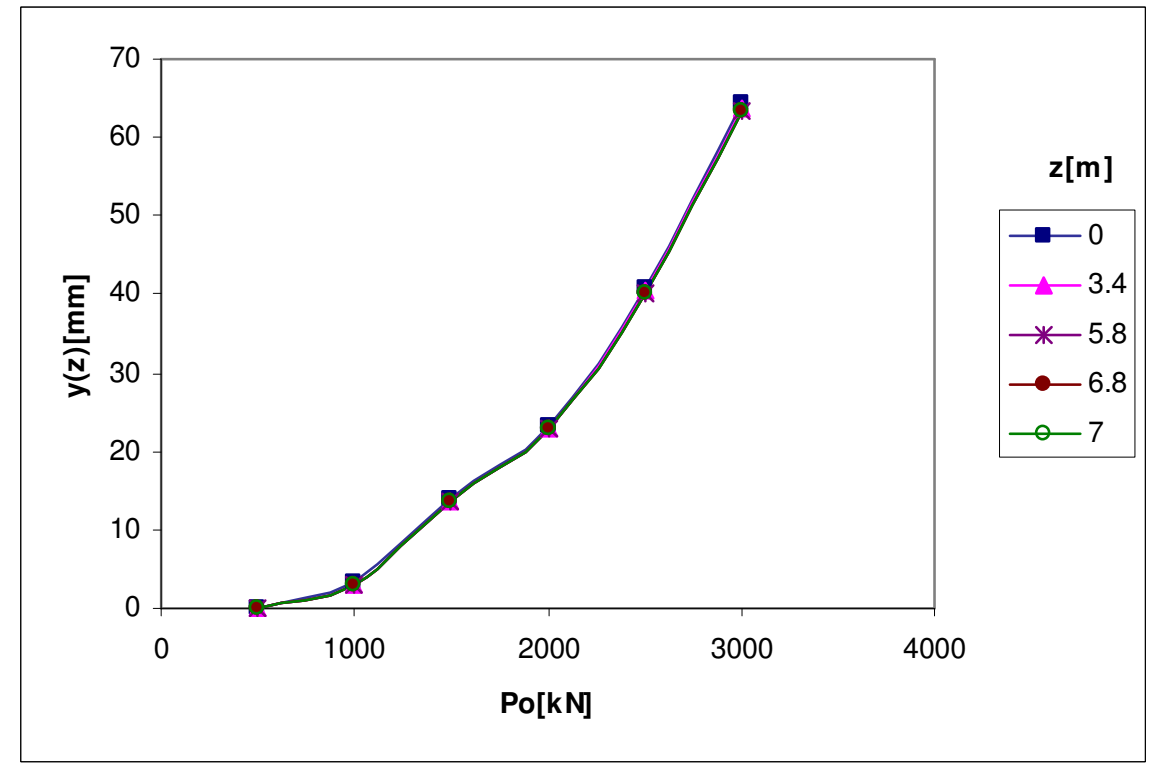

Figura 57 - Projeções das curvas de transferência de carga nos planos y- $P_{\circ}$ (similar à Figura 55c).

Da mesma forma, a relação $y-P_{o}$ deve ser analisada. Ela mostra que há pequena variação dos deslocamentos ao longo da profundidade, devido à elevada rigidez da estaca. Uma ampliação desse gráfico para a carga de 2000 kN, ilustrada na Figura 58, mostra que a distância entre os pontos das curvas representam os encurtamentos sofridos pelas seções da estaca em profundidade. Em cada ponto $P_{0}$, é como se fosse possível ler os deslocamentos da estaca ao longo da profundidade: 


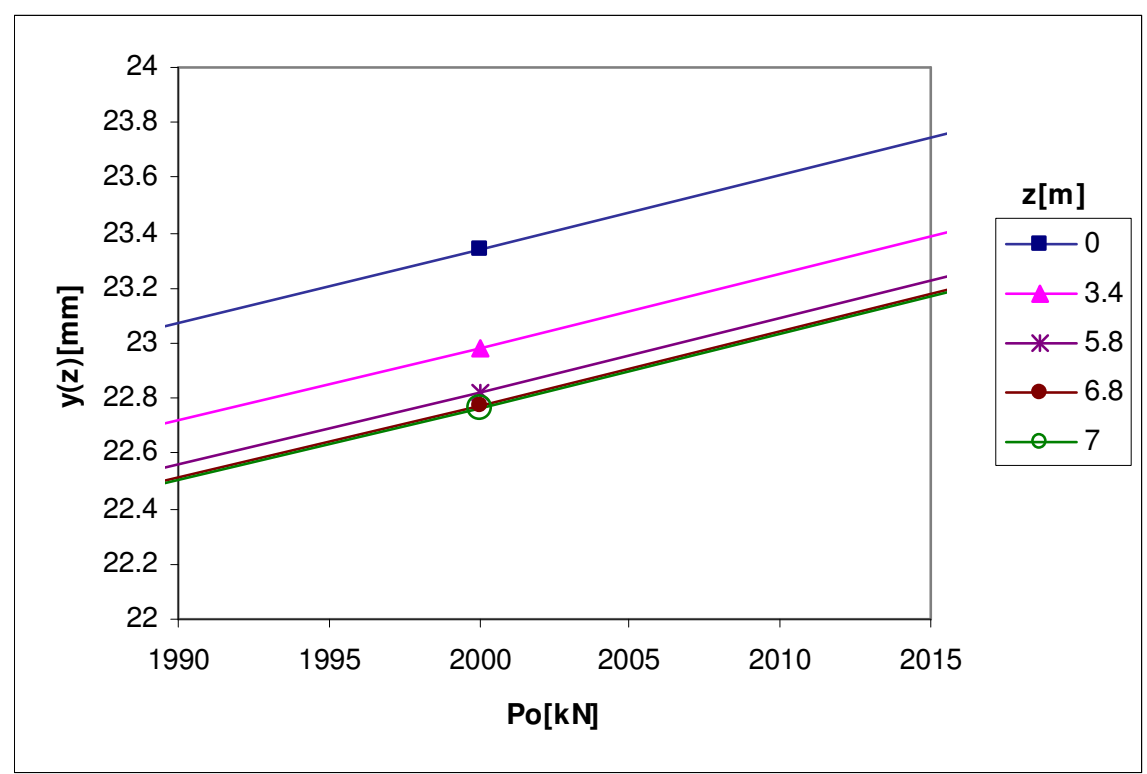

Figura 58 - Projeções das curvas de transferência de carga nos planos y-Po

Nesse caso, observe-se que as curvas y- $\mathrm{P}_{0}$ são similares à própria curva cargarecalque para cada profundidade, e, descontando-se a parcela de carga transferida, permitem a obtenção dos coeficientes $b_{2}$ da Figura 33 em cada ponto do fuste que se queira analisar. Note-se que os recalques foram medidos no topo do bloco, e, portanto, há uma pequena diferença do resultado obtido para $z=0$ (recalque no ponto de imersão da estaca no terreno - Figura 44).

A partir daqui, percebe-se como viável a nova proposta dos ajustes polinomiais como alternativa vantajosa em relação à consideração usual. A adoção de um valor constante para o atrito, no trecho entre os instrumentos, leva a descontinuidades inconvenientes de serem avaliadas, pois exigem que se trabalhe a solução trecho a trecho, gerando uma "curva" para cada profundidade. Por outro lado, os ajustes polinomiais resultam funções contínuas, e o estudo da função matemática da superfície $y-\tau-P_{0}$ pode ser proposto para se obterem, de forma contínua, os valores de transferência de carga, tanto em profundidade quanto em relação ao estágio de carga. Isso permite a determinação do parâmetro B em qualquer ponto do fuste e estágio de carregamento.

Portanto, para agilizar as análises, propõe-se aqui o uso de polinômios para ajuste do atrito lateral, da carga e dos deslocamentos em função da profundidade $z$, de forma a se obterem funções contínuas, salvo haja descontinuidade física evidente no sistema estaca-solo. A escolha de funções polinomiais se deve pela facilidade de derivação e integração e por permitirem bons ajustes (interpolados). 
Para que se possa avançar com esta proposta, analisa-se, a seguir, a funcionalidade desses ajustes polinomiais, para posteriormente avançar na avaliação das relações $\tau-P_{\circ} e$, finalmente, na definição do parâmetro $B$.

\subsection{PROPOSTA DE AJUSTES POLINOMIAIS $\tau(z)$ e y(z) PARA ANÁLISE DOS DADOS DA INSTRUMENTAÇÃO}

Como já exposto, o método usual de admitir o atrito lateral constante nos trechos instrumentados leva a bruscas descontinuidades e à necessidade de se avaliar separadamente cada trecho. Acrescente-se a isso que, em geral, a instrumentação não coincide exatamente com as camadas de solo num perfil muito estratificado, e com isso não é possível definir, com algum refinamento, a reação de camadas individuais.

A fim de se obterem as funções $\tau\left(P_{0}\right)$ e $y\left(P_{0}\right)$ para solucionar matematicamente 0 parâmetro $B$, propõe-se aqui agilizar a análise, ajustando-se inicialmente as funções de transferência de carga a polinômios $\tau(z)$ e $y(z)$, que são funções matemáticas simples de interpretar, derivar e integrar. No Apêndice E, a partir do item E.5, são apresentadas as formas polinomiais propostas e o significado físico de parte dos seus coeficientes.

$\mathrm{Na}$ metodologia de análise empregada ,considerou-se comparar entre si: a) os valores usuais no centro de cada trecho instrumentado; b) os polinômios ajustados aos valores de carga obtidos da instrumentação e aos valores calculados usualmente no centro de cada trecho instrumentado; c) os polinômios de $\tau(z)$, obtidos por derivadas, e os de $\mathrm{y}(\mathrm{z})$, obtidos por integração dos polinômios ajustados $\mathrm{N}(\mathrm{z})$. Propõe-se, assim, demonstrar que, se ajustado um polinômio, sua derivada ou sua integral resultarão valores no centros dos trechos instrumentados muito próximos dos obtidos usualmente, constituindo-se assim um processo rápido de análise dos dados da instrumentação.

Considerando que os extensômetros resultam diretamente os valores de encurtamentos medidos (dy/dz), sugere-se que a primeira função a ser ajustada seja a das cargas $\mathrm{N}(\mathrm{z})$, dada pela expressão (27), aqui reproduzida como (134): 


$$
N(z)=-E \cdot S \cdot \frac{d y(z)}{d z}
$$

No caso da estaca barrete, tomando-se as cargas em profundidade para cada estágio de carregamento, tem-se (Figura 59):

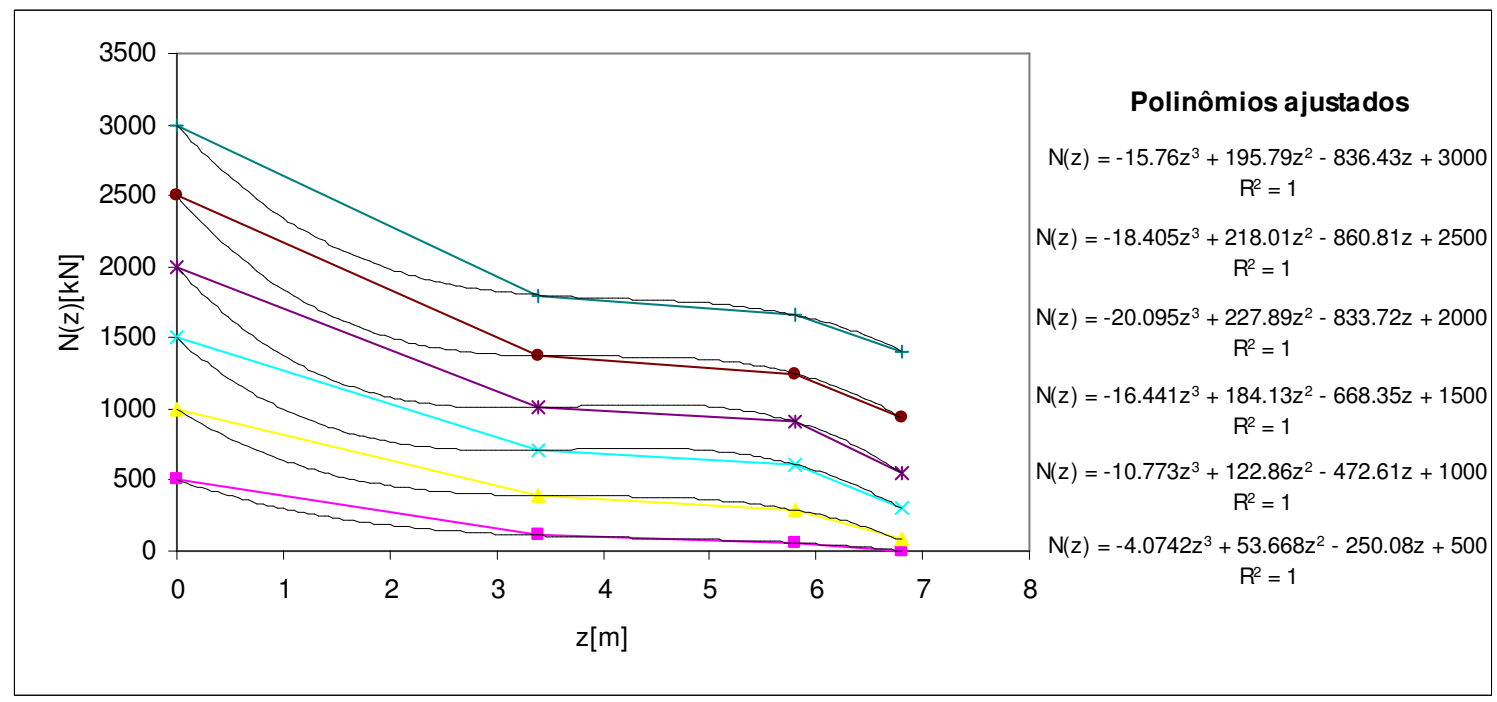

Figura 59 - Polinômios N(z) ajustados aos dados de instrumentação dy/dz.

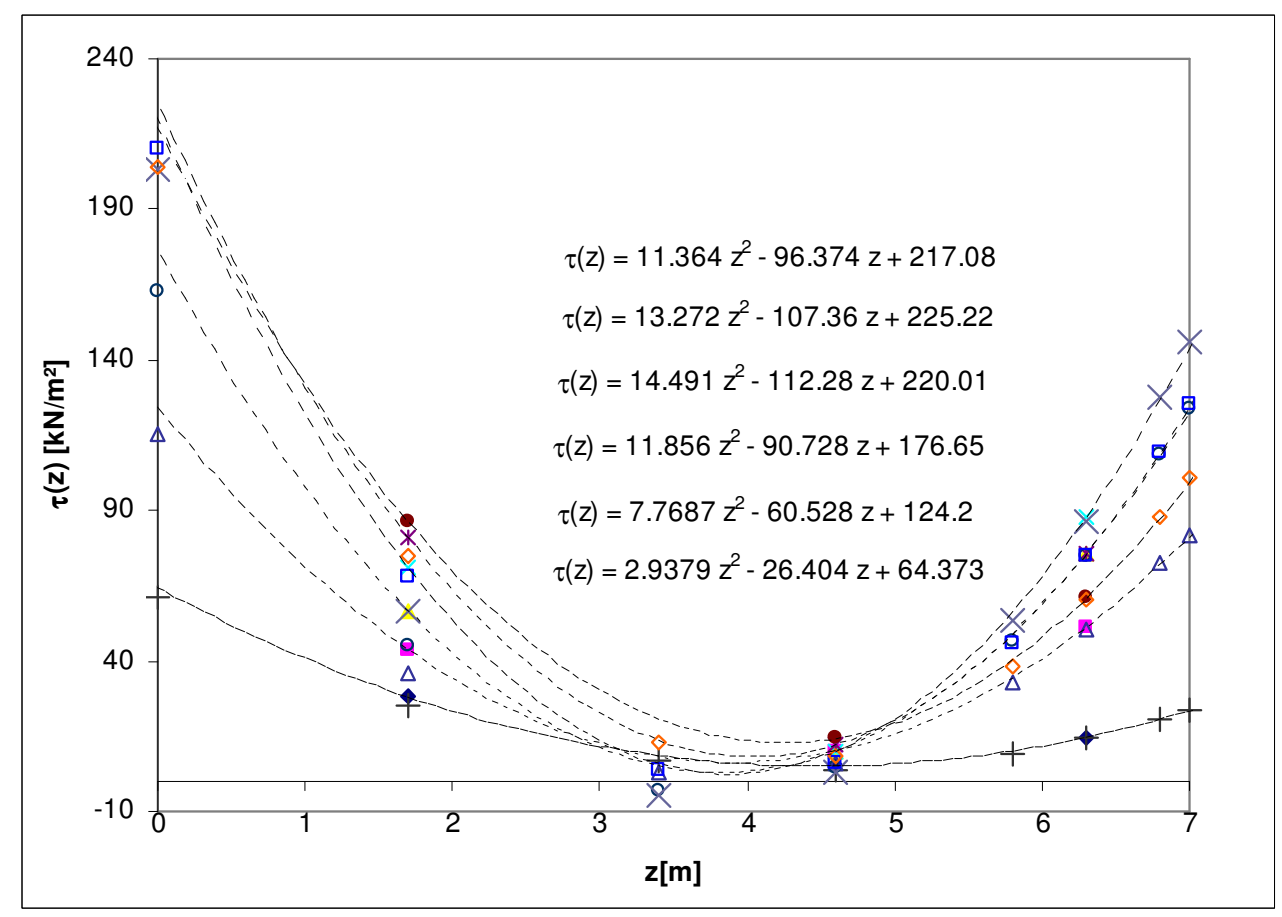

Figura 60 - Polinômios $\tau(z)$ ajustados aos valores usuais de $\tau$ nos pontos médios dos trechos.

Tendo-se os polinômios da carga $\mathrm{N}(\mathrm{z})$, em seguida sugere-se, como metodologia, achar os polinômios do atrito $\tau(z)$ por derivação e dos deslocamentos por integração. A partir destes, obtidos por ajuste, sugere-se compar=a-los em valor com os obtidos 
usualmente nos pontos médios de cada trecho instrumentado. A Tabela 24 mostra os valores dos coeficientes dos polinômios $\tau(z)$ obtidos por derivação dos polinômios da Figura 59, os quais podem ser comparados com os obtidos por ajuste nos pontos médios da Figura 60. Os símbolos na primeira coluna da tabela correspondem aos símbolos da Figura 60 para facilitar a comparação.

Tabela 24 - Coeficientes do polinômios $\tau(z)$ derivados de $N(z)$

\begin{tabular}{cccc}
\hline \multicolumn{4}{c}{$\tau(\mathrm{z})=\mathrm{a}_{2} \cdot \mathrm{z}^{2}+\mathrm{a}_{1} . \mathrm{z}+\mathrm{a}_{0}$} \\
\hline $\mathrm{P}_{\mathrm{o}}[\mathrm{kN}]$ & $\mathrm{a}_{2}$ & $\mathrm{a}_{1}$ & $\mathrm{a}_{0}$ \\
\hline$\diamond 3000$ & 11.5316 & -95.5049 & 204.0065 \\
$\square 2500$ & 13.4669 & -106.3440 & 209.9540 \\
$\times 2000$ & 14.7037 & -111.1680 & 203.3452 \\
$\circ 1500$ & 12.0300 & -89.8213 & 163.0123 \\
$\Delta 1000$ & 7.8830 & -59.9338 & 115.2707 \\
+500 & 2.9811 & -26.1793 & 60.9946 \\
\hline
\end{tabular}

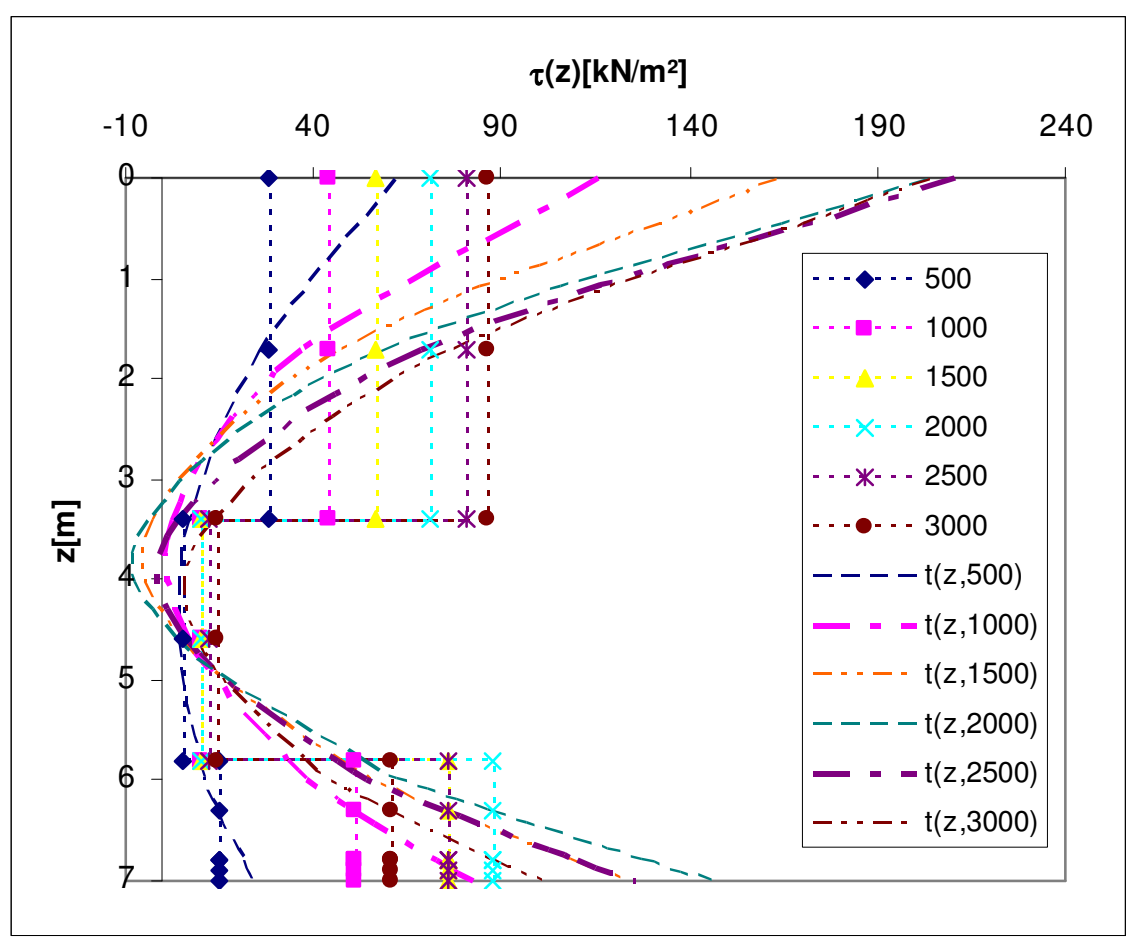

Figura 61 - Comparação entre os polinômios $\tau(z)$ ajustados e o método usual ( $\tau$ constante por camadas).

É interessante observar que, nesse caso, os polinômios derivados nos estágios de carga intermediários de 1500 e $2000 \mathrm{kN}$ indicaram valores de atrito negativos (Figura 61), sendo que os ajustados pelo valor calculado usualmente nos pontos médios não (Figura 60). Obviamente, na prática, esse tipo de circunstância deve ser verificada para interpretar o seu significado, somente devendo-se considerar efetivo esse valor negativo para o caso em que a estaca estiver sujeita a tal efeito. Nesse caso, trata-se necessariamente de aproximação matemática. É conveniente truncar 
valores abaixo de um determinado nível considerado adequado pelo resultado da instrumentação, de modo a evitar funções de transferência de carga ajustadas incompatíveis com a realidade. Note-se, contudo, que no ponto médio entre os instrumentos, aqui tomado como referência, o polinômio oferece bons resultados.

A Figura 61 ilustra como os polinômios $\tau(z)$ derivados de $N(z)$ sugerem a variação do atrito lateral em comparação com os valores constantes adotados no método usual para o ponto médio de cada trecho instrumentado. Percebe-se que no topo e na ponta da estaca os polinômios apresentam valores bem maiores de atrito do que o valor constante admitido usualmente, contudo isso deve ser considerado com ressalvas, pois não há instrumentos de medida nesses dois pontos. Deve-se sempre atentar para o fato de se tomarem aqui os pontos médios dos trechos instrumentados como referência.

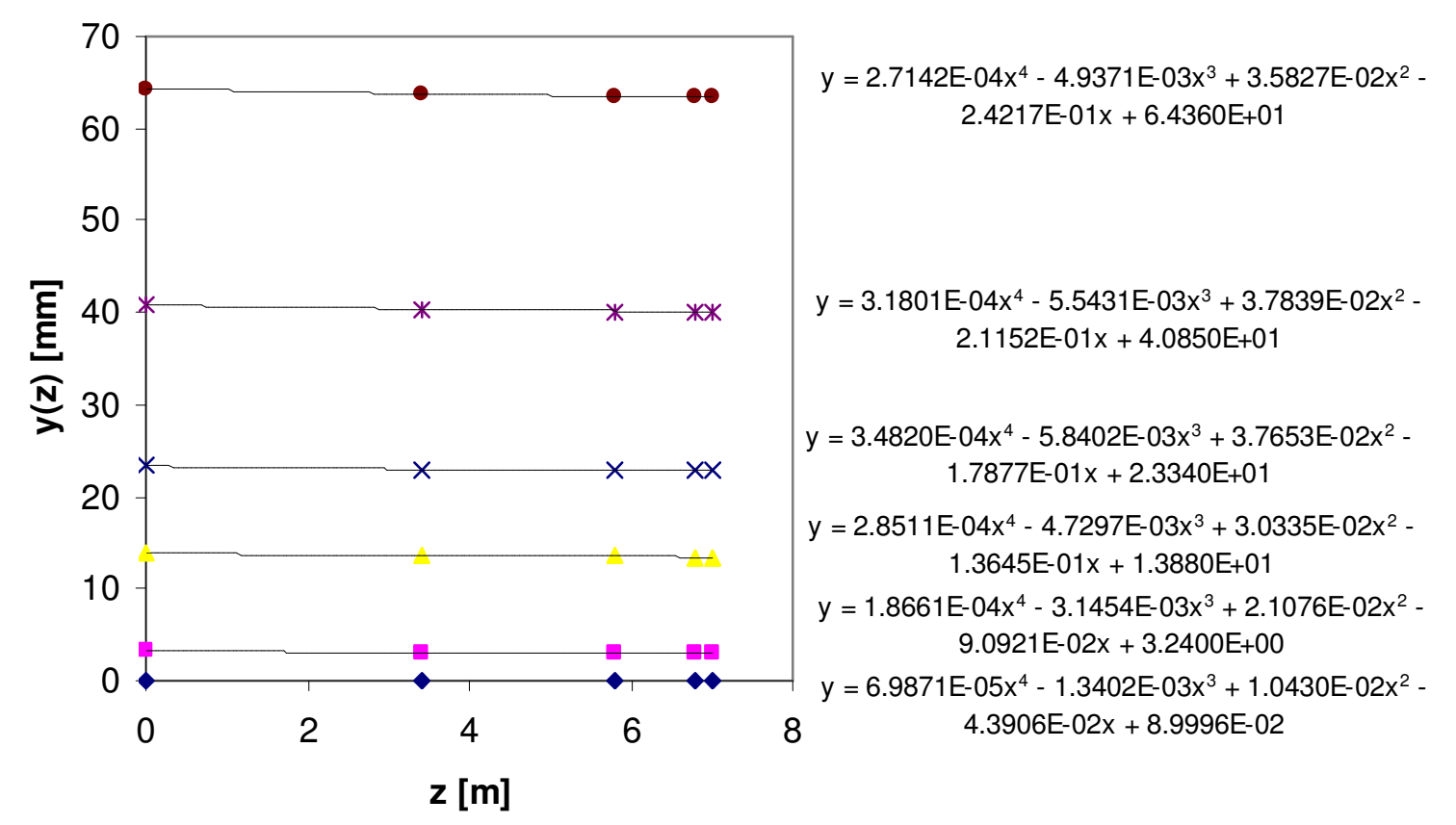

Figura 62 - Valores dos polinômios y(z) ajustados .

Para a comparação dos deslocamentos, os pontos de interesse não são mais os médios de cada trecho, mas sim os próprios pontos instrumentados em que foram medidas as cargas, ou seja, $z=3,4 \mathrm{~m}, 5,8 \mathrm{~m}$ e $6,8 \mathrm{~m}$, pois sua determinação é feita pela integração da carga transferida acima do ponto de medida.

Como o polinômio dos deslocamentos deve ser do quarto grau neste caso, visto que o das cargas resultou de grau três, o ajuste por mínimos quadrados exige mais dois 
pontos, os quais não estão disponíveis na instrumentação pelo método usual. Dessa forma, a metodologia sugerida é a de lançar-se mão dos deslocamentos estimados no ponto de imersão da estaca no terreno $(z=0)$ e da ponta da estaca $(z=7,0 \mathrm{~m})$. Mesmo não sendo valores medidos (apenas estimados), estes são valores de interesse e referência para aplicação das análises de comportamento da estaca e, portanto, usá-los nesse comparativo torna-se apropriado e interessante.

Finalmente, chega-se à relação $\tau(z)-y(z)$, desta vez a partir dos polinômios derivados e integrados de $N(z)$. Como os valores de deslocamentos são muito pequenos, optou-se por apresentar 0 detalhe para a carga $P_{0}=2000 \mathrm{kN}$, a fim de ilustrar comparativamente as duas soluções (Figura 63). Observem-se os valores negativos do método polinomial proposto que podem ser truncados no valor mínimo medido de atrito a partir da profundidade de $1,7 \mathrm{~m}$, como já sugerido.

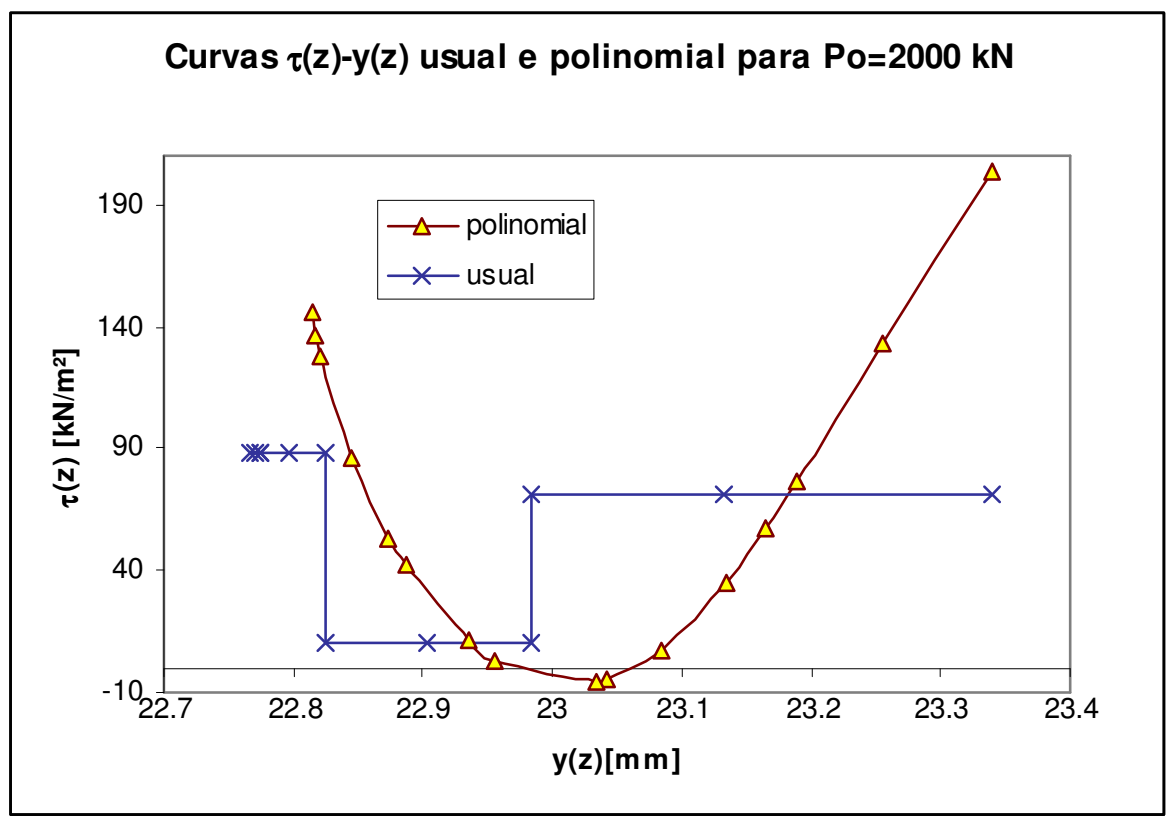

Figura 63 - Ampliação em detalhe da forma da relação $\tau$-y para o estágio de carga de 2000 kN

A Figura 64 apresenta enfim as curvas $\tau\left(P_{0}\right)$ e y $\left(P_{o}\right)$ calculadas, substituindo-se os valores de $z$ nos polinômios $\tau(z)$ da Tabela 24 e y(z) da Figura 62, em comparação com os valores usuais para o ponto médio do trecho instrumentado. A diferença entre os valores se dá pelo fato do cisalhamento calculado, no ponto médio, pelos polinômios, ocorrer num trecho curvo, enquanto pelo método usual, ocorre sobre uma reta vertical (constante), como se vê na Figura 61. 


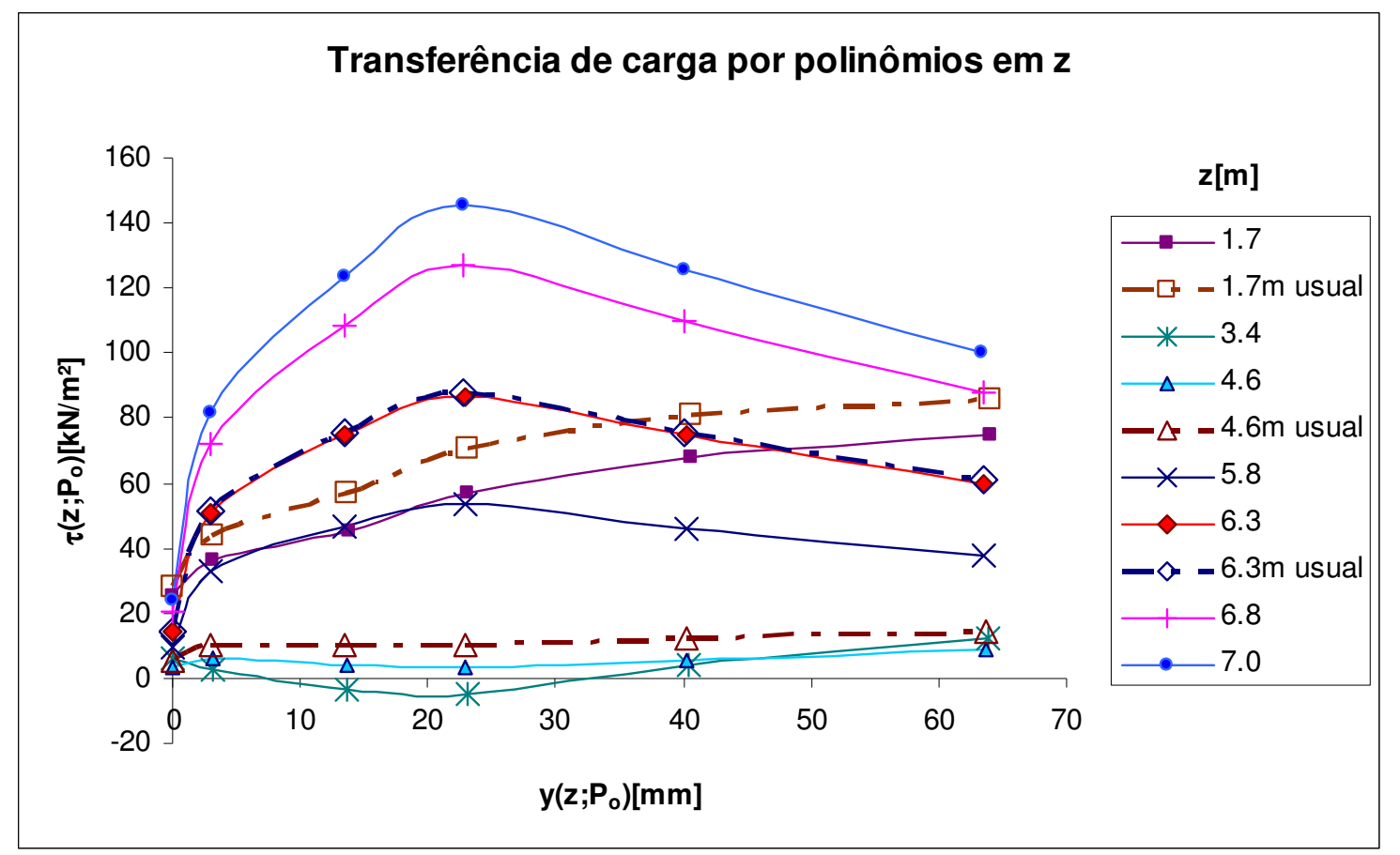

Figura 64 - Comparação entre as curvas de transferência de carga obtidas a partir dos polinômios ajustados e pelo método usual.

As curvas para as profundidades de 6,8 e 7,0m foram extrapoladas a partir dos valores admitidos para o trecho da ponta no método usual. Para a profundidade de $3,4 \mathrm{~m}$ que gerou valores negativos, pode-se sugerir a adoção do mesmo polinômio da profundidade $4,6 \mathrm{~m}$.
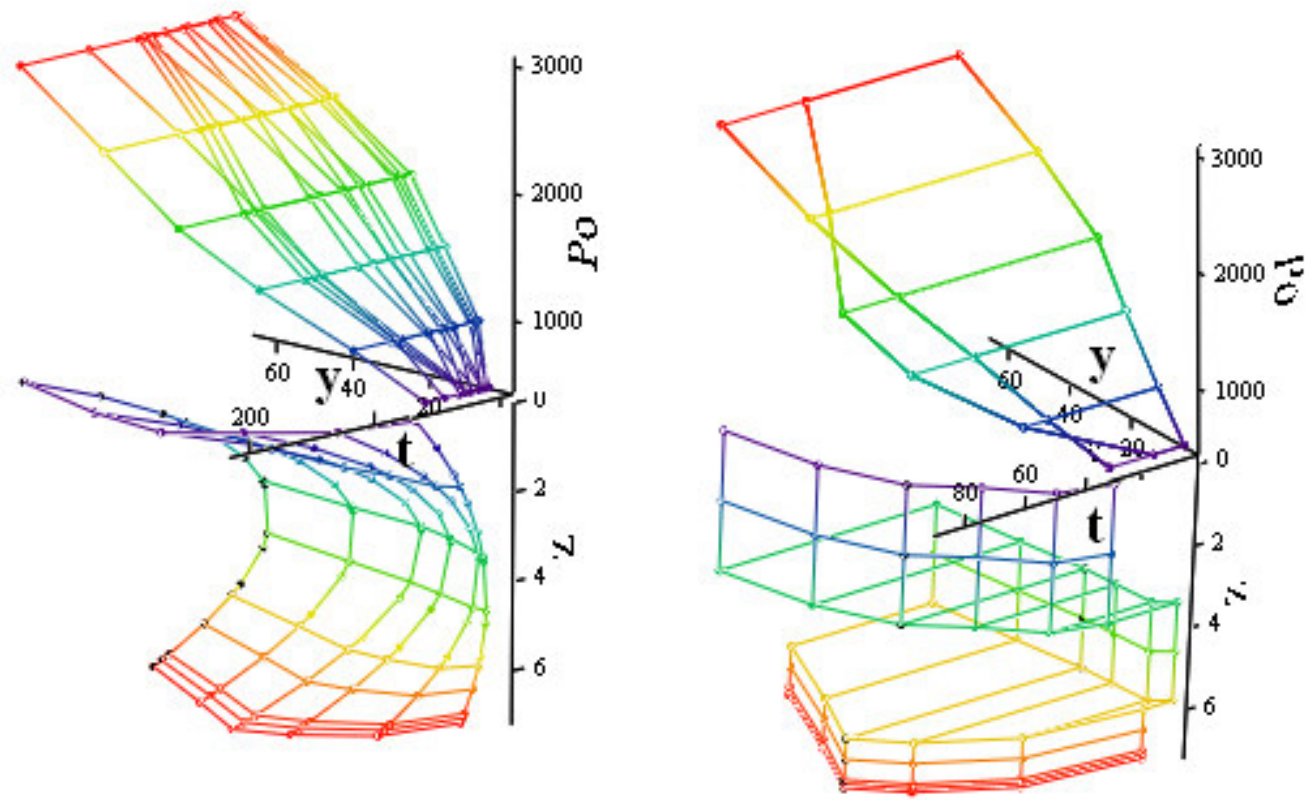

Figura 65 - Superfícies t-y-z e y-t-Po para comparação entre: a) polinômios e b) usual; notar que a escala do eixo $t$ (atrito) é diferente nas duas figuras. 
A Figura 65 apresenta a comparação entre as superfícies ajustadas por polinômios (a) e a superfície ajustada pelo método usual (b). Deve-se atentar para que os valores polinomiais relativos ao atrito nos pontos médios dos trechos considerados correspondam exatamente aos pontos obtidos pelo método usual, visto que os ajustes polinomiais resultaram em coeficiente de determinação $R^{2}$ iguais a 1,0.

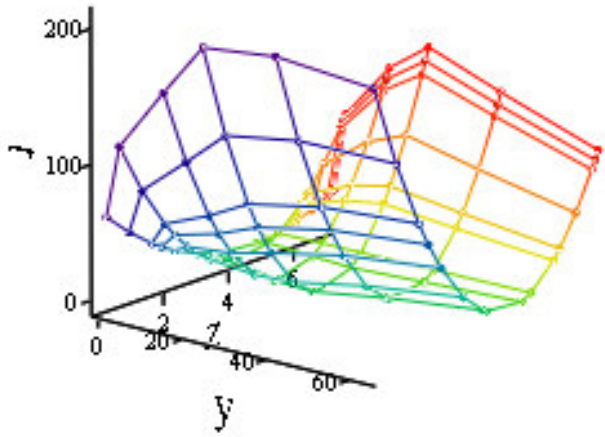

Figura 66 - Superfície t-y-z vista por outro ângulo

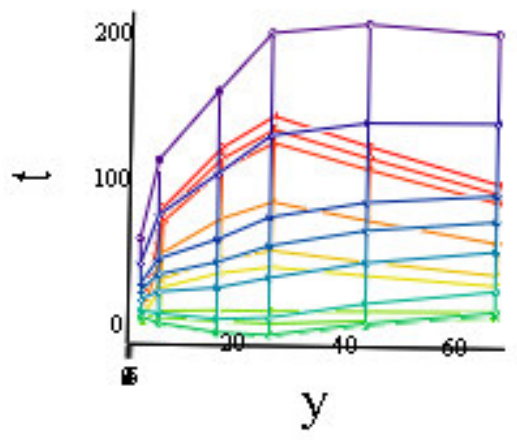

Figura 67 - Projeção t-y das curvas de transferência de carga.

A Figura 66 apresenta a superfície $\tau$-y-z da Figura 65 por outro ângulo e a Figura 67 apresenta a mesma superfície, porém, em projeção no plano $\tau$-y.

Assim, demonstra-se que é possível obter os valores de cisalhamento no centro dos elementos definidos pela instrumentação da estaca a partir das derivadas dos polinômios ajustados da carga ao longo da profundidade, bem como se pode obter seus deslocamentos na mesma profundidade a partir da integração dos mesmos polinômios $\mathrm{N}(\mathrm{z})$. Isso gera funções contínuas que permitem a obtenção dos valores em qualquer profundidade e estágio de carregamento por interpolação, resguardadas as observações de truncamento e extrapolação mencionadas.

Demonstrada a aplicabilidade dos ajustes polinomiais, pode-se propor que se obtenha a função matemática correspondente ao parâmetro B para aplicação na solução da EDO2, a partir das funções matemáticas $\tau\left(P_{\circ}\right)$ e y $\left(P_{0}\right)$ que podem ser definidas como se apresenta a seguir. 


\subsection{PROPOSTA DE AJUSTES POLINOMIAIS $\tau\left(\mathbf{P}_{\mathrm{O}}\right)$ e y($\left(\mathrm{P}_{\mathrm{O}}\right)$ PARA ANÁLISE DA VARIAÇÃO DE $\tau$ E y COM Po}

Considerando que $\tau$ e y dependem de $P_{0}$, como visto anteriormente, pode-se analisar esta variação para se determinar a expressão matemática do parâmetro $B$, ora pesquisado, e concluir-se a formulação proposta para a transferência de carga.

Assim, para se analisar a variação de $\tau$ e y com $P_{0}$, de modo a se obter o diagrama $\tau$-y adequado, fixam-se os valores de $z$ e tomam-se os valores de $\tau$ e y em função de $\mathrm{P}_{\mathrm{o}}$, como apresentado nos gráficos da Figura 49 e da Figura 64, porém, aplicados a diversas profundidades escolhidas para representar trechos de 1/10 do comprimento, bem como os pontos de instrumentação e os pontos médios entre eles.

Os valores assim obtidos de $\tau\left(\mathrm{P}_{0}\right)$ e $\mathrm{y}\left(\mathrm{P}_{\mathrm{o}}\right)$ podem ser vistos respectivamente na Figura 68 e na Figura 69:

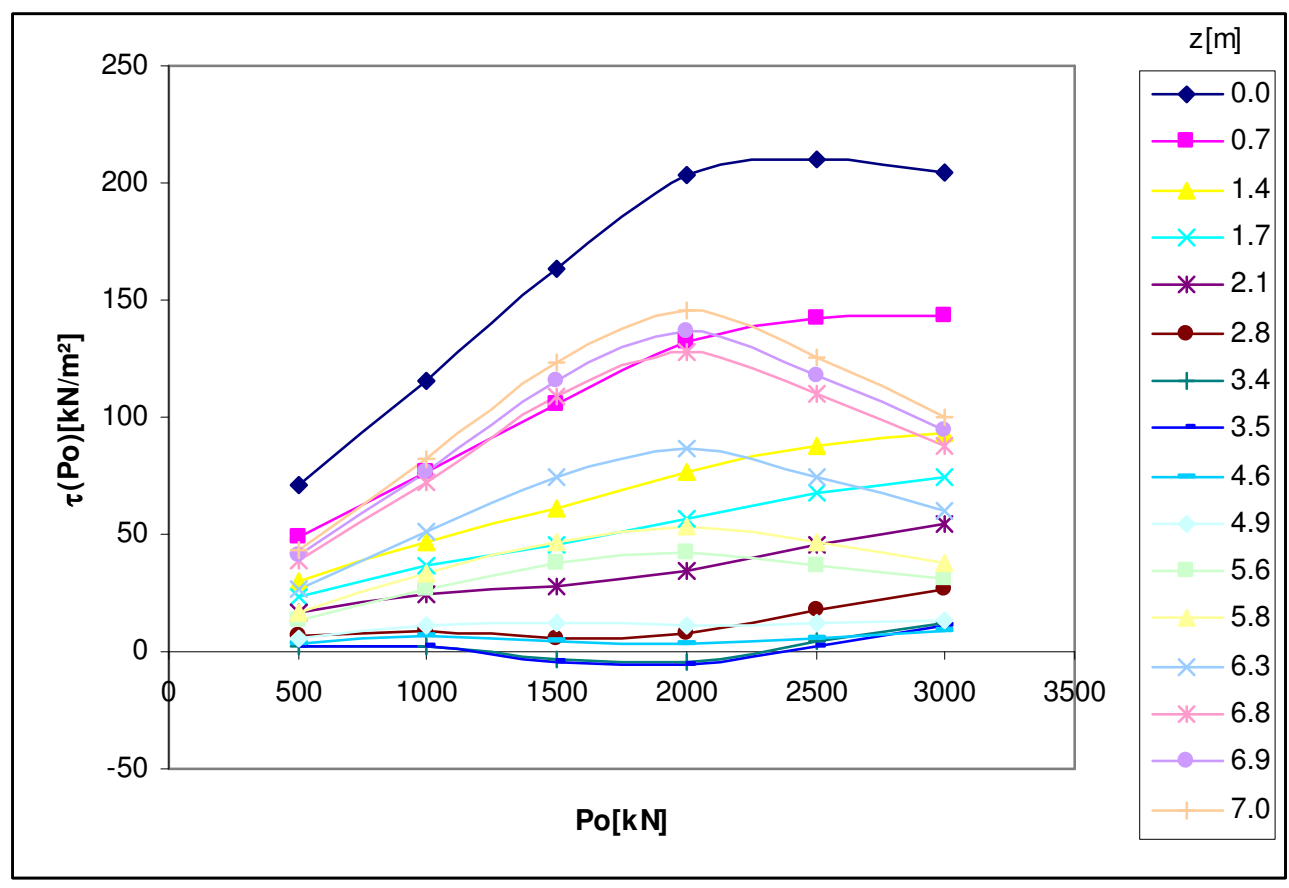

Figura 68 - Curvas $\tau\left(P_{\circ}\right)$ para trechos $\Delta z=L / 10$. 


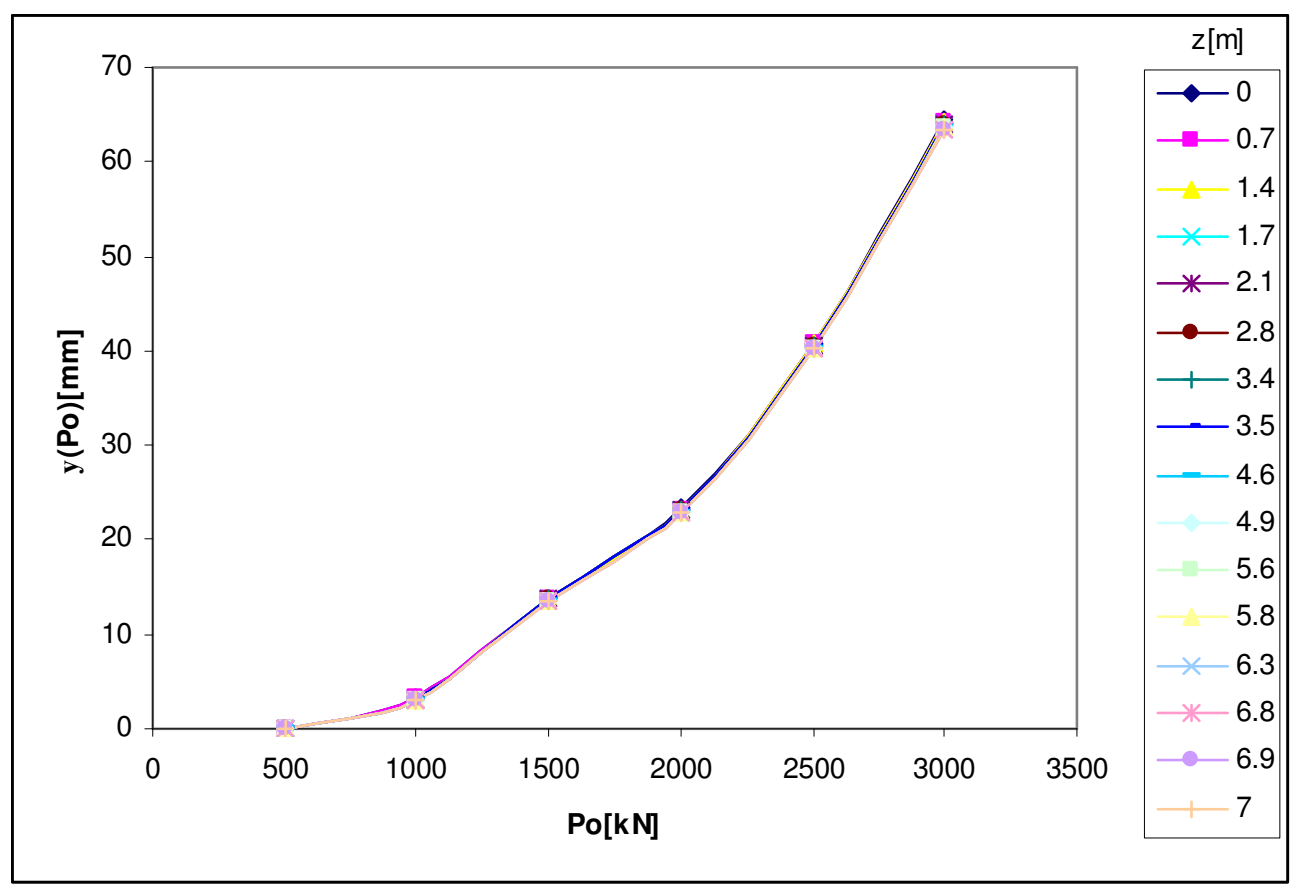

Figura $69-$ Curvas $y\left(P_{0}\right)$ para trechos $\Delta z=L / 10$.

Como já mencionado, verifica-se que, pela quase sobreposição das curvas na Figura 69, a rigidez da estaca é bastante elevada.

A partir disso, foram analisadas as possíveis regressões polinomiais para esses gráficos, resultando em ajustes polinomiais do terceiro e quarto grau. De fato, não há por ora análise física que defina o ajuste como polinomial com tais graus, porém foram escolhidos como uma forma simples de analisar o problema. Outras funções, contudo, podem ser usadas em novas análises.

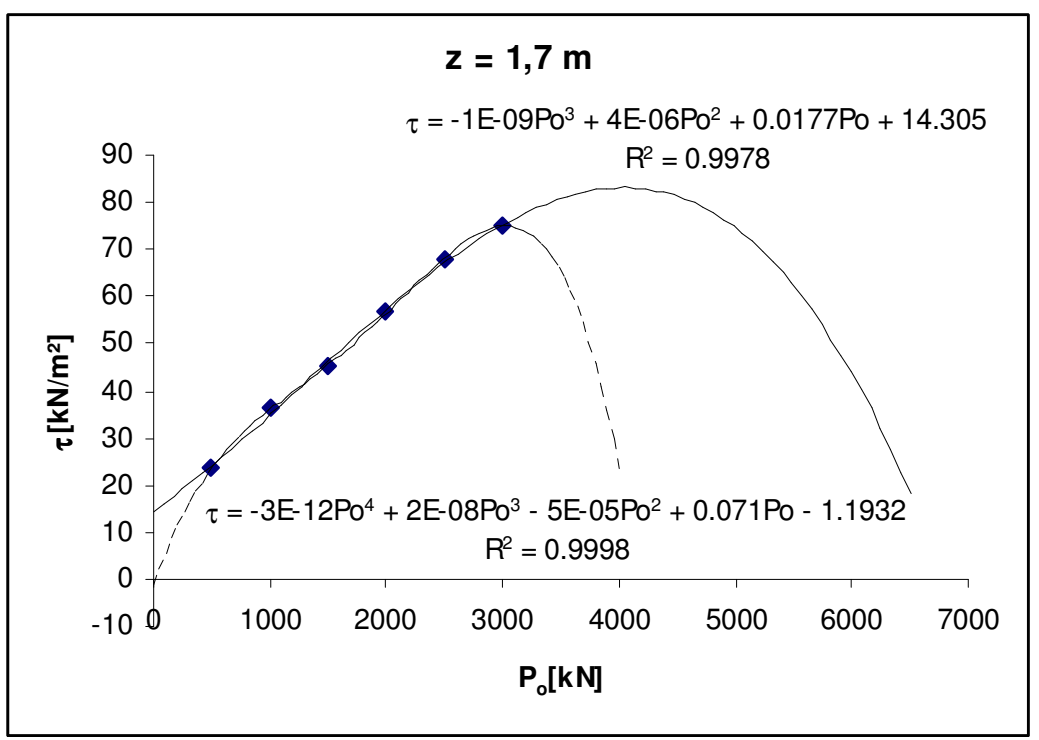

Figura 70 - Polinômio ajustados para a relação $\tau$ - $P_{0}$ a $z=1,7 m$ 
Para os valores de $\tau$ em função de $P_{0}$, exemplifica-se a análise na profundidade de $1,7 \mathrm{~m}$, procedendo-se similarmente para as profundidades correspondentes ao ponto médio dos outros trechos instrumentados, ou seja, 4,6 e 6,3 m de profundidade.

Na profundidade de 1,7m (Figura 70), considerou-se que o polinômio de quarto grau ajustado resultou num decréscimo abrupto, e que o de terceiro grau estaria mais coerente.

Arbitrou-se também que a tendência mais coerente seria a de decréscimo do atrito com o avanço dos estágios de carga, o que resultou em melhores ajustes com o polinômio de terceiro grau, exceto para o trecho de 4,6m, que, como já denotado anteriormente, apresenta-se com comportamento anômalo.

O mesmo se fez para os valores de y em função de $P_{0}$ :

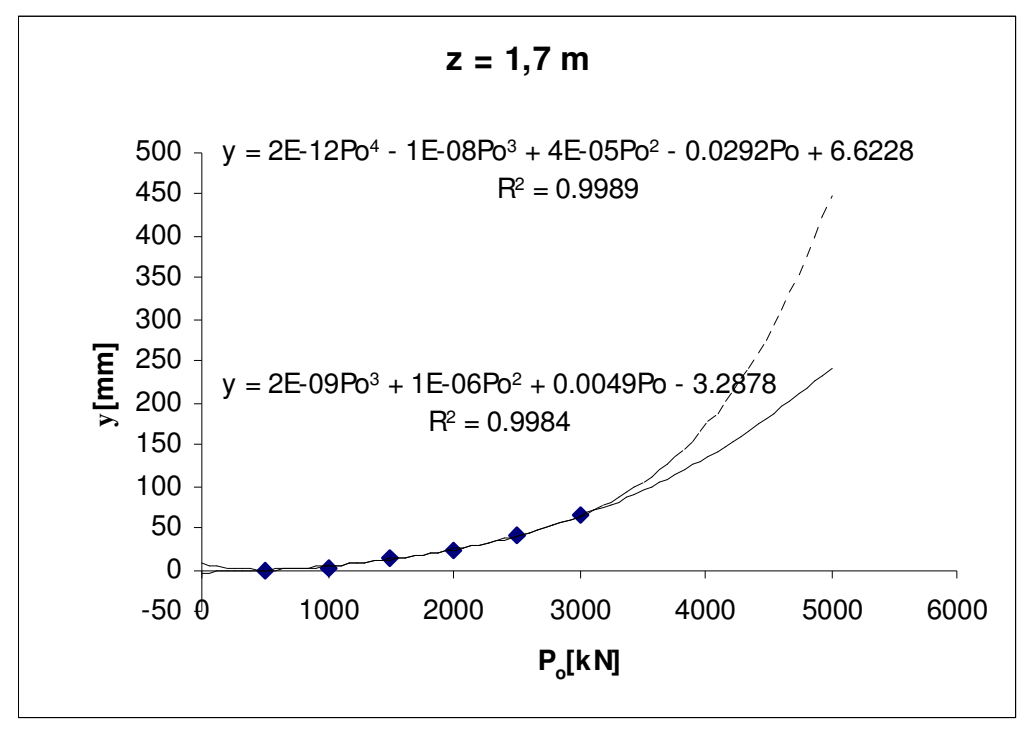

Figura 71 - Polinômio ajustados para a relação y- $P_{0}$ a $z=1,7 m$

Para os ajustes de $y\left(P_{o}\right)$, os polinômios ajustados do quarto grau tiveram seus coeficientes de determinação $R^{2}$ em torno 0,9989 , enquanto os de terceiro grau resultaram em torno de $R^{2} \cong 0,9983$, portanto, um pouco menores. Considerando que os dois valores são muito próximos, optou-se assim pelos polinômios de menor grau, ou seja, os de terceiro, que ficam coerentes com o grau já adotado para o atrito. Isso tem sua coerência também no fato de que, matematicamente, a fim de se obterem diagramas $\tau\left(P_{0}\right)-y\left(P_{0}\right)$ assintóticos num valor maior do que zero, o grau dos polinômios $\tau\left(P_{o}\right)$ e $y\left(P_{o}\right)$ devem ser os mesmos, resultando no comportamento esperado para o parâmetro $B$. 
Tendo-se tais valores, pode-se agora comparar os resultados $\tau$-y usuais com os obtidos pelos polinômios em $z$ para cada par $\left(z ; P_{0}\right)$ e com os polinômios em $P_{0}$, como demonstrado acima. A Figura 72 exemplifica essas comparações para as profundidades dos pontos médios dos trechos instrumentados: 1,7; 4,6 e 6,3m:

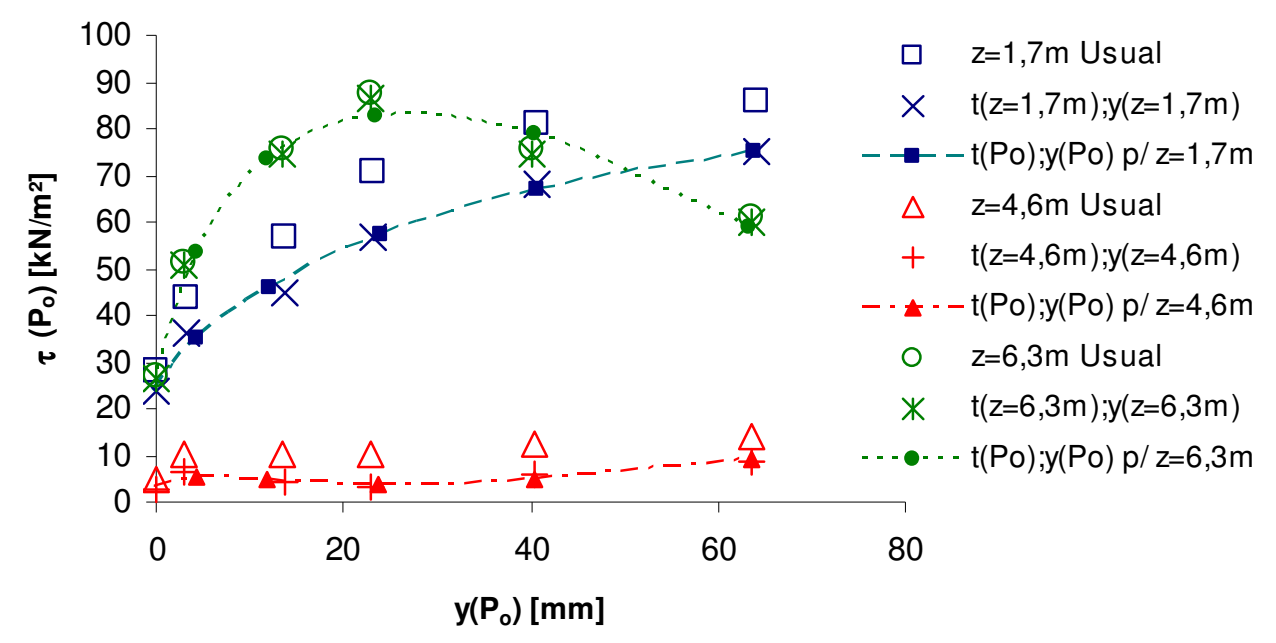

Figura 72 - Comparação das curvas $\tau\left(P_{0}\right)-y\left(P_{o}\right), \tau(z)-y(z)$ e os obtidos usualmente para as profundidades médias dos trechos instrumentados

Os valores obtidos pelos polinômios $\tau\left(\mathrm{P}_{0}\right)$ e $\mathrm{y}\left(\mathrm{P}_{\mathrm{o}}\right)$ diferem pouco dos ajustes obtidos pelos polinômios $\tau(z)$ e y(z) do item 5.3, visto que os ajustes foram bons. Percebe-se assim que $\mathrm{o}$ ajuste proposto em $\mathrm{P}_{\mathrm{o}}$ representa bem os valores de atrito unitário $\mathrm{e}$ recalques obtidos pelos polinômios em z. Em ambos os casos os valores são relativamente menores do que os valores obtidos pelo método "usual", pois o polinômio apresenta certa curvatura nessa região, como já discutido. Deve-se atentar para o fato de que tal diferença reduz-se quando o ponto de análise coincide com o ponto da instrumentação, pois a curva ajustada passa exatamente sobre este.

Voltando à análise matemática, demonstra-se enfim a expressão do parâmetro $B\left(P_{0}\right)=\tau\left(P_{0}\right) / y\left(P_{0}\right)$, considerando-o neste caso como a razão entre dois polinômios do terceiro grau, de forma a indicar uma nova equação possível para ajuste da função de transferência de carga $\tau\left(P_{0}\right)=f\left[y\left(P_{o}\right)\right]$. 


\subsection{DETERMINAÇÃO DA EQUAÇÃO DO PARÂMETRO $B\left(P_{\circ}\right)=\tau\left(P_{\circ}\right) / y\left(P_{\circ}\right)$}

Após se admitir que ambos os polinômios de $\tau\left(\mathrm{P}_{0}\right)$ e y $\left(\mathrm{P}_{\mathrm{o}}\right)$, ajustados com o mesmo grau (terceiro), resulta em boa aproximação da função de transferência de carga, analisa-se agora a função matemática assim gerada, buscando-se elucidar a questão levantada anteriormente no item 5.1.1.

Os polinômios $\tau\left(P_{0}\right)$ e $y\left(P_{0}\right)$ usados nessa análise constam do Apêndice $E$, sendo aqui adotado como exemplo a profundidade de $6,3 \mathrm{~m}$ :

$$
\begin{aligned}
& \tau\left(\mathrm{P}_{\mathrm{o}}\right)=-3,5211 \mathrm{E}-09 \cdot \mathrm{P}_{\mathrm{o}}{ }^{3}-5,6197 \mathrm{E}-06 \cdot \mathrm{P}_{\mathrm{o}}{ }^{2}+7,0841 \mathrm{E}-02 \cdot \mathrm{P}_{\mathrm{o}}-8,1958 \mathrm{E}+00 \\
& \mathrm{y}\left(\mathrm{P}_{\mathrm{o}}\right)=1,4962 \mathrm{E}-09 \cdot \mathrm{P}_{\mathrm{o}}{ }^{3}+1,3433 \mathrm{E}-06 \cdot \mathrm{P}_{\mathrm{o}}{ }^{2}+4,07057 \mathrm{E}-03 \cdot \mathrm{P}_{\mathrm{o}}-3,2260 \mathrm{E}+00
\end{aligned}
$$

Resultando $B\left(P_{o}\right)=\tau\left(P_{o}\right) / y\left(P_{o}\right)$, após simplificações, na função racional do tipo:

$$
\frac{\tau\left(\mathrm{P}_{\mathrm{o}}\right)}{\mathrm{y}\left(\mathrm{P}_{\mathrm{o}}\right)}=-2,35336+\frac{3766,69}{\mathrm{P}_{\mathrm{o}}-547,69}-\frac{5409,80 \cdot \mathrm{P}_{\mathrm{o}}-4,6341 \mathrm{E}+07}{\mathrm{P}_{\mathrm{o}}{ }^{2}+1445,50 \cdot \mathrm{P}_{\mathrm{o}}+3,93678 \mathrm{E}+06}
$$

Procedendo-se ao cálculo, podem-se confrontar os resultados com a divisão dos polinômios $\tau\left(z=6,3 ; P_{0}\right)$ e $y\left(z=6,3 ; P_{0}\right)$ do item 5.6 e com os valores obtidos nos pontos médios dos trechos instrumentados (procedimento usual do item 5.3). Os valores da divisão de $\tau$ por y para cada $P_{0}$ foram também calculados por meio dos polinômios ajustados em função de $z$ para $z=6,3 \mathrm{~m}$. Os resultados estão na Tabela 25 , a partir da qual basta proceder à comparação.

Tabela 25 - Comparação dos valores de $B$ para $z=6,3 m$ pelas três formulações.

\begin{tabular}{cccc}
\hline $\mathrm{z}=6,3 \mathrm{~m}$ & $\tau\left(6,3 ; \mathrm{P}_{\mathrm{o}}\right) / \mathrm{y}\left(6,3 ; \mathrm{P}_{\mathrm{o}}\right)$ & $\tau\left(\mathrm{P}_{\mathrm{o}}\right) / \mathrm{y}\left(\mathrm{P}_{\mathrm{o}}\right)$ & usual \\
\hline $500 \mathrm{kN}$ & 331846.243 & -72.451 & 10168.055 \\
$1000 \mathrm{kN}$ & 16.648 & 12.388 & 17.012 \\
$1500 \mathrm{kN}$ & 5.515 & 6.177 & 5.605 \\
$2000 \mathrm{kN}$ & 3.790 & 3.521 & 3.852 \\
$2500 \mathrm{kN}$ & 1.854 & 1.954 & 1.884 \\
$3000 \mathrm{kN}$ & 0.945 & 0.926 & 0.961 \\
\hline
\end{tabular}

Colocados os valores da Tabela 25 em um diagrama $\mathrm{B}\left(\mathrm{P}_{\mathrm{o}}\right)=f\left(\mathrm{P}_{\mathrm{o}}\right)$, tem-se como resultado um gráfico com aspecto hiperbólico, como mostra a Figura 73 para o caso de $z=6,3 m$ : 


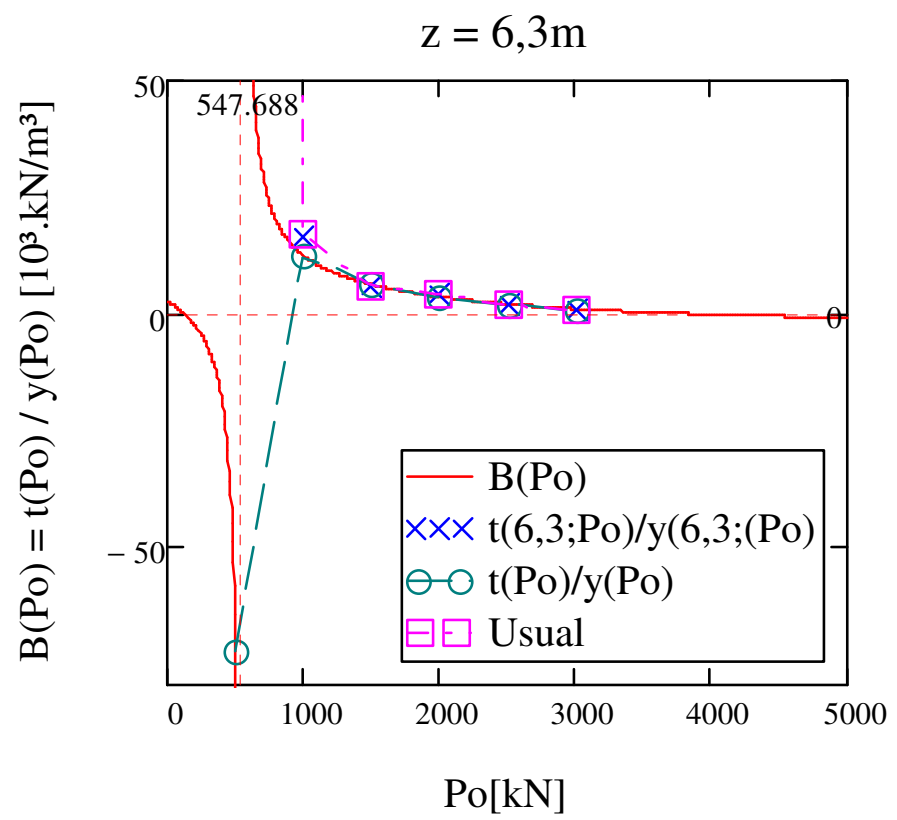

Figura 73 - Gráfico do quociente dos polinômios $\tau\left(P_{0}\right) / y\left(P_{o}\right)$ e comparação com os valores usuais A tendência de $B$ para zero, com o aumento das cargas $P_{0}$, é coerente com 0 aspecto hiperbólico do diagrama $\tau-\mathrm{y}$, no qual a curva tende a uma assíntota em $\mathrm{f}_{\max }$ ou para um valor residual. Pode-se ver que os valores de $B(z=6,3 m$; $\left.P_{0}=500 \mathrm{kN}\right)=10168.10^{3} \mathrm{kN} / \mathrm{m}^{3}$ e $331846 \mathrm{kN} / \mathrm{m}^{3}$ da Tabela 25 não aparecem no gráfico da Figura 73 por questões de escala. Como os valores para $P_{0}=500 \mathrm{kN}$ estão muito perto da raiz do denominador, ou seja, da assíntota da hipérbole $(547,7 \mathrm{kN})$, qualquer pequena variação na carga faz com que se varie muito o valor de $B$, como se observa na primeira linha da Tabela 25.

Tendo em vista o bom ajuste com os valores usuais, pode-se dizer que é perfeitamente possível utilizar a aproximação de $B\left(P_{0}\right)$ pela expressão (137) como sendo função racional de dois polinômios de mesmo grau $\left(\tau\left(P_{0}\right)\right.$ e $\left.y\left(P_{0}\right)\right)$, sobretudo acima de $547,7 \mathrm{kN}$.

Para as demais profundidades o comportamento se repete. Isso demonstra a validade de se admitir a aproximação polinomial por $\mathrm{P}_{\mathrm{o}}$ como aqui proposta. Assim, 0 produto desta função $B\left(P_{0}\right)$ pela função $y\left(P_{0}\right)$ deve resultar na função $\tau\left(P_{0}\right)$, e a solução da EDO2 que rege os deslocamentos da estaca pode ser obtida ao se fixar um valor particular de z (caso geral da equação de derivadas parciais).

Por fim, tendo-se definido a forma da função do parâmetro $B$, basta introduzi-la na solução da EDO2 e obter a solução geral do problema de transferência de carga 
para cada profundidade. Para se tratar o problema como Equação Diferencial de Derivadas Parciais, como na nova formulação matemática proposta, outras etapas matemáticas devem ainda ser desenvolvidas para identificação da função que descreve a superfície $\mathrm{P}_{\mathrm{o}}-\mathrm{z}-\mathrm{y}-\tau$ de solução da transferência de carga.

É importante pontuar que a nova proposta de interpretação dos ensaios instrumentados com os polinômios de interpolação permite uma forma rápida de se obterem as funções de transferência de carga do sistema em profundidade.

\subsection{APLICAÇÃO DA NOVA ABORDAGEM E DOS AJUSTES POLINOMIAIS}

Exime-se aqui de se apresentar a aplicação detalhada desta proposta, remetendo-se para tanto ao exemplo do item 6.3.2. Contudo tecem-se comentários de um roteiro que, junto ao exemplo desenvolvido, permitirão elucidar eventuais pontos não esclarecidos ao longo desta demonstração.

Primeiramente, para se discretizar a estaca em maior quantidade de elementos do que os apresentados na Figura 33, deve-se ter disponíveis as curvas carga-recalque $\left(\mathrm{P}_{\mathrm{o}}-\mathrm{y}\right)$ das profundidades $\mathrm{z}$ relativas às interfaces das camadas de solo (ver Figura 57). Como os dados de instrumentação não correspondem exatamente a essas profundidades, os ajustes polinomiais, por serem funções contínuas, permitem por interpolação que se obtenham os valores correspondentes (como feito para obtenção da Figura 69). Com isso, têm-se as curvas $\left(P_{0}-y\right)$ em praticamente qualquer profundidade e pode-se aproximar seu trecho inicial a uma reta para se obter os valores dos coeficientes $b_{2(i)}$ em cada interface de camada.

Alternativamente, com os polinômios também se pode obter as tensões de atrito ou cisalhamento $(\tau)$ e os deslocamentos $(y)$ para as profundidades $(z)$ do ponto médio da espessura de cada camada, construindo-se diretamente as curvas de transferência de carga $\tau\left(P_{o}\right)-y\left(P_{o}\right)$ (Figura 72 ). Com estas curvas pode-se aplicar as simplificações como sugeridas pelos diversos autores no item 5.1.1 para obteremse, por exemplo, os valores de $f_{\max }$ e $y_{1}$ (Figura 37) das Leis de Cambefort modificadas.

Tendo-se 0 valor de $f_{\max }$ em cada camada, pode-se proceder a correção dos coeficientes empíricos dos métodos semiempíricos de cada uma, o que culmina na 
proposta da Metodologia Semiempírica Unificada (MSU), sem, contudo, encerraremse outras aplicações. Pode-se, como discutido, avançar e determinar a equação polinomial para o parâmetro B em função dos estágios de carga nas profundidades de interesse (ver Figura 73).

Tendo-se tais informações para cada camada, a caracterização do problema fica completa, permitindo-se analisar matematicamente toda a transferência de carga em qualquer profundidade e estágio de carregamento, bem como aplicar a iteração proposta no item 4.8, considerando-se como ponta a base do elemento de estaca correspondente à camada e o mesmo para o topo.

Finalizando, apenas para ilustrar uma das interpretações possíveis que a proposta deste capítulo permite quando aplicada à MSU, no exemplo da estaca Barrete, a análise da Figura 57 e de Figura 58 demonstra que dada a rigidez elevada da estaca, os valores de $\mathrm{y}(\mathrm{z})$ (e portanto de $b_{2(\mathrm{i})}$ ) em profundidade são muito próximos, mesmo na região em que a transferência de carga ao solo foi menor (nível B da instrumentação). Isto indica que para estacas do tipo rígida, a consideração de um valor único de coeficiente característico médio de resistência por atrito lateral $\left(\mathrm{K}_{\mathrm{Lg}}\right.$ do método Expedito de teste, por exemplo) pode ser suficiente para definir o problema de deslocamento da estaca ao longo da profundidade, sem que as camadas de solo tenham grande influência isoladamente. Já para estacas compressívei,s pode-se sugerir que o modelo de somatória das camadas (alguns modelos do método Mediado de teste) permitiria uma melhor definição do problema. Com isso, pode-se atribuir uma espécie de critério para escolha do modelo de método semiempírico a ser adotado para a estaca analisada.

Vê-se, portanto, que a proposta do presente capítulo permite que se explore o ensaio de prova de carga instrumentado de forma mais interessante do que apenas atribuindo-se valores constantes de atrito aos trechos delimitados pelas posições dos instrumentos.

Por outro lado, no Capítulo 6, a proposição da Metodologia Semiempírica Unificada se faz com base em ensaios não instrumentados (que são os mais comuns), com aplicação do conceito de Hierarquias dos Solos para se estimar a contribuição de cada camada de solo. Embora não se tenha a precisão do ensaio instrumentado, esta proposta permite também que se corrijam os resultados para cada camada, como será visto adiante. 


\section{PROPOSIÇÃO DA METODOLOGIA SEMIEMPÍRICA UNIFICADA PARA CORREÇÃO DOS COEFICIENTES EMPÍRICOS}

Enfim, após transcorridas todas as análises anteriores sobre cada etapa da metodologia, com suas respectivas considerações conceituais, pode-se enfim propôla de maneira completa, culminado com a correção dos coeficientes empíricos dos métodos.

Para um melhor entendimento, a proposição será dividida em suas etapas com respectivo detalhamento e aplicação a um exemplo completo.

A estaca de exemplo é a G202, tipo raiz, cujas características são aqui reproduzidas: $\mathrm{D}=250 \mathrm{~mm} ; \mathrm{L}=20,92 \mathrm{~m} ; \mathrm{Kr}=63 \mathrm{kN} / \mathrm{mm}$, solo do Guarujá (litoral - SP). A sondagem será apresentada oportunamente, dentro do desenvolvimento da proposição da MSU.

Inicia-se, portanto, a proposição da Metodologia Semiempírica Unificada

\subsection{PRIMEIRA ETAPA: PREVISÃO (ESTIMATIVA) DA CAPACIDADE DE CARGA}

Nesta etapa, toma-se a sondagem de referência para a estaca a ser testada e aplicam-se os métodos semiempíricos de interesse. Como já mencionado, para evitar a aplicação repetitiva a cada método, aqui se propuseram dois métodos, no item 2.11, o Mediado e Expedito, cujas características permitem exemplificar a gama de métodos analisados. Os valores dos coeficientes empíricos desses métodos foram estabelecidos pelas médias dos valores dos métodos analisados, apresentados no item 2.6, e constam das tabelas dos sub-itens de 2.11. É importante verificar que o entendimento da aplicação da MSU a esses métodos permite total compreensão da aplicação a qualquer outro, sendo perfeitamente válidas todas as indicações aqui apresentadas.

Como o interesse para aplicação da metodologia é a correção dos coeficientes de tipo de solo, tomam-se os valores de $\Delta \mathrm{L}$ referentes a cada camada, somando-se os trechos do fuste que se encontram atravessando o mesmo tipo de solo, ainda que 
sejam camadas alternadas. Para cada camada distinta de solo, aplicam-se os coeficientes da Tabela 10, Tabela 11 e Tabela 12. Sugere-se que o coeficiente parcial $k_{\mathrm{tD}}$ seja calculado apenas para os métodos que o utilizam, ou se existirem vários diâmetros envolvidos na pesquisa.

Da aplicação desses métodos, obtêm-se as cargas de ruptura estimadas pelo método Mediado: $P_{R}, P_{R 3 D}, P_{R 8 D}, P_{R N}, P_{R N 3 D}, P_{R N 8 D}$, e mais uma pelo Expedito:

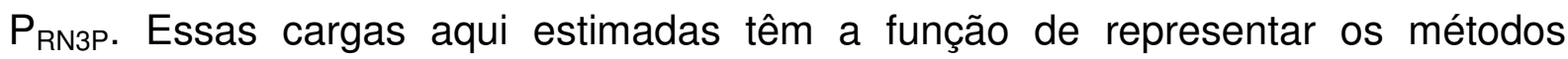
semiempíricos pesquisados e suas diferentes considerações de embutimento da ponta e da somatória ou média das camadas, conforme a Tabela 6. Quando se aplica a MSU a um método específico, obtém-se obviamente a sua estimativa com suas próprias considerações para a ponta e o atrito. Por outro lado, a proposta de se variar a consideração de embutimento e de atrito permite avaliar qual delas melhor corresponde ao solo local, como exemplificado no item 2.8. Não se trataria, portanto de se modificar o método em estudo, apenas da verificação de sua adequação com a consideração de outros tipos de embutimento para o solo do local em estudo.

Assim, demonstra-se o exemplo de aplicação à estaca raiz G202 (AMANN, 2000)

\subsubsection{Exemplo de aplicação da previsão}

A Figura 74 apresenta a sondagem referente à estaca G202, relativamente estratificada em termos de tipos de solo, com camada alternadas, sendo portanto um exemplo bastante ilustrativo. O valor de SPT considerado no trecho em questão está acima da cota da base da camada indicada na tabela de dados da figura.

Tabela 26 - Resumo da sondagem da estaca G202 para o fuste e para a ponta

\begin{tabular}{cccccc}
\hline Camada no. & Solo & $\begin{array}{c}\mathrm{N}_{\mathrm{SPT}} \\
\text { médio }(\mathrm{F})\end{array}$ & $\Delta \mathrm{L} / \mathrm{L}$ & $\Delta \mathrm{L} / \mathrm{L}(3 \mathrm{D})$ & $\Delta \mathrm{L} / \mathrm{L}(8 \mathrm{D})$ \\
\hline 1 & Argila silto arenosa & 3 & 0,043 & 0,045 & 0,048 \\
2 & Areia siltosa & 7,96 & 0,7127 & 0,707 & 0,688 \\
3 & Argila siltosa & 3,4 & 0,239 & 0,248 & 0,264 \\
4 & Silte arenoso & 15 & 0,006 & - & - \\
\hline Embutimento & Solo & $\mathrm{N}_{\text {SPT }}(\mathrm{P})$ & $\mathrm{N}_{\text {med }}(\mathrm{P})$ & $\mathrm{N}_{\text {médio }}$ (Fuste) $=5,9$ \\
8D & Areia siltosa & 3 & 23,3 & & \\
3D & Areia siltosa & 13 & 26 & & \\
Ponta & Silte arenoso & 15 & 15 & & \\
3D & Silte arenoso & 50 & - & & \\
\hline
\end{tabular}


Pode-se assim apresentar o resumo da sondagem na Tabela 26. É importante ressaltar que para cada condição de embutimento os valores de $\Delta \mathrm{L} / \mathrm{L}$ mudam, pois o trecho sujeito a atrito muda.

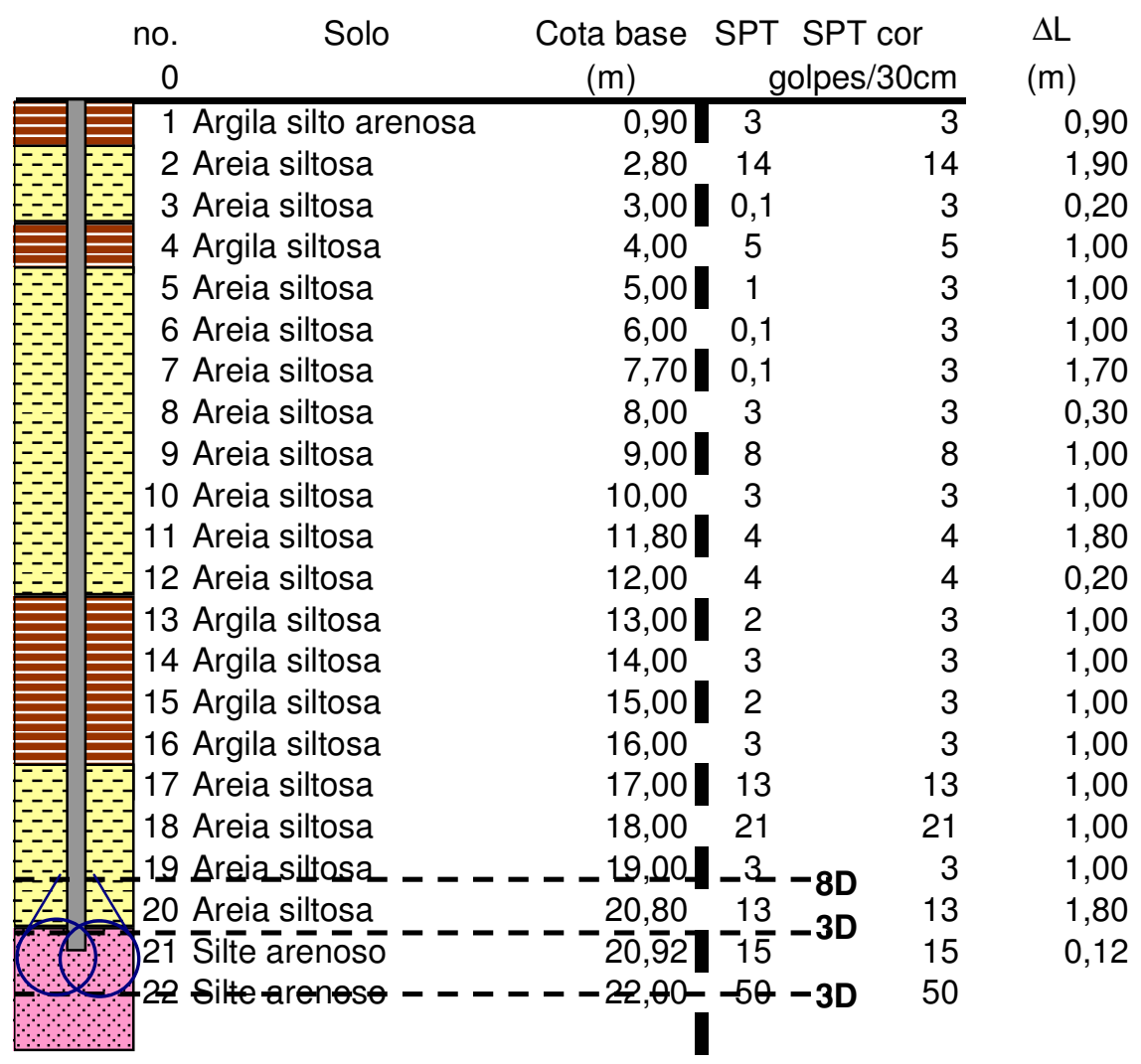

Figura 74 - Sondagem de referência para a estaca G202 (AMANN, 2000)

Das tabelas dos métodos Mediado e Expedito, resultam:

Tabela 27 - Valores dos coeficientes parciais empíricos do Método Mediado

\begin{tabular}{cccccc}
\hline Solo & $\mathrm{k}_{\mathrm{tD}}$ & $\mathrm{k}_{\mathrm{tEL}}$ & $\mathrm{k}_{\mathrm{ts}}(\%)$ & $\mathrm{k}_{\mathrm{te}}(\mathrm{kPa})$ & $\mathrm{k}_{\mathrm{tEP}}(\mathrm{kPa})$ \\
\hline Argila silto arenosa & 1,00 & 0,439 & 3,92 & 320,00 & 0,474 \\
Areia siltosa & 1,00 & 0,439 & 2,44 & 670,00 & 0,474 \\
Argila siltosa & 1,00 & 0,439 & 4,29 & 243,33 & 0,474 \\
Silte arenoso & 1,00 & 0,439 & 2,87 & 510,00 & 0,474 \\
\hline
\end{tabular}

Para o método Expedito, adota-se para o fuste a média global de $\mathrm{K}_{\mathrm{ts}} \mathrm{k}_{\mathrm{te}}=14 \mathrm{kN} / \mathrm{m}^{2} \mathrm{e}$ os valores de $\mathrm{k}_{\mathrm{tEP}}$ da Tabela 27.

Sendo estaca tipo raiz, tanto para o Mediado, quanto Expedito, vêm da Tabela 12 que $\mathrm{k}_{\mathrm{tEL}}=0,44$ e $\mathrm{k}_{\mathrm{tEP}}=0,47$. Assim, $\mathrm{K}_{\mathrm{LEX}}=6,2 \mathrm{kPa}$.

Assim, desenvolvendo-se os cálculos como apresentado em 2.12, têm-se os valores da Tabela 17, aqui reproduzida como Tabela 28. Essa tabela representa a aplicação 
de diversos métodos, considerando que o método Mediado permite a possibilidade de todas as condições de embutimento usuais e outras que se queiram investigar.

Tabela 28 - Cargas de ruptura estimadas pelos diversos modelos de consideração do atrito lateral e do embutimento da ponta par os métodos de teste.

\begin{tabular}{ccll}
\hline Modelo & Estimativa & \multicolumn{1}{c}{ Cálculo } & \multicolumn{1}{c}{$(\mathrm{kN})$} \\
\hline Somatória & $\mathrm{P}_{\mathrm{R}}$ & $=\mathrm{P}_{\mathrm{L}}+\mathrm{P}_{\mathrm{P}}$ & $=928,41$ \\
das & $\mathrm{P}_{\mathrm{R} 3 \mathrm{D}}$ & $=\mathrm{P}_{\mathrm{L} 3 \mathrm{D}}+\mathrm{P}_{\mathrm{P} 3 \mathrm{D}}$ & $=1021,47$ \\
camadas & $\mathrm{P}_{\mathrm{R} 8 \mathrm{D}}$ & $=\mathrm{P}_{\mathrm{L} 8 \mathrm{D}}+\mathrm{P}_{\mathrm{P} 8 \mathrm{D}}$ & $=944,87$ \\
\hline \multirow{3}{*}{ Média } & $\mathrm{P}_{\mathrm{RN}}$ & $=\mathrm{P}_{\mathrm{LN}}+\mathrm{P}_{\mathrm{P}}$ & $=779,30$ \\
& $\mathrm{P}_{\mathrm{RN} 3 \mathrm{D}}$ & $=\mathrm{P}_{\mathrm{LN} 3 \mathrm{D}}+\mathrm{P}_{\mathrm{P} 3 \mathrm{D}}$ & $=888,16$ \\
& $\mathrm{P}_{\mathrm{RN} 8 \mathrm{D}}$ & $=\mathrm{P}_{\mathrm{LN} 8 \mathrm{D}}+\mathrm{P}_{\mathrm{P} 8 \mathrm{D}}$ & $=797,26$ \\
\hline Expedito & $\mathrm{P}_{\mathrm{RN} 3 \mathrm{P}}$ & $=\mathrm{P}_{\mathrm{LN} 3 \mathrm{D}}+\mathrm{P}_{\mathrm{P} 3}$ & $=849,61$ \\
\hline
\end{tabular}

Passa-se então para a próxima etapa da metodologia semiempírica unificada.

\subsection{SEGUNDA ETAPA: VERIFICAÇÃO DO DESEMPENHO}

Nesta etapa, é executada a prova de carga e são aplicados os critérios de ruptura do item 3.2, com todas as considerações do capítulo 3. Enfim, comparam-se os valores obtidos pelos critérios com os valores das capacidades de carga estimadas na etapa anterior, com auxílio da Figura 15, aqui reproduzida como Figura 75.

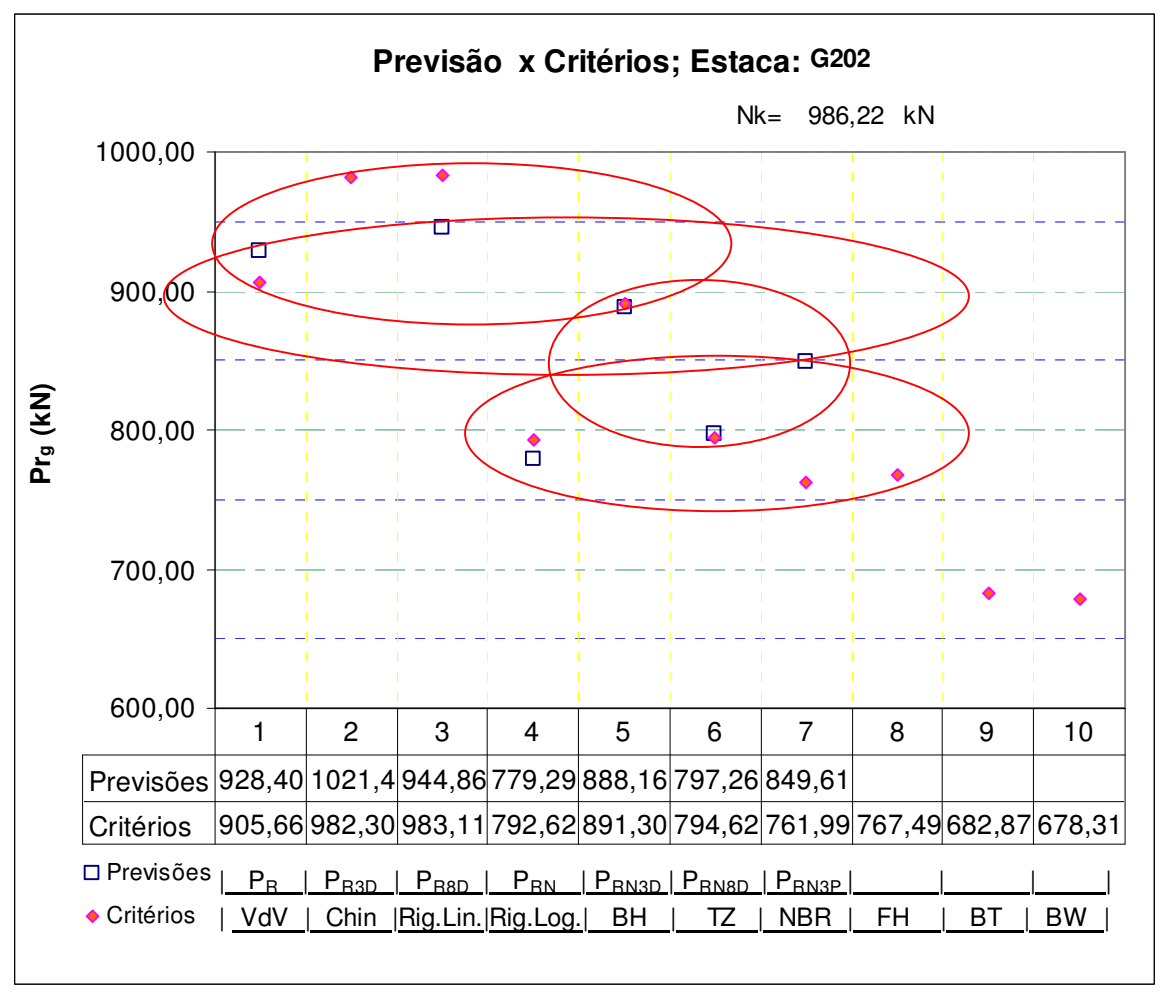

Figura 75 - Comparação das previsões (estimativas) semiempíricas com os critérios de ruptura. 
Legenda da Figura 75: VdV = Van der Veen; Chin= Chin; Rig.Lin.= Rigidez por ajuste linear; Rig.Log.= Rigidez por ajuste logarítmico; $\mathrm{BH}=$ Brinch Hansen; $\mathrm{TZ}=$ Terzaghi $(0,1 \mathrm{D})$; NBR = NBR 6122; FH = Fuller e Hoy; BT = Butler e Hoy; BW = De Beer e Wallays

Ao se obter esta comparação entre os valores de capacidade de carga estimados e as cargas de ruptura dos critérios, têm-se duas possibilidades dentro da Metodologia Semiempírica Unificada, como segue.

\subsubsection{Escolha do critério de ruptura adequado ao método semiempírico e ao sistema solo-estaca em estudo}

Se o interesse for apenas por se determinar qual o critério de ruptura mais adequado para um método semiempírico qualquer que se esteja analisando, basta identificar no diagrama da Figura 75 o que mais se aproxima (análise na horizontal, circundando os métodos e critérios que se encontram na mesma faixa de valores com amplitude adotada, por exemplo, de $100 \mathrm{kN}$ ), sendo que o resultado do critério pode ser superior ao da estimativa semiempírica, de modo a admitir-se certo conservadorismo, ou até levemente inferior, se o critério adequado em questão resultar em valores de estimativa baixos, como os de recalque limite e de ajuste de retas, conforme discutido nos itens 3.6.2 e 3.6.3. De fato, considerando-se a discussão do item 3.6.4, isto poderia ser assumido também em relação aos de ajuste matemático, resguardando-se o valor da ruptura estrutural da estaca.

Após esse procedimento, reforçando, desde que o interesse seja apenas escolher o critério mais adequado ao método, não é necessário corrigir o método semiempírico, pois assume-se que, como discutido no item 3.5, ao se comparar sempre o mesmo método semiempírico com o mesmo critério de ruptura, a dispersão dos resultados é reduzida e evita-se a incerteza de escolha do critério de ruptura a ser adotado. Isso permite que se classifique o método como conservador, ou não, de maneira conceitualmente adequada, mas, evidentemente, não otimiza o projeto, pois não fica definida a condição limite oferecida pela prova de carga.

Note-se que, dessa forma, cada método semiempírico pesquisado pode ser comparado com um critério de ruptura diferente. Não há inconveniente nisso, à luz do item 3.5, considerando que o critério fica incorporado ao método e que essa forma é mais adequada do que classificar métodos com base em um critério que não faz parte de sua concepção. 
Deve-se considerar, contudo, que, para alguns casos particulares de solos regionais e tipos de estaca, é possível que se identifique como sendo mais adequado um critério diferente do usado pelo autor na concepção do método semiempírico, pois a metodologia proposta na Figura 75 permite que se faça isso. Neste caso, não se considera uma impropriedade usar, para comparação, outro critério (desde que seja sempre utilizado o mesmo critério); apenas se trata de uma característica do local e estaca em estudo, a qual a Metodologia Semiempírica Unificada permite determinar, demonstrando ao mesmo tempo as razões para que isso ocorra.

Para o caso do exemplo, analisando-se a Figura 75, podem-se associar os seguintes critérios aos métodos semiempíricos de teste, como apresenta a Tabela 29:

Tabela 29 - Critérios mais próximos dos valores das estimativas semiempíricas

\begin{tabular}{ccl}
\hline Modelo & Estimativa & \multicolumn{1}{c}{ Critérios $( \pm 100 \mathrm{kN})$} \\
\hline $\begin{array}{c}\text { Somatória } \\
\text { das }\end{array}$ & $\mathrm{P}_{\mathrm{R}}$ & VdV; BH; \\
camadas & $\mathrm{P}_{\mathrm{R} 3 \mathrm{D}}$ & Chin; Rig Lin \\
\hline \multirow{2}{*}{ Média } & $\mathrm{P}_{\mathrm{RN}}$ & RdV; Chin; Rig.Lin.; BH \\
& $\mathrm{P}_{\mathrm{RN} 3 \mathrm{D}}$ & VdV; BH \\
& $\mathrm{P}_{\mathrm{RN} 8 \mathrm{D}}$ & Rig.Log.; TZ; NBR; FH \\
\hline Expedito & $\mathrm{P}_{\mathrm{RN} 3 \mathrm{P}}$ & VdV; BH; Rig.Log.; TZ; NBR; FH \\
\hline
\end{tabular}

No contexto da escolha do critério adequado ao método, a Tabela 29 resume as possibilidades, sendo a decisão final, agora, dependente de outra escolha, como por exemplo, dentre os métodos possíveis, o que mais se aproxima da carga máxima de ensaio.

Fazendo-se um parêntesis, observa-se, curiosamente, que o método Expedito apresenta grande gama de critérios com os quais suas estimativas se aproximam com precisão de 100 kN. Para a escolha de qual seria o método semiempírico mais interessante a se aplicar neste caso, ele sem dúvida têm grande probabilidade de resultar nas melhores estimativas quando comparado aos critérios de ruptura.

\subsubsection{Escolha do critério de ruptura para correção do método semiempírico no local em estudo}

Outra forma de se aplicar a comparação da Figura 75, é na escolha do critério a ser considerado na correção dos métodos semiempíricos, quando se opta por não 
utilizar o critério de ruptura originalmente empregado pelo seu autor. Embora pareça similar às considerações do item anterior, aqui as possibilidades se ampliam e outras restrições devem ser usadas para escolha do critério.

Em princípio, pode ser considerado como válido qualquer critério adotado que resulte maior do que o valor da parcela de atrito lateral, obtida na etapa seguinte da MSU, pois isso permite a definição de uma parcela de ponta. Antecipando essa etapa, para o exemplo da estaca G202, pode-se escolher qualquer critério com valor acima de Alr=696kN.

Outra consideração a ser feita, é o intervalo entre a carga máxima alcançada no ensaio (neste caso, $900 \mathrm{kN}$ ) e o limite da ruptura estrutural (986 KN), para não se subestimar a capacidade de carga da estaca, nem superestimá-la em demasia, conforme discutido no item 3.6. Sendo assim, poder-se-ia escolher entre os critérios de Van der Veen (VdV), Chin ou da Rigidez com ajuste linear (Rig. Lin.), os quais estão entre estes dois limites.

Para auxiliar na escolha do critério de ruptura mais adequado ao solo e estaca do exemplo, pode-se, ainda, ranqueá-los por quantidade de aparições na Tabela 29, obtendo-se: VdV (4); BH (4); Rig. Log. (3); TZ (3); NBR (3); FH (3); Chin (2); e Rig Lin (2).

Para se decidir, por exemplo, entre Van der Veen e Brinch Hansen, pode-se, então, tomar o que mais se aproxima da carga máxima de ensaio (aqui considerado como o preferível, conforme indicação de FELLENIUS, 2006), qual seja, Van der Veen, com 905 kN, contra Brinch Hansen, com 891 kN, sendo que $P_{\text {omax }}=900 \mathrm{kN}$.

Outra forma de escolha, seria comparar os resultados do ranqueamento dos critérios com o intervalo entre a carga máxima e a ruptura estrutural, sendo que neste caso o resultado continua sendo o critério de Van der Veen. As razões para essa grande proximidade do critério de Van der Veen à $P_{\text {omax }}$ podem ser vistas no item 3.6.4.

Definido o critério de ruptura, pode-se dizer, pela Tabela 29, que as estimativas semiempíricas $P_{R}, P_{R 8 D}, P_{R N 3 D}$ e $P_{R N 3 P}$ seriam as mais indicadas para o caso em questão. Trata-se, portanto, de um caminho inverso ao do item anterior, no qual se escolheu, primeiramente, o critério mais próximo a cada método semiempírico, e, posteriormente, o que mais se aproximava da carga de ruptura. 
Definindo-se os métodos semiempíricos mais adequados ao local em questão, podese, assim, pesquisar a adequação dos modelos de somatória dos SPT's das camadas do fuste, ou da média de seus valores, ou, ainda, das condições de embutimento, definindo qual delas melhor se adequa ao caso e critério em questão. Pode-se, ainda, experimentar aplicar um determinado método com estas diversas alternativas (como, aliás, foi feito para o método de teste Mediado) e verificar-se qual dessas modificações mais se aproxima do resultado do critério de ruptura adotado.

Dessa forma, dentre as estimativas semiempíricas, a que mais se aproxima do critério de Van der Veen é, pela Figura 75, a $P_{\text {RN3D }}$ (cisalhamento lateral calculado pela média e consideração de 3D acima e abaixo da ponta como embutimento), demonstrando quais os modelos, para o fuste e para o embutimento da ponta, mais interessantes para o caso em questão.

Isso demonstra a versatilidade e as possibilidades da Metodologia Semiempírica Unificada, pois ela tem flexibilidade de aplicação, oferecendo, ao mesmo tempo, as razões conceituais para cada escolha feita. Evidentemente, quanto maior o número de ensaios realizados num determinado local para o tipo de estaca em questão, maior será a confiança no método e critério escolhidos. Procura-se aqui demonstrar, pela MSU, apenas a forma conceitualmente mais adequada de se fazer tais escolhas.

Convém lembrar também, que, depois de separada a parcela de atrito, a parcela de ponta é atribuída pela diferença de valores entre o valor atrito e o resultado do critério de ruptura escolhido. Com isso, atribui-se à ponta um valor de mobilização parcial, que permite definir apenas sua rigidez e não a ruptura. Sendo assim, sempre há uma certa "reserva de ponta".

Esse processo, como já comentado, é distinto do utilizado para atribuição de valores baseado no ensaio de cone, onde a ponta é o valor conhecido e o atrito apenas correlacionado. Aqui é a parcela de atrito é que será o valor conhecido com maior certeza, e a ponta apenas estimada.

O importante é ter-se mente que, se for feita a correção para um determinado critério, este deve ser sempre utilizado no local em questão (a menos que outras análises permitam mudança), pois, assim procedendo, a reserva de ponta deve se 
manter relativamente a mesma que foi considerada inicialmente na correção dos métodos. Critério escolhido, passa-se à etapa de Aferição e correção dos métodos.

\subsection{TERCEIRA ETAPA: AFERIÇÃO E CORREÇÃO DOS MÉTODOS SEMIEMPÍRICOS}

Nesta etapa, que é subdividida em aferição e adequação, a aferição feita mediante a separação das parcelas de atrito de ponta, bem como a adequação, podem ser desenvolvidas para o fuste como um todo, conforme o método Expedito e outros analisados, ou para trechos do fuste, se for possível a aplicação do método, considerando um solo heterogêneo, ou ainda para cada camada, mediante ensaios instrumentados ou o emprego do conceito de hierarquias dos solos.

\subsubsection{Aferição pela separação das parcelas de atrito e ponta}

Como já comentado, se a estaca não dispuser de dados de instrumentação, o recurso aqui sugerido é o emprego dos métodos das Leis de Cambefort modificadas por Massad, com auxílio do método da Rigidez na definição dos trechos da curva carga-recalque, conforme apresentado no item 4.3.

A aplicação do método (ver Capítulo 4) é feita identificando-se os trechos (para o qual se propõe usar a Rigidez), ajustando-os às equações próprias, tomando-se em seguida os coeficientes das equações para aplicação às expressões do método que levam aos valores de atrito (cisalhamento) lateral na ruptura e as eventuais cargas residuais. A Figura 76 apresenta um resumo de toda a aplicação dessa metodologia.

Fazendo os comentários, o gráfico superior à esquerda apresenta as curvas hiperbólicas da relação entre 0 atrito desenvolvido no ensaio $\mu$ Alr e a rigidez estrutural $\mathrm{Kr}$ da estaca, evidenciando o ponto de interseção e os resultados obtidos. É indicado, ainda, como reta horizontal tracejada mais espessa nesse diagrama, o valor de $\mathrm{Kr}$ calculado pelo módulo de elasticidade estimado da estaca.

No gráfico superior da direita, tem-se o ajuste dos trechos pelo diagrama da Rigidez, conforme proposto no item 4.5.1. O traço horizontal superior marca o valor de 2.Kr estrutural e o tracejado horizontal com terminação em circunferências indica o valor 
de $\mathrm{Kr} / \mathrm{C}$ calculado, o qual na interseção com a curva Rig ${ }_{45}$ resulta no valor de $\mu \mathrm{Alr}$, conforme também proposto no item 4.5.1.

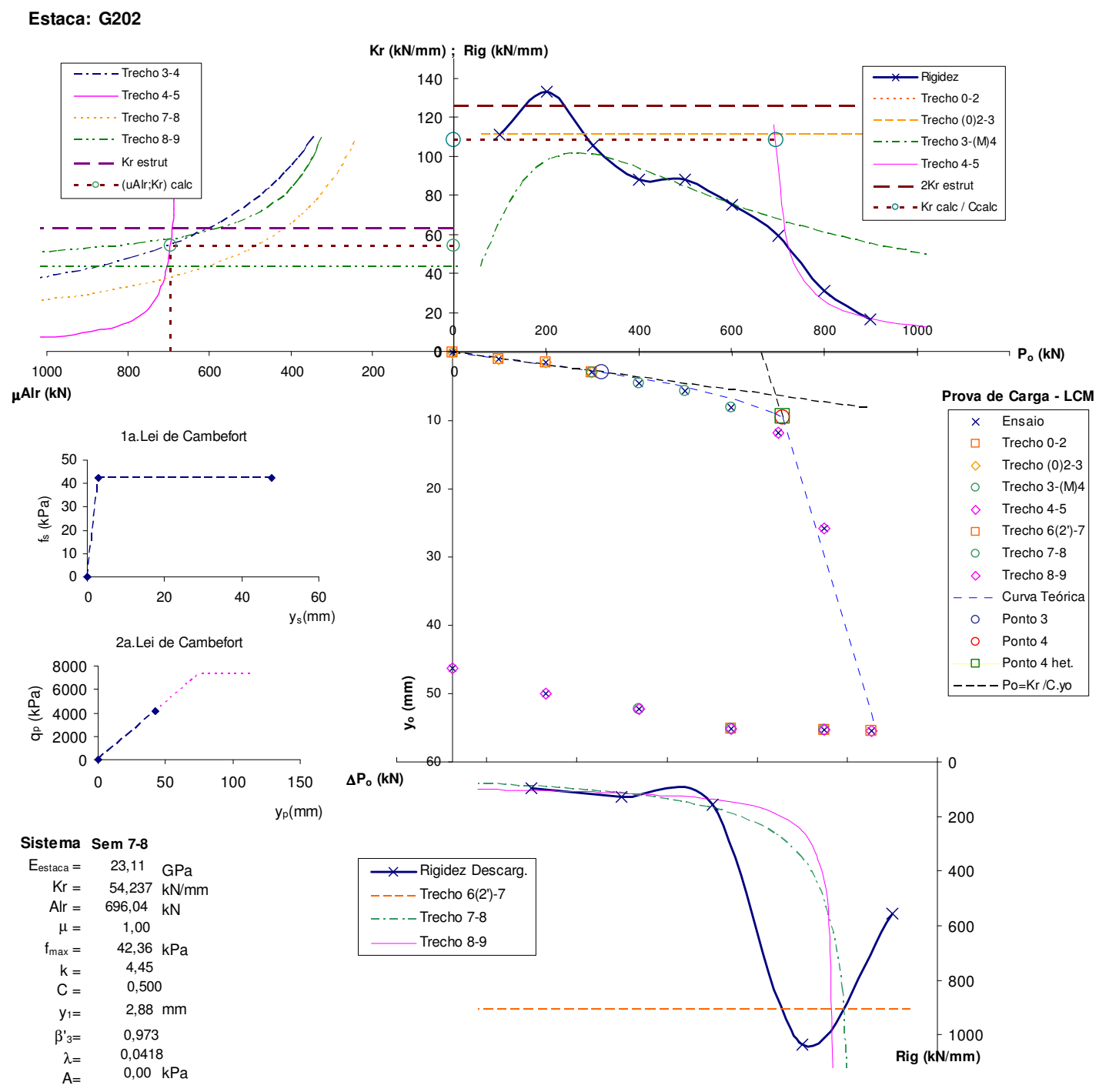

Figura 76 - Resumo da aplicação das Leis de Cambefort e da Rigidez para separação da parcela de atrito

Logo abaixo deste diagrama de Rigidez, encontra-se a curva carga-recalque, indicação dos pontos considerados em cada trecho, os pontos 3 e 4 calculados, o ajuste da curva teórica ao carregamento e a interseção da reta de inclinação $\mathrm{Kr} / \mathrm{C}$ com a reta do trecho 4-5, que define o atrito desenvolvido $\mu$ Alr, o qual deve coincidir com o obtido no diagrama de Rigidez.

Abaixo da curva carga-recalque, encontra-se o diagrama de Rigidez do descarregamento, para melhor definição dos trechos dessa região, notando-se que este se encontra com o eixo das rigidezes e das cargas invertido, iniciando no mesmo alinhamento vertical do último ponto de ensaio e com a mesma escala da 
prova de carga, a fim de se ter a correspondência entre os pontos de cada gráfico. Como em geral a quantidade de pontos no descarregamento é pequena, a boa definição da Rigidez fica prejudicada, porém é possível identificar os trechos em questão.

Logo ao lado, tem-se uma tabela com o resumo dos valores obtidos e a indicação de que tipo de sistema foi considerado para a solução, neste caso "sem o trecho 7-8", o qual indicou o valor de $\mu_{\mathrm{reb}} / \mu$ incompatível com o observado, sendo, portanto, desconsiderado.

Finalmente, acima da tabela de resultados, têm-se os diagramas da primeira e segunda Leis de Cambefort para a fase de carregamento, os quais indicam o comportamento global da estaca. Como a resistência máxima de ponta não foi alcançada, o diagrama indica a consideração da ruptura convencional para um deslocamento da ponta de $\mathrm{y}_{2}=0,3 \mathrm{D}$ (Figura 32) neste caso.

Enfim, tendo-se o valor de $\mu$ Alr e o valor do coeficiente de carga residual (majorador do atrito) $\mu=1$ (estaca escavada no primeiro carregamento), acha-se o valor de Alr = $696 \mathrm{KN}$, sendo, portanto, $\mathrm{f}_{\max }=42,36 \mathrm{kPa}$, o qual será usado na correção dos métodos semiempíricos.

Caso seja possível a separação do atrito em duas camadas (solo heterogêneo), pode-se adequar a camada superior e a inferior do fuste de forma diferenciada, considerando a ponta apoiada na camada inferior (embutimento 0D). De forma geral, pode-se ainda considerar a segunda camada justamente na região de embutimento da ponta, de forma a se obter o atrito na camada superior e assim ajustar de forma mais adequada a correção do fuste, sendo que para a ponta pode-se considerar os valores de Rigidez da "ponta fictícia", ilustrada no item $4.8\left(\mathrm{R}_{1} \mathrm{~S}\right)$. Este procedimento não é aqui apresentado.

Fazendo um parêntesis, convém observar que os critérios de Butler e Hoy (BT) ou de DeBeer e Wallays (BW) resultaram em valores muito próximos do atrito lateral separado e não da ruptura propriamente dita, como já discutido no item 3.6.3. Evidentemente, caso essa estaca fosse cravada ou sofresse um segundo carregamento, seus resultados seriam comparáveis ao atrito desenvolvido no ensaio ( $\mu \mathrm{A} / \mathrm{r})$, ou seja, com cargas residuais, e assim haveria alguma parcela de ponta considerada como reserva, caso estes métodos fossem adotados. 
Para o exemplo da estaca G202, para a carga máxima de ensaio, tem-se carga na ponta de 900-696 = 204 kN. Em relação ao critério de Van der Venn adotado na etapa anterior, tem-se $906-696=210 \mathrm{kN}$, os quais não representam a ruptura da ponta, mas sim o valor de solicitação máxima aplicada, podendo-se considerar ainda alguma reserva de capacidade de carga, até que se alcance a ruptura propriamente dita, ou a ruptura estrutural da estaca.

\subsubsection{Aferição por ajustes polinomiais da instrumentação}

Se houver dados de instrumentação, propõe-se aplicar os ajustes polinomiais do item 5.5, e com eles calcular o atrito médio por cisalhamento de cada camada de solo. Considerando-se que nem sempre as camadas de solo coincidem com a posição dos instrumentos, o objetivo da proposta de uso dos polinômios é obter os valores do cisalhamento ' $\tau$ ' e dos recalques ' $y$ ', continuamente em profundidade $(z)$, e com isso determinar os diagramas da primeira Lei de Cambefort (MASSAD, 1992) rapidamente, em qualquer profundidade.

Para exemplificar o procedimento escolheu-se a estaca Barrete, visto que a G202 não possui instrumentação. Os dados dos polinômios dessa estaca encontram-se no item 5.5, já referido. Aplicam-se então as seguintes etapas:

a) Pela sondagem identificam-se as camadas de solo a serem analisadas e a cota do ponto médio de cada uma, sempre em relação ao ponto do fuste em que a estaca penetra no solo $(z=0)$ e não em relação ao nível do terreno ou topo da estaca, pois as expressões só valem para o trecho da estaca em contato com o solo. No caso da estaca Barrete (ver Figura 42), tem-se: $z_{\text {(Sil-arg-are) }}=0,70 \mathrm{~m} ; z_{\text {(Are-arg-sil) }}=1,70 \mathrm{~m} ; z_{\text {(Sil-arg- }}$ are) $=2,10 \mathrm{~m} ; z_{(\text {Sil-are })}=4,60 \mathrm{~m} ; z_{(\text {Sil-are })}=6,30 \mathrm{~m}$. Note-se que as camadas de caolinita foram incluídas nas camadas imediatamente acima, devido às suas pequenas espessuras, embora pudessem também ser levadas em conta separadamente pelo procedimento proposto;

b) Ajustam-se os polinômios $\mathrm{N}(\mathrm{z})$ a partir dos resultados dos extensômetros para cada estágio de carga $\mathrm{P}_{0}$;

c) Obtêm-se os polinômios $\tau(z)$ por derivação dos $N(z)$ e os $y(z)$ por integração dos mesmos (ver item 5.5 e o Apêndice E); 
d) Substituem-se os valores de $z$ do item a, obtendo-se os valores de $\tau$ e y para cada estágio de carga $P_{0}$;

e) Num diagrama $y$ - $\tau$ traçam-se as curvas $\tau=f(y)$ com mesmo valor de $z$, sendo que cada ponto destas curvas indica um estágio de carga (ver Figura 49);

f) Cada uma destas curvas representa um polinômio $\tau\left(P_{o}\right)_{z=c t e}$ e $y\left(P_{o}\right)_{z=c t e}$, cujas equações, no caso da estaca Barrete, estão dadas respectivamente na Tabela 68 e na Tabela 69.

Seguindo-se estas etapas, obtém-se o diagrama da Figura 77, que representa a primeira Lei de Cambefort para cada profundidade das camadas. As retas tracejadas indicam a simplificação que pode ser feita para se adotar um modelo elastoplástico como o de Massad (1992), no qual a inclinação da reta inicial indica o valor médio do parâmetro $B$, válido até que se atinja o recalque de mobilização plena do atrito $\left(\mathrm{y}_{1}\right.$ da Figura 37).

1a. Lei de Cambefort por ajuste polinomial - Estaca

Barrete

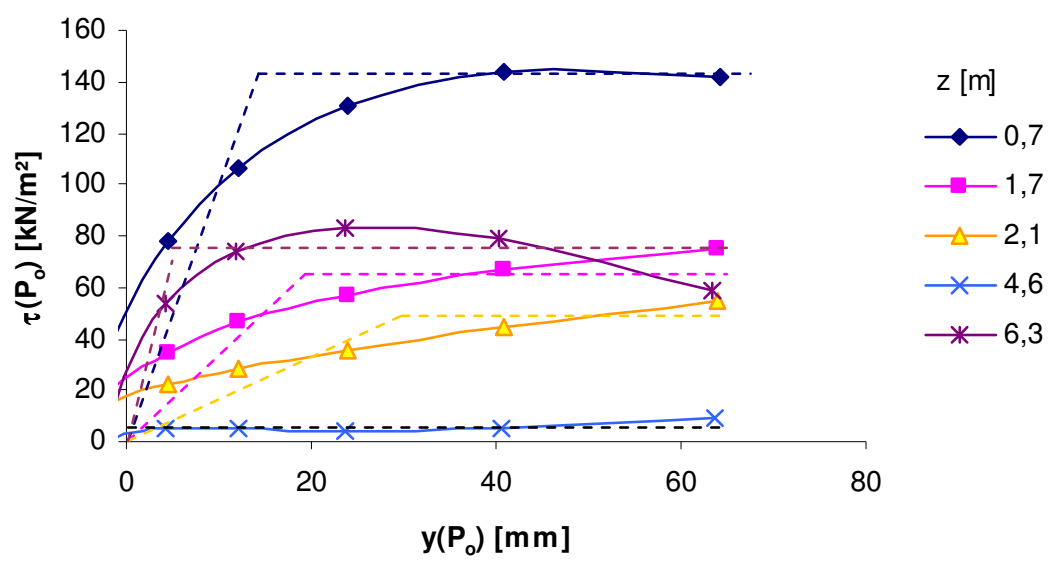

Figura 77 - Aplicação dos ajustes polinomiais para obtenção da 1a․ lei e Cambefort em profundidades distintas dos pontos da instrumentação.

O valor de $\tau$, correspondente aos patamares das retas tracejadas da Figura 77, indicam os valores máximos de atrito que são usados para correção dos coeficientes empíricos de cada camada. Neste exemplo foi analisado apenas o primeiro carregamento da estaca, devendo-se considerar, portanto, que se tratam de valores parciais. 
A distribuição de camadas do item 'a' supra, mostra que dispondo-se dos dados de instrumentação é, portanto, possível diferenciar o comportamento de camadas de mesmo tipo de solo em diferentes posições do fuste. Isso não pode ser feito pela simples separação das parcelas de atrito e ponta, onde cada tipo de solo é considerado em "bloco", mesmo que ocorra em diferentes posições no fuste. Tal refinamento vale também para diferentes trechos de uma espessa camada de mesmo solo.

Portanto, para as profundidades $z_{(\text {Sil-arg-are })}=0,70 \mathrm{~m} ; z_{\text {(Are-arg-sil) }}=1,70 \mathrm{~m} ; z_{\text {(Sil-arg-are) }}=$ $2,10 \mathrm{~m} ; z_{\text {(Sil-are) }}=4,60 \mathrm{~m} ; z_{(\text {Sil-are })}=6,30 \mathrm{~m}$, têm-se respectivamente os seguintes valores de $\tau_{\max }: 142,0 ; 67,0 ; 44,4 ; 4,6$ e 73,5 KN/m². Comparados aos respectivos valores de SPT, a saber: $24 ; 31 ; 25 ; 24$ e 50 golpes, resultam os seguintes valores de coeficientes característicos corrigidos $\mathrm{K}_{\mathrm{Lgi}}$ cor: 5,$92 ; 2,16 ; 1,78 ; 0,2 ; 1,47 \mathrm{KN} / \mathrm{m}^{2}$.

Note-se que o primeiro e terceiro valores correspondem à correção do mesmo tipo de solo (Silte argilo-arenoso). Como já mencionado, esse procedimento permite que se considerem independentemente as camadas, ainda que do mesmo tipo de solo. Porém, para a forma usual dos métodos semiempíricos brasileiros, a estimativa de resistência considera o tipo de solo e seu resultado de sondagem, o que aqui deve levar a valores semelhantes de $\mathrm{K}_{\mathrm{Lg}}$, para a mesma camada de solo. Considerando, adicionalmente, que os valores de resistência muito próximos ao topo da estaca podem sofrer algumas influências, devidas ao ajuste polinomial (ver Capítulo 5),

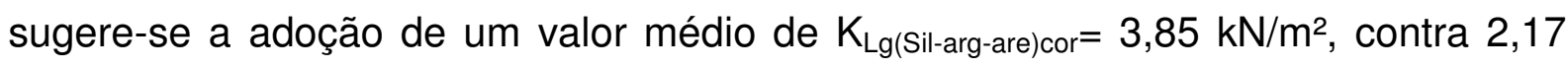
$\mathrm{kN} / \mathrm{m}^{2}$, estimado pelo método Mediado de teste. Para a Areia argilo-siltosa e o Silte arenoso, os valores estimados foram respectivamente 3,4 e $3,05 \mathrm{kN} / \mathrm{m}^{2}$.

Raciocínio semelhante pode ser adotado para o caso do silte arenoso, cujos valores corrigidos também diferem bastante $(0,2$ e 1,47 kN/m²), porém, neste caso, talvez fosse interessante também investigar a baixa resistência (ou possível anomalia do extensômetro) da camada de profundidade 4,6m.

Para a segunda Lei de Cambefort, na ponta, pode-se aplicar a compatibilidade de rigidezes proposta no item 4.8. Para isso é preciso relacionarem-se as cargas $N(z=L)$ com os recalques $y(z=L)$, que podem ser obtidos a partir dos polinômios $N(z)$ da Figura 59 e dos y(z) usados logo acima. A Figura 78 apresenta o resultado da 
relação entre $\mathrm{N}(\mathrm{z})$ e $\mathrm{y}(\mathrm{z})$ para os pontos instrumentados, calculados a partir desses polinômios.

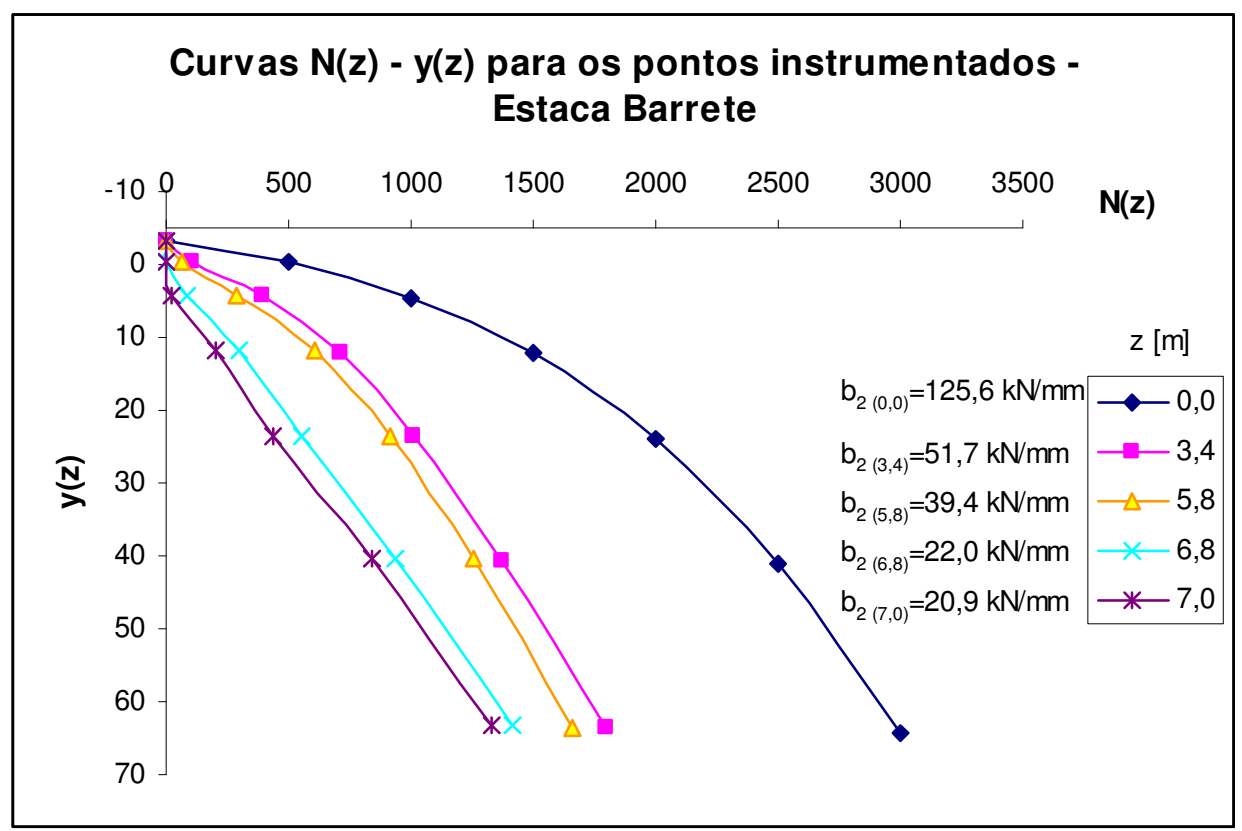

Figura 78 - Curvas $N(z)$ versus $y(z)$ com indicação da rigidez $b_{2}$ nos pontos instrumentados.

As rigidezes tangentes $b_{2(z)}$, no início das curvas do topo de cada trecho instrumentado, podem ser usadas, conforme indicado no item 4.8, como uma forma alternativa de se obter a primeira Lei de Cambefort em cada trecho. Sendo aqui o interesse em se obter a segunda lei relativa à ponta $(z=7,0 \mathrm{~m})$, toma-se $b_{2(7,0)}$ igual à rigidez da ponta, obtendo-se R.S $=20,9 \mathrm{kN} / \mathrm{mm}$, o que resulta $R=31,2 \mathrm{kPa} / \mathrm{mm}$. A análise dessa estaca para solo homogêneo, apresentada no Apêndice $F$, resultou R.S=24,9 $\mathrm{kN} / \mathrm{mm}$ e $\mathrm{R}=37,7 \mathrm{kPa} / \mathrm{mm}$, bastante próximos, indicando a boa aproximação da proposta.

\subsubsection{Correção dos coeficientes empíricos dos métodos empregando a Hierarquia dos Solos (AMANN, 2000)}

Enfim, é chegada a etapa de correção dos coeficientes, a qual deve seguir um roteiro cuidadoso dentro da Metodologia Semiempírica Unificada. Os passos para isso são indicados e comentados com o exemplo da estaca G202, na sequência. O importante é considerar que, para cada forma de embutimento, obtêm-se valores de correção diferentes, devendo-se cuidar de sua adoção criteriosa. 


\subsubsection{Correção do coeficiente característico $K_{L g}$}

Tomando-se a expressão (13), o valor de $\mathrm{f}_{\max }=42,36 \mathrm{kPa}$ e o SPT médio para o fuste de 5,9 golpes $/ 30 \mathrm{~cm}$ de penetração, obtêm-se um valor de $\mathrm{K}_{\mathrm{Lg}}$ :

$$
\mathrm{K}_{\mathrm{Lg}}=\frac{\mathrm{f}_{\max }}{N_{\mathrm{SPT}}}=\frac{42,36}{5,9}=7,20 \mathrm{kN} / \mathrm{m}^{2}
$$

Este valor já permite corrigir-se o método Expedito, visto que anteriormente $\mathrm{K}_{\mathrm{LEX}}=6,2$ $\mathrm{kPa}$. Nesse caso, a correção pode ser feita sobre o produto $\mathrm{k}_{\mathrm{ts}} \cdot \mathrm{k}_{\mathrm{te}}=\mathrm{k}_{\mathrm{tf}}$, porém, este é dado por uma relação com o ensaio de campo, sobre o qual não se tem dados de correlação. Sendo assim, é mais adequado corrigir o tipo de estaca $\mathrm{k}_{\mathrm{tEL}}=7,2$ / $14=$ 0,51 , contra o 0,44 anterior. Isso significa que, para este tipo de solo, a resistência por cisalhamento lateral da estaca raiz é 0,51 vezes o atrito desenvolvido pela luva do ensaio de cone, no mesmo solo, com seu respectivo valor de SPT.

Para o método Mediado, contudo, deve-se considerar a distribuição do atrito entre as camadas, o que se propõe aqui ser feito com o conceito de Hierarquia dos Solos (AMANN, 2000), como segue.

\subsubsection{Correção dos coeficientes característicos $K_{L g(i)}$ de cada camada pela Hierarquia dos Solos}

Para cálculo dos coeficientes característicos $\mathrm{K}_{\mathrm{Lg}(\mathrm{i})}$ de cada camada, deve-se tomar a expressão (14) da generalização dos métodos semiempíricos e substituírem-se os valores Tabela 26 para cada camada de solo:

$$
7,2=\frac{1}{5,9} \cdot\left(\mathrm{K}_{\mathrm{Lg}_{\text {(Argsilare) }}} \cdot 3 \cdot 0,043+\mathrm{K}_{\mathrm{Lg}(\text { Are sil) }} \cdot 7,96 \cdot 0,7127+\mathrm{K}_{\mathrm{Lg}(\text { Argsil) }} \cdot 3,4 \cdot 0,239+\mathrm{K}_{\mathrm{Lg}(\text { Sil are) }} \cdot 15 \cdot 0,006\right)
$$

Nesse exemplo, considera-se o caso de embutimento "OD", ou seja, ponta apenas apoiada sobre a camada portante. Para os demais casos de embutimento, basta substituir os valores correspondentes da Tabela 26.

Como a expressão (139) apresenta 4 incógnitas (uma para cada camada de solo), é necessário obter-se alguma relação entre elas para que seja possível a solução. Nesse ponto é que entra o conceito de Hierarquia dos Solos, como segue. 


\section{A aplicação das Hierarquias dos Solos na atribuição dos valores corrigidos}

O conceito de Hierarquia dos Solos apresenta a possibilidade de se atribuir relações entre as resistências dos solos de mesmo SPT a partir da experiência brasileira na aplicação dos métodos semiempíricos. A generalização dos métodos, proposta no item 2.5, permitiu a observação clara dessa possibilidade e uma forma de quantificar esta relação entre dois tipos de solo, a partir da análise de vários métodos distintos.
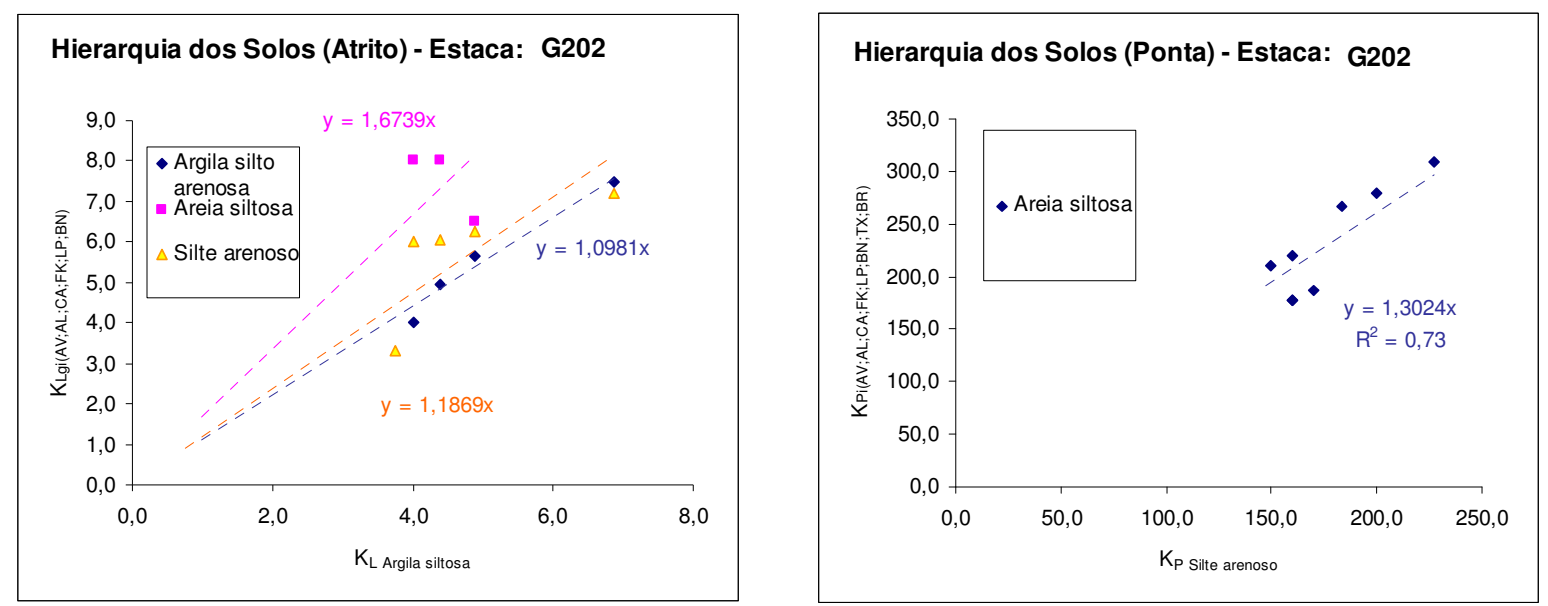

Figura 79 - Aplicação das Hierarquias dos Solos de atrito e ponta para definição das relações de resistência entre camadas de solo

$\mathrm{Na}$ Figura 79, vêem-se os gráficos que apresentam a dispersão da relação, por exemplo, entre os valores dos métodos AV, AL, CA, FK, LP, BN (ver item 2.6), para o atrito lateral e ponta, escolhendo-se como solo de referência a argila siltosa e o silte arenoso, respectivamente. A camada de solo a ser escolhida como referência deve ser aquela que permite menor dispersão entre os resultados dos demais solos na Figura 79, embora se trabalhe com as médias e não com ajustes propriamente. Esta escolha é necessária, pois, apesar das Hierarquias serem evidentes, dependendo do tipo de solo e da quantidade de amostras usadas na concepção de cada método semiempírico, alguns podem levar a maiores dispersões que outros, quando comparados dois a dois. Também se recomenda que o solo adotado como referência do atrito lateral não seja o mesmo solo adotado para a ponta, quando possível, evitando-se correções duplas. Deve-se lembrar que a correção de ponta neste caso é apenas indicativa, visto que a ruptura não ocorre de fato.

Cada ponto do diagrama da Figura 79 representa o resultado do valor de $\mathrm{K}_{\mathrm{Lg}}$ ou $\mathrm{K}_{\mathrm{Pg}}$ calculado conforme indicado na Tabela 5 , e com as tabelas de coeficientes dos métodos semiempíricos, dadas no item B.1 do Apêndice B, para cada método, 
comparados os demais solos em relação ao solo de referência adotado. Assim, a inclinação das retas indica o valor das razões médias entre os $\mathrm{K}_{\mathrm{Lg}(\mathrm{i})}$ e entre os $\mathrm{K}_{\mathrm{Pg}(\mathrm{i})}$, de cada solo em relação ao solo de referência, para o conjunto de métodos tomados na análise.

\section{Cálculo do coeficiente característico $K_{L g(i)}$ da camada de referência}

Tendo-se estes valores, substituem-se todos os $\mathrm{K}_{\mathrm{Lg}}$ dos demais solos pela sua relação com o solo de referência:

$$
7,2=\frac{1}{5,9} \cdot K_{\text {Lg(Arg sil) }} \cdot(1,098 \cdot 3 \cdot 0,043+1,674 \cdot 7,96 \cdot 0,7127+1,0 \cdot 3,4 \cdot 0,239+1,187 \cdot 15 \cdot 0,006)
$$

Agora resta, portanto, apenas uma variável a ser calculada: $\mathrm{K}_{\mathrm{Lg}(\mathrm{Arg}-\mathrm{sil})}=4,02 \mathrm{kPa}$; este valor corrige o anterior, $4,59 \mathrm{kPa}$.

\section{Correção dos coeficientes característicos das demais camadas de solo}

Tendo-se o coeficiente característico da camada de solo da camada de referência, basta aplicar os valores das relações da Figura 79 para se obter os valores corrigidos das demais camadas:

Tabela 30 - Valores dos coeficientes característicos de cada camada corrigidos e adotados anteriormente das tabelas do método

\begin{tabular}{ccc}
\hline Solo & $\mathrm{K}_{\mathrm{Lg}(\mathrm{i}) \text { cor }}(\mathrm{kPa})$ & $\mathrm{K}_{\mathrm{Lg} \text { (i)anterior }(\mathrm{kPa})}$ \\
\hline Argila silto-arenosa & 4,41 & 5,51 \\
Areia siltosa & 6,72 & 7,18 \\
Argila siltosa & 4,02 & 4,59 \\
Silte arenoso & 4,77 & 6,44 \\
\hline
\end{tabular}

Percebe-se, portanto, que para esta consideração de embutimento (OD) os valores dos coeficientes do atrito estimados pelo método Mediado estavam ligeiramente superiores ao valor separado pelo método das Leis de Cambefort.

\subsubsection{Correção dos coeficientes parciais $k_{t(i)}$ dos métodos}

Tendo-se os valores dos coeficientes característicos de cada camada, podem-se corrigir os coeficientes parciais empíricos dos métodos. Algumas considerações contudo são feitas para orientar este procedimento, como segue. 


\section{Correção do coeficiente parcial de dimensão ou diâmetro $\left(k_{t D}\right)$}

O coeficiente parcial de dimensão ou diâmetro é adotado apenas em alguns métodos. Sendo assim, sugere-se que ele seja considerado apenas para os casos em que o método semiempírico analisado emprega tal coeficiente em sua formulação. Para esses casos recomenda-se a aplicação da forma geral dada na expressão (19), com os coeficientes $a_{D}$ e $b_{D}$ iguais a 1,0 .

Caso a pesquisa do solo local incluia diferentes diâmetros de estacas, esses coeficientes podem ser corrigidos para representarem a variação de resistência em função das dimensões da estaca. Não sendo este o caso, os valores $a_{D}=b_{D}=1,0$ são mantidos. Para o exemplo da estaca G202, adota-se, portanto, $\mathrm{k}_{\mathrm{t}}=1,0$.

\section{Correção do coeficiente parcial de tipo de solo $\left(\boldsymbol{k}_{t s}\right)$}

O coeficiente parcial de tipo de solo foi discutido no item 2.9.1, onde se demonstra que se trata da medida de uma característica intrínseca do solo, que é a sua razão de atrito, obtida com o ensaio de CPT. Assim, é um coeficiente que não depende dos demais, sendo corrigível a rigor somente com os resultados de ensaios CPT ou outro que permita obter a razão de atrito do solo no mesmo ponto de medida.

Dessa forma, fixa-se o coeficiente $k_{\text {ts }}$ como base de referência, não sendo assim passível de correção. Adota-se, portanto, para seus valores os constantes nas tabelas de tipo de solo em cada método (neste caso a Tabela 10), a menos que se tenham resultados deste ensaio de CPT na região para este tipo de solo local.

\section{Correção do coeficiente parcial de tipo de estaca para o fuste $\left(k_{t E L}\right)$}

Considerando a correção de tipo de estaca, este é um coeficiente que pode ser corrigido pela Metodologia Semiempírica Unificada de maneira direta, a exemplo do que foi feito para o método Expedito. Conceitualmente, trata-se da relação entre o valor de resistência por cisalhamento lateral da estaca em relação ao valor da luva de atrito do ensaio CPT. Embora comumente não se tenha o valor do CPT, apenas do SPT, dada a separação do atrito já demonstrada, pode-se corrigir este valor tendo-se por base os valores dos demais coeficientes parciais. 
Para isso, parte-se da expressão (17), isolando o $\mathrm{k}_{\mathrm{tEL}}$, e adota-se, por ora, o valor de $\mathrm{K}_{\mathrm{te}}$ das tabelas dos métodos semiempíricos. Substitui-se, então, os demais valores para cada camada.

$$
\mathrm{k}_{\mathrm{tELCor}}=\frac{\mathrm{K}_{\mathrm{Lg}(\mathrm{i}) \mathrm{cor}}}{\left(\mathrm{k}_{\mathrm{tsL}} \cdot \mathrm{k}_{\mathrm{te}} \cdot \mathrm{k}_{\mathrm{tD}}\right)_{(\mathrm{i})}}
$$

O resultado pode ser visto na Tabela 31.

Tabela 31 - Valores corrigidos do coeficiente parcial de tipo de estaca $\mathrm{k}_{\mathrm{tEL}}$

\begin{tabular}{ccc}
\hline Solo & $\mathrm{k}_{\mathrm{tEL} \text { cor }}(\mathrm{kPa})$ & $\mathrm{k}_{\mathrm{tEL}}$ anterior $(\mathrm{kPa})$ \\
\hline Argila silto-arenosa & 0,35 & 0,44 \\
Areia siltosa & 0,41 & 0,44 \\
Argila siltosa & 0,38 & 0,44 \\
Silte arenoso & 0,33 & 0,44 \\
\hline
\end{tabular}

Comparando-se com os valores anteriores, percebe-se que eram todos constantes, sofreram reduções e agora variam em função do tipo de solo. Esses coeficientes $\mathrm{k}_{\mathrm{tEL}}$ corrigidos, variando com o tipo de solo, representam coeficientes de tipo de estaca similares aos de Décourt-Quaresma. Para a obtenção de coeficientes iguais a um valor constantes, independente do tipo de solo (como ocorre em praticamente todos os métodos semiempíricos), deve-se adotar o valor médio como resultado da correção. Neste caso $\mathrm{k}_{\mathrm{tEL} L o r m}=0,37$, contra o valor de 0,44 anterior.

Esse novo valor é então usado para corrigir provisoriamente o coeficiente parcial de tipo de ensaio, $\mathrm{k}_{\mathrm{te}}$.

\section{Correção do coeficiente parcial de tipo de ensaio ou sondagem $\left(\boldsymbol{k}_{t e}\right)$}

Este coeficiente relaciona o CPT com o ensaio de campo realizado no local. Geralmente, o ensaio realizado é o SPT, mas pode ser qualquer outro, como, por exemplo, o ensaio pressiométrico. Da mesma maneira que para $\mathrm{k}_{\mathrm{ts}}$, o ideal é que a correção seja feita por correlações entre os dois ensaios, executados no solo típico do local em estudo.

Se essas correlações forem disponíveis, primeiramente aplica-se a correção para $\mathrm{k}_{\mathrm{ts}}$ e $k_{\text {te }} e$, posteriormente, para $k_{t E L}$, podendo-se tomá-lo também como a média. Recalcula-se, então, nova correção para o produto $k_{t s} \cdot k_{t e}=k_{t t c o r}$ com base neste valor, como segue mais adiante. 
Se tais correlações não estão disponíveis para o local, é possível corrigir provisoriamente seu valor a partir da correção do $\mathrm{k}_{\mathrm{tELcorm}}$, como visto acima.

Com o valor de $\mathrm{k}_{\mathrm{tEL} L o r m}$ constante, adotado pela média, pode-se agora corrigir provisoriamente o coeficiente parcial de tipo de ensaio $k_{t e}$, similarmente ao que se fez para $k_{t E L}$.

$$
\mathrm{k}_{\text {teProv }}=\frac{\mathrm{K}_{\mathrm{Lg}(\mathrm{i}) \text { cor }}}{\left(\mathrm{k}_{\mathrm{tsL}} \cdot \overline{\mathrm{k}_{\mathrm{tELCorm}} \cdot \mathrm{K}_{\mathrm{tD}}}\right)_{(\mathrm{i})}}
$$

O resultado se apresenta na Tabela 32.

Tabela 32 - Correção provisória dos coeficientes de tipo de ensaio $k_{t e}$

\begin{tabular}{ccc}
\hline Solo & $\mathrm{k}_{\text {te Prov }}(\mathrm{kPa})$ & $\mathrm{k}_{\text {te anterior }}(\mathrm{kPa})$ \\
\hline Argila silto-arenosa & 306 & 320 \\
Areia siltosa & 749 & 670 \\
Argila siltosa & 254 & 243 \\
Silte arenoso & 450 & 510 \\
\hline
\end{tabular}

Essa correção de $k_{\text {te }}$ é dita "provisória" (índice "Prov"), pois, como já esclarecido, a rigor ela deve ser feita por correlações entre CPT e SPT para o solo local.

\section{Correção do coeficiente parcial de tipo de estaca para a ponta $\left(k_{t E P}\right)$}

Para a correção do coeficiente parcial de tipo de estaca para a ponta, primeiramente deve-se adotar o critério de ruptura adequado ao método em análise, como feito no item 6.2, em particular para o exemplo da G202, no tem 6.2.2. Assim, foi adotado o critério de Van der Veen com $906 \mathrm{kN}$ como o mais próximo do valor máximo alcançado no ensaio, resultando por diferença com o atrito separado de $696 \mathrm{kN}$ de carga máxima de solicitação da ponta igual a $210 \mathrm{kN}$. Isso resulta em tensão de solicitação $4278 \mathrm{kPa}$.

É importante reforçar que esse valor não exprime a tensão de ruptura do solo da ponta da estaca, mas sim o valor que se pode atribuir ao se considerar o atrito lateral separado e o critério de ruptura adotado no caso em estudo. Assim, novamente, ressalta-se que pela Metodologia Semiempírica Unificada (MSU), esse valor não guarda relação direta com o que seria obtido pela ponta do cone num ensaio CPT, como se faz usualmente em muitos métodos, mas sim é o valor otimizado para compatibilizar as estimativas semiempíricas com os critérios de ruptura, no caso particular estudado. 
De fato, esse é o grande diferencial da MSU, o de resultar correções dos métodos semiempíricos otimizadas em relação ao critério de ruptura adotado e o sistema solo-estaca estudado. Trata-se, em última análise, de uma proposta mais realista de consideração do comportamento da ponta da estaca, dado que se identifica mais precisamente o nível de solicitação da mesma no ensaio.

\section{Cálculo do coeficiente característico de ponta $K_{P g}$}

Para a correção dos coeficientes de ponta, primeiramente se calcula o coeficiente característico $\mathrm{K}_{\mathrm{Pg}}$ pela expressão (12), considerando-se o SPT médio da ponta em função do tipo de embutimento do método em análise. A expressão (143) apresenta o exemplo de cálculo para o embutimento de 8D acima e 3D abaixo, pela divisão da tensão de ponta pelo SPT médio do embutimento em cada caso, usando os valores da Tabela 26. A Tabela 33 apresenta os valores resultantes para cada embutimento:

$$
\mathrm{K}_{\mathrm{Pg}(8 \mathrm{D})}=\frac{4278}{23,3}=184 \mathrm{kPa}
$$

Tabela 33 - Valores do coeficiente característico de ponta para cada condição de embutimento

\begin{tabular}{ccc}
\hline Embutimento & $\mathrm{K}_{\mathrm{Pg} \text { cor }}(\mathrm{kPa})$ & $\mathrm{K}_{\mathrm{Pg} \text { anterior }}(\mathrm{kPa})$ \\
\hline OD & 285 & 242 \\
3D & 164 & 242 \\
8D & 184 & 252 \\
3SPT & 164 & 242 \\
\hline
\end{tabular}

Observa-se que, para a consideração de ponta apenas apoiada na camada portante (embutimento OD), o valor do coeficiente característico aumenta e para as demais diminui, efeito claro do valor e SPT médio adotado em cada caso.

Deve-se lembrar que os valores da Tabela 33 correspondem aos métodos de teste Mediado e Expedito, sendo que em uma situação corrente de correção de um método semiempírico apenas o embutimento próprio do método seria considerado, a menos que se pretendesse pesquisar modificações para o caso local.

\section{Correção do coeficiente parcial de tipo de estaca $k_{t E P}$}

Com tais valores dos coeficientes característicos, a correção do coeficiente parcial de tipo de estaca $\mathrm{k}_{\text {tEP }}$ se processa da mesma forma que para o atrito lateral: 


$$
\mathrm{k}_{\mathrm{tEP}(\mathrm{i}) \mathrm{cor}}=\frac{\mathrm{K}_{\mathrm{Pg}(\mathrm{i}) \mathrm{cor}}}{\left(\mathrm{k}_{\mathrm{ts}} \cdot \mathrm{k}_{\mathrm{te}} \cdot \mathrm{k}_{\mathrm{tD}}\right)_{(\mathrm{P})}}
$$

Comenta-se da expressão (144) que o coeficiente $\left(\mathrm{k}_{\mathrm{ts}}\right)_{\mathrm{P}}$ para $\mathrm{O}$ caso da ponta não deve significar o mesmo que a razão de atrito, constando da expressão proposta para considerar a variação do solo em métodos que eventualmente apresentem valores constantes de coeficientes de tipo de ensaio $\left(k_{t e}\right)_{P}$ sem variação do tipo de solo. No caso geral dos métodos semiempíricos brasileiros, todos consideram o coeficiente de tipo de ensaio variável com o tipo de solo, e, portanto, pode-se assumir a substituição do produto $\left(\mathrm{k}_{\mathrm{ts}} \cdot \mathrm{k}_{\mathrm{te}}\right)_{\mathrm{P}}=\left(\mathrm{k}_{\mathrm{te}}\right)_{\mathrm{P}}$.

Com relação a este novo coeficiente $\left(k_{\mathrm{te}}\right)_{\mathrm{p}}$, deve-se ainda considerar que, sendo uma característica da correlação entre os ensaios de campo, deveria ser corrigido por correlações entre estes, a exemplo do $k_{t e}$ do fuste. Sendo a pretensão da correção dos coeficientes com base na experiência brasileira, observa-se que, em geral, são adotados valores de $\left(k_{\mathrm{te}}\right)_{\mathrm{P}}=\mathrm{k}_{\mathrm{te}}$, visto que se trata da relação entre a prova de carga e o cone. Outros métodos adotam um coeficiente único para o produto [ $\left.\left(k_{\text {te }}\right)_{\text {P. }} k_{\text {tEP }}\right]$, o que pode aparentar o uso de coeficientes $\left(k_{t e}\right)_{p}$ e $k_{t e}$ distintos, mas as análises apresentadas no Apêndice $B$ demonstram que é possível separar-se os dois efeitos e encontrar um valor de $\mathrm{k}_{\mathrm{tEP}}$ independente do tipo de solo, mesmo nesses métodos.

Dessa forma, conclui-se que, pela experiência brasileira, deve-se adotar $\left(k_{t e}\right)_{\mathrm{P}}=k_{t e}$. Esse procedimento, contudo, exclui todos os coeficientes passíveis de correção, o que seria aparentemente um limitante da Metodologia Semiempírica Unificada (MSU).

Neste ponto, deve-se interpretar a MSU para verificar que a diferença entre os valores de $k_{\text {te }}$ do fuste e da ponta $\left(k_{\mathrm{te}}\right)_{\mathrm{p}}$ se deve ao fato de se adotar o valor de tensão na ponta mobilizado e não de ruptura, valor este advindo da adoção de um critério de ruptura em particular, podendo-se simbolizá-lo por $\left(\mathrm{k}_{\mathrm{te}}\right)_{\text {Pcrit. }}$ Isso implica na necessidade de acrescentar um coeficiente que considere esse procedimento, aqui identificado por $\mathrm{k}_{\mathrm{tc}}=\left(\mathrm{k}_{\mathrm{te}}\right)_{\text {Pcrit }} / \mathrm{k}_{\mathrm{te}}$.

Toda essa discussão foi necessária para que, ao corrigir o valor do coeficiente de tipo de estaca da ponta, $\mathrm{k}_{\mathrm{tEP}}$, não se cometesse o erro de incluir no mesmo, além da relação entre a ponta da estaca e a ponta do cone, a influência da adoção do critério 
de ruptura. Este deve ser feito por um coeficiente à parte, advindo da própria Metodologia.

Também deve-se observar que a correção pode ser aplicada a mais de um tipo de solo, caso a região de embutimento atravesse mais de uma camada. Nesse caso, o valor médio do SPT da camada e seu respectivo peso [acima ou abaixo da ponta, conforme a expressão (16)] devem ser considerados no cálculo do coeficiente característico de resistência pela ponta $\left(\mathrm{K}_{\mathrm{pg}(\mathrm{i})}\right)$, para cada camada no trecho de embutimento, separando-se a influência de cada camada por meio das Hierarquias dos Solos da ponta, como consta na Figura 79, analogamente ao que se fez para 0 fuste.

Demonstrando esse cálculo para o caso do embutimento 8D acima e 3D abaixo

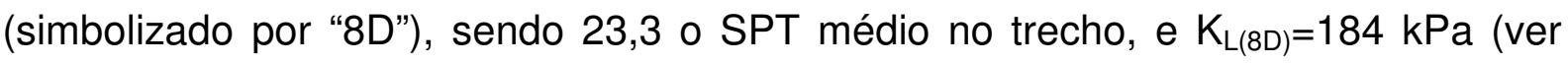
Tabela 33), tem-se, a partir das expressões (12) e (16):

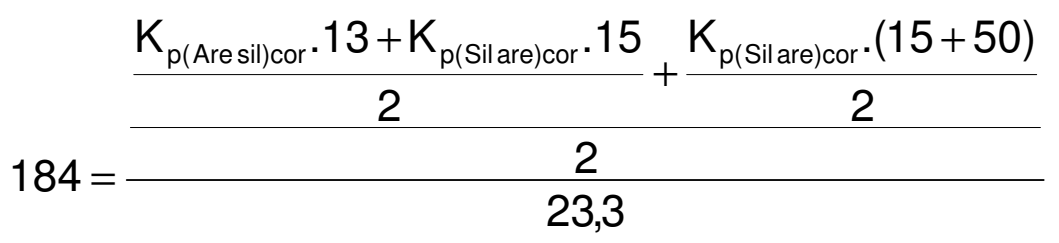

Substituindo-se $K_{p g(A r e-s i l)}=1,3 . K_{p g(S i l-a r e)}$ da Figura 79, devido às Hierarquias dos Solos, obtém-se $\mathrm{K}_{\text {pg(Sil-are)cor }}=176$ kPa e $\mathrm{K}_{\text {pg(Are-sil)cor }}=229 \mathrm{kPa}$ contra $242 \mathrm{kPa}$ e $317 \mathrm{kPa}$ respectivamente aplicado anteriormente. A redução é significativa, porém deve-se lembrar que esses dados de correção são relativos à mobilização da ponta (advinda do critério de ruptura adotado) e não da ruptura do solo da ponta do cone, como o valor anterior considerava.

Finalmente, pode-se corrigir o valor do coeficiente parcial de tipo de estaca $\mathrm{k}_{\mathrm{tEP}(\mathrm{i})}$ para cada camada (i) do trecho de embutimento, utilizando-se a expressão (144), substituindo-se $\mathrm{k}_{\mathrm{ts}}$ por $\mathrm{k}_{\mathrm{tc}}$, como já discutido, e adotando-se para $\left(\mathrm{k}_{\mathrm{te}}\right)_{\mathrm{P}}$ os mesmo valores já corrigidos de $k_{\text {te }}$ para o fuste. Embora a correção se faça em relação ao valor considerado anteriormente, aqui se busca a correção para que o método seja aplicado com novas tabelas de coeficientes empíricos, e não aplicar o método original com um fator de correção posterior. Nesse sentido o método é corrigido para o caso em questão, sendo já aplicados os valores corrigidos obtidos anteriormente. 
Continuando o exemplo para o embutimento $8 \mathrm{D}$, considerando em um primeiro momento $\mathrm{k}_{\mathrm{tc}}=1,0$, tem-se:

$$
\mathrm{k}_{\mathrm{tEP}(\text { Aresil)cor }}=\frac{229}{(1,0.749 \cdot 1,0)_{(\mathrm{P})}}=0,31
$$

O mesmo raciocínio, se aplicado ao Silte arenoso, resulta em $\mathrm{K}_{\mathrm{tEP}(\mathrm{Sil}-\text {-are)cor }}=0,39$. O valor anterior era de 0,47 , independente do tipo de solo e aplicando o mesmo processo de correção pela média independente do tipo de solo, resulta em $\mathrm{k}_{\mathrm{tEP} c \mathrm{r}}=0,35$. A redução também é significativa, porém deve-se lembrar que se refere à mobilização parcial da ponta, conforme o critério de ruptura adotado, e não em relação à ponta do cone, conforme já mencionado.

Para finalizar esta correção, ao se adotar a média independente do solo, dever-se-ia corrigir provisoriamente o valor de $\mathrm{k}_{\mathrm{te}}$, como feito para o caso do fuste. Como aqui se considera que o valor de $\mathrm{k}_{\text {te }}$ deve ser o mesmo do fuste, este não pode ser alterado, então corrige-se o coeficiente $\mathrm{k}_{\mathrm{tc}}$, que leva em consideração a influência do critério de ruptura, como já mencionado.

Assim, tem-se para a Areia siltosa:

$$
\mathrm{k}_{\mathrm{tc}(\text { Aresil) }}=\frac{229}{(0,35 \cdot 749 \cdot 1,0)_{(\mathrm{P})}}=0,87
$$

Para o Silte arenoso, resulta em $\mathrm{k}_{\mathrm{tc}(\mathrm{Sil}-\text { are })}=1,12$.

Para outras considerações de embutimento, os cálculos são análogos, contudo os valores corrigidos serão diferentes, a exemplo do que ocorrerá quando se estiver corrigindo diversos métodos: cada um gerará sua própria tabela de coeficientes parciais empíricos a ser empregada na previsão (estimativa) de capacidade de carga de outras estacas.

Também é importante atentar para o fato de que tais valores corrigidos são de aplicação exclusiva ao solo do local em estudo, obtendo-se, portanto, diferentes valores de coeficientes empíricos corrigidos para cada local, solo e tipo de estaca ensaiada. 


\subsection{CORREÇÃO DOS MÉTOdOS PARA MAIS DE UMA ESTACA ENSAIADA NO SOLO LOCAL}

A Metodologia Semiempírica Unificada aqui proposta permite a correção dos valores dos métodos semiempíricos com a possibilidade de se modificar inclusive sua forma de aplicação. Permite até mesmo propor novos métodos semiempíricos, mas não se encerram por aí suas possibilidades de aplicação.

De fato, pode-se aplicar a metodologia de correção proposta a uma estaca individual ensaiada em um determinado local e, posteriormente, aplicar o método atualizado ao projeto de outra estaca. Quando verificado o desempenho dessa nova estaca, pode-se então obter outros dados a se considerar na correção do método, de modo a se melhorar as correções para uso em projeto de uma terceira estaca a ser ensaiada no mesmo local, e assim por diante.

Por outro lado, pode-se também ensaiar quase simultaneamente mais de uma estaca, para só então analisar os resultados e propor as correções do método semiempírico.

Deve-se considerar ainda que, via de regra, o que aqui se chama de "mesmo local" pode ser interpretado como as "regiões representativas" do projeto de revisão da NBR6122. Considera-se, assim, que as sondagens dentro de uma região representativa apresentam a mesma estratigrafia básica, com tipos de solo semelhantes, podendo, todavia, apresentarem espessuras e profundidades diferentes.

No projeto, em geral, tomam-se as diversas sondagens para compor um perfil médio representativo. De fato, pode-se simplesmente adotar, para cada camada, o valor médio de $\mathrm{f}_{\max }$ obtido, realizando-se a seguir as correções como demonstrado acima.

Para o caso de estacas ensaiadas na mesma região geológica, mas em regiões representativas distintas, de modo que há certas mudanças na estratigrafia e tipos de solo, pode-se sugerir agrupar as camadas de solo pela sua característica principal, ou seja: silte arenoso argiloso e silte arenoso podem ser tratados como o silte, assim como argila arenosa e argila siltosa podem ser considerados predominantemente como argila, como se faz no método Décourt-Quaresma. Isto permite uma aplicação razoável da MSU para correção dos métodos. 
Alternativamente, pode-se indicar o cálculo direto das correções dos coeficientes de atrito pelo mesmo processo já apresentado, calculando-se todas as estacas como se fossem uma única estaca, atravessando todas as respectivas camadas de solo, e com os valores de comprimento e atrito somados.

Como exemplo de aplicação dessa alternativa, escolheram-se as estacas G201 e G202 (aplicação individual da MSU no Apêndice F), ambas do tipo raiz com D=25 $\mathrm{cm}$ e instaladas no Guarujá-SP, porém com estratigrafias apenas semelhantes, podendo-se dizer que pertencem à mesma região geológica, mas a regiões representativas distintas. A somatória dos comprimentos resulta $\mathrm{L}=20,92+32,00=52,92 \mathrm{~m}$; o SPT médio global ao longo dos fustes $\mathrm{N}_{\text {medG }}=5,87$ golpes; a soma dos atritos separados Alr $_{G}=696+751=1447 \mathrm{kN}$. Assim obtém-se o coeficiente característico global $\mathrm{K}_{\mathrm{LG}}=5,93 \mathrm{kPa}$. Tomando-se a camada de areia siltosa como referência (comum às duas estacas), as análises pelas Hierarquias dos Solos resultam na Tabela 34.

A partir dos valores dessa tabela, procedem-se as correções dos coeficientes parciais como já demonstrado.

Tabela 34 - Correção simultânea para as estacas G201 e G202 instaladas no Guarujá-SP.

\begin{tabular}{ccccc}
\hline Solo & $\Delta \mathrm{L} / \mathrm{L}$ & $\mathrm{N}_{\text {méd }}$ & $\mathrm{K}_{\mathrm{Lg}} / \mathrm{K}_{\text {Lesc }}$ & $\mathrm{K}_{\mathrm{Lcor}}$ \\
\hline Argila silto-arenosa & 0,215 & 3,15 & 0,746 & 6,90 \\
Areia siltosa & 0,529 & 3,20 & 1,000 & 9,25 \\
*Argila siltosa & 0,095 & 6,93 & 0,682 & 6,31 \\
*Areia argilo-siltosa & 0,109 & 4,00 & 0,967 & 8,94 \\
**Silte arenoso & 0,052 & 15,67 & 0,849 & 7,85 \\
\hline
\end{tabular}

Legenda: * solos presentes numa das estacas e não na outra; ${ }^{* *}$ o silte arenoso de uma estaca e o silte areno-argiloso da outra foram considerados ambos como silte arenoso.

Em todo o caso, cuidado especial deve ser dado aos solos de suporte da ponta e às considerações de embutimento, pois, para que tais análises sejam válidas, as condições devem ser as mesmas em todas as estacas estudadas. Sugere-se que no caso de serem diferentes, as análises sejam feitas pelo modelo de embutimento "OD", ou seja, consideração apenas do valor de SPT na cota da ponta. Isso porque, desta forma, não se deixa de considerar nenhuma das camadas em relação ao comportamento por atrito lateral, e, no caso de as pontas apoiarem-se em diferentes camadas, podem-se obter valores de coeficientes empíricos relativos à ponta para cada uma delas individualmente. 
Outro aspecto a se considerar é que, mesmo que os solos da ponta sejam os mesmos, cada estaca apresenta uma mobilização de ponta própria, visto que não rompem literalmente, tendo isto de ser levado em conta. Sugere-se adotar a média das tensões mobilizadas de ponta, considerando ainda o seu desvio padrão. Em termos de projeto, caso a ordem de grandeza dos valores entre si seja muito diferente, pode-se adotar a menor tensão de ponta, ou outro critério, e homogeneizar todas as estacas para este valor. Embora isso não leve em conta a fração de mobilização da resistência de cada ponta propriamente dita, pode-se dizer que os coeficientes empíricos assim ajustados conduzirão os valores de ponta para esta tensão adotada.

Evidentemente isto pode afastar um pouco as estimativas semiempíricas dos resultados obtidos nos critérios de ruptura, não significando que este ajuste imponha conservadorismo, mas apenas uma homogeneização para tornar a análise coerente.

No exemplo das estacas G201 e G202, para a ponta apoiada em silte arenoso (aproximando-se o comportamento entre o silte arenoso e o silte areno-argiloso), considerando-se para ambas o critério de Van der Veen, resulta $449 \mathrm{kN}$ para a ponta da G201 (37\% de $\mathrm{P}_{\text {omax(i) }}$ ) e 206kN para a ponta da G202 (23\% de $\mathrm{P}_{\text {omax(i) }}$ ), correspondendo respectivamente a $q_{p}=9149 \mathrm{kPa}$ e $4155 \mathrm{kPa}$. Considerando esta amplitude significativa em relação à própria média, sugere-se adotar alguma forma de homogeneização para as estacas analisadas.

Para estacas escavadas, a NBR 6122 preconiza que no máximo 20\% da carga admissível seja suportada pela ponta, o que poderia ser um critério de homogeneização para este caso. Para os exemplos dados ter-se-ia, para a ponta, $240 \mathrm{kN}$ e 180 kN e as tensões de 4889 kPa e 3667kPa. Neste caso a média das tensões resulta $4278 \mathrm{kPa}$, com os valores extremos representando $\pm 18 \%$ em relação à média, contra $\pm 37,5 \%$ sem esta homogeneização. A partir disso, o ajuste dos coeficientes empíricos de ponta se faz da mesma forma já descrita. Embora assim não se esteja considerando a fração de mobilização da ponta propriamente dita, configura-se num critério que considera a carga aplicada.

Verifica-se, portanto, que a adoção dos critérios de ruptura pode também ser influenciada quando se analisa mais de uma estaca. Assim, deve sempre ser 
considerado o fato de que o critério escolhido influencia no valor de mobilização da ponta, conforme já discutido.

Evidentemente este procedimento leva a certo grau de afastamento dos resultados em relação ao critério de ruptura inicialmente adotado, não devendo contudo este fato ser considerado como conservadorismo ou falta de segurança do método analisado, mas apenas como consequência do critério de homogeneização da fração de ponta em relação à carga máxima.

Uma forma de se tentar melhorar tais análises passa por adotar um critério de mobilização da ponta aplicando-se o método das Leis de Cambefort durante a execução do ensaio.

\subsection{EXEMPLOS DE APLICAÇÃO DA METODOLOGIA SEMIEMPÍRICA UNIFICADA A ESTACAS DE DIVERSAS REGIÕES}

Para se exemplificar a aplicação da Metodologia Semiempírica Unificada de forma mais ampla, foram escolhidas algumas estacas ensaiadas em diversas regiões do estado de São Paulo e em outras regiões brasileiras. Foram aplicados os métodos de teste Mediado e Expedito, e após a definição do critério de ruptura e a separação das parcelas de atrito e ponta, procederam-se as correções dos seus coeficientes, seguindo-se o desenvolvimento e as análises expostas no corpo do presente trabalho.

Os resultados são apresentados no Apêndice F, no qual, para cada estaca, são apresentadas, em figuras similares à Figura 80, as seguintes informações: localização; tipo da estaca; dimensões; camadas de solo do fuste e do embutimento da ponta; tipo de embutimento considerado; resultados dos critérios de ruptura; critério escolhido; tensão mobilizada na ponta; análise pela Hierarquia dos Solos e os valores corrigidos dos coeficientes dos dois métodos semiempiricos de teste.

Em relação à separação do atrito lateral pelas Leis de Cambefort modificada, com auxílio do método da Rigidez, apresentam-se gráficos similares aos da Figura 76, onde constam as informações complementares: diagrama de Rigidez do carregamento e do descarregamento, ajuste do modelo das Leis de Cambefort modificadas à curva carga-recalque, diagrama da relação $\mu \mathrm{Alr} \times \mathrm{Kr}$, bem como o tipo de sistema usado no seu ajuste; diagramas da primeira e segunda Leis de 
Cambefort para o carregamento; valores dos demais parâmetros do modelo baseado nas Leis de Cambefort modificadas.

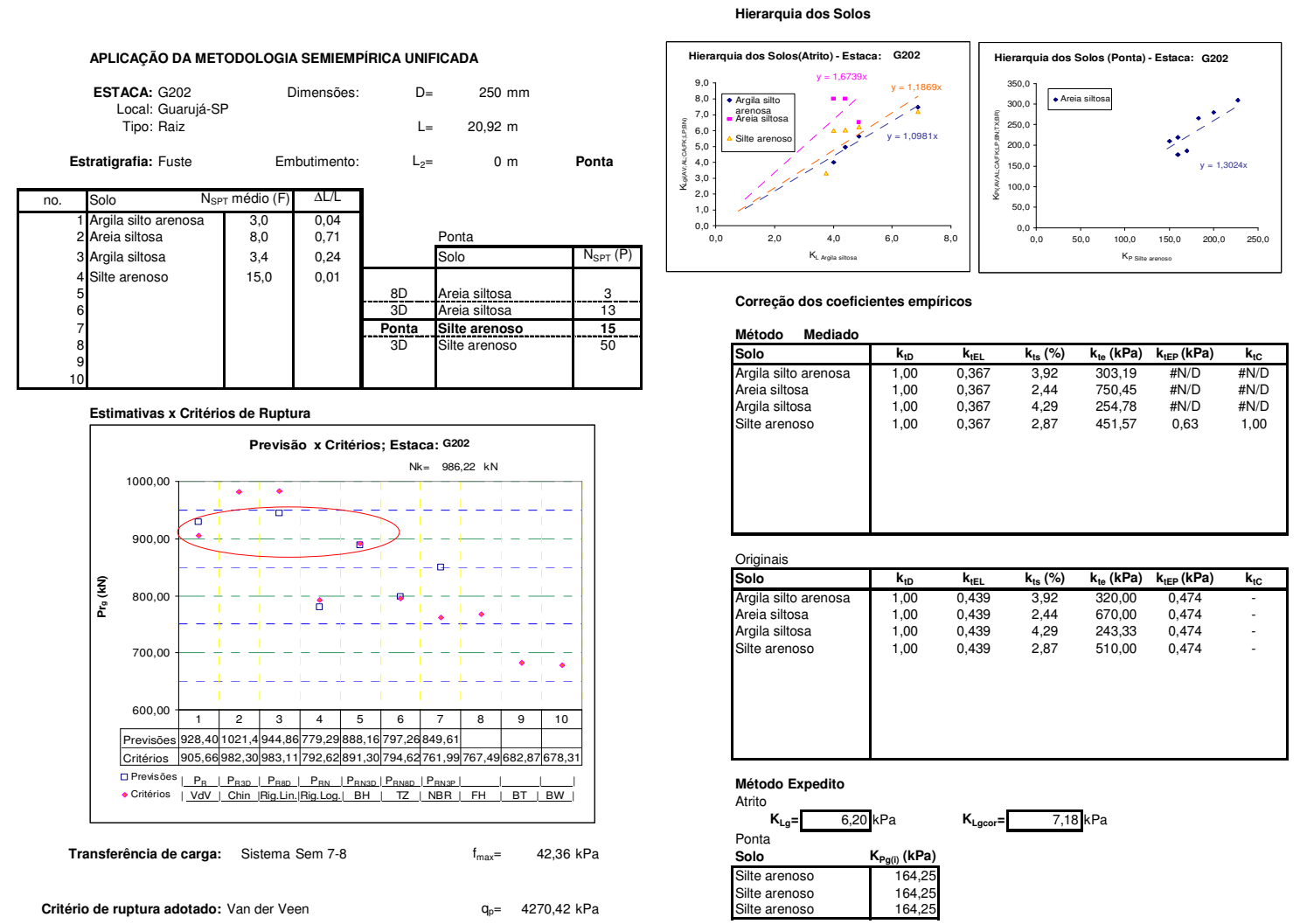

Figura 80 - Forma de apresentação dos resultados da Metodologia Semiempírica Unificada aplicada a solos de diversas regiões do país. 


\section{CONCLUSÕES E CONSIDERAÇÕES FINAIS}

Neste capítulo, são tecidas as considerações finais acerca do desenvolvimento da proposta da Metodologia Semiempírica Unificada (MSU), considerando a justificativa inicial e os objetivos aqui elencados e conclusivamente alcançados.

Partindo-se da advertência de que os métodos semiempíricos não são universais e devem ser aplicados com ressalvas a solos de locais diferentes dos originalmente pesquisados pelos seus autores (Velloso e Alonso, 2000), somada à preconização da norma brasileira de fundações, NBR 6122 (1996), de se comprovar a aplicabilidade dos métodos semiempíricos ao solo do local da obra, propôs-se o desenvolvimento de uma Metodologia Semiempírica Unificada (MSU). Essa Metodologia tinha como premissa constituir-se numa base de análise sólida, que demonstrasse não só a aplicabilidade de um método semiempírico, mas que permitisse também proceder à correção destes métodos, caso não fossem aplicáveis ao caso em estudo.

A constatação de que, nas publicações técnicas brasileiras, adota-se um certo paradigma de classificação dos métodos em conservadores ou contra a segurança, com raras investigações acerca das causas deste comportamento, fortaleceu a proposta, cujo desenvolvimento levantou questões não comumente debatidas no meio técnico.

Assim, foi desenvolvida e apresentada a Metodologia Semiempírica Unificada (MSU), que permite atribuir valores corrigidos aos coeficientes empíricos dos solos nos diversos métodos semiempíricos. A Metodologia perpassa três etapas: a Previsão (estimativa) da capacidade de carga pelos métodos semiempíricos; a Verificação de desempenho da estaca, com a comparação dos critérios de ruptura com as estimativas semiempíricas; e, finalmente, a Aferição por meio da separação das parcelas de atrito e de ponta com a posterior Correção dos coeficientes empíricos parciais, à luz do conceito das Hierarquias dos Solos (AMANN, 2000).

O desenvolvimento pleno desta Metodologia Semiempírica Unificada exigiu flexibilidade para atender a uma série de propostas, a saber: agregar as diferentes proposições e considerações existentes no processo de projeto de fundações; 
considerar e valorizar as décadas de experiência brasileira com a aplicação dos métodos semiempíricos; corrigir os coeficientes dos métodos semiempiricos de forma consistente e otimizada; permitir sua aplicação ao desenvolvimento de novos métodos; ser aplicável a solos e estacas nunca antes pesquisados. Diversas análises tiveram de ser desenvolvidas para se chegar, com alguma precisão, a uma forma conceitualmente coerente de aplicação da MSU, de modo a proporcionar os resultados otimizados pretendidos.

Diante da extensão das análises desenvolvidas, torna-se conveniente apresentar as conclusões obtidas a partir da retomada dos objetivos específicos do trabalho, como segue.

\subsection{SOBRE OS OBJETIVOS ESPECÍFICOS}

\section{Relação conceitual entre os métodos semiempíricos, teóricos e empíricos}

Estabeleceram-se as relações conceituais entre os métodos semiempíricos, teóricos e os empíricos, demonstrando, sobretudo, que as considerações de embutimento da ponta (8 diâmetros acima e 3 diâmetros abaixo da ponta da estaca, 3D acima e abaixo da ponta, etc.), adotadas em diversos métodos semiempíricos, são oriundas dos métodos teóricos (item 2.10), assim como, a somatória dos SPT's das camadas já era utilizada nos métodos empíricos, para determinação da profundidade de parada da cravação de estacas (item 2.3).

Verificou-se que, embora os métodos semiempíricos especifiquem qual a condição de embutimento adotada em sua concepção, é necessário avaliar-se a sondagem para verificar sua adequação. No caso de solos com resistências muito díspares na região de embutimento adotada, os resultados de resistência da ponta podem fugir da realidade (item 2.8). Sugere-se que o embutimento seja adotado como premissa de projeto e controlada a sua execução em obra, para, então, ser considerado no método semiempírico. Recomenda-se que no caso de análise de mais de uma estaca para o solo local, considere-se apenas um valor de SPT na cota da ponta, para permitir maior flexibilidade de análise quando há estacas com ponta apoiada em camadas diferentes. 


\section{Definição da metodologia de concepção dos métodos semiempíricos}

Analisando-se criticamente os métodos semiempíricos brasileiros, definiram-se as considerações metodológicas de suas concepções, a saber (itens 2.4 e 2.6): comparação da estaca ao ensaio de CPT; uso de correlações entre o ensaio de CPT e os ensaios SPT; consideração da resistência de cisalhamento (atrito) lateral por meio de somatória das resistências individuais das camadas ou por média geral ao longo do fuste; consideração de diferentes formas de embutimento da ponta.

O reconhecimento dessas características dos métodos permitiu a sua generalização (item 2.5), com a qual se podem identificar os coeficientes parciais de influência (item 2.9), bem como a definir o conceito de Hierarquias dos Solos (AMANN, 2000) [item 2.7]. Com esse conceito pode-se estimar a resistência de um dado solo a partir de outro, o que se constituiu na chave do processo de aferição e correção dos métodos semiempíricos (item 6.3.3), no caso de provas de carga não instrumentadas.

Com base nessas características, foi proposta, ainda, a criação de dois métodos semiempíricos de teste, o Mediado e o Expedito (item 2.11), para simplificar a aplicação nas análises do trabalho.

Os valores de seus coeficientes empíricos foram atribuídos pela média geral dentre os métodos semiempíricos pesquisados, daí o nome Mediado. O expedito considera apenas a média dos SPT's dos solos do fuste, independentemente do tipo de solo, e três valores de SPT's em torno da ponta. Já o mediado admite as três diferentes formas de consideração do embutimento da ponta, para verificação da adequabilidade ao solo local, além de utilizar tanto o atrito por somatória das camadas como pela média. Obtém-se, assim, 7 valores de estimativas semiempíricas da capacidade de carga, que representam os diferentes modelos dos métodos semiempíricos, e que foram comparados aos critérios de ruptura.

\section{Consideração do tipo de ensaio de campo nos métodos semiempíricos}

Discutiu-se a forma de consideração do tipo de ensaio de campo nos métodos semiempíricos, de modo a determinar-se o real efeito de eventuais correções nos valores das sondagens (itens 2.4 .1 e 2.4.2). As correções de sondagem por meio de ensaios de torque, energia, densidade relativa da areia, e outras, podem ser usadas satisfatoriamente apenas em alguns métodos, sendo, porém, menos adequadas do 
que o uso de correlações específicas para o local da obra (ALBIERO, 1990). Isso justifica a proposta de correção exclusiva para cada caso pesquisado.

Assim sendo, outros tipos de ensaio de campo, além do CPT e do SPT, podem ser utilizados, desde que se estabeleçam as correlações de comportamento entre a estaca e o ensaio, para o solo local, corrigindo-se, assim, o coeficiente parcial de tipo de ensaio (item 2.9.2).

\section{Identificação e discussão do "paradigma atual" de análise de aplicabilidade dos métodos e proposta de uma nova forma de análise}

Discutiu-se o aqui chamado "paradigma atual" de análise de aplicabilidade dos métodos por meio de sua classificação em "conservador" e "contra a segurança", demonstrando que se trata de uma questão relativa ao critério de ruptura escolhido, e, portanto, não sendo absoluta, tal classificação deixa de ter sentido para atestar a aplicabilidade dos métodos (item 3.5). Verificou-se, também, que cada método semiempírico possui intrinsecamente um critério de ruptura inerente, desde a sua concepção (itens 2.4 .3 e 2.4.4). Dessa forma, a comparação com outro critério qualquer perde o sentido, para efeito de classificação do método, visto que, assim, se avalia o método com uma base de julgamento que não faz parte de sua concepção.

Como nova forma de análise, propôs-se comparar todos os 9 critérios de ruptura com as estimativas semiempíricas (item 3.7.1), estabelecendo-se um procedimento para adoção do critério de ruptura mais adequado ao método semiempírico (item 3.7.2), considerando a estaca e o solo local, bem como à verificação de desempenho e correção dos coeficientes empíricos (item 3.7.3).

Resumidamente, o procedimento consiste em verificar quais os critérios de ruptura que mais se aproximam do método semiempírico em estudo e, ao mesmo tempo, da carga máxima do ensaio (FELLENIUS, 2006), sem superar o valor da resistência estrutural da estaca. Isso garante a otimização da análise, à medida que permite, inclusive, verificar qual o método semiempírico que melhor se adéqua ao local em estudo.

Uma constatação importante dessa análise, é que, ao se adotar um critério de ruptura, a parcela de carga da ponta fica definida pela diferença entre o seu resultado e a parcela de atrito lateral, obtido na etapa de aferição da MSU. Como, 
em geral, a ponta é apenas parcialmente mobilizada nas provas de carga, não chegando à ruptura de fato, o valor assim calculado guarda certa reserva de resistência, a qual não pode ser quantificada com bom grau de confiança.

Esse fato evidencia uma incompatibilidade intrínseca, porém raramente debatida, entre a concepção dos métodos semiempíricos, baseados em correlações com o CPT, cuja ponta é a medida de maior confiabilidade, e a verificação de desempenho pelas provas de carga, nas quais, ao contrário, o valor do atrito é verificado de forma mais confiável do que o da ponta. A adoção de coeficientes de segurança da ponta maiores do que os do atrito, só é eficiente para atribuição da carga admissível, em nada favorecendo a estimativa da carga de ruptura.

\section{Aproveitamento e valorização da experiência brasileira com os métodos semiempiricos no desenvolvimento da MSU}

A generalização dos métodos semiempíricos, a definição das Hierarquias dos Solos e a proposta de correção dos coeficientes parciais, só foram possíveis a partir da discussão das bases conceituais, extraídas da análise crítica da experiência de uso e aplicação dos métodos (item 2.6). Também a proposta de criação dos métodos semiempíricos de teste, Mediado e Expedito, só foi possível a partir dos valores dos coeficientes dos métodos analisados. Dessa forma, atendeu-se plenamente à proposta de se aproveitar a vasta experiência brasileira, valorizando, assim, o conhecimento adquirido pelo meio técnico nacional.

Determinação das relações dos critérios de ruptura da curva carga-recalque entre si e com os métodos de transferência de carga

Com a análise dessas relações, verificou-se que os critérios de recalque limite e os de interseção de retas resultam valores próximos ao atrito lateral desenvolvido no ensaio (incluídas as eventuais cargas residuais), e não à ruptura propriamente dita (itens 3.6.2 e 3.6.3).

Pela comparação com os métodos de transferência de carga, mesmo os critérios de ajuste matemático demonstraram-se em certa medida conservadores e muito influenciados pelo último ponto de carregamento do ensaio de prova de carga (item 3.6.4).

Demonstrou-se, à luz das Leis de Cambefort modificadas por Massad (1992), que o método de Van der Veen modificado por Aoki (1976), por exemplo, resulta em cerca 
de $70 \%$ da carga de ruptura pretensamente real, nos casos em que seu ajuste à curva carga-recalque é muito bom. Para estacas cravadas a coerência é melhor, pois a curva de ensaio tende a uma ruptura mais brusca. Isso vai de encontro ao que verificaram experimentalmente Décourt e Niyama (1994). Se a prova de carga avançar e se aproximar da ruptura de fato, a curva deixa de ter bom ajuste, embora o resultado fique cada vez mais próximo do real, devido ao último ponto de ensaio apresentar grande influência no resultado do critério.

É por esse motivo que o critério de Van der Veen tende a resultar valores mais próximos da carga máxima de ensaio, como se observou nos exemplos de aplicação da MSU (Apêndice F).

\section{Determinação do critério de ruptura mais adequado a cada metodologia semiempírica}

Propôs-se uma forma gráfica de se avaliar e escolher qual o critério de ruptura mais adequado a um determinado método semiempírico, bastando verificar a proximidade entre os seus resultados para o caso em estudo (item 3.7.1). Com isso, dá-se abertura para avaliar a possibilidade de outro critério de ruptura substituir, vantajosamente, o critério adotado na concepção do método semiempírico estudado, promovendo-se flexibilidade de aplicação dos critérios, de forma conceitualmente coerente. É importante que, após definida a substituição, este novo critério seja sempre empregado para o solo e tipo de estaca em questão.

Dedução de nova abordagem matemática da transferência de carga, para análise de ensaios instrumentados

A necessidade de uma nova abordagem matemática da transferência de carga surgiu da identificação de uma aparente inconsistência. Ao se compararem as formas usuais de representação das curvas de atrito, versus deslocamento do fuste $(y-\tau)$, às formas polinomiais de ajuste dos dados instrumentados, aqui proposta, verificou-se que nenhuma correspondia ao quociente da derivada segunda pela própria função (item 5.1.1), que é a definição matemática do parâmetro $B$ desses métodos.

A solução da inconsistência foi obtida pela percepção de uma variável não considerada na formulação usual, qual seja, a carga aplicada em cada estágio do ensaio, que se constitui na entrada de energia do sistema (item 5.4). Com isso, a 
abordagem matemática das funções de transferência de carga, passa de Equação Diferencial de Segunda Ordem para Equação Diferencial Parcial.

O ajuste dos resultados de instrumentação das estacas a polinômios, foi proposto para permitir a obtenção das curvas de transferência de carga, de forma contínua, em qualquer profundidade e nível de carga, o que permite aferir o atrito máximo de cada camada de solo (item 6.3.2). Assim, por simples derivação ou integração da função das cargas ao longo do fuste, obtêm-se rapidamente, sem as descontinuidades da análise usual, as funções de atrito e recalque ao longo do fuste, e delas, o atrito atribuído a cada camada individualmente, mesmo que haja grande número de camadas e poucos pontos de instrumentação.

Relação dos diversos métodos de transferência de carga entre si, bem como com o método da Rigidez, para separação das parcelas de atrito e ponta

Demonstrou-se, a partir da dedução da solução da Equação Diferencial da transferência de carga de estacas, a base matemática e conceitual comum dos diversos métodos de transferência de carga. Isso evidenciou a possibilidade de correlacioná-los entre si, de modo a evitar a necessidade de aplicação de mais de um deles na separação das parcelas de atrito e de ponta (item 4.1). Escolheu-se, assim, o uso do método das Leis de Cambefort Modificadas por Massad (1992).

A separação das parcelas de atrito e de ponta pelo método da Rigidez (DÉCOURT, 1999), em comparação com as Leis de Cambefort Modificadas, permitiu identificarem-se as semelhanças entre estes métodos e propor-se a utilização do diagrama de Rigidez como auxiliar na melhor definição dos trechos da curva cargarecalque, evitando-se, assim, o uso duplo dos métodos (item 4.5).

\section{Proposta de solução simultânea do atrito e da rigidez estrutural da estaca no método das Leis de Cambefort Modificadas}

A fim de se agilizar o processo de separação do atrito lateral, propôs-se uma nova forma de solução para o método das Leis de Cambefort modificadas por Massad, considerando-se as expressões matemáticas de cada trecho como equações de um sistema cujas variáveis são a rigidez estrutural da estaca e o atrito majorado das cargas residuais. Desta forma obtêm-se simultaneamente estas incógnitas, evitandose o uso de valores de rigidez incompatíveis com as curvas ajustadas, e definindose melhor as bases matemáticas do método (item 4.3). 
Atribuição do atrito a cada camada de solo do fuste a partir do conceito de Hierarquia dos Solos

A partir da separação da parcela de atrito pelos métodos de transferência de carga, propôs-se a correção dos coeficientes empíricos parciais de cada camada de solo do fuste. Para se distribuir os valores adequados a cada camada, recorreu-se ao conceito de Hierarquia dos Solos (AMANN, 2000), o qual permite determinar, para um mesmo valor de SPT, os coeficientes de resistência dos solos em relação aos outros (item 6.3.3).

\section{Separação dos coeficientes empíricos de tipo de estaca dos de tipo de solo}

Propôs-se a correção dos coeficientes parciais com base na generalização dos métodos e fixando-se, com bases conceituais, os valores do coeficiente de tipo de solo, como referencial. Os coeficientes de tipo de estaca encontrados inicialmente variavam com o solo, como proposto pelo método Décourt-Quaresma, porém, optouse por adotar o seu valor médio, independentemente do tipo de solo, por ser o mais comum na experiência brasileira. A partir disso, se propôs a correção provisória dos coeficientes de tipo de ensaio, que embora dependam da realização de ensaios para serem corrigidos, permitiu a consideração dos coeficientes de tipo de estaca independentemente do tipo de solo (item 6.3.3.3).

\section{Aplicação da MSU a solos de diversas regióes e avaliação de suas potencialidades}

Demonstrou-se que a Metodologia Semiempírica Unificada (MSU) possui muitas aplicações, desde a correção dos métodos semiempíricos existentes até a criação de novos métodos semiempíricos. Destaca-se, de modo bastante incisivo, que os valores corrigidos, obtidos pela MSU, são de uso e aplicação restrita ao local em estudo, podendo e devendo ser reaplicada a cada novo local onde se desempenhe um projeto.

\subsection{SOBRE O OBJETIVO GERAL: A PROPOSIÇÃO DA MSU PARA CORREÇÃO DOS MÉTODOS SEMIEMPÍRICOS}

O grande número de análises e novas propostas desenvolvidas no presente trabalho, tiveram a finalidade principal de se detalhar, de forma otimizada, todas as 
etapas de aplicação da Metodologia Semiempírica Unificada. Contudo, é possível resumir sua proposição e forma de aplicação como segue:

\section{Primeira etapa: Previsão (estimativa) da capacidade de carga}

Aplicam-se aqui os métodos semiempíricos, sejam eles os usuais, os métodos de teste aqui desenvolvidos, ou novos métodos em desenvolvimento. O importante é que se conheça a base conceitual de sua aplicação, como o tipo de ensaio de campo, a forma de consideração do solo do fuste e do embutimento da ponta, o qual deve estar de acordo com a sondagem. Seus resultados devem ser confrontados com os da etapa seguinte.

\section{Segunda etapa: Verificação de desempenho}

Aplicam-se os critérios de ruptura disponíveis, dando-se preferência ao critério adotado na concepção do método semiempírico em análise. Do confronto entre os seus resultados e os das estimativas semiempíricas, pode-se obter: a confirmação da adequação do critério original; a proposta de adoção de um critério mais adequado às condições locais (desde que a partir de então ele seja sempre o utilizado); ou a identificação de qual das estimativas semiempíricas (com respectivas formas de consideração do solo do fuste e de embutimento da ponta) mais se aproxima do critério de ruptura adotado. Em qualquer caso, sugere-se adotar o critério que mais se aproxime da carga máxima de ensaio, sem ultrapassar a carga de ruptura estrutural da estaca. Seu resultado será usado para a determinação da parcela de ponta, após a separação das parcela de atrito da etapa seguinte.

\section{Terceira etapa: Aferição e Correção dos coeficientes parciais empíricos}

Nesta etapa, procede-se a separação da parcela de atrito lateral, pela aplicação do método das Leis de Cambefort modificadas, auxiliado pelo método da Rigidez na definição dos trechos da curva carga-recalque. Sugere-se o uso dos sistemas propostos para solução simultânea do atrito e da rigidez da estaca, embora se possam utilizar as formas originalmente propostas pelos seus autores. Detalhe importante é a obtenção do atrito sem as cargas residuais, o que o método escolhido permite fazer sem dificuldades. De posse do valor do atrito lateral, a parcela de ponta é atribuída por diferença entre ele e o resultado do critério de ruptura adotado. A partir de então, procede-se a Correção dos coeficientes. 
Para a Correção dos coeficientes, é necessário distribuir-se o valor de atrito lateral entre as camadas de solo, a menos que se tenha adotado uma estimativa semiempírica que use a média ao longo do fuste. Essa atribuição pode ser feita de duas formas: a) com uso dos ajustes polinomiais de ensaios instrumentados, quando for o caso, tomando-se então o atrito máximo no ponto médio de cada camada; b) ou, como é o mais comum, utilizando-se as relações entre os coeficientes das Hierarquias dos Solos.

Tendo-se os valores de atrito em cada camada, ponderam-se seus valores em relação às suas espessuras, com a formulação proposta no item 6.3.3, e obtêm-se diretamente os valores dos coeficientes parciais corrigidos. Alguns ajustes podem ser necessários, dependendo da decisão de se adotar os coeficientes parciais de tipo de estaca variando com o tipo de solo (como propõe o método DécourtQuaresma) ou não (como os demais métodos brasileiros consideram).

\subsection{CONSIDERAÇÕES FINAIS}

Enfim, o processo de desenvolvimento da Metodologia Semiempírica Unificada permitiu um conhecimento conceitual aprofundado dos métodos semiempíricos, bem como dos critérios de ruptura e dos métodos de transferência de carga. Tal conhecimento, por si só, pode justificar o porte do trabalho, porém, não se deve perder de vista o aspecto prático de sua aplicação à realidade de projeto. Se bem utilizada, a MSU permite uma estimativa mais adequada da capacidade de carga com otimização de recursos, à medida que substitui as incertezas da mera classificação do paradigma atual por uma forma conceitualmente consistente de avaliar e explicar o comportamento dos métodos semiempíricos, com melhorias em sua aplicação.

Evidentemente, como toda nova proposta, apenas com seu uso e avaliação se poderá medir o impacto das possibilidades que a mesma permite. Contudo, independentemente de seu uso pelo meio técnico, fica aqui marcada a proposta de uma nova visão sobre a forma de se avaliar a adequabilidade dos métodos semiempíricos em relação aos critérios de ruptura, alertando-se para a inadequação conceitual que se vem praticando nos últimos anos. Se a contribuição for, meramente, iniciar o debate sobre o tema, o objetivo já foi alcançado. 


\subsection{SUGESTÕES PARA TRABALHOS FUTUROS}

Com base nas análises aqui desenvolvidas, podem-se propor as seguintes pesquisas complementares:

- Tratamentos estatísticos mais elaborados sobre as Hierarquias dos Solos, de modo a estabelecerem-se, conceitual e fisicamente, as resistências relativas entre os solos de mesmo valor de SPT;

- Aprofundamento de interpretação do diagrama de Rigidez, em relação aos métodos de transferência de carga, para otimização de seu uso;

- Análise aprofundada dos métodos de extrapolação matemática da curva carga-recalque,para definição de sua aplicabilidade;

- Desenvolvimento da solução da nova abordagem matemática da transferência de carga por Equações Diferenciais Parciais, aplicada a ensaios instrumentados, com inclusão do tempo de carregamento nas análises;

- Estudo de inter-relação entre a mecânica dos solos dos estados críticos e a ruptura por cisalhamento do solo do fuste, em relação à transferência de carga;

- Aplicação da Metodologia Semiempírica Unificada a outros casos com mais de uma estaca instalada no local, de modo a atestarem-se quantitativamente seus benefícios, em termos de ganho de confiabilidade do projeto e de economia de recursos.

Ainda há muito o que se esclarecer sobre o mecanismo de transferência de carga, e é ele quem permitirá o avanço científico dos métodos utilizados em projeto de fundações por estacas, ainda que eles estejam calcados na valoração de parâmetros puramente empíricos. 


\section{BIBLIOGRAFIA}

ALBIERO, J.H. O emprego de fórmulas empíricas na previsão da carga última de Estacas. 1990. 253p. Tese (Livre-Docência) - Escola de Engenharia de São Carlos, Universidade de São Paulo, São Carlos, 1990.

ALBUQUeRQue, P.J.R., MASSAD, F., CARVALHO, D., FERREIRA, M. A. M. Comportamento à compressão de estacas escavadas, hélice contínua e hélice tipo ômega, em solo residual de diabásio. Campinas: UNICAMP/EPUSP/FAPESP/CNPq/ABMS/FUNDESP, 2001. 198 p.

ALLEDI, C.T.D.B.; POLIDO, U.F. Capacidade de carga de estacas hélice-contínua: previsão por métodos semi-empíricos versus provas de carga. In: SEMINÁRIO DE ENGENHARIA DE FUNDAÇÕES ESPECIAIS E GEOTECNIA, 6, 2008, São Paulo. Anais... SEFE VI. São Paulo: ABEF, 2008. p. 249-262.

ALLEDI, C.T.D.B.; POLIDO, U.F.; ALBUQUERQUE, P.J.R. Provas de carga em estacas hélice-contínua monitoradas em solos sedimentares. In: CONGRESSO BRASILEIRO DE MECÂNICA DOS SOLOS E ENGENHARIA GEOTÉCNICA, 13, 2006, Curitiba. Anais... COBRAMSEG XIII. Curitiba: ABMS, 2006. v. 2. p. 10671072.

ALONSO, U.R. Correlações entre Resultados de Ensaios de Penetração Estática e Dinâmica para a cidade de São Paulo. Revista Solos e Rochas, São Paulo, v. 3, n. 3, p. 19-25, dez. 1980.

Estimativa da Curva Carga-Recalque de Estacas a partir dos Resultados de Sondagens à Percussão. Revista Solos e Rochas, São Paulo, v. 4, p. 19-32, 1981.

Estimativa da Transferência de Carga de Estacas Escavadas a partir do SPT. Revista Solos e Rochas, São Paulo, v. 4, p. 21-27, 1983.

. Dimensionamento de Fundações Profundas. São Paulo: Edgard Blücher, 1991. p. 1-9.

Reavaliação do dimensionamento estrutural de estacas raiz face à exigência do ensaio MB-3472 da ABNT. Revista Solos e Rochas, São Paulo, v. 16, n. 1, p. 41-44, 1993.

Correlações entre o atrito lateral medido e com o torque e o SPT. Revista Solos e Rochas, São Paulo, v. 17, n. 3, dez. 1994.

Estacas hélice contínua com monitoramento eletrônico - previsão da capacidade de carga através do ensaio SPT-T. In: SEMINÁRIO DE ENGENHARIA DE FUNDAÇÕES ESPECIAIS, 3, 1996, São Paulo. Anais... SEFE III. São Paulo: ABEF/ABMS, 1996. v. 2. p. 141-151.

Estimativa da adesão em estacas a partir do atrito lateral medido com torque no ensaio SPT-T. Revista Solos e Rochas, São Paulo, v. 20, n. 1, p. 47-59, 1997. 
ALONSO, U.R. Previsão e controle das fundações. São Paulo: Editora Edgar Blücher, 2ª reimpressão., 1998. p. 62-69.

Projeto e desempenho das fundações (retrospectiva da experiência brasileira). In: SEMINÁRIO DE ENGENHARIA DE FUNDAÇÕES ESPECIAIS, 5, 2004, São Paulo. Anais... SEFE V. São Paulo: ABEF/ABMS, 2004, v. 2, p. 1-34.

A experiência brasileira no projeto de fundações. In: SEMINÁRIO DE ENGENHARIA DE FUNDAÇÕES ESPECIAIS, 6, 2008, São Paulo. Anais... SEFE VI. São Paulo: ABEF/ABMS, 2008. v. 1. p. 1-34.

ASSOCIAÇÃO BRASILEIRA DE NORMAS TÉCNICAS. NBR 6122: Projeto e execução de fundações. Rio de Janeiro. 1996. 33 p.

2006.8 p.

NBR 12131: Estacas-Provas de Carga-Método de ensaio. Rio de Janeiro.

NBR 13208: Estacas-ensaio de carregamento dinâmico. Rio de Janeiro. 2006. 12 p.

AMANN, K.A.P. Avaliação crítica dos métodos semi-empíricos de estimativa da carga de ruptura, aplicados a estacas raiz. 2000. 230p. Dissertação (Mestrado) Escola Politécnica da Universidade de São Paulo, São Paulo, 2000.

Avaliação crítica de métodos semi-empíricos aplicados a estacas hélicecontínua e ômega. In: SEMINÁRIO DE ENGENHARIA DE FUNDAÇÕES ESPECIAIS, 5, 2004, São Paulo. Anais... SEFE V. São Paulo: ABEF/ABMS, 2004. v. 2. p. 308-318.

Discussão de conceito e validação da hierarquia dos solos a partir das análises dos métodos semi-empíricos para previsão da capacidade de carga de estacas. In: CONGRESSO BRASILEIRO DE MECÂNICA DOS SOLOS E ENGENHARIA GEOTÉCNICA, 13, 2006, Curitiba. Anais... COBRAMSEG XIII. Curitiba: ABMS, 2006. p. 811-816.

Análise matemática e paramétrica dos métodos de interpretação da curva carga recalque de estacas. In: CONGRESSO NACIONAL DE GEOTECNIA, 11, 2008, Coimbra. Anais... XI GEO. Coimbra: SPG, 2008. v. 4. p. 75-82. CD-ROM.

Simulação parametrizada de provas de carga utilizando as leis de Cambefort modificadas por Massad (1992, 1993). In: CONGRESSO BRASILEIRO DE MECÂNICA DOS SOLOS E ENGENHARIA GEOTÉNICA, 14, 2008, Búzios. Anais... COBRAMSEG XIV. Rio de Janeiro: ABMS, 2008. p. 869-876.

Comparação analítica de métodos de transferência de carga para interpretação de provas de carga de estacas. In: SEMINÁRIO DE ENGENHARIA DE FUNDAÇÕ̃ES ESPECIAIS, 6, 2008, São Paulo. Anais... SEFE VIII. São Paulo: ABEF/ABMS, 2008. v. 1. p. 397-412. 
AMANN, K.A.P; MASSAD, F. Estacas raiz: avaliação crítica e proposta de melhoria dos métodos semi-empíricos de estimativa da carga de ruptura. In: SEMINÁRIO DE ENGENHARIA DE FUNDAÇÕES ESPECIAIS, 4, 2000, São Paulo. Anais... SEFE IV. São Paulo: ABEF/ABMS, 2000. v. 1. p. 273-279.

AMANN, K.A.P; MASSAD, F. Avaliação da "hierarquia dos solos" e generalização dos métodos semi-empíricos de estimativa da carga de ruptura de estacas. In: CONGRESSO BRASILEIRO DE MECÂNICA DOS SOLOS E ENGENHARIA DE FUNDAÇÕES, 12, 2002, São Paulo. Anais... COBRAMSEF XIV. São Paulo: ABMS, 2002, v. 3, p. 1321-1332.

ANTUNES, W.R., CABRAL, D.A. Capacidade de carga de estacas hélice contínua. In: SEMINÁRIO DE ENGENHARIA DE FUNDAÇÕES ESPECIAIS, 3, 1996, São Paulo. Anais... SEFE III. São Paulo: ABEF/ABMS, 1996. v. 2. p. 105-110.

AOKI, N. Considerações sobre Projeto e Execução de Fundações Profundas. In: SEMINÁRIO DE FUNDAÇÕES DA SOCIEDADE MINEIRA DE ENGENHEIROS, 1979, Belo Horizonte. Anais... p. 1-32.

Sobre a origem do método Aoki-Velloso. [entrevista pessoal]. São Carlos, Escola de Engenharia de São Carlos da Universidade de São Paulo. Entrevista concedida em 20 de março de 2007.

. Dogma do fator de segurança. In: SEMINÁRIO DE ENGENHARIA DE FUNDAÇÕ̃ES ESPECIAIS, SEFE VI, 2008, São Paulo. Anais... São Paulo: ABEF/ABMS v.1 p. 9-42.

AOKI, N. ; ALONSO, U.R. Provas de Carga em Estacas de Concreto Armado Centrifugado. In: CONGRESSO BRASILEIRO DE MECÂNICA DOS SOLOS E ENGENHARIA DE FUNDAÇÕES, 8, 1986, Porto Alegre. Anais... COBRAMSEG VIII. Porto Alegre: ABMS, 1986, v. 6, p. 287-295.

AOKI, N. ; LOPES, F.R. An approximate method to estimate the bearing capacity of piles. In: CONGRESSO PANAMERICANO DE MECÂNICA DOS SOLOS E ENGENHARIA DE FUNDAÇÕES, 5, 1986, Porto Alegre. Anais... Buenos Aires, 1975, p. 367-376.

AOKI, N. ; VELLOSO, D. A. Estimating Stresses and Settlements due to Deep Foundations by the Theory of Elasticity. In: CONGRESSO PANAMERICANO DE MECÂNICA DOS SOLOS E ENGENHARIA DE FUNDAÇÕES, 5, 1986, Porto Alegre. Anais... Buenos Aires, 1975, p. 377-386.

AZEVEDO Jr., N. ; NIYAMA, S. Determinação do Módulo de Elasticidade de Estacas de Concreto. In: CONGRESSO BRASILEIRO DE MECÂNICA DOS SOLOS E ENGENHARIA GEOTÉCNICA, 9, 1990, Salvador. Anais... COBRAMSEG IX. Salvador: ABMS, 1990. v. 2. p. 519-522.

BAGUELIN, F. ; VENON, J.P. Influence de la Compressibilité des Pieux sur la Mobilisation des Efforts Résistants. In: Le Comportement des Sols Avant la Rupture. Bulletin de Liaison des Laboratories des Ponts et Chaussées, n. Spécial, p. 308-322, Mai. 1971. 
BRASFOND FUNDAÇÕES ESPECIAIS S.A. Estacas Raiz. Catálogo. 1991. 38 p.

BURIN, S.M. Estimativa da carga de ruptura de estacas a partir de resultados de provas de carga. 1989. 149 p. Dissertação (Mestrado) - Escola Politécnica da Universidade de São Paulo, São Paulo, 1989.

CABRAL, D.A. O uso da estaca raiz como fundação de obras normais. In: CONGRESSO BRASILEIRO DE MECÂNICA DOS SOLOS E ENGENHARIA DE FUNDAÇÕES, 8, 1986, Porto Alegre. Anais... COBRAMSEF VIII. Porto Alegre: ABMS, 1986. v. 6. p. 71-82.

CABRAL, D.A.; ANTUNES, W.R.; FERREIRA, M. (2000). Apresentação não formal.

CABRAL, D.A.; FEITOSA, G.O.; GOTLIEB, M. Um caso de reformulação de fundações com emprego de estacas raiz. In: SEMINÁRIO DE ENGENHARIA DE FUNDAÇÕES ESPECIAIS, 2, 1991, São Paulo. Anais... SEFE I. São Paulo: ABEF/ABMS, 1991, v. 1, p. 58-68.

CAMBEFORT, M. Essai sur le comportement en terrain homogène des pieux isolés et des groupes de pieux. Annales - L'INSTITUTE DU BATIMENT ET DES TRAVAUX PUBLIC, $\mathrm{n}$. 204, p. 1478-1518, Dec. 1964.

CARVALHO, et.al. Concurso para previsão do comportamento de estacas raiz. São Paulo: ABEF/ABMS/CTIC, 2004. 184 p.

CHIN, F. K. Estimation of the Ultimate Load of Piles not Carried to Failure. In: SOUTHEAST ASIAN CONFERENCE ON SOIL ENGINEERING, 2, 1970, Singapore. Proc... 1970, p. 81-92.

CINTRA, J.C.; AOKI, N. Carga admissível em fundações profundas. São Carlos: EESC/USP, 1 ed. 1999. 21 p.

CORRÊA, R.S. Previsão da carga de ruptura de estacas raiz a partir de sondagens de simples reconhecimento. 1988. 131p. Dissertação (Mestrado) Escola Politécnica da Universidade de São Paulo, São Paulo, 1988.

COYLE, H.M. ; REESE, L.C. Load transfer for axially loaded piles in clay. Journal of the Soil Mechanics and Foundation Division - ASCE, v. 92, n. SM2, p. 1-26, Mar. 1966.

CRAIG, R.F. Mecânica dos solos. Rio de Janeiro: Livros Técnicos e Científicos, 7ạ . ed, 2007. p. 254-261.

DANZIGER, B. R. ; VELLOSO, D. A. Correlações entre SPT e os resultados dos ensaios de penetração contínua. In: CONGRESSO BRASILEIRO DE MECÂNICA DOS SOLOS E ENGENHARIA DE FUNDAÇÕES, 8, 1986, Porto Alegre. Anais... COBRAMSEF VIII. Porto Alegre: ABMS, 1986, v. 6, p. 103-113. 
DAVISSON, M.T. High Capacity Piles. In: Proceedings, Lecture Series, Innovation in Foundation Construction. Illinois: American Society of Civil Engineers - ASCE, 1972. 52 p.

DÉCOURT, L. Predicted and measured behavior of non displacements piles in residual soils. In: DEEP FOUDATIONS ON BORED AND AUGER PILES, 2, 1993, Ghent. Proc... BAP II, p. 369-376.

Discussão da Nota Técnica "Reavaliação dos métodos de capacidade de carga à tração de estacas tipo raiz" de Urbano Rodriguez Alonso - Revista Solos e Rochas, vol. 18, no. 1, Abril de 1995, pp. 45-49. Revista Solos e Rochas, São Paulo, v. 18, n. 3, p. 173175, dez. 1995.

DÉCOURT, L. Análise e Projeto de Fundações Profundas - Estacas. In: Fundações: teoria e prática. 1 ed. São Paulo-SP: ABMS/ABEF/Pini, 1996. p. 265301.

. Sobre a origem do método Décourt-Quaresma. [entrevista pessoal]. São Paulo, Sede da Luciano Décourt Engenheiros Consultores. Entrevista concedida em 12 de abril de 2007.

A. Ruptura de fundações avaliada com base no conceito de rigidez. In: SEMINÁRIO DE ENGENHARIA DE FUNDAÇÕES ESPECIAIS, 3, 1996, São Paulo. Anais... SEFE III. São Paulo: ABEF/ABMS, 1996, p. 215-254.

. Provas de carga em estacas podem dizer muito mais do têm dito. In: SEMINÁRIO DE ENGENHARIA DE FUNDAÇÕES ESPECIAIS, 6, 2008, São Paulo. Anais... SEFE VI. São Paulo: ABEF/ABMS, 2008, p. 221-245.

DÉCOURT, L. \& NIYAMA, S. Predicted and measured behavior of displacement piles in residual soils. In: INTERNATIONAL CONFERENCE ON SOIL MECHANICS AND FOUNDATION ENGINEERING, 13, 1994, New Delhi. Proc... ICSMFE XIII, v. 1 p. 143-146.

DÉCOURT, L. ; QUARESMA, A.R. Como calcular (rapidamente) a capacidade de carga limite de uma estaca. Revista Construção, São Paulo, n. 1800, ago. 1982. Separata.

DÉCOURT, L. ; QUARESMA FILHO, A. Practical apliccations of the Standard Penetration Test complemented by the Torque measurements, SPT-T; present estage and future trends. In: INTERNATIONAL CONFERENCE ON SOIL MECHANICS AND FOUNDATION ENGINEERING, 13, 1994, New Delhi. Proc... v. 2 p. 447-486.

DE GENNARO, V.; FRANK, R. Elasto-plastic analysis of the interface behavior between granular media and structure. In: Computer and Geotechnics. : Elsevier, 2002. Eletronic edition.

FELLENIUS, B.H. Test Loading of Piles and New Proof. Journal of the Soil Mechanics and Foundation Division - ASCE, v. 101, n. GT9, p. 855-869, Sep. 1975. 
FELLENIUS, B.H. The analysis of results from routine pile load tests. Ground Engineering, p. 19-31, Sep. 1980.

Limit states design for deep foundations. In: INTERNATIONAL CONFERENCE ON DESIGN AND CONSTRUCTION OF DEEP FOUNDATIONS, 1994, Orlando. Proc... FHWA. v. 2 p. 415-426.

What capacity value to choose from the results a static loading test. Fulcrum. Deep Foundation Institute, p. 19-22, Winter 2001.

Basics of Foundation Design. USA: eletronic edition, 2006. 275 p. Disponível em: <http://www.fellenius.net>. Acesso em set. 2006.

FLEMING, W. G.L.. A new method for single piles settlement prediction and analysis. Géotechnique, v. 42, n. 3, p. 411-425. 1982.

FLEMING, W.G.L.; WELTMAN, A.J.; RANDOLPH, M.F. ; ELSON, W.K. Piling

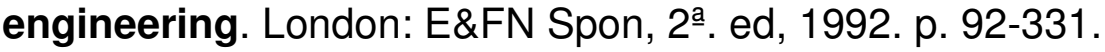

FONSECA, A.V.; SANTOS, J.A.; ESTEVES,E.C.; MASSAD, F. Analysis of piles in residual soil from granite considering residual loads. Soils and Rocks. v. 30: ABMS/ABGE/SPG, n. 1, p. 63-80. jan-apr. 2007.

FRANK, R. Calcul des fondations superficielles et profundes. Paris: Presses de l'École Nationale des Ponts et Chaussées, 1999. 141 p.

GOTLIEB, M.; PENNA, A. S. D.; ROMAN JR., R. ; RODRIGUES, L.H.B. Um método simples para a avaliação da tensão admissível no topo de estacas tipo hélicecontínua. In: SEMINÁRIO DE ENGENHARIA DE FUNDAÇÕES ESPECIAIS, 4, 2000, São Paulo. Anais... SEFE IV. São Paulo: ABEF/ABMS, 2000, v. 1, p. 312-319.

HACHICH, W. ; NADER, J. J. Correlações entre Parâmetros: Análise Crítica. In: " Solos da Cidade de São Paulo. São Paulo: ABMS, 1993. p. 181-192.

HALDAR, S. ; BABU, G.L.S. Load resistance factor design of axially loaded pile based on load test results. Journal of Geotechnical and Geoenvoironmental Engineering - ASCE, p. 1106-1117, Aug. 2008.

KAREZ, M. B. ; ROCHA, E. A. C. Estacas tipo hélice-contínua previsão da capacidade de carga. In: SEMINÁRIO DE ENGENHARIA DE FUNDAÇÕES ESPECIAIS, 4, 2000, São Paulo. Anais... SEFE IV. São Paulo: ABEF/ABMS, 2000, v. 1, p. $274-278$.

LAZO, G. Previsão do Comportamento de Estacas Pré-moldadas na região da Grande São Paulo, Brasil, por meio de Modelos Matemáticos. 1996. 222p. Tese (Doutorado) - Escola Politécnica da Universidade de São Paulo, São Paulo, 1996.

LIZZI, F. The design of large diameter cast-in-place bored piles using a 'pilot' pile and congruence equations. Ground Engineering. v. 14, n. 4, p. 24-33. May. 1981. 
MARQUES, J.A.F.; MASSAD, F. Provas de carga instrumentadas em estacas escavadas com bulbos, executadas na região praieira de Maceió, Alagoas. Revista Solos e Rochas, São Paulo, v. 27, n. 3, p. 243-260, 2004.

MARZIONNA, J.D. O projeto geotécnico de fundações e a norma brasileira NBR6122- Projeto e execução de fundações. In: SEMINÁRIO DE ENGENHARIA DE FUNDAÇÕES ESPECIAIS - SEFE VI, 2008, São Paulo. Anais... São Paulo: ABEF/ABMS, v. 1, p. 43-57.

MASSAD, F. Notes on the interpretation of failure load from routine pile load tests. Revista Solos e Rochas, São Paulo, v. 9, n. 1, p. 33-36, 1986.

Análise da transferência de carga de duas estacas instrumentadas, quando submetidas à compressão axial. In: SEMINÁRIO DE ENGENHARIA DE FUNDAÇÕES ESPECIAIS, 2, 1991, São Paulo. Anais... SEFE II. São Paulo: ABEF/ABMS, 1991, v. 1, p. 235-244.

MASSAD, F. Comportamento de estacas escavadas de elevadas compressibilidades. In: SEMINÁRIO DE ENGENHARIA DE FUNDAÇÕES ESPECIAIS, 2, 1991, São Paulo. Anais... SEFE II. São Paulo: ABEF/ABMS, 1991, v. 1 , p. 245-254.

. Estacas escavadas em compressão axial: comportamento e parâmetros visando a estimativa dos recalques. In: SEMINÁRIO DE ENGENHARIA DE FUNDAÇÕES ESPECIAIS, 2, 1991, São Paulo. Anais... SEFE II. São Paulo: ABEF/ABMS, 1991, v. 1, p. 255-264.

Sobre a interpretação de Provas de Carga em Estacas considerando as Cargas Residuais na Ponta e a Reversão do Atrito Lateral. Parte I: Solos Relativamente Homogêneos. Revista Solos e Rochas, São Paulo, v. 15, n. 2, p. 103-115, 1992.

Sobre a interpretação de Provas de Carga em Estacas considerando as Cargas Residuais na Ponta e a Reversão do Atrito Lateral. Parte II: Estaca Embutida em Camada mais Resistente. Revista Solos e Rochas, São Paulo, v. 16, n. 2, p. 93-112, 1993.

Considerações sobre a forma da curva carga recalque de estacas solicitadas axialmente. São Carlos: Escola de Engenharia de São Carlos da Universidade de São Paulo, Publicação 045/94. 1994. 35 p.

- Limites das extrapolações em provas de carga verticais interrompidas prematuramente. In: CONGRESSO BRASILEIRO DE MECÂNICA DOS SOLOS E ENGENHARIA DE FUNDAÇÕES, 10, 1994, Foz do Iguaçu. Anais... COBRAMSEF X. Curitiba: ABMS, 1994, v. 1, p. 93-112.

Sobre algumas representações da curva carga-recalque de estacas solicitadas axialmente. In: CONGRESSO BRASILEIRO DE MECÂNICA DOS SOLOS E ENGENHARIA DE FUNDAÇÕES, 10, 1994, Foz do Iguaçu. Anais... COBRAMSEF X. Foz do Iguaçu: ABMS, 1994, v. 1, p. 287-294. 
MASSAD, F. The analysis of piles considering soil stiffness and residual stresses. In: PANAMERICAN CONFERENCE OF SOIL MECHANICS AND FOUNDATION ENGINEERING, 10, 1995, Guadalajara. Proc... v. 2, p. 1199-1210.

. Novo método para a interpretação de provas de carga cíclicas, estáticas ou dinâmicas, em estacas verticais. In: CONGRESSO BRASILEIRO DE MECÂNICA DOS SOLOS E ENGENHARIA GEOTÉCNICA, 12, 2002, São Paulo. Anais... COBRAMSEG XII. São Paulo: ABMS, 2002, v. 3, p. 1627-1638.

Fundamentação matemática do método da rigidez de Décourt e definição de seu campo de aplicação. In: SEMINÁRIO DE ENGENHARIA DE FUNDAÇÕES ESPECIAIS, 6, 2008, São Paulo. Anais... SEFE VIII. São Paulo: ABEF/ABMS, 2008, v. 1, p. 117-131.

MASSAD, F.; LAZO, G. Método gráfico para interpretar a curva carga-recalque de provas de carga verticais em estacas rígidas e curtas. In: CONGRESSO BRASILEIRO DE MECÂNICA DOS SOLOS E ENGENHARIA GEOTÉCNICA, 11, 1998, Brasília. Anais... COBRAMSEG XI. Brasília: ABMS, 1998, v. 3, p. 1407-1414.

MASSAD, F.; MARQUES, J.A.F. Provas de carga instrumentadas em estacas escavadas com bulbos, executadas na região praieira de Maceió, Alagoas. Revista Solos e Rochas, São Paulo, v. 27, n. 3, p. 243-260, dez. 2004.

MELO, B. Análise de provas de carga à compressão à luz do conceito de rigidez. 2009. 219p. Dissertação (Mestrado) - Faculdade de Engenharia Civil, Arquitetura e Urbanismo da Universidade Estadual de Campinas, São Paulo, 2009.

MELLO, V.F.B. Fundações e elementos estruturais enterrados. São Paulo: EPUSP, 1975. Apostila de apoio às aulas

MONTEIRO, P.F.F. A estaca ômegafranki - capacidade de carga. In: SEMINÁRIO DE ENGENHARIA DE FUNDAÇÕES ESPECIAIS, 4, 2000, São Paulo. Anais... SEFE IV. São Paulo: ABEF/ABMS, 2000, v. 2, p. 356-369.

MYLONAKIS, G. Winkler modulus for axially loaded piles. Géotechnique, Paris, v. 51, n. 5, p. 455-461, 2001.

NIELSEN NETO, H. Filosofia básica. São Paulo: Atual, 3ª̣. ed, 1991. 311 p.

NIYAMA, S.; AOKI, N.; CHAMECKI,P.R. Verificação do Desempenho - Provas de Carga Estáticas. In: Fundações: teoria e prática. 1 ed. São Paulo-SP: ABMS/ABEF/Pini, 1996. p. 726-739.

POULOS, H.G. ; DAVIS, E.H. Pile Foundation Analysis and Design. New York: John Wiley and Sons, 1980. 397 p. (Series in Geotechnical Engineering)

QUARESMA, A.R. ; DÉCOURT, L. ; QUARESMA Fo., A.R. ; ALMEIDA, M.S.S. ; DANZIGER, F. Investigações geotécnicas. In: Fundações: teoria e prática. 1ª ed. São Paulo: ABMS/ABEF/Pini, 1996. p. 119-162. 
RANDOLPH, M.F. Design methods for pile groups and piled rafts. In: INTERNATIONAL CONFERENCE ON SOIL MECHANICS AND FOUNDATION ENGINEERING, 13, 1994, New Delhi. Proc... v. 5 p. 61-82.

RANDOLPH, M.F. ; WROTH, C.P. Analysis of Deformation Vertically Loaded Piles. Journal of the Soil Mechanics and Foundation Division - ASCE, v. 104, n. GT12, p. 1465-1488, Dec. 1978.

RANZINI, S.M.T. SPT-F. Revista Solos e Rocha, São Paulo, v. 11, p. 29-30, dez. 1978.

ROCHA, R. ; YASSUDA, A.J. ; MASSAD, E. Provas de Carga em Estaca tipo Raiz Instrumentada. In: SEMINÁRIO DE ENGENHARIA DE FUNDAÇÕES ESPECIAIS, 1, 1985, São Paulo. Anais... SEFE I. São Paulo: ABEF/ABMS, 1985, v. 1, p. 179-193.

SCHMERTMANN, J.H. Static of SPT. Journal of the Soil Mechanics and Foundation Division - ASCE, v. 105, n. GT15, 655 p. May. 1979.

SCHNAID, F. Ensaios de campo: e suas aplicações à engenharia de fundações. $1^{\mathrm{a}}$. ed. São Paulo: Oficina de Textos, 2000.

SOUZA, A. Estaca Piloto Instrumentada: uma ferramenta para o estudo da capacidade de carga de estacas, quando submetidas a esforços axiais de compressão. 2001. 296 p. Tese (Doutorado) - Escola Politécnica da Universidade de São Paulo, São Paulo, 2001.

TEIXEIRA, A. H. Sondagens, metodologia, erros mais comuns. novas normas de execução. In: SIMPÓSIO DA ASSOCIAÇÃO BRASILEIRA DE MECÂNICA DOS SOLOS, 1, 1977, Recife. Anais... ABMS, 1977, p. 41-61.

TEIXEIRA, A. H. Um Aperfeiçoamento das Sondagens de Simples Reconhecimento à Percussão. In: Solos do Estado de São Paulo. São Paulo: ABMS, 1993. p. 7593.

. Uma retrospectiva e as tendências da engenharia de fundações no Brasil. In: SEMINÁRIO DE ENGENHARIA DE FUNDAÇÕES ESPECIAIS, 4, 2000, São Paulo. Anais... SEFE IV. São Paulo: ABEF/ABMS, 2000, v. 1, p. 1-22.

TITI, H. H. e ABU-FARSAKH, M. Y. Assesment of direct cone penetration test methods for predicting the ultimate capacity of friction driven piles. Journal of the Soil Mechanics and Foundation Division - ASCE, p. 935-944. Sep. 2004.

VARGAS, M. Fundações de edifícios. São Paulo: Grêmio Politécnico, 1979. p. 9091.

VEEN, C. V. Design The Bearing Capacity of Piles. In: INTERNATIONAL CONFERENCE ON SOIL MECHANICS AND FOUNDATION ENGINEERING, 3, 1953, Amsterdam. Proc... v. 2 p. 84-90. 
VELLOSO, D. A.; ALONSO, U.R. Previsão, Controle e Desempenho de Fundações. In: Previsão de Desempenho x Comportamento Real. São Paulo: ABMS/NRSP, 2000. p. 95-139.

VELLOSO, D. ; LOPES, F.R. Concepção de obras de fundações. In: Fundações: teoria e prática. 1‥ ed. São Paulo: ABMS/ABEF/Pini, 1996. p. 211-226.

Fundações. Rio de Janeiro: COPPE-UFRJ, 2002. v.2, 472p.

Fundações. São Paulo: Oficina de Textos, 2004. v. 1, 226 p.

VÉSIC, A. S. A Study of Bearing Capacity of Deep Foundations. Atlanta: Georgia Institute of Technologie, 1967. (Final report, proj. B-189).

Load Transfer in Pile-soil Systems. Durham: Duke University, 1970. 60 p. (Soil Mechanics Series, n. 23).

. Principles of Pile Foundations Design. Durham: Duke University, 1975. 60 p. (Soil Mechanics Series, n. 38).

Design On the Significance of Residual Loads for Load response of Piles. In: INTERNATIONAL CONFERENCE ON SOIL MECHANICS AND FOUNDATION ENGINEERING, 10, 1977, Stockholm. Proc... v. 3 p. 373-379.

YANG, Q.J. Determination of load capacity of a pile - an alternative. In: CONGRESSO BRASILEIRO DE MECÂNICA DOS SOLOS E ENGENHARIA DE FUNDAÇÕES, 10, 1994, Foz do Iguaçu. Anais... COBRAMSEF X. Foz do Iguaçu: ABMS, 1994, v. 1, p. 159-166.

ZHU, H.; CHANG, M.F. Load transfer curves along bored piles considering modulus degradation. Journal of the Soil Mechanics and Foundation Division - ASCE, $p$. 764-773. Sep. 2002. 
KURT ANDRÉ PEREIRA AMANN

\section{METODOLOGIA SEMIEMPÍRICA UNIFICADA}

PARA A ESTIMATIVA DA

\section{CAPACIDADE DE CARGA DE ESTACAS}

v.2

São Paulo 
KURT ANDRÉ PEREIRA AMANN

\section{METODOLOGIA SEMIEMPÍRICA UNIFICADA}

PARA A ESTIMATIVA DA

\section{CAPACIDADE DE CARGA DE ESTACAS}

Tese apresentada à Escola Politécnica da Universidade de São Paulo para obtenção do título de Doutor em Engenharia

Área de Concentração:

Engenharia Geotécnica

Orientador: Prof. Doutor

Faiçal Massad

v.2

São Paulo

2010 
Ficha Catalográfica

Amann, Kurt André Pereira

Metodologia Semiempírica Unificada para a estimativa da capacidade de carga de estacas / Kurt André Pereira Amann. - São Paulo, 2010.

2v.

Tese (Doutoamento) - Escola Politécnica da Universidade de São Paulo. Departamento de Engenharia de Estruturas e Fundações. 


\section{RESUMO}

A pesquisa parte do fato de que os métodos semiempíricos de estimativa da capacidade de carga de estacas não devem ser empregados indiscriminadamente em qualquer região do país sem as devidas adequações às características do solo local. Constata-se, com isso, que não existem metodologias específicas para proceder tais adequações e que o meio técnico acaba por realizar a mera classificação dos métodos em "conservador" ou "contra a segurança", o que se constitui num certo paradigma. Assim, o presente trabalho propõe uma Metodologia Semiempírica Unificada (MSU), em três etapas. Na primeira delas, o projetista estima a capacidade de carga a partir da otimização das melhores práticas adotadas pelos diversos métodos semiempíricos utilizados no Brasil. Discutem-se ainda o embutimento da ponta e a criação de novos métodos semiempíricos. Na segunda etapa, realiza-se a verificação de desempenho com base nos critérios de ruptura aplicados à curva carga-recalque de provas de carga. Nessa etapa, as imprecisões do dito paradigma são apontadas e faz-se uma nova proposta de aplicação dos critérios de ruptura. Na terceira etapa, faz-se uma retroanálise para aferição da estimativa semiempírica unificada da primeira etapa. Propõe-se, assim, o uso da separação das parcelas de atrito e ponta por meio de métodos de transferência de carga, bem como pela proposta de ajustes polinomiais, no caso de ensaios instrumentados. A análise crítica desse processo gerou a proposta de uma nova abordagem matemática da transferência de carga. A correção dos valores adotados para os coeficientes semiempíricos de cada camada, individualmente, é feita pela proposta de aplicação do conceito de Hierarquia dos Solos (AMANN, 2000). Os resultados de correção dos métodos semiempíricos, contudo, são específicos para o solo de cada local em estudo. Assim, são utilizados, como exemplo, ensaios em diversas regiões do país, o que permite a verificação da aplicabilidade da metodologia proposta.

Palavras-chave: Fundações por estacas. Critérios de ruptura. Carga de ruptura. Capacidade de carga; Transferência de carga; Métodos semiempíricos. 


\begin{abstract}
The research starts from the fact that the semiempirical methods for estimating the pile load capacity shouldn't be used indiscriminately in any country's region without making proper adjustments to the local soil characteristics. It is verified, from this, that there are no specific methodologies to make such adjustments and the geotechnical engineers find themselves forced to perform a simple classification of the methods in "conservative" or "against the safety", which constitutes a form of paradigm. In this context, this paper proposes a Unified Semiempirical Methodology (MSU) in three steps. In the first, the designer estimates the foundation load capacity from the optimization of best practices adopted by different semiempirical methods used in Brazil. A discussion is also made the toe embedment and the creation of new semiempirical methods. In the second step, the verification of the foundation performance is carried out, based on the failure criteria applied to the load-settlement curve of load tests. At this step, the inaccuracies from that paradigm are outlined and a new proposal is made for applying the failure criteria. In the third step, a backanalysis is accomplished to admeasure the unified semiempirical estimative from the first step. It is, thus, proposed to separate both shaft friction and toe resistance from the total load, by means of load transfer methods, and by the proposal of polynomial adjustments in the case of instrumented piles. With the critical analysis of this process, a new mathematical approach to load transfer is presented. The correction of the coefficients of the semiempirical methods is made by the application of the Soils's Hierarchy concept (AMANN, 2000). The results of semiempirical methods correction, however, are specific to the soils of each particular site. The applicability, of the proposed methodology, is illustrated using pile load tests from various parts of the country.
\end{abstract}

Keywords: Pile foudation; Failure criteria; Failure load; Bearing capacity; Load transfer; Semiempirical methods. 


\section{SUMÁRIO}

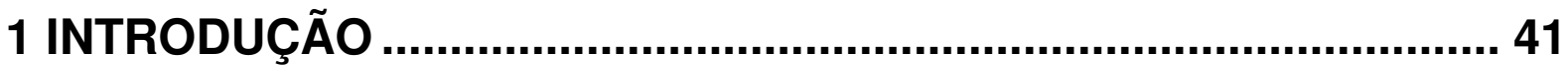

1.1 O PROJETO DE FUNDAÇÕES POR ESTACAS.................................. 42

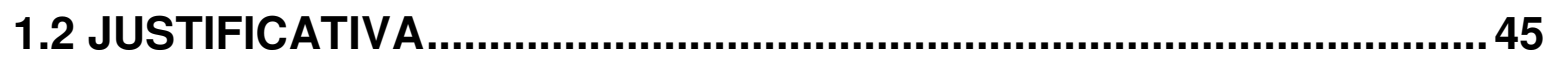

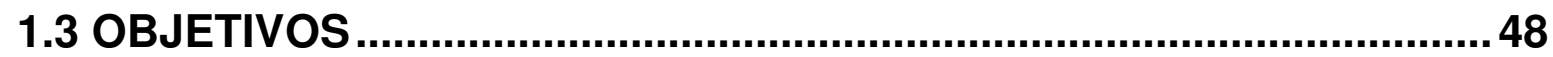

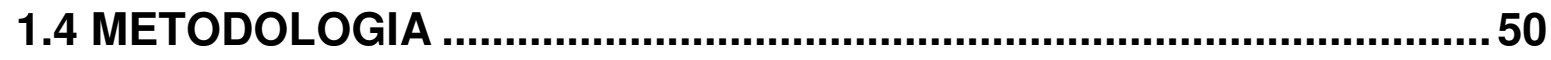

1.5 ESTRUTURA E ORGANIZAÇÃO DO TRABALHO .............................53

2 PREVISÃO DA CAPACIDADE DE CARGA ................................. 57

2.1 CAPACIDADE DE CARGA DE ESTACAS …...................................57

2.2 MÉTODOS TEÓRICOS .................................................................58

2.3 MÉTODOS EMPÍRICOS ................................................................62

2.4 MÉTODOS SEMIEMPÍRICOS ..........................................................63 63

2.4.1 A semelhança entre a estaca e o ensaio CPT ....................................64

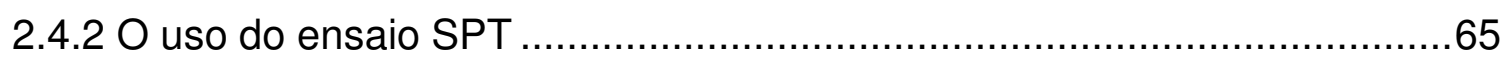

2.4.2. 10 uso dos valores de torque SPT-T e a correção da sondagem pelo $N_{\text {eq }} . . . .66$

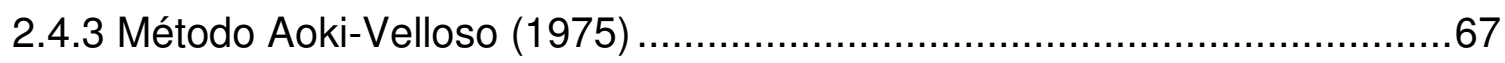

2.4.4 Método Décourt-Quaresma (1978) e Décourt (1996a).............................70

2.5 GENERALIZAÇÃO DOS MÉTODOS SEMIEMPÍRICOS (AMANN 2000)

2.6 APRESENTAÇÃO DOS MÉTODOS SEMIEMPÍRICOS ANALISADOS

2.7 CONCEITUAÇÃO DAS HIERARQUIAS DOS SOLOS (AMANN, 2000)

2.8 EXEMPLO DE APLICAÇÃO DO CONCEITO DE HIERARQUIAS DOS SOLOS E DA GENERALIZAÇÃO DOS MÉTODOS SEMIEMPÍRICOS..... 80

2.9 DISCUSSÃO DOS COEFICIENTES PARCIAIS DE INFLUÊNCIA .......82

2.9.1 Consideração do coeficiente parcial de tipo de solo $\left(\mathrm{k}_{\mathrm{ts}}\right)$. .83

2.9.2 Consideração do coeficiente parcial de tipo de ensaio de campo ou

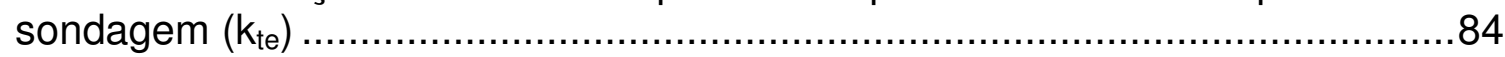

2.9.3 Consideração dos coeficientes parciais de tipo de estaca $\left(\mathrm{k}_{\mathrm{tE}}\right) \ldots \ldots \ldots \ldots \ldots . . . . .66$

2.9.4 Consideração do coeficiente parcial de dimensões ou diâmetro $\left(\mathrm{k}_{\mathrm{tD}}\right)$.......87

2.10 DISCUSSÃO DAS CONDIÇÕES DE EMBUTIMENTO DA PONTA... 88 
2.11 PROPOSTA DE MÉTODOS DE TESTE PARA EXEMPLIFICAR A APLICAÇÃO DA METODOLOGIA SEMIEMPIRICA UNIFICADA (MSU) .. 89

2.11.1 Método Mediado de teste.............................................................90

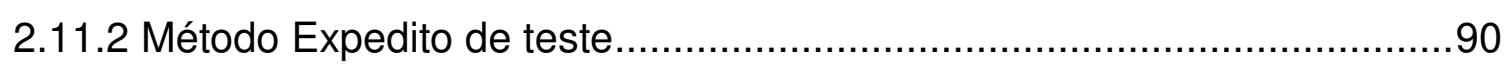

2.12 EXEMPLO DE APLICAÇÃO DOS MÉTODOS DE TESTE................. 91

3 VERIFICAÇÃO DO DESEMPENHO DE ESTACAS........................ 95

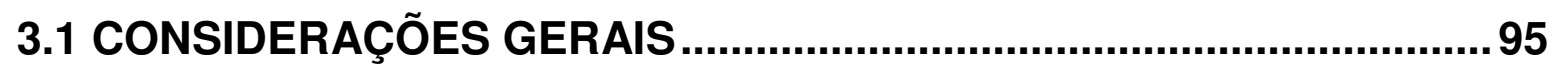

3.2 CRITÉRIOS DE RUPTURA ANALISADOS ......................................96

3.3 APLICAÇÃO DOS CRITÉRIOS A UM CASO DE OBRA ......................98

3.4 DISCUSSÃO DA FORMA DE APLICAÇÃO DOS CRITÉRIOS.............99

3.5 DISCUSSÃO DO PARADIGMA DE VERIFICAÇÃO DA APLICABILIDADE DOS MÉTODOS SEMIEMPÍRIÇOS ............................100

3.6 COMPARAÇÃO ENTRE OS CRITÉRIOS DE RUPTURA E OS MÉTODOS DAS LEIS DE CAMBEFORT MODIFICADAS POR MASSAD (1992) E DAS DUAS RETAS DE MASSAD E LAZO (1998) ....................102

3.6.1 Breve descrição do método das Leis de Cambefort modificadas por Massad (1992) e das Duas Retas (MASSAD e LAZO, 1998) .........................102

3.6.2 Discussão da comparação com os critérios de recalque limite ................105

3.6.3 Discussão da comparação com os critérios de rigidez tangente limite e

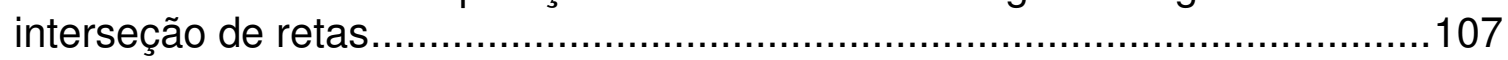

3.6.4 Discussão da comparação com os critérios de ajuste matemático ..........109

3.7 PROPOSTA DE NOVA FORMA DE CONSIDERAÇÃO DOS CRITÉRIOS DE RUPTURA

3.7.1 Exemplo de comparação entre métodos semimpíricos e critérios de ruptura.

3.7.2 Proposta de consideração dos critérios

3.7.3 Correção dos coeficientes empíricos dos métodos semiempíricos a partir

de provas de carga e dos critérios de ruptura

\section{AFERIÇÃO DA PARCELA DE ATRITO LATERAL PELOS}

MÉTODOS DE TRANSFERÊNCIA DE CARGA E DA RIGIDEZ DE DÉCOURT (2008)

4.1 DEDUÇÃO GERAL DA EQUAÇÃO DIFERENCIAL DA

TRANSFERÊNCIA DE CARGA DE ESTACAS AO SOLO (AMANN, 2008c)

4.1.1 Função $\tau(z)$ incógnita: solução pela Equação Diferencial Ordinária de 2aa․ Ordem (EDO2) . 
4.2 MÉTODO DAS LEIS DE CAMBERFORT MODIFICADAS POR MASSAD 134

4.3 PROPOSTA PARA DETERMINAÇÃO SIMULTÂNEA DE Kr E Alr COM AJUSTE OTIMIZADO DA CURVA CARGA-RECALQUE 137

4.3.1 Análise do caso de solo heterogêneo 139

4.3.2 Solução do sistema para a curva completa (estaca compressível). 140

4.3.3 Solução para curva com trecho 7-8 (descarregamento) pouco desenvolvido (estaca intermediária).

4.3.4 Solução para curva com trechos 7-8 e 3-4 (parabólicos) pouco desenvolvidos (estaca curta).

4.3.5 Solução para curva sem descarregamento

4.4 EXEMPLO DE APLICAÇÃO DA SOLUÇÃO DO SISTEMA A UMA ESTACA METÁLICA CRAVADA COMPRESSÍVEL (LONGA). 149

4.5 SEPARAÇÃO DAS PARCELAS DE ATRITO E PONTA PELO MÉTODO DA RIGIDEZ DE DÉCOURT (2008).

4.5.1 Proposta de interpretação do diagrama de Rigidez para definição dos trechos da curva no método das Leis de Cambefort modificadas.

4.6 EXEMPLO DE APLICAÇÃO DA COMPARAÇÃO ENTRE O MÉTODO DA RIGIDEZ E O MÉTODO DAS LEIS DE CAMBEFORT MODIFICADAS

4.7 OBTENÇÃO DOS DEMAIS PARÂMETROS DO MÉTODO DAS LEIS DE CAMBEFORT MODIFICADAS 165

4.8 PROPOSTA DE ITERAÇÃO PARA SEPARAÇÃO DA CONTRIBUIÇÃO DAS CAMADAS DE SOLO HETEROGÊNEO NO ATRITO LATERAL

5 A AFERIÇÃO DO ATRITO DAS CAMADAS POR AJUSTES POLINOMIAIS DE ENSAIOS INSTRUMENTADOS E A NOVA ABORDAGEM MATEMÁTICA DA TRANSFERÊNCIA DE CARGA.. 172

5.1 DISCUSSÃO CONCEITUAL DO PARÂMETRO B = $\tau(z) / y(z) \ldots . . . . . .173$

5.1.1 Formas matemáticas usuais do parâmetro $\mathrm{B}=\tau(\mathrm{z}) / \mathrm{y}(\mathrm{z}) \ldots \ldots \ldots \ldots \ldots \ldots \ldots \ldots . . .174$

5.2 APRESENTAÇÃO DA PROVA DE CARGA DE EXEMPLO ..............178 5.3 RESULTADOS DA INSTRUMENTAÇÃO E APLICAÇÃO DA FORMA DE ANÁLISE USUAL ...................................................................182

5.4 NOVA ABORDAGEM MATEMÁTICA DA TRANSFERÊNCIA DE CARGA 
5.5 PROPOSTA DE AJUSTES POLINOMIAIS $\tau(z)$ e y(z) PARA ANÁLISE DOS DADOS DA INSTRUMENTAÇÃO

5.6 PROPOSTA DE AJUSTES POLINOMIAIS $\tau\left(P_{0}\right)$ e y(Po) PARA

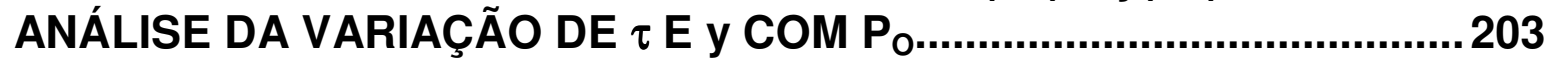

5.7 DETERMINAÇÃO DA EQUAÇÃO DO PARÂMETRO $B\left(P_{o}\right)=\tau\left(P_{o}\right) / y\left(P_{o}\right)$

5.8 APLICAÇÃO DA NOVA ABORDAGEM E DOS AJUSTES

POLINOMIAIS

6 PROPOSIÇÃO DA METODOLOGIA SEMIEMPÍRICA UNIFICADA PARA CORREÇÃO DOS COEFICIENTES EMPÍRICOS................... 211

6.1 PRIMEIRA ETAPA: PREVISÃO (ESTIMATIVA) DA CAPACIDADE DE

CARGA

6.1.1 Exemplo de aplicação da previsão.

6.2 SEGUNDA ETAPA: VERIFICAÇÃO DO DESEMPENHO

6.2.1 Escolha do critério de ruptura adequado ao método semiempírico e ao sistema solo-estaca em estudo.

6.2.2 Escolha do critério de ruptura para correção do método semiempírico no local em estudo.

6.3 TERCEIRA ETAPA: AFERIÇÃO E CORREÇÃO DOS MÉTODOS SEMIEMPÍRICOS

6.3.1 Aferição pela separação das parcelas de atrito e ponta.........................219

6.3.2 Aferição por ajustes polinomiais da instrumentação

6.3.3 Correção dos coeficientes empíricos dos métodos empregando a Hierarquia dos Solos (AMANN, 2000).

6.3.3.1 Correção do coeficiente característico $K_{L g}$

6.3.3.2 Correção dos coeficientes característicos $K_{L g(i)}$ de cada camada pela

Hierarquia dos Solos

6.3.3.3 Correção dos coeficientes parciais $k_{t(i)}$ dos métodos

6.4 CORREÇÃO DOS MÉTODOS PARA MAIS DE UMA ESTACA ENSAIADA NO SOLO LOCAL

6.5 EXEMPLOS DE APLICAÇÃO DA METODOLOGIA SEMIEMPÍRICA UNIFICADA A ESTACAS DE DIVERSAS REGIÕES

7 CONCLUSÕES E CONSIDERAÇÕES FINAIS

7.1 SOBRE OS OBJETIVOS ESPECÍFICOS. 242

7.2 SOBRE O OBJETIVO GERAL: A PROPOSIÇÃO DA MSU PARA CORREÇÃO DOS MÉTODOS SEMIEMPÍRICOS 
7.4 SUGESTÕES PARA TRABALHOS FUTUROS.

APÊNDICE A - REVISÃO BIBLIOGRÁFICA DOS EVENTOS

TÉCNICO-CIENTÍFICOS DA DÉCADA (2000-2010)

APÊNDICE B - SOBRE A GENERALIZAÇÃO DOS MÉTODOS E AS HIERARQUIAS DOS SOLOS

B.1 VALORES DOS COEFICIENTES EMPÍRICOS DE CADA MÉTODO 278

B.1.1 Valores atribuídos por outros autores 280

B.2 HIERARQUIAS DOS SOLOS (AMANN, 2002, 2004 e 2006)............. 281

B.2.1 Definição dos grupos de solos (Amann, 2000) .281

B.2.2 Valores dos coeficientes característicos de resistência e as hierarquias282 B.3 CORRELAÇÕES ENTRE OS COEFICIENTES EMPÍRICOS PARA COMPARAÇÃO DIRETA ENTRE OS DIVERSOS MÉTODOS ................286 B.4 DISCUSSÃO DAS CONDIÇÕES DE EMBUTIMENTO DA PONTA.. 289 B.5 EXEMPLO DE APLICAÇÃO DA GENERALIZAÇÃO DOS MÉTODOS E DAS HIERARQUIAS DOS SOLOS 291

B.6 ANÁLISE DO COEFICIENTE DE TIPO DE SOLO $\left(\mathrm{k}_{\mathrm{ts}}\right) \ldots \ldots \ldots \ldots \ldots \ldots . . . . . . . . . .294$ B.7 ANÁLISE DO COEFICIENTE PARCIAL DE TIPO DE ENSAIO $\left(k_{\mathrm{te}}\right) 296$ B.8 ESTIMATIVA DOS VALORES DO COEFICIENTE PARCIAL DE TIPO DE ESTACA $\left(k_{\mathrm{tE}}\right)$ 298

B.9 COEFICIENTE DE DIMENSÃO OU DIÂMETRO $\left(\mathrm{k}_{\mathrm{t}}\right)$ 305

B.10 DISCUSSÃO SOBRE USO DA MÉDIA AO LONGO DO FUSTE OU DA SOMATÓRIA DAS CAMADAS PARA CÁLCULO DO CISALHAMENTO LATERAL (AMANN, 2000 e 2006) E PROPOSTA DO MÉTODO EXPEDITO DE TESTE 308

B.11 DISCUSSÃO ESTATÍSTICA DA VALIDADE DAS REGRESSÕES 311

B.12 GENERALIZAÇÃO DE MÉTODOS ESTATÍSTICOS 312 APÊNDICE C - CONSIDERAÇÕES SOBRE OS CRITÉRIOS DE RUPTURA

C.1 ANÁLISE, DISCUSSÃO E APLICAÇÃO DOS CRITÉRIOS DE RUPTURA A UM CASO REAL 314

C.1.1 NBR 6122 (1996) 314

Aplicação do critério da NBR 6122. 316

C.1.2 Terzaghi (1943) 318

Aplicação do critério de Terzaghi 318

C.1.3 Fuller \& Hoy (1970). 319 
Aplicação do critério de Fuller e Hoy .................................................................. 320

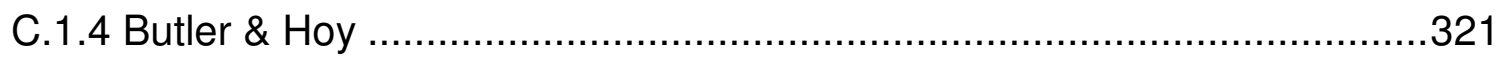

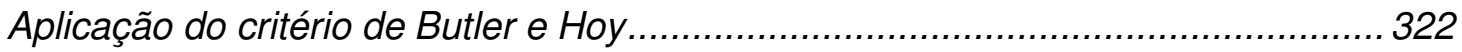

C.1.5 De Beer (1968) e De Beer \& Wallays (1972) .....................................323

Aplicação do critério de De Beer e Wallays...................................................... 324

Comparação com o critério de Housel (Creep).................................................... 325

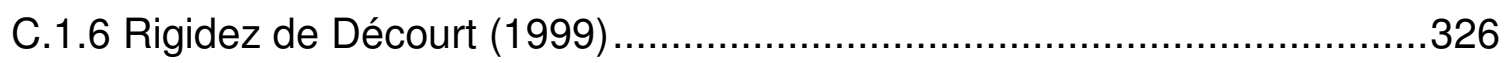

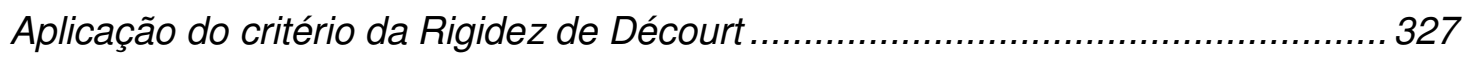

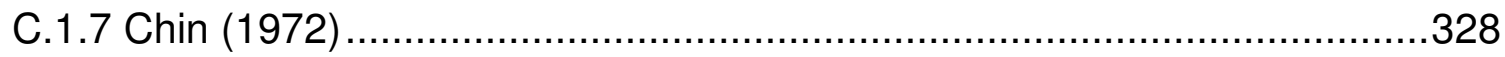

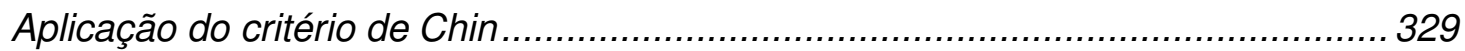

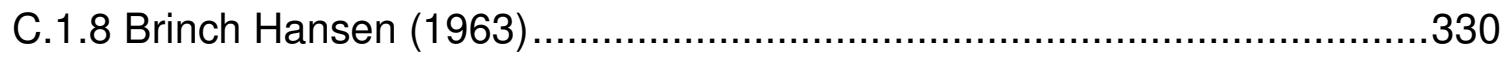

Aplicação do critério de Brinch Hansen 80\%................................................... 331

C.1.9 Van der Veen (1953) e a generalização de Aoki (1976) .........................332

Aplicação do critério de Van der Veen generalizado ............................................ 333

Comparação com o critério de Mazurkiewicz (1970) .......................................... 333

C.2 CONSIDERAÇÕES SOBRE OS CRITÉRIOS DE RUPTURA ............ 334

C.3 ANÁLISE CRÍTICA DOS CRITÉRIOS DE VAN DER VEEN (1953) E

CHIN (1972)

C.3.1 PARAMETRIZAÇÃO DO CRITÉRIO DE VAN DER VEEN (AMANN, 2008a).

C.3.2 PARAMETRIZAÇÃO DO CRITÉRIO DE CHIN (AMANN, 2008a).

APÊNDICE D - DEDUÇÃO DA EXPRESSÃO GERAL DE TRANSFERÊNCIA DE CARGA

D.1 A SOLUÇÃO DA EDO DE 2ª ORDEM HOMOGÊNEA COM COEFICIENTES CONSTANTES

D.2 SOLUÇÃO DA EDO DE 2ª ORDEM NÃO-HOMOGÊNEA COM COEFICIENTES CONSTANTES

D.3 DEFINIÇÃO DOS COEFICIENTES DE RIGIDEZ DO SISTEMA SOLO-

ESTACA (AMANN, 2008C)

D.4 EXPRESSÃO GERAL DA TRANSFERÊNCIA DE CARGA DE ESTACAS (AMANN, 2008c).

D.5 EXPRESSÕES DE MASSAD (1992) E RANDOLPH E WROTH (1978)

A PARTIR DA EXPRESSÃO GERAL (AMANN, 2008c)

D.6 MODIFICAÇÃO DOS MÉTODOS COM BASE NA

CORRESPONDÉNCIA ENTRE AMBOS (AMANN, 2008c)

D.7 COMPARAÇÃO COM O MÉTODO DE FLEMING (1992), APUD

AMANN (2008c). 
APÊNDICE E - ANÁLISE DE ENSAIOS INSTRUMENTADOS.......... 365

E.1 TABELAS DE APLICAÇÃO DA ANÁLISE USUAL ......................... 365

E.2 COMENTÁRIOS SOBRE AS FIGURAS TRIDIMENSIONAIS DE

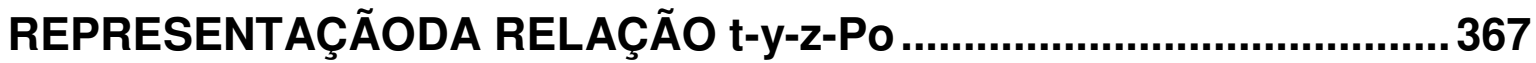

E.3 TABELAS DOS POLINÔMIOS AJUSTADOS AOS PONTOS DE ENSAIO

E.4 PROPOSTA DE AJUSTES POLINOMIAIS $\tau\left(P_{0}\right)$ e y( $\left(P_{0}\right)$ PARA ANÁLISE DA VARIAÇÃO DE $\tau$ E y COM Po

E.4.1 Ajuste das cargas na ponta para o estágio de carga $P_{0}=500 \mathrm{kN}$ 369

E.5 PROPOSTA DE AJUSTE POLINOMIAL PARA A FUNÇÃO DE CISALHAMENTO $\tau(z)$

E.6 PROPOSTA DE AJUSTE POLINOMIAL PARA A FUNÇÃO DE DESLOCAMENTO y(z) 376

E.7 FÓRMULAS GERAIS PARA AS FUNÇÕES PARTINDO DO VALOR INICIAL DA PONTA DA ESTACA $(z=L)$ 377

E.8 PROPOSTA DE AJUSTE POLINOMIAL DE SUPERFÍCIE PARA AS EXPRESSÕES $\tau\left(z ; P_{0}\right)$ E y(z; $\left.P_{0}\right)$ 379

E.9 DEDUÇÃO DA EXPRESSÃO DO COEFICIENTE C DE DISTRIBUIÇÃO DO ATRITO LATERAL AO LONGO DO FUSTE 380 APÊNDICE F - RESULTADOS DA APLICAÇÃO DA MSU A DIVERSOS TIPOS DE ESTACA E SOLOS 


\section{APÊNDICE A - REVISÃO BIBLIOGRÁFICA DOS EVENTOS TÉCNICO-CIENTíFICOS DA DÉCADA (2000-2010)}

Este apêndice apresenta uma tabela resumo dos principais eventos técnicocientíficos da década de 2000 a 2010. A atenção foi concentrada sobre os Congressos Brasileiros de Mecânica dos Solos e Engenharia Geotécnica (COBRAMSEG's), e incluiu-se o Seminário de Fundações Especiais (SEFE) de 2008.

Os trabalhos selecionados versam sobre as análises de aplicabilidade dos métodos semiempíricos em diversos solos de distintas regiões do país.

$\mathrm{Na}$ Tabela 35 constam colunas com o evento considerado, sobrenome do autor, cidade e estado dos ensaios, o tipo de solo pesquisado, o tipo de estaca ensaiada, os métodos semiempíricos analisados, o tipo de sondagem utilizada, o critério de ruptura adotado e as conclusões publicadas pelos autores, as quais evidenciam o aqui chamado paradigma de classificação dos métodos.

Convém comentar que alguns trabalhos não apresentam detalhes sobre algumas destas informações, o que se indica com um traço na célula da tabela. As siglas dos métodos aqui analisados foram mantidas ( $D Q, A V, A L$, etc.), e outros métodos que eventualmente tenham sido analisados foram escritos por extenso. Alguns métodos que omitiram o critério de ruptura aparentemente adotaram a carga máxima de ensaio como ruptura de comparação, não sendo porém esclarecido no trabalho.

As conclusões apresentadas, sobretudo com a terminologia "conservadores", "subestimam", "superestimam", "satisfatórios", "mais próximo", "melhor", etc., demonstram 0 aqui chamado paradigma de classificação dos métodos semiempíricos discutido em bases conceituais no Capítulo 3.

Poucos métodos propuseram algum tipo de correção, modificação ou correção dos métodos para o solo e tipo de estaca em questão, como é a proposta que aqui se coloca. 
$\stackrel{\circ}{\stackrel{2}{N}}$

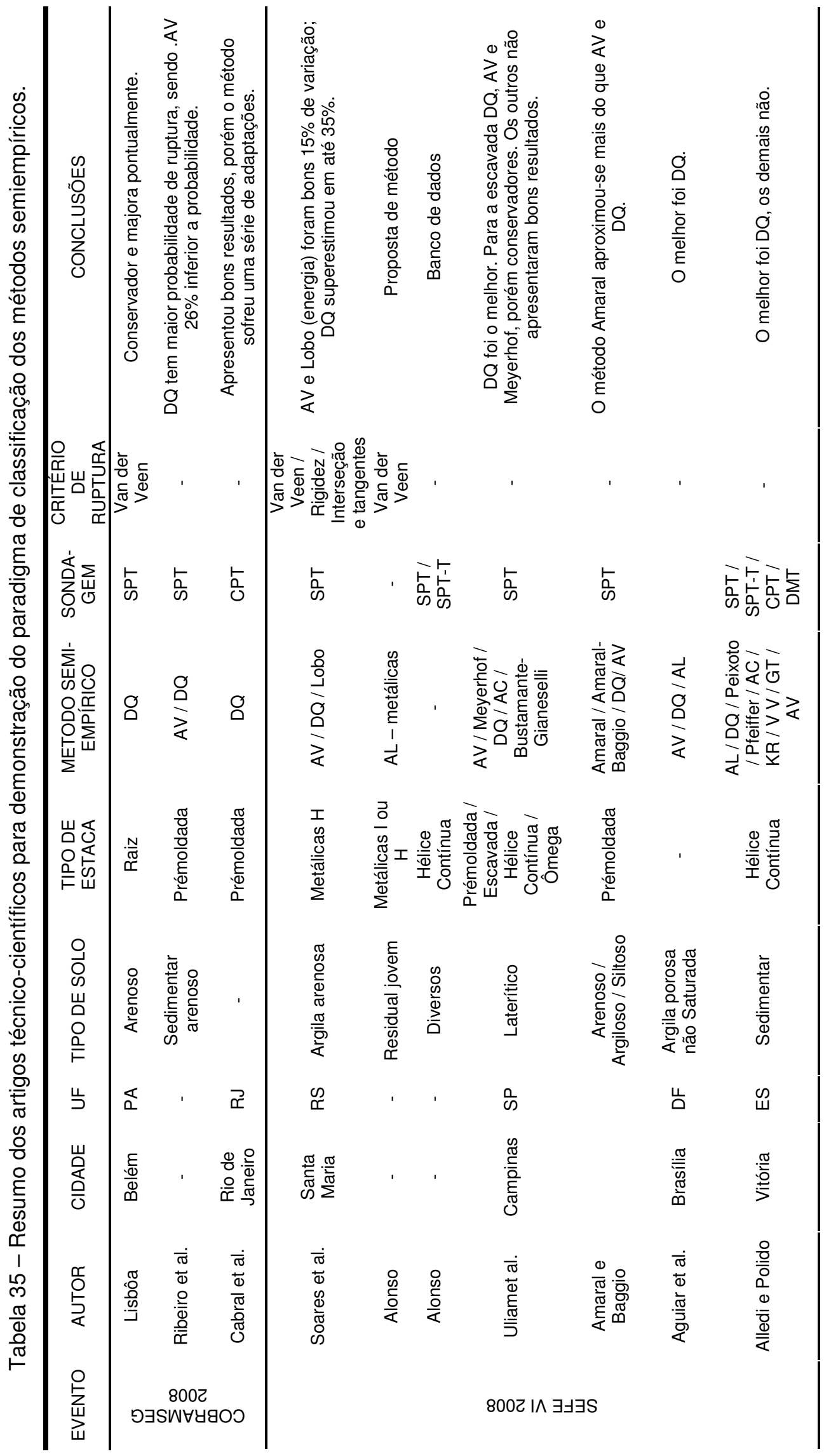


ลิ

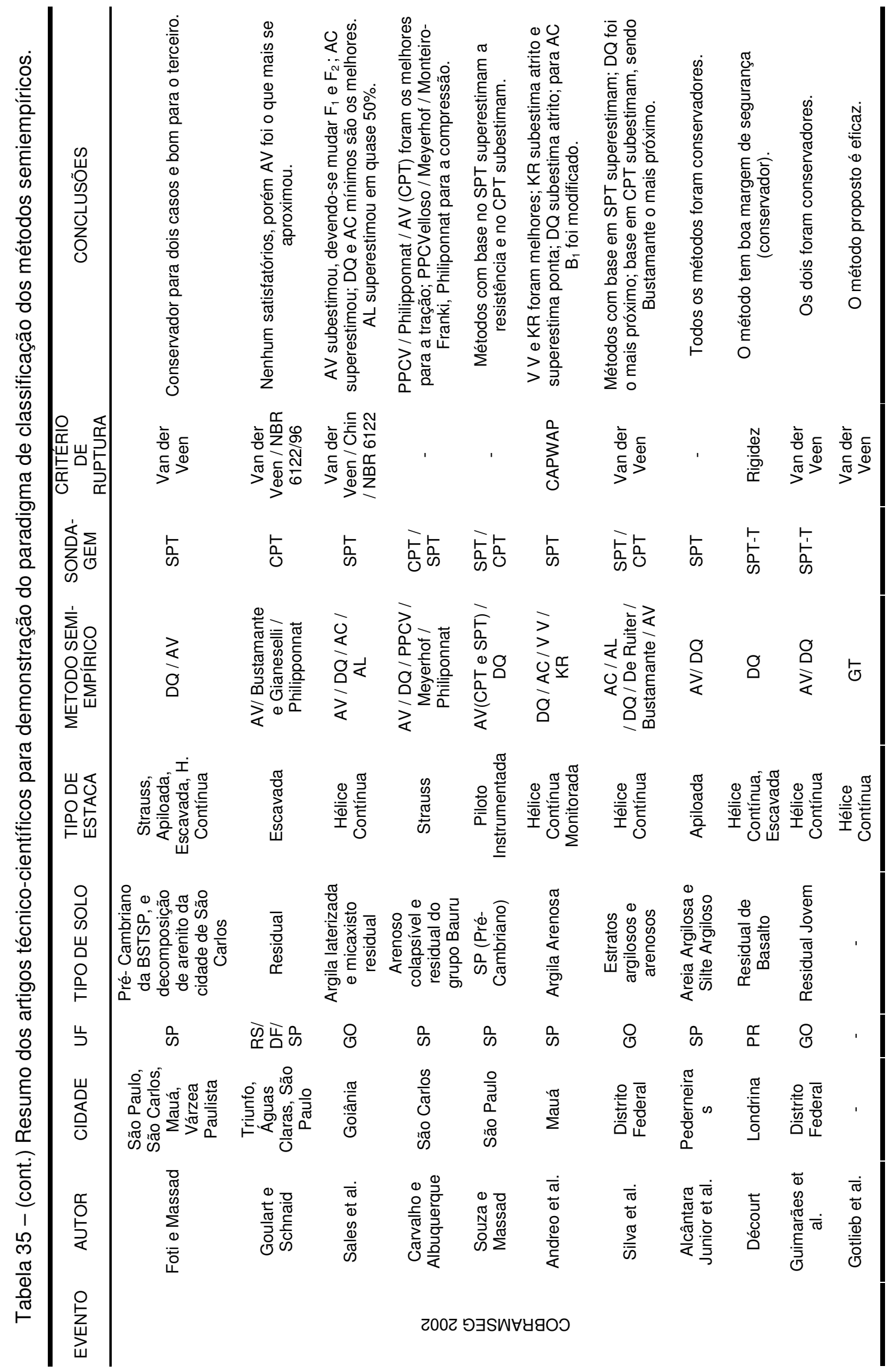




\section{APÊNDICE B - SOBRE A GENERALIZAÇÃO DOS MÉTODOS E AS HIERARQUIAS DOS SOLOS}

Neste apêndice, discutem-se os trabalhos de Amann (2000, 2002, 2004 e 2006), que buscou comprovar a generalização dos diversos métodos semiempíricos para os tipos de estacas mais utilizados. Discutem-se também a correspondência entre os fatores empíricos dos diversos métodos e a Hierarquia dos Solos (AMANN, 2000), como forma de se apropriar valores coerentes pela resistência relativa dos diversos tipos de solo com mesmos valores de SPT.

\section{B.1 VALORES DOS COEFICIENTES EMPÍRICOS DE CADA MÉTODO}

Antes de se discutir as Hierarquias, é conveniente apresentar os valores atribuídos pelos autores aos coeficientes dos seus respectivos métodos.

A Tabela 36 apresenta os valores dos coeficientes empíricos dos métodos de David Cabral (1986, 1999) e Cabral et al. (2004) respectivamente para estacas escavadas, raiz, ômega, e da Brasfond (1989) para estacas raiz. Nesta tabela, os valores em itálico foram admitidos por correlação (AMANN, 2000), não tendo sido estabelecidos no método original.

Tabela 36 - Coeficientes empíricos dos métodos para estacas raiz, em função do solo (AMANN, 2002) e valores dos coeficientes empíricos do Método de Cabral et al. para estacas Ômega, Raiz e da Fundesp para Escavada de Grande Diâmetro, e Brasfond para estacas Raiz (AMANN, 2004)

\begin{tabular}{|c|c|c|c|c|c|c|c|c|}
\hline \multirow{2}{*}{ Solo } & \multicolumn{2}{|c|}{$\begin{array}{l}\text { Fundesp (CB) } \\
\text { (Ômega) }\end{array}$} & \multicolumn{2}{|c|}{$\begin{array}{l}\text { Fundesp (CA) } \\
\text { (Esc. Gde. D) }\end{array}$} & \multicolumn{2}{|c|}{$\begin{array}{c}\text { David Cabral (CA) } \\
\text { (Raiz) }\end{array}$} & \multicolumn{2}{|c|}{$\begin{array}{l}\text { Brasfond (BR) } \\
\text { (Raiz) }\end{array}$} \\
\hline & $\begin{array}{c}\beta_{2} \\
\mathrm{kN} / \mathrm{m}^{2} \\
\end{array}$ & $\begin{array}{c}\beta_{1} \\
\mathrm{kN} / \mathrm{m}^{2}\end{array}$ & $\begin{array}{c}\beta_{2} \\
\mathrm{kN} / \mathrm{m}^{2}\end{array}$ & $\begin{array}{c}\beta_{1} \\
\mathrm{kN} / \mathrm{m}^{2}\end{array}$ & $\begin{array}{c}\beta_{2} \\
\mathrm{kN} / \mathrm{m}^{2}\end{array}$ & $\begin{array}{c}\beta_{1} \\
\mathrm{kN} / \mathrm{m}^{2}\end{array}$ & $\begin{array}{c}\beta_{\mathrm{B}} \\
\mathrm{kN} / \mathrm{m}^{2}\end{array}$ & $\alpha_{B}$ \\
\hline Areia & 320 & 5,4 & 250 & 3,0 & 300 & 7,0 & 270 & 5,0 \\
\hline Areia siltosa & 260 & 5,0 & 200 & 3,3 & 280 & 8,0 & 210 & 5,0 \\
\hline Areia argilosa & 280 & 4,7 & 200 & 3,5 & 230 & 8,0 & 180 & 5,0 \\
\hline Silte & 120 & 3,0 & 120 & 2,3 & 180 & 5,0 & 150 & 5,0 \\
\hline Silte arenoso & 250 & 4,2 & 150 & 2,5 & 200 & 6,0 & 150 & 5,0 \\
\hline Silte argiloso & 180 & 3,2 & 110 & 2,0 & 100 & 3,5 & 100 & 5,0 \\
\hline Argila & 156 & 3,0 & 100 & 2,4 & 100 & 5,0 & 80 & 5,0 \\
\hline Argila arenosa & 175 & 3,9 & 140 & 2,5 & 150 & 5,0 & 120 & 5,0 \\
\hline Argila siltosa & 120 & 2,5 & 110 & 2,0 & 100 & 4,0 & 80 & 5,0 \\
\hline
\end{tabular}

A Tabela 37 traz os valores dos coeficientes empíricos referentes aos métodos para estacas hélice-contínua. 
Tabela 37 - Valores dos coeficientes empíricos dos métodos semiempíricos para estacas HéliceContínua e comparação com Décourt-Quaresma (AMANN, 2004)

\begin{tabular}{|c|c|c|c|c|c|c|c|c|c|c|c|c|c|}
\hline \multirow{3}{*}{ Solo } & \multicolumn{7}{|c|}{ Décourt - Quaresma } & \multicolumn{2}{|c|}{ Alonso } & \multicolumn{2}{|c|}{ Antunes-Cabral } & \multicolumn{2}{|c|}{ Karez-Rocha } \\
\hline & \multirow{2}{*}{$C_{p D Q}$} & \multicolumn{2}{|c|}{ HLC } & \multicolumn{2}{|c|}{ Escavada } & \multicolumn{2}{|c|}{ Raiz } & \multirow{2}{*}{$\alpha_{\mathrm{AL}}$} & \multirow{2}{*}{$\beta_{\mathrm{AL}}$} & \multirow{2}{*}{$\mathrm{B}_{1}$} & \multirow{2}{*}{$\mathrm{B}_{2}$} & \multirow{2}{*}{$\mathrm{K}_{\mathrm{LKR}}$} & \multirow{2}{*}{$\mathrm{K}_{\mathrm{PKR}}$} \\
\hline & & $\alpha_{D Q}$ & $\beta_{\mathrm{DQ}}$ & $\alpha_{D Q}$ & $\alpha_{D Q}$ & $\beta_{\mathrm{DQ}}$ & $\beta_{\mathrm{DQ}}$ & & & & & & \\
\hline Areia & 400 & 0,30 & 1,00 & 0,50 & 0,60 & 0,50 & 1,50 & 0,65 & 200 & 4,0 a 5,0 & 200 a 250 & 4,90 & 290 \\
\hline arenoso & 250 & 0.30 & 1.00 & 0.60 & 0.75 & 0.60 & 1.50 & 0.65 & 150 & & 100 a 200 & 4.90 & 250 \\
\hline argiloso & 200 & & & & & & (1,50 & 0,05 & 100 & 2,5 d 3,5 & 100 d $\angle 00$ & 4,90 & 200 \\
\hline Argila & 120 & 0,30 & 1,00 & 0,85 & 0,90 & 0,85 & 1,50 & 0,65 & 100 & 2,0 a 3,5 & 100 a 150 & 4,90 & 210 \\
\hline
\end{tabular}

Tabela 38 - Valores de $K_{F K}$ e $\alpha_{F K}$ sugeridos por Monteiro [g=FK] (2000) e Laprovitera(1988) [g=LP] apud Velloso e Lopes (2002).

\begin{tabular}{lcccc}
\hline \multicolumn{1}{c}{ Solos } & $\mathrm{K}_{\mathrm{FK}} \mathrm{kN} / \mathrm{m}^{2}$ & $\alpha_{\mathrm{FK}}(\%)$ & $\mathrm{K}_{\mathrm{LP}} \mathrm{kN} / \mathrm{m}^{2}$ & $\alpha_{\mathrm{LP}}(\%)$ \\
\hline Areia & 730 & 2,1 & 600 & 1,4 \\
Areia siltosa & 680 & 2,3 & 530 & 1,9 \\
Areia silto-argilosa & 630 & 2,4 & 530 & 2,4 \\
Areia argilosa & 540 & 2,8 & 530 & 3,0 \\
Areia argilo-siltosa & 570 & 2,9 & 530 & 2,8 \\
Silte & 480 & 3,2 & 480 & 3,0 \\
Silte arenoso & 500 & 3,0 & 480 & 3,0 \\
Silte areno-argiloso & 450 & 3,2 & 380 & 3,0 \\
Silte argiloso & 320 & 3,6 & 300 & 3,4 \\
Silte argilo-arenoso & 400 & 3,3 & 380 & 3,0 \\
Argila & 250 & 5,5 & 250 & 6,0 \\
Argila arenosa & 440 & 3,2 & 480 & 4,0 \\
Argila areno-siltosa & 300 & 3,8 & 300 & 4,5 \\
Argila siltosa & 260 & 4,5 & 250 & 5,5 \\
Argila silto-arenosa & 330 & 4,1 & 300 & 5,0 \\
\hline
\end{tabular}

Tabela 39 - Fatores $F_{1 g}$ e $F_{2 g}$ em função do tipo de estaca (MONTEIRO [FK], 2000 e BENEGAS [BN], 1993, apud VELLOSO e LOPES, 2002)

\begin{tabular}{ccccc}
\hline Tipo de estaca & $\mathrm{F}_{1 \mathrm{FK}}$ & $\mathrm{F}_{2 \mathrm{FK}}$ & $\mathrm{F}_{1 \mathrm{BN}}$ & $\mathrm{F}_{2 \mathrm{BN}}$ \\
\hline Franki & 2,30 & 3,00 & 2,50 & 3,00 \\
Metálica & 1,75 & 3,50 & 2,40 & 3,40 \\
Pré-moldada cravada & 2,50 & 3,50 & 2,00 & 3,50 \\
Strauss & 4,20 & 3,90 & - & - \\
Raiz & 2,20 & 2,40 & - & - \\
Hélice contínua & 3,00 & 3,80 & - & - \\
Esc. Gde. Diâmetro & 3,50 & 4,50 & 4,5 & 4,5 \\
Ômegafranki & 2,50 & 3,20 & - & - \\
\hline
\end{tabular}

A Tabela 38 e a Tabela 39 apresentam os valores dos coeficientes do método Monteiro-Franki (2000), Laprovitera (1988) e Benegas (1993), apud Velloso e Lopes (2002). Estes últimos autores adotam para a região de influência da ponta 1D acima e abaixo da sua profundidade, como já mencionado. A Tabela 40 apresenta os coeficientes do método de Teixeira (1996). 
Tabela 40- Coeficientes de cisalhamento lateral e ponta do método de Teixeira (1996) para diversos tipos de estaca (VELLOSO e ALONSO, 2000).

\begin{tabular}{|c|c|c|c|c|}
\hline $\begin{array}{c}\text { Estaca } \\
\mathrm{K}_{\mathrm{LTX}}\left(\mathrm{kN} / \mathrm{m}^{2}\right)\end{array}$ & $\begin{array}{c}\text { Prémoldada } \\
4,0\end{array}$ & $\begin{array}{c}\text { Franki } \\
5,0\end{array}$ & $\begin{array}{c}\text { Escavada } \\
4,0 \\
\end{array}$ & $\begin{array}{c}\text { Raiz } \\
6,0 \\
\end{array}$ \\
\hline Solo & \multicolumn{4}{|c|}{$\mathrm{K}_{\mathrm{PTX}}\left(\mathrm{kN} / \mathrm{m}^{2}\right)$} \\
\hline Areia & 400 & 340 & 270 & 260 \\
\hline Areia siltosa & 360 & 300 & 240 & 220 \\
\hline Areia argilosa & 300 & 240 & 200 & 190 \\
\hline Silte arenoso & 260 & 210 & 160 & 160 \\
\hline Silte argiloso & 160 & 120 & 110 & 110 \\
\hline Argila arenosa & 210 & 160 & 130 & 140 \\
\hline Argila siltosa & 110 & 100 & 100 & 100 \\
\hline
\end{tabular}

Para o método P.P.C.Velloso (1981) os coeficientes são apresentados na Tabela 41, sendo que, para estacas cravadas $\alpha_{C V}=1,0$, para escavadas 0,5 , e $\lambda_{\mathrm{CV}}=0,7$ para estacas tracionadas e 1,0 para comprimidas. $O$ coeficiente $\beta_{\mathrm{cv}}$ se refere à dimensão da estaca $\left(\mathrm{k}_{\mathrm{tD}}\right)$ e será discutido mais adiante.

Tabela 41 - Coeficientes de cisalhamento lateral e ponta do método de PPC Velloso (1981) para diversos tipos de estaca (VELLOSO e ALONSO, 2000).

\begin{tabular}{|c|c|c|c|c|c|}
\hline \multirow{2}{*}{ Solos (submersos) } & & \multicolumn{2}{|c|}{ Fuste } & \multicolumn{2}{|c|}{ Ponta } \\
\hline & & $a^{\prime}\left(k N / m^{2}\right)$ & $b^{\prime}$ & $\mathrm{a}\left(\mathrm{kN} / \mathrm{m}^{2}\right)$ & $\mathrm{b}$ \\
\hline Areia (sedimentar) & & 5,0 & 1,0 & 600 & 1,0 \\
\hline Argila (sedimentar) & & 6,3 & 1,0 & 250 & 1,0 \\
\hline Areia siltosa (residual de gnaisse) & & 8,5 & 1,0 & 500 & 1,0 \\
\hline \multirow{2}{*}{ Silte arenoso (residual de gnaisse) } & (RJ) & 8,0 & 1,0 & 400 & 1,0 \\
\hline & $(\mathrm{MG})$ & 12,1 & 0,74 & 470 & 0,96 \\
\hline
\end{tabular}

\section{B.1.1 Valores atribuídos por outros autores}

Apresentam-se aqui os valores atribuídos por Danziger e Velloso (1985) [subscrito DV] e Alonso (1980) [subscrito AL] que pesquisaram, por meio de ensaios CPT e correlações com ensaios SPT, valores para os coeficientes empíricos do método Aoki-Velloso em solos diversos.

Esses valores serão também considerados na composição de valores médios para cada coeficiente.

Apresenta-se a seguir a conceituação das Hierarquias dos Solos e o condensado das pesquisas de Amann (2000, 2002, 2004 e 2006). 
Tabela 42 - Valores dos coeficientes de tipo de ensaio $\left(K_{D V}\right.$ ou $\left.K_{A L} \equiv k_{t e}\right)$ e tipo de solo $\left(\alpha_{A L} \equiv k_{t s}\right)$ obtidos por Danziger e Velloso (1985) e Alonso (1980), apud Décourt (1996a)

\begin{tabular}{lccc}
\hline \multicolumn{1}{c}{ Solos } & $\begin{array}{c}\mathrm{K}_{\mathrm{DV}} \\
\mathrm{kN} / \mathrm{m}^{2}\end{array}$ & $\begin{array}{c}\mathrm{K}_{\mathrm{AL}} \\
\mathrm{kN} / \mathrm{m}^{2}\end{array}$ & $\alpha_{\mathrm{AL}}(\%)$ \\
\hline Areia & 600 & - & - \\
Areia siltosa & 530 & - & - \\
Areia silto-argilosa & 530 & - & - \\
Areia argilosa & 530 & 560 & 2,00 \\
Areia argilo-siltosa & - & 617 & 1,80 \\
Silte & 480 & - & - \\
Silte arenoso & 480 & 510 & 1,30 \\
Silte areno-argiloso & 380 & 310 & 2,95 \\
Silte argiloso & 300 & - & - \\
Silte argilo-arenoso & 270 & 270 & 3,00 \\
Argila & 250 & - & - \\
Argila arenosa & 480 & 270 & 2,90 \\
Argila areno-siltosa & - & - & - \\
Argila siltosa & 250 & - & 2,70 \\
Argila silto-arenosa & 380 & 320 & 2,35 \\
\hline
\end{tabular}

\section{B.2 HIERARQUIAS DOS SOLOS (AMANN, 2002, 2004 e 2006)}

Apresentam-se aqui os valores dos coeficientes característicos, ordenados decrescentemente, para cada tipo de solo, evidenciando as hierarquias e discutindo seus resultados, conforme os trabalhos de Amann (2002, 2004 e 2006).

\section{B.2.1 Definição dos grupos de solos (Amann, 2000)}

É importante, antes de avançar nas discussões das hierarquias, introduzir-se a definição de alguns termos sugeridos por Amann (2000), para fazer referência a três grupos de solo definidos conforme sua composição:

- Solos simples: são os solos que apresentam apenas um componente, ou seja, areia pura, argila pura e silte puro;

- Solos compostos: são os solos que apresentam em sua composição dois tipos de solos simples, ou seja, areia siltosa, areia argilosa, silte arenoso, silte argiloso, argila arenosa e argila siltosa;

- Solos mistos: são os solos que apresentam em sua composição os três tipos de solos simples em proporções diversas, ou seja, areia silto-argilosa, areia argilo-siltosa, silte areno-argiloso, silte argilo-arenoso, argila areno-siltosa e argila silto-arenosa.

Parece evidente que o comportamento de cada tipo de solo "composto" é definido principalmente pelo solo "simples" que se apresenta em maior proporção na sua composição. Assim, a areia argilosa deve apresentar um comportamento 
predominantemente arenoso, bem como um silte argiloso deve apresentar comportamento siltoso. Da mesma forma, um solo "misto" deve apresentar comportamento similar ao do solo composto do qual se origina, assim como uma areia argilo-siltosa deve comportar-se de forma análoga à areia argilosa, bem como um silte argilo-arenoso deve comportar-se como um silte argiloso.

\section{B.2.2 Valores dos coeficientes característicos de resistência e as hierarquias}

Com os valores apresentados desde a Tabela 36 à Tabela 39, podem-se calcular os coeficientes característicos de resistência utilizando as expressões da Tabela 5 e verificarem-se facilmente as mencionadas hierarquias, como mostram a Tabela $43 \mathrm{e}$ a Tabela 44, respectivamente, para o cisalhamento lateral e para a ponta, ambas aplicadas ao caso de estacas raiz.

Tabela 43 - Hierarquia dos solos e coeficientes $\mathrm{K}_{\mathrm{Lg}}$ dos Métodos Aoki-Velloso (AV), David Cabral

(CA) e Brasfond (BR) para o cisalhamento lateral de estacas raiz (AMANN, 2002)

\begin{tabular}{lccc}
\hline \multicolumn{1}{c}{ Solo da camada } & $\begin{array}{c}\mathrm{K}_{\mathrm{LAV}} \\
\mathrm{kN} / \mathrm{m}^{2}\end{array}$ & $\begin{array}{c}\mathrm{K}_{\mathrm{LCA}} / \beta_{0} \\
\mathrm{KN} / \mathrm{m}^{2}\end{array}$ & $\begin{array}{c}\mathrm{K}_{\mathrm{LBR}} \\
\mathrm{KN} / \mathrm{m}^{2}\end{array}$ \\
\hline Areia argilosa & 9,00 & 8,00 & 5,00 \\
Areia silto-argilosa & 8,40 & 8,00 & 5,00 \\
Areia siltosa & 8,00 & 8,00 & 5,00 \\
Areia & 7,00 & 7,00 & 5,00 \\
Areia argilo-siltosa & 7,00 & 7,00 & 5,00 \\
Silte areno-argiloso & 6,30 & 6,30 & 5,00 \\
Silte arenoso & 6,05 & 6,00 & 5,00 \\
\hline Argila & 6,00 & 5,00 & 5,00 \\
Silte & 6,00 & 5,00 & 5,00 \\
Argila silto-arenosa & 4,95 & 5,00 & 5,00 \\
Argila arenosa & 4,40 & 5,00 & 5,00 \\
Argila siltosa & 4,20 & 4,00 & 5,00 \\
Argila areno-siltosa & 4,20 & 4,00 & 5,00 \\
Silte argiloso & 3,91 & 3,50 & 5,00 \\
Silte argilo-arenoso & 3,75 & 3,30 & 5,00 \\
\hline
\end{tabular}

Note-se que na Tabela 43 e Tabela 44 há uma nítida separação entre solos de comportamento arenoso (acima do traço divisor horizontal entre o silte arenoso e a argila e entre o silte areno argiloso e o silte) e os de comportamento argiloso (abaixo). 
Tabela 44 - Hierarquia dos solos e fatores $\mathrm{K}_{\mathrm{Pg}}$ dos Métodos Décourt-Quaresma (DQ), Aoki-Velloso (AV), David Cabral (CA) e Brasfond (BR) para o solo da ponta de estacas raiz (AMANN, 2002)

\begin{tabular}{lcccc}
\hline \multicolumn{1}{c}{$\begin{array}{c}\text { Solo } \\
\text { da ponta }\end{array}$} & $\begin{array}{c}\mathrm{K}_{\mathrm{PDQ}} \\
\mathrm{kN} / \mathrm{m}^{2}\end{array}$ & $\begin{array}{c}\mathrm{K}_{\mathrm{PAV}} \\
\mathrm{kN} / \mathrm{m}^{2}\end{array}$ & $\begin{array}{c}\mathrm{K}_{\mathrm{PCA}} / \beta_{0} \\
\mathrm{kN} / \mathrm{m}^{2}\end{array}$ & $\begin{array}{c}\mathrm{K}_{\mathrm{PBR}} \\
\mathrm{KN} / \mathrm{m}^{2}\end{array}$ \\
\hline Areia & 200 & 333 & 300 & 270 \\
Areia siltosa & 180 & 267 & 280 & 210 \\
Areia silto-argilosa & 167 & 233 & 245 & 197 \\
Areia argilosa & 160 & 200 & 230 & 180 \\
Silte arenoso & 150 & 183 & 200 & 150 \\
Areia argilo-siltosa & 145 & 167 & 188 & 150 \\
Silte areno-argiloso & 140 & 150 & 180 & 140 \\
\hline Silte & 138 & 133 & 180 & 137 \\
Argila arenosa & 130 & 117 & 150 & 120 \\
Argila silto-arenosa & 125 & 110 & 140 & 115 \\
Argila areno-siltosa & 123 & 100 & 130 & 108 \\
Silte argilo-arenoso & 120 & 83 & 115 & 100 \\
Silte argiloso & 120 & 77 & 100 & 100 \\
Argila siltosa & 111 & 73 & 100 & 80 \\
Argila & 102 & 67 & 100 & 80 \\
\hline
\end{tabular}

A partir da generalização, pode-se comparar o método Décourt-Quaresma e o método de Alonso para estacas Hélice-Contínua (ver valores Tabela 37). Para isso, consideraram-se três casos: o estudo de Alonso (1996), com $h_{\text {SPT }}=45 \mathrm{~cm}$ (Tabela

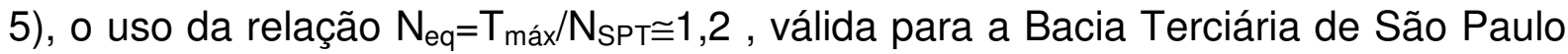
e sua sugestão de adoção de $\mathrm{f}_{\mathrm{SAL}}=6,0 \mathrm{kN} / \mathrm{m}^{2}$. Os dois primeiros resultam nos valores do cisalhamento de torque $\left(f_{\mathrm{SAL}}\right)$ calculados pelas expressões (148) e (149) e o terceiro resulta em $\mathrm{K}_{\mathrm{LAL}}=3,9 \mathrm{kN} / \mathrm{m}^{2}$ :

$$
\begin{gathered}
\mathrm{f}_{\mathrm{SAL}}=\frac{\overline{\mathrm{T}}}{0,18} \cong 15+5 \cdot \mathrm{N}_{\mathrm{SPT}} \Rightarrow \mathrm{K}_{\mathrm{LAL}}=0,65 \frac{\overline{\mathrm{T}_{\max }}}{0,184} \cdot \frac{1}{\overline{\mathrm{N}_{\mathrm{SPT}}}}=3,25+\frac{9,75}{\overline{\mathrm{N}_{\mathrm{SPT}}}} \\
\mathrm{K}_{\mathrm{LAL}}=0,65 \cdot \frac{1}{0,184} \cdot \frac{\overline{\mathrm{T}_{\max }}}{\overline{\mathrm{N}_{\mathrm{SPT}}}}=0,65 \cdot \frac{1}{0,184} \cdot 1,2=0,65 \cdot 6,52=4,24
\end{gathered}
$$

Para Décourt-Quaresma, tem-se a expressão (150), para $\beta_{\mathrm{DQ}}=1,0$ :

$$
\mathrm{K}_{\mathrm{LDQ}}=10 \cdot 1,0 \cdot\left(\frac{1}{3}+\frac{1}{\overline{\mathrm{N}_{\mathrm{SPT}}}}\right)=\frac{10}{3}+\frac{10}{\overline{\mathrm{N}_{\mathrm{SPT}}}}=3,3+\frac{10}{\overline{\mathrm{N}_{\mathrm{SPT}}}}
$$

O resultado gráfico pode ser visto na Figura 81, que também inclui comparações com outros métodos para Hélice Contínua, verificando-se que as expressões obtidas 
são muito próximas, indicando que os resultados obtidos pelos dois métodos devem ser muito semelhantes. A reta horizontal em $\mathrm{K}_{\mathrm{LAL}}=4,24 \mathrm{kN} / \mathrm{m}^{2}$ representa o resultado da expressão (149), enquanto a horizontal $\mathrm{K}_{\mathrm{LAL}}=3,90 \mathrm{kN} / \mathrm{m}^{2}$ indica $\mathrm{O}$ valor obtido para $\mathrm{f}_{\mathrm{SAL}}=6,0 \mathrm{kN} / \mathrm{m}^{2}$. A reta horizontal correspondente ao valor de $\mathrm{K}_{\mathrm{LKR}}=4,9 \mathrm{kN} / \mathrm{m}^{2}$, representa o método Karez-Rocha e pode-se, ainda, comparar este gráfico com os valores de $\mathrm{K}_{\mathrm{LAC}}=\mathrm{B}_{1}$, do método Antunes-Cabral, os quais variam de 2,0 a 5,0 kN/m², mostrando que os resultados são muito próximos, bastando que se caia numa determinada faixa de valores de SPT para que as diferenças entre os resultados destes métodos reduzam ou aumentem. Também o método de Gotlieb et al. (2000) pode ser assim comparado, pois apresenta um valor constante de $2,0 \mathrm{kN} / \mathrm{m}^{2}$, que corresponde ao valor mínimo de Antunes-Cabral, indicando ser bastante conservador em relação aos demais.

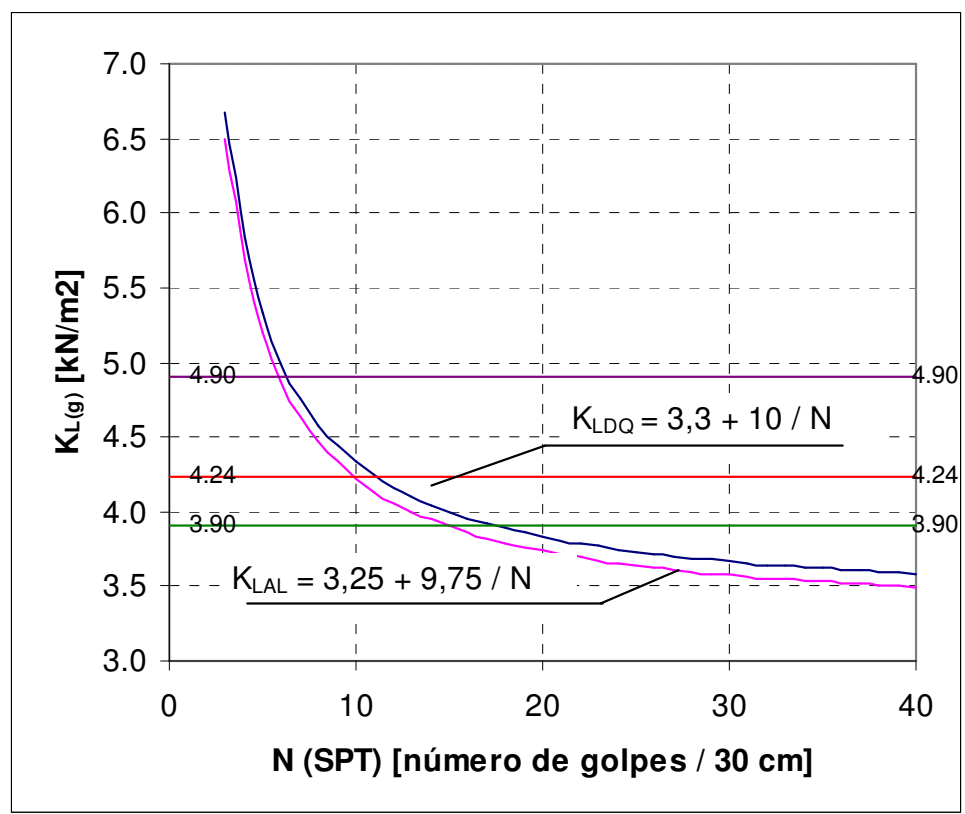

Figura 81 - Comparação gráfica entre os coeficientes de cisalhamento lateral $\left(\mathrm{K}_{\mathrm{Lg}}\right)$ do método de Alonso (AL) e Décourt-Quaresma (DQ) apud Amann (2004).

Uma comparção similar pode ser feita para os valores dos coeficientes característicos da ponta, tomando-se como referência o valor obtido para o coeficiente $K_{\mathrm{PAL}}$, do método de Alonso (1996), como mostra a Figura 82 (ver item seguinte), construída a partir da Tabela 37. 
De uma maneira mais ilustrativa, a Tabela 7, item 2.7, mostra a hierarquia para os coeficientes característicos do fuste para as estacas padrão dos métodos, como se comenta a seguir.

As setas indicam a mudança de posição na hierarquia que aparentemente alguns métodos apresentam para alguns tipos de solo (indicado sempre pelo código numérico em itálico ao lado esquerdo do valor do coeficiente). Sobre isso, Amann (2006) comenta que para o cisalhamento lateral: a) a areia argilosa aparece como a de maior resistência em três dos cinco métodos e é terceira e quarta nos demais, indicando que realmente deve apresentar um dos maiores valores entre os solos; b) a areia siltosa ocupa a segunda posição em quatro dos cinco métodos e é a primeira em um deles; c) a areia ocupa terceira posição em quatro dos cinco métodos e é primeira em um deles; d) o silte arenoso é o quarto em três métodos, o quinto em um e sétimo no outro; e) a argila arenosa aparece em quinto em dois métodos e sexto colocado em um dos métodos, sendo que nos outros dois é o penúltimo solo; f) a argila aparece em quinto e sétimo uma vez, e em sexto duas vezes, indicando a sua posição mais provável; g) o silte aparece em sexto, em sétimo duas vezes, em quarto e, questionavelmente, uma vez em segundo lugar; h) a argila siltosa aparece em quinto, em sétimo, e em oitavo três vezes; i) o silte argiloso é o nono em todos os métodos, indicando ser realmente o solo de menor resistência ao cisalhamento, quando comparado a outros de mesmo SPT.

De forma mais ampla, pode-se verificar que as hierarquias são válidas para os métodos aplicados a outros tipos de estacas, como se pode ver na Tabela 8, que apresenta os valores dos coeficientes característicos de resistência de ponta para as estacas padrão de cada método.

Amann (2006), focando inicialmente apenas os solos puros da Tabela 8 (areia, silte ou argila), comenta que se pode verificar a tendência geral de que quanto menor a granulometria do solo menor seu coeficiente de resistência pela ponta, para um mesmo valor de SPT. Há apenas duas exceções: os valores "mínimos" de AntunesCabral (AC) para estacas Hélice-Contínua apresentam o silte igual à argila, o que não invalida a hierarquia proposta; e o método de Cabral et al. (CB) para estaca Ômega, que apresenta valor maior para a argila do que para o silte, o que nesse caso poderia invalidá-la. 
Como apenas este método fugiu da tendência geral, imagina-se que a ponta da estaca Ômega pode comportar-se diferentemente em solos finos (coesivos), mas os valores do método de Monteiro-Franki (FK) para a mesma estaca mantêm a coerência com a hierarquia, indicando que os solos estudados por Cabral et al. (CB) apresentam algum tipo de particularidade a ser pesquisada. Um estudo comparativo entre os dois métodos para elucidar tal questão exigiria número razoável de provas de carga.

Pode-se observar na mesma Tabela 8 que para os solos "compostos" (exemplo: silte arenoso), tem-se em geral que: a) a presença de silte reduz a resistência de ponta das areias, mas pode aumentá-la um pouco nas argilas; b) a presença de argila reduz a resistência de ponta em areias (de forma mais significativa que o silte), o mesmo ocorrendo em siltes; c) a presença de areia eleva a resistência de ponta nos siltes e nas argilas.

\section{B.3 CORRELAÇÕES ENTRE OS COEFICIENTES EMPÍRICOS PARA COMPARAÇÃO DIRETA ENTRE OS DIVERSOS MÉTODOS}

As mesmas análises desenvolvidas por Amann (2000, 20002, 2004 e 2006) para verificação das Hierarquias dos Solos permitem inferir a possibilidade de se desenvolver uma Metodologia Unificada para se estimar empiricamente a carga de ruptura de estacas, dadas as semelhanças existentes entre os métodos. Tais análises basicamente se desenvolveram buscando identificar entre os coeficientes empíricos dos diversos métodos aqueles que são semelhantes, os que correspondem exclusivamente à consideração do tipo de solo ou de estaca, os que consideram mais de um fator intrinsecamente, etc., de maneira que se possa utilizar este conhecimento para tentar separar os coeficientes parciais que compõem os característicos. Os passos e conclusões que levam a isso serão agora discutidos para posteriormente compor-se à Metodologia Unificada.

Inicialmente, parte-se da identificação de semelhança dos coeficientes semiempíricos, de forma que a Tabela 9 apresenta alguns exemplos da expectativa de composição dos mesmos, em relação aos coeficientes parciais dados nas expressões (17) e (18) do texto. 
Pode-se considerar, em linhas gerais, que quanto menos coeficientes um método leva em consideração, mais coeficientes parciais cada coeficiente seu deve conter. Poder-se-ia inclusive considerar que todos os métodos que não distinguem coeficientes de consideração do diâmetro (ou dimensões) da estaca admitem um coeficiente $\mathrm{k}_{\mathrm{tD}}$ inerente, contudo, por ora, este não aparece incluído na coluna "significado incorporado" da Tabela 9.

A partir disto, Amann (2000) realizou correlações entre os coeficientes empíricos dos métodos aplicados a estacas raiz, identificando que muitos apresentavam correlações tão boas que indicavam representar o mesmo tipo de grandeza. Destacam-se as correlações apresentadas na Tabela 45.

Tabela 45 - Correlações lineares $(y=a \cdot x+b)$ entre os coeficientes dos métodos semi-empíricos para estacas raiz, com indicação do coeficiente de determinação estatístico $\left(R^{2}\right)$ e seus valores críticos para 95\% de confiança, apud Amann (2002)

\begin{tabular}{cccccc}
\hline$y$ & $x$ & $a$ & $b$ & $R^{2}$ & $R^{2}{ }_{\text {crítico } 5 \%}$ \\
\hline$\beta_{1}$ & $\alpha_{A V} \cdot K$ & 0,4909 & $-0,3684$ & 0,9303 & 0,4436 \\
$C_{P} \cdot \alpha_{D Q}$ & $\alpha_{B}$ & 0,4607 & 76,812 & 0,9919 & 0,9025 \\
$C_{P} \cdot \alpha_{D Q}$ & $\beta_{2}$ & 0,4400 & 66,000 & 0,9666 & 0,9025 \\
$C_{P} \cdot \alpha_{D Q}$ & $K$ & 0,1140 & 86,551 & 0,9805 & 0,9025 \\
$\alpha_{B}$ & $\beta_{2}$ & 0,7911 & 3,704 & 0,9422 & 0,4436 \\
$\alpha_{B}$ & $K$ & 0,2251 & 37,985 & 0,9823 & 0,4436 \\
$\beta_{2}$ & $K$ & 0,8119 & 51,407 & 0,9649 & 0,4436 \\
\hline
\end{tabular}

Algo semelhante pode ser feito, portanto, comparando-se os coeficientes característicos da estaca, $\mathrm{K}_{\mathrm{Lg}}$ e $\mathrm{K}_{\mathrm{Pg}}$ (sendo "g" um índice associado à sigla do método semiempírico analisado), como se vê na Tabela 46 (AMANN, 2004) para comparação dos métodos de estacas hélice-contínua (o gráfico pode ser visto na Figura 82).

Tabela 46 - Regressões entre os coeficientes característicos de ponta (KPg) do método de Alonso $(A L)$ e dos métodos Décourt-Quaresma (DQ) , Antunes-Cabral (AC) e Karez-Rocha (KR) AMANN (2004)

\begin{tabular}{|c|c|c|c|}
\hline \multirow{2}{*}{$\boldsymbol{K}_{P g}$} & \multicolumn{3}{|c|}{$\boldsymbol{K}_{P A L}=\boldsymbol{a} \cdot \boldsymbol{K}_{\boldsymbol{P g}}+\boldsymbol{b}$} \\
\cline { 2 - 4 } & $\boldsymbol{a}$ & $\boldsymbol{b}$ & $\boldsymbol{R}^{\mathbf{2}}$ \\
\hline \multirow{2}{*}{$\boldsymbol{K}_{P D Q}$} & 1,92 & 0 & 0,3750 \\
\cline { 2 - 4 } & 1,12 & 68,54 & 0,9406 \\
\hline \multirow{2}{*}{$\boldsymbol{K}_{P A C \min }$} & 1,14 & 0 & 0,2857 \\
\cline { 2 - 4 } & 0,67 & 66,67 & 0,6667 \\
\hline \multirow{2}{*}{$\boldsymbol{K}_{P A C \max }$} & 0,76 & 0 & 0,9394 \\
\hline \multirow{2}{*}{$\boldsymbol{K}_{P K R}$} & 1,00 & $-50,00$ & 1,000 \\
\cline { 2 - 4 } & 0,61 & 0 & 0,7333 \\
\hline
\end{tabular}


Observa-se na Figura 82 que os valores do método de Alonso (1996) (que seriam representados pela reta a 45 graus (1:1), passando pela origem) representam uma espécie de média entre Décourt-Quaresma, mais conservador, e Karez-Rocha, o mais arrojado. Pode-se mencionar ainda o método de Gotlieb et al. (2000), que indica o valor constante $60 \mathrm{kN} / \mathrm{m}^{2}$, está nas proximidades de Décourt-Quaresma, portanto, também é conservador em relação aos demais. Deve-se lembrar, contudo, que o método de Gotlieb et al. utiliza valores até 8D acima da ponta, e DécourtQuaresma apenas 3D acima, o que significa que em casos onde o solo da ponta muda bruscamente de resistência pode haver distorções.

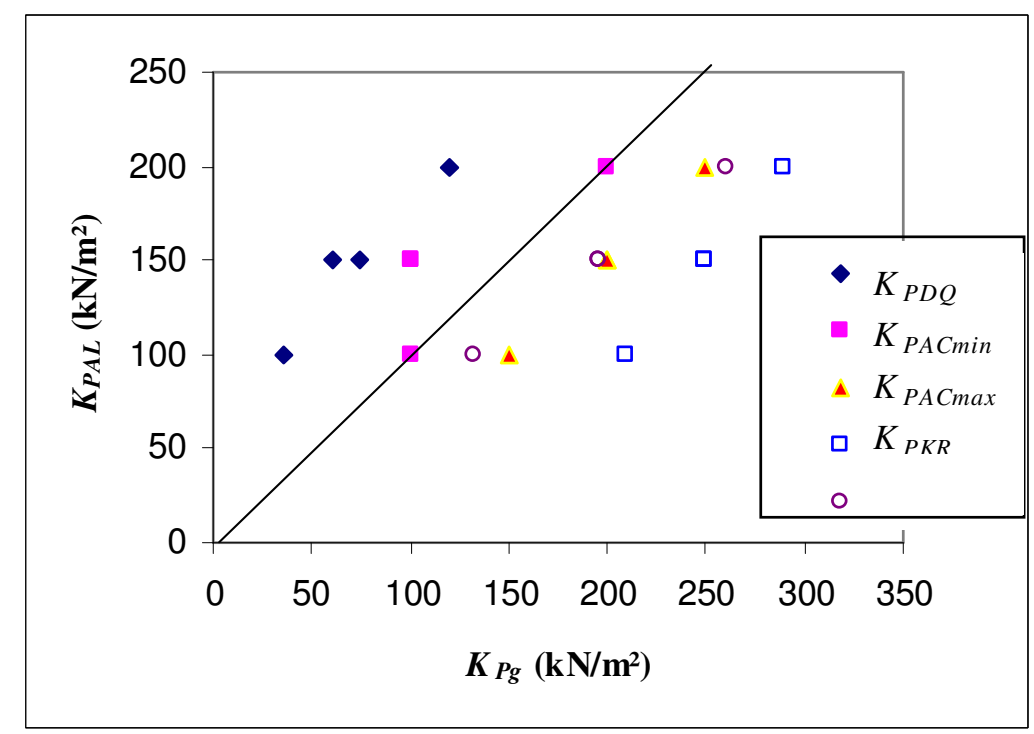

Figura 82 - Comparação gráfica entre os fatores de ponta do método de Alonso (AL) e dos métodos Décourt-Quaresma (DQ), Antunes-Cabral (AC) e Karez-Rocha (KR) apud AMANN (20004)

Na análise de Amann (2004), a boa correlação (Tabela 46) para os valores máximos de $B_{2}$, sugeridos pelo método Antunes-Cabral com o $\beta_{A L}$ de Alonso, indicam uma boa correspondência entre os métodos, denotando que o método de Alonso é conservador (em relação a Antunes-Cabral) ao considerar apenas $76 \%$ da resistência de ponta daquele método. Em relação a Décourt-Quaresma, AntunesCabral resultaria em um valor 2,53 vezes maior para a contribuição da ponta. Para Karez-Rocha, a resistência de ponta é considerada de forma bastante significativa, representando $64 \%$ a mais do que para Alonso, e 3,15 vezes mais do que DécourtQuaresma. 
Tal situação díspare pode ser justificada pelo fato de que as estacas escavadas, e a própria Hélice Contínua, apresentam o seu estado-limite evidenciado mais por recalques excessivos do que por ruptura física do solo. Mesmo em provas de carga, geralmente não se identifica a mobilização da ponta, sendo difícil estabelecer qual seria sua colaboração na carga de ruptura extrapolada da curva carga-recalque (MASSAD 1992).

Das conclusões de Amann (2004), pode-se extrair o seguinte: "Comparando-se os fatores $\mathrm{K}_{\mathrm{Pg}}$ (Figura 82) dos métodos, conclui-se que Décourt-Quaresma é o mais conservador para a resistência de ponta, enquanto o Karez-Rocha é o mais ousado. O método de Alonso (1996) aparece como o mediano, embora a sua consideração de 3 a 9 valores de torque mínimo acima da ponta (em função do diâmetro) tende a torná-lo um pouco mais conservador. Pelas análises, podem-se considerar válidas as seguintes relações aproximadas entre a resistência de ponta dos métodos: $\mathrm{K}_{\mathrm{PAL}} /$ $\mathrm{K}_{\mathrm{PDQ}}=1,50$ a 1,$92 ; \mathrm{K}_{\mathrm{PAL}} / \mathrm{K}_{\mathrm{PKR}}=0,61 ; \mathrm{K}_{\mathrm{PAL}} / \mathrm{K}_{\mathrm{PAC}}=0,76$. Esta diversidade de valores se deve provavelmente à incerteza gerada pela existência de poucas provas de carga com mobilização efetiva da ponta”.

Essas análises levam à conclusão de que dadas as semelhanças e correspondências entre os coeficientes dos métodos, ao se determiná-las pode-se muito bem sugerir a conversão de um método em outro. Isso não é interessante para que se estime o resultado de um método pela aplicação do outro, mesmo porque assim a dispersão seria absurdamente alta, mas é importante para entender como cada método se comporta em relação aos demais.

Nesse contexto, as conclusões a respeito dos métodos são praticamente as mesmas em diversos casos comuns, demonstrando-se que a aplicação de todos os métodos para sua comparação posterior é relativamente desnecessária e pode ser substituída por uma análise como a feita por Amann (2004), aqui demonstrada.

\section{B.4 DISCUSSÃO DAS CONDIÇÕES DE EMBUTIMENTO DA PONTA}

Outro fator de influência a ser discutido é o embutimento da ponta na camada portante, que se dá pela constatação de que a resistência medida tende a ficar constante somente após uma dada profundidade crítica de penetração do cone na 
camada de solo (ALBIERO, 1990). Considera-se assim que o embutimento a ser considerado para estacas deve estar entre 10 e 20 vezes o seu diâmetro (D). Para Van der Veen e Boersma (1972) apud Albiero (1990), esse valor é da ordem de 8D. Para Philliponnat (apud ALBIERO, 1990) fica-se em 3D, devendo ser sempre maior do que $3,0 \mathrm{~m}$.

Esta questão do embutimento influencia também a consideração da resistência média de ponta do cone. Considera-se seu valor igual à média entre a região de influência superior e inferior à profundidade da ponta, sendo considerados respectivamente da ordem de $8 D$ e 3,0 a 3,5D por Begemann (1963) e Sanglerat (1965); já Philliponnat et al (1978) consideram ambos, superior e inferior, como 3D. Monteiro (2000), como exemplo brasileiro, modificou o método de Aoki e Velloso (1975) que tomava apenas o valor do CPT na profundidade da ponta, sugerindo considerar-se como a média entre a região de influência superior, 7D acima, e 3,5D abaixo da ponta. Aqui, contudo, ao se confrontar com a variabilidade do solo, isso pode ser considerado um preciosismo, sendo perfeitamente possível incluir seu critério dentro do 8D e 3,5D proposto por Begeman (1963), como exposto por Albiero (1990).

É interessante notar que, salvo nos casos em que há variação brusca de resistência do solo na ponta, os valores de $\overline{N_{P}}$ e $N_{P}$ são muito próximos $\left(K_{P g(P)} \cong K_{P g}\right)$. Portanto, especial atenção deve ser dada à consideração do embutimento na camada portante da ponta nos métodos que adotam esse critério, pois caso a estaca não tenha o embutimento de 8D (ou qual seja o valor) acima da ponta, os resultados podem sofrer variações bruscas em função do SPT na região de transição das camadas. Mais coerente nesses casos, seria adotar o embutimento conforme o seu comprimento médio verificado na sondagem, dada a cota de parada da ponta após a execução, e não fixá-lo no método. Isto feito, o atrito lateral deve ser considerado somente até este limite, não avançando na região da ponta.

Atenção especial deve ser dada a estas considerações da região de influência da ponta, pois tudo indica que as mesmas são oriundas das formulações teóricas de capacidade de carga. Para se verificar isso propõe-se aqui distinguir três situações, as quais podem ser vistas na Figura 8: a) a consideração apenas do valor do CPT na profundidade da ponta, como no método Aoki-Veloso, que está relativamente de 
acordo com a formulação teórica de Berezantzev e de Vésic; b) a consideração de 3D, acima ou abaixo da ponta, como no método de Philliponnat, está de acordo com a teoria de Skempton e Bishop; c) a consideração de 8D acima e 3,5D abaixo da ponta, do método Aoki-Velloso, adaptado por Monteiro (2000), que está de acordo com a teoria de Meyerhof e De Beer.

Note-se também que a adoção de três valores de SPT (Décourt-Quaresma), 1,0m acima e 1,0m abaixo da ponta, remete ao que se considera como região de embutimento da mesma, como visto acima. Para estacas de $20 \mathrm{~cm}$ de diâmetro, por exemplo, isso representaria 5D de região de influência e, para $30 \mathrm{~cm}$ de diâmetro, 3,33D de região de influência, reduzindo o multiplicador de $D$ para estacas de maior diâmetro. Em um intervalo de diâmetros de $10 \mathrm{~cm}$ (raiz) a $250 \mathrm{~cm}$ (EGD), isso representa a variação da consideração do embutimento desde 10D até 0,4D.

Pode-se ver, portanto, que essas considerações teóricas também influenciaram os métodos semiempíricos que utilizam o SPT, sendo mais uma ligação entre esses dois tipos de métodos.

\section{B.5 EXEMPLO DE APLICAÇÃO DA GENERALIZAÇÃO DOS MÉTODOS E DAS HIERARQUIAS DOS SOLOS}

Como exemplo da total correspondência entre a metodologia de análise de Amann (2004) aqui mostrada e a metodologia usual, citam-se os trabalhos de Alledi e Polido (2008) e Alledi, Polido e Albuquerque (2006), dos quais se comentam as análises dos métodos de previsão de capacidade de carga aplicados a estacas hélicecontínua instrumentadas em campo experimental de Vitória-ES (solo sedimentar do Quaternário da orla continental com camadas alternadas de argila e areia).

Tratam-se, nesses trabalhos, de duas estacas, EH1 ( $L=8,0 \mathrm{~m})$ e $E H 2(L=12,0 \mathrm{~m})$, de $0,4 \mathrm{~m}$ de diâmetro, instrumentadas. Sobre as curvas carga-recalque foram aplicados diversos critérios de ruptura baseados em recalque limite e em interseção de retas, não sendo usados Van der Veen, Chin ou Rigidez. Como o ensaio foi levado a um bom nível de deformação (>10\%.D), os resultados desses critérios foram semelhantes, adotando-se respectivamente os valores de $700 \mathrm{kN}$ e $1000 \mathrm{kN}$. Seguem-se agora as considerações sobre as análises dos métodos semiempíricos 
aplicados, comparadas às que seriam obtidas pela metodologia de análise de Amann (2004).

A) Considerações relativas ao atrito lateral: o método de Décourt-Quaresma aplicado com os valores de SPT superestimou um pouco o atrito na EH1 e na EH2, sendo que, após corrigido pelos valores do torque (SPT-T), seus resultados se aproximaram dos experimentais, estando a favor da segurança. O método de Alonso (usando SPT-T) apresentou resultados também próximos aos experimentais e aos de Décourt-Quaresma corrigidos pelo SPT-T, o que está de acordo com a análise de Amann (2004) da figura B.2 feita acima, visto que ambos os métodos (DQ e $A L$ ) são muito semelhantes. O método de Karez-Rocha superestimou em $67 \%$ a $80 \%$ o atrito, o que também está coerente com Amann (2004), pela mesma figura B.2, onde se vê que o valor de $4,9 \mathrm{kN} / \mathrm{m}^{2}$, atribuído por este método, é superior ao admitido por Décourt-Quaresma e por Alonso (para SPT > 6), sobretudo corrigidos pelo torque que neste solo reduz um pouco o valor do atrito estimado.

B) Considerações relativas à ponta: para a estaca EH1, de Antunes-Cabral (AC), foi o método que mais se aproximou do valor experimental. Já DécourtQuaresma (DQ) subestimou seu valor, coerentemente com a análise de Amann (2004) sobre a figura B.3, onde DQ em resulta valores ligeiramente inferiores aos valores mínimos propostos por AC. Corrigido pelo torque, DQ resultou em valores ligeiramente acima dos experimentais. Já o método de Gotlieb et al (GT) superestimou em 4,5 vezes o valor da ponta, o que aparentemente não está coerente com a análise de Amann (2004) feita anteriormente, na qual seu valor estaria próximo ao de Décourt-Quaresma, e portanto deveria subestimá-la. Contudo ao se observar que na região de 8.D acima da ponta a sondagem associada a esta estaca EH1 apresenta grande heterogeneidade isto fica explicado, visto que DQ utiliza valores no entorno de apenas 1,0m (acima e abaixo) da ponta. Este efeito fica comprovado pela observação de que na estaca EH2 os métodos de DécourtQuaresma (DQ) e Gotlieb et al (GT) foram os que mais se aproximaram dos valores experimentais da ponta, concluindo-se, assim, a demonstração da coerência com a análise de Amann (2004) acima apresentada, visto que para essa segunda estaca a variação do SPT dentro de 8.D acima da ponta não era expressiva. O método AokiVelloso modificado por Monteiro (FK) se aproximou do valor da ponta da EH1 (portanto o método de Aoki-Velloso original é conservador, visto que no modificado 
ele considera o embutimento, ou seja, a região 8.D acima da ponta) e superestimou exageradamente na EH2 (onde talvez o método original não errasse tanto, pois considera apenas o valor de SPT na profundidade da ponta), indicando que a questão do embutimento (8.D) e do coeficiente $F_{1 A V}$ neste caso precisam ser ajustados para estacas hélice neste solo.

C) Considerações relativas aos resultados da carga de ruptura: O método de DQ, aplicado com o SPT, superestimou um pouco o resultado dos ensaios e, após corrigido pelo torque, foi o que mais se aproximou dos mesmos. Considerando que esse método foi elaborado com base no critério de ruptura convencional de recalque de $10 \%$.D , pode-se dizer que isto o aproxima da forma como a análise foi feita no trabalho em questão, favorecendo tal proximidade de valores. O método de Alonso SPT-T também se aproximou, como esperado, sendo que, ao empregá-lo com os valores SPT e não de torque, superestimou em $52 \%$ a $54 \%$ nas duas estacas, o que é explicado pela relação $\mathrm{K}_{\mathrm{PAL}} / \mathrm{K}_{\mathrm{PDQ}}=1,50$ (resistência de ponta $50 \%$ maior do que Décourt-Quaresma, o qual a subestimou) extraída da figura B.3 e da análise de Amann (2004) acima, visto que tal diferença se deve sobretudo às condições de ponta. O método Karez-Rocha resultou 75\% superior, o que está de acordo com as observações parciais sobre a ponta e o atrito acima realizadas. O método de Gotlieb et al. para a EH1 superestimou em 90\%, também de acordo com a questão da ponta. O método Aoki-Velloso modificado por Monteiro superestimou em $75 \%$ para a EH2 a carga de ruptura. Em certo sentido pode-se inferir que se fosse feita a extrapolação da carga de ruptura pelo critério de Van der Veen (1953), como utilizado por Aoki e Velloso (1975), certamente tal diferença seria menor, visto que, como se demonstrará mais adiante, os critérios de recalque limite e de interseção de retas resultam em valores de carga de ruptura menores do que os extrapolados por Van der Veen.

Assim, demonstra-se que a metodologia de análise de Amann (2000, 2002, 2004) permite prever as tendências dos resultados de um método em relação a outro (evidentemente não em relação ao ensaio) sem a necessidade da aplicação de todos para isso. Disto também se infere a possibilidade de se estabelecer a Metodologia Semiempírica Unificada. 
Particularmente interessantes são também as análises apresentadas acima sobre a natureza dos coeficientes (se consideram apenas a influência do tipo de solo ou também o tipo de estaca) e sobre os prováveis valores dos fatores de tipo de estaca, os quais convergem para diversos métodos e tipos de estacas. Esses valores convergentes podem ser utilizados diretamente na proposta de Metodologia Unificada que será apresentada mais adiante.

\section{B.6 ANÁLISE DO COEFICIENTE DE TIPO DE SOLO $\left(\mathbf{k}_{\mathrm{ts}}\right)$}

Amann (2000) considera que dentre os coeficientes parciais aqui descritos o único que se pode considerar com influência exclusiva do tipo de solo é o $\mathrm{k}_{\mathrm{ts}}$, ou seja, a razão de atrito, que correlaciona a resistência de cisalhamento lateral com a resistência da ponta do solo. Pode-se dizer que esse coeficiente mede uma relação que é uma característica intrínseca do solo, independendo do tipo de ensaio empregado, desde que este possa medir ao mesmo tempo as resistências por cisalhamento lateral e pela ponta. Evidentemente, o ensaio que permite esta verificação é o CPT, podendo-se aqui considerá-lo como ensaio de referência. Outro tipo de ensaio que permitiria essa determinação seria a instalação de uma estaca piloto (LIZZI, 1981 e SOUZA, 2001). Não se deve atribuir portanto a inerência de um eventual coeficiente de tipo de ensaio nesse coeficiente, pois o CPT (com luva de atrito) foi elaborado especificamente para medir essa característica do solo.

Por outro lado, é possível dizer que esse coeficiente parcial é inerente aos demais, visto que eles podem variar com o tipo de solo. Contudo, separar tal coeficiente dos demais exigiria adotar-se um valor base para cada outro coeficiente parcial e isso acabaria por gerar redundâncias desnecessárias. Assim, a separação só é interessante nos métodos específicos para um único tipo de estaca, como os de David Cabral (CA), por exemplo, sendo aplicada aos coeficientes empíricos e não aos parciais. Amann (2000) calculou para este método (CA) a relação entre os coeficientes característicos de resistência por cisalhamento lateral e pela ponta, obtendo-se assim valores de $\mathrm{k}_{\mathrm{ts}}$ próximos dos propostos originalmente no método Aoki-Velloso. Os detalhes desse procedimento podem ser vistos a seguir.

Uma forma de se isolar os valores desse coeficiente nos métodos semiempíricos, é calcular a razão entre os coeficientes característicos de resistência $K_{\mathrm{Lg}}$ e $\mathrm{K}_{\mathrm{Pg}}$. 
Também se pode considerar diretamente a análise apresentada no item B.3, que permite montar tabelas como a Tabela 9, e inferir, para o método de David Cabral, por exemplo, (AMANN, 2000), um hipotético coeficiente $\alpha_{C A}$, ou $\mathrm{k}_{\mathrm{ts}(\mathrm{CA})}$, verificando-se que $\beta_{1}$ deste método corresponde ao produto $\alpha_{A v} \cdot K_{A V}$ e que $\beta_{2}$ corresponde a $K_{A V}$. Assim, observa-se, na Tabela 47, que existe uma outra aparente "hierarquia" para os valores do coeficiente hipotético $\alpha_{\mathrm{CA}}$, calculado pelo quociente entre os fatores de atrito lateral e ponta $\beta_{1}$ e $\beta_{2}$ (Tabela 36) e que esta corresponde praticamente à hierarquia do coeficiente $\alpha_{A V}$ (comparação conforme o item B.3) a menos do silte, o qual se apresenta entre a areia argilosa e a argila arenosa.

Também se deve observar que os valores apresentados para cada tipo de solo, nos dois casos, estão coerentes entre si, podendo ser correlacionados, e também estão coerentes com os valores citados por Schmertmann (1979), para areias $\left(\alpha_{\mathrm{AV}} \cong 1 \%\right.$ a $2 \%$ ) e argilas ( $\alpha_{A V} \cong 6 \%$ a $8 \%$, em função da sua consistência). A única dispersão de valores que chamou a atenção foi a da areia pura, porém seus valores continuam coerentes com a mencionada literatura.

Como observa Amann (2000), Schmertmann (1979) estudou, teórica e experimentalmente, a relação entre o CPT e o SPT, comprovando as relações empíricas obtidas por diversos autores, entre eles Teixeira (1977). Esses trabalhos indicam resultados coerentes com a proposição aqui colocada.

Tabela 47 - Comparação entre as hierarquias dos coeficientes $\mathrm{k}_{\mathrm{ts}}$ para os métodos de David Cabral $\left(\alpha_{C A}\right)$ e Aoki- Velloso $\left(\alpha_{A V}\right)$, apud Amann (2000)

\begin{tabular}{cccc}
\hline $\begin{array}{c}\text { Hierarquia } \\
\text { do Solo }\end{array}$ & $\alpha_{\mathrm{CA}}(\%)$ & $\begin{array}{c}\text { Hierarquia } \\
\text { do Solo }\end{array}$ & $\alpha_{\mathrm{AV}}(\%)$ \\
\hline $\begin{array}{c}\text { Argila } \\
\text { Argila siltosa }\end{array}$ & 5,00 & Argila & 6,00 \\
Silte argiloso & 3,00 & Argila siltosa & 4,00 \\
Areia argilosa & 3,48 & Silte argiloso & 3,40 \\
Argila arenosa & 3,33 & Areia argilosa & 3,00 \\
Silte arenoso & 3,00 & Silte & 3,00 \\
Areia siltosa & 2,86 & Argila arenosa & 2,40 \\
Silte & 2,78 & Silte arenoso & 2,20 \\
Areia & 2,33 & Areia siltosa & 2,00 \\
& & Areia & 1,40 \\
\hline
\end{tabular}

A verificação das Hierarquias neste caso serve para reforçar a idéia de que o coeficiente parcial $\mathrm{k}_{\mathrm{ts}}$ pode ser considerado um coeficiente parcial "exclusivamente" do tipo de solo, pois mede uma relação que é característica intrínseca do solo, 
independendo do tipo de ensaio empregado ou, neste caso, do tipo de método semiempírico considerado.

Por ter esta característica, em princípio, esse coeficiente é aqui considerado como base para as correções dos demais coeficientes na Metodologia Semiempírica Unificada. De fato sua correção só deve ser feita a rigor a partir da execução de ensaios CPT (aqui considerada a sondagem de referência) no solo do local em estudo, pois, como já mencionado, é um ensaio específico para medir este coeficiente.

A análise de todos os métodos semiempíricos aqui estudados e cujos valores dos coeficientes estão no item B.1, em conjunto com a Tabela 42, que apresenta resultados de ensaios realizados por Alonso (1980), permite apresentar os valores médios de $\mathrm{k}_{\mathrm{ts}}$ e seus desvios, comopode ser visto na Tabela 10.

\section{B.7 ANÁLISE DO COEFICIENTE PARCIAL DE TIPO DE ENSAIO $\left(\mathbf{k}_{\mathrm{te}}\right)$}

Este coeficiente se presta a considerar outros tipos de ensaio de campo ou sondagem executada, correlacionando-o com o ensaio CPT, aqui considerado como de ensaio de referência. No caso geral dos métodos brasileiros, o ensaio mais empregado é o SPT, para o qual diversos autores já citados no item anterior pesquisaram seus valores, os quais são apresentados no item B.1.

Trata-se de outro coeficiente que se poderia considerar apenas corrigível por ensaios, nesse caso necessitando-se de ambos, CPT e SPT, para se estabelecerem as correlações, as quais podem ainda ser simples, como a proposta por AokiVelloso, ou complexas, considerando outros efeitos e ajustes estatísticos.

Sobre isso convém avaliar o trabalho de Albiero (1990), que, buscando avaliar melhor a forma de entrada de dados dos ensaios de campo nos métodos semiempíricos, discutiu diversas correlações entre os resultados CPT e SPT, considerando diversos fatores distintos levantados em trabalhos de diversos autores como Meyerhof (1956), Velloso (1959), Meigh e Nixon (1961), Schmertmann (1970), Aoki-Velloso (1975), P.P.C. Velloso (1986), Danziger e Velloso (1986), Robertson e Campanella (1983), Verbrugge (1976), Rodin et al (1974), Wroth (1988), Clayton et al (1988), Zervogiannis e Kalteziotis (1988), Weber e De Beer (1988) entre outros. 
Citam-se como fatores de influência a granulometria, a compacidade ou a rigidez, etc., todos levados em conta para tentar representar de maneira mais próxima possível da real o coeficiente de tipo de ensaio.

Albiero (1990) discutiu também diversas proposições de correção dos valores do ensaio SPT em solos arenosos para compensar a influência da profundidade, entre as quais estão: Gibbs e Holta (1957), Teng (1962), Bazaraa (1967), Peck, Hansen e Thorburn (1974), Seed et al (1989), Liao e Whitman (1986), Skempton (1986), Clayton et al (1988). Diante disso, Albiero (1990) propõe diversos modelos de ajuste dos valores do SPT para aplicação com os métodos semiempíricos e discute seu tratamento estatístico.

Albiero (1990) constatou ao final que mais importante do que se considerar o tipo de solo (argiloso ou arenoso) e a correção dos valores do ensaio de campo é a consideração de correlações específicas para o local estudado, pois as correlações para as amostras de um mesmo local se mostraram mais coerentes com os resultados obtidos do que as correlações globais de todo o conjunto amostral. Isso porque, ao se restringir a análise às amostras do local, retira-se boa parte da incerteza e da variabilidade das diferentes equipes de sondagem envolvidas no ensaio de campo e mesmo a variabilidade inerente aos mesmos tipos de solo de região para região.

A constatação de que as análises aplicadas ao local específico dos ensaios resultaram melhor desempenho é algo que vai de encontro à Metodologia Unificada a ser proposta. Nesta mesma linha, de forma paralela, embora posterior a Albiero (1990), Amann (2000) propôs obter os coeficientes de correção dos métodos semiempíricos exclusivamente para a obra ou solo da região, resultando assim, em uma redução significativa do desvio padrão.

Outra consideração importante para analisar o resultado apresentado por Albiero é que se um método semi-empírico foi criado sem a consideração de tais correções dos ensaios de campo, muito provavelmente o uso das mesmas não deve melhorar significativamente seu desempenho em relação à previsão da carga de ruptura. Assim, correções como as de energia, ou de comprimento das hastes, de profundidade, de tensão efetiva, só fazem sentido na criação de novos métodos, ou 
quando aplicadas aos métodos que utilizaram tais considerações em sua elaboração, tornando-as intrínsecas.

Considerando que alguns métodos podem ser desenvolvidos diretamente para um determinado tipo de ensaio, o estudo de correlações entre os mesmos deveriam ser considerados sempre para o solo do local em de estudo, exigindo, claro, ensaios e análises estatísticas para tal. Fica evidente que é bastante interessante a execução de mais de um tipo de ensaio sempre que possível para se melhorar tais análises.

Contudo, sabendo-se que esta não é a realidade nas obras brasileiras, e que aqui a proposta de pesquisa seja adequar os valores dos coeficientes empíricos a partir da experiência semiempírica brasileira, propõe-se a adequação provisória (até que se obtenham correlações entre ensaios) deste coeficiente com base nas Hierarquias dos Solos, deixando-se claro, porém, que a forma ideal para isso seja o uso de correlações específicas para o solo da região em estudo.

Aplicando-se a metodologia de separação desse coeficiente parcial já descrita no item B.3, e já exemplificada para o coeficiente $\mathrm{k}_{\mathrm{ts}}$, obtém-se a Tabela 11, que apresenta os valores de $k_{\text {te }}$ médios e seus desvios, considerando os valores dos coeficientes empíricos apresentados do item B.1.

\section{B.8 ESTIMATIVA DOS VALORES DO COEFICIENTE PARCIAL DE TIPO DE ESTACA $\left(k_{\mathrm{tE}}\right)$}

Todos os métodos semiempíricos partem de um tipo estaca de referência e alguns posteriormente, são ampliados para outros tipos de estaca por meio de coeficientes que levem em conta a influência do método executivo da estaca na sua capacidade de carga, o que aqui é simbolizado por $\mathrm{k}_{\mathrm{tE}}$. Exemplos desses métodos são o de Aoki-Velloso e o de Décourt-Quaresma, sendo que para este último a estaca de referência é a pré-moldada de concreto cravada. Outros autores preferem publicar métodos individuais para cada tipo de estaca, com novas tabelas de coeficientes empíricos, como por exemplo, o método de David Cabral para estaca raiz, e seus congêneres aplicados pela Fundesp para estacas escavadas de grande diâmetro e Ômega. Boa parte deles, contudo, restringem-se a um único tipo de estaca, como ocorre para os métodos aplicados a estacas hélice-contínua. 
Aqui apresenta-se a revisão dos trabalhos de Amann (2002, 2004 e 2006) que procurou isolar este coeficiente da influência do tipo de solo e da sondagem nos diversos métodos, verificando se a hierarquia dos solos poderia eventualmente ser alterada em função do processo de instalação, ou método executivo.

Exemplificando o procedimento já descrito no item B.3, com os valores do item B.1, Amann (2006) relacionou (Tabela 48) os coeficientes característicos do método de David Cabral para estacas raiz, escavadas e ômega, obtendo valores para os coeficientes parciais de tipo de estaca em relação à estaca de referência, aqui considerada a estaca raiz.

Tabela 48 - Ajustes estatísticos entre as estacas dos métodos de Cabral, apud Amann(2006) e R ${ }^{2}$ crítico para $95 \%$ de confiança.

\begin{tabular}{ccc}
\hline Reta ajustada & $\mathrm{R}^{2}$ & $\mathrm{R}^{2}$ crítico 5\% \\
\hline $\mathrm{K}_{\mathrm{PCA} \text { (esc. c/ lama) }}=0,8134 . \mathrm{K}_{\mathrm{PCA} \text { (raiz) }}$ & 0,8081 & 0,4436 \\
$\mathrm{~K}_{\mathrm{PCB} \text { (ômega) }}=1,088 . \mathrm{K}_{\mathrm{PCA} \text { (raiz) }}$ & 0,5909 & 0,4436 \\
$\mathrm{~K}_{\mathrm{PCB} \text { (ômega) }}=1,3422 . \mathrm{K}_{\mathrm{PCA} \text { (esc. c/ lama) }}$ & 0,8354 & 0,4436 \\
$\mathrm{~K}_{\mathrm{CA}} \cong \mathrm{K}_{\mathrm{AV}}=2,7773 . \mathrm{K}_{\mathrm{PCA} \text { (raiz) }}$ & 0,9103 & 0,4436 \\
\hline
\end{tabular}

Assim, considerando a estaca raiz como padrão para os métodos de Cabral, os coeficientes angulares das retas da Tabela 48 indicam o valor da relação das estacas escavada e ômega com a raiz. Apesar da correlação aparentemente baixa (ver adiante como avaliar a correlação com base nos valores de $\mathrm{R}^{2}$ crítico) entre a ômega e a raiz, vê-se que, entre a ômega e escavada, a correlação é relativamente boa e o produto $0,8134 \times 1,3422=1,0917$ é bem próximo do 1,088 obtido estatisticamente.

Isto resulta no coeficiente $\mathrm{k}_{\mathrm{tsP}(\mathrm{CA})}=2,7773$, que é próximo do $\mathrm{k}_{\mathrm{tsP}(\mathrm{AV})}=3,0$ adotado por Corrêa (1988) para estaca raiz no método Aoki-Velloso, demonstrando boa correlação entre esses métodos. Também o coeficiente de determinação $R^{2}=0,9103$ indica que os coeficientes de Cabral apresentam boa relação com os de AokiVelloso, validando essa analogia. Coeficientes $\mathrm{k}_{\mathrm{tsP}}$ para outros tipos de estacas seriam obtidos por correlação direta com os valores dos coeficientes característicos $\mathrm{K}_{\mathrm{Pg}}$ calculados, ou, neste caso, aproximadamente pelo produto de 2,7773 pelos demais coeficientes apresentados na Tabela 48.

Essa metodologia pode ser aplicada também aos outros métodos, como os de Teixeira e da Brasfond, por exemplo, tanto para ponta quanto atrito lateral. 
Estas relações representam coeficientes de tipo de estaca semelhantes aos do método Décourt-Quaresma (que incluem a influência do tipo de solo, como mostrado na Tabela 3). Verificou-se pela análise dessa tabela que 0 método DécourtQuaresma considera o coeficiente de tipo de estaca variável com o tipo de solo, enquanto é possível admitir, pela análise dos valores atribuídos a $F_{1 A V}$ e $F_{2 A V}$, e pelas correlações dos valores de $\mathrm{k}_{\mathrm{ts}}$ obtidos para os outros métodos (mostradas adiante), que praticamente todos os demais consideram um valor constante para este coeficiente. Diante disso, em um primeiro momento pode-se considerar que a metodologia empregada neste método carregou a influência de tipo de solo nos coeficientes $\alpha_{D Q}$ e $\beta_{D Q}$, e pode-se pretender isolar essa influência para obter-se um coeficiente constante.

Antes disso, porém, pode-se discutir a questão do ponto de vista físico do atrito, considerando que o valor do coeficiente de atrito estático depende das duas superfícies entre as quais se analisa o fenômeno. Desta forma, mantendo-se o mesmo tipo de estaca, a alteração do tipo de solo deve necessariamente alterar o ângulo de atrito no contato $(\delta)$ fuste-solo e com isso o valor do coeficiente empírico de tipo de estaca deveria de fato mudar com o tipo de solo, como sugerido no método Décourt-Quaresma (1996a). Por outro lado, considerando-se que este coeficiente relaciona, em última análise, o comportamento da estaca com o do cone (considerando o CPT como ensaio de referência) e que a ruptura possa ocorrer por cisalhamento do solo ao redor da estaca e não na interface, os demais métodos poderiam indicar que a influência do processo de instalação da estaca altera as condições do entorno da estaca de forma proporcional para todos os tipos de solo em relação ao observado para o cone.

Não se pretende aqui elucidar tal questão, mesmo porque exigiria um extenso programa de ensaios, sendo, contudo, fundamental esta discussão para 0 entendimento de como os métodos consideram esse efeito. De fato, para atender aos objetivos propostos de definição da Metodologia Semiempírica Unificada, propõe-se aqui valorizar a experiência brasileira a qual indica, para a maioria dos métodos, que o coeficiente de tipo de estaca pode ser considerado constante e independente do tipo de solo, e interpreta-se assim que os valores adotados pelos diversos autores se referem às médias ajustada dos valores individuais de cada tipo 
de solo. Na etapa de aferição e correção dos coeficientes, contudo, as duas formas de análise serão consideradas para atender à proposta de metodologia unificada.

De qualquer forma, para se obterem valores similares ao $F_{1 A V}$ e $F_{2 A V}$ de Aoki-Velloso que se referem ao tipo de estaca no exemplo do método de David Cabral, propõe-se determinar os valores para o coeficiente de tipo de ensaio $\mathrm{k}_{\mathrm{te}(\mathrm{CA})}=\mathrm{K}_{\mathrm{CA}}$ (similar ao $\mathrm{K}_{\mathrm{AV}}$ ) relacionando-se os coeficientes característicos $\mathrm{K}_{\mathrm{P}(\mathrm{CA})}$ do método de Cabral com o coeficiente $K_{P(A V)}=K_{A V}$ de Aoki-Velloso e, em seguida, isolar-se o efeito do tipo de estaca.

Amann (2002) faz uma comparação entre os coeficientes empíricos dos métodos de Cabral, Décourt-Quaresma e Aoki-Velloso aplicados a estacas raiz e escavados de Grande Diâmetro, mostrada nos gráficos da Figura 83, e demonstra que há uma tendência ao alinhamento dos pontos, indicando, como já mencionado, que o coeficiente de tipo de estaca para esses métodos pode ser considerado independente do tipo de solo.

Sendo assim, o coeficiente do tipo de estaca (em relação à estaca "padrão" de cada método), fica definido como sendo o coeficiente angular da reta de correlação passando pela origem. Pode-se então dizer que a resistência por atrito lateral da estaca raiz é aproximadamente 2,2 vezes a resistência da estaca escavada de grande diâmetro, e que para a resistência de ponta esta relação é de aproximadamente 1,2 vezes.

Portanto, se, à primeira vista, esses coeficientes podem ser interpretados como levando em consideração a influência do tipo da estaca e de uma parcela de influência do tipo de solo, a análise de tendência da Figura 83 permite dizer que a variação observada se refere à dispersão de amostras.

Com isso, Amann (2006) conclui que as hierarquias dos solos apresentadas na Tabela 42 e Tabela 43 não devem sofrer alterações em função do tipo de estaca, visto que há essa indicação de que o fator de tipo da estaca não depende do tipo do solo.

Procedimento semelhante foi aplicado por Amann (2004) ao avaliar os dados da Tabela 36 do texto, em que o método de Cabral (CA) desenvolvido para estacas 
Ômega é similar aos métodos desenvolvidos para estacas escavadas de grande diâmetro (EGD) e estacas raiz. Estas análises são apresentada a seguir.
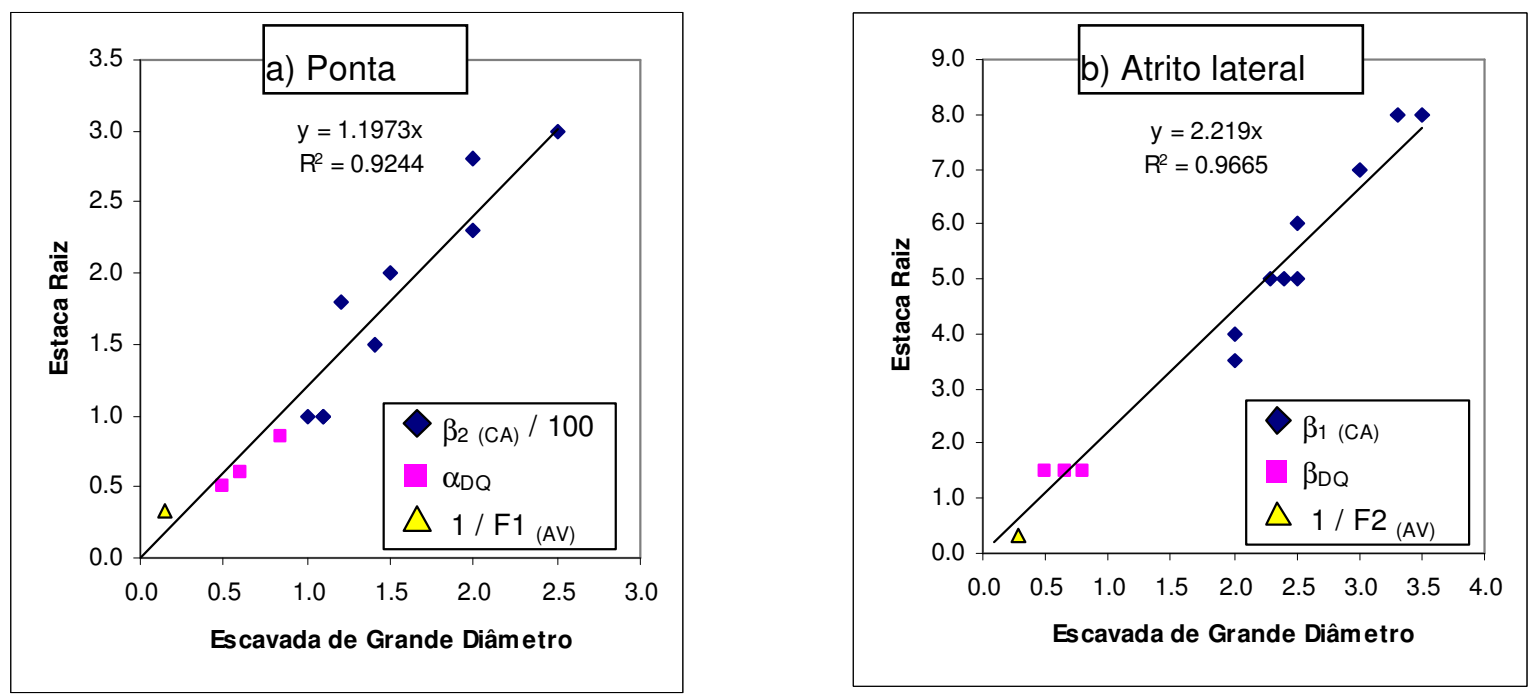

Figura 83 - Correlações entre os coeficientes empíricos do método David Cabral e dos métodos Décourt-Quaresma e Aoki-Velloso, para estacas raiz e para estacas escavadas de grande diâmetro, apud Amann (2002)
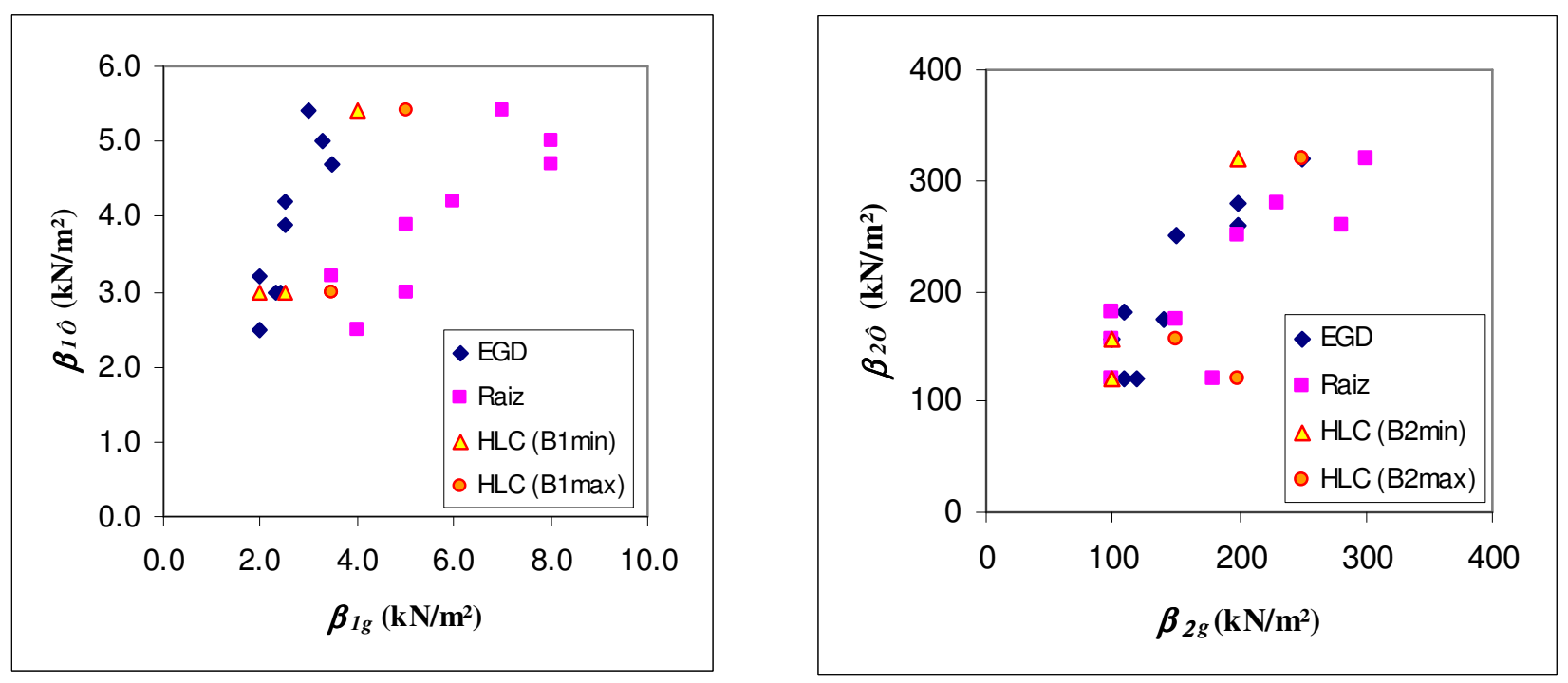

Figura 84 - Comparação gráfica dos fatores de atrito lateral $\left(K_{\mathrm{Lg}}=\beta_{1}\right)$ e de ponta $\left(\mathrm{K}_{\mathrm{Pg}}=\beta_{2}\right)$ do método de Cabral et al (CA) entre estacas Ômega (Ô) e Raiz (R) e Escavadas de Grande Diâmetro (EGD) apud Amann (2004)

A Figura 84 apresenta graficamente as correlações entre os fatores $\beta_{1}$ e $\beta_{2}$ propostos para estacas Ômega, com os mesmos propostos para estacas Raiz $(R)$ e Escavadas de Grande Diâmetro (EGD) pelo método de Cabral. Incluem-se ainda na figura os valores de $B_{1}$ e $B_{2}$, máximo e mínimo do método Antunes-Cabral para estacas Hélice-Contínua, em comparação com os valores para estaca Ômega, 
apenas para os solos puros (areias, siltes e argilas). Verifica-se que cada conjunto de valores pode ser ajustado linearmente (apesar da dispersão) e que é possível estabelecer uma relação entre os mesmos, como segue.

Tabela 49 - Regressões lineares entre os coeficientes de atrito lateral $\left(K_{\mathrm{Lg}}=\beta_{1}\right)$ e de ponta $\left(\mathrm{K}_{\mathrm{Pg}}=\beta_{2}\right)$ do método de Cabral et al (CA), entre estacas Ômega (Ô) e Raiz (R) e Escavadas de Grande Diâmetro (EGD), e método Antunes-Cabral para estacas Hélice -Contínua $\left(B_{1}\right.$ e $\left.B_{2}\right)$, apud Amann (2004).

\begin{tabular}{|c|c|c|c|}
\hline \multirow{2}{*}{$\boldsymbol{\beta}_{\boldsymbol{g}}$} & \multicolumn{3}{|c|}{$\boldsymbol{\beta}_{\hat{O}}=\boldsymbol{a} \cdot \boldsymbol{\beta}_{\boldsymbol{g}}+\boldsymbol{b}$} \\
\cline { 2 - 4 } & $\boldsymbol{a}$ & $\boldsymbol{b}$ & $\boldsymbol{R}^{\mathbf{2}}$ \\
\hline \multirow{2}{*}{$\boldsymbol{\beta}_{\boldsymbol{I R}}$} & 0,67 & 0 & 0,7079 \\
\cline { 2 - 4 } & 0,54 & 0,80 & 0,7554 \\
\hline \multirow{2}{*}{$\boldsymbol{\beta}_{\mathbf{I E G D}}$} & 1,49 & 0 & 0,7352 \\
\cline { 2 - 4 } & 1,62 & $-0,35$ & 0,7401 \\
\hline \multirow{2}{*}{$\boldsymbol{\beta}_{2 \boldsymbol{R}}$} & 1,09 & 0 & 0,5909 \\
\cline { 2 - 4 } & 0,79 & 62,35 & 0,7042 \\
\hline \multirow{2}{*}{$\boldsymbol{\beta}_{2 E G D}$} & 1,34 & 0 & 0,8354 \\
\cline { 2 - 4 } & 1,28 & 10,52 & 0,8376 \\
\hline
\end{tabular}

\begin{tabular}{|c|c|c|c|}
\hline \multirow{2}{*}{$\boldsymbol{B}_{\boldsymbol{g}}$} & \multicolumn{3}{|c|}{$\boldsymbol{\beta}_{\hat{O}}=\boldsymbol{a} \cdot \boldsymbol{B}_{\boldsymbol{g}}+\boldsymbol{b}$} \\
\cline { 2 - 4 } & $\boldsymbol{a}$ & $\boldsymbol{b}$ & $\boldsymbol{R}^{\mathbf{2}}$ \\
\hline \multirow{2}{*}{$\boldsymbol{B}_{\text {Imin }}$} & 1,34 & 0 & 0,9411 \\
\cline { 2 - 4 } & 1,29 & 0,14 & 0,9423 \\
\hline \multirow{2}{*}{$\boldsymbol{B}_{\text {Imax }}$} & 0,97 & 0 & 0,8400 \\
\cline { 2 - 4 } & 1,6 & $-2,60$ & 1,000 \\
\hline \multirow{2}{*}{$\boldsymbol{B}_{2 \min }$} & 1,53 & 0 & 0,9431 \\
\cline { 2 - 4 } & 1,82 & $-44,00$ & 0,9715 \\
\hline \multirow{2}{*}{$\boldsymbol{B}_{2 \max }$} & 1,02 & 0 & 0,5033 \\
\cline { 2 - 4 } & 1,64 & $-129,33$ & 0,5916 \\
\hline
\end{tabular}

Da Tabela 49, pode-se observar primeiramente que a maior dispersão ocorre para o fator de ponta de estacas ômega em relação às estacas Raiz $\left(\beta_{2 R}\right)$. Já para as Escavadas de Grande Diâmetro, a dispersão é melhor, indicando que o comportamento da ponta de estacas Ômega seria mais próximo deste tipo de estaca do que da Raiz.

De maneira geral, pode-se dizer que o atrito lateral de estacas Ômega deve ser da ordem de 0,65 vezes o atrito de estacas Raiz $\left(\beta_{10} / \beta_{1 R} \cong 0,65\right)$ e em torno de 1,5 vezes o atrito das Escavadas de Grande Diâmetro $\left(\beta_{10} / \beta_{1 \mathrm{EGD}} \cong 1,50\right)$. Para a ponta das estacas Ômega, avalia-se da ordem de 1,0 (apesar da dispersão) em relação à ponta de estacas Raiz $\left(\beta_{20} / \beta_{2 R} \cong 1,00\right)$, e em torno de 1,3 vezes a ponta das Escavadas $\left(\beta_{2 \hat{O}} / \beta_{2 E G D} \cong 1,30\right)$.

Para avaliar se a dispersão interferiu significativamente na atribuição desses valores, Amann (2004) analisou a relação $\beta_{R} / \beta_{E G D}$, usando os valores aqui atribuídos a $\beta_{\hat{o}} / \beta_{\mathrm{R}}$ e $\beta \hat{o} / \beta_{\mathrm{EGD}}$, e, depois comparar com valores já obtidos por Amann (2000).

Considerando-se a proporção (151), obtém-se: $\beta_{1 R}=2,30$. $\beta_{1 E G D}$ e $\beta_{2 R}=1,30 . \beta_{2 E G D}$, que comparados aos valores obtidos por Amann (2000), a saber: $\beta_{1 \mathrm{R}}=2,22$. $\beta_{1 \mathrm{EGD}} \mathrm{e}$ $\beta_{2 R}=1,20 . \beta_{2 E G D}$, demonstram a validade dessas relações para estes três tipos de estacas, considerando o método de Cabral et al. 


$$
\frac{\beta_{\mathrm{R}}}{\beta_{\mathrm{EGD}}}=\frac{\beta_{\mathrm{O}} / \beta_{\mathrm{EGD}}}{\beta_{\mathrm{O}} / \beta_{\mathrm{R}}}
$$

Estes valores podem ser utilizados, por exemplo, para se atribuir um valor de $\alpha_{D Q}$ para estaca Ômega. Para isso, apesar de Décourt-Quaresma considerar que a ponta de estacas raiz se comporte similarmente a de estacas escavadas (mesmos valores de $\alpha_{D Q}$ em função do solo), admite-se aqui que $\beta_{2 R}=1,20 . \beta_{2 E G D}$, conforme demonstrado. Devido à dispersão observada para a relação com a estaca Raiz, usou-se a estaca escavada como parâmetro para a estimativa, ficando os valores de $\alpha_{D Q}$ para estaca Ômega iguais aos valores para estacas escavadas corrigidos pela relação $\beta_{2 O} / \beta_{2 E G D} \cong 1,30$.

Os valores estimados para estaca Ômega são: 0,65, 0,78 e 1,10, respectivamente para areia, silte e argila. Os valores de $\mathrm{K}_{\mathrm{LDQ}}$ para estacas Ômega ficam: a) para areias: $C_{p D Q} \cdot \alpha_{D Q}=260 \mathrm{kN} / \mathrm{m}^{2}$; b) para siltes: $195 \mathrm{kN} / \mathrm{m}^{2}$; e c) para argilas: 133 $\mathrm{kN} / \mathrm{m}^{2}$. Note-se que esses valores aproximam-se muito dos propostos para os valores máximos de $B_{2}$ do método Antunes-Cabral, indicando que a ponta de estacas Ômega poderia comportar-se como a de estacas Hélice-Contínua, mas isto indicaria que a estaca Ômega compacta pouco o solo abaixo da ponta durante sua instalação.

Ao se analisar a Tabela 49 pode-se ter a impressão de que, pela boa correlação apresentada para os fatores $B_{2 \min }\left(R^{2}=0,9431\right)$, a resistência de ponta para estacas Ômega seja de ordem de 1,53 vezes a das estacas Hélice-Contínua. Contudo, quando se aplica a correção de 1,53 aos valores de $B_{2 \min }$ encontram-se para areia o valor $306 \mathrm{kN} / \mathrm{m}^{2}$ e para o silte e a argila $153 \mathrm{kN} / \mathrm{m}^{2}$, os quais não se ajustam com o comportamento verificado na Figura 82 para os vários métodos empregados.

Por outro lado, a correlação para $B_{2 \max }\left(R^{2}=0,5033\right)$ que não foi das melhores mostra-se compatível com os valores que se obtiveram com os fatores $\mathrm{K}_{\mathrm{LDQ}}$ para estacas Ômega, a saber: para areias $255 \mathrm{kN} / \mathrm{m}^{2}$; b) para siltes: $204 \mathrm{kN} / \mathrm{m}^{2}$; e c) para argilas: $153 \mathrm{kN} / \mathrm{m}^{2}$, indicando a proximidade de comportamento entre a ponta das duas estacas, o que deve ser verificado com as provas de carga instrumentadas levadas à ruptura física do solo. 
Para o cisalhamento lateral, pode-se considerar a correlação para $B_{1 \min }\left(R^{2}=\right.$ 0,9411), que indica ser o cisalhamento de estacas Ômega 1,34 vezes maior que o da Hélice-Contínua. Observa-se que Décourt-Quaresma considera este valor como 1,50 , o que estaria de acordo com a correlação para $B_{1 \max }\left(R^{2}=1,0000\right)$, que indica um valor em torno de 1,60. Pode-se considerar então que valores da ordem de 1,4 devem expressar razoavelmente bem a relação entre os atritos da estaca Ômega e Hélice-Contínua.

Enfim, resumindo (AMANN, 2004):

1) A comparação entre os fatores $K_{L g}$ do atrito lateral e para a ponta do método Antunes-Cabral para Hélice-Contínua (HLC) com o método de Cabral para estacas Ômega (Ô), Raiz (R) e Escavadas de Grande Diâmetro (EGD) indica as seguintes relações para atrito lateral: $\mathrm{K}_{\mathrm{LO}} / \mathrm{K}_{\mathrm{LR}} \cong 0,65 ; \mathrm{K}_{\mathrm{LO}} / \mathrm{K}_{\mathrm{LEGD}} \cong 1,50 ; \mathrm{K}_{\mathrm{LO}} / \mathrm{K}_{\mathrm{LHLC}} \cong 1,4(1,34$ a 1,6) e para a ponta: $K_{P O ̂} / K_{P R} \cong 1,0 ; K_{P O ̂} / K_{P E G D} \cong 1,30 ; K_{P O ̂} / K_{P H L C} \cong 1,0$ (ver item seguinte).

2) As análises indicam que os métodos consideram o comportamento da ponta de estacas Ômega com um comportamento similar à ponta das Hélice-Contínua, o que indicaria que a primeira não compacta muito o solo abaixo da ponta. Contudo convém realizar maiores estudos em provas de carga onde se alcance a mobilização efetiva da resistência de ponta para confirmação desse comportamento.

3) Sugere-se atribuir, com base nas análises realizadas, o fator $\alpha_{D Q}$ para estacas Ômega como sendo 0,65 para areias, 0,78 para siltes e 1,10 para argilas.

Com estas análises, pode-se perceber que há a possibilidade de se estabelecer uma Metodologia Unificada, visto que os métodos apresentam muitas semelhanças e até mesmo os coeficientes de tipo de estaca entre métodos diferentes apresentam valores coerentes quando comparadas outras estacas com suas estacas-padrão (ou de referência). Com isso, procura-se que a Metodologia Unificada aproveite a experiência brasileira de décadas de uso dos métodos semiempíricos.

\section{B.9 COEFICIENTE DE DIMENSÃO OU DIÂMETRO $\left(\mathbf{k}_{\mathrm{tD}}\right)$}

Uma série de outras variáveis poderiam ser introduzidas para análise da correção dos valores de capacidade de carga, como a influência da forma da estaca. Décourt (1996a) comenta que não há conclusões claras a respeito desta, sendo um tema 
controverso. Outras variáveis ainda são objeto de estudo e por ora não serão consideradas.

Por outro lado, a influência das dimensões da estaca é considerada em alguns poucos métodos a partir do efeito de semelhança e escala entre a estaca e o cone do ensaio CPT.

Assim, da análise de semelhança, surge a ideia de que a influência da dimensão reduzida do cone em relação às estacas de pequeno diâmetro é praticamente desprezível. Porém, para estacas de grande diâmetro, Albiero (1990) cita De Beer (1963) que sugere um coeficiente de influência parcial (aqui simbolizado por $\mathrm{k}_{\mathrm{tD}}$ ) com o qual relaciona-se o diâmetro $D$ da estaca ao do cone $\left(d_{c}=3,568 \mathrm{~cm}\right)$ para efeitos de tensão desenvolvida:

$$
\mathrm{k}_{\mathrm{tD}}=1,01-0,01 \cdot\left(\frac{\mathrm{D}}{\mathrm{d}_{\mathrm{c}}}\right)
$$

Velloso e Lopes (2002) também citam uma metodologia similar e mais recente, exposta em Holeyman et al.(1997), para considerar o efeito de escala em argilas rijas fissuradas:

$$
0,476 \leq \mathrm{k}_{\mathrm{tD}} \leq 1,-0,01 \cdot\left(\frac{\mathrm{D}}{\mathrm{d}_{\mathrm{c}}}-1\right)
$$

Dos métodos aqui analisados, destacam-se o de David Cabral para estacas raiz:

$$
\mathrm{k}_{\mathrm{tD}(\mathrm{CA}) \text { Raiz }}=\beta_{0}=1+0,11 \cdot \mathrm{p}-0,01 \cdot \mathrm{D}
$$

onde $p$ é a pressão de injeção da argamassa das estacas raiz $\left(p \leq 4,0 \mathrm{kgf} / \mathrm{cm}^{2}\right)$, e $D$ em [cm], e para estacas escavadas de grande diâmetro:

$$
\mathrm{k}_{\mathrm{tD}(\mathrm{CA}) \mathrm{EGD}}=\beta_{0}=1,5-0,4 \cdot \mathrm{D}
$$

Também pode-se citar o método de P.P.C.Velloso, o qual considera apenas para a ponta: 


$$
\mathrm{k}_{\mathrm{tD}(\mathrm{CV})}=\beta_{\mathrm{CV}}=1,016-0,016 \cdot\left(\frac{\mathrm{D}}{\mathrm{d}_{\mathrm{c}}}\right)
$$

Convém notar a semelhança entre estas expressões, às quais se traduzem em relações lineares entre $k_{t D}$ e $D$.

De fato, verifica-se que as expressões (152) e (153) são idênticas e que comparadas às demais podem todas ser escritas na forma da expressão unificada (19).

Também o método Aoki-Velloso, a partir de modificação feita por Aoki (1985) apud Cintra e Aoki (1999), sugere uma consideração de efeito de escala para estacas prémoldadas, porém atribui tal coeficiente ao de tipo de estaca. Aqui se considera que, na verdade, os dois efeitos estariam sobrepostos neste caso, podendo ser expressado por:

$$
k_{t E(A V)} \cdot k_{t D(A V)}=\frac{1}{F_{1 A V}}=\frac{1}{1+\frac{D}{80}}
$$

Lembrar que D está em [cm]. Para analisar esta expressão, verificou-se qual seria o valor de $D$ para assumir-se $F_{1 A V}=1,75$, que era o valor anteriormente adotado, e obteve-se $D=60 \mathrm{~cm}$. Assim, para diâmetros menores do que este os valores de $F_{1 A V}$ seriam sempre menores do que 1,75, e acima disto, maiores. Tomando-se a média dos diâmetros usuais dessas estacas, com o produto igual a 1,75, pode-se obter o $\mathrm{k}_{\mathrm{tE}}$ médio nessa faixa de valores, separando-se assim os dois coeficientes. $O$ mesmo pode ser feito para o fuste, considerando coeficiente $F_{2 A V}=2 . F_{1 A V}$, como indicam Cintra e Aoki (1999) com a observação de que $1 \leq F_{2 A V} / F_{1 A V} \leq 2$, sendo este o valor mais conservador.

Para simplificar a análise e comparar essa expressão às demais, admite-se inicialmente $\mathrm{k}_{\mathrm{tE}}=1,0$ e monta-se um gráfico $\mathrm{k}_{\mathrm{tD}} \mathrm{XD}$ comparativo apresentado na Figura 7 , onde se verifica que a curva dada pela expressão (157) resulta em valores contidos entre os calculados para o método de David Cabral para estacas raiz com pressões de injeção de argamassa entre 0 e $4 \mathrm{kgf} / \mathrm{cm}^{2}$ no intervalo de 0 a $100 \mathrm{~cm}$ de diâmetro. Nesse mesmo intervalo, o método de P.P.C.Velloso aparece como uma espécie de reta limite superior até o diâmetro de $150 \mathrm{~cm}$, podendo-se dizer que essa 
reta representaria uma aproximação linearizada da curva da expressão (157) em um intervalo de 0 a $220 \mathrm{~cm}$ de diâmetro.

Para o fuste, a curva (157), que é então dividida por 2 devido à relação entre $F_{1 A v} e$ $F_{2 A V}$, aparece abaixo do valor mínimo da expressão (153) para argilas fissuradas, podendo-se questionar se é importante o emprego dos coeficientes $\mathrm{k}_{\mathrm{tD}}$ no fuste, sendo que o mesmo não é considerado no método P.P.C.Velloso, mas o é no método de David Cabral para estacas raiz.

Já a reta para estacas escavadas de grande diâmetro aparece muito acima das demais e, comparando-se todas as retas, a (152)=(153) aparece como uma espécie de média geral, e é representada pela expressão unificada (19) com coeficientes iguais a 1,0 .

Dada a escassez de informações para correção desse coeficiente, ele apenas será corrigido na aplicação da Metodologia Semiempírica Unificada quando houver mais de um diâmetro em análise no caso em estudo.

\section{B.10 DISCUSSÃO SOBRE USO DA MÉDIA AO LONGO DO FUSTE OU DA SOMATÓRIA DAS CAMADAS PARA CÁLCULO DO CISALHAMENTO LATERAL (AMANN, 2000 e 2006) E PROPOSTA DO MÉTODO EXPEDITO DE TESTE}

Um aspecto interessante é o fato de alguns métodos, como o de Teixeira e da Brasfond entre outros, adotarem um valor único constante para a resistência por cisalhamento lateral, desconsiderando completamente o comportamento distinto entre solos arenosos e argilosos. De fato, a maioria dos métodos não detalha os coeficientes empíricos para solos mistos (ver item B.2.1), desprezando o efeito do solo em menor quantidade (exemplo: adota-se para a areia silto argilosa o valor da areia siltosa). Parte dos métodos desconsidera até mesmo os solos compostos, atribuindo valor apenas ao solo puro principal (areia, argila ou silte). Sendo assim, Amann (2000) colocou a questão da importância de se considerar a ação de cada camada isolada, para cada tipo de solo e da possibilidade de se adotar um único valor de coeficiente para todo o fuste. 
Amann (2006) ampliou sua análise através dos métodos Aoki-Velloso (AV), Monteiro-Franki (FK), David Cabral (CA), Cabral et al.(CB) (embora esses dois últimos tenham o coeficiente de tipo de estaca incorporado), ajustando-se uma reta passando pela origem dos eixos cartesianos em um diagrama de $\mathrm{k}_{\mathrm{tE}}=\mathrm{K}_{\mathrm{g}} \mathrm{x}$ $1 / \mathrm{k}_{\mathrm{ts}}=1 / \alpha_{\mathrm{g}}$, sendo $\alpha$ a razão entre o atrito e a ponta para cada solo (Figura 85 ).

Aplicando esse raciocínio para os demais métodos, observa-se em todos eles uma tendência linear, embora com alguma dispersão (Tabela 50). O método de MonteiroFranki apresenta linearidade ainda maior que Aoki-Velloso, indicando que houve um ajuste baseado neste último Observa-se que seria possível adotar um valor de cisalhamento lateral médio tendendo a ser constante, independentemente do tipo de solo, mas com algum erro de dispersão, o qual os métodos que consideram valores distintos para cada tipo de solo pretendem minimizar.

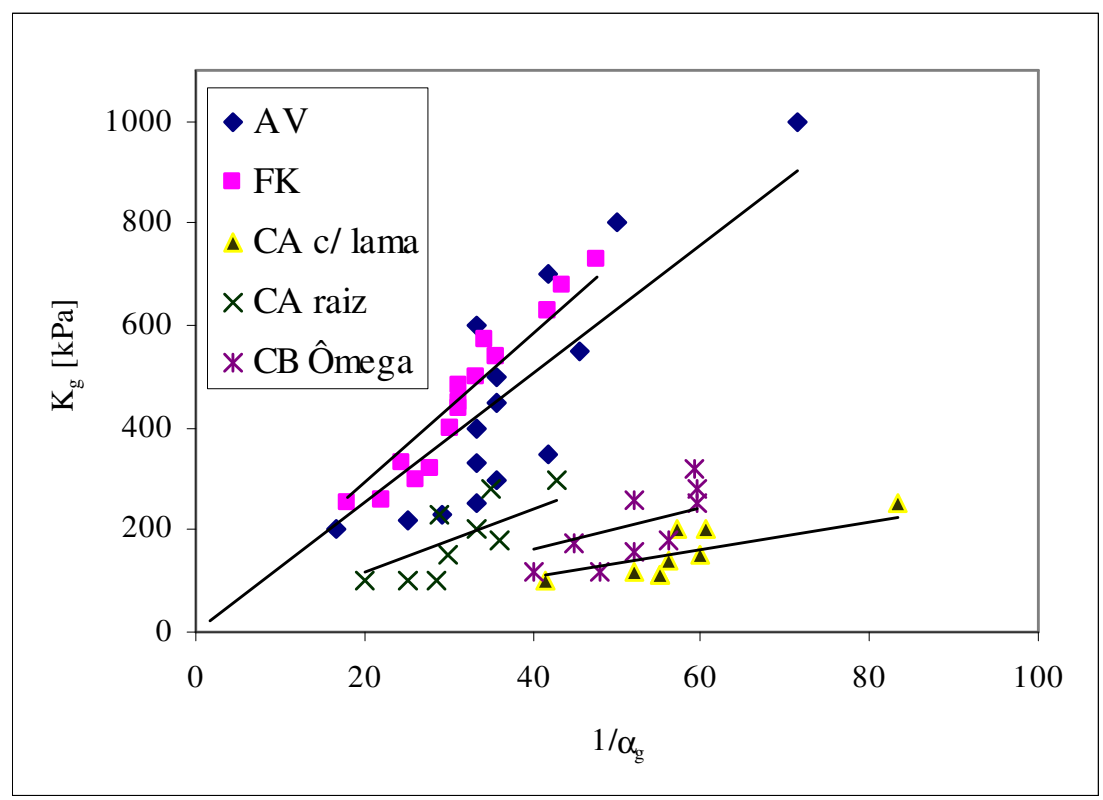

Figura 85 - Regressão linear, passando pela origem, para determinação da tendência do valor do produto K. $\alpha_{A V}$, dos métodos Aoki-Velloso (AV), Monteiro-Franki (FK), David Cabral (CA), Cabral et al (CB) (AMANN, 2006)

Tabela 50 - Regressões entre $K_{g}$ e 1/ $\alpha_{g}$ e $R^{2}$ crítico com 95\% de confiança (AMANN, 2006)

\begin{tabular}{ccc}
\hline Reta ajustada & $\mathrm{R}^{2}$ & $\mathrm{R}^{2}$ crítico $5 \%$ \\
\hline $\mathrm{K}_{\mathrm{AV}}=12,6440 .\left(1 / \alpha_{\mathrm{AV}}\right)$ & 0,7104 & 0,2642 \\
$\mathrm{~K}_{\mathrm{FK}}=14,5840 .\left(1 / \alpha_{\mathrm{FK}}\right)$ & 0,9040 & 0,2642 \\
$\mathrm{~K}_{\mathrm{PCA} \text { (raiz) }}=6,0059 .\left(1 / \alpha_{\mathrm{CAr}}\right)$ & 0,5726 & 0,4436 \\
$\mathrm{~K}_{\mathrm{PCA} \text { (esc. c/ lama) }}=4,0128 .\left(1 / \alpha_{\mathrm{CAe}}\right)$ & 0,4557 & 0,4436 \\
$\mathrm{~K}_{\mathrm{PCB} \text { (ômega) }}=2,6906 .\left(1 / \alpha_{\mathrm{CB} \hat{0}}\right)$ & 0,6361 & 0,4436 \\
\hline
\end{tabular}


Os coeficientes angulares muito abaixo de 12,6 para os métodos de David Cabral indicam a influência do fator de estaca que neles se encontram inerentes. A comparação com outros tipos de estacas poderia ajudar a discernir sobre isso, considerando que o valor da ordem de 12,6 a 14,6 representaria o valor médio para o ensaio de cone.

Amann (2000) comenta que a aparente independência do tipo de solo foi também constatada por Teixeira (1993), onde este autor analisou os valores do produto $\mathrm{K}_{\mathrm{Av}} \cdot \alpha_{\mathrm{AV}}$, do método Aoki-Velloso, em função do diâmetro $\mathrm{D}_{50}$ de cada tipo de solo, conforme proposto por Robertson, Campanella \& Wightman (1983) apud Teixeira (1993). Considerando para $K_{A V}$ e $\alpha_{A V}$ os valores médios adaptados dos trabalhos de Searle (1979) e Schmertann (1969), apud Teixeira (1993), o produto desses dois coeficientes empíricos tende a um valor praticamente constante de $13 \mathrm{kN} / \mathrm{m}^{2}$, com máximo de 13,4 e mínimo de $12,3 \mathrm{kN} / \mathrm{m}^{2}$, ou seja, com valores muito próximos aos da Tabela 50. Isso explicaria porque a resistência por atrito lateral, do método original de Décourt-Quaresma, depende apenas do SPT, e independe do tipo de solo ao longo do fuste.

Teixeira (1993) sugere ainda que, se os valores propostos por Aoki-Velloso, para os fatores empíricos $K_{A V}$ e $\alpha_{A V}$ forem ajustados, o seu produto tende ao valor praticamente constante de $10 \mathrm{kN} / \mathrm{m}^{2}$. Deve-se atentar para o fato de que, analisando estatisticamente estes valores sem qualquer ajuste, obtém-se $12,6 \mathrm{kN} / \mathrm{m}^{2}$, contudo verifica-se que a dispersão é relativamente grande (Figura 85 ) para permitir a consideração absoluta da tendência a um valor constante, independente do tipo de solo, representando, portanto, uma simplificação.

Para que essa verificação seja feita na Metodologia Semiempírica Unificada, propõese aqui a consideração de um Método Expedito de teste, o qual apresenta apenas um valor $\mathrm{K}_{\mathrm{Lg}}$ para o fuste e um $\mathrm{K}_{\mathrm{Pg}}$ para a ponta, aplicados à média do SPT ao longo do fuste e à média de três SPT em torno da ponta. Esse método pode ser comparado a um outro método de teste para verificação, como se apresentará oportunamente. 


\section{B.11 DISCUSSÃO ESTATÍSTICA DA VALIDADE DAS REGRESSÕES}

Alguns testes de hipótese estatísticos podem ser aplicados para medir a significância das regressões apresentadas até aqui. Assim, em função do número de solos (ou número de pontos usados nos ajustes) em cada método, a Tabela 51 apresenta os valores de correlação que devem ser considerados como críticos nessa análise (ex.: há apenas $5 \%$ de chance do valor de " $\mathrm{R}^{2 "}$ calculado ser maior que o crítico da tabela, caso não haja correlação real, portanto $95 \%$ de confiança na regressão).

Tabela 51 - Valores críticos dos coeficientes de correlação e determinação das regressões

\begin{tabular}{cccccc}
\hline Método & \multirow{2}{*}{ Solos } & \multicolumn{2}{c}{$\mathrm{R}$ crítico } & \multicolumn{2}{c}{$\mathrm{R}^{2}$ crítico } \\
& & $5 \%$ & $1 \%$ & $5 \%$ & $1 \%$ \\
\hline FK, AV & 15 & 0,5140 & 0,6410 & 0,2642 & 0,4109 \\
TX, BR & 7 & 0,7540 & 0,8750 & 0,5685 & 0,7656 \\
CA, CB & 9 & 0,6660 & 0,7980 & 0,4436 & 0,6368 \\
CV, DQ & 4 & 0,9500 & 0,9990 & 0,9025 & 0,9980 \\
AL, AC, KR & 3 & 1,0000 & 1,0000 & 1,0000 & 1,0000 \\
\hline
\end{tabular}

Embora essa tabela, ao ser comparada com as demais aqui apresentadas, mostre que são perfeitamente válidos a grande maioria dos ajustes realizados, do ponto de vista estatístico as análises aqui efetuadas configuram-se como ajustes ou correlações lineares entre duas esperanças matemáticas (ou seja, resultados médios, com melhor ajuste estatístico) obtidas quando da criação de cada método.

A discussão nesse sentido poderia indicar que mais interessante seria o cálculo das razões médias e seus desvios, permitindo que a dispersão resultante fosse calculada, do que os ajustes passando pela origem. Deve-se ressaltar, contudo que tais análises buscam muito mais identificar as semelhanças e correlações do ponto de vista qualitativo do que quantitativo, ou seja: o que se pretende não é aplicar um modelo para estimar em quanto resultariam os coeficientes de um método a partir de outro, mas sim demonstrar que os diversos métodos se ajustam de forma muito semelhante às grandezas estimadas e, portanto, essas semelhanças permitem a proposição de uma Metodologia Unificada. 


\section{B.12 GENERALIZAÇÃO DE MÉTODOS ESTATíSTICOS}

Métodos puramente estatísticos (regressão múltipla) como o de Vorcaro e Velloso (2000) apud Velloso e Lopes (2002) em geral não apresentam clara correspondência com o entendimento físico do fenômeno. Tal dificuldade viu-se refletida na impossibilidade de Alledi e Polido (2008), no exemplo de análise do item B.5, de calcularem as cargas de ponta e atrito lateral separadamente para a comparação. Embora este tipo de procedimento não seja recomendável para estimativa das parcelas individuais a partir dos métodos semiempíricos (AMANN, 2000), é possível obter-se uma correspondência aproximada entre a carga de ruptura do método estatístico e as cargas lateral e de ponta a partir do conceito de hierarquias dos solos.

Primeiramente, a carga de ruptura estimada pelo método de Vorcaro-Velloso pode ser descrita na seguinte forma matemática geral:

$$
P_{r V V}=a \cdot\left(b \cdot X_{P}^{n}+c \cdot X_{L}\right)+d \cdot e^{\left[f \cdot \ln X_{P}+g \cdot \ln X_{P} \cdot \ln X_{L}+h \cdot \ln X_{L}\right]^{m}}
$$

onde: $X_{P}=A_{p} \cdot N_{p}$

$X_{L}=U \cdot \Sigma N \cdot \Delta L$

$\mathrm{e}=$ base do logaritmo neperiano $2,718 \ldots$

Os valores dos coeficientes da expressão B.8 são dados em função do tipo de estaca e tipo de solo da ponta. Para os tipos de estacas, tem-se a Tabela 52.

Tabela 52 - Valores dos coeficientes da expressão B.8 em função do tipo de estaca

\begin{tabular}{cccccc}
\hline Estaca & $\mathrm{a}$ & $\mathrm{n}$ & $\mathrm{d}$ & $\mathrm{g}$ & $\mathrm{m}$ \\
\hline Prémoldada & 1 & $1 / 2=0,5$ & 0 & - & - \\
Franki & 0 & - & 1 & 0 & $1 / 3=0,333$ \\
Hélice-contínua & 0 & - & 1 & 1 & $1 / 2=0,5$ \\
Escavadas & 0 & - & 1 & 0 & 1,0 \\
\hline
\end{tabular}

Os coeficientes b, c, f, h são todos funções do tipo de solo da ponta, divididos em 5 grupos, e não serão detalhados aqui por fugir ao escopo. Remete-se a Velloso e Lopes (2002). 
Para se obter uma indicação do valor de carga lateral e de ponta separadamente, propõe-se achar o valor do coeficiente característico de ponta da estaca $\left(\mathrm{K}_{\mathrm{PVV}}\right)$, fazendo:

$$
\begin{aligned}
& P_{r V V}=R_{p}+R_{L}=A_{p} \cdot N_{p} \cdot K_{p V V}+A_{L} \cdot \bar{N} \cdot K_{L V V}=X_{p} \cdot K_{p V V}+\frac{X_{L}}{L} \cdot K_{L V V} \Rightarrow \\
& \Rightarrow P_{r V V}=X_{p} \cdot K_{p V V}+k \cdot X_{p} \cdot K_{p V V} \Rightarrow P_{r V V}=X_{p} \cdot K_{p V V} \cdot\left(1+K_{v V}\right) \Rightarrow \\
& \Rightarrow K_{p V V}=\frac{P_{r V V}}{X_{p} \cdot\left(1+k_{v V}\right)}
\end{aligned}
$$

O valor do "coeficiente de conversão atrito-ponta (kvv)" para estacas circulares é então dado por:

$$
\mathrm{K}_{\mathrm{v} V}=\frac{\frac{\mathrm{X}_{\mathrm{L}}}{\mathrm{L}} \cdot \mathrm{K}_{\mathrm{LVV}}}{\mathrm{X}_{\mathrm{p}} \cdot \mathrm{K}_{\mathrm{p} V V}}=\frac{1}{\mathrm{~L}} \cdot \frac{\mathrm{X}_{\mathrm{L}}}{\mathrm{X}_{\mathrm{p}}} \cdot \frac{\mathrm{K}_{\mathrm{LVV}}}{\mathrm{K}_{\mathrm{p} V V}}=\frac{4 \cdot \sum \mathrm{N} \cdot \Delta \mathrm{L}}{\mathrm{L} \cdot \mathrm{D} .} \cdot \frac{\mathrm{K}_{\mathrm{LVV}}}{\mathrm{K}_{\mathrm{p} V V}}
$$

$\mathrm{Na}$ expressão (160) a única incógnita é a relação entre $\mathrm{K}_{\mathrm{LVV}}$ e $\mathrm{K}_{\mathrm{PVV}}$, a qual deve necessariamente ser adotada com base na instrumentação da estaca. Isso ocorre porque, sendo um método estatístico, nada garante que a soma das cargas obtidas substituindo-se $X_{P}$ e $X_{L}$ iguais a zero, cada um por seu turno, resultem no valor de Prvv.

Se não houver instrumentação sugere-se o uso da hierarquia dos solos dada para um outro método, ou pela média como referência. No caso de Alledi e Polido (2008) poder-se-ia adotar o mesmo valor da relação dada hierarquicamente pelo método Décourt-Quaresma ( $\left.K_{L D Q} / K_{P D Q}\right)$, que foi o método que mais se aproximou da ruptura do ensaio (embora tendo-se os dados de instrumentação se saberia que o mesmo subestima a ponta e superestima o atrito, mas de qualquer forma sugere-se aqui uma aproximação), ou então do método de Alonso para os solos do local.

Assim, pode-se utilizar o conceito de hierarquia dos solos como um critério para resolver a questão. Esse mesmo procedimento será usado na Metodologia Semiempírica Unificada após a separação entre atrito e ponta. 


\section{APÊNDICE C - CONSIDERAÇÕES SOBRE OS CRITÉRIOS DE RUPTURA}

\section{C.1 ANÁlise, discussÃo E APLICAÇÃo dOS CRITÉRIOS DE RUPTURA A UM CASO REAL}

Os trabalhos de Fellenius $(1980,2006)$ são ricos em comentários que auxiliam no entendimento da aplicação dos critérios. Considera-se, contudo de absoluta importância destacar que este autor recomenda-os mais como critério de parada do ensaio de prova de carga em execução do que sua aplicação posterior.

Estas observações serão aqui apresentadas a partir de um exemplo de aplicação que poderá ilustrar o entendimento da forma como são aqui utilizados os critérios de ruptura.

O exemplo escolhido foi a estaca E013 dos tanques da Alemoa, em Santos-SP, já analisada por Massad (1994). É uma estaca tipo tubo metálico preenchido com concreto, de comprimento $45,0 \mathrm{~m}$, diâmetro $0,46 \mathrm{~m}$; e rigidez estrutural de 197 $\mathrm{kN} / \mathrm{mm}$, instalada num solo quaternário marinho da Baixada Santista.

A Tabela 19 apresenta os dados de prova de carga do tipo carregamento lento, no primeiro ciclo de carga (com cargas residuais de instalação), omitidos os dados do descarregamento. O gráfico obtido desta tabela de dados é mostrado na Figura 9.

Enquanto se apresentam e discutem os critérios aqui considerados de maior interesse, os mesmos serão aplicados a esse ensaio de prova de carga, e suas considerações enriquecerão a proposição da Metodologia Semiempírica Unificada.

\section{C.1.1 NBR 6122 (1996)}

A norma brasileira de fundações baseia-se no critério de Davisson (1972) para definir a carga de ruptura convencional, sendo conveniente comentá-lo para contextualização do critério da NBR6122. O critério de Davisson é provavelmente o mais conhecido e extensamente usado na América do Norte (FELLENIUS, 2001). Ele estabelece um recalque limite para a ponta da estaca que é somado à sua deformação elástica para obter-se o correspondente recalque no topo. Este valor 
indica, na interseção com a curva de ensaio, a carga limite procurada (Figura 87). O recalque $\left(\delta_{b}\right)$ da ponta é definido por Davisson em função do diâmetro (em $\left.\mathrm{mm}\right)$ da estaca pela expressão:

$$
\delta_{\mathrm{b}}=\frac{\mathrm{D}}{120}+4,0(\mathrm{~mm})
$$

Trata-se de uma modificação do antigo critério de recalque limite usual de 1,5 polegadas $(38,1 \mathrm{~mm})$ de deslocamento do topo para a carga máxima (FELLENIUS, 1994). Para a NBR 6122, porém, considera-se para o recalque da ponta o valor:

$$
\delta_{b}=\frac{D}{30}
$$

A Figura 86, foi aqui elaborada para mostrar a comparação do recalque admitido para a ponta em cada critério, mostrando que a norma brasileira é menos conservadora. Isto ocorre porque o critério de Davisson foi desenvolvido em conjunto com a análise da equação da onda para estacas cravadas ensaiadas de acordo com os ensaios rápidos (QML), sendo indicado também como bom critério para correlação de resultados de provas de carga estáticas e dinâmicas. Niyama et al. (1996) explicam que ele conduz a cargas limite muito reduzidas ao se analisarem ensaios lentos (SML), por isso na adaptação da NBR 6122 esta resulta valores maiores de recalques.

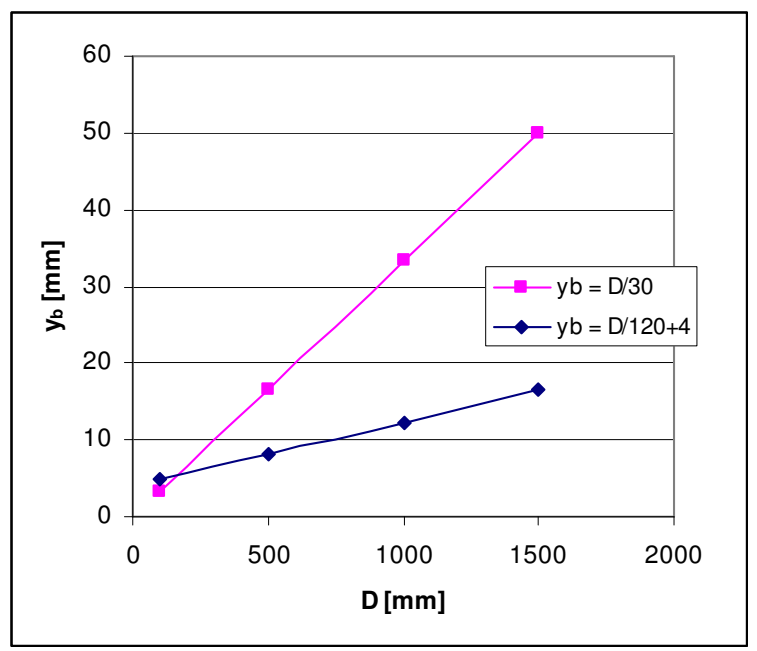

Figura 86 - Comparação entre os valores atribuídos ao recalque da ponta dos critérios de Davisson (1972) e da NBR 6122 (2005) 
Note-se que 0,03.D [expressão (162)] é da ordem de grandeza do deslocamento do topo que mobiliza plenamente a resistência por atrito lateral. A expressão matemática que define os critérios da NBR 6122 e de Davisson é:

$$
\delta-\delta_{\mathrm{b}}=\mathrm{P} \cdot \frac{\mathrm{E} \cdot \mathrm{S}}{\mathrm{L}}=\frac{\mathrm{P}}{\mathrm{Kr}} \Rightarrow \delta=\frac{\mathrm{P}}{\mathrm{Kr}}+\delta_{\mathrm{b}}
$$

onde: $\delta$ : recalque do topo da estaca $[\mathrm{mm}]$;

$\mathrm{P}$ : carga aplicada no topo da estaca [kN];

Kr: rigidez estrutural da estaca.

Fellenius (1994) pondera que esse tipo de critério empírico não considera realmente a forma da curva carga-recalque, nem a real transferência de carga aplicada ao solo. No entanto, Fellenius $(1980,2001)$ o indica por ser de fácil aplicação e ter o mérito de permitir ao engenheiro, durante a execução do ensaio, determinar o máximo deslocamento para uma determinada carga admissível, considerando as dimensões da estaca. Assim, de acordo com a proposta de Fellenius (1975), podem ser estabelecidas especificações de contratação incluindo um critério de aceitação de acordo com a velocidade do método de ensaio. "As especificações podem simplesmente estabelecer para o ensaio pelo menos duas vezes a carga de projeto, como usual, e exigir que numa determinada carga de ensaio igual a pelo menos um fator $F$ (de 1,5 a 1,8 ) vezes a carga de projeto, o deslocamento deve ser menor do que a compressão elástica da estaca, mais $0,15 "(4 \mathrm{~mm})$, mais um valor igual ao diâmetro dividido por 120" (ou no caso da NBR6122, apenas dividido por 30).

\section{Aplicação do critério da NBR 6122}

Com os dados da rigidez da estaca acima apresentados, substituídos nas expressões acima, tem-se a reta da Figura 87. A interseção entre a curva de ensaio e a reta da norma resulta nas coordenadas do recalque e da carga de ruptura convencional (não física, $\mathrm{P}_{\mathrm{Rc}}$ ) indicadas na figura. O processo é gráfico, porém, a fim de refinar o critério, podem-se calcular os coeficientes da reta que liga os dois pontos da curva entre os quais passa a reta da norma e, por um sistema de equações acham-se as coordenadas da interseção. 


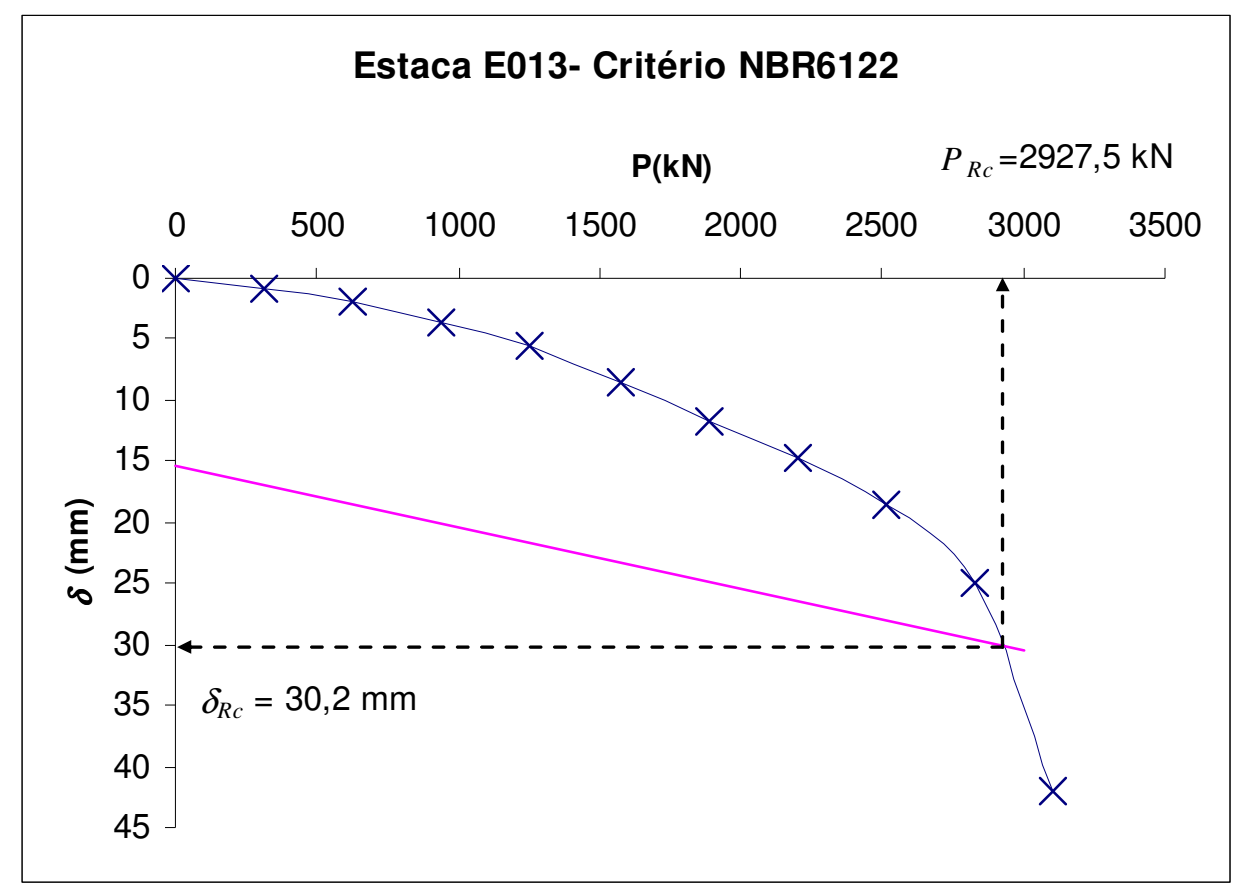

Figura 87 - Critério da NBR6122 aplicado a estaca E013 - Alemoa

Novamente destaca-se que o valor $D / 30$, ou $3,3 \%$ de $D$ é da ordem de grandeza do deslocamento necessário para se mobilizar plenamente o atrito lateral ao longo da estaca ( 1 a 2 \% de D , apud DÉCOURT, 1996a). Somando-se este valor ao encurtamento elástico da estaca, pode-se considerar, grosso modo, que neste ponto se esteja apenas no princípio da mobilização da ponta. Definir a carga de ruptura convencional aqui garante certamente uma reserva de ponta, mas não indica a verdadeira ruptura da estaca, que pode não ocorrer de fato como é o mais comum. Esta reserva de ponta, que é em princípio uma incógnita, influencia a comparação deste resultado com as cargas de ruptura semiempíricas que eventualmente se aproximem dele. Em outras palavras, se uma daquelas cargas de ruptura estimadas semiempiricamente coincidir com o resultado obtido pelo critério da norma, isto poderia ser um indicativo de que o critério semiempírico usado para o atrito e/ou a ponta, nesse caso, é conservador; porém, isso só poderia ser atestado, de fato, se houvessem ocorrências sistemáticas, as quais deveriam ser avaliadas estatisticamente.

Caso a curva de ensaio não tenha se desenvolvido até o ponto de interseção, este fato indica que o ensaio deveria ter sido estendido. Alguns autores (BURIN, 1989) sugerem extrapolar a curva utilizando a equação de Van der Veen ou outra que se ajuste bem aos dados, porém, esse não é o procedimento mais adequado. Neste 
sentido a análise inicial é que este critério seria o primeiro indicador do necessário desenvolvimento do ensaio de prova de carga a ser considerado no projeto do sistema de reação contratado para o ensaio.

Dos comentários de Fellenius (2006) extrai-se que o critério de Davisson, do qual o da NBR6122 é derivado, é muito influenciado pela precisão dos dados de ensaio, incluindo o módulo de elasticidade da estaca, que é, na maioria das vezes, simplesmente estimado. Fica aqui a recomendação para os cuidados devidos em sua aplicação.

\section{C.1.2 Terzaghi (1943)}

O critério de Terzaghi, usado na norma inglesa (NIYAMA et al., 1996), considera a carga de ruptura como a que resulta num recalque de $10 \%$ do diâmetro da estaca. De fato, Craig (2004) cita a norma BS 8004, na qual esse critério é usado tanto para provas de carga SML quanto CRP.

Frank (1999) mostra que também na França as normas de fundações do Ministério da Habitação e Transportes definem o valor de "carga limite" da mesma forma. Trata-se de um critério bastante simples e conservador, como justificam Fleming et al. (1992), que não consideram de todo importante a exata definição da carga última "desde que um adequado fator de segurança seja claramente demonstrado". Estes autores consideram que este critério "é preferível por dar uma baixa estimativa da carga última, visto ser indesejável que a plastificação geral do solo ao redor da estaca seja iniciada".

A este respeito, é interessante a opinião de Fellenius (1980): "Estas definições não consideram o encurtamento elástico da estaca, que pode ser substancial para estacas longas, enquanto é desprezível para estacas curtas".

\section{Aplicação do critério de Terzaghi}

O critério de Terzaghi que estabelece o recalque limite de 0,1.D foi utilizado por Décourt na elaboração do método Décourt-Quaresma. Trata-se de um critério empírico com base na observação de um grande número de provas de carga relatadas por diversos autores em que a ruptura da estaca se avizinhava desta 
ordem de deslocamento do topo (DÉCOURT, 1996a). Aplicado à estaca E013, encontra-se o valor limite de $46 \mathrm{~mm}$. Verifica-se pela Tabela 19 que o recalque máximo atingido no ensaio foi de $41,97 \mathrm{~mm}$, não se alcançando o valor deste critério. Neste caso fica claro que mais um estágio de carga fez falta no ensaio. Pode-se considerar então que este seria um outro interessante critério de parada do ensaio, como mencionado pela norma de ensaio NBR12131, a fim de que se possam separar as parcelas de ponta do atrito lateral.

Novamente, a extrapolação da curva, mesmo que por um pequeno trecho reto com a mesma inclinação do trecho final não é adequado, apesar de dar uma idéia do que se poderia esperar de valor para este critério, mas o resultado seria mera especulação. A única certeza é que a carga para este critério seria um pouco maior do que $3104 \mathrm{kN}$, e portanto maior que a obtida pela NBR 6122.

Décourt (1996a) comenta que, no caso das estacas escavadas, a mobilização adequada da ponta para definição do seu comportamento exige um recalque no topo da estaca de cerca de $30 \%$ do diâmetro (sem garantias de definição da ruptura). Neste caso, a necessidade de se avançar com o ensaio seria ainda maior para uma perfeita análise. E ainda que assim fosse feito, a ponta poderia não apresentar ruptura clara, havendo uma reserva incerta de resistência que não poderia ser considerada. Esta incerteza é o motivo da expressão de cálculo da carga admissível de ponta apresentar coeficiente de segurança maior do que 0 do atrito lateral admissível em alguns métodos.

\section{C.1.3 Fuller \& Hoy (1970)}

Este critério estabelece um valor limite de rigidez tangente ao trecho final da curva igual a 0,05 polegadas $/ \mathrm{tf}$ ou $0,14 \mathrm{~mm} / \mathrm{kN}$ (FELLENIUS, 1980). Ele subestima a carga de ruptura para estacas longas, cujo deslocamento elástico é muito maior do que nas curtas, o que restringe o uso deste critério nestes casos. A rigidez tangente $\left(K_{t}\right)$ do elemento de fundação (estaca-solo), que leva à ruptura, fica então definida pelo inverso do limite dado acima, ou seja: 20 tf/polegada. Assim, Burin (1989), após uma conversão de unidades, apresenta como valor limite para a rigidez tangente $K_{t}=7,0$ $\mathrm{kN} / \mathrm{mm}$. Para comparação, se aplicado este critério à curva exponencial de Van der Veen (1953) (mais adiante discutido), Burin (1989) conclui que: 


$$
P_{\mathrm{RFH}}=\mathrm{P}_{\mathrm{Rvdv}}-\mathrm{K}_{\mathrm{t}} \cdot \mathrm{a}_{\mathrm{vdv}}
$$

\section{Aplicação do critério de Fuller e Hoy}

A reta que representa a rigidez tangente limite deste critério está indicada na Figura 88. O critério de ruptura refere-se à carga correspondente ao ponto de tangência dessa reta com a curva de ensaio. Observa-se na figura, contudo, que na tentativa de tangenciar a curva, a reta não tangencia, mas intercepta a curva pelo ponto de carga máxima.

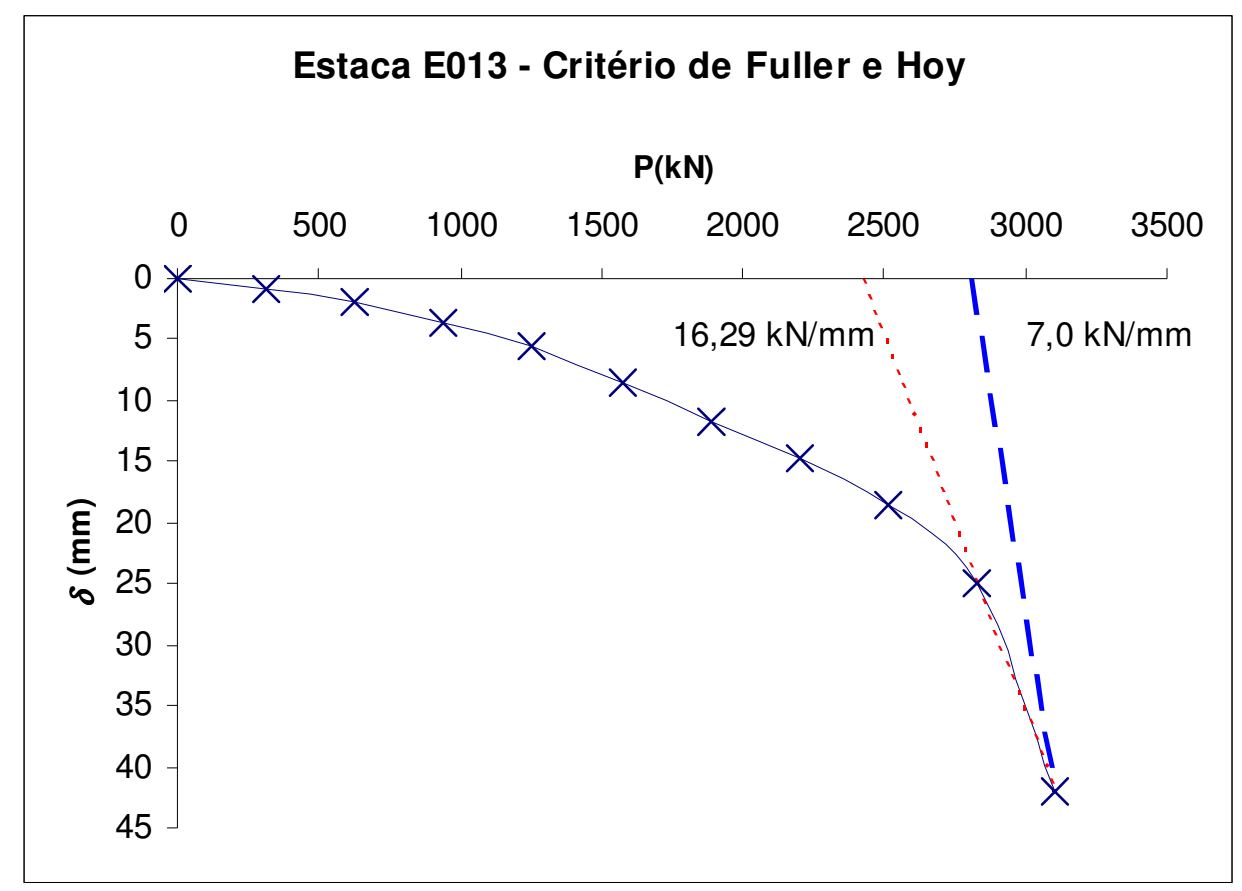

Figura 88 - Critério de Fuller e Hoy aplicado a estaca E013 - Alemoa

Isto ocorre porque a rigidez tangente da curva no último estágio de carga ainda é de $16,29 \mathrm{kN} / \mathrm{mm}$, ou seja, seria necessário ainda a elevação das cargas de ensaio para que houvesse a perda de rigidez que correspondesse ao critério. Fato é que, sendo a estaca relativamente "longa", nada garante que a continuidade do ensaio conduziria a curva até este valor, pois dependendo do solo da ponta sua capacidade de carga pode conduzir a uma rigidez residual maior do que a definida pelo critério, a qual então nunca seria atingida. Em todo o caso, seria importante que se tivesse uma definição mais clara da tendência do solo nesta fase de carregamento, exigindo de fato a continuidade do ensaio. 
A aplicação deste critério a uma curva extrapolada, assim como para os outros critérios, também não é adequada. Se outra prova de carga fosse realizada no local e se verificasse a possibilidade de atingir rigidezes menores, este ensaio poderia então ser desprezado. Caso esta fosse a única prova de carga disponível, restaria portanto admitir que a menor rigidez alcançada no ensaio foi de $16,29 \mathrm{kN} / \mathrm{mm}$, bem como dizer que a carga de ruptura seria maior do que $3104 \mathrm{kN}$, sem maiores conclusões a respeito.

Algo que se pode aproveitar do critério, é que existe uma tendência à linearização do trecho final da curva, e que, sua rigidez limite pode ser calculada por métodos de transferência de carga para a ponta, como o proposto por Massad (1992), mais adiante discutido.

\section{C.1.4 Butler \& Hoy}

Esse critério define a ruptura convencional no ponto de interseção das retas pseudoelástica e pseudoplástica da curva de ensaio. A inclinação da reta pseudoelástica é obtida pelo trecho linear do início do descarregamento da curva carga recalque. Quando não se dispõe do descarregamento, Fellenius (1980) sugere utilizar a mesma inclinação estimada pela reta de Davisson, partindo da origem do diagrama, ou tangenciando o trecho inicial da curva. A reta pseudoplástica por sua vez fica definida pela mesma inclinação do critério de Fuller \& Hoy, tangenciando o trecho final do carregamento da curva carga-recalque.

Apesar desse critério depender da escala adotada na construção da curva cargarecalque (se for aplicado graficamente), Fellenius (1980) justifica a sua indicação pela semelhança com o critério de Davisson e por servir de baliza, juntamente com o critério de Chin (1972), para verificar sua precisão. Fellenius (1980), partindo de sua experiência, demonstra as seguintes análises:

Em alguns casos a carga limite de Davisson pode ser obtida sem que o intérprete [ou analista do ensaio] esteja disposto a aceitar que a estaca alcançou a ruptura. Nestes casos, o valor obtido pelo [critério] de Chin será muito maior do que o limite [indicado pelo] de Davisson. 
No entanto, a inclinação de Butler \& Hoy, de 0,05 polegadas/tf, não

é alcançada a menos que a ruptura esteja iminente, e portanto a

ausência desta ruptura indica, em adição ao valor elevado de Chin, que o valor de Davisson é impreciso. As razões para isto podem ser a adoção equivocada de valores de módulo de elasticidade ou comprimento da estaca, [ou da área devido a variações do diâmetro] ou imprecisão e erros nos valores da carga e dos deslocamentos [anotados durante o ensaio].

Da mesma maneira, como observado para Davisson, esse é um critério de aceitação para o ensaio de prova de carga. No entanto exige deslocamentos grandes o bastante para alcançar o ponto de tangência de Fuller e Hoy, valendo ainda as mesmas restrições já comentadas para estacas longas.

\section{Aplicação do critério de Butler e Hoy}

A aplicação deste critério fica claramente prejudicada pela falta da curva de descarregamento (omitida) do ensaio (para dela se extrair experimentalmente a inclinação da reta de compressão elástica) e pela indefinição do ponto de tangência da reta de rigidez limite (de Fuller e Hoy) sobre a curva do ensaio.

A carga referente ao critério de ruptura deve ser a que corresponde à interseção entre a reta de compressão elástica tangente ao trecho inicial da curva e a reta de rigidez tangente $7 \mathrm{kN} / \mathrm{mm}$. Como não foi possível achar o ponto de tangência desta com a curva, constata-se que a interseção poderia se dar em algum ponto além da carga máxima de ensaio e com valor menor que o obtido pelo critério de Fuller e Hoy. Sem este último valor, só se pode afirmar que a carga de ruptura seria maior do que 3104 kN, porém sem sua definição.

Apenas para exemplificar, sua aplicação tem o processo iniciado com a sugestão de Fellenius (1980) de calcular a inclinação da reta de compressão elástica pela expressão (163), com $\delta_{b}=0$, inserindo-a no gráfico de forma a tangenciar o trecho inicial da curva de ensaio, como se vê na Figura 89.

Qualquer tentativa de se obter uma conclusão nessa condição de incerteza da posição da reta de rigidez tangente limite, seria o equivalente a empregar um outro critério qualquer. 


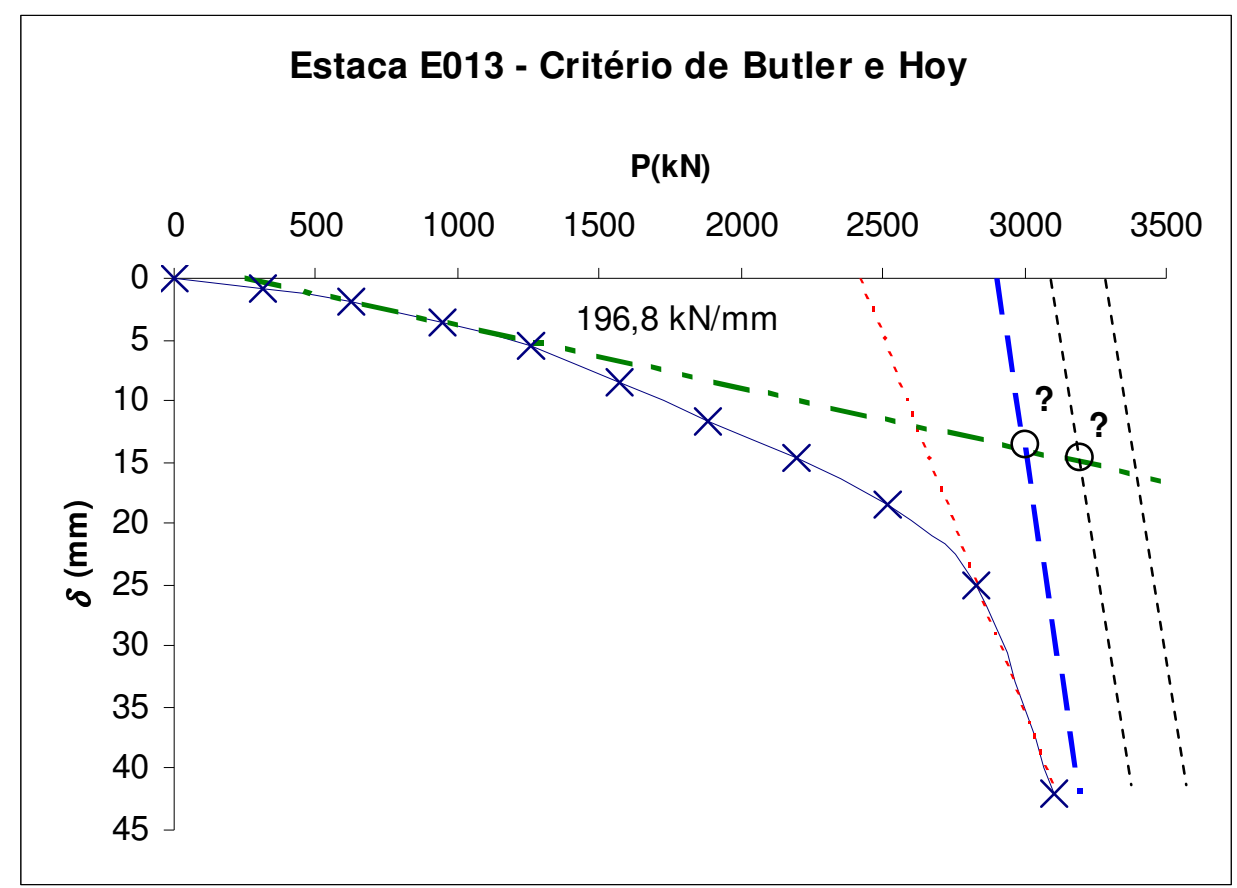

Figura 89 - Critério de Butler e Hoy aplicado a estaca E013 - Alemoa

Remete-se, então, para o próximo item onde se apresentam as análises de Amann (2008a), mais com a intenção de discutir conceitos do que estabelecer valores

\section{C.1.5 De Beer (1968) e De Beer \& Wallays (1972)}

Burin (1989) comenta que estes critérios foram elaborados sobre estudos em estacas tipo Franki ensaiadas pelo procedimento de carregamento lento (SML). Fellenius (2001) faz indicação destes critérios caso seja difícil identificar alguma tendência na análise dos dados, pois se usa aqui o artifício de representar os resultados em escala bilogarítmica. Assim, quando a dispersão dos dados é de uma ou duas ordens de grandeza, as relações tornam-se lineares, mostrando então uma clara tendência.

O diagrama bilogarítmico resultante $(\log \delta \times \log P)$ deve apresentar duas linhas aproximadamente retas, desde que o número de pontos da curva seja tal que permita o desenvolvimento da tendência linear, e que a ponta tenha sido mobilizada no ensaio. A interseção das duas retas, ou o ponto de mudança da inclinação, indica a carga de ruptura, ou a chamada "carga de fluência" (NIYAMA, 1996).

Fellenius (2001) alerta que: "determinar a inclinação e a posição das linhas para interpretá-las com alguma 'lei matemática' não é conveniente; a linearidade 
(logarítmica) tem mais o efeito de ocultar detalhes do que revelá-los". Contudo, a interseção das retas é útil como indicador de onde ocorre uma mudança na resposta da estaca para a carga aplicada (FELLENIUS, 2006).

Burin (1989) comenta que este critério é similar ao de Housel (ver próximo item), pois "a partir de um determinado ponto, o equilíbrio é obtido às custas de grandes deslocamentos, presumindo-se que a capacidade de carga foi excedida".

Sobre este critério, Frank (1999) menciona a experiência francesa:

[...] a carga de fluência ['fluage' Qc] representa o fim do trecho linear da curva de carregamento. Para cargas superiores a ela, a penetração [recalque] da estaca não mais se estabiliza no tempo quando a carga aplicada é mantida constante. Ela é cerca de 1/1,5 (ou 2/3) de QI [carga limite correspondente ao recalque de 10\% do diâmetro] de acordo com as provas de carga estudadas pelo LNPC [Laboratório Nacional de 'Ponts et Chaussées']. Seu valor é deduzido a partir de fórmulas empíricas, pelo ensaio de prova de carga ou medido diretamente.

\section{Aplicação do critério de De Beer e Wallays}

Esse critério busca separar a reta do trecho pseudoelástico da reta do pseudoplástico pela mudança de inclinação da relação $\log (\delta) \times \log (P)$.

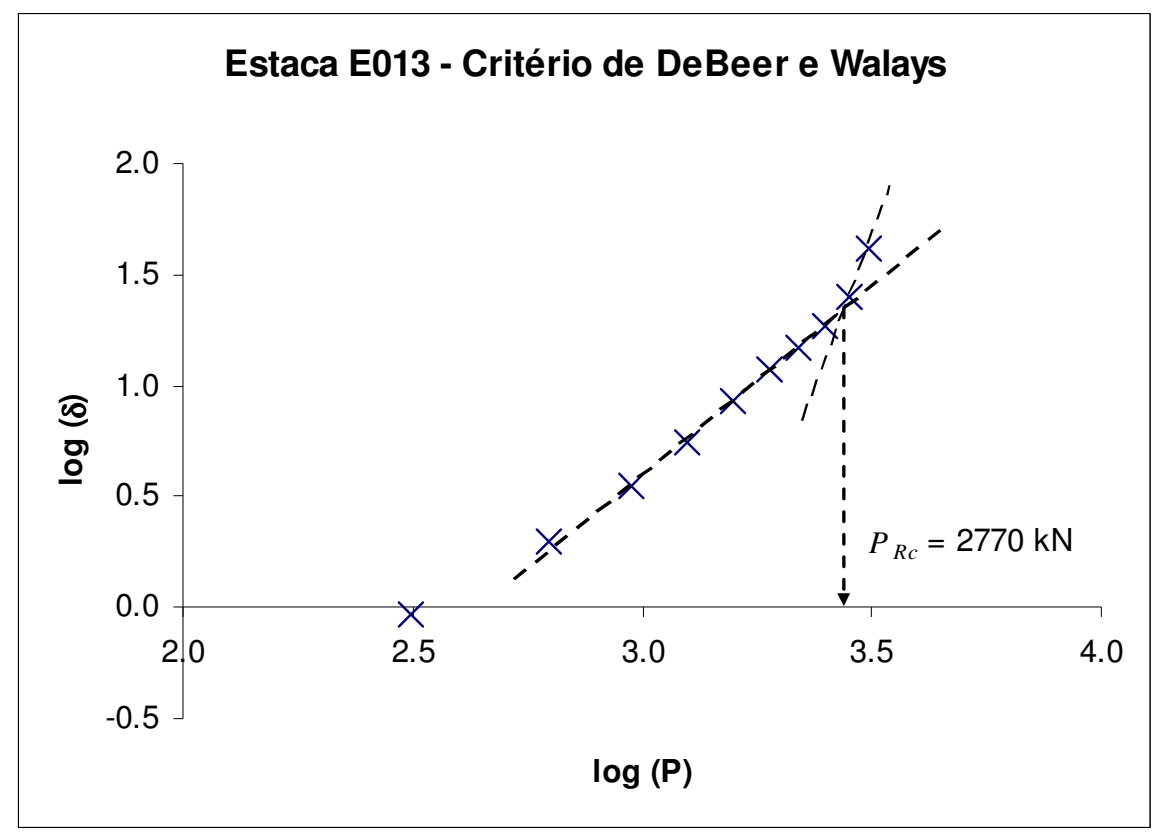

Figura 90 - Critério de De Beer e Wallays aplicado a estaca E013 - Alemoa 
Com atenção, pode-se discernir, nos últimos dois pontos da Figura 90, a mudança de inclinação que define a chamada carga de fluência. Caso houvesse um estágio de carga a menos neste ensaio, também este critério não poderia ser aplicado. Assim, para aplicação deste critério não haveria necessidade de se estender 0 ensaio. Apesar de mais alguns pontos definirem melhor o trecho pseudoplástico, o resultado do critério possivelmente não mudaria, indicando que a carga de ruptura deste deve estar necessariamente próxima da carga transferida por atrito lateral no ensaio (incluída a carga residual), como discutido no critério anterior.

\section{Comparação com o critério de Housel (Creep)}

O critério de Housel, que só é aplicável sob as condições de carregamento a tempo constante, busca definir a carga de ruptura por meio desta mesma mudança de comportamento entre os trechos, e assim muito provavelmente a carga de fluência utilizada nas normas européias que o utilizam deve referir-se em grande parte à capacidade de carga transferida por atrito lateral mais a carga residual, com pequeníssima consideração de ponta.

Fellenius (1980) cita a proposta de Housel (1966) de realizar ensaios com intervalos de tempo constantes, com duração de uma hora para cada um dos oito estágios de carga. Isso permitiria analisar o deslocamento da estaca no tempo o que não é possível no ensaio do tipo lento.

Num diagrama da carga pelo deslocamento dos últimos 30 minutos de cada estágio de 60 minutos, tem-se a formação de duas retas cuja interseção indica a "carga de fluência" ou "creep load", tomada como deflagradora da ruptura. Este procedimento é adotado pela norma francesa NF P 94-150 (FRANK, 1999). Fellenius (2006) indica que este deslocamento limite de "creep" pode ser medido num ensaio rápido tomando-se os pontos entre 6 e 10 minutos, com estágios de carga a cada 10 minutos, deixando clara a diferença entre este procedimento e o que seria um ensaio com velocidade de penetração constante (CRP) que é o adotado como alternativa ao ensaio lento pela norma inglesa BS 8004 (CRAIG, 2007). Com este procedimento obtém-se um resultado francamente não-drenado, mais interessante que o ensaio lento devido à incerteza quanto às suas condições de drenagem. 


\section{C.1.6 Rigidez de Décourt (1999)}

Décourt (1999) propôs um critério cuja expressão matemática é similar a usada por Chin e Brinch Hansen (logo a seguir apresentados), sendo, contudo a variável das ordenadas o inverso da empregada por Chin, o que resulta diretamente no valor da rigidez (secante) do topo do elemento de fundação, como apresentado no expressão (81) do item 4.5 do texto, ou, como prefere Fellenius (2006), na forma da expressão (82) do mesmo item.

A Figura 91 mostra os pontos da curva, indicando a formação de uma linha que tende a interceptar o eixo das abscissas. Uma regressão linear ou logarítmica sobre essa linha, em geral definida nos últimos cinco pontos levantados no ensaio, define a carga de ruptura como sendo aquela que resulta em rigidez $(\mathrm{P} / \delta)$ igual a zero. Graficamente, num diagrama da rigidez (ponto a ponto) contra as cargas, a ruptura é dada na interseção da reta ajustada com o eixo das cargas. É um critério que naturalmente usa uma extrapolação para obtenção da ruptura, que é matematicamente definida pela raiz da equação (81), ou seja, pela assíntota da hipérbole (82).

Os resultados do uso do critério de Décourt são muito similares àqueles de Chin (FELLENIUS, 2006). A vantagem dele é a de se observar de forma direta, já durante o ensaio, qual a carga máxima a ser obtida, tão logo uma linha de tendência reta comece a se desenvolver. Neste sentido, ambos Chin e Décourt permitem contínua verificação durante o ensaio, desde que 0 ensaio seja realizado com 0 acompanhamento de um diagrama carga-recalque, permitindo se predizer qual a carga máxima que será aplicada e se o sistema tem capacidade para tal.

Deve-se ter cuidado para não cometer alguns equívocos na análise com os critérios de Hansen, Chin, e Décourt, por se achar que a extrapolação da curva indicaria uma carga de ruptura "exata". Como já mencionado, qualquer que seja o critério usado, o valor da capacidade de carga para uso em projeto de fundações por estaca não deve ser maior que a máxima carga aplicada à estaca no ensaio (FELLENIUS, 2006). 
Décourt (2008) propõe que com as análises extraídas do diagrama de Rigidez é possível obter-se maiores informações sobre o comportamento da estaca, inclusive a separação entre atrito e ponta como se apresenta no item 4.5 do texto.

\section{Aplicação do critério da Rigidez de Décourt}

Este critério define a carga de ruptura $P_{R}$ para a relação $P / \delta=0$, que neste caso foi obtida por ajuste linear, visto ser a estaca de deslocamento. Como já apresentado, Décourt (2008) ampliou o critério, sugerindo ajustar não só o fim da curva, mas também o trecho referente ao atrito lateral $\left(R_{\mathrm{L}}\right)$ e obter uma indicação de seu valor.

É importante verificar que para encontrar a carga de ruptura Décourt toma sempre os últimos pontos da curva, verificando até onde o ajuste é bom. Neste caso apenas os dois últimos pontos foram considerados, e isto está coerente com o resultado do critério de De Beer e Wallays. Décourt (2008) mostra que o valor do atrito indicado possui uma parcela de ponta, não quantificada e, portanto, esse é um limite superior para o valor real. Note-se que o valor de atrito é próximo ao do resultado dos critérios anteriores (incluindo-se a carga residual), sendo que aqui há a vantagem de se ter uma idéia do quanto a ponta poderia ainda suportar.

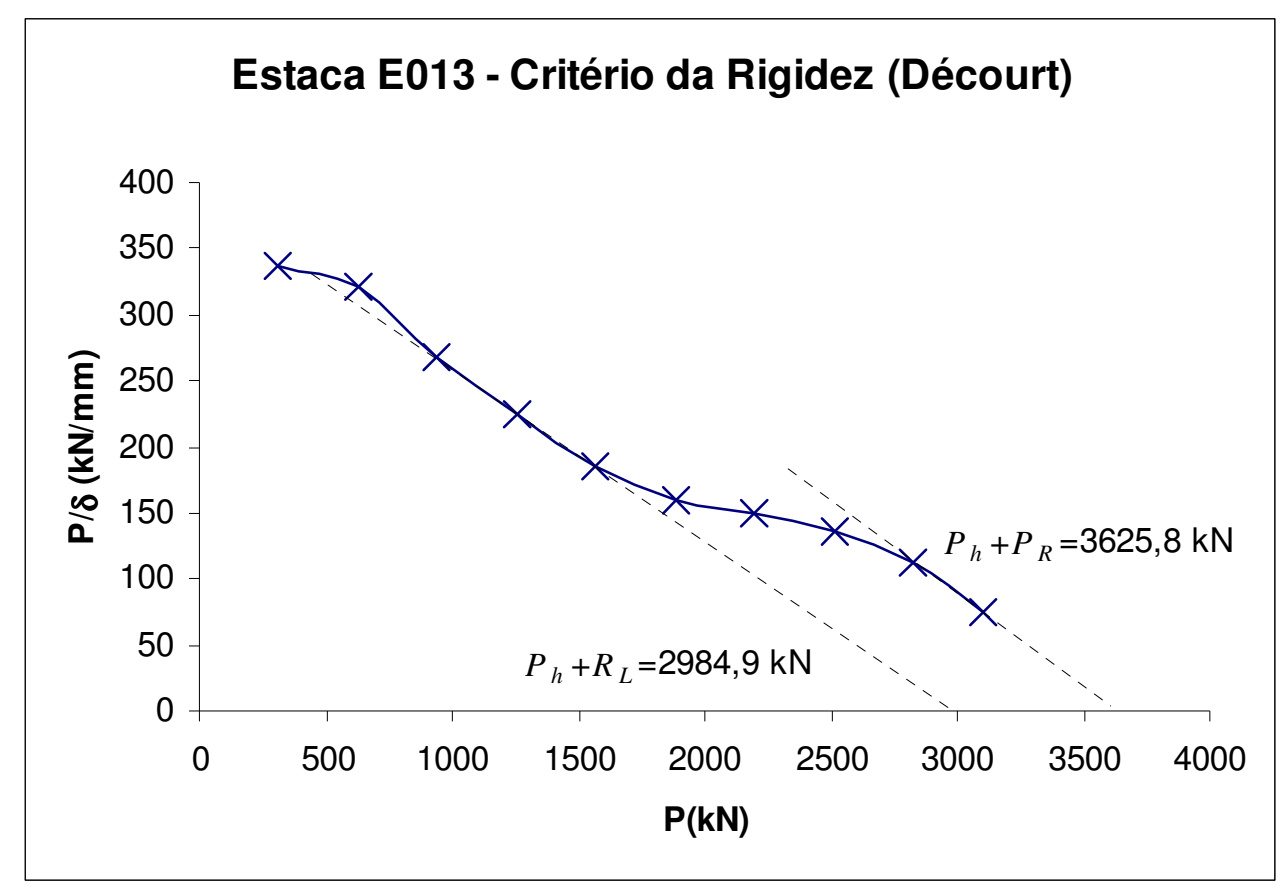

Figura 91 - Critério de Rigidez de Décourt aplicado à estaca E013 - Alemoa. 
Deve-se enfatizar, que tal valor de atrito da Figura 91 se refere ao desenvolvido no ensaio e instalação, e não ao atrito máximo resistido pelo solo. Massad (2008) verifica que a carga residual $\left(P_{h}\right)$ de instalação da estaca cravada, ou de eventuais carregamentos prévios, está incorporada ao valor do atrito assim obtido, devendo ser separada do mesmo para se estabelecer o valor máximo suportado pelo solo, que é o que interessa para a Metodologia Semiempírica Unificada.

\section{C.1.7 Chin (1972)}

Este critério também é chamado de Chin-Kondner, pois baseia-se, assim como Brinch Hansen (apresentado no próximo item), nos estudos de Kondner sobre a curva tensão-deformação de solos coesivos ensaiados ao adensamento rápido. A proposta de Chin é aproximar a curva obtida no ensaio a uma hipérbole do tipo da expressão (82) do texto. Note-se que esta expressão é muito semelhante à usada por Brinch Hansen a menos da raiz quadrada (que resulta em uma função de segundo grau). A carga de ruptura é dada pela assíntota da hipérbole, expressa pelo inverso do coeficiente angular $\left(1 / c_{1 C}\right)$ da reta de regressão linear.

O critério de Chin é indicado por Fellenius (1980) porque permite uma contínua verificação do ensaio durante sua execução, e fornece uma estimativa da máxima carga que será aplicada durante o teste. Qualquer irregularidade ou mudanças na inclinação da reta de Chin indicam que alguma coisa está errada ou com a estaca ou com o equipamento de ensaio.

Após alguma variação inicial, os pontos do gráfico indicam uma linha reta que normalmente não começa a materializar-se antes que a carga de ensaio tenha passado do limite de Davisson (próximo ao sétimo estágio de carga). A carga de ruptura de Chin é 20 a 40\% maior do que o limite de Davisson e se assim não for, é recomendável revisar os dados, como já exposto anteriormente (FELLENIUS, 1980). O valor obtido por este critério tem a vantagem adicional de ser menos sensível a imprecisões dos valores da carga e dos recalques que o critério de Davisson.

O critério de Chin nem sempre é adequado aos ensaios lentos, pois foi desenvolvido para estágios com tempo de carregamento constantes. Se assim for, ele é aplicável a ambos os ensaios lentos e rápidos. 


\section{Aplicação do critério de Chin}

Fellenius (2008) privilegia os pontos do final da curva para ajustar as funções de critério de ruptura, e neste caso foram escolhidos os três últimos, resultando ruptura de $3774,3 \mathrm{kN}$. Aqui o ajuste foi feito também para todos os pontos e, como menciona Fellenius (2008), vê-se que este critério sofre pouca influência de imprecisões, pouco alterando $(5 \%)$ o valor obtido $(3985,7 \mathrm{kN})$.

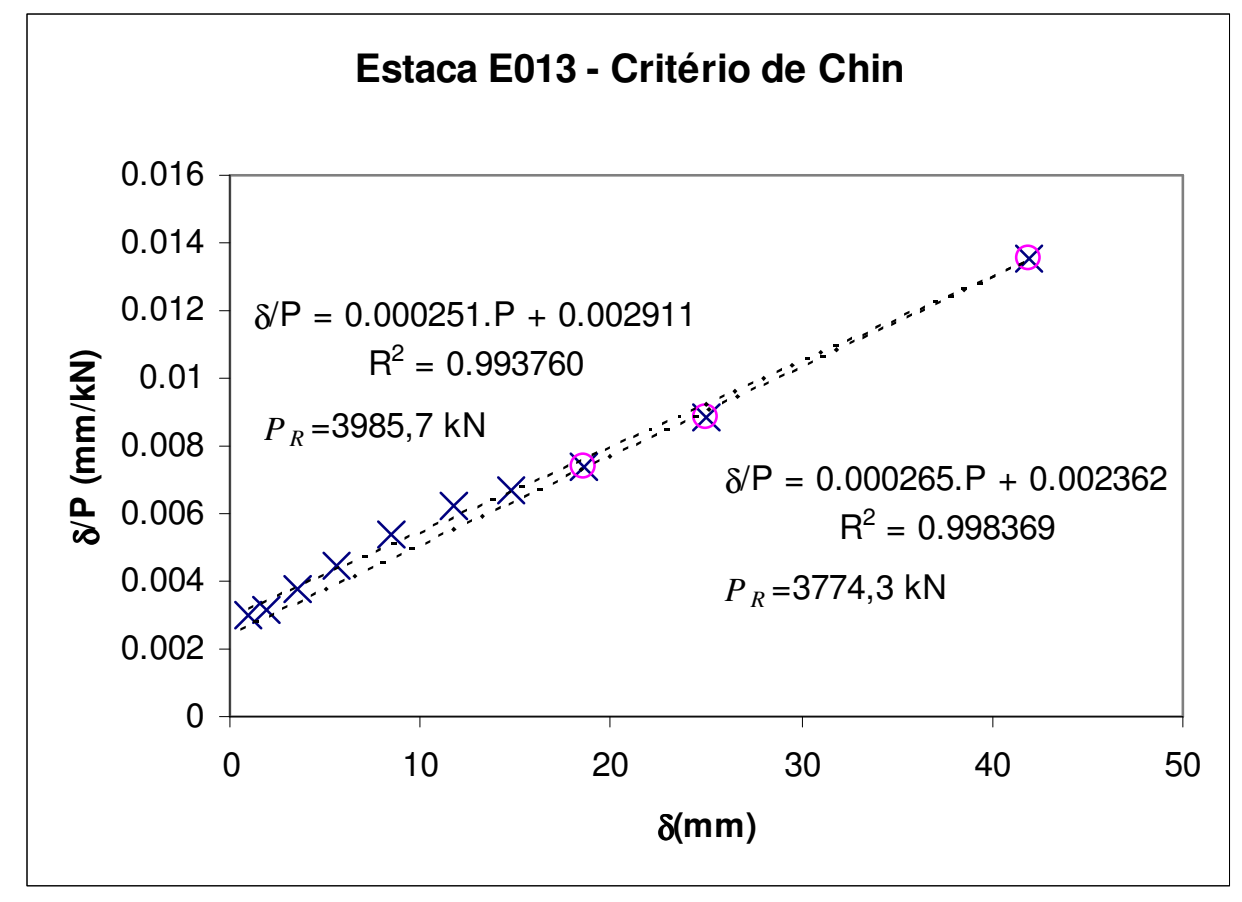

Figura 92 - Critério de Chin aplicado à estaca E013 - Alemoa

É interessante ainda verificar que a curva ajustada aos pontos, resulta em um coeficiente de determinação muito bom ( $\mathrm{R}^{2}=0,9938$ da Figura 92), o que não indica, contudo, que o valor da ruptura esteja mais ou menos correto, mas apenas a possibilidade de se ajustar bem os pontos do ensaio.

Estes critérios que fazem extrapolação da curva carga-recalque devem ser avaliados com cautela. Massad (1994) esclarece o assunto e define que sem a mobilização da ponta, nada se pode afirmar sobre a extrapolação obtida. É importante ter em mente que a carga de ruptura indicada por Chin só seria alcançada com valores de recalque muitíssimo elevados. Com isto, alguns autores adotam na prática de engenharia um valor de carga de ruptura convencional $\left(\mathrm{P}_{\mathrm{Rc}}\right)$ aplicando um "coeficiente de redução" entre 80 e 90\% do valor obtido neste critério $\left(P_{\mathrm{RChin}}\right)$, como relata Yang (1994). Este autor propõe ainda um procedimento matemático para 
obtenção do ponto de máxima curvatura da curva de Chin de forma a nele estabelecer 0 valor adequado de $\mathrm{P}_{\mathrm{Rc}}$ sem a necessidade de se arbitrar um coeficiente de redução. Massad (2008) comenta que ao se considerar, como no critério de Décourt (2008), a ruptura convencional para o recalque de 0,1.D, também se elimina o problema da superestimativa de Chin.

\section{C.1.8 Brinch Hansen (1963)}

Segundo Burin(1989), Brinch Hansen elaborou o critério a partir de análises do trabalho de Kondner (1963) sobre a curva tensão $(\sigma)$-deformação $(\varepsilon)$ de solos, que aplicada aos recalques da estaca resulta na equação de parábola do tipo:

$$
\sigma=\frac{\sqrt{\varepsilon}}{a \cdot \varepsilon+b} \Rightarrow \frac{\sqrt{\delta}}{P}=a \cdot \delta+b
$$

Esta expressão possui um ponto de máximo a partir do qual tende a um valor residual. Para este método existem dois critérios:

a) Critério de 90\%: "A carga de ruptura é a correspondente ao dobro do recalque medido para 90\% daquela mesma carga", aplicado a ensaios de penetração constante - CRP- (apud NIYAMA et al. 1996), podendo ser equacionado pela interseção entre a curva carga-recalque e a curva $\mathrm{P}=f\left(2 . \delta_{0,9 \mathrm{P}}\right)$.

b) Critério de 80\%: recomendado por Fellenius (1980), indica que "a carga de ruptura corresponde ao recalque quatro vezes maior que o medido para $80 \%$ daquela carga". O ponto de máximo, para o critério de $80 \%$, indica a carga de ruptura e seu respectivo recalque, dado por:

$$
\mathrm{P}_{\mathrm{RBH}}=\frac{1}{2 \cdot \sqrt{a \cdot b}} ; \delta_{\mathrm{RBH}}=\frac{\mathrm{b}}{\mathrm{a}}
$$

Burin (1989) menciona, a título de comparação, que se este critério fosse aplicado a uma curva carga-recalque com equação dada pelo critério de Van der Veen (1953) discutido mais adiante - e de Chin (1972), este critério resultaria respectivamente em $P_{R B H}=0,998$. $P_{\text {Rvdv }}$ e $P_{R B H}=0,917$. $P_{\text {Rchin. }}$ Burin (1989) observa que o critério serve para qualquer forma de curva, ou seja, é um limite arbitrário para a rigidez tangente do sistema estaca-solo, similar a Fuller \& Hoy, porém com uma equação associada. Para sua aplicação é necessário que a curva carga-recalque do ensaio 
tenha alcançado o ponto de máximo $\left(0,8 \cdot P_{\mathrm{RBH}} \times 0,25 \delta_{\mathrm{RBH}}\right)$. Muito embora ele até permita extrapolar a curva, sem atingir este ponto, os ajustes matemáticos não são bons, visto que é o trecho final da curva que deve ser utilizado no processo.

Fellenius (2006) indica este critério pois usualmente resulta em um valor de $P_{R}$ que coincide com aquele que é subjetivamente aceito como a carga última determinada em resultados de ensaios estáticos. $O$ valor resultante é apenas ligeiramente inferior ao de Chin (1972), porém, está mais sujeito a erros devido à imprecisão dos dados de carga-recalque do que este outro.

\section{Aplicação do critério de Brinch Hansen $80 \%$}

Esse critério de recalque limite também pode ser ajustado matematicamente, considerando os quatro últimos pontos, resultando em $3497,4 \mathrm{kN}$, como se mostra na Figura 93.

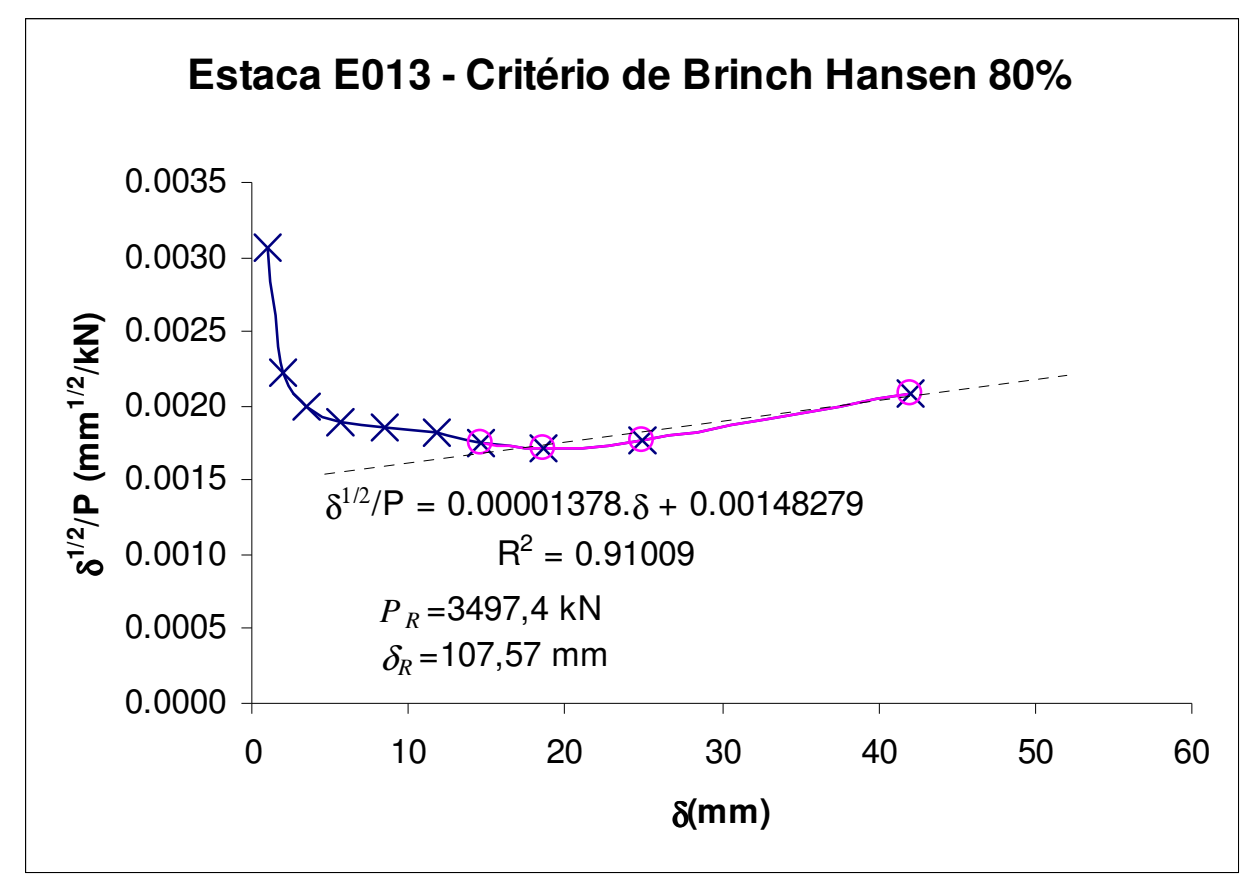

Figura 93 - Critério de Brinch Hansen 80\% aplicado à estaca E013 - Alemoa

Deve-se cuidar dos pontos escolhidos, sempre dos últimos para os primeiros, pois conforme sejam podem-se obter coeficientes negativos, inviabilizando o critério. Embora não seja a proposta do critério, pode-se ajustar a curva aos pontos do ensaio. 


\section{C.1.9 Van der Veen (1953) e a generalização de Aoki (1976)}

O critério de Van der Veen (1953), é muito difundido no Brasil, (NIYAMA et al, 1996) sobretudo na sua versão modificada por Aoki (1976). Esse critério considera que a curva carga-recalque pode ser expressa pela função exponencial do tipo:

$$
P=P_{R} \cdot\left(1-e^{-a . \delta}\right)
$$

que é semelhante à função de crescimento biológico em culturas de bactérias (Van der Veen, 1953).

Aoki (1976) sugeriu permitir o ajuste da reta de regressão sem a obrigatoriedade de passar pela origem do diagrama, o que ficou conhecido como critério de "Van der Veen generalizado por Aoki", sendo definido pela expressão (20) do item 3.6.4.. A sua aplicação consiste em ajustar os pontos do ensaio a uma reta do tipo da expressão (21) do mesmo item.

Embora muito utilizado no Brasil também é alvo de críticas, não constando das recomendações de Fellenius (2006), embora constasse no artigo de Fellenius (1980). Décourt e Niyama (1994) identificaram problemas com a extrapolação da carga de ruptura em provas de carga interrompidas antes da ruptura propriamente dita. Procederam nesta análise a sucessivas determinações da carga de ruptura num mesmo ensaio, retirando-se a cada vez um ponto no final da curva e identificaram uma grande variação dos resultados. Recomendam assim que este critério somente seja usado quando: a) as estacas são de deslocamento (cravadas); b) quando o carregamento for monotônico (sem descarregamento); c) a carga máxima do ensaio atingir pelo menos $2 / 3$ da carga de ruptura convencional. Nos outros casos a carga de ruptura extrapolada não é confiável, o que indica que mais alguns estágio de carga fazem muita diferença no resultado final.

Amann (2008b) verificou as razões destas observações ao analisar os métodos de transferência de carga, como aqui apresentado no item 3.6.4. Ainda sobre este aspecto, Massad (1994b) já apresentara uma série de conclusões utilizando análises baseadas nas Leis Modificadas de Cambefort. 


\section{Aplicação do critério de Van der Veen generalizado}

Utilizou-se para este critério o ajuste num programa computacional com variação incremental da carga de ruptura testada, obtendo-se a curva ajustada da Figura 94 e a carga de ruptura nela indicada.

Sendo este critério o mais difundido no Brasil, as críticas feitas a ele merecem ser analisadas. Remete-se assim para o trabalho de Amann (2008a) e às análises críticas apresentadas no item 3.6.4.

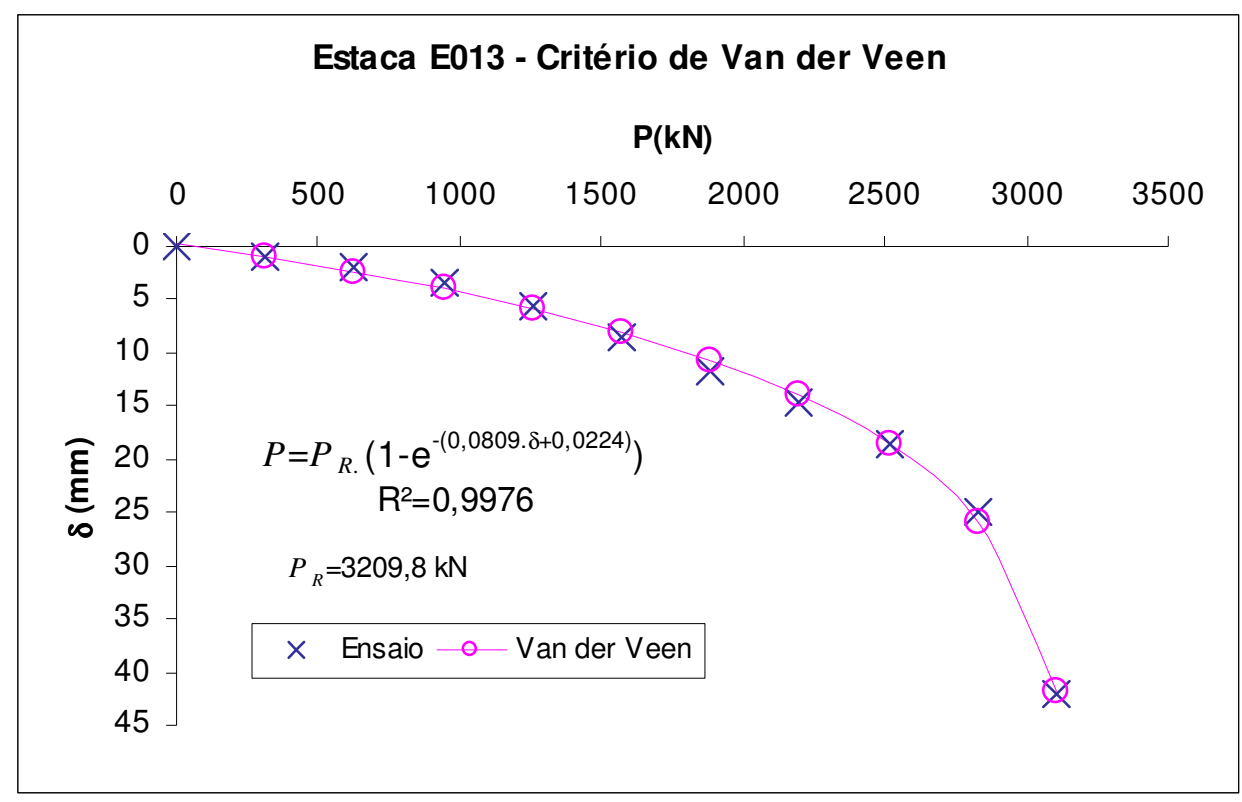

Figura 94 - Critério de Van der Veen aplicado à estaca E013 - Alemoa

\section{Comparação com o critério de Mazurkiewicz (1970)}

O critério de Mazurkiewicz (1970) apud Massad (1986) já foi muito utilizado para definição gráfica da carga de ruptura, tendo hoje sido deixado de lado por uma série de razões, entre as quais a difusão da informática. Ele realiza a extrapolação do valor da carga de ruptura a partir de recalques equiespaçados (cuja escolha do intervalo pode influenciar no resultado) sobre a curva de ensaio, aplicados ao processo gráfico de construção de parábolas (localização do ponto de máximo). Apesar de se considerar que a curva assim obtida é uma parábola (em virtude do processo de construção gráfica), Massad (1986) demonstrou que na verdade se trata de uma exponencial. 
Em seu trabalho, Massad (1986) identificou a similaridade deste método gráfico com o processo matemático proposto por Asaoka para a estabilização do adensamento. Partindo-se também dos recalques equiespaçados, tomam-se as cargas correspondentes, obtendo-se "n" cargas (quanto mais valores, maior a precisão). Cada carga obtida é relacionada com a sua subsequente, ou seja, correlacionam-se as cargas $P_{n+1}$ com as $P_{n}$ numa regressão linear $\left.P_{n+1}=a+b . P_{n}\right)$. A interseção desta reta com a reta $P_{n+1}=P_{n}$ define a ruptura $\left(P_{R}=a /(1-b)\right)$, ou seja, a assíntota para a qual tende a curva exponencial similar à da Van der Veen (1953).

A mesma constatação é reforçada por Burin (1989), que, seguindo outro caminho, mostra que a expressão matemática deste critério seria:

$$
\frac{d P}{d \delta}=a \cdot\left(P_{R}-P\right)
$$

Assim, a hipótese sobre a forma da curva é que seja a mesma de Van der Veen, pois derivando-se a expressão original de Veen obtém-se:

$$
\frac{\mathrm{dP}}{\mathrm{d} \delta}=\mathrm{a} \cdot \mathrm{P}_{\mathrm{R}} \cdot \mathrm{e}^{-\mathrm{a} . \delta}
$$

Substituindo-se (168) em (169) e isolando-se o recalque $\delta$ tem-se:

$$
\delta=-\frac{1}{\mathrm{a}} \cdot \ln \left(1-\frac{\mathrm{P}}{\mathrm{P}_{\mathrm{R}}}\right)
$$

que é a própria expressão (167).

Assim, este critério não será aqui aplicado, em função da semelhança com Van der Veen e consta aqui apenas para esclarecimento.

\section{C.2 CONSIDERAÇÕES SOBRE OS CRITÉRIOS DE RUPTURA}

Resumindo-se os resultados da aplicação dos diversos critérios à estaca E013 da Alemoa, apresentadas na Tabela 53, pode-se verificar que há duas tendências distintas: uma que conduz à carga de ruptura em torno de $2700 \mathrm{kN}$ e outra em torno de $3700 \mathrm{kN}$. 
Os valores da Tabela 53, cuja aplicação não foi possível, aparecem com a indicação de que a carga de ruptura seria maior do que 3104,0 kN por dedução lógica. Por outro lado, se, como sugerido na comparação com o método das Leis de Cambefort Modificadas por Massad (1992), se fosse tomada a reta de rigidez tangente limite como igual à reta de mobilização da ponta (e não a reta de Fuller e Hoy, com inclinação $\mathrm{K}_{\text {tlim }}$ visto que este valor limite pode não ser alcançável pela estaca), o resultado do critério de Butler e Hoy indicaria pouco mais de 2578 kN (avaliação de MASSAD, 1994), relativamente próximo ao de De Beer e Wallays (2700 kN). Convém acrescentar que o método da Rigidez de Décourt (1999) modificado por Décourt (2008) indicou um valor de atrito desenvolvido no ensaio de 2984,9 kN (considerando a carga residual).

\begin{tabular}{cc} 
Tabela 53 - Valores dos critérios de ruptura aplicados à estaca E013-A \\
\cline { 2 - 2 } Critério & $\begin{array}{c}\text { Capacidade de carga } \\
\text { da estaca E013 (kN) }\end{array}$ \\
\hline NBR6122 2006 & 2927,5 \\
Terzaghi 1943 & $>3104,0$ \\
Fuller \& Hoy 1970 & $>3104,0$ \\
Butler \& Hoy 1977 & $>3104,0$ \\
De Beer e Wallays 1972 & 2770,0 \\
Décourt (Rigidez) 1999 & 3625,8 \\
Chin-Kondner 1970 & 3985,7 \\
Brinch Hansen (80\%) 1963 & 3497,4 \\
Veen por Aoki 1976 & 3209,8 \\
\hline
\end{tabular}

Destas considerações verifica-se que os critérios que buscam definir a região de mudança de comportamento da estaca para ali adotar a carga de ruptura convencional estão na verdade obtendo um valor de carga próxima ao valor do atrito lateral desenvolvido no ensaio (incluindo a carga residual). Inclui-se nestas considerações o critério da NBR 6122, que partindo de um recalque D/30 somado ao recalque elástico da estaca, não foge muito desta região.

Na prática, como indica Fellenius (2006), os critérios fornecem boas indicações para o executante do ensaio saber qual nível de recalque deve alcançar (sobretudo para aplicação dos métodos de separação das parcelas de atrito e ponta), contudo não refletem necessariamente a ruptura da estaca. Os próprios comentários de Fellenius aqui apresentados indicam que ele utiliza frequentemente mais de um critério para 
definir em que ponto parar o ensaio (não necessariamente indicando a ruptura), cruzando informações com base em sua experiência.

Neste contexto cabe a questão relativa à discussão do paradigma atual: com o que se têm comparado os métodos semiempíricos para atestá-los conservadores ou contra a segurança? Percebe-se então, com tal incerteza, que ao se pretender julgar um método semiempírico deve-se necessariamente considerar qual o critério de ruptura utilizado em sua concepção, pois este torna-se assim parte integrante do método e o uso de um único critério não levará a qualquer conclusão quanto ao nível de segurança da estimativa semiempírica. É fato, porém, que poucos autores deixam claro qual foi o critério utilizado na criação dos métodos, e isto deve ser mudado.

De qualquer modo, criar um ranque, uma classificação da "melhor" estimativa para a "pior" com base em um critério escolhido aleatoriamente torna-se um verdadeiro jogo de azar cujos resultados são absolutamente incertos; também não há estatística que, neste cenário, garanta que a adição de mais duas ou três estacas na análise melhorará as estimativas ou permitirá melhores conclusões. Ainda que assim se procedesse, isso não permitiria que se tivesse a menor noção do motivo da variabilidade, nem quais são as principais fontes de erro nos resultados dos métodos semiempíricos. Esta é uma lacuna que a Metodologia Semiempírica Unificada pretende cobrir.

Também os critérios que extrapolam matematicamente a curva de ensaio são preocupantes, pois não se pode dizer dos seus resultados quanto é efetivamente a parcela correspondente à ponta, nem se a curva extrapolada corresponderia à realidade caso o ensaio fosse levado adiante. Na tentativa de obter ao menos uma idéia a respeito, Amann (2008b) buscou avaliar os critérios de Van der Veen e Chin quando aplicados a uma estaca com correspondência de comportamento às Leis de Cambefort modificadas por Massad (1992), ou seja, comportamento da ponta elastoplástico dado em função dos parâmetros do solo da teoria da elasticidade. Pode-se desta forma avaliar, ainda que estimativamente, como as curvas extrapoladas por aqueles critérios se comportam, supondo o solo da ponta com comportamento próximo ao teórico. Mais adiante são apresentadas as conclusões deste trabalho. 
Ainda que se sugira separar a parcela de atrito pelos métodos de transferência de carga a assim corrigir os coeficientes dos métodos semiempíricos, para a ponta ficase na dependência de o quanto ela foi efetivamente mobilizada, o que dependerá do desenvolvimento de cada ensaio. $O$ critério de parada do ensaio com recalques da ordem de $10 \%$ a $30 \%$ do diâmetro, juntamente com o acompanhamento do avanço da mobilização da ponta (em termos de rigidez) poderiam estabelecer certa homogeneidade da qual carecem os ensaios de controle executados no Brasil (baseados no valor da carga de trabalho, que é apenas uma estimativa inicial de projeto).

Torna-se assim imperativo, para se continuar a aplicar tal metodologia, não só estabelecer de forma cautelosa o critério de ruptura a ser adotado, como também utilizá-los como critério de parada das provas de carga e não só como critérios de atribuição da carga de ruptura. Como alternativa sugere-se aqui uma nova forma de consideração dos critérios, como exposto no item 3.7.

\section{C.3 ANÁLISE CRÍTICA DOS CRITÉRIOS DE VAN DER VEEN (1953) E CHIN (1972)}

Apresenta-se aqui um estudo dos critérios de ruptura de Van der Veen e de Chin, buscando suas correspondências com a curva teórica dada pelas análises das Leis de Cambefort modificadas por Massad (1992) e suas atualizações (MARQUES e MASSAD, 2004). O processo utilizado para esta análise passa pela parametrização das equações dos critérios, como segue.

\section{C.3.1 PARAMETRIZAÇÃO DO CRITÉRIO DE VAN DER VEEN (AMANN, 2008a)}

Para se interpretar como a função matemática proposta por Van der Veen (1953) atende à representação da curva carga-recalque e para analisar a sua parametrização, ou normalização, primeiramente analisa-se a função exponencial "fundamental" e suas modificações, para que se tenha uma função conveniente que apresente uma tendência assintótica a um valor $P_{r}$ de ruptura procurado. A seqüência de manipulações pode ser observada na Figura 95. 

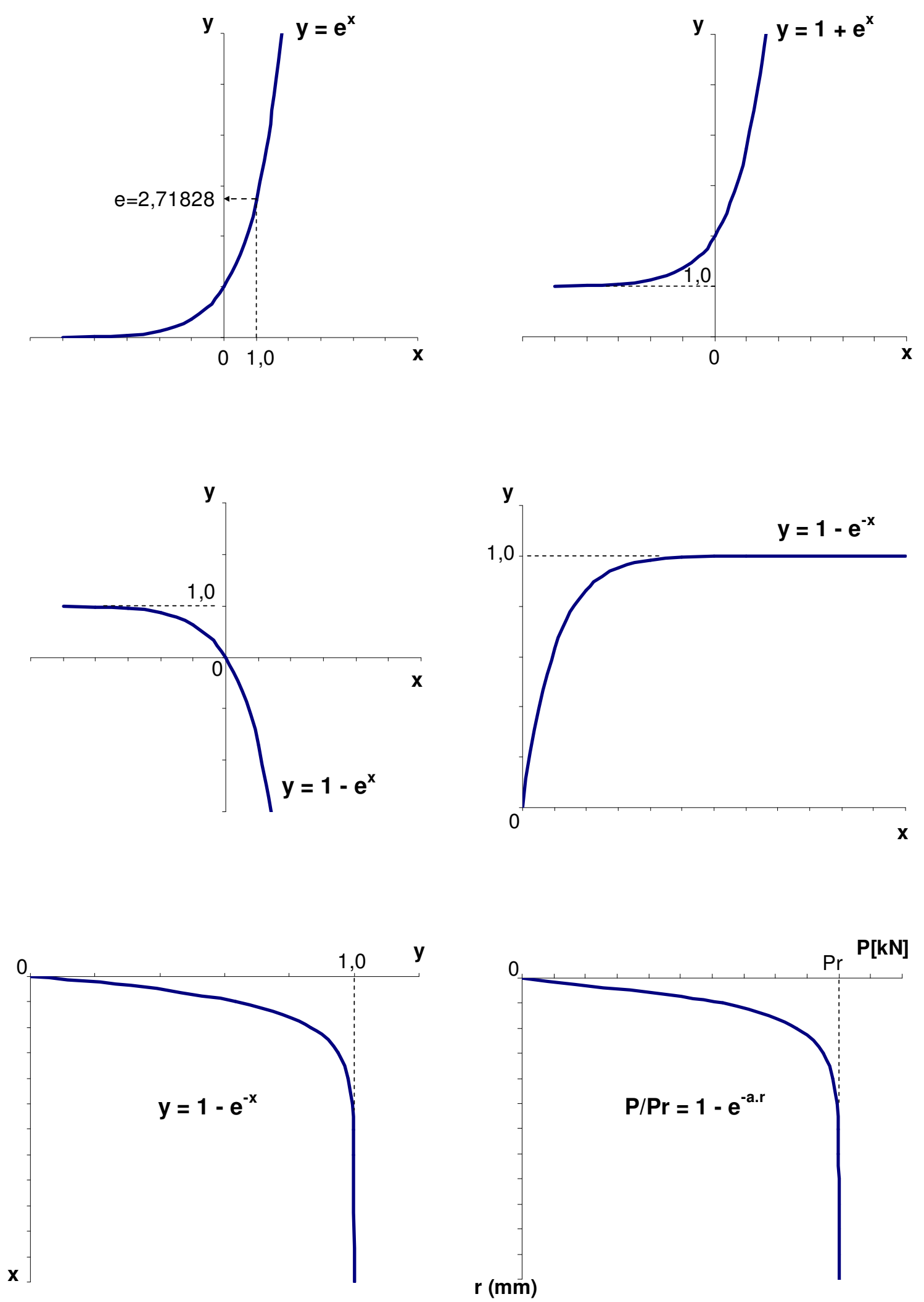

Figura 95 - Transformações matemáticas desde a função exponencial até a expressão de Van der Veen 
Note-se que observada desta maneira, na Figura 95, a curva é exatamente a mesma que a original, com o mesmo traçado gráfico da exponencial fundamental como se fosse um "gabarito", apenas com modificações da escala gráfica dos eixos, representadas pelos parâmetros 'a' e ' $\mathrm{P}_{\mathrm{r}}$ '.

Esta noção será explorada fortemente na proposta a ser apresentada no presente trabalho. Serão aqui usados os símbolos ' $r$ ' e ' $P_{r}$ ' para representar respectivamente os recalques e a carga de ruptura do critério, cuidando-se de não confundi-los com o $\delta$ ou $\mathrm{P}_{\mathrm{R}}$ usados até então para os recalques medidos no ensaio de prova de carga.

Assim, Amann (2008a) propôs utilizar a função parametrizada, considerando assim os valores reais de carga e recalque como sendo "afetados por fatores de escala gráfica". Desta forma, os valores da função parametrizada podem ser tabelados como apresentado na Tabela 22 do item 3.6.4 do texto, a qual é a tabela base para o traçado da curva parametrizada que funciona como uma linha de influência da carga no recalque. No trecho final foram escolhidos valores de $P / P_{r}$ que resultassem mais próximos de valores inteiros de recalques.

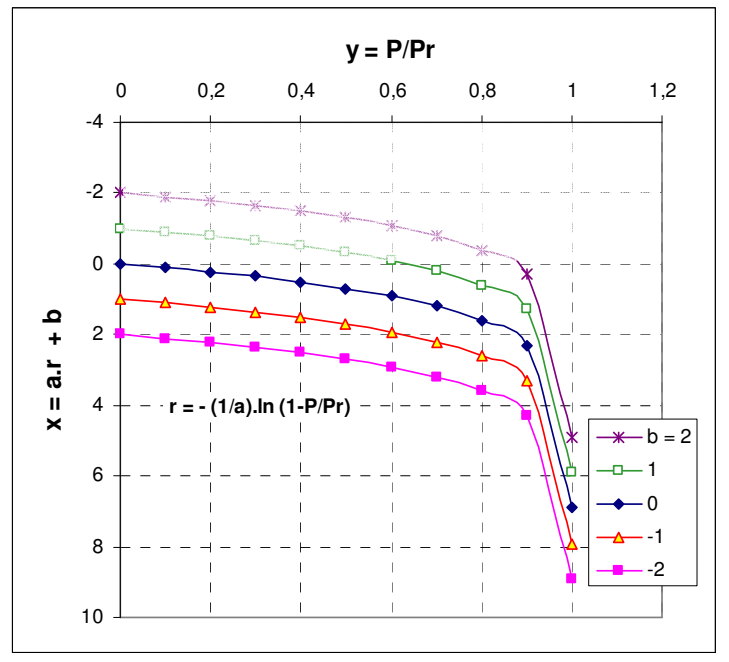

a)

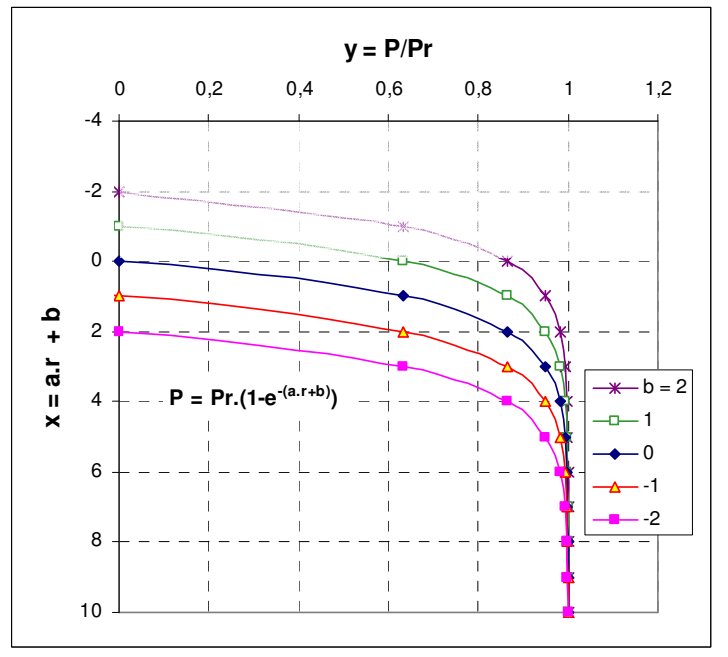

b)

Figura 96 - Curvas exponenciais com diferentes valores do parâmetro 'b': a) com estágios de carga constantes; b) com recalques equiespaçados

Como o melhor ajuste pode eventualmente não passar pela origem do diagrama, Aoki (1976) propôs a inclusão do parâmetro 'b' na reta de regressão, o qual possibilita um ajuste da posição da curva em função de eventuais problemas de instrumentação ou outros detalhes do comportamento do sistema solo-estaca. Pode 
ainda refletir o efeito das cargas residuais instaladas se for aplicado o critério a um carregamento posterior ao primeiro.

Na Figura 96, analisa-se a influência de 'b', observando-se que o mesmo desloca o diagrama no eixo dos recalques e, portanto, indicaria um hipotético valor de recalque que seria mais provável para a carga "zero" do ensaio, seja devido a calibragem da instrumentação ou outro efeito, como o de variação de temperatura durante o ensaio, ou um carregamento anterior. É importante observar na Figura 96 (b) que se a curva do critério for definida pelos recalques equiespaçados, perde-se a noção de 'deslocamento vertical' da curva para as cargas próximas da ruptura, pois as cargas de ruptura obtidas ficam praticamente sobre a assíntota e não mais indicadas pela extremidade de uma reta (que lembra a reta 4-5 das Leis de Cambefort Modificadas) que aparecem quando se analisa a curva a partir dos incrementos de carga constantes.

Isto mostra que a tendência para a carga de ruptura não se modifica para os valores de 'b' diferentes de zero. Fisicamente, ele só influencia o recalque para o qual ocorre a ruptura, ou, na leitura aqui proposta, a posição da escala do eixo dos recalques em relação à curva exponencial fundamental.

Dessa forma, propôs-se a parametrização apresentada na Figura 12 do item 3.6.4.

\section{C.3.2 PARAMETRIZAÇÃO DO CRITÉRIO DE CHIN (AMANN, 2008a)}

Aqui demonstra-se a possibilidade de parametrização da hipérbole de Chin, analogamente ao que se fez para Van der Veen.

Primeiramente, observe-se na Figura 97 o gráfico da função exponencial de Chin, onde se vê a assíntota vertical que define o critério de ruptura e assíntota horizontal, que é uma relação dos coeficientes da função hiperbólica.

Deve-se observar que para efeito do critério só interessa o quadrante inferior direito da hipérbole. 


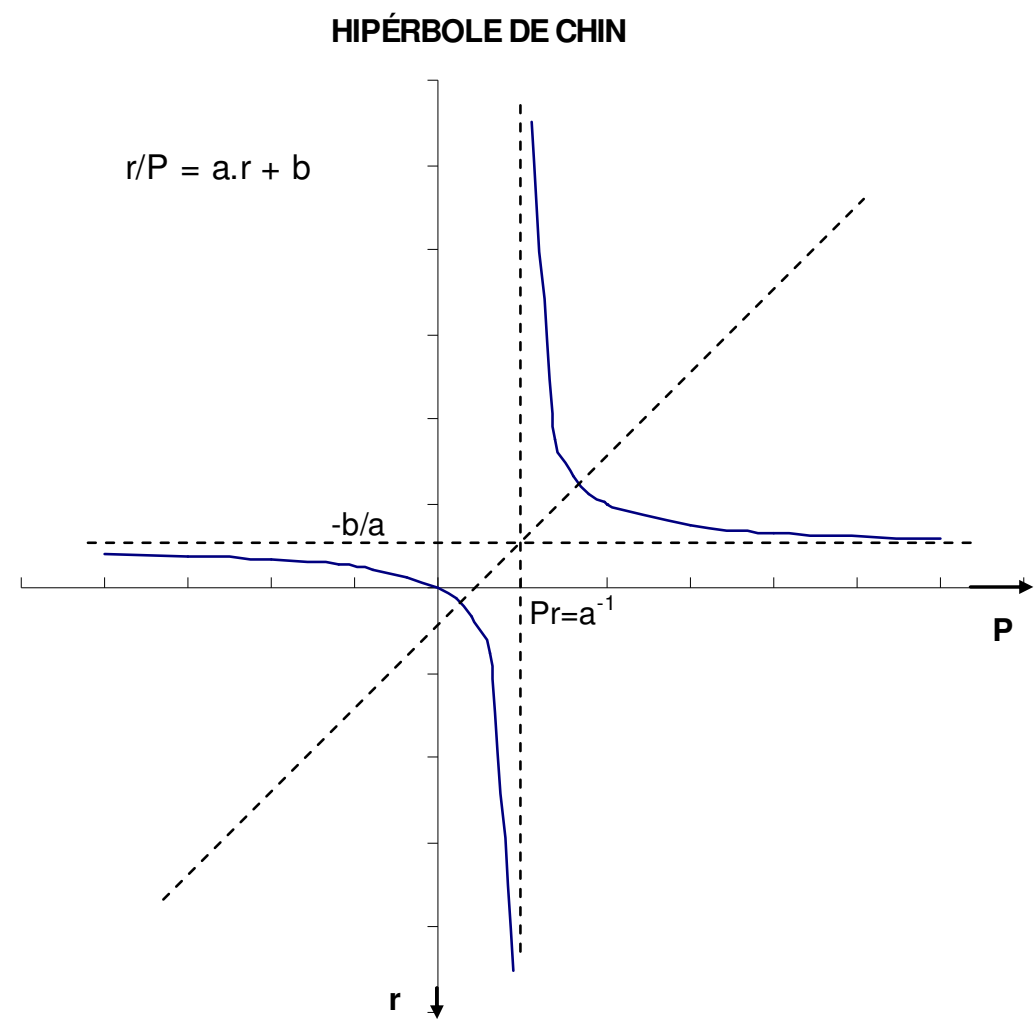

Figura 97 - Gráfico da hipérbole de Chin na sua forma fundamental.

É possível escrever a equação desta hipérbole de forma parametrizada pelos valores de ' $a$ ', 'b' e 'P/P' conforme segue:

$$
\frac{r}{P}=a \cdot r+b \Rightarrow r=\frac{P / P_{r}}{1-P / P_{r}} \cdot \frac{b}{a}
$$

Desta forma, pode-se representar a hipérbole parametrizada com os seguintes valores da Tabela 54:

Tabela 54 - Valores da hipérbole de Chin parametrizada

\begin{tabular}{cc}
\hline$r . a / b$ & $P / P r$ \\
\hline 0 & 0 \\
0.25 & 0.2 \\
1.00 & 0.5 \\
1.50 & 0.6 \\
4.00 & 0.8 \\
9.00 & 0.9 \\
99.0 & 0.99 \\
999.0 & 0.999 \\
\hline
\end{tabular}

Esta tabela pode ser representada pelo gráfico da Figura 98: 

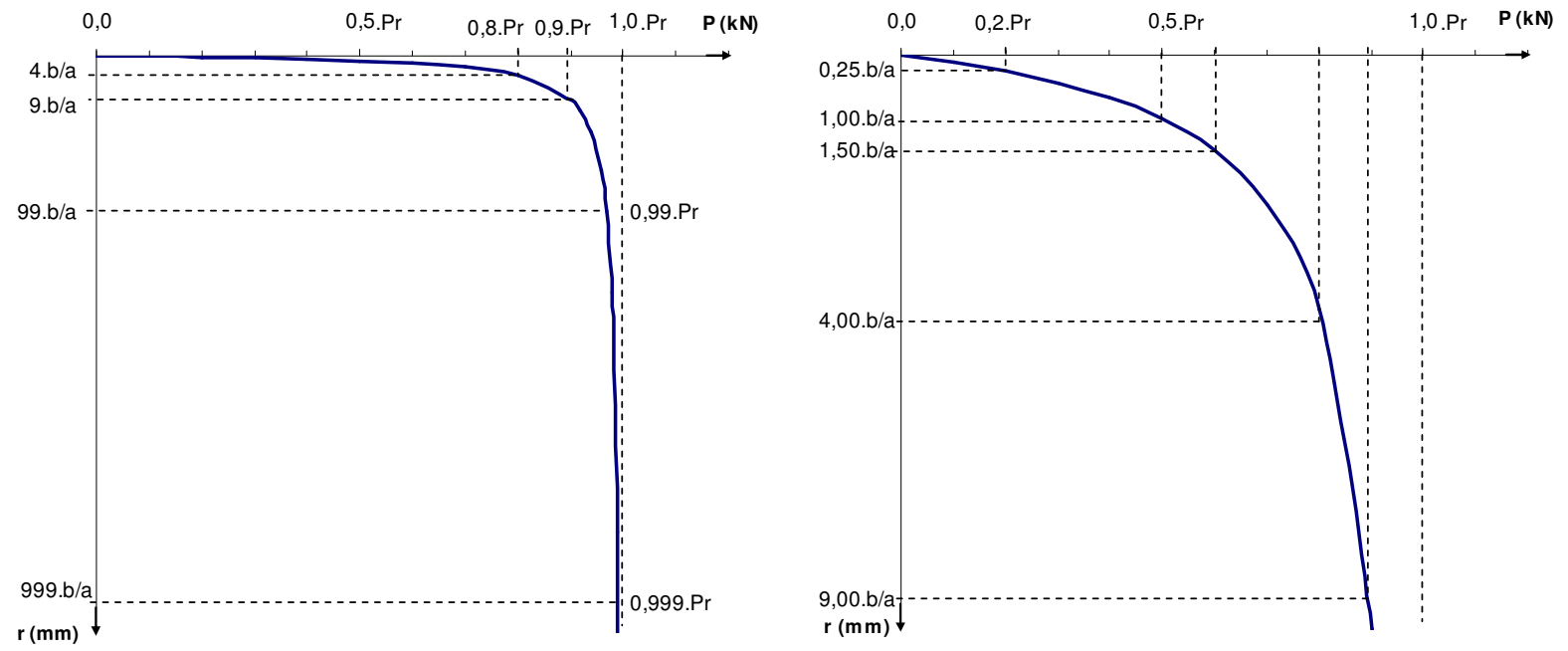

Figura 98 - Gráfico da hipérbole de Chin parametrizada em duas escalas diferentes.

Assim, sempre para r.a/b $=4$ tem-se 0,8.P. Da mesma maneira que para Van der Veen, pode-se aqui estabelecer um recalque máximo, embora para se obter a mesma precisão de Veen, o valor de Chin seja muito maior. Neste sentido, o uso da exponencial de Veen permite uma boa precisão da carga de ruptura, sem ter que se avançar tanto no valor dos recalques. Adotar r.a/b $=9$ como critério leva, então, a $90 \%$ da carga de ruptura desta critério.

Portanto "b/a" é o fator de escala do eixo "r", ou de forma mais precisa, o fator de escala do eixo horizontal $\left(P / P_{r}\right)$ é $P_{r}$ e do eixo "r" é "b. $P_{r}$ ", visto que $P r=1 / a$.

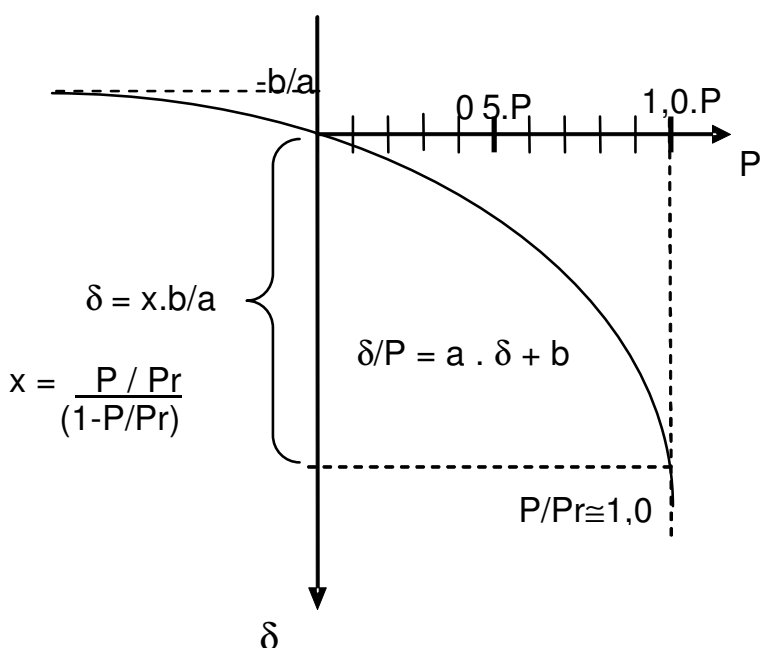

Figura 99 - Curva de Chin parametrizada. 


\section{APÊNDICE D - DEDUÇÃO DA EXPRESSÃO GERAL DE TRANSFERÊNCIA DE CARGA}

Apresenta-se aqui um estudo das soluções matemáticas das Equações Diferenciais de Segunda Ordem (EDO) homogênea e não-homogênea com coeficientes constantes.

\section{D.1 A SOLUÇÃO DA EDO DE 2a ORDEM HOMOGÊNEA COM COEFICIENTES CONSTANTES}

Dando continuidade à dedução da função de transferência de carga, deve-se proceder a solução da EDO homogênea dada pela expressão (30) com coeficiente $B$ constante, como alguns métodos adotam.

A expressão (30) é aqui reproduzida como (172):

$$
y^{\prime \prime}-\frac{U}{E . S} \cdot B \cdot y=0
$$

cuja forma geral é (ABUNAHMAN, 1979):

$$
o(z) y^{\prime \prime}+p(z) \cdot y^{\prime}+q(z) \cdot y=r(z)
$$

Trata-se de uma EDO Linear (todas as funções apresentam uma única variável) homogênea [pois $r(z)=0$ ] e de coeficientes constantes (considerando-se $B$ constante). Deve-se achar a função $y(z)$ que verifica a igualdade da equação, apoiando-se no Teorema da Existência e Unicidade, onde o determinante Wronskiano indica as soluções linearmente independentes (L.I.) para o Problema de Valor Inicial (PVI, o qual prova que, dado um determinado valor inicial qualquer $\mathrm{z}_{\mathrm{c}}$, a solução da EDO é única, e sem ele, contudo, várias soluções - família de curvas são obtidas). Prova-se que toda a solução geral da EDO pode ser escrita na forma de soma ou combinação linear (produto pelos coeficientes $c_{1}$ e $c_{2}$ ) de suas soluções, homogênea e particular:

$$
y(z)=c_{1} \cdot y_{1}(z)+c_{2} \cdot y_{2}(z)
$$


cujo Wronskiano, para que a solução seja única (linearmente independente - L.I.) deve resultar em:

$$
W_{\text {y1y2 }}(z)=\left|\begin{array}{cc}
y_{1} & y_{2} \\
y_{1}^{\prime} & y_{2}^{\prime}
\end{array}\right|=y_{1}(z) \cdot y_{2}^{\prime}(z)-y_{1}^{\prime}(z) \cdot y_{2}(z) \neq 0
$$

Pelo Teorema de Abel, prova-se que o Wronskiano $\left(\mathrm{W}_{\mathrm{y} 1 \mathrm{y} 2}\right)$ é determinado pela solução da EDO dada por:

$$
\begin{gathered}
W^{\prime}{ }_{y 1 y 2}(z)+p(z) \cdot W_{y 1 y 2}(z)=0 \Rightarrow \\
\Rightarrow W_{y 1 y 2}(z)=c \cdot e^{-\int p(z) \cdot d z}
\end{gathered}
$$

surgindo, assim, a função exponencial como solução, visto que sua derivada resulta no produto da mesma pela derivada do seu expoente. Aplicadas a (173):

$$
y(z)=e^{(t . z)} \Rightarrow y^{\prime}(z)=t \cdot e^{(t . z)} \Rightarrow y^{\prime \prime}(z)=t \cdot t \cdot e^{(t . z)}=t^{2} \cdot e^{(t . z)}
$$

Substituindo-se as derivadas (178) em (173) com $r(z)=0$ (homogênea) e com os coeficientes constantes, tem-se:

$$
\begin{aligned}
& 0 . t^{2} \cdot e^{(t . z)}+p \cdot t \cdot e^{(t . z)}+q \cdot e^{(t . z)}=0 \Rightarrow\left(o \cdot t^{2}+p \cdot t+q\right) \cdot e^{(t . z)}=0 \Rightarrow \\
& \Rightarrow 0 . t^{2}+p \cdot t+q=0
\end{aligned}
$$

que é a Equação Característica da EDO. A solução de (179) se faz como equação de segundo grau, que é equivalente ao se determinarem os autovalores do Operador Diferencial Linear, devendo-se observar o discriminante $\Delta=\mathrm{p}^{2}$ - 4.o.q. Para a EDO (172), tem-se $0=1,0, p=0$ e $q=-U . B /(E . S)$, resultando portanto em $\Delta>0$, com duas raízes reais e distintas $t_{1}$ e $t_{2}$ :

$$
\begin{aligned}
& \mathrm{t}_{1}=\frac{-\mathrm{p}+\sqrt{\Delta}}{2.0}=\frac{1}{2} \cdot \sqrt{\frac{4 . U \cdot \mathrm{B}}{\mathrm{E} . S}}=\sqrt{\frac{\mathrm{U} \cdot \mathrm{B}}{\mathrm{E} . S}} \\
& \mathrm{t}_{2}=\frac{-\mathrm{p}-\sqrt{\Delta}}{2.0}=-\frac{1}{2} \cdot \sqrt{\frac{4 . U \cdot \mathrm{B}}{\mathrm{E} . S}}=-\sqrt{\frac{U . B}{\mathrm{E} . S}}
\end{aligned}
$$




$$
y(z)=c_{1} \cdot e^{t 1 \cdot z}+c_{2} \cdot e^{t 2 \cdot z}=c_{1} \cdot e^{t \cdot z}+c_{2} \cdot e^{-t . z}
$$

$\mathrm{Na}$ expressão (181), note-se que se tem um caso particular em que $t_{1}=-t_{2}=t$ e lembrando que as funções hiperbólicas são dadas por:

$$
\mathrm{e}^{(\mathrm{t} . \mathrm{z})}=\cosh (\mathrm{t} . \mathrm{z})+\sinh (\mathrm{t} . \mathrm{z})=\frac{\mathrm{e}^{(\mathrm{t} . \mathrm{z})}+\mathrm{e}^{-(\mathrm{t} . \mathrm{z})}}{2}+\frac{\mathrm{e}^{(\mathrm{t} . \mathrm{z})}-\mathrm{e}^{-(\mathrm{t} . \mathrm{z})}}{2}
$$

pode-se escrever a solução (181) na forma (183), como adotada em Randolph e Wroth (1978) (com c $\mathrm{C}_{1}=\mathrm{A}$ e $\mathrm{C}_{2}=\mathrm{B}$ ), ou na forma (184), como em Massad (1995):

$$
\begin{gathered}
y(z)=A \cdot e^{(t . z)}+B \cdot e^{-(t . z)}=\frac{(M+N)}{2} \cdot e^{(t . z)}+\frac{(M-N)}{2} \cdot e^{-(t . z)} \\
y(z)=M \cdot \cosh (t \cdot z)+N \cdot \sinh (t \cdot z)=(A+B) \cdot \cosh (t \cdot z)+(A-B) \cdot \sinh (t \cdot z)
\end{gathered}
$$

Note-se que este B da expressão (184) é apenas um coeficiente da solução conforme Randolph e Wroth (1978), e não o parâmetro B das expressões (172), (180) e (185). O parâmetro t da expressão (184) é dado por:

$$
t=\sqrt{\frac{U \cdot B}{E \cdot S}} \Rightarrow t^{2}=\frac{U \cdot B}{E \cdot S}
$$

Fisicamente, o parâmetro $t$ define a característica de deformação da estaca em relação ao solo do fuste, via o parâmetro $B$, o que será discutido mais adiante. No trabalho de Randolph e Wroth (1978) o parâmetro t é simbolizado por $\mu$.

Pela expressão (27) do texto, ao se derivar a expressão (185), tem-se a expressão das cargas multiplicada pelo negativo do produto E.S:

$$
N(z)=-E \cdot S \cdot t \cdot[M \cdot \sinh (t \cdot z)+N \cdot \cosh (t . z)]=-E \cdot S \cdot t \cdot\left(A \cdot e^{(t . z)}-B \cdot e^{-(t . z)}\right)
$$

Os coeficientes $\mathrm{M}$ e $\mathrm{N}$ da expressão podem ser determinados resolvendo-se o sistema de equações dado por (183) ou (185) e (186):

$$
M=\frac{y(z)}{\cosh (t . z)}-N \cdot \frac{\sinh (t . z)}{\cosh (t . z)}
$$




$$
N=-y(z) \cdot \sinh (t \cdot z)-\frac{P_{c}}{E \cdot S \cdot t} \cdot \cosh (t . z)
$$

Substitui-se (188) em (187) e aplica-se, então, para simplificação, a relação hiperbólica " $\cosh ^{2}(x)-\sinh ^{2}(x)=1$ ". Deve-se ao mesmo tempo especificar um valor inicial (ou de contorno), aqui representado por $z=z_{c}$, em que são conhecidos os valores de $\mathrm{y}\left(\mathrm{z}_{\mathrm{c}}\right)=\mathrm{y}_{\mathrm{c}}$ e $\mathrm{N}\left(\mathrm{z}_{\mathrm{c}}\right)=\mathrm{P}_{\mathrm{c}}$. Obtém-se, assim:

$$
\begin{aligned}
& M=y_{c} \cdot\left[\frac{\sinh ^{2}\left(t \cdot z_{c}\right)}{\cosh \left(t \cdot z_{c}\right)}+\frac{1}{\cosh \left(t \cdot z_{c}\right)}\right]+\frac{P_{c}}{E \cdot S \cdot t} \cdot \sinh \left(t \cdot z_{c}\right) \Rightarrow \\
& \Rightarrow M=y_{c} \cdot \cosh \left(t \cdot z_{c}\right)+\frac{P_{c}}{E \cdot S \cdot t} \cdot \sinh \left(t \cdot z_{c}\right)
\end{aligned}
$$

Para os coeficientes A e B da expressão (186), simplificando-se com a relação $e^{-(\text {t.z) }}$ $=1 / \mathrm{e}^{(\mathrm{t} . z)}$, tem-se:

$$
\begin{aligned}
& A=\frac{e^{-\left(t . z_{c}\right)}}{2} \cdot\left(y_{c}-\frac{P_{c}}{E . S . t}\right) \\
& B=\frac{e^{\left(t . z_{c}\right)}}{2} \cdot\left(y_{c}+\frac{P_{c}}{E \cdot S . t}\right)
\end{aligned}
$$

Então, substituindo-se (188) e (189) em (184) obtém-se:

$$
\begin{aligned}
& y(z)=\left(y_{c} \cdot \cosh \left(t \cdot z_{c}\right)+\frac{P_{c}}{E \cdot S \cdot t} \cdot \sinh \left(t \cdot z_{c}\right)\right) \cdot \cosh (t \cdot z)+ \\
& +\left(-y_{c} \cdot \sinh \left(t \cdot z_{c}\right)-\frac{P_{c}}{E \cdot S \cdot t} \cdot \cosh \left(t \cdot z_{c}\right)\right) \cdot \sinh (t \cdot z)
\end{aligned}
$$

$$
\begin{aligned}
& \text { 2. } \sinh (a) \cdot \cosh (b)=\sinh (a+b)+\sinh (a-b) \\
& 2 \cdot \cosh (a) \cdot \sinh (b)=\sinh (a+b)-\sinh (a-b) \\
& 2 \cdot \sinh (a) \cdot \sinh (b)=\cosh (a+b)-\cosh (a-b) \\
& 2 \cdot \cosh (a) \cdot \cosh (b)=\cosh (a+b)+\cosh (a-b) \\
& -\cosh (a)=\cosh (a) \\
& -\sinh (a)=\sinh (-a)
\end{aligned}
$$


A qual deve ser resolvida desenvolvendo-se os produtos das funções hiperbólicas como soma de funções hiperbólicas da soma dos argumentos (t.z) e (t. $z_{\mathrm{c}}$ ). Convém lembrar aqui as relações hiperbólicas (193).

Assim, obtém-se:

$$
y(z)=y_{c} \cdot \cosh \left[t \cdot\left(z_{c}-z\right)\right]+\frac{P_{c}}{E \cdot S \cdot t} \cdot \sinh \left[t \cdot\left(z_{c}-z\right)\right]
$$

Partindo-se de (190) e (191), de maneira mais simples, considerando-se que os produtos entre $\left[\mathrm{e}^{(\mathrm{t} . z)}\right]$ e $\left[\mathrm{e}^{-(\mathrm{t} . z)}\right]$ se fazem pela soma dos expoentes, obtém-se da substituição de (190) e (191) em (183):

$$
y(z)=\frac{e^{-t \cdot\left(z_{c}-z\right)}}{2} \cdot\left(y_{c}-\frac{P_{c}}{\text { E.S.t }}\right)+\frac{e^{t \cdot\left(z_{c}-. z\right)}}{2} \cdot\left(y_{c}+\frac{P_{c}}{\text { E.S.t }}\right)
$$

De forma análoga, ou, como em (27), pela derivada de (194), chega-se à expressão das cargas:

$$
N(z)=y_{c} \cdot E \cdot S \cdot t \cdot \sinh \left[t \cdot\left(z_{c}-z\right)\right]+P_{c} \cdot \cosh \left[t \cdot\left(z_{c}-z\right)\right]
$$

e como em (26) do texto, pela derivada de (196), tem-se a expressão do cisalhamento:

$$
\tau(z)=\frac{t}{U} \cdot\left\{y_{c} \cdot E \cdot S \cdot t \cdot \cosh \left[t \cdot\left(z_{c}-z\right)\right]+P_{c} \cdot \sinh \left[t \cdot\left(z_{c}-z\right)\right]\right\}
$$

A expressão (197) pode ser considerada a função que ajusta os pontos experimentais de medidas da resistência por cisalhamento. Demonstra-se a seguir a solução da EDO não-homogênea.

\section{D.2 SOLUÇÃO DA EDO DE 2a ORDEM NÃO-HOMOGÊNEA COM COEFICIENTES CONSTANTES}

Cambefort (1964) admitiu uma função linear aproximada para a relação entre $\tau(z)$ e $y(z)$ que poderia apresentar um intercepto das ordenadas $A_{c}$ diferente de zero (Figura 36) e com uma inclinação $B_{c}$ : 


$$
\tau(z)=B_{c} \cdot y(z)+A_{c}
$$

Isto é o mesmo que alterar o parâmetro B, expressão (120), para:

$$
B=\frac{\tau(z)}{y(z)}=\frac{B_{c} \cdot y(z)+A_{c}}{y(z)}=B_{c}+\frac{A_{c}}{y(z)}
$$

Sendo $B_{C}$ constante e $A_{C}$ uma função em $z$, similar a $\tau(z)$. Por outro lado, a substituição de (198) em (25) resulta:

$$
\begin{aligned}
& y^{\prime \prime}-\frac{U}{E \cdot S} \cdot\left(B_{c} \cdot y+A_{c}\right)=0 \Rightarrow y^{\prime \prime}-\frac{U}{E \cdot S} \cdot B_{c} \cdot y-\frac{U}{E \cdot S} \cdot A_{c}=0 \Rightarrow \\
& \Rightarrow y^{\prime \prime}-\frac{U}{E \cdot S} \cdot B_{c} \cdot y=\frac{U}{E \cdot S} \cdot A_{c}
\end{aligned}
$$

e portanto agora $r(z)=U . A_{c} /(E . S) \neq 0$, tornando a equação diferencial de segunda ordem não-homogênea com sua solução geral, sendo composta pela combinação linear entre a solução particular $\left[y_{p}(z)\right]$ para $r(z) \neq 0$ e por uma solução complementar, que pode ser a da equação homogênea associada $\left[\mathrm{y}_{\mathrm{H}}(\mathrm{z})\right.$, para $\mathrm{r}(\mathrm{z})=0$ ], modificandose a expressão (174) para:

$$
y(z)=c_{1} \cdot y_{H}(z)+c_{2} \cdot y_{P}(z)
$$

A solução da equação homogênea associada já foi obtida no item anterior [expressão (194)], portanto resta encontrar a solução particular $\left[y_{p}(z)\right]$, que em geral é considerada do tipo polinomial, exponencial $\left[\mathrm{y}_{\mathrm{p}}(\mathrm{z})=\mathrm{A} \cdot \mathrm{e}^{\mathrm{az}}\right]$ ou trigonométrica $\left[y_{p}(z)=A \cdot \operatorname{sen}(c \cdot z)+B \cdot \cos (c \cdot z)\right]$, ou uma combinação destas, dependendo da forma da função $r(z)$ e da equação diferencial. Devem-se multiplicar essas soluções por $z^{h}$ caso haja termos em comum com a solução da homogênea associada, sendo $h$ o menor inteiro positivo que elimine esses termos em comum.

No caso da EDO não-homogênea (200) proposta por Cambefort (1964), pode-se considerar para solução que $A_{c}$ é um polinômio em z, por exemplo, do primeiro grau, com o coeficiente de $z$ igual a zero [ $b_{c}=0$ na expressão (202)]. Contudo, $B_{c}$ deve ser constante para permitir a aplicação do Método dos Coeficientes a Determinar (ou Método de Descartes) na solução do problema, caso contrário deve-se utilizar o Método da Variação dos Parâmetros. 


$$
y^{\prime \prime}-\frac{U}{E . S} \cdot B_{c} \cdot y=\frac{U}{E . S} \cdot\left(a_{c}+z \cdot b_{c}\right)
$$

Sugere-se aqui que se pode considerar $b_{c}$ da expressão (202) diferente de zero, caso as curvas $y-\tau$ obtidas em diferentes profundidades guardem alguma proporcionalidade entre $\mathrm{si}$, considerando tanto o valor de $\mathrm{f}_{\max }$ quanto de $\mathrm{y}_{1}$ (Figura 37), o que mudaria o valor de $A_{c}=a_{c}+z \cdot b_{c}$, mas não $\circ B_{c}$ (correspondendo a retas paralelas com interceptos $\mathrm{a}_{\mathrm{C}}$ variando com a profundidade). De fato, a expressão de $A_{c}$ poderia ser qualquer uma em função de $z$, inclusive polinômios de qualquer grau, desde que $\mathrm{B}_{\mathrm{c}}$ continue constante ().

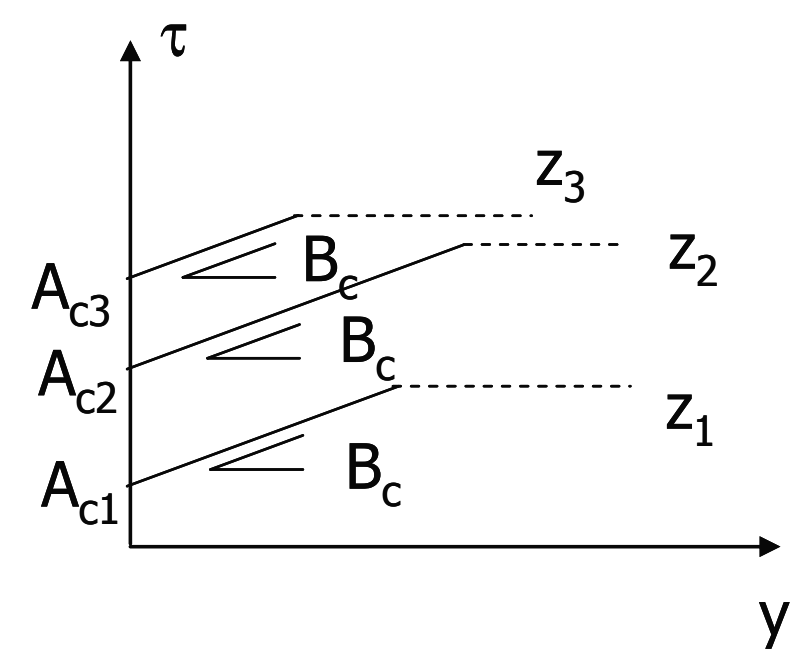

Figura 100 - Variação dos valores dos interceptos do eixo $\tau$ dados pelo polinômio $A_{C}=a_{C}+b_{C} \cdot z$, para cada profundidade $\mathrm{z}$, com $\mathrm{B}_{\mathrm{C}}=$ constante.

Sendo $B_{c}$ constante, o roteiro de aplicação do Método dos Coeficientes a Determinar se faz como segue:

g) Encontrar a solução para a equação homogênea associada $y_{H}(z)$ [já foi obtida no item anterior, expressão (194)];

h) Verificar o grau da função $r(z)$ da EDO não-homogênea, igual a $m$ : na expressão (202) $m=1$;

i) Verificar o número de ordem da menor derivada da EDO nãohomogênea igual a $h$ : na expressão (202) $h=0$ para y, portanto ao multiplicar a solução por $z^{h}=1$, nada alterando, já que $m+h=1$; 
j) Adotar a solução $y_{p}(z)$ como um polinômio de grau $m+h$ (neste caso, igual a 1):

$$
y_{p}(z)=a+z \cdot b
$$

k) Calcular as derivadas primeira, segunda, etc. (até o maior número de ordem das derivadas da EDO) de $y_{p}(z)$ :

$$
\begin{aligned}
& y_{P}^{\prime}(z)=b \\
& y_{P}^{\prime \prime}(z)=0
\end{aligned}
$$

I) Substituir (203), (204) e (205) em (202) e separar os coeficientes de z:

$$
\begin{aligned}
& 0-\frac{U}{E \cdot S} \cdot B_{c} \cdot(a+z \cdot b)=\frac{U}{E \cdot S} \cdot\left(a_{c}+z \cdot b_{c}\right) \Rightarrow \\
& \Rightarrow-\frac{U}{E \cdot S} \cdot B_{c} \cdot a-\frac{U}{E \cdot S} \cdot B_{c} \cdot z \cdot b=\frac{U}{E \cdot S} \cdot a_{c}+\frac{U}{E \cdot S} \cdot z \cdot b_{c}
\end{aligned}
$$

m) Determinar os coeficientes por semelhança:

$$
a=-\frac{a_{c}}{B_{c}} \therefore b=-\frac{b_{c}}{B_{c}} \Rightarrow y_{p}(z)=-\frac{1}{B_{c}} \cdot\left(a_{c}+z \cdot b_{c}\right)
$$

Considerando que se atribuiu neste caso $A_{c}=\left(a_{c}+z \cdot b_{c}\right)$.

n) Escrever a solução geral como soma da solução homogênea com a particular [buscar a solução homogênea da expressão (194) ou (195)]:

$$
\begin{aligned}
& y(z)=A \cdot e^{(t . z)}+B \cdot e^{-(t . z)}-\frac{A_{c}}{B_{c}} \Rightarrow \\
& \Rightarrow y(z)=\frac{e^{-t .\left(z_{c}-z\right)}}{2} \cdot\left(y_{c}-\frac{P_{c}}{E . S . t}\right)+\frac{e^{t \cdot\left(z_{c}-\cdot z\right)}}{2} \cdot\left(y_{c}+\frac{P_{c}}{E . S . t}\right)-\frac{A_{c}}{B}
\end{aligned}
$$




$$
y(z)=y_{c} \cdot \cosh \left[t \cdot\left(z_{c}-z\right)\right]+\frac{P_{c}}{E \cdot S \cdot t} \cdot \sinh \left[t \cdot\left(z_{c}-z\right)\right]-\frac{A_{c}}{B_{c}}
$$

Observa-se que, qualquer que seja o polinômio ou função adotada para $A_{c}$ a solução geral [(208)ou (209)] será sempre a solução da homogênea subtraída do quociente desse polinômio pelo parâmetro $B_{c}$ (constante).

Neste momento, já se tem condições de se demonstrar que os métodos de transferência de carga são todos derivados dessa mesma dedução geral. As expressões (208) e (209) são análogas, respectivamente, às propostas por Cambefort (1964) e Baguelin e Venon (1971). Quando $A_{c}$ é considerado zero, essas expressões recaem respectivamente nas soluções de Randolph e Wroth (1978) e de Massad (1992).

Ao se discutir o coeficiente t e sua relação com as rigidezes do sistema solo-estaca, o que permite o entendimento das expressões e a substituição da simbologia utilizada pelos diversos autores, ficam mais claras as assertivas acerca de que os métodos são casos particulares dessa dedução geral, o que permite manipulá-los com maior desenvoltura.

\section{D.3 DEFINIÇÃO DOS COEFICIENTES DE RIGIDEZ DO SISTEMA SOLO- ESTACA (AMANN, 2008C)}

Tendo-se a solução da EDO dada pela expressão (209), pode-se desenvolver as análises sobre como a rigidez do sistema aparece na solução e como se potencializar seus uso.

Em seu método baseado nas Leis de Cambefort Modificadas, Massad (1992) estabelece alguns coeficientes de rigidez do sistema solo-estaca, alguns já explicitados anteriormente por Baguelin e Venon (1971). Aqui pretende-se reforçar o significado desses coeficientes e ampliar o conceito para uma série de outros pontos de interesse do sistema solo-estaca, de modo a permitir mais facilmente análises em solo estratificado. Essas definições de novos coeficientes de rigidez auxiliarão na interpretação dos métodos para aplicação na Metodologia Semiempírica Unificada. Assim, segue conforme discutido sucintamente em Amann (2008c): 
A primeira rigidez que se buscará definir é a do solo do fuste. Para isso, da expressão (24) do texto, pode-se considerar que a carga transferida ao solo por atrito lateral até a profundidade de contorno $z_{c}, T\left(z_{c}\right)$, seja dada por:

$$
\begin{aligned}
& \mathrm{T}\left(\mathrm{z}_{\mathrm{c}}\right)=\mathrm{U} \cdot \int_{0}^{z_{\mathrm{c}}} \tau\left(\mathrm{z}_{\mathrm{c}}\right) \cdot \mathrm{dz}=\mathrm{U} \cdot\left[\tau\left(\mathrm{z}_{\mathrm{c}}\right) \cdot \mathrm{z}_{\mathrm{c}}-\tau(0) \cdot 0\right]=\mathrm{U} \cdot \tau\left(\mathrm{z}_{\mathrm{c}}\right) \cdot \mathrm{z}_{\mathrm{c}} \Rightarrow \\
& \Rightarrow \mathrm{U} \cdot \tau\left(\mathrm{z}_{\mathrm{c}}\right)=\frac{\mathrm{T}\left(\mathrm{z}_{\mathrm{c}}\right)}{\mathrm{z}_{\mathrm{c}}}
\end{aligned}
$$

Assim, substituindo-se (210) em (120) e a seguir em (185), sempre para a profundidade $z_{c}$, tem-se:

$$
\begin{aligned}
& t^{2}=\frac{U}{E \cdot S} \cdot B=\frac{U}{E \cdot S} \cdot \frac{\tau\left(z_{c}\right)}{y\left(z_{c}\right)}=\frac{1}{E \cdot S} \cdot \frac{T\left(z_{c}\right)}{y\left(z_{c}\right)} \cdot \frac{1}{z_{c}} \Rightarrow \\
& \Rightarrow t^{2}=\frac{1}{E \cdot S \cdot z_{c}} \cdot K s_{c}
\end{aligned}
$$

Como se pode ver na expressão (211), a relação (212):

$$
\mathrm{Ks}_{\mathrm{c}}=\frac{\mathrm{T}\left(\mathrm{z}_{\mathrm{c}}\right)}{\mathrm{y}\left(\mathrm{z}_{\mathrm{c}}\right)}
$$

ou seja, a relação entre a carga transferida por atrito lateral e o deslocamento, definindo o que se pode chamar de Rigidez (do solo) do fuste $\left(\mathrm{Ks}_{\mathrm{c}}\right)$, desde o topo da estaca até a profundidade $z_{c}$, e que funciona como um coeficiente de "mola de Winkler" para o fuste no trecho.

Assim como estabeleceu Massad (1992), aqui também se define a Rigidez (estrutural) da estaca $\left(\mathrm{Kr}_{\mathrm{c}}\right)$ neste mesmo trecho, do topo até a profundidade $\mathrm{z}_{\mathrm{c}}$, ficando:

$$
\mathrm{Kr}_{\mathrm{c}}=\frac{\mathrm{E} \cdot \mathrm{S}}{\mathrm{z}_{\mathrm{c}}} \Rightarrow \mathrm{E} \cdot \mathrm{S}=\mathrm{Kr}_{\mathrm{c}} \cdot \mathrm{z}_{\mathrm{c}}
$$

Substituindo (213) em (211), tem-se:

$$
\mathrm{t}^{2}=\frac{1}{\text { E.S. } \mathrm{z}_{\mathrm{c}}} \cdot \mathrm{K}_{\mathrm{Sc}}=\frac{\mathrm{K}_{\mathrm{Sc}}}{\mathrm{Kr}_{\mathrm{c}}} \cdot \frac{1}{\mathrm{z}_{\mathrm{c}}{ }^{2}}=\frac{\mathrm{k}_{\mathrm{c}}}{\mathrm{z}_{\mathrm{c}}{ }^{2}}
$$

Em (214) pode-se ver a relação: 


$$
\mathrm{k}_{\mathrm{c}}=\frac{\mathrm{Ks}_{\mathrm{c}}}{\mathrm{Kr}_{\mathrm{c}}}
$$

que é chamada por Massad (1992) de Coeficiente de Rigidez Relativa (solo do) fuste - estaca $\left(k_{c}\right)$ desde topo até a profundidade $z_{c}$. Convém notar que, se for analisada a estaca como um todo, tem-se $z_{c}=L$ e, portanto, pode-se eliminar os índices "c" atribuídos para as rigidezes acima.

De (215), a expressão (185) pode ser escrita como:

$$
t=\frac{\sqrt{k_{c}}}{z_{c}}
$$

De (211) e (216), pode-se dizer que:

$$
t^{2}=\frac{k_{c}}{z_{c}{ }^{2}}=\frac{1}{E . S} \cdot \frac{T\left(z_{c}\right)}{y\left(z_{c}\right)} \cdot \frac{1}{z_{c}}
$$

Isolando-se $k_{c}$ em (217), tem-se:

$$
k_{c}=\frac{z_{c}}{E . S} \cdot \frac{T\left(z_{c}\right)}{y\left(z_{c}\right)}=\frac{1}{K r_{c}} \cdot \frac{T\left(z_{c}\right)}{y\left(z_{c}\right)}
$$

que corresponde à expressão de k em Massad (1992), como se nota ao se substituírem as simbologias.

Isolando-se o produto E.S em (218), tem-se:

$$
E . S=\frac{z_{c}}{k_{c}} \cdot \frac{T\left(z_{c}\right)}{y\left(z_{c}\right)}
$$

relação esta que será útil ao se comparar com a simbologia de Randolph e Wroth (1978).

De forma análoga ao que se fez para o fuste, pode-se definir a Rigidez (do solo) da ponta (Kp) dada pela relação (220), cuja profundidade fica definida por $z=L$ (comprimento da estaca) e que indica por $\mathrm{N}(\mathrm{L})$ a carga que chega na ponta: 


$$
\mathrm{Kp}=\frac{\mathrm{N}(\mathrm{L})}{\mathrm{y}(\mathrm{L})}
$$

Também se pode definir pela expressão (221) um coeficiente de Rigidez relativa (solo da) ponta - (solo do) fuste $\left(k_{p s}\right)$, simbolizado por Baguelin e Venon (1971) pela letra "m":

$$
\mathrm{k}_{\mathrm{ps}}=\frac{\mathrm{Kp}}{\mathrm{Ks}}
$$

Tem-se ainda, como sendo definido nesta tese, o Coeficiente de rigidez relativa (solo da) ponta - estaca $\left(k_{\text {pr }}\right)$, definido pela expressão (222):

$$
\mathrm{k}_{\mathrm{pr}}=\frac{\mathrm{Kp}}{\mathrm{Kr}}
$$

O mesmo princípio aplicado para a ponta pode ser usado para definir a rigidez de outros pontos do fuste, como por exemplo o topo da estaca, definido para $z=0$. Isso representa a própria rigidez secante da curva carga-recalque, chamada por Décourt (1999) simplesmente de Rigidez (Rig), e que para o trecho inicial da curva cargarecalque em Massad e Lazo (1998) denomina-se de $b_{2}$ :

$$
\mathrm{Kz}(\mathrm{z}=0)=\mathrm{Kz}_{\mathrm{o}}=\frac{\mathrm{N}(0)}{\mathrm{y}(0)}
$$

Quando se analisam outro pontos ao longo do comprimento da estaca, pode-se considerá-la como a rigidez $\mathrm{Kz}$ do sistema solo-estaca no topo de um elemento de estaca, na profundidade $z$ considerada. Para o caso de se analisar um ponto de interesse, como a profundidade $z_{c}$, onde os valores de carga, deslocamento e atrito são conhecidos (condição inicial ou de contorno), pode-se então defini-la como a Rigidez da Condição de Contorno $\left(\mathrm{Kp}_{\mathrm{c}}\right)$, cuja simbologia aqui adotada faz referência ao se considerar uma "ponta fictícia" na posição $z_{c}$ :

$$
\mathrm{Kp}_{\mathrm{c}}=\frac{\mathrm{N}\left(\mathrm{z}_{\mathrm{c}}\right)}{\mathrm{y}\left(\mathrm{z}_{\mathrm{c}}\right)}=\frac{\mathrm{P}_{\mathrm{c}}}{\mathrm{y}_{\mathrm{c}}}
$$

Essa adoção de referência à ponta fictícia é devida à expressão (224) definir a rigidez do sistema solo-estaca abaixo da profundidade $z_{c}$, incluindo a ponta, ou seja, fuste e ponta conjugados, como se a estaca fosse dividida em duas partes (acima e 
abaixo de $z_{c}$ ) o que permite análises com solo estratificado, como sugerido por Massad (1993) e Fleming et al (1992), ao aplicar-se o método de Randolph e Wroth (1978). É importante ressaltar que quando se considera como condição de contorno a ponta, $z_{\mathrm{C}}=\mathrm{L}$ e então se tem $K \mathrm{p}_{\mathrm{C}}=\mathrm{Kp}$.

A proposta de definição da rigidez da condição de contorno aqui apresentada tem o objetivo de permitir análises diretas com os dados de instrumentação em profundidade para definição do comportamento na região acima e abaixo da mesma. De fato, como proposto no item 4.8, pode-se fazer a compatibilização entre as rigidezes do fuste até $z_{c}$ (ponta fictícia) e abaixo de $z_{c}$ (topo fictício), rigidez essa que considera o fuste de $z_{c}$ até a ponta. Observando-se a Figura 33, nota-se que esta proposta indicaria que a posição ideal da instrumentação seria na interface entre camadas, embora pode-se propor formas de se ajustar a análise quando isso não ocorre, como se propõe no Capítulo 5.

Pode-se agora explicitar essas rigidezes acima discutidas nas soluções da EDO (209). Primeiramente, procura-se fatorá-la e deixar a expressão de $y(z)$ em função de $y_{c}$ (deformação no ponto $z_{c}$ ) e $N(z)$ em função de $P_{c}$ (carga no eixo da estaca no ponto $z_{c}$ ). Assim a expressão (194) pode ser reescrita como:

$$
y(z)=y_{c} \cdot\left\{\cosh \left[t \cdot\left(z_{c}-z\right)\right]+\frac{P_{c}}{y_{c} \cdot t \cdot E \cdot S} \cdot \sinh \left[t \cdot\left(z_{c}-z\right)\right]\right\}
$$

Analisando-se (225), o termo $\mathrm{P}_{\mathrm{d}}$ /( $\mathrm{y}_{\mathrm{c}}$.t.E.S), vem de (215), (216), (217) e (224) que:

$$
\frac{\mathrm{P}_{\mathrm{c}}}{\mathrm{y}_{\mathrm{c}} \cdot \mathrm{t} \text {.E.S }}=\frac{\mathrm{P}_{\mathrm{c}}}{\mathrm{y}_{\mathrm{c}}} \cdot \frac{\mathrm{z}_{\mathrm{c}}}{\sqrt{\mathrm{K}_{\mathrm{c}}}} \frac{1}{\mathrm{Kr}_{\mathrm{c}} \cdot \mathrm{z}_{\mathrm{c}}}=\frac{\mathrm{Kp}_{\mathrm{c}}}{\mathrm{Kr}_{\mathrm{c}} \cdot \sqrt{\frac{\mathrm{Ks}_{\mathrm{c}}}{\mathrm{Kr}_{\mathrm{c}}}}}=\frac{\mathrm{Kp}_{\mathrm{c}}}{\sqrt{\mathrm{Ks}_{\mathrm{c}} \cdot \mathrm{Kr}_{\mathrm{c}}}}
$$

Detendo-se um momento em (226), é importante notar que a raiz do produto das rigidezes da estaca e do solo do fuste [ver (227)] é na verdade a média geométrica que representa o que aqui se chama de Rigidez Equivalente do Sistema (solo do) fuste-estaca (Ksr). 


$$
\begin{aligned}
& \mathrm{Ksr}=\mathrm{Kr} \cdot \sqrt{\mathrm{K}}=\mathrm{Kr} \cdot \sqrt{\frac{\mathrm{Ks}}{\mathrm{Kr}}}=\mathrm{Kr} \cdot \frac{\sqrt{\mathrm{Ks}}}{\sqrt{\mathrm{Kr}}}=\sqrt{\mathrm{Ks}} \cdot \frac{\mathrm{Kr}}{\sqrt{\mathrm{Kr}}}=\sqrt{\mathrm{Ks}} \cdot \sqrt{\mathrm{Kr}} \Rightarrow \\
& \Rightarrow \mathrm{Ksr}=\sqrt{\mathrm{Ks}_{\mathrm{c}} \cdot \mathrm{Kr}_{\mathrm{c}}}
\end{aligned}
$$

Essa rigidez equivalente representa uma "mola de Winkler" que responde como se fosse o conjunto estaca e solo atuando juntos, uma mola equivalente, por assim dizer.

Substituindo-se (227) em (226), verifica-se que a relação dada em (228) define um Coeficiente de Rigidez Relativo entre o solo (fuste e ponta)-estaca abaixo de $z_{c}$ e o solo (fuste)-estaca acima de $z_{c}\left(\lambda_{c}\right)$, ou seja, trata-se de um coeficiente que engloba toda a estaca, solo mais estaca do fuste (em duas regiões) e da ponta. Sua utilidade é comparar trechos distintos da estaca, como acima e abaixo da instrumentação (Figura 33), ou de verificar o equilíbrio da ponta, entre a estaca e o solo abaixo dela, podendo resultar em um comportamento parabólico, hiperbólico ou elíptico (MASSAD,1993). Essa relação é aqui simbolizada por $\lambda_{c}$, sendo que para o caso de $\mathrm{z}_{\mathrm{c}}=\mathrm{L}$ pode ser denominado de Coeficiente de Rigidez Relativa solo (ponta-fuste)estaca, e simbolizada por $\lambda$ (sem índices), como em Massad (1993).

$$
\frac{P_{c}}{y_{c} \cdot \text { t.E.S }}=\frac{K p_{c}}{\sqrt{K s_{c} \cdot K r_{c}}}=\frac{K p_{c}}{K s r}=\lambda_{c}
$$

Portanto, agora se pode reescrever a expressão (225) e, analogamente, a (196) como sendo:

$$
\begin{aligned}
& N(z)=\frac{P_{c}}{\lambda_{c}} \cdot\left\{\sinh \left[t \cdot\left(z_{c}-z\right)\right]+\lambda_{c} \cdot \cosh \left[t \cdot\left(z_{c}-z\right)\right]\right\} \\
& y(z)=y_{c} \cdot\left\{\cosh \left[t \cdot\left(z_{c}-z\right)\right]+\lambda_{c} \cdot \sinh \left[t \cdot\left(z_{c}-z\right)\right]\right\}
\end{aligned}
$$

Definidas as rigidezes do sistema, e sua relação com os coeficientes adotados em cada método, agora parte-se finalmente para a transformação da expressão (229) na expressão geral da transferência de carga de estacas. 


\section{D.4 EXPRESSÃO GERAL DA TRANSFERÊNCIA DE CARGA DE ESTACAS (AMANN, 2008c)}

As expressões (229) e (230) funcionam como equações paramétricas do problema, pois uma retorna o valor do deslocamento e a outra o valor da carga no ponto deslocado, porém as duas não estão acopladas de maneira a representar a rigidez do sistema em profundidade $\mathrm{K}_{\mathrm{z}}=\mathrm{N}(\mathrm{z}) / \mathrm{y}(\mathrm{z})$. Para obtenção da expressão geral de transferência de carga que permitirá a demonstração dos demais métodos, inicia-se relacionando-se uma com a outra para se chegar à compatibilidade entre deslocamentos e cargas.

Pode-se fazer isso inicialmente pela rigidez $K_{z}$ dada pela relação entre (230) e (229):

$$
\mathrm{Kz}=\frac{\mathrm{N}(\mathrm{z})}{\mathrm{y}(\mathrm{z})}=\frac{\frac{\mathrm{P}_{\mathrm{c}}}{\lambda_{\mathrm{c}}} \cdot\left\{\sinh \left[\mathrm{t} \cdot\left(\mathrm{z}_{\mathrm{c}}-\mathrm{z}\right)\right]+\lambda_{\mathrm{c}} \cdot \cosh \left[\mathrm{t} \cdot\left(\mathrm{z}_{\mathrm{c}}-\mathrm{z}\right)\right]\right\}}{\mathrm{y}_{\mathrm{c}} \cdot\left\{\cosh \left[\mathrm{t} \cdot\left(\mathrm{z}_{\mathrm{c}}-\mathrm{z}\right)\right]+\lambda_{\mathrm{c}} \cdot \sinh \left[\mathrm{t} \cdot\left(\mathrm{z}_{\mathrm{c}}-\mathrm{z}\right)\right]\right\}}
$$

e, em seguida, dividindo-se numerador e denominador por "cosh[t. $\left.\left(\mathrm{z}_{\mathrm{c}}-\mathrm{z}\right)\right]$ ":

$$
\begin{gathered}
K z=\frac{N(z)}{y(z)}=\frac{\frac{P_{c}}{\lambda_{c}} \cdot\left\{\frac{\sinh \left[t \cdot\left(z_{c}-z\right)\right]}{\cosh \left[t \cdot\left(z_{c}-z\right)\right]}+\lambda_{c} \cdot \frac{\cosh \left[t \cdot\left(z_{c}-z\right)\right]}{\cosh \left[t \cdot\left(z_{c}-z\right)\right]}\right\}}{y_{c} \cdot\left\{\frac{\cosh \left[t \cdot\left(z_{c}-z\right)\right]}{\cosh \left[t \cdot\left(z_{c}-z\right)\right]}+\lambda_{c} \cdot \frac{\sinh \left[t \cdot\left(z_{c}-z\right)\right]}{\cosh \left[t \cdot\left(z_{c}-z\right)\right]}\right\}} \\
N(z)=y(z) \cdot K z=y(z) \cdot \frac{P_{c}}{y_{c} \cdot \lambda_{c}} \cdot\left(\frac{\tanh \left[t \cdot\left(z_{c}-z\right)\right]+\lambda_{c}}{1+\lambda_{c} \cdot \tanh \left[t \cdot\left(z_{c}-z\right)\right]}\right\}
\end{gathered}
$$

Considerando (226) e (228), pode-se chegar a:

$$
\mathrm{N}(\mathrm{z})=\mathrm{y}(\mathrm{z}) \cdot \mathrm{Kz}=\mathrm{y}(\mathrm{z}) \cdot \frac{\mathrm{Ks}_{\mathrm{c}}}{\sqrt{\mathrm{k}_{\mathrm{c}}}} \cdot\left(\frac{\tanh \left[\mathrm{t} \cdot\left(\mathrm{z}_{\mathrm{c}}-\mathrm{z}\right)\right]+\lambda_{\mathrm{c}}}{1+\lambda_{\mathrm{c}} \cdot \tanh \left[\mathrm{t} \cdot\left(\mathrm{z}_{\mathrm{c}}-\mathrm{z}\right)\right]}\right) \Rightarrow \mathrm{y}(\mathrm{z}) \cdot \mathrm{Kr} \mathrm{r}_{\mathrm{c}} \cdot \sqrt{\mathrm{k}_{\mathrm{c}}} \cdot \beta_{\mathrm{c}}
$$

Esta é a expressão geral da transferência de carga. Note-se a semelhança com a expressão deduzida por Massad (1995), visto ter-se aqui adotado a mesma linha de dedução, porém com destaque para o conceito de rigidez do solo e para a possibilidade de se adotar uma profundidade qualquer $\left(z_{c}\right)$ como condição de contorno. Demonstra-se agora que a partir dessa expressão pode-se chegar àquela 
deduzida por Randolph e Wroth (1978), considerando-se a simbologia específica de cada um desses métodos.

\section{D.5 EXPRESSÕES DE MASSAD (1992) E RANDOLPH E WROTH (1978) A PARTIR DA EXPRESSÃO GERAL (AMANN, 2008c)}

Para melhor comparação entre os métodos, primeiramente deve-se definir a simbologia e as expressões usadas nos trabalhos de Massad (1992) e Randolph e Wroth (1978). A Tabela 55 sintetiza essas informações.

Randolph e Wroth (1978) utilizam a profundidade da ponta como condição de contorno. Tomando $z_{c}=L$ e procurando traduzir os termos da expressão (234) na simbologia desses autores na Tabela 55, e considerando inicialmente o solo homogêneo com módulo de cisalhamento $G=G_{L}=G_{b}$ constante, tem-se:

$$
\begin{gathered}
\lambda_{c}=\lambda=\frac{P_{b}}{w_{b} \cdot E \cdot S \cdot \mu_{r}}=\frac{P_{b}}{w_{b} \cdot r_{0} \cdot G} \cdot \frac{1}{\pi \cdot \lambda_{r} \cdot r_{0} \cdot \mu_{r}} \cdot \frac{L}{L}=\frac{P_{b}}{w_{b} \cdot r_{0} \cdot G} \cdot \frac{w_{s} \cdot r_{0} \cdot G}{P_{s}} \cdot \mu_{r} \cdot L \\
w_{b}=\frac{P_{b}}{r_{0} \cdot G} \cdot \frac{\eta \cdot(1-v)}{4} \Rightarrow \frac{P_{b}}{w_{b} \cdot r_{0} \cdot G}=\frac{4}{\eta \cdot(1-v)} \\
K_{s_{c}}=\frac{T\left(z_{c}\right)}{y\left(z_{c}\right)}=\frac{P_{s}}{w_{s}}=\frac{2 \cdot \pi}{\zeta} \cdot \frac{L}{r_{0}} \cdot r_{0} \cdot G \Rightarrow \frac{P_{s}}{w_{s} \cdot r_{0} \cdot G}=\frac{2 \cdot \pi}{\zeta} \cdot \frac{L}{r_{o}}
\end{gathered}
$$

Substituindo-se as expressões (235), (236) e (237) em (234) e com a simbologia da Tabela 55, tem-se:

$$
\begin{aligned}
& N(z)=\frac{y(z)}{\mu_{r} \cdot L} \cdot \frac{2 \cdot \mu}{\zeta} \cdot \frac{L}{r_{0}} \cdot r_{0} \cdot G \cdot\left(\frac{\tanh \left[\mu_{r} \cdot(L-z)\right]+\frac{P_{b}}{w_{b} \cdot r_{0} \cdot G} \cdot \frac{w_{s} \cdot r_{0} \cdot G}{P_{s}} \cdot \mu_{r} \cdot L}{1+\frac{P_{b}}{w_{b} \cdot r_{0} \cdot G} \cdot \frac{1}{\pi \cdot \lambda_{r} \cdot r_{0} \cdot \mu_{r}} \cdot \frac{L}{L} \cdot \tanh \left[\mu_{r} \cdot(L-z)\right]}\right) \\
& N(z)=\frac{y(z)}{\mu_{r} \cdot L} \cdot \frac{2 \cdot \pi}{\zeta} \cdot \frac{L}{r_{0}} \cdot r_{0} \cdot G \cdot\left(\frac{\tanh \left[\mu_{r} \cdot(L-z)\right]+\frac{4}{\eta \cdot(1-v)} \cdot \frac{\zeta}{2 \cdot \pi} \cdot \frac{r_{o}}{L} \cdot \mu_{r} \cdot L}{\left.1+\frac{4}{\eta \cdot(1-v)} \cdot \frac{L}{\pi \cdot \lambda_{r} \cdot r_{0} \cdot} \cdot \frac{\tanh \left[\mu_{r} \cdot(L-z)\right]}{\mu_{r} \cdot L}\right)}\right)
\end{aligned}
$$

Aplicando em (239) a distributiva e substituindo para a carga no topo: $\mathrm{z}=0 ; \mathrm{N}(0)=\mathrm{P}_{\mathrm{t}}$ $; y(0)=w_{t} ;$ tem-se, finalmente: 


$$
\frac{P_{t}}{G \cdot r_{0} \cdot w_{t}}=\frac{\frac{4}{\eta \cdot(1-v)}+\frac{2 \cdot \pi}{\zeta} \cdot \frac{L}{r_{0}} \cdot \frac{\tanh \left[\mu_{r} \cdot L\right]}{\mu_{r} \cdot L}}{1+\frac{4}{\eta \cdot(1-v)} \cdot \frac{1}{\pi \cdot \lambda_{r}} \cdot \frac{L}{r_{0}} \cdot \frac{\tanh \left[\mu_{r} \cdot L\right]}{\mu_{r} \cdot L}}
$$

A expressão (240) é a mesma deduzida por Randolph e Wroth (1978) para estacas flexíveis em solos homogêneos. Foram introduzidos coeficientes para considerar a não-homogeneidade do solo $(\rho)$ para o fuste e $(\xi)$ para a ponta (RANDOLPH, 1994), os quais não serão aqui abordados, restringindo o trabalho ao solo homogêneo, que já permite a comparação aqui pretendida.

Tabela 55 - Parâmetros, simbologia e expressões dos métodos de Massad(1992) e Randolph e Wroth (1978)

\begin{tabular}{|c|c|c|c|}
\hline Parâmetro & Símbolo & Massad & Randolph e Wroth \\
\hline Profundidade de contorno & $\mathrm{Z}_{\mathrm{c}}$ & $\mathrm{h} ;(\mathrm{h}=\mathrm{L})$ & $\mathrm{L}$ \\
\hline Deformação de contorno & $\mathrm{y}_{\mathrm{c}}=\mathrm{y}\left(\mathrm{z}_{\mathrm{c}}\right)$ & $\mathrm{y}_{1}$ & $\mathbf{W}_{\mathbf{S}(1)}$ \\
\hline Carga de contorno & $P_{c}=N\left(z_{c}\right)$ & Alr & Os \\
\hline Perímetro & U & $\pi . \mathrm{D}$ & $2 . \pi . r_{0}$ \\
\hline Área da seção transversal & $\mathrm{S}$ & $\pi . D^{2} / 4$ & $\pi \cdot r_{0}^{2}$ \\
\hline Módulo de Elasticidade & $\mathrm{E}$ & $\mathrm{E}$ & $E$ \\
\hline Rigidez da estaca & $\mathrm{Kr}$ & $\mathrm{Kr}=\mathrm{E} . \mathrm{S} / \mathrm{h}$ & $\lambda_{r} \cdot \mathrm{G} \cdot \pi \cdot r_{0}^{2} / L$ \\
\hline Módulo de cisalhamento do solo & - & - & $\mathrm{G}=\mathrm{E}_{f} /[2 \cdot(1+v)]$ \\
\hline Módulo elasticidade solo do fuste & $E_{f}$ & - & - \\
\hline $\begin{array}{r}\text { Relação módulos de elasticidade da } \\
\text { estaca/cisalhamento do solo }\end{array}$ & - & - & $\lambda_{r}=E / G$ \\
\hline Tensão de cisalhamento (atrito) & - & $f_{\max }($ ruptura) & $\tau_{\mathrm{o}(\max )}$ \\
\hline Carga de atrito mobilizada pelo fuste & $\mathrm{T}(\mathrm{z})$ & Alr (ruptura $z=h$ ) & $P_{s}(p / z=L)$ \\
\hline Recalque de mobilização do atrito & $y(z)$ & $y_{1}(p / z=h)$ & $\mathrm{w}_{\mathrm{s}}$ \\
\hline Rigidez do solo do fuste & $\mathrm{Ks}_{\mathrm{c}}=\mathrm{T}(\mathrm{z}) / \mathrm{y}(\mathrm{z})$ & Alr/y $y_{1}$ & $\mathrm{P}_{\mathrm{s}} / \mathrm{w}_{\mathrm{s}}$ \\
\hline Coeficiente de Poisson & $v$ & $v$ & $\mathrm{v}$ \\
\hline Raio de influência dos recalques & - & - & $r_{m}=2,5 \cdot L \cdot(1-v)$ \\
\hline $\begin{array}{l}\text { Coeficiente de Influência dos } \\
\text { recalques ao redor da estaca }\end{array}$ & - & - & $\zeta=\ln \left(r_{m} / r_{0}\right)$ \\
\hline Relação tensão de atrito - recalque & B & $\mathrm{f}_{\max } / \mathrm{y}_{1}$ & $\tau_{0} / w_{s}=G /\left(\zeta . r_{0}\right)$ \\
\hline $\begin{array}{r}\text { Coeficiente de Rigidez relativa solo } \\
\text { (fuste)-estaca }\end{array}$ & $\mathrm{k}_{\mathrm{c}}=(\mathrm{t} \cdot \mathrm{L})^{2}=\mathrm{Ks}_{\mathrm{c}} / \mathrm{Kr}_{\mathrm{c}}$ & $\mathrm{k}=\left(\mathrm{Alr} / \mathrm{y}_{1}\right) \cdot(1 / \mathrm{Kr})$ & $\left(\mu_{r} \cdot L\right)^{2}$ \\
\hline Tensão atuante na ponta & - & qp (ruptura) & - \\
\hline Área da ponta & - & $\mathrm{Sp}$ & - \\
\hline Relação de dimensões fuste-ponta & - & - & $\eta=r_{0} / r_{b}$ \\
\hline Carga atuante na ponta & $N(L)$ & qp.Sp (ruptura) & $\mathrm{P}_{\mathrm{b}}$ \\
\hline Recalque da ponta & $y(L)$ & $\mathrm{y}_{\mathrm{h}} ; \mathrm{y}_{2}$ (ruptura) & $w_{b}=P_{b} \cdot(1-v) \cdot \eta /\left(4 \cdot G \cdot r_{0}\right)$ \\
\hline Rigidez do solo da ponta & $\mathrm{Kp}$ & qp.Sp/y 2 & $\mathrm{P}_{\mathrm{b}} / \mathrm{w}_{\mathrm{b}}$ \\
\hline $\begin{array}{r}\text { Coeficiente de rigidez relativa solo } \\
\text { (ponta-fuste)-estaca }\end{array}$ & $\lambda_{\mathrm{c}}=\mathrm{Kp}_{\mathrm{c}} /\left(\mathrm{Kr}_{\mathrm{c}} \cdot \mathrm{Ks_{ \textrm {c } }}\right)^{1 / 2}$ & $\lambda=\mathrm{Kp} /\left(\mathrm{Kr} \cdot \mathrm{k}^{1 / 2}\right)$ & $P_{b} / w_{b} \cdot w_{s} / P_{s .} \mu_{r} \cdot L$ \\
\hline Carga no topo da estaca & $\mathrm{N}(0)$ & $P_{0}$ & $P_{t}$ \\
\hline Recalque no topo da estaca & $y(0)$ & $\mathrm{y}_{0}$ & $w_{t}$ \\
\hline
\end{tabular}

Propõe-se aqui verificar que pela expressão (238), com algumas substituições e simbolizando $\beta_{c}(0)=\beta_{3}$, pode-se escrever: 


$$
\mathrm{Ksr}=\frac{\mathrm{P}_{\mathrm{t}}}{\mathrm{w}_{\mathrm{t}}} \cdot \frac{1}{\beta_{3}}=\frac{\mathrm{P}_{\mathrm{s}}}{\mathrm{w}_{\mathrm{s}}} \cdot \frac{1}{\mu_{\mathrm{r}} \cdot \mathrm{L}}=\frac{\mathrm{P}_{\mathrm{b}}}{\mathrm{w}_{\mathrm{b}}} \cdot \frac{1}{\lambda}
$$

Onde: $P_{s}$ : carga de atrito mobilizado pelo fuste; $P_{b}$ : carga na ponta da estaca; $w_{s}$ : recalque do fuste; $w_{b}$ recalque da ponta. Essas igualdades (241) são aqui propostas como uma forma de estimativa rápida da relação entre os recalques do topo, do fuste e da ponta da estaca em solos homogêneos com módulo de cisalhamento constante com a profundidade e podem ser estendidas para os demais métodos.

Interessante é demonstrar também a relação entre o recalque da ponta e do topo apresentada por Randolph (1994), que pode ser deduzida a partir da expressão

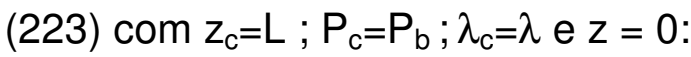

$$
\frac{P_{b}}{N(z)}=\frac{P_{b}}{P_{t}}=\frac{\lambda}{\left\{\cosh \left[\mu_{r} \cdot L\right]+\lambda \cdot \tanh \left[\mu_{r} \cdot L\right]\right\}}=\frac{\frac{4}{\eta \cdot(1-v)} \cdot \frac{1}{\cosh \left[\mu_{r} \cdot L\right]}}{\frac{4}{\eta \cdot(1-v)}+\frac{2 \cdot \pi}{\zeta} \cdot \frac{L}{r_{0}} \cdot \frac{\tanh \left[\mu_{r} \cdot L\right]}{\mu_{r} \cdot L}}
$$

Esta expressão é bastante útil para separar o deslocamento da ponta do fuste. Logo adiante, identificar-se-á a validade dessas expressões. Note-se que essa expressão guarda certa relação com o coeficiente $\mathrm{w}_{2}$ da expressão (50) do Método de Marques e Massad (2007).

Os comentários da substituição da simbologia do método das Leis de Cambefort modificadas por Massad (1992) estão detalhados no item 4.1.2, fazendo-se aqui apenas referência às expressões da carga na profundidade z'=L-h' (243) e da carga no topo da estaca, por substituição de $z=0$ na expressão (234):

$$
\begin{aligned}
& \mathrm{P}^{\prime}=\frac{\operatorname{Alr}}{\sqrt{\mathrm{k}}} \cdot\left(\frac{\tanh \left[\frac{\mathrm{h}^{\prime}}{\mathrm{L}} \cdot \sqrt{\mathrm{k}}\right]+\lambda}{1+\lambda \cdot \tanh \left[\frac{\mathrm{h}^{\prime}}{\mathrm{L}} \cdot \sqrt{\mathrm{k}}\right]}\right)=\frac{\text { Alr }}{\sqrt{\mathrm{k}}} \cdot \beta^{\prime} \\
& \mathrm{N}(0)=\mathrm{P}_{\mathrm{o}}=\frac{\operatorname{Alr}}{\mathrm{y}_{1}} \cdot \frac{\mathrm{y}_{\mathrm{o}}}{\sqrt{\mathrm{k}}} \cdot\left(\frac{\tanh (\sqrt{\mathrm{k}})+\lambda}{1+\lambda \cdot \tanh (\sqrt{\mathrm{k}})}\right)=\frac{\text { Alr }}{\sqrt{\mathrm{k}}} \cdot \frac{\mathrm{y}_{\mathrm{o}}}{\mathrm{y}_{1}} \cdot \beta^{\prime}{ }_{3}
\end{aligned}
$$

É importante observar que tecnicamente as expressões (244) e (240) são idênticas e ambas são válidas apenas no trecho inicial de mobilização do atrito lateral no topo 
(pseudoelástico). Depois de atingido $f_{\max }$ no topo da estaca, o atrito vai sendo mobilizado para profundidades crescentes e com isso o valor de z (ou de h') varia na expressão (243), resultando numa variação de $\beta^{\prime}$ desde o valor de $\beta_{3}$ até o valor de $\lambda$, onde então $f_{\max }$ atinge a ponta da estaca (Figura 18). Essa variação reflete 0 comportamento da ponta em conjunto com o atrito lateral. A partir desse ponto a carga transferida ao solo por atrito fica constante e percebe-se então a atuação da ponta isolada de maneira mais evidente, de modo que a rigidez do solo da ponta, e não mais do solo do fuste, controla os recalques.

Essa consideração não é feita no método de Randolph e Wroth (1978), para o qual não há valor limite de $\tau$ e, portanto, o resultado é que a expressão (240) indica apenas os recalques no trecho inicial pseudoelástico da curva carga-recalque. Contudo, dada a correspondência entre os métodos, como aqui demonstrado, é possível fazer-se a modificação de um em função do outro, de modo a permitir a análise pós trecho pseudoelástico pelo método de Randolph e Wroth, a partir da formulação de Massad (1992). Outros métodos podem ser analogamente deduzidos e modificados a partir da expressão geral (234), conforme se demonstra no próximo item.

\section{D.6 MODIFICAÇÃO DOS MÉTODOS COM BASE NA CORRESPONDÊNCIA ENTRE AMBOS (AMANN, 2008c)}

No item anterior demonstrou-se a correspondência entre os métodos e que a partir disso pode-se modificar o método de Randolph e Wroth (1978) para analisar toda a curva, da mesma maneira que alguns parâmetros do método das Leis de Cambefort modificadas por Massad (1992) podem ser calculados por meio das considerações de Randolph e Wroth (1978) em relação ao cisalhamento do solo, como é o caso, por exemplo, do recalque para mobilização plena do atrito lateral $\mathrm{y}_{1}$.

Como já mencionado, para Massad (1992) a função adotada para o parâmetro B foi modificada, a partir do trabalho de Baguelin e Venon (1971), sobre a primeira Lei de Cambefort, para permitir a consideração de cargas residuais na ponta devido a descarregamentos em provas de carga. Enquanto a função original é linear do tipo 
$\tau=A_{c}+B_{c} \cdot y$, Massad (1992) considera $A_{c}$ desprezível no primeiro carregamento e, portanto:

$$
B=\frac{f_{\max }}{y_{1}}
$$

Randolph e Wroth (1978), por sua vez, deduziram B para estacas circulares de raio $r_{o}$ em função do módulo de cisalhamento do solo do fuste $G$ (que é correlacionável com $\left.f_{\max }\right)$ :

$$
\mathrm{B}=\frac{\tau}{\mathrm{w}_{\mathrm{s}}}=\frac{\mathrm{G}}{\zeta \cdot \mathrm{r}_{\mathrm{o}}}
$$

Para que se possa analisar a curva carga-recalque até a plena mobilização do atrito lateral ou do cisalhamento ao longo de todo o fuste da estaca, como se faz no método das Leis de Cambefort Modificadas, o valor de $\tau$ deve ser limitado a um valor $\tau_{\max }$. Para este valor deve-se associar um recalque $\mathrm{w}_{\mathrm{s} 1}$ que corresponde a $\mathrm{y}_{1}$ das Leis de Cambefort Modificadas. Como a função em questão é linear, estas modificações não alteram 0 valor de $B$ para qualquer $y(z)<w_{s 1}$. Pode-se então comparar os dois métodos, obtendo-se:

$$
B=\frac{f_{\max }}{y_{1}}=\frac{\tau_{\max }}{w_{s 1}}=\frac{G}{\zeta \cdot r_{0}} \Rightarrow y_{1}=f_{\max } \cdot \frac{\zeta \cdot r_{0}}{G}=\frac{f_{\max }}{E_{f}} \cdot \zeta \cdot r_{0} \cdot 2 \cdot(1+v)
$$

Esta, portanto, é a forma de se obter os parâmetros das Leis de Cambefort a partir do método de Randolph e Wroth (1978). Massad (2008), de forma independente chegou a conclusões semelhantes, atribuindo assim significado geotécnico aos parâmetros. Randolph e Wroth (1978), por sua vez, deduziram B para estacas circulares de raio $r_{0}$ em função do módulo de cisalhamento do solo do fuste $G$ (que é correlacionável com $f_{\max }$ ) a partir da expressão (24). Chega-se assim a:

$$
\mathrm{T}(\mathrm{z})=\mathrm{U} \cdot \int_{0}^{z} \tau(\mathrm{z}) \cdot \mathrm{dz}=\mathrm{U} \cdot\left[\tau_{\max } \cdot(\mathrm{z})-\tau(0) \cdot 0\right]=\frac{\mathrm{P}_{\mathrm{s}}}{\mathrm{L}} \cdot \mathrm{z}
$$

Então, após o topo da estaca mobilizar totalmente o cisalhamento lateral $\tau_{\max }$, a carga no topo passa a ser expressa por: 


$$
P_{t}=P_{s} \cdot \frac{z}{L}+G \cdot r_{0} \cdot w_{s 1} \cdot \frac{\frac{4}{\eta \cdot(1-v)}+\frac{2 \cdot \pi}{\zeta} \cdot \frac{L}{r_{0}} \cdot \frac{\tanh \left[\mu_{r} \cdot(L-z)\right]}{\mu_{r} \cdot L}}{1+\frac{4}{\eta \cdot(1-v)} \cdot \frac{1}{\pi \cdot \lambda_{r}} \cdot \frac{L}{r_{0}} \cdot \frac{\tanh \left[\mu_{r} \cdot(L-z)\right]}{\mu_{r} \cdot L}}
$$

Ou, adimensionalmente, como preferem Randolph e Wroth:

$$
\frac{P_{t}}{G \cdot r_{0} \cdot w_{t}}=\frac{w_{s 1}}{w_{t}} \cdot\left[\frac{2 \cdot \pi}{\zeta} \cdot \frac{L}{r_{0}} \cdot \frac{z}{L}+\frac{\frac{4}{\eta \cdot(1-v)}+\frac{2 \cdot \pi}{\zeta} \cdot \frac{L}{r_{0}} \cdot \frac{\tanh \left[\mu_{r} \cdot(L-z)\right]}{\mu_{r} \cdot L}}{\left.1+\frac{4}{\eta \cdot(1-v)} \cdot \frac{1}{\pi \cdot \lambda_{r}} \cdot \frac{L}{r_{0}} \cdot \frac{\tanh \left[\mu_{r} \cdot(L-z)\right.}{\mu_{r} \cdot L}\right]}\right]
$$

Essa é a expressão de Randolph e Wroth modificada por Amann (2008c) para permitir o cálculo das cargas e recalques no topo da estaca, depois de atingido o atrito máximo.

\section{D.7 COMPARAÇÃO COM O MÉTODO DE FLEMING (1992), APUD AMANN (2008c)}

Para os demais métodos, as considerações e forma de análise são semelhantes quando se trata de compará-los e verificar suas correspondências. Exemplificando para o método de Fleming (1992), este utiliza funções de transferência de carga hiperbólicas para ponta e atrito [expressão (126), mas sua formulação também se utiliza de deduções de transferência de carga baseadas em Randolph e Wroth (1978). Em seu trabalho, Fleming (1992) relata que "a inclinação tangente (MS) na origem da curva hiperbólica de seu método é similar a $\zeta . \tau_{\max } /(2 . \mathrm{G})$, conforme apontado por Randolph (1991)". Analisando-se essa afirmativa, chega-se, pela expressão (247) a:

$$
\begin{gathered}
\mathrm{M}_{\mathrm{s}}=\frac{\zeta \cdot \tau_{\max }}{2 \cdot \mathrm{G}} \\
\mathrm{y}_{1}=\frac{\zeta \cdot \tau_{\max }}{\mathrm{G}} \cdot \mathrm{r}_{\mathrm{o}}=2 \cdot \mathrm{M}_{\mathrm{s}} \cdot \mathrm{r}_{\mathrm{o}} \Rightarrow \mathrm{M}_{\mathrm{s}}=\frac{\mathrm{y}_{1}}{2 \cdot \mathrm{r}_{0}}=\frac{\mathrm{y}_{1}}{\mathrm{D}}
\end{gathered}
$$

Portanto, pela análise da expressão (252), demonstra-se que o fator Ms de Fleming não é mais que uma forma de estimativa do $\mathrm{y}_{1}$ na Figura 37 a partir do diâmetro D. Fleming (1992) mesmo indica que os valores esperados para Ms estão entre 0,001 e 
0,004, que são valores próximos dos apontados por Décourt (1996) para se localizar o ponto 1 do seu método de previsão da curva (Décourt,1995), como também foi observado por Massad (2008).

Assim, verifica-se que os demais métodos de transferência podem ser também deduzidos com esta mesma metodologia de análise embasada na expressão geral aqui deduzida.

Como um adendo, o item E.9 do Apêndice seguinte apresenta a dedução do coeficiente $\mathrm{C}$ de distribuição do atrito lateral ao longo do fuste. 


\section{APÊNDICE E - ANÁLISE DE ENSAIOS INSTRUMENTADOS}

Neste apêndice, apresentam-se as tabelas dos valores calculados no Capítulo5, bem como a demonstração do significado dos coeficientes dos polinômios de ajuste (item E.5).

\section{E.1 TABELAS DE APLICAÇÃO DA ANÁLISE USUAL}

A aplicação da análise atual considera valores constantes de atrito lateral em cada trecho instrumentado. Para a estaca Barrete, do exemplo, tem-se:

Tabela 56 - Atrito lateral unitário $\tau\left[\mathrm{kN} / \mathrm{m}^{2}\right]$ para ca,da trecho $\Delta z$ em cada estágio de carga $\mathrm{P}_{\mathrm{o}}[\mathrm{kN}]$.

\begin{tabular}{cccc}
\hline \multirow{2}{*}{$\mathrm{P}_{\mathrm{o}}[\mathrm{kN}]$} & $\Delta \mathrm{z}_{1}$ & $\Delta \mathrm{z}_{2}$ & $\Delta \mathrm{z}_{3}$ \\
\cline { 2 - 4 } & $0-3,4[\mathrm{~m}]$ & $3,4-5,8[\mathrm{~m}]$ & $5,8-6,8[\mathrm{~m}]$ \\
\hline 500 & 27.98 & 5.08 & 14.63 \\
1000 & 43.76 & 10.16 & 51.22 \\
1500 & 56.67 & 10.16 & 75.61 \\
2000 & 71.02 & 10.16 & 87.80 \\
2500 & 81.06 & 12.20 & 75.61 \\
3000 & 86.08 & 14.23 & 60.98 \\
\hline
\end{tabular}

O gráfico correspondente é o da Figura 45, no item 5.3.

A carga na ponta é usualmente estimada considerando-se a mesma taxa linear de transferência de carga do trecho final nos $20 \mathrm{~cm}$ abaixo do nível "A" de instrumentação.

Tabela 57 - Valores de carga calculados considerando trecho linear na ponta.

\begin{tabular}{ccccccc}
\hline $\mathrm{P}_{\mathrm{o}}[\mathrm{kN}]$ & 500 & 1000 & 1500 & 2000 & 2500 & 3000 \\
\hline $\mathrm{P}_{\mathrm{p}}[\mathrm{kN}]$ & -12 & 38 & 238 & 478 & 878 & 1360 \\
$\mathrm{P}_{\mathrm{p}} / \mathrm{P}_{\mathrm{o}}[\%]$ & $-2,4$ & 3,80 & 15,87 & 23,9 & 35,12 & 45,33 \\
\hline
\end{tabular}

Os valores negativos se devem ao prolongamento da reta ajustada para extrapolação da ponta. Nesse caso, os valores deveriam ser iguais a zero, devido à ponta ainda não ter sido mobilizada.

Tabela 58 - Valores da integral (N.dz) em [kN.m] para cada trecho de estaca

\begin{tabular}{ccccccc}
\hline$\Delta \mathrm{z}[\mathrm{m}]$ & $\mathrm{P}_{0}=500[\mathrm{kN}]$ & $\mathrm{P}_{0}=1000$ & $\mathrm{P}_{0}=1500$ & $\mathrm{P}_{0}=2000$ & $\mathrm{P}_{\mathrm{o}}=2500$ & $\mathrm{P}_{\mathrm{o}}=3000$ \\
\hline 3.4 & 1037 & 2363 & 3757 & 5117 & 6579 & 8160 \\
2.4 & 204 & 816 & 1584 & 2304 & 3144 & 4152 \\
1.0 & 30 & 185 & 455 & 730 & 1095 & 1535 \\
0.2 & $-1,2$ & 11,8 & 53,8 & 102,8 & 181,8 & 277 \\
\hline
\end{tabular}


A Tabela 58 mostra os valores da integral (N.dz) calculadas em [kN.m] para cada trecho de estaca enterrada.

Os encurtamentos trecho a trecho são então calculados, dividindo-se essas áreas (N.dz) pelo respectivo produto E.S do trecho em questão, resultando:

Tabela 59 - Valores de encurtamento por trecho em [m]

\begin{tabular}{cccccccc}
\hline $\mathrm{P}_{\mathrm{o}}=$ & 500 & 1000 & 1500 & 2000 & 2500 & 3000 & $\mathrm{kN}$ \\
\hline $\mathrm{y}(-2,0)-\mathrm{y}(-0,5)=$ & $1,26 \mathrm{E}-05$ & $2,53 \mathrm{E}-05$ & $3,79 \mathrm{E}-05$ & $5,05 \mathrm{E}-05$ & $6,32 \mathrm{E}-05$ & $7,58 \mathrm{E}-05$ & $\mathrm{~m}$ \\
$\mathrm{y}(-0,5)-\mathrm{y}(0,0)=$ & $1,74 \mathrm{E}-05$ & $3,47 \mathrm{E}-05$ & $5,21 \mathrm{E}-05$ & $6,95 \mathrm{E}-05$ & $8,69 \mathrm{E}-05$ & $1,04 \mathrm{E}-04$ & $\mathrm{~m}$ \\
$\mathrm{y}(0,0)-\mathrm{y}(3,4)=$ & $7,21 \mathrm{E}-05$ & $1,64 \mathrm{E}-04$ & $2,61 \mathrm{E}-04$ & $3,56 \mathrm{E}-04$ & $4,57 \mathrm{E}-04$ & $5,67 \mathrm{E}-04$ & $\mathrm{~m}$ \\
$\mathrm{y}(3,4)-\mathrm{y}(5,8)=$ & $1,42 \mathrm{E}-05$ & $5,67 \mathrm{E}-05$ & $1,10 \mathrm{E}-04$ & $1,60 \mathrm{E}-04$ & $2,18 \mathrm{E}-04$ & $2,88 \mathrm{E}-04$ & $\mathrm{~m}$ \\
$\mathrm{y}(5,8)-\mathrm{y}(6,8)=$ & $2,08 \mathrm{E}-06$ & $1,29 \mathrm{E}-05$ & $3,16 \mathrm{E}-05$ & $5,07 \mathrm{E}-05$ & $7,61 \mathrm{E}-05$ & $1,07 \mathrm{E}-04$ & $\mathrm{~m}$ \\
$\mathrm{y}(6,8)-\mathrm{y}(7,0)=$ & $-8,34 \mathrm{E}-08$ & $8,20 \mathrm{E}-07$ & $3,74 \mathrm{E}-06$ & $7,14 \mathrm{E}-06$ & $1,26 \mathrm{E}-05$ & $1,92 \mathrm{E}-05$ & $\mathrm{~m}$ \\
\hline
\end{tabular}

Por fim, conhecendo-se os recalques no topo do bloco $(z=-2,0 \mathrm{~m})$, pode-se calcular o deslocamento y $[\mathrm{mm}]$ de cada ponto $z$ em questão (ver Figura 46 ):

Tabela 60 - Valores de encurtamento por trecho em [m]

\begin{tabular}{ccccccc}
\hline $\mathrm{z}[\mathrm{m}]$ & $500 \mathrm{kN}$ & $1000 \mathrm{kN}$ & $1500 \mathrm{kN}$ & $2000 \mathrm{kN}$ & $2500 \mathrm{kN}$ & $3000 \mathrm{kN}$ \\
\hline$-2,0$ & 0,1200 & 3,3000 & 13,9700 & 23,4600 & 41,0000 & 64,5400 \\
$-0,5$ & 0,1074 & 3,2747 & 13,9321 & 23,4095 & 40,9368 & 64,4642 \\
0,0 & 0,0900 & 3,2400 & 13,8800 & 23,3400 & 40,8500 & 64,3600 \\
3,4 & 0,0179 & 3,0758 & 13,6189 & 22,9844 & 40,3928 & 63,7930 \\
5,8 & 0,0038 & 3,0191 & 13,5089 & 22,8243 & 40,1744 & 63,5045 \\
6,8 & 0,0017 & 3,0062 & 13,4773 & 22,7736 & 40,0983 & 63,3978 \\
7,0 & $0,0018^{*}$ & 3,0054 & 13,4735 & 22,7665 & 40,0857 & 63,3786 \\
\hline
\end{tabular}

Como o atrito lateral é usualmente considerado constante em cada trecho, para se traçarem os gráficos representativos da relação entre $\tau(z)$ e $y(z)$ há a necessidade de se calcular o deslocamento do ponto médio de cada trecho considerado da estaca, conforme a metodologia usual já exposta acima. A Tabela 61 mostra o resultado cuja gráfico corresponde à Figura 47.

Tabela 61 - Deslocamentos y em mm para os pontos médios dos trechos da estaca.

\begin{tabular}{ccccccc}
\hline$z[\mathrm{~m}]$ & $500 \mathrm{kN}$ & $1000 \mathrm{kN}$ & $1500 \mathrm{kN}$ & $2000 \mathrm{kN}$ & $2500 \mathrm{kN}$ & $3000 \mathrm{kN}$ \\
\hline 1.7 & 0.0425 & 3.1399 & 13.7261 & 23.1330 & 40.5880 & 64.0410 \\
4.6 & 0.0098 & 3.0454 & 13.5618 & 22.9023 & 40.2811 & 63.6458 \\
6.3 & 0.0022 & 3.0109 & 13.4904 & 22.7959 & 40.1337 & 63.4490 \\
6.9 & 0.0017 & 3.0058 & 13.4753 & 22.7699 & 40.0919 & 63.3881 \\
\hline
\end{tabular}




\section{E.2 COMENTÁRIOS SOBRE AS FIGURAS TRIDIMENSIONAIS DE REPRESENTAÇÃODA RELAÇÃO t-y-z-Po}

A Figura 52 apresenta uma série de representações tridimensionais obtidas com o "software" Mathcad® da PTC. A Figura 52(a) apresenta tridimensionalmente a relação $\tau, y, z$ para cada valor de $P_{0}$. A representação das projeções deste gráfico (a) nos planos $\tau-z, y-z$ e $\tau-y$ encontram-se respectivamente na Figura 45 , Figura 46 e Figura 47. A Figura 52(b) foi construída ligando-se os pontos de mesmo valor de z, o que explicita as curvas $\tau\left(P_{0}\right)-y\left(P_{0}\right)$ projetadas em planos paralelos ao $\tau-y$, como visto na Figura 51. Como o atrito é considerado constante nos trechos entre instrumentação da estaca, as curvas se repetem no topo, no meio e na base de cada trecho (local da instrumentação). A Figura 52(c) apresenta a sobreposição da Figura 52(a) e (b), de forma a apresentar o que seria a superfície de transferência de carga $y-\tau-z$ da estaca em estudo. A Figura 52(d) apresenta a mesma Figura 52(c) em outro ângulo de visualização. A projeção desse gráfico (c) ou (d) no plano $\tau-y$ pode ser vista na Figura 49.

A Figura 53 apresenta os gráficos análogos aos da Figura 52, considerando agora no terceiro eixo o valor de $P_{0}$ ao invés de $z$. A Figura 53 (a) apresenta a variação das curvas de transferência de carga com o aumento de $P_{0}$. A projeção no plano $\tau-y$ desse gráfico pode ser vista na Figura 51 e também na Figura 55, esta com a gradação de cores. A Figura 53 (b) foi construída ligando-se os pontos de mesmo valor de $P_{0}$ e sua projeção no plano $\tau-y$ pode ser vista na Figura 47. Essas curvas parecem pequenas retas devido à escala, mas a Figura 54 apresenta uma ampliação em $P_{0}=3000 \mathrm{kN}$, para melhor visualização e cuja projeção $\tau$-y se vê na Figura 48 . A Figura 53(c) apresenta a sobreposição dos gráficos (a) e (b), para visualização da superfície $y-\tau-P_{0}$ de transferência de carga e a Figura $53(d)$ o mesmo sob outro ângulo de visualização. A projeção no plano $\tau-y$ destes últimos pode ser vista na Figura 49.

A Figura 55 acima apenas reproduz as projeções das curvas de transferência de carga nos planos $\mathrm{P}_{0}-\tau(\mathrm{a}), \tau-\mathrm{y}$ (b) e y- $\mathrm{P}_{0}$ (c). Note-se que nessa última projeção a elevada rigidez da estaca faz com que as curvas de cada trecho fiquem muito próximas entre si. Verifica-se assim que é possível encontrarem-se relações 
matemáticas $\tau-P_{0}, \tau-y$ e y- $P_{\circ}$ para cada profundidade $z$. A Figura 55(d) foi construída com recursos de edição de figuras e busca apresentar a sobreposição numa única figura dos espaços $y-\tau-z$ e $\tau-y-P_{0}$, evidenciando a relação da projeção no plano y$\tau$ com as superfícies geradas em cada espaço.

\section{E.3 TABELAS DOS POLINÔMIOS AJUSTADOS AOS PONTOS DE ENSAIO}

Sugere-se aqui obter os polinômios de ajuste da carga pelos resultados da instrumentação (Figura 59) e, a partir destes, achar os polinômios do atrito por derivação e dos deslocamentos por integração (Tabela 24).

No gráfico da Figura 61, compararam-se os pontos obtidos desses polinômios com as parábolas ajustadas (linhas tracejadas) por mínimos quadrados aos três pontos médios dos trechos instrumentados, a saber: $z$ igual a 1,7m, 4,6m e 6,3m. Comparando-se os valores dos coeficientes dos polinômios da Tabela 24 com os das parábolas ajustadas na Figura 60, vê-se que a proximidade entre os mesmos indicam coerência entre a derivada da função $\mathrm{N}(\mathrm{z})$ das cargas ajustadas e o método usual.

As equações ajustadas por mínimos quadrados apresentadas no gráfico da Figura 62 podem ser comparadas aos polinômios integrados da carga apresentados na Tabela 62.

Tabela 62 - Valores dos coeficientes dos polinômios integrados de N(z), com y em [mm]

\begin{tabular}{cccccc}
\hline \multicolumn{7}{c}{$\mathrm{y}(\mathrm{z})=\mathrm{a}_{4} \cdot \mathrm{z}^{4}+\mathrm{a}_{3} \cdot \mathrm{z}^{3}+\mathrm{a}_{2} \cdot \mathrm{z}^{2}+\mathrm{a}_{1} \cdot \mathrm{z}+\mathrm{a}_{0}$} \\
\hline $\mathrm{P}_{\mathrm{o}}[\mathrm{kN}]$ & $\mathrm{a}_{4}$ & $\mathrm{a}_{3}$ & $\mathrm{a}_{2}$ & $\mathrm{a}_{1}$ & $\mathrm{a}_{0}$ \\
\hline 3000 & $2.7376 \mathrm{E}-04$ & $-4.5346 \mathrm{E}-03$ & $2.9059 \mathrm{E}-02$ & $-2.0845 \mathrm{E}-01$ & $6.4360 \mathrm{E}+01$ \\
2500 & $3.1970 \mathrm{E}-04$ & $-5.0492 \mathrm{E}-03$ & $2.9906 \mathrm{E}-02$ & $-1.7371 \mathrm{E}-01$ & $4.0850 \mathrm{E}+01$ \\
2000 & $3.4907 \mathrm{E}-04$ & $-5.2782 \mathrm{E}-03$ & $2.8964 \mathrm{E}-02$ & $-1.3897 \mathrm{E}-01$ & $2.3340 \mathrm{E}+01$ \\
1500 & $2.8559 \mathrm{E}-04$ & $-4.2647 \mathrm{E}-03$ & $2.3219 \mathrm{E}-02$ & $-1.0422 \mathrm{E}-01$ & $1.3880 \mathrm{E}+01$ \\
1000 & $1.8714 \mathrm{E}-04$ & $-2.8457 \mathrm{E}-03$ & $1.6419 \mathrm{E}-02$ & $-6.9483 \mathrm{E}-02$ & $3.2400 \mathrm{E}+00$ \\
500 & $7.0772 \mathrm{E}-05$ & $-1.2430 \mathrm{E}-03$ & $8.6881 \mathrm{E}-03$ & $-3.4741 \mathrm{E}-02$ & $8.9996 \mathrm{E}-02$ \\
\hline
\end{tabular}

Nota-se assim uma boa concordância entre os valores dos coeficientes obtidos com os polinômios integrados, comparando-se os ajustados com o método usual. 


\section{E.4 PROPOSTA DE AJUSTES POLINOMIAIS $\tau\left(\mathbf{P}_{0}\right)$ e y(Po) PARA ANÁLISE DA VARIAÇÃO DE $\tau$ E y COM Po}

Considerando que $\tau$ e y dependem de $\mathrm{P}_{0}$, como proposto na nova abordagem matemática, pode-se determinar a expressão matemática do parâmetro $B$ ao se obterem as expressões de $\tau\left(P_{0}\right)$ e $y\left(P_{0}\right)$.

\section{E.4.1 Ajuste das cargas na ponta para o estágio de carga $P_{0}=500 \mathrm{kN}$}

Antes de tudo, convém corrigir a inclinação do trecho próximo à ponta para o carregamento de $500 \mathrm{kN}$, que aparentemente não representava de forma real o que ocorre com a ponta nesse caso. A carga de $60 \mathrm{kN}$ no ponto $z=5,80 \mathrm{~m}$ é um dado, porém considerar que a carga se anule somente na ponta não parece condizente, bastando para concluir isso observar a inclinação das demais retas usuais para $P_{0}=1000$ e $1500 \mathrm{kN}$. Propõe-se aqui considerar a variação de $\tau$ linear entre esse dois valores e extrapolar essa variação para 500 kN:

Tabela 63 - Linearização das inclinações $[\tau(\mathrm{z})$.U] no trecho $\Delta \mathrm{z}=6,8-5,8 \mathrm{~m}$ para estimativa da inclinação para $\mathrm{P}_{0}=500 \mathrm{kN}$

\begin{tabular}{cc}
\hline $\mathrm{P}_{\mathrm{o}}(\mathrm{kN})$ & $\Delta \mathrm{N}(\mathrm{z}) / \Delta \mathrm{z}$ \\
\hline 1500 & 310 \\
1000 & 210 \\
500 & 110 \\
\hline
\end{tabular}

Assim, o valor obtido é de $110 \mathrm{kN} / \mathrm{m}$, e, partindo-se de $\mathrm{N}(5,8)=60 \mathrm{kN}$, chega a $\mathrm{N}(\mathrm{z})=0$ para $\mathrm{z}=6,345 \mathrm{~m}$. Isso significa que $\mathrm{o}$ atrito desenvolvido até a profundidade de $6,345 \mathrm{~m}$ corresponde à carga de $500 \mathrm{kN}$. Com essa inclinação, matematicamente obtém-se $\mathrm{N}(6,8)=-50 \mathrm{kN}$, o que não representa aqui atrito negativo, mas inicialmente apenas um valor de ajuste, embora a estaca seja cravada com ensaio no primeiro carregamento, desconsiderando-se em primeira aproximação a carga residual no trecho. Deve-se atentar para que essa estimativa se trata meramente de procurar aproximar à realidade empiricamente o resultado observado, sendo que não se pode com precisão indicar exatamente o que ocorre. Com essas considerações, o polinômio de ajuste da carga $N(z)$ para $P_{0}=500 \mathrm{kN}$ fica: 


$$
N(z)=-6,237 \cdot z^{3}+73,56 \cdot z^{2}-292,72 \cdot z+500
$$

Os demais polinômios continuam os mesmos da Figura 59. É importante considerar que a proposta de uso dos polinômios se justifica, pois os valores de atrito são usualmente considerados constantes e a carga como sendo linear, para simplificação. Considera-se aqui que o ajuste polinomial seja preferível nesta análise em relação ao usual simplificado por resultar funções contínuas. De qualquer forma, deve-se considerar que a diferença entre os valores é pequena (ver Figura 60).

A Tabela 55 apresenta os polinômios $\tau(z)$ derivados dos polinômios da Figura 59, sendo que 0 referente a $P_{0}=500 \mathrm{kN}$ foi obtido pela derivada da expressão corrigida (253). De forma semelhante se obtém os polinômios integrados da Tabela 65.

Tabela 64 - Coeficientes dos polinômios $\tau(z)$ derivados de $N(z)$ com $P_{o}=500 \mathrm{kN}$ corrigido.

\begin{tabular}{cccc}
\hline \multicolumn{4}{c}{$\tau(z)=a_{2} \cdot z^{2}+a_{1} \cdot z+a_{0}$} \\
\hline $\mathrm{P}_{\circ}[\mathrm{kN}]$ & $\mathrm{a}_{2}$ & $\mathrm{a}_{1}$ & $\mathrm{a}_{0}$ \\
\hline 3000 & 11.5316 & -95.5049 & 204.0065 \\
2500 & 13.4669 & -106.3440 & 209.9540 \\
2000 & 14.7037 & -111.1680 & 203.3452 \\
1500 & 12.0300 & -89.8213 & 163.0123 \\
1000 & 7.8830 & -59.9338 & 115.2707 \\
500 & 4.5635 & -35.8847 & 71.3963 \\
\hline
\end{tabular}

Tabela 65 - Coeficientes dos polinômios y(z) integrados de N(z), $P_{0}=500$ kN corrigido (y em [mm])

\begin{tabular}{cccccc}
\hline \multicolumn{7}{c}{$\mathrm{y}(\mathrm{z})=\mathrm{a}_{4} \cdot \mathrm{z}^{4}+\mathrm{a}_{3} \cdot \mathrm{z}^{3}+\mathrm{a}_{2} \cdot \mathrm{z}^{2}+\mathrm{a}_{1} \cdot \mathrm{z}+\mathrm{a}_{0}$} \\
\hline $\mathrm{P}_{\mathrm{o}}[\mathrm{kN}]$ & $\mathrm{a}_{4}$ & $\mathrm{a}_{3}$ & $\mathrm{a}_{2}$ & $\mathrm{a}_{1}$ & $\mathrm{a}_{0}$ \\
\hline 3000 & $2.7376 \mathrm{E}-04$ & $-4.5346 \mathrm{E}-03$ & $2.9059 \mathrm{E}-02$ & $-2.0845 \mathrm{E}-01$ & $6.4360 \mathrm{E}+01$ \\
2500 & $3.1970 \mathrm{E}-04$ & $-5.0492 \mathrm{E}-03$ & $2.9906 \mathrm{E}-02$ & $-1.7371 \mathrm{E}-01$ & $4.0850 \mathrm{E}+01$ \\
2000 & $3.4907 \mathrm{E}-04$ & $-5.2782 \mathrm{E}-03$ & $2.8964 \mathrm{E}-02$ & $-1.3897 \mathrm{E}-01$ & $2.3340 \mathrm{E}+01$ \\
1500 & $2.8559 \mathrm{E}-04$ & $-4.2647 \mathrm{E}-03$ & $2.3219 \mathrm{E}-02$ & $-1.0422 \mathrm{E}-01$ & $1.3880 \mathrm{E}+01$ \\
1000 & $1.8714 \mathrm{E}-04$ & $-2.8457 \mathrm{E}-03$ & $1.6419 \mathrm{E}-02$ & $-6.9483 \mathrm{E}-02$ & $3.2400 \mathrm{E}+00$ \\
500 & $1.0834 \mathrm{E}-04$ & $-1.7038 \mathrm{E}-03$ & $1.0170 \mathrm{E}-02$ & $-3.4742 \mathrm{E}-02$ & $7.0683 \mathrm{E}-02^{*}$ \\
\hline
\end{tabular}

Considerando que um determinado ponto numa profundidade ' $z$ ' somente se desloca se estiver sob ação da força aplicada no eixo da estaca na profundidade em questão, o polinômio integrado para $P_{0}=500 \mathrm{kN}$, a rigor, deveria resultar em zero no mesmo ponto ' $z$ ', que é raiz do polinômio das cargas $N(z)$, ou seja, se torna então a condição de contorno. Para isso $o$ valor de $\mathrm{y}_{0}=\mathrm{a}_{\circ}$ deve ser 7,0683E-02 mm, e não 8,9996E-02 mm, como foi obtido pelo cálculo da somatória dos encurtamentos trecho a trecho (Tabela 62), admitindo-se o módulo do concreto do bloco igual ao da estaca. Isso resulta em um erro relativo de $21,46 \%$, o que parece ser uma correção perfeitamente admissível, dada a adoção mencionada do valor do módulo. Essa 
correção pode também ser cabível para os demais polinômios integrados em cada estágio de carga $\mathrm{P}_{\mathrm{o}}$, porém, como nos demais casos, o valor da raiz ' $\mathrm{z}$ ' do polinômio supera o comprimento da estaca, ou seja, há um ponto de singularidade na mudança brusca do material de concreto para solo, não se podendo usar este mesmo valor como condição de contorno, pois a função polinomial é válida somente no intervalo $0 \leq \mathrm{z} \leq \mathrm{L}$.

Tabela 66 - Valores de $\tau\left[\mathrm{kN} / \mathrm{m}^{2}\right]$ calculados por derivação dos polinômios $\mathrm{N}(\mathrm{z})$

\begin{tabular}{ccccccc}
\hline $\mathrm{z}(\mathrm{m})$ & $\mathrm{P}_{\mathrm{o}}=500 \mathrm{kN}$ & 1000 & 1500 & 2000 & 2500 & 3000 \\
\hline 0 & 71.3963 & 115.2707 & 163.0123 & 203.3452 & 209.9540 & 204.0065 \\
0.7 & 48.5131 & 77.1797 & 106.0321 & 132.7324 & 142.1120 & 142.8036 \\
1.4 & 30.1022 & 46.8141 & 60.8413 & 76.5293 & 87.4675 & 92.9016 \\
1.7 & 23.5808 & 36.1651 & 45.0828 & 56.8533 & 68.0885 & 74.9745 \\
2.1 & 16.1635 & 24.1738 & 27.4399 & 34.7357 & 46.0206 & 54.3006 \\
2.8 & 6.6970 & 9.2588 & 5.8279 & 7.3518 & 17.7713 & 27.0005 \\
3.4 & 2.1424 & 2.6233 & -3.3133 & -4.6512 & 4.0618 & 12.5951 \\
3.5 & 1.7027 & 2.0692 & -3.9948 & -5.6225 & 2.7195 & 11.0015 \\
4.6 & 2.8903 & 6.3795 & 4.3891 & 3.1027 & 5.7312 & 8.6926 \\
4.9 & 5.1309 & 10.8659 & 11.7282 & 11.6578 & 12.2087 & 12.9062 \\
5.6 & 13.5533 & 26.8523 & 37.2738 & 41.9124 & 36.7496 & 30.8100 \\
5.8 & 16.7812 & 32.8388 & 46.7380 & 53.2033 & 46.1853 & 38.0011 \\
6.3 & 26.4480 & 50.5640 & 74.6088 & 86.5767 & 74.4881 & 60.0148 \\
6.8 & 38.3966 & 72.2308 & 108.4947 & 127.3019 & 109.5243 & 87.7944 \\
6.9 & 41.0601 & 77.0371 & 115.9936 & 136.3292 & 117.3395 & 94.0422 \\
7.0 & 43.8149 & 82.0011 & 123.7332 & 145.6505 & 125.4241 & 100.5206 \\
\hline
\end{tabular}

Tabela 67 - Valores de y[mm] calculados por integração dos polinômios N(z)

\begin{tabular}{ccccccc}
\hline$z(m)$ & $P_{0}=500 \mathrm{kN}$ & 1000 & 1500 & 2000 & 2500 & $3000 \mathrm{kN}$ \\
\hline 0 & $7.0683 \mathrm{E}-02$ & $3.2400 \mathrm{E}+00$ & $1.3880 \mathrm{E}+01$ & $2.3340 \mathrm{E}+01$ & $4.0850 \mathrm{E}+01$ & $6.4360 \mathrm{E}+01$ \\
0.7 & $5.0789 \mathrm{E}-02$ & $3.1985 \mathrm{E}+00$ & $1.3817 \mathrm{E}+01$ & $2.3255 \mathrm{E}+01$ & $4.0741 \mathrm{E}+01$ & $6.4227 \mathrm{E}+01$ \\
1.4 & $3.7718 \mathrm{E}-02$ & $3.1678 \mathrm{E}+00$ & $1.3769 \mathrm{E}+01$ & $2.3189 \mathrm{E}+01$ & $4.0653 \mathrm{E}+01$ & $6.4114 \mathrm{E}+01$ \\
1.7 & $3.3547 \mathrm{E}-02$ & $3.1569 \mathrm{E}+00$ & $1.3751 \mathrm{E}+01$ & $2.3164 \mathrm{E}+01$ & $4.0619 \mathrm{E}+01$ & $6.4070 \mathrm{E}+01$ \\
2.1 & $2.8903 \mathrm{E}-02$ & $3.1438 \mathrm{E}+00$ & $1.3730 \mathrm{E}+01$ & $2.3134 \mathrm{E}+01$ & $4.0577 \mathrm{E}+01$ & $6.4014 \mathrm{E}+01$ \\
2.8 & $2.2396 \mathrm{E}-02$ & $3.1232 \mathrm{E}+00$ & $1.3694 \mathrm{E}+01$ & $2.3084 \mathrm{E}+01$ & $4.0507 \mathrm{E}+01$ & $6.3921 \mathrm{E}+01$ \\
3.4 & $1.7637 \mathrm{E}-02$ & $3.1067 \mathrm{E}+00$ & $1.3665 \mathrm{E}+01$ & $2.3042 \mathrm{E}+01$ & $4.0449 \mathrm{E}+01$ & $6.3846 \mathrm{E}+01$ \\
3.5 & $1.6876 \mathrm{E}-02$ & $3.1040 \mathrm{E}+00$ & $1.3660 \mathrm{E}+01$ & $2.3034 \mathrm{E}+01$ & $4.0440 \mathrm{E}+01$ & $6.3833 \mathrm{E}+01$ \\
4.6 & $8.7347 \mathrm{E}-03$ & $3.0746 \mathrm{E}+00$ & $1.3605 \mathrm{E}+01$ & $2.2956 \mathrm{E}+01$ & $4.0335 \mathrm{E}+01$ & $6.3697 \mathrm{E}+01$ \\
4.9 & $6.6344 \mathrm{E}-03$ & $3.0668 \mathrm{E}+00$ & $1.3590 \mathrm{E}+01$ & $2.2935 \mathrm{E}+01$ & $4.0307 \mathrm{E}+01$ & $6.3661 \mathrm{E}+01$ \\
5.6 & $2.3914 \mathrm{E}-03$ & $3.0501 \mathrm{E}+00$ & $1.3556 \mathrm{E}+01$ & $2.2886 \mathrm{E}+01$ & $4.0243 \mathrm{E}+01$ & $6.3577 \mathrm{E}+01$ \\
5.8 & $1.4693 \mathrm{E}-03$ & $3.0459 \mathrm{E}+00$ & $1.3548 \mathrm{E}+01$ & $2.2874 \mathrm{E}+01$ & $4.0225 \mathrm{E}+01$ & $6.3554 \mathrm{E}+01$ \\
6.3 & $9.3201 \mathrm{E}-05$ & $3.0372 \mathrm{E}+00$ & $1.3528 \mathrm{E}+01$ & $2.2844 \mathrm{E}+01$ & $4.0184 \mathrm{E}+01$ & $6.3498 \mathrm{E}+01$ \\
6.8 & $6.1479 \mathrm{E}-04$ & $3.0321 \mathrm{E}+00$ & $1.3515 \mathrm{E}+01$ & $2.2821 \mathrm{E}+01$ & $4.0148 \mathrm{E}+01$ & $6.3446 \mathrm{E}+01$ \\
6.9 & $1.0189 \mathrm{E}-03$ & $3.0316 \mathrm{E}+00$ & $1.3513 \mathrm{E}+01$ & $2.2817 \mathrm{E}+01$ & $4.0141 \mathrm{E}+01$ & $6.3436 \mathrm{E}+01$ \\
7.0 & $1.5399 \mathrm{E}-03$ & $3.0314 \mathrm{E}+00$ & $1.3511 \mathrm{E}+01$ & $2.2814 \mathrm{E}+01$ & $4.0135 \mathrm{E}+01$ & $6.3427 \mathrm{E}+01$ \\
\hline
\end{tabular}

Tendo-se os polinômios em ' $z$ ' (Tabela 64 e Tabela 65), parte-se para a análise da variação dos resultados com $\mathrm{P}_{\mathrm{o}}$. $\mathrm{O}$ fato de se propor aqui a utilização dos valores obtidos pelos polinômios, e não os obtidos pelo método usual, já foi justificado, tendo em vista a questão da descontinuidade gerada neste último. 
Assim, para se analisar a variação de $\tau$ e y com $P_{0}$, de modo a se obter o diagrama $\tau-y$ adequado, procedeu-se da seguinte maneira: fixaram-se os valores de ' $z$ ' e tomaram-se os valores de $\tau$ e y em função de $P_{0}$, como apresentado nos gráficos da Figura 56 e da Figura 64, porém aplicados a diversas profundidades escolhidas para representar $1 / 10$ do comprimento, bem como os pontos de instrumentação e os pontos médios dos trechos instrumentados.

Os valores obtidos de $\tau\left(\mathrm{P}_{\mathrm{o}}\right)$ e y $\left(\mathrm{P}_{\mathrm{o}}\right)$ podem ser vistos respectivamente na Tabela 66 e na Tabela 67, e sua representação gráfica na Figura 68 e na Figura 69.

Verifica-se pelos valores da Tabela 67 e pela quase sobreposição das curvas na Figura 69, que a rigidez da estaca é bastante elevada.

A partir disso, foram analisadas as possíveis regressões polinomiais para esses gráficos, resultando em ajustes entre o terceiro e o quarto grau. De fato, não há por ora análise física que defina o ajuste como polinomial com tais graus, porém foram escolhidos como uma forma simples de analisar o problema. Outras funções, contudo podem ser usadas em novas análises.

Para os valores de $\tau$ em função de $P_{o}$, exemplifica-se a análise com as profundidades correspondentes ao ponto médio dos trechos instrumentados: 1,7 ; 4,6 e 6,3 $\mathrm{m}$ de profundidade.

Na profundidade de 1,7m (Figura 101 a), considerou-se que o polinômio de quarto grau ajustado resultou num decréscimo abrupto, e que o de terceiro grau estaria mais coerente. Arbitrou-se, assim, que a tendência mais coerente seria a de possível decréscimo do atrito com a elevação de carga, a qual é obtida pelos ajustes do terceiro grau, exceto para o trecho de 4,6m, que, como já denotado anteriormente, apresenta-se com comportamento anômalo. Este, portanto, foi o grau de polinômio escolhido nos ajustes. O mesmo se fez para os valores de y em função de $P_{\circ}$ (ver Figura 101).

Para os ajustes de $y\left(P_{0}\right)$, os polinômios ajustados do quarto grau tiveram seus coeficientes de determinação $R^{2}$ em torno 0,9989 , enquanto os de terceiro grau resultaram em torno de $R^{2} \cong 0,9983$, portanto, um pouco menores. Considerando que os dois valores são muito próximos, optou-se assim pelos polinômios de menor grau, ou seja, os de terceiro, que ficam coerentes com o grau já adotado para o atrito. Isso 
tem sua coerência também no fato de que, matematicamente, a fim de se obterem diagramas $\tau\left(P_{0}\right)-y\left(P_{o}\right)$ assintóticos num valor maior do que zero, o grau dos polinômios $\tau\left(P_{0}\right)$ e y $\left(P_{o}\right)$ devem ser os mesmos, resultando no comportamento esperado para o parâmetro $\mathrm{B}$.

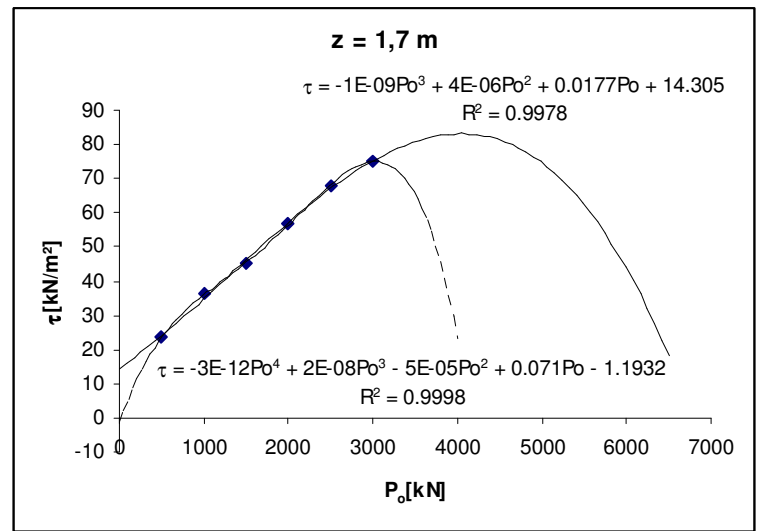

a)

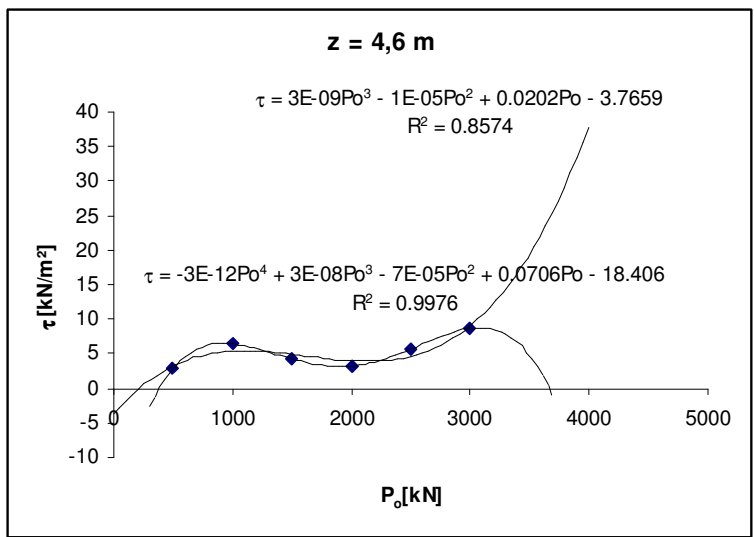

c)

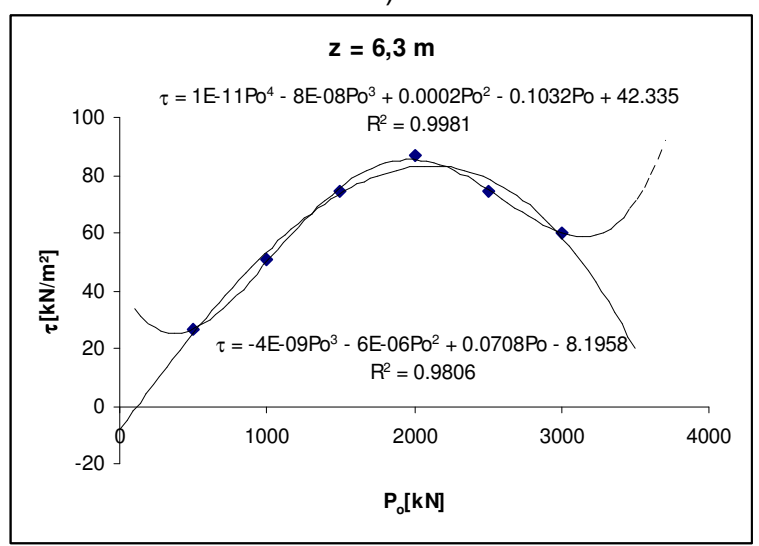

e)

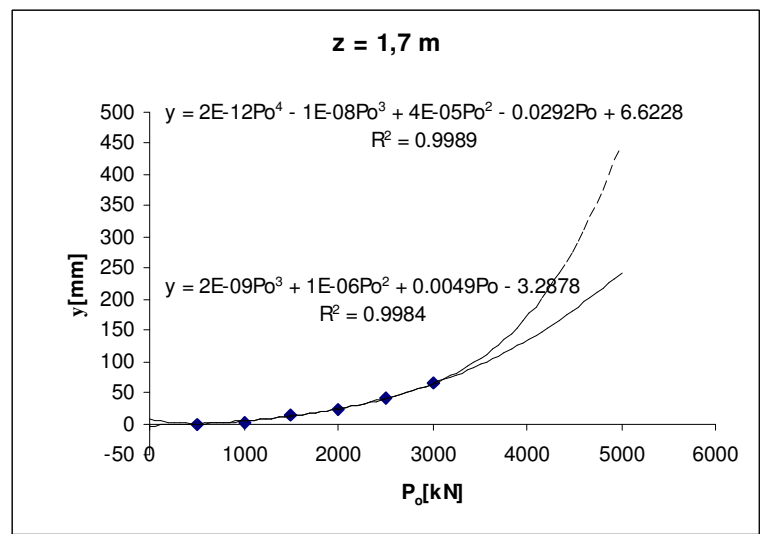

b)

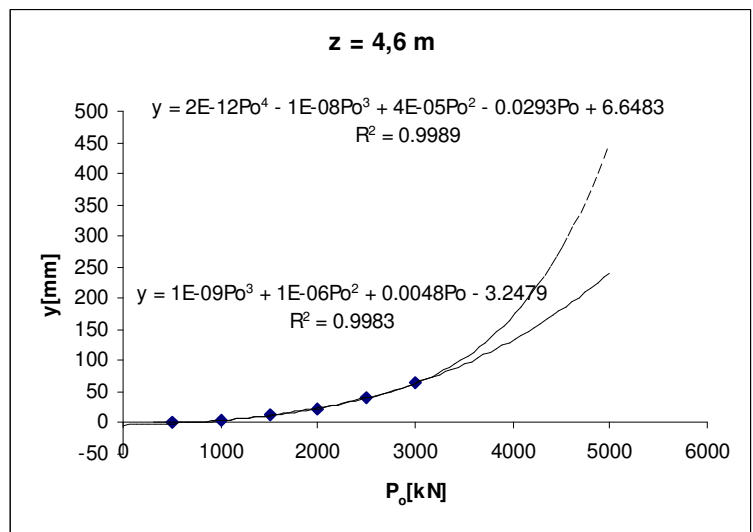

d)

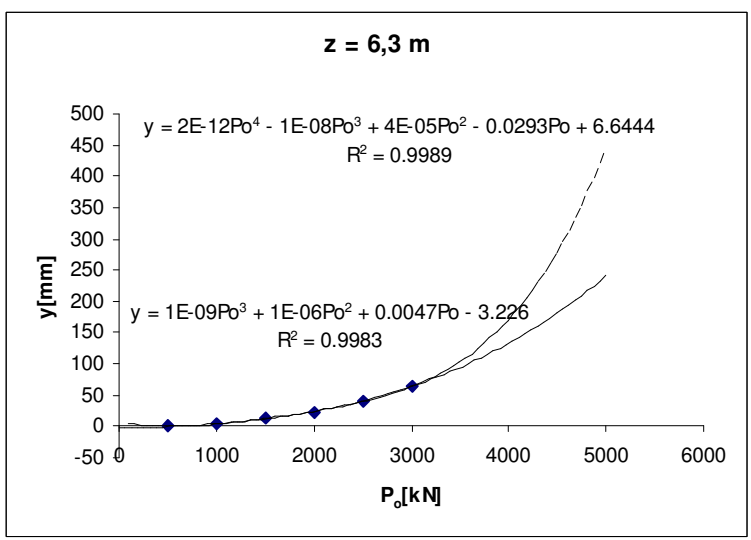

f)

Figura 101 - Ajustes polinomiais para: a) relação $\tau-P_{0}$ a $z=1,7 \mathrm{~m}$; b) relação y-Po a $z=1,7 \mathrm{~m}$; c) relação $\tau-P_{o}$ a $\left.z=4,6 m ; d\right)$ a relação $y-P_{o}$ a $\left.z=4,6 m ; e\right)$ relação $y-P_{o}$ a $z=6,3 m ;$ f) relação y- $P_{o}$ a $z=6,3 m$.

Aplicados a cada uma das profundidades indicadas, os valores dos coeficientes dos polinômios obtidos resultam nos apresentados na Tabela 68 . 
Tabela 68 - Valores dos coeficientes das regressões polinomiais $\tau\left(P_{0}\right) \mathrm{kN} / \mathrm{m}^{2}$

\begin{tabular}{ccccc}
\hline \multicolumn{5}{c}{$\tau\left(\mathrm{P}_{\mathrm{o}}\right)=\mathrm{a}_{3} . \mathrm{P}_{\mathrm{o}}{ }^{3}+\mathrm{a}_{2} . \mathrm{P}_{\mathrm{o}}{ }^{2}+\mathrm{a}_{1} . \mathrm{P}_{\mathrm{o}}+\mathrm{a}_{0}$} \\
\hline $\mathrm{z}(\mathrm{m})$ & $\mathrm{a}_{3}$ & $\mathrm{a}_{2}$ & $\mathrm{a}_{1}$ & $\mathrm{a}_{0}$ \\
\hline 0 & $-1.1931 \mathrm{E}-08$ & $3.3090 \mathrm{E}-05$ & $6.5285 \mathrm{E}-02$ & $3.1062 \mathrm{E}+01$ \\
0.7 & $-6.6574 \mathrm{E}-09$ & $1.9397 \mathrm{E}-05$ & $4.1279 \mathrm{E}-02$ & $2.3610 \mathrm{E}+01$ \\
1.4 & $-2.4688 \mathrm{E}-09$ & $8.0510 \mathrm{E}-06$ & $2.3429 \mathrm{E}-02$ & $1.6931 \mathrm{E}+01$ \\
1.7 & $-1.0058 \mathrm{E}-09$ & $3.9073 \mathrm{E}-06$ & $1.7664 \mathrm{E}-02$ & $1.4304 \mathrm{E}+01$ \\
2.1 & $6.3511 \mathrm{E}-10$ & $-9.4693 \mathrm{E}-07$ & $1.1736 \mathrm{E}-02$ & $1.1023 \mathrm{E}+01$ \\
2.8 & $2.6544 \mathrm{E}-09$ & $-7.5971 \mathrm{E}-06$ & $6.1988 \mathrm{E}-03$ & $5.8884 \mathrm{E}+00$ \\
3.4 & $3.5219 \mathrm{E}-09$ & $-1.1429 \mathrm{E}-05$ & $6.3527 \mathrm{E}-03$ & $2.1016 \mathrm{E}+00$ \\
3.5 & $3.5890 \mathrm{E}-09$ & $-1.1899 \mathrm{E}-05$ & $6.8180 \mathrm{E}-03$ & $1.5256 \mathrm{E}+00$ \\
4.6 & $2.8663 \mathrm{E}-09$ & $-1.3917 \mathrm{E}-05$ & $2.0229 \mathrm{E}-02$ & $-3.7698 \mathrm{E}+00$ \\
4.9 & $2.2044 \mathrm{E}-09$ & $-1.3461 \mathrm{E}-05$ & $2.6525 \mathrm{E}-02$ & $-4.8831 \mathrm{E}+00$ \\
5.6 & $-1.1496 \mathrm{E}-10$ & $-1.0720 \mathrm{E}-05$ & $4.5614 \mathrm{E}-02$ & $-6.9290 \mathrm{E}+00$ \\
5.8 & $-9.7684 \mathrm{E}-10$ & $-9.5057 \mathrm{E}-06$ & $5.2198 \mathrm{E}-02$ & $-7.3717 \mathrm{E}+00$ \\
6.3 & $-3.5189 \mathrm{E}-09$ & $-5.6314 \mathrm{E}-06$ & $7.0858 \mathrm{E}-02$ & $-8.2027 \mathrm{E}+00$ \\
6.8 & $-6.6144 \mathrm{E}-09$ & $-5.5918 \mathrm{E}-07$ & $9.2659 \mathrm{E}-02$ & $-8.6396 \mathrm{E}+00$ \\
6.9 & $-7.2999 \mathrm{E}-09$ & $5.9900 \mathrm{E}-07$ & $9.7396 \mathrm{E}-02$ & $-8.6798 \mathrm{E}+00$ \\
7.0 & $-8.0075 \mathrm{E}-09$ & $1.8051 \mathrm{E}-06$ & $1.0226 \mathrm{E}-01$ & $-8.7041 \mathrm{E}+00$ \\
\hline
\end{tabular}

Tabela 69 - Valores dos coeficientes das regressões polinomiais y $\left(P_{0}\right) \mathrm{mm}$

\begin{tabular}{ccccc}
\hline \multicolumn{5}{c}{$y\left(\mathrm{P}_{\mathrm{o}}\right)=\mathrm{b}_{3} . \mathrm{P}_{\mathrm{o}}{ }^{3}+\mathrm{b}_{2} . \mathrm{P}_{\mathrm{o}}{ }^{2}+\mathrm{b}_{1} . \mathrm{P}_{\mathrm{o}}+\mathrm{b}_{0}$} \\
\hline $\mathrm{z}(\mathrm{m})$ & $\mathrm{b}_{3}$ & $\mathrm{~b}_{2}$ & $\mathrm{~b}_{1}$ & $\mathrm{~b}_{0}$ \\
\hline 0 & $1.5064 \mathrm{E}-09$ & $1.3187 \mathrm{E}-06$ & $4.9989 \mathrm{E}-03$ & $-3.2982 \mathrm{E}+00$ \\
0.7 & $1.5057 \mathrm{E}-09$ & $1.3207 \mathrm{E}-06$ & $4.9542 \mathrm{E}-03$ & $-3.2962 \mathrm{E}+00$ \\
1.4 & $1.5041 \mathrm{E}-09$ & $1.3254 \mathrm{E}-06$ & $4.9154 \mathrm{E}-03$ & $-3.2909 \mathrm{E}+00$ \\
1.7 & $1.5032 \mathrm{E}-09$ & $1.3278 \mathrm{E}-06$ & $4.8999 \mathrm{E}-03$ & $-3.2879 \mathrm{E}+00$ \\
2.1 & $1.5021 \mathrm{E}-09$ & $1.3312 \mathrm{E}-06$ & $4.8799 \mathrm{E}-03$ & $-3.2832 \mathrm{E}+00$ \\
2.8 & $1.5001 \mathrm{E}-09$ & $1.3370 \mathrm{E}-06$ & $4.8461 \mathrm{E}-03$ & $-3.2740 \mathrm{E}+00$ \\
3.4 & $1.4988 \mathrm{E}-09$ & $1.3411 \mathrm{E}-06$ & $4.8179 \mathrm{E}-03$ & $-3.2654 \mathrm{E}+00$ \\
3.5 & $1.4986 \mathrm{E}-09$ & $1.3417 \mathrm{E}-06$ & $4.8132 \mathrm{E}-03$ & $-3.2640 \mathrm{E}+00$ \\
4.6 & $1.4971 \mathrm{E}-09$ & $1.3457 \mathrm{E}-06$ & $4.7640 \mathrm{E}-03$ & $-3.2479 \mathrm{E}+00$ \\
4.9 & $1.4969 \mathrm{E}-09$ & $1.3460 \mathrm{E}-06$ & $4.7515 \mathrm{E}-03$ & $-3.2437 \mathrm{E}+00$ \\
5.6 & $1.4966 \mathrm{E}-09$ & $1.3453 \mathrm{E}-06$ & $4.7254 \mathrm{E}-03$ & $-3.2344 \mathrm{E}+00$ \\
5.8 & $1.4965 \mathrm{E}-09$ & $1.3449 \mathrm{E}-06$ & $4.7190 \mathrm{E}-03$ & $-3.2319 \mathrm{E}+00$ \\
6.3 & $1.4962 \mathrm{E}-09$ & $1.3432 \mathrm{E}-06$ & $4.7057 \mathrm{E}-03$ & $-3.2260 \mathrm{E}+00$ \\
6.8 & $1.4957 \mathrm{E}-09$ & $1.3412 \mathrm{E}-06$ & $4.6975 \mathrm{E}-03$ & $-3.2207 \mathrm{E}+00$ \\
6.9 & $1.4955 \mathrm{E}-09$ & $1.3408 \mathrm{E}-06$ & $4.6966 \mathrm{E}-03$ & $-3.2197 \mathrm{E}+00$ \\
7.0 & $1.4954 \mathrm{E}-09$ & $1.3404 \mathrm{E}-06$ & $4.6960 \mathrm{E}-03$ & $-3.2188 \mathrm{E}+00$ \\
\hline
\end{tabular}

Apesar da pequena variação dos valores dos coeficientes de $y\left(P_{o}\right)$, não se deve tentar considerá-los como um único valor médio constante, pois são inversamente proporcionais à rigidez do sistema estaca-solo. Assim, o pequeno valor absoluto é devido à elevada rigidez da estaca, e a pequena variação relativa entre eles se deve à variação de rigidez do solo ao longo do comprimento da estaca. Portanto, dentro dos valores dos coeficientes $a_{i}$ e $b_{j}$ dos polinômios está embutido o valor de $z$, o que pode ser identificado fazendo-se um ajuste matemático de superfície (item E.8). 
Tendo-se tais valores, pode-se agora comparar os resultados $\tau$-y usuais com os obtidos pelos polinômios em z para cada par $\left(z ; P_{0}\right)$ e com os polinômios em $P_{0}$ como demonstrado acima. A Figura 72 exemplifica essas comparações para as profundidades dos pontos médios dos trechos instrumentados: 1,7; 4,6 e 6,3m.

Os valores obtidos pelos polinômios $\tau\left(P_{o}\right)$ e $y\left(P_{o}\right)$ diferem pouco dos $\tau(z)$ e $y(z)$, visto que os ajustes foram bons.

É evidente que apesar do cuidado de se escolher os polinômios do terceiro grau para os ajustes de $\tau\left(\mathrm{P}_{\mathrm{o}}\right)$ e y $\left(\mathrm{P}_{\mathrm{o}}\right)$, como sendo aqueles que indicariam decréscimo do atrito com a elevação da carga, não se pode dizer que isso realmente aconteça sem que se avance no carregamento para constatação.

\section{E.5 PROPOSTA DE AJUSte POLINOMIAL PARA A FUnçÃo de CISALHAMENTO $\tau(z)$}

De forma geral, propõe-se aqui que a variação de resistência do solo com a profundidade $[\tau(z)]$ pode ser aproximada por um polinômio de grau " $n$ " e coeficientes " $a_{i}$ " (com "i" variando de 0 a " $n$ "), e, assim, integrando-se, tem-se as seguintes fórmulas gerais a partir dos valores iniciais do topo da destaca $\left(z=0 ; y_{0} ; P_{0}\right)$ :

$$
\begin{gathered}
\tau(z)=\sum_{i=0}^{n}\left(a_{i} \cdot z^{i}\right) \\
N(z)=P_{o}-U \cdot\left[\sum_{i=0}^{n}\left(\frac{a_{i}}{(i+1)} \cdot z^{(i+1)}\right)\right] \\
y(z)=y_{\circ}-\frac{1}{E \cdot S} \cdot\left\{P_{0} \cdot z-U \cdot\left[\sum_{i=0}^{n}\left(\frac{a_{i}}{(i+2) \cdot(i+1)} \cdot z^{(i+2)}\right)\right]\right\}
\end{gathered}
$$

Assim, se $\tau(z)$ for, por exemplo, um polinômio de grau $n=3, N(z)$ será um polinômio de grau $n+1=4$, e $y(z)$ será um polinômio de grau $m=n+2=5$ com as seguintes formas, considerando as constantes de integração em relação aos valores para o topo da estaca $\left(z=0 ; P_{\circ}\right.$ e $\left.y_{0}\right)$ :

$$
\tau(z)=a_{\circ}+a_{1} \cdot z+a_{2} \cdot z^{2}+a_{3} \cdot z^{3}
$$




$$
\begin{gathered}
N(z)=P_{\circ}-U \cdot\left(a_{0} \cdot z+\frac{a_{1}}{2} \cdot z^{2}+\frac{a_{2}}{3} \cdot z^{3}+\frac{a_{3}}{4} \cdot z^{4}\right) \\
y(z)=y_{\circ}-\frac{1}{E \cdot S} \cdot\left[P_{0} \cdot z-U \cdot\left(\frac{a_{0}}{2} \cdot z^{2}+\frac{a_{1}}{6} \cdot z^{3}+\frac{a_{2}}{12} \cdot z^{4}+\frac{a_{3}}{20} \cdot z^{5}\right)\right] \Rightarrow \\
\Rightarrow y(z)=y_{\circ}-\frac{1}{E \cdot S} \cdot P_{0} \cdot z+\frac{U}{E \cdot S} \cdot\left(\frac{a_{0}}{2} \cdot z^{2}+\frac{a_{1}}{6} \cdot z^{3}+\frac{a_{2}}{12} \cdot z^{4}+\frac{a_{3}}{20} \cdot z^{5}\right)
\end{gathered}
$$

\section{E.6 PROPOSTA DE AJUSTE POLINOMIAL PARA A FUNÇÃo dE DESLOCAMENTO y(z)}

Por outro lado, se partirmos da função dos deslocamentos $y(z)$ como sendo um polinômio com grau $m=5$, por exemplo, obtém-se com outra notação:

$$
\begin{gathered}
y(z)=y_{0}-\frac{P_{0}}{E \cdot S} \cdot z+\frac{U}{E \cdot S} \cdot\left(b_{2} \cdot z^{2}+b_{3} \cdot z^{3}+b_{4} \cdot z^{4}+b_{5} \cdot z^{5}\right) \\
N(z)=P_{0}-U \cdot\left(2 \cdot b_{2} \cdot z+3 \cdot b_{3} \cdot z^{2}+4 \cdot b_{4} \cdot z^{3}+5 \cdot b_{5} \cdot z^{4}\right) \\
\tau(z)=2 \cdot b_{2}+6 \cdot b_{3} \cdot z+12 \cdot b_{4} \cdot z^{2}+20 \cdot b_{5} \cdot z^{3}
\end{gathered}
$$

Resultando, assim, em outras fórmulas gerais:

$$
\begin{gathered}
y(z)=y_{0}-\frac{P_{0}}{E \cdot S} \cdot z+\frac{U}{E \cdot S} \cdot \sum_{j=2}^{m}\left(b_{j} \cdot z^{j}\right) \\
N(z)=P_{o}-U \cdot \sum_{j=2}^{m}\left[j \cdot b_{j} \cdot z^{(j-1)}\right] \\
\tau(z)=\sum_{j=2}^{m}\left[j \cdot(j-1) \cdot b_{j} \cdot z^{(j-2)}\right]
\end{gathered}
$$

Convém notar que $y_{0}, \mathrm{P}_{0}, \mathrm{U}, \mathrm{E}$ e $\mathrm{S}$ demonstram o significado físico dos coeficientes dos polinômios. Esse é um aspecto interessante dos ajustes polinomiais propostos.

As relações entre as fórmulas gerais partindo-se de $\tau(z)$ ou de $y(z)$ são imediatas:

$$
\mathrm{n}=\mathrm{m}-2
$$




$$
a_{i}=(i+1) \cdot(i+2) \cdot b_{i+2}
$$

Dessa maneira pode-se converter uma função na outra sem dificuldades.

\section{E.7 FÓRMULAS GERAIS PARA AS FUNÇÕES PARTINDO DO VALOR INICIAL DA PONTA DA ESTACA $(z=L)$}

O polinômio de ajuste da função $\tau(z)$ pode ser deduzido partindo-se da ponta (apo, para $z=L$ ), considerando-se um polinômio análogo ao $(257)$, com coeficientes $\left(a p_{i}\right)$ relativos à ponta, fazendo a variável mudar de $z$ para $h^{\prime}=L-z$ :

$$
\tau(z)=a p_{0}+a p_{1} \cdot(L-z)+a p_{2} \cdot(L-z)^{2}+a p_{3} \cdot(L-z)^{3}
$$

Cuja fórmula geral é imediata:

$$
\tau(z)=\sum_{i=0}^{n}\left(a p_{i} \cdot(L-z)^{i}\right)
$$

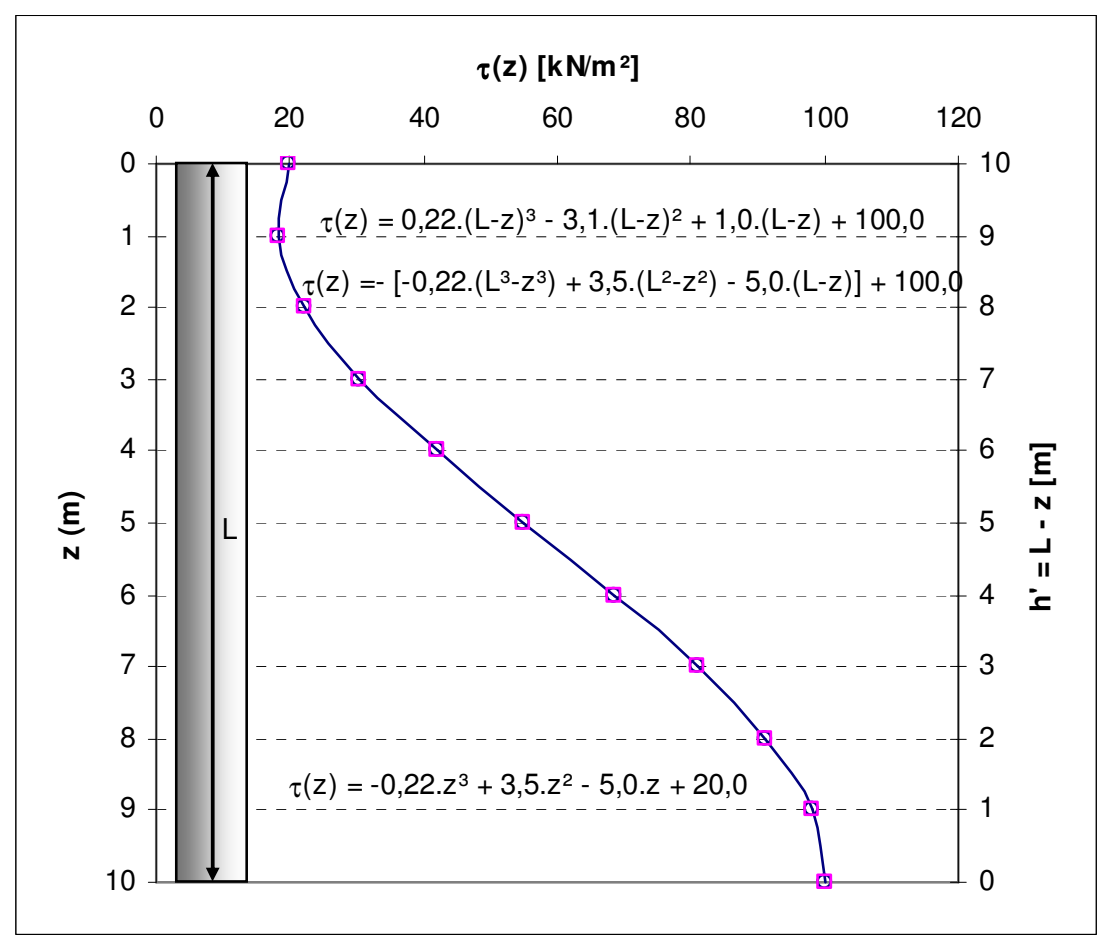

Figura 102 - Exemplo de curva ajustada e formas de apresentação da função $\tau(z)$ correspondente em função do comprimento $L$ da estaca. 
A Figura 102 mostra um exemplo de como a mesma curva ajustada pode se apresentar de diversas formas matemáticas, conforme (257), (268) e ainda na forma menos interessante da expressão (270).

$$
\tau(z)=a p_{o}-\sum_{i=1}^{n}\left(a_{i} \cdot\left(L^{i}-z^{i}\right)\right)
$$

A relação entre os fatores $a_{i}$ da expressão geral (257) e os respectivos $a p_{i} d a$ expressão (268) pode ser demonstrada como sendo igual a:

$$
\mathrm{ap}_{\mathrm{i}}:=(-1) \cdot\left[\mathrm{a}_{\mathrm{i}}+\sum_{\mathrm{k}=0}^{\mathrm{n}}\left[\frac{\prod_{\mathrm{p}=0}^{\mathrm{i}}(\mathrm{k}-\mathrm{p})}{\mathrm{i} !(\mathrm{k}-\mathrm{i})} \mathrm{a}_{\mathrm{k}} \cdot \mathrm{L}^{\mathrm{k}-\mathrm{i}}\right]\right]_{; \operatorname{com} 0 \leq \mathrm{i} \leq \mathrm{n}}
$$

A expressão (271) pode ser usada para obter-se a expressão de qualquer polinômio, partindo-se de uma profundidade $\mathrm{z}=\mathrm{L}$ ou de outro valor qualquer, desde que já se tenham os valores dos fatores $a_{i}$ do polinômio relativo ao topo da estaca. Portanto, ela não se restringe apenas à função $\tau(z)$, podendo ser aplicada para se obter os valores $\mathrm{bp}_{\mathrm{i}}$ a partir da forma dada em (265).

A expressão das cargas $\mathrm{N}(\mathrm{z})$ também pode ser expressa de outra forma, considerando para esse caso a carga da ponta $P_{p}$ como constante de integração e não mais $P_{0}$, como em (255):

$$
\begin{aligned}
P_{0}=N(z)+T(z)=N(L)+T(L)=P_{p}+U \cdot \int_{0}^{L} \tau(z) \cdot d z \Rightarrow \\
\Rightarrow N(z)+U \cdot \int_{0}^{z} \tau(z) \cdot d z=P_{p}+U \cdot \int_{0}^{L} \tau(z) \cdot d z \Rightarrow \\
\Rightarrow N(z)=P_{p}+U \cdot \int_{0}^{L} \tau(z) \cdot d z-U \cdot \int_{0}^{z} \tau(z) \cdot d z=P_{p}+U \cdot \int_{z}^{L} \tau(z) \cdot d z \Rightarrow \\
\Rightarrow N(z)=P_{p}+U \cdot \int_{z}^{L} \tau(z) \cdot d z
\end{aligned}
$$

Assim, tanto a expressão (27) quanto a (272) podem ser utilizadas para cálculo da carga axial atuante na estaca na profundidade $z$, desde que se disponha dos valores iniciais do topo ou da ponta, respectivamente. 
Como o mais interessante é ter-se a expressão em função de $h^{\prime}=L-z$, para simplificar a dedução sugere-se aqui determinar-se a expressão (255) a partir da (254) e aplicar a conversão dos coeficientes dada em (271), para obtenção da expressão na forma geral (273):

$$
N(z)=P_{p}+U \cdot\left[\sum_{i=0}^{n}\left(\frac{a p_{i}}{(i+1)} \cdot(L-z)^{(i+1)}\right)\right]
$$

Analogamente, a expressão (271) pode ser aplicada para a forma dada em (264), substituindo-se $a_{i}$ e ap respectivamente por $b_{i}$ e bp $p_{i}$.

Procede-se de forma semelhante para a expressão dos deslocamentos $y(z)$, por analogia com a expressão (27), pode-se dizer que a deformação ou o encurtamento medido desde a profundidade $z$ até a ponta $\left(z=L ; y(L)=y_{p}\right)$ é dado por:

$$
y(z)-y_{p}=\frac{1}{E \cdot S} \cdot \int_{z}^{L} N(z) \cdot d z
$$

Portanto, observa-se que para a constante de integração passar da condição inicial do topo $\left[y(0)=y_{0}\right]$ para a da ponta $\left[y(L)=y_{p}\right]$, passa-se da expressão (28) para a (274). Sugere-se também obter a expressão (256) por integração a partir da (254) e aplicar a conversão dada em (271) para obter a expressão de y(z) na forma:

$$
y(z)=y_{p}+\frac{1}{E \cdot S} \cdot\left\{P_{p} \cdot(L-z)+U \cdot\left[\sum_{i=0}^{n}\left(\frac{a p_{i}}{(i+2) \cdot(i+1)} \cdot(L-z)^{(i+2)}\right)\right]\right\}
$$

Assim, aplicadas aos dados de instrumentação, o ajuste com tais polinômios permite rápida definição do problema e determinação das demais grandezas do ensaio em profundidade.

\section{E.8 PROPOSTA DE AJUSTE POLINOMIAL DE SUPERFÍCIE PARA AS EXPRESSÕES $\tau\left(z ; P_{0}\right)$ E y(z;Po)}

Embora não seja estritamente necessário, pode-se buscar ajustar os pontos medidos na instrumentação da estaca a uma equação de superfície com três variáveis para se modelar a influência conjunta de $P_{o}$ e z. Considerem-se os polinômios em $z$ dados como exemplo de ajuste de $\tau$ e $y$ : 


$$
\begin{gathered}
y(z)=b_{\circ}+b_{1} \cdot z+b_{2} \cdot z^{2}+b_{3} \cdot z^{3}+b_{4} \cdot z^{4} \\
\tau(z)=a_{\circ}+a_{1} \cdot z+a_{2} \cdot z^{2}
\end{gathered}
$$

Considere-se que cada um dos valores de $a_{i}$ e $b_{j}$ destes polinômios em z são, na verdade, dados por outros diferentes polinômios em $\mathrm{P}_{\mathrm{o}}$, por exemplo, do terceiro grau, com coeficientes:

... e assim por diante

$$
\begin{aligned}
& b_{0}\left(P_{o}\right)=b_{00}+b_{01} \cdot P_{0}+b_{02} \cdot P_{0}^{2}+b_{03} \cdot P_{o}^{3} \\
& b_{1}\left(P_{o}\right)=b_{10}+b_{11} \cdot P_{0}+b_{12} \cdot P_{0}^{2}+b_{13} \cdot P_{0}^{3} \\
& b_{2}\left(P_{0}\right)=b_{20}+b_{21} \cdot P_{0}+b_{22} \cdot P_{0}{ }^{2}+b_{23} \cdot P_{0}^{3}
\end{aligned}
$$

$$
\begin{aligned}
& a_{0}\left(P_{0}\right)=a_{00}+a_{01} \cdot P_{0}+a_{02} \cdot P_{0}{ }^{2}+a_{03} \cdot P_{0}{ }^{3} \\
& a_{1}\left(P_{0}\right)=a_{10}+a_{11} \cdot P_{0}+a_{12} \cdot P_{0}{ }^{2}+a_{13} \cdot P_{0}{ }^{3} \\
& a_{2}\left(P_{0}\right)=a_{20}+a_{21} \cdot P_{0}+a_{22} \cdot P_{0}{ }^{2}+a_{23} \cdot P_{0}{ }^{3}
\end{aligned}
$$

... e assim por diante

Fazendo-se a substituição dos polinômios dados em (278) e (279) nos polinômios (276) e (277), encontra-se a forma da função de superfície que aproxima os pontos experimentais. Por fim, as expressões das superfícies aproximadas na forma $a_{i j}$ e $b_{j i}$ podem ser obtidas por uma regressão múltipla na forma:

$$
\begin{aligned}
& \tau\left(z ; P_{o}\right)=a_{23} \cdot P_{0}^{3} \cdot z^{2}+a_{13} \cdot P^{3} \cdot z+a_{03} \cdot P^{3}+a_{22} \cdot P^{2} \cdot z^{2}+a_{12} \cdot P^{2} \cdot z+ \\
& +a_{02} \cdot P^{2}+a_{21} \cdot P o \cdot z^{2}+a_{11} \cdot P o \cdot z+a_{01} \cdot P o+a_{20} \cdot z^{2}+a_{10} \cdot z+a_{00} \\
& y\left(z ; P_{0}\right)=b_{43} \cdot P o^{3} \cdot z^{4}+b_{33} \cdot P_{0}^{3} \cdot z^{3}+b_{23} \cdot P_{0}^{3} \cdot z^{2}+b_{13} \cdot P_{0}^{3} \cdot z+b_{03} \cdot P o^{3}+ \\
& +b_{42} \cdot \mathrm{Po}^{2} \cdot \mathrm{z}^{4}+\mathrm{b}_{32} \cdot \mathrm{Po}^{2} \cdot \mathrm{z}^{3}+\mathrm{b}_{22} \cdot \mathrm{PO}^{2} \cdot \mathrm{z}^{2}+\mathrm{b}_{12} \cdot \mathrm{Po}^{2} \cdot \mathrm{z}+\mathrm{b}_{02} \cdot \mathrm{Po}^{2}+\mathrm{b}_{41} \cdot \mathrm{Po} \cdot \mathrm{z}^{4}+ \\
& +b_{31} \cdot \operatorname{Po} \cdot z^{3}+b_{21} \cdot \text { Po } \cdot z^{2}+b_{11} \cdot \text { Po } \cdot z+b_{01} \cdot \text { Po }+b_{40} \cdot z^{4}+b_{30} \cdot z^{3}+b_{20} \cdot z^{2}+b_{10} \cdot z+b_{00}
\end{aligned}
$$

Essas expressões permitem interpolar qualquer valor de $\tau$ e y dados $z$ e $P_{0}$.

\section{E.9 DEDUÇÃO DA EXPRESSÃO DO COEFICIENTE C DE DISTRIBUIÇÃO DO ATRITO LATERAL AO LONGO DO FUSTE}

O coeficiente C do método das Leis de Cambefort modificadas por Massad (2002) representa a distribuição do atrito ao longo da profundidade. Massad (2002) o traduz como sendo a relação entre o valor médio da carga transferida ( $\left.\mathrm{Al}-\mathrm{Al} \mathrm{I}_{\text {med }}\right)$ e $\mathrm{o}$ atrito 
lateral total (Al). Para seu cálculo, Massad (2002) cita Leonards e Loveel (1979), também citados por Fellenius (1980), os quais apresentam nomogramas e fórmulas para o cálculo de $\mathrm{C}$, informando que para os casos mais comuns de camadas heterogêneas o mesmo varia de 0,5 a 0,8 .

Buscando-se relacionar a forma de análise dos ensaios instrumentados e do método das Leis de Cambefort modificadas, propõe-se aqui uma forma de cálculo do valor de $C$ calcada nos ajustes polinomiais da instrumentação, conforme apresentado no Capítulo 5.

Parte-se inicialmente de uma estaca em solo homogêneo com distribuição de atrito constante em profundidade, que, embora seja uma aproximação, permite representar de forma adequada bom número de casos práticos. Assumindo-se que o atrito lateral tenha se mobilizado plenamente ao longo de todo o comprimento da estaca, apresentando eventualmente uma parcela de ponta mobilizada $P_{p}$ (ver Figura 103), pelo modelo das Leis de Cambefort modificadas, exatamente neste momento a curva carga-recalque no topo atinge o ponto 4 (Figura 19), e a dedução da expressão do recalque no topo quando isso ocorre pode ser obtida a partir da expressão (28), da seguinte forma:

$$
\begin{aligned}
& y_{o}-y_{p}=\frac{P_{o}+P_{p}}{2} \cdot \frac{L}{E \cdot S}=\frac{\left(A l+P_{p}\right)+P_{p}}{2} \cdot \frac{1}{K r}=\frac{A l}{2 \cdot K r}+\frac{P_{p}}{K r} \Rightarrow \\
& \Rightarrow y_{o}=y_{p}+\frac{A l}{2 \cdot K r}+\frac{P_{p}}{K r}
\end{aligned}
$$

Onde $y_{p}$ : recalque na ponta da estaca; $y_{0}$ : recalque no topo da estaca;

$$
\mathrm{y}_{\mathrm{z} 1}-\mathrm{y}_{\mathrm{z} 2}=\frac{1}{2} \cdot \frac{\left(\mathrm{N}_{\mathrm{z} 2}-\mathrm{N}_{\mathrm{z} 1}\right)}{\mathrm{Kr}}+\frac{\mathrm{N}_{\mathrm{z} 2}}{\mathrm{Kr}}
$$

Aplicando-se a mesma dedução para dois pontos ao longo do fuste, nas profundidades $z_{1}$ e $z_{2}$, chega-se à expressão geral, onde o valor $1 / 2$ corresponde a $C$, visto que $o$ atrito foi considerado constante. 


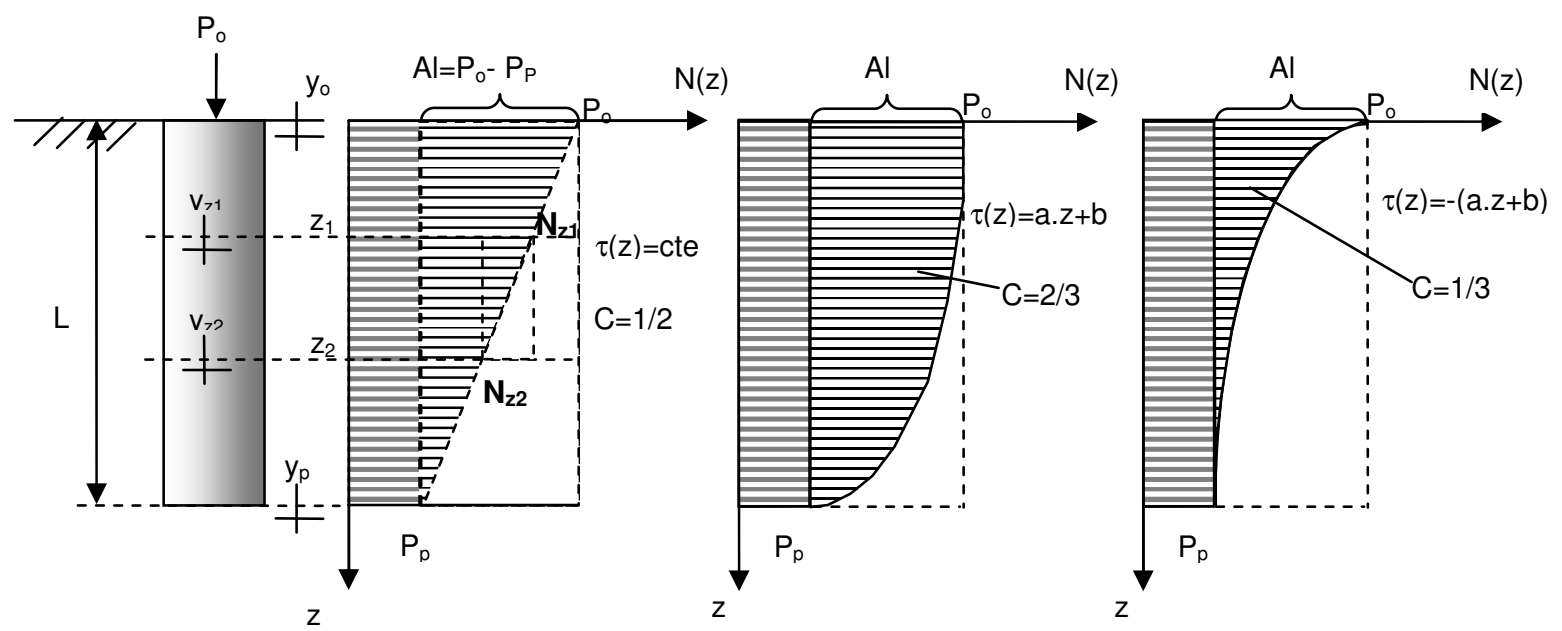

Figura 103 - Distribuição da força normal para atrito constante com determinação de C

Comparando-se as áreas $\mathrm{Al} . \Delta \mathrm{z} \mathrm{com}$ as áreas hachuradas relativas ao atrito $\mathrm{Al}$, na Figura 103, e isolando-se C, pode-se expressá-lo como:

$$
C=\frac{\int_{z_{1}}^{z_{2}} N(z) \cdot d z-N\left(z_{2}\right) \cdot\left(z_{2}-z_{1}\right)}{\left[N\left(z_{1}\right)-N\left(z_{2}\right)\right] \cdot\left(z_{2}-z_{1}\right)}
$$

Desta forma, tendo-se as leituras da instrumentação $d y / d z$, obtêm-se $N(z)$, a partir do qual, se comparados dois pontos instrumentados às profundidades $z_{1}$ e $z_{2}$, podese obter o valor de $\mathrm{C}$ correspondente, bem como para a estaca como um todo. 


\section{APÊNDICE F - RESULTADOS DA APLICAÇÃO DA MSU A DIVERSOS TIPOS DE ESTACA E SOLOS}

Neste Apêndice, apresentam-se os resultados da aplicação da MSU às estacas discutidas como exemplo, a algumas estacas ensaiadas nos campos experimentais brasileiros e em outras diversas localidades do país, buscando demonstrar a sua aplicabilidade praticamente irrestrita.

A apresentação se fará em três páginas para cada aplicação, com os dados da estaca, da sondagem, apresentação da separação do atrito e comparação com os critérios de ruptura, além dos valores corrigidos e os anteriormente considerados na aplicação dos métodos de teste Mediado e Expedito. A Tabela 70 resume as características principais das estacas, apresentadas em ordem de citação no texto, incluído o item em que foi citada, quando for o caso:

Tabela 70 - Estacas escolhidas para exemplo de aplicação da MSU

\begin{tabular}{|c|c|c|c|c|c|}
\hline No. & Identific. & Referência & Local & Item & $\begin{array}{l}\text { Obs. } \\
\end{array}$ \\
\hline 1 & $\mathrm{EH} 2$ & Alledi e Polido (2008) & Vitória - ES & 2.8 & $\begin{array}{c}\text { Estaca Hélice em solo do } \\
\text { litoral capixaba }\end{array}$ \\
\hline 2 & G202 & $\begin{array}{l}\text { Amann (2000) apud } \\
\text { Corrêa (1988) }\end{array}$ & Guarujá -SP & $\begin{array}{l}2.12 \\
3.7 \\
4.3\end{array}$ & $\begin{array}{l}\text { Estaca Raiz em solo do } \\
\text { litoral paulista }\end{array}$ \\
\hline 3 & E013 & $\begin{array}{l}\text { Massad (1994) apud } \\
\text { Danziger (1980) }\end{array}$ & $\begin{array}{l}\text { Alemoa - } \\
\text { Santos }\end{array}$ & 3.13 & $\begin{array}{c}\text { Estaca tubada metálica em } \\
\text { solo do litoral paulista }\end{array}$ \\
\hline 4 & Penha & $\begin{array}{l}\text { Massad (1992 e 1993) } \\
\text { apud Raiz Eng.(1990) }\end{array}$ & Penha - SP & $\begin{array}{l}4.4 \mathrm{e} \\
4.6\end{array}$ & $\begin{array}{c}\text { Estaca tubada metálica em } \\
\text { solo terciário paulistano }\end{array}$ \\
\hline 5 & G201 & $\begin{array}{l}\text { Amann (2000) apud } \\
\text { Corrêa (1988) }\end{array}$ & Guarujá - SP & 4.6 & $\begin{array}{c}\text { Estaca Raiz em solo do } \\
\text { litoral paulista }\end{array}$ \\
\hline 6 & G603 & $\begin{array}{l}\text { Amann (2000) apud } \\
\text { Rocha et al. (1985) }\end{array}$ & São Paulo & 4.5 .1 & $\begin{array}{c}\text { Estaca Raiz instrumentada } \\
\text { em solo terciário paulistano } \\
\text { Estaca barrete }\end{array}$ \\
\hline 7 & Barrete & ABEF (1989) & USP-SP & 5.2 & $\begin{array}{l}\text { instrumentada em solo } \\
\text { terciário paulistano }\end{array}$ \\
\hline 8 & PC19 & $\begin{array}{l}\text { Melo (2008) apud } \\
\text { Soares et al (2008) }\end{array}$ & Recife - SE & - & $\begin{array}{c}\text { Estaca cravada em solo do } \\
\text { litoral sergipano }\end{array}$ \\
\hline 9 & CON-3 & $\begin{array}{l}\text { Melo (2008) apud } \\
\text { Segantini (2008) }\end{array}$ & $\begin{array}{l}\text { Ilha Solteira - } \\
\text { SP }\end{array}$ & - & $\begin{array}{l}\text { Estaca escavada em solo } \\
\text { do interior paulista }\end{array}$ \\
\hline 10 & ESC 3 & Albuquerque (2000) & $\begin{array}{l}\text { Campinas - } \\
\text { SP }\end{array}$ & - & $\begin{array}{c}\text { Estaca escavada } \\
\text { instrumentada em solo do } \\
\text { interior paulista }\end{array}$ \\
\hline 11 & ESC 1 & Albuquerque (2000) & $\begin{array}{l}\text { Campinas - } \\
\text { SP }\end{array}$ & - & $\begin{array}{c}\text { Estaca escavada } \\
\text { instrumentada em solo do } \\
\text { interior paulista }\end{array}$ \\
\hline 12 & PC25 & Penna (1985) & $\begin{array}{l}\text { Santo André - } \\
\text { SP }\end{array}$ & - & $\begin{array}{c}\text { Estaca cravada em solo } \\
\text { terciário paulistano }\end{array}$ \\
\hline
\end{tabular}

Nos gráficos seguintes, na separação da parcela de atrito, quando a adoção da rigidez $\mathrm{Kr}$ da estaca obtida pelo sistema proposto resultou diferente da rigidez 
teórica, porém os valores de atrito para ambos não apresentavam diferenças significativas entre si (interseção das hipérboles próximas à região das assíntotas ver item 4.3), foram mantidos os valores obtidos pelo sistema.

A escolha do critério de ruptura seguiu a recomendação de Fellenius (2006) sendo o mais próximo possível da carga máxima de ensaio. Pela grande influência exercida pelo último ponto de ensaio no valor da ruptura (ver item 3.6.4), o método de Van der Veen (1953), modificado por Aoki (1976), acabou por ser o escolhido na maioria dos casos, o que não significa que seu valor represente a ruptura real, apenas que foi o mais próximo da carga máxima de ensaio nos casos estudados.

A indicação do sistema utilizado para obtenção simultânea dos valores de $\mu \mathrm{Alr}$ e $\mathrm{Kr}$ segue a seguinte legenda: "Completo", corresponde ao apresentado no item 4.3.2, ou seja, ajuste da curva completa (carregamento e descarregamento); "Sem 7-8", corresponde ao apresentado em 4.3.3 (sem a consideração do ajuste do trecho 7-8); "DRM", corresponde ao item 4.3.4 (sem consideração do trecho 7-8 nem do 3-4, ambos parabólicos); "DRM-C", corresponde ao item 4.3.5 (desconsiderado o ajuste do descarregamento, ou seja, trechos 7-8 e 8-9). 


\section{APLICAÇÃO DA METODOLOGIA SEMIEMPÍRICA UNIFICADA}

ESTACA: EH2

Local: Vitória-ES

Tipo: Hélice contínua
Dimensões:

$\mathrm{D}=\quad 400 \mathrm{~mm}$

$\mathrm{L}=\quad 12 \mathrm{~m}$

Estratigrafia: Fuste

Embutimento:

$\mathrm{L}_{2}=$

$3,2 \mathrm{~m}$

8D 3D

\begin{tabular}{|c|c|c|c|c|c|c|}
\hline no. & Solo & $\mathrm{N}_{\mathrm{SPT}}$ médio $(\mathrm{F})$ & $\Delta \mathrm{L} / \mathrm{L}$ & & \multirow{2}{*}{\multicolumn{2}{|c|}{ Ponta }} \\
\hline & \begin{tabular}{|l} 
Areia \\
Areia siltosa
\end{tabular} & $\begin{array}{l}19,5 \\
27,7\end{array}$ & $\begin{array}{l}0,24 \\
0,52\end{array}$ & & & \\
\hline 3 & Argila & 6,0 & 0,10 & & Solo & $\mathrm{N}_{\mathrm{SPT}}(\mathrm{P})$ \\
\hline & Areia argilosa & 22,0 & 0,14 & $8 D$ & Areia siltosa & 8 \\
\hline 6 & & & & $3 \mathrm{D}$ & Āreia & 11 \\
\hline 7 & & & & Ponta & Areia & 15 \\
\hline 8 & & & & $3 \mathrm{D}$ & Āreia & 15 \\
\hline 10 & & & & & & \\
\hline
\end{tabular}

Estimativas x Critérios de Ruptura

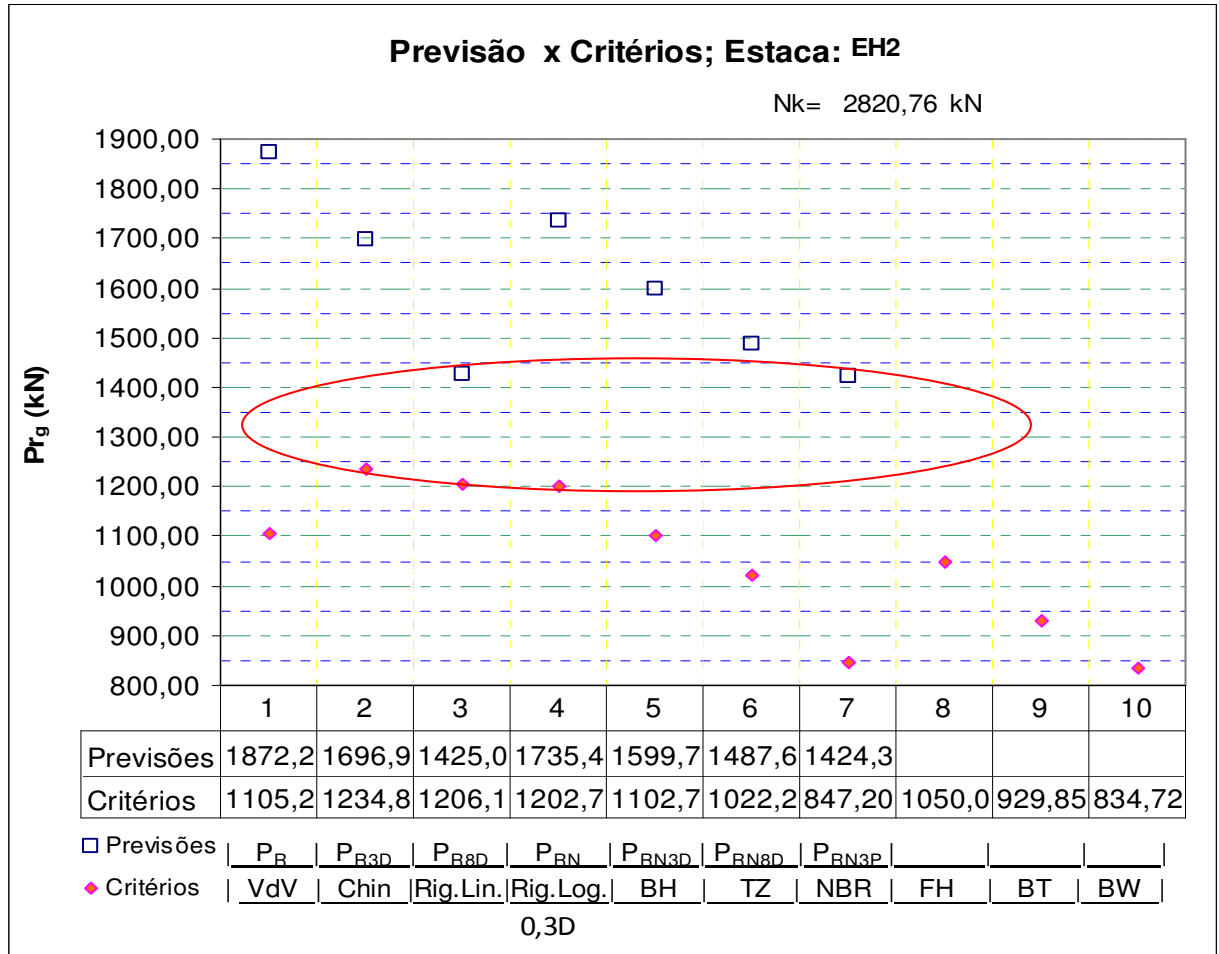

Transferência de carga: Sistema Sem 7-8

$f_{\max }=\quad 54,82 \mathrm{kPa}$

Critério de ruptura adotado: Chin

$q_{p}=3248,47 \mathrm{kPa}$ 


\section{Hierarquia dos Solos}

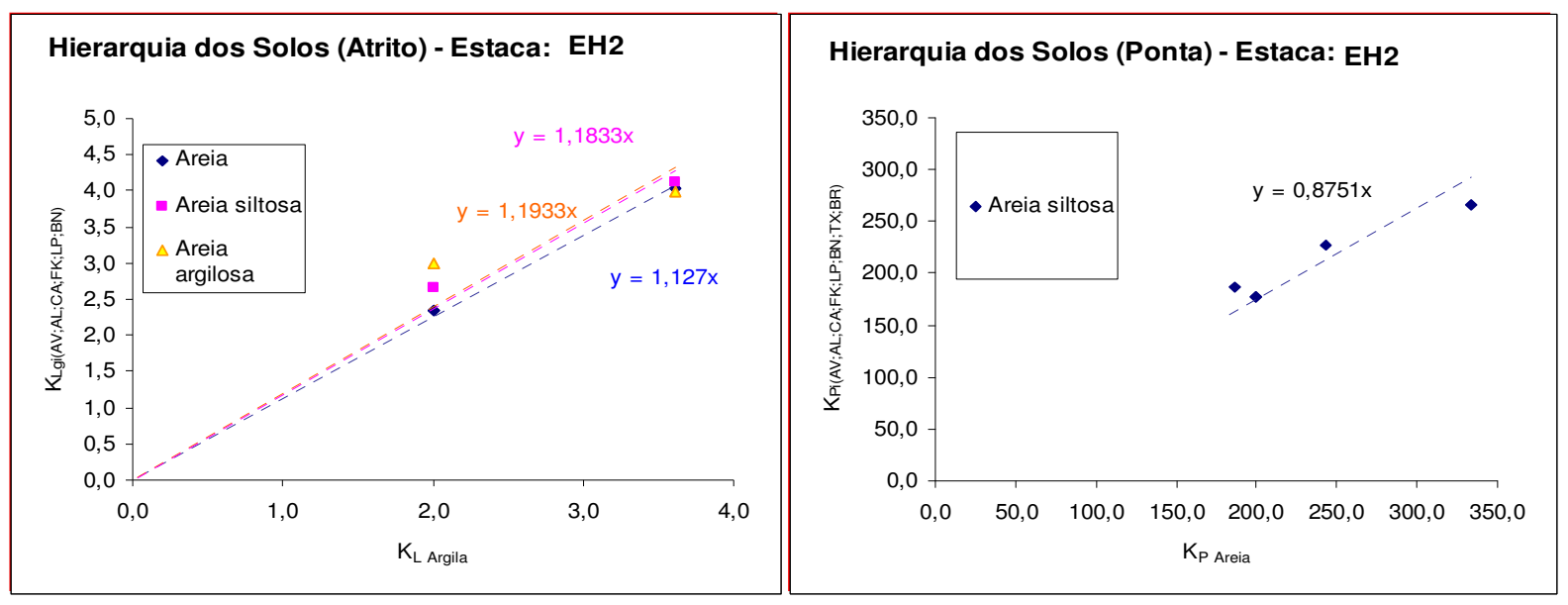

Correção dos coeficientes empíricos

Método Mediado

\begin{tabular}{|c|c|c|c|c|c|c|}
\hline Solo & $k_{t D}$ & $k_{\mathrm{tEL}}$ & $k_{t s}(\%)$ & $\mathrm{k}_{\mathrm{te}}(\mathrm{kPa})$ & $\mathrm{k}_{\mathrm{tEP}}(\mathrm{kPa})$ & $k_{\mathrm{tc}}$ \\
\hline Areia & 1,00 & 0,153 & 1,90 & 798,90 & 0,38 & 0,85 \\
\hline Areia siltosa & 1,00 & 0,153 & 2,44 & 654,49 & 0,51 & 1,15 \\
\hline Argila & 1,00 & 0,153 & 5,41 & 249,21 & $\# \mathrm{~N} / \mathrm{D}$ & \#N/D \\
\hline Areia argilosa & 1,00 & 0,153 & 3,12 & 515,75 & \#N/D & \#N/D \\
\hline
\end{tabular}

Originais

\begin{tabular}{|c|c|c|c|c|c|c|}
\hline Solo & $k_{t D}$ & $k_{t E L}$ & $\mathbf{k}_{\mathrm{ts}}(\%)$ & $\mathrm{k}_{\mathrm{te}}(\mathrm{kPa})$ & $\mathrm{k}_{\mathrm{tEP}}(\mathrm{kPa})$ & $\mathbf{k}_{\mathrm{tc}}$ \\
\hline Areia & 1,00 & 0,257 & 1,90 & 776,67 & 0,325 & - \\
\hline Areia siltosa & 1,00 & 0,257 & 2,44 & 670,00 & 0,325 & - \\
\hline Argila & 1,00 & 0,257 & 5,41 & 233,33 & 0,325 & - \\
\hline Areia argilosa & 1,00 & 0,257 & 3,12 & 556,67 & 0,325 & - \\
\hline
\end{tabular}

Método Expedito

Atrito

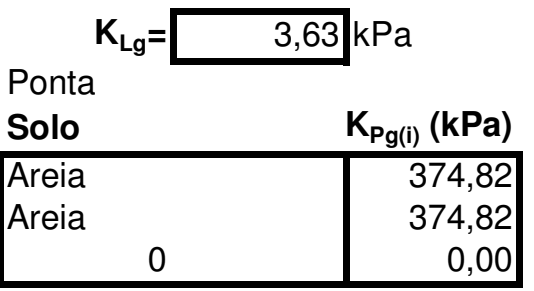


Estaca: EH2

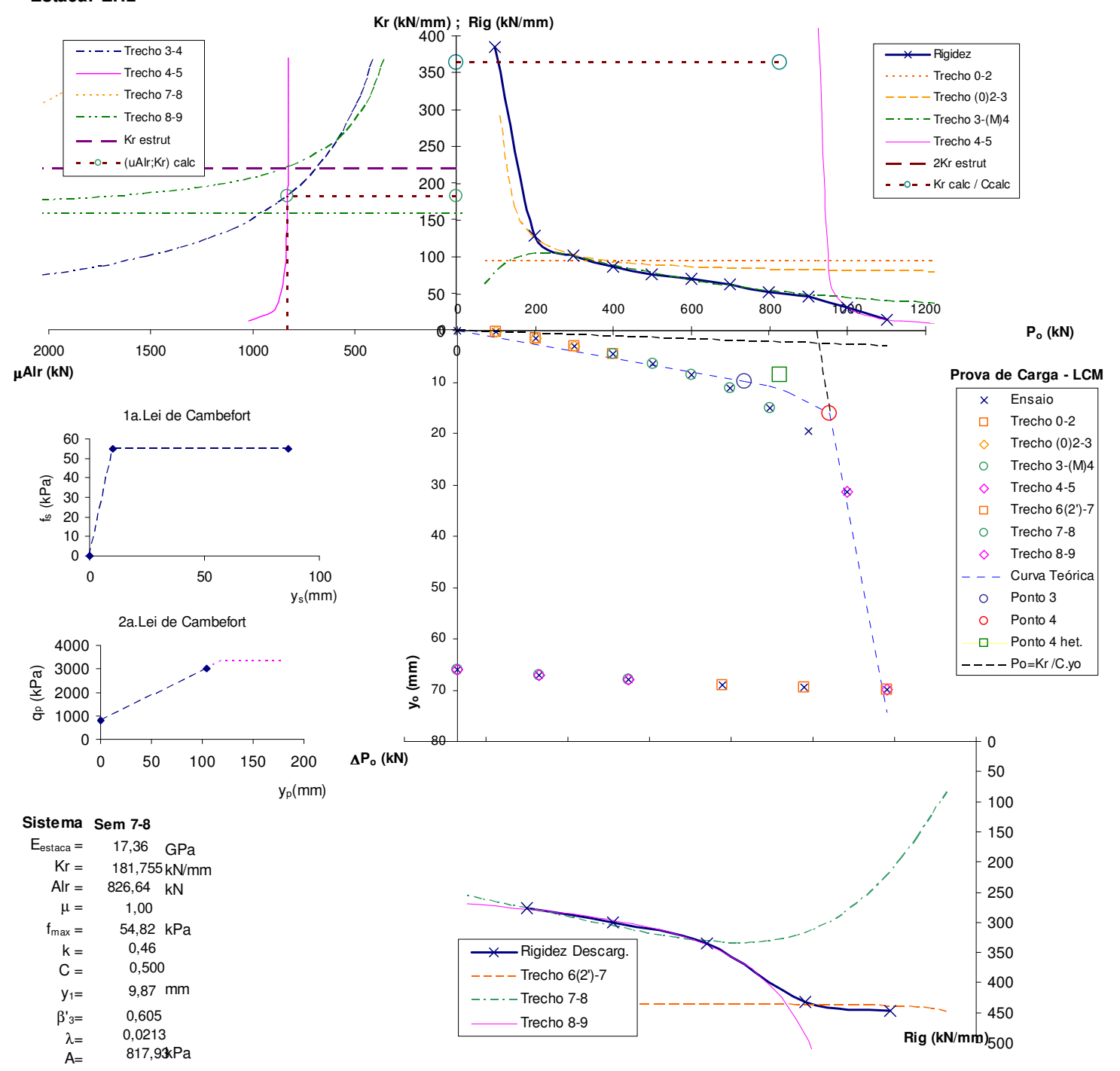




\section{APLICAÇÃO DA METODOLOGIA SEMIEMPÍRICA UNIFICADA}

ESTACA: G202

Local: Guarujá-SP

Tipo: Raiz
Dimensões:

$\mathrm{D}=$

$L=\quad 20,92 \mathrm{~m}$

Estratigrafia: Fuste

Embutimento:

$\mathrm{L}_{2}=$

$0 \mathrm{~m}$

Ponta

\begin{tabular}{|c|c|c|c|c|c|c|}
\hline no. & Solo & $\bar{V}_{\mathrm{SPT}}$ médio $(\mathrm{F})$ & $\Delta \mathrm{L} / \mathrm{L}$ & & \multirow{2}{*}{\multicolumn{2}{|c|}{ Ponta }} \\
\hline & $\begin{array}{l}\text { Argila silto arenosa } \\
\text { Areia siltosa }\end{array}$ & $\begin{array}{l}3,0 \\
8,0\end{array}$ & $\begin{array}{l}0,04 \\
0,71\end{array}$ & & & \\
\hline 3 & Argila siltosa & 3,4 & 0,24 & & Solo & $\mathrm{N}_{\mathrm{SPT}}(\mathrm{P})$ \\
\hline & Silte arenoso & 15,0 & 0,01 & $8 D$ & Areia siltosa & 3 \\
\hline 6 & & & & $3 \mathrm{D}$ & Äreia siltosa & 13 \\
\hline 7 & & & & Ponta & Silte arenoso & $\overline{15}$ \\
\hline 8 & & & & $3 \mathrm{D}$ & Silte arenoso & 50 \\
\hline 10 & & & & & & \\
\hline
\end{tabular}

Estimativas x Critérios de Ruptura

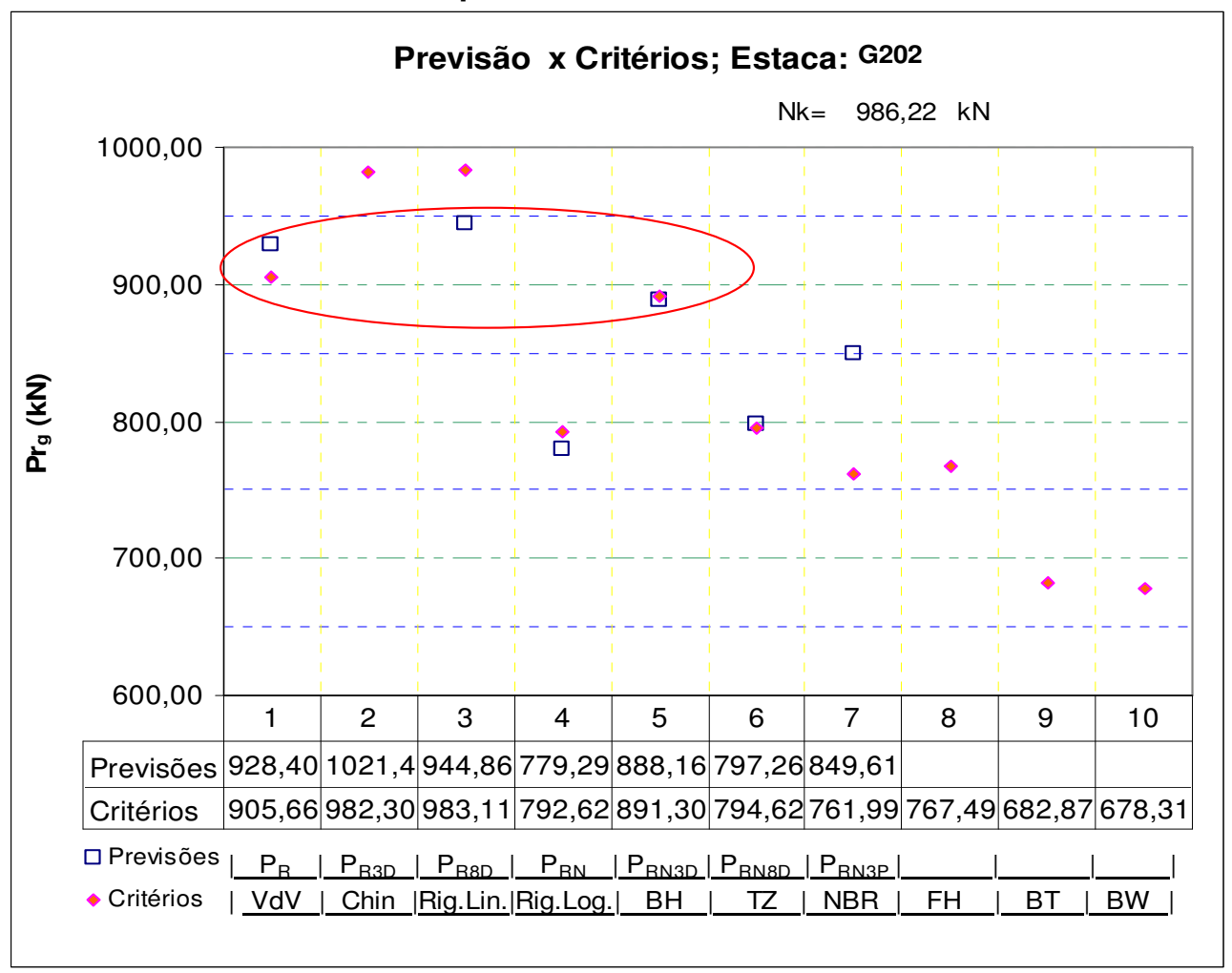

Transferência de carga: Sistema Sem 7-8

$f_{\max }=\quad 42,36 \mathrm{kPa}$

Critério de ruptura adotado: Van der Veen

$\mathrm{q}_{\mathrm{p}}=\quad 4270,42 \mathrm{kPa}$ 
Hierarquia dos Solos

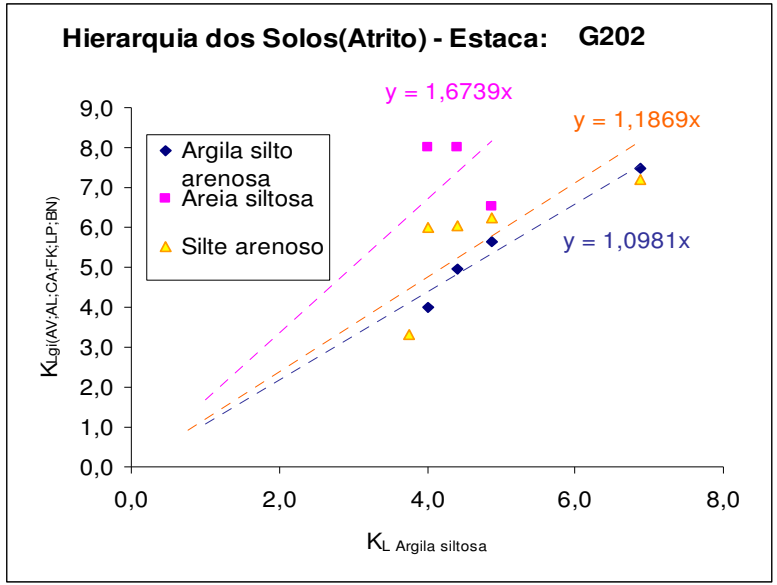

Hierarquia dos Solos (Ponta) - Estaca: G202

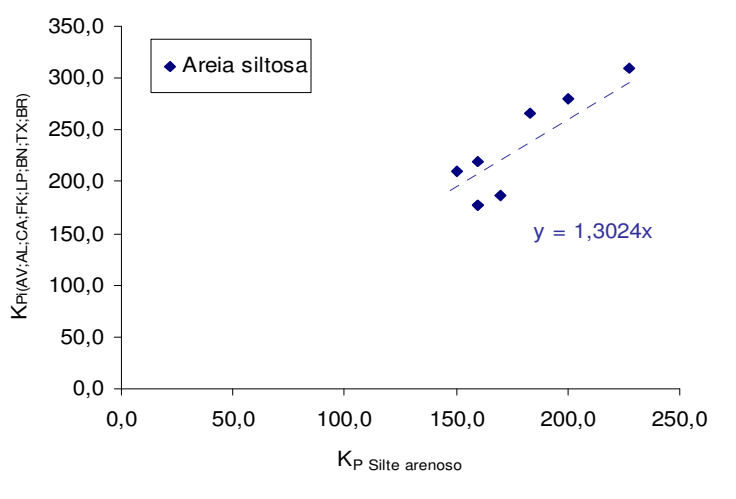

Correção dos coeficientes empíricos

Método Mediado

\begin{tabular}{|c|c|c|c|c|c|c|}
\hline Solo & $\mathbf{k}_{\mathrm{tD}}$ & $\mathbf{k}_{\mathrm{tEL}}$ & $\mathbf{k}_{\mathrm{ts}}(\%)$ & $\mathrm{k}_{\mathrm{te}}(\mathrm{kPa})$ & $\mathrm{k}_{\mathrm{tEP}}(\mathrm{kPa})$ & $\mathbf{k}_{\mathrm{tc}}$ \\
\hline Argila silto arenosa & 1,00 & 0,367 & 3,92 & 303,19 & \#N/D & \#N/D \\
\hline Areia siltosa & 1,00 & 0,367 & 2,44 & 750,45 & \#N/D & \#N/D \\
\hline Argila siltosa & 1,00 & 0,367 & 4,29 & 254,78 & \#N/D & \#N/D \\
\hline Silte arenoso & 1,00 & 0,367 & 2,87 & 451,57 & 0,63 & 1,00 \\
\hline
\end{tabular}

Originais

\begin{tabular}{|c|c|c|c|c|c|c|}
\hline Solo & $\mathbf{k}_{\mathrm{tD}}$ & $\mathbf{k}_{\mathrm{tEL}}$ & $\mathbf{k}_{\mathrm{ts}}(\%)$ & $\mathrm{k}_{\mathrm{te}}(\mathrm{kPa})$ & $k_{\mathrm{tEP}}(\mathrm{kPa})$ & $\overline{\mathbf{k}_{\mathrm{tC}}}$ \\
\hline Argila silto arenosa & 1,00 & 0,439 & 3,92 & 320,00 & 0,474 & - \\
\hline Areia siltosa & 1,00 & 0,439 & 2,44 & 670,00 & 0,474 & - \\
\hline Argila siltosa & 1,00 & 0,439 & 4,29 & 243,33 & 0,474 & - \\
\hline Silte arenoso & 1,00 & 0,439 & 2,87 & 510,00 & 0,474 & - \\
\hline
\end{tabular}

\section{Método Expedito}

Atrito
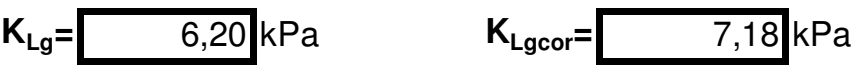

Ponta

Solo $\quad \mathrm{K}_{\mathrm{Pg}(\mathrm{i})}(\mathrm{kPa})$

Silte arenoso

164,25

Silte arenoso

164,25

Silte arenoso

164,25 
Estaca: G202

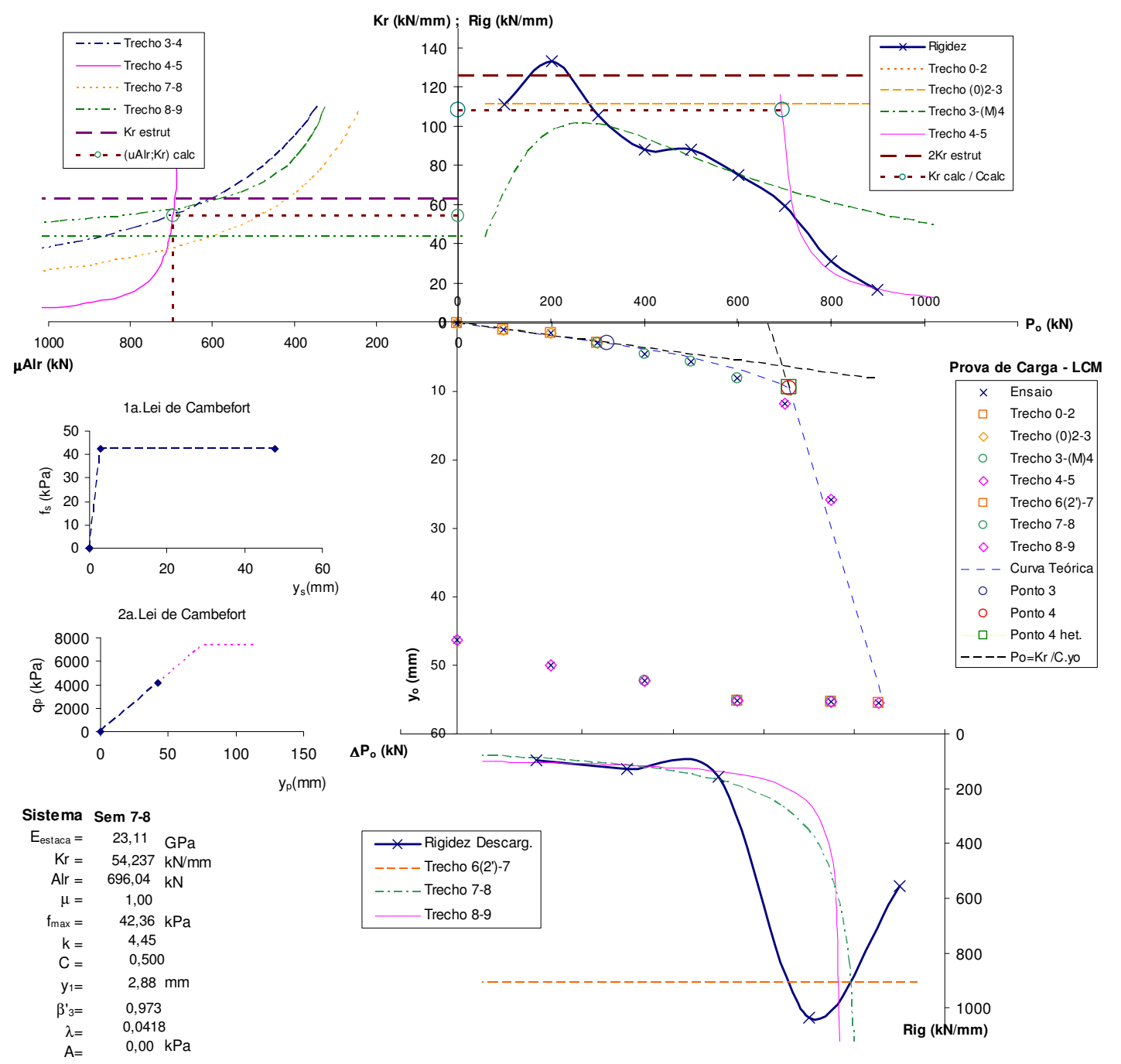




\section{APLICAÇÃO DA METODOLOGIA SEMIEMPÍRICA UNIFICADA}

ESTACA: E013 Dimensões: $\quad D=\quad 460 \mathrm{~mm}$

Local: Alemoa-Santos

Tipo: Pré-moldada cravada

$L=\quad 45 \mathrm{~m}$

Estratigrafia: Fuste

Embutimento:

$\mathrm{L}_{2}=$

$0 \mathrm{~m}$

Ponta

\begin{tabular}{|c|c|c|c|c|c|c|}
\hline no. & Solo & $\mathrm{N}_{\mathrm{SPT}}$ médio $(\mathrm{F})$ & $\Delta \mathrm{L} / \mathrm{L}$ & & \multirow{2}{*}{\multicolumn{2}{|c|}{ Ponta }} \\
\hline & $\begin{array}{l}\text { Argila arenosa } \\
\text { Argila }\end{array}$ & $\begin{array}{l}3,0 \\
8,1\end{array}$ & $\begin{array}{l}0,11 \\
0,49\end{array}$ & & & \\
\hline \multirow{6}{*}{$\begin{array}{r}4 \\
5 \\
6 \\
7 \\
8 \\
9 \\
10\end{array}$} & \multirow[t]{6}{*}{ Areia } & \multirow[t]{6}{*}{17,7} & \multirow[t]{6}{*}{0,40} & & $\widehat{\text { Solo }}$ & $\mathrm{N}_{\mathrm{SPT}}(\mathrm{P})$ \\
\hline & & & & $8 D$ & Areia & 17 \\
\hline & & & & $3 \mathrm{D}$ & Áreia & 26 \\
\hline & & & & Ponta & Areia & 26 \\
\hline & & & & $3 D^{-}$ & Āreia & 26 \\
\hline & & & & & & \\
\hline
\end{tabular}

Estimativas x Critérios de Ruptura

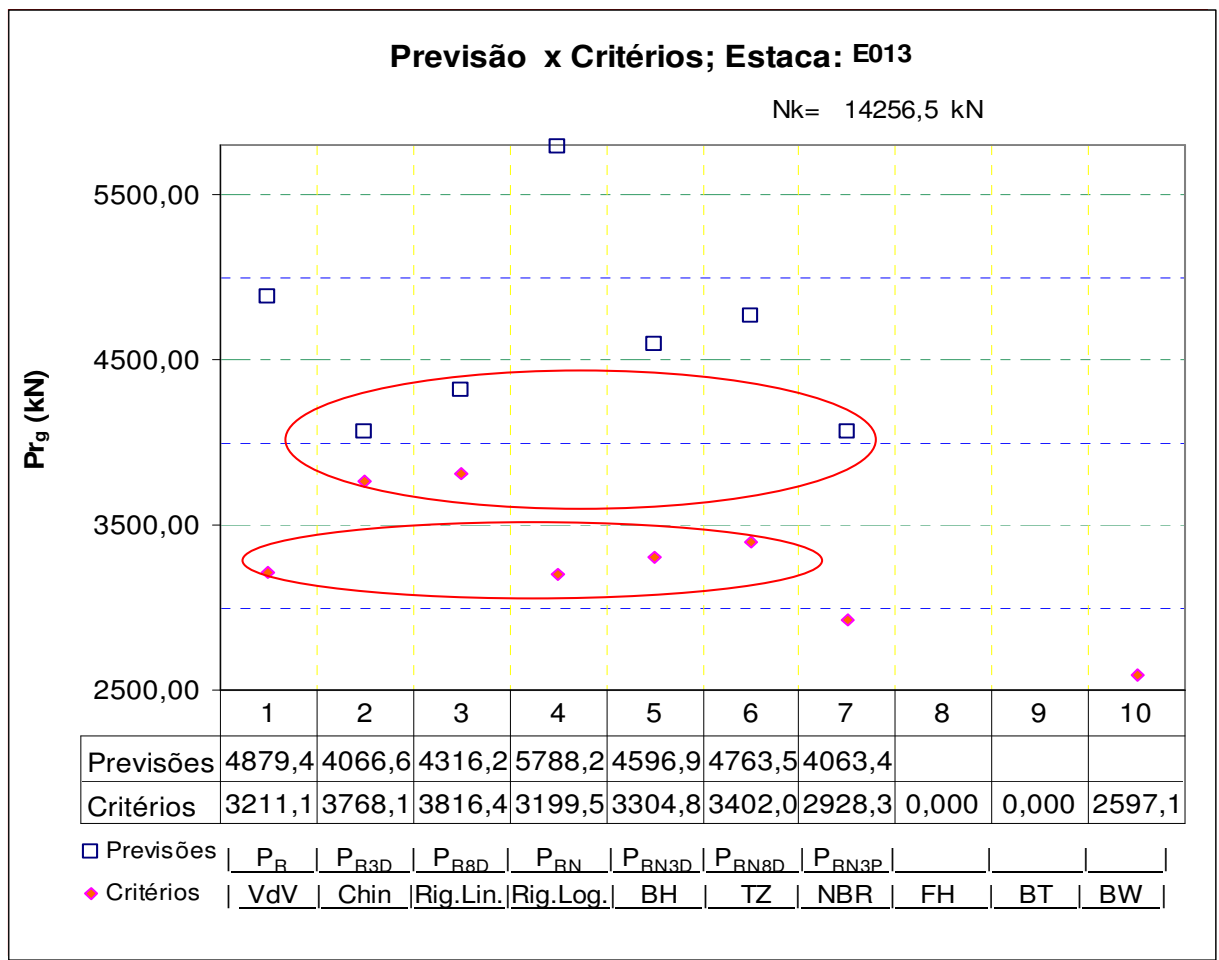

Transferência de carga: Sistema Completa $f_{\max }=\quad 25,71 \mathrm{kPa}$

Critério de ruptura adotado: Van der Veen

$\mathrm{q}_{\mathrm{p}}=9262,44 \mathrm{kPa}$ 
Hierarquia dos Solos

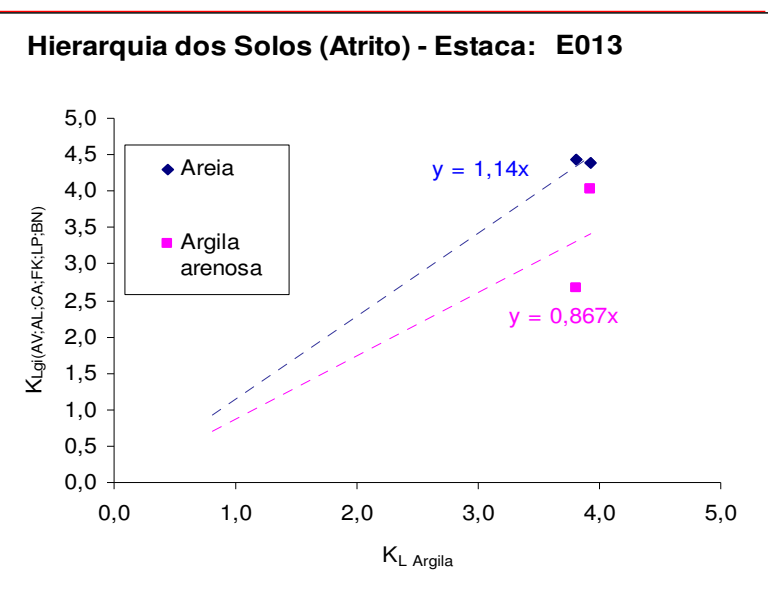

Hierarquia dos Solos (Ponta) - Estaca: E013

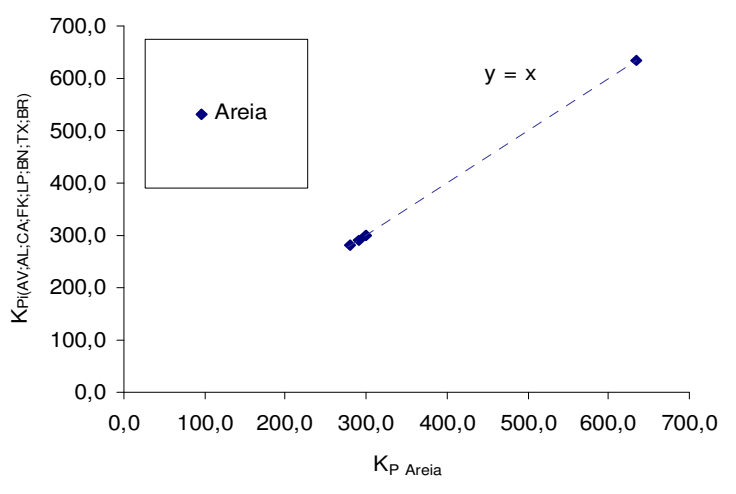

Correção dos coeficientes empíricos

Método Mediado

\begin{tabular}{|c|c|c|c|c|c|c|}
\hline Solo & $\mathbf{k}_{\mathrm{tD}}$ & $\mathbf{k}_{\mathrm{tEL}}$ & $\mathbf{k}_{\mathrm{ts}}(\%)$ & $\mathrm{k}_{\mathrm{te}}(\mathrm{kPa})$ & $\mathrm{k}_{\mathrm{tEP}}(\mathrm{kPa})$ & $\mathrm{k}_{\mathrm{tC}}$ \\
\hline Argila arenosa & 1,00 & 0,152 & 3,27 & 363,63 & $\# \mathrm{~N} / \mathrm{D}$ & $\# \mathrm{~N} / \mathrm{D}$ \\
\hline Argila & 1,00 & 0,152 & 5,41 & 253,05 & $\# \mathrm{~N} / \mathrm{D}$ & \#N/D \\
\hline Areia & 1,00 & 0,152 & 1,90 & 820,56 & 0,43 & 1,00 \\
\hline
\end{tabular}

Originais

\begin{tabular}{|c|c|c|c|c|c|c|}
\hline Solo & $\mathbf{k}_{\mathrm{tD}}$ & $\mathbf{k}_{\mathrm{tEL}}$ & $\mathbf{k}_{\mathrm{ts}}(\%)$ & $\mathrm{k}_{\mathrm{te}}(\mathrm{kPa})$ & $\mathrm{k}_{\mathrm{tEP}}(\mathrm{kPa})$ & $\mathbf{k}_{\mathrm{tC}}$ \\
\hline Argila arenosa & 1,00 & 0,286 & 3,27 & 423,33 & 0,571 & - \\
\hline Argila & 1,00 & 0,286 & 5,41 & 233,33 & 0,571 & - \\
\hline Areia & 1,00 & 0,286 & 1,90 & 776,67 & 0,571 & - \\
\hline
\end{tabular}

\section{Método Expedito}

Atrito
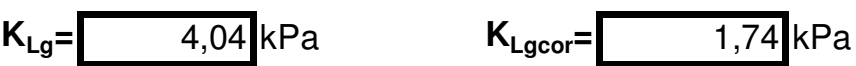

Ponta

\begin{tabular}{|ll|r|} 
Solo & & $\mathbf{K}_{\mathbf{P g}(\mathbf{i})}(\mathbf{k P a})$ \\
\hline Areia & & 1068,74 \\
& 0 & 0,00 \\
& 0 & 0,00 \\
\hline
\end{tabular}


Estaca: E013

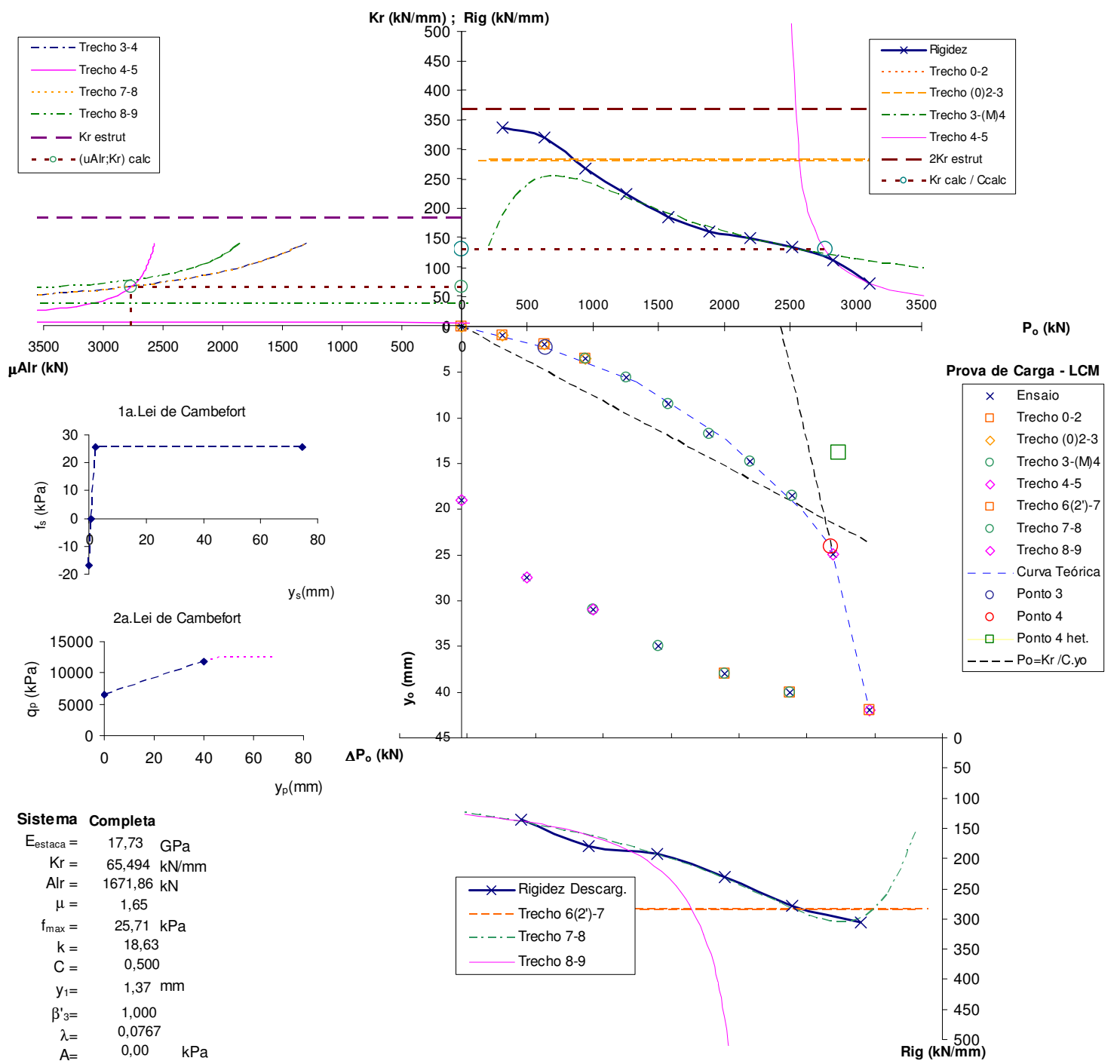




\section{APLICAÇÃO DA METODOLOGIA SEMIEMPÍRICA UNIFICADA}

ESTACA: Penha Local: Penha - SP

Tipo: Escavada
Dimensões:

$\mathrm{D}=$

$\mathrm{L}=$

$\mathrm{L}_{2}=$

Embutimento:
$342 \mathrm{~mm}$

$20,6 \mathrm{~m}$

Estratigrafia: Fuste

$0 \mathrm{~m}$

Ponta

\begin{tabular}{|c|c|c|c|c|c|c|}
\hline no. & Solo & $\overline{N_{S P T} \text { médio }(F)}$ & $\Delta \mathrm{L} / \mathrm{L}$ & & \multirow{2}{*}{\multicolumn{2}{|c|}{ Ponta }} \\
\hline & \multirow[t]{7}{*}{\begin{tabular}{|l} 
Argila \\
Areia
\end{tabular}} & \multirow[t]{7}{*}{$\begin{array}{l}17,0 \\
17,1\end{array}$} & \multirow[t]{7}{*}{$\begin{array}{l}0,34 \\
0,66\end{array}$} & & & \\
\hline 3 & & & & & Solo & $\mathrm{N}_{\mathrm{SPT}}(\mathrm{P})$ \\
\hline 5 & & & & $8 \mathrm{D}$ & Areia & 17 \\
\hline 6 & & & & $3 \mathrm{D}$ & Āreia & 20 \\
\hline 7 & & & & Ponta & Areia & 20 \\
\hline 8 & & & & $3 \mathrm{D}$ & Āreia & 20 \\
\hline 10 & & & & & & \\
\hline
\end{tabular}

Estimativas x Critérios de Ruptura

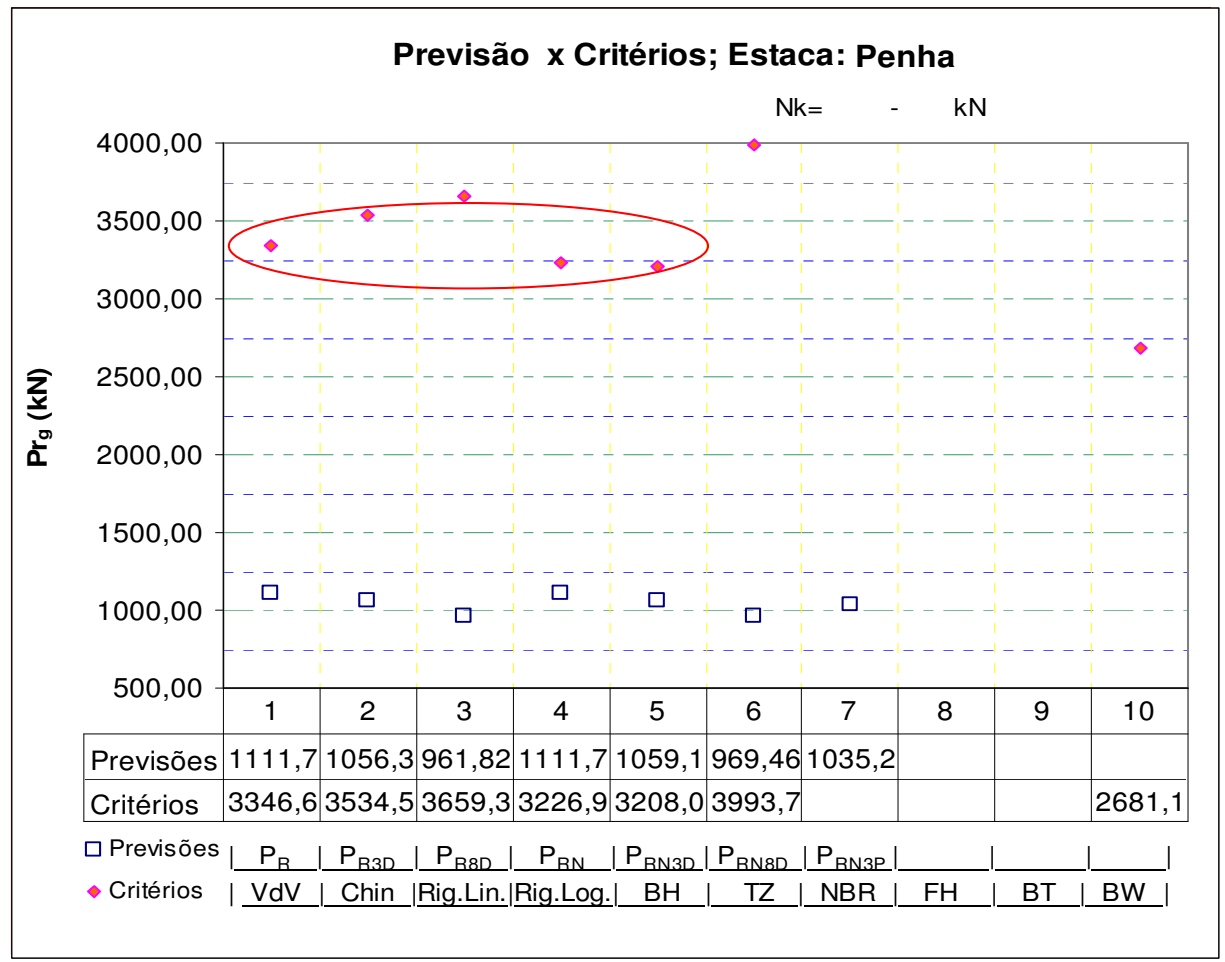

Transferência de carga: Sistema Completo $f_{\max }=\quad 73,19 \mathrm{kPa}$ 
Hierarquia dos Solos

Hierarquia dos Solos (Atrito) - Estaca: Penha

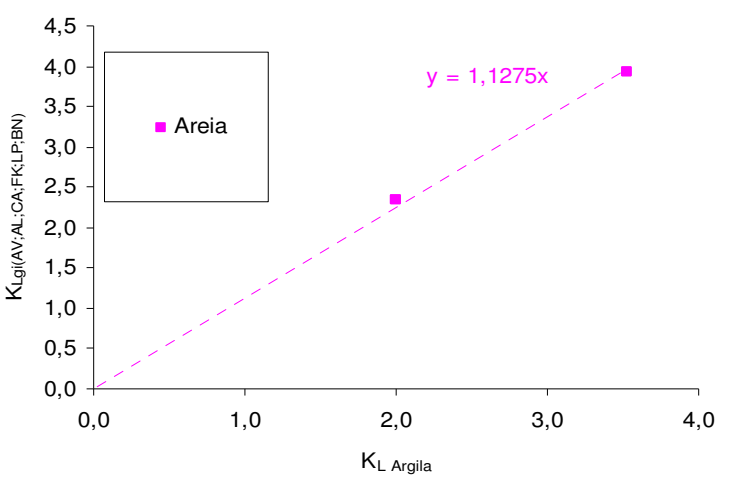

Hierarquia dos Solos (Ponta) - Estaca: Penha

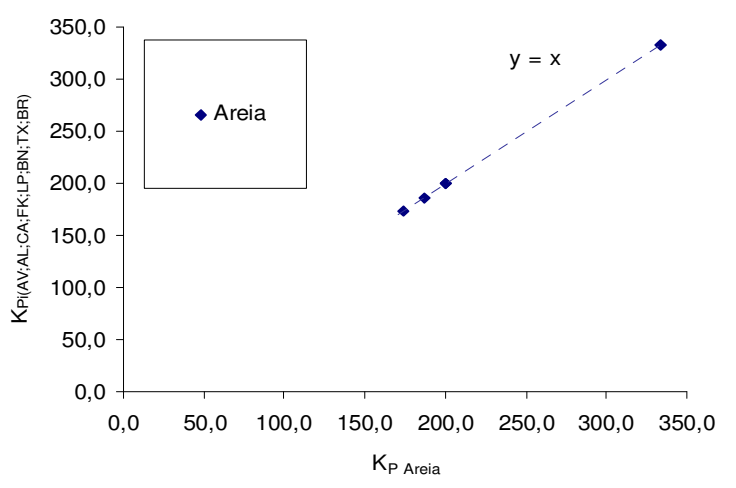

Correção dos coeficientes empíricos

Método Mediado

\begin{tabular}{|c|c|c|c|c|c|c|}
\hline Solo & $k_{t D}$ & $\mathbf{k}_{\mathrm{tEL}}$ & $\mathbf{k}_{\mathrm{ts}}(\%)$ & $\mathrm{k}_{\mathrm{te}}(\mathrm{kPa})$ & $\mathrm{k}_{\mathrm{tEP}}(\mathrm{kPa})$ & $\mathbf{k}_{\mathrm{tC}}$ \\
\hline Argila & 1,00 & 0,307 & 5,41 & 237,67 & \#N/D & \#N/D \\
\hline Areia & 1,00 & 0,307 & 1,90 & 762,23 & - & 1,00 \\
\hline
\end{tabular}

Originais

\begin{tabular}{|c|c|c|c|c|c|c|}
\hline Solo & $\mathbf{k}_{\mathrm{tD}}$ & $k_{\mathrm{tEL}}$ & $\mathbf{k}_{\mathrm{ts}}(\%)$ & $\mathrm{k}_{\mathrm{te}}(\mathrm{kPa})$ & $\mathrm{k}_{\mathrm{tEP}}(\mathrm{kPa})$ & $\mathbf{k}_{\mathrm{tc}}$ \\
\hline Argila & 1,00 & 0,199 & 5,41 & 233,33 & 0,365 & - \\
\hline Areia & 1,00 & 0,199 & 1,90 & 776,67 & 0,365 & - \\
\hline
\end{tabular}

Método Expedito

Atrito
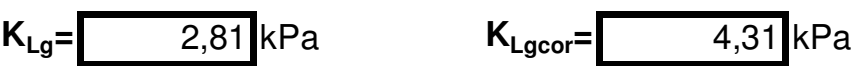

Ponta

\begin{tabular}{|cc|r|} 
Solo & & \multicolumn{1}{c|}{$\mathbf{K}_{\mathbf{P g}(\mathbf{i})}(\mathbf{k P a})$} \\
\hline Areia & & - \\
& 0 & 0,00 \\
& 0 & 0,00 \\
\hline
\end{tabular}


Estaca: Penha

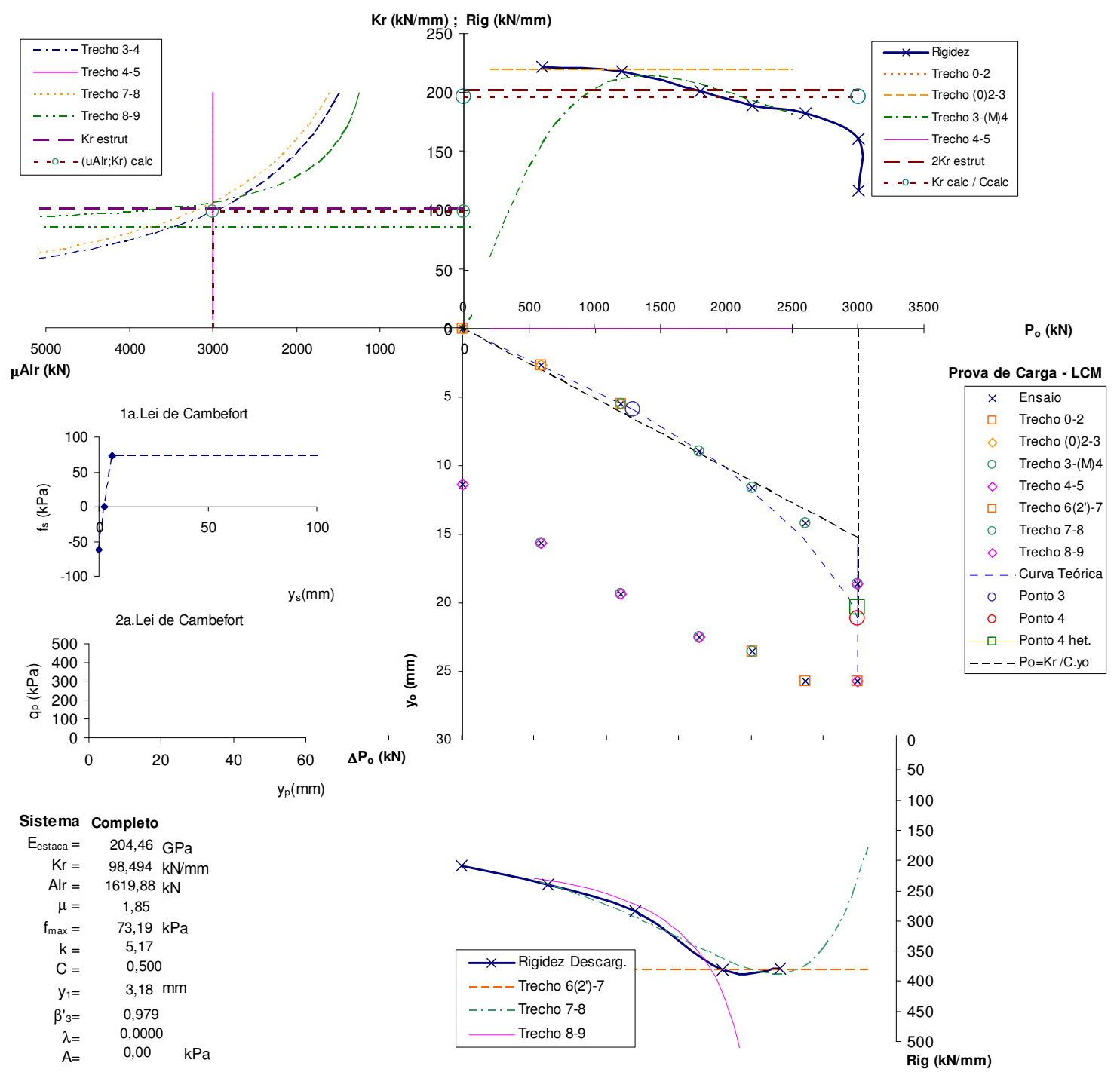




\section{APLICAÇÃO DA METODOLOGIA SEMIEMPÍRICA UNIFICADA}

ESTACA: G201

Local: Guarujá-SP

Tipo: Raiz
Dimensões:

$\mathrm{D}=$

$\mathrm{L}=$

$\mathrm{L}_{2}=$

Embutimento:

$250 \mathrm{~mm}$

$32 \mathrm{~m}$

Estratigrafia: Fuste

$0 \mathrm{~m}$

Ponta

\begin{tabular}{|c|c|c|c|c|c|c|}
\hline no. & Solo & $\mathrm{N}_{\mathrm{SPT}}$ médio $(\mathrm{F})$ & $\Delta \mathrm{L} / \mathrm{L}$ & & \multirow{2}{*}{\multicolumn{2}{|c|}{ Ponta }} \\
\hline & \multirow{7}{*}{$\begin{array}{l}\text { Argila silto arenosa } \\
\text { Areia siltosa } \\
\text { Areia argilo siltosa } \\
\text { Silte areno argiloso }\end{array}$} & $\begin{array}{l}3,2 \\
6,9\end{array}$ & $\begin{array}{l}0,33 \\
0,41\end{array}$ & & & \\
\hline & & 4,1 & 0,18 & & Solo & $\mathrm{N}_{\mathrm{SPT}}(\mathrm{P})$ \\
\hline $\begin{array}{l}4 \\
5\end{array}$ & & 27,9 & 0,08 & $8 \mathrm{D}$ & Silte areno argiloso & 10 \\
\hline 6 & & & & $3 \mathrm{D}$ & Silte areno argiloso & 22 \\
\hline 7 & & & & Ponta & Silte areno argiloso & 50 \\
\hline $\begin{array}{l}8 \\
9\end{array}$ & & & & $3 \mathrm{D}$ & Silte areno argiloso & 50 \\
\hline 10 & & & & & & \\
\hline
\end{tabular}

Estimativas x Critérios de Ruptura

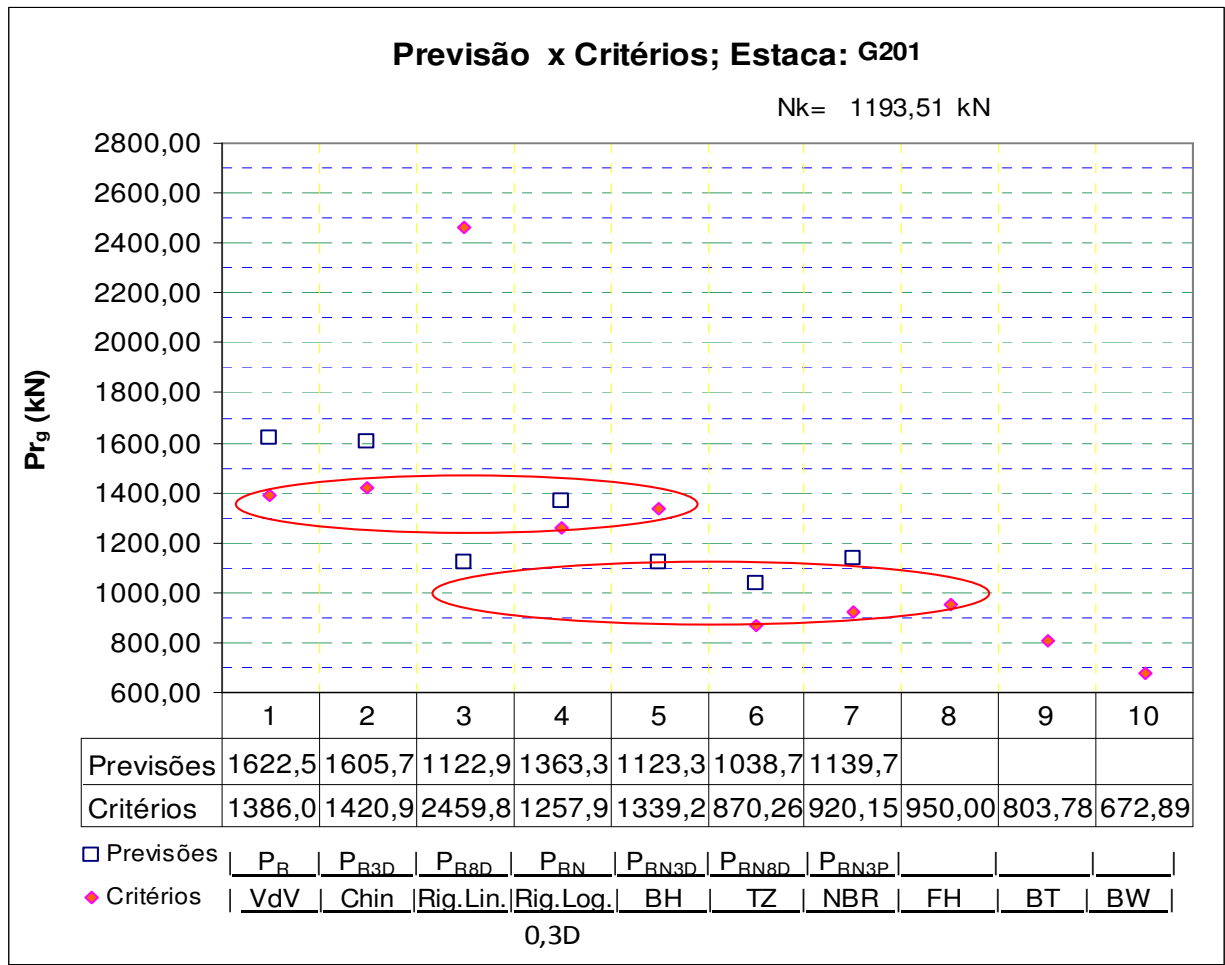

Transferência de carga: Sistema Sem 7-8

$f_{\max }=\quad 29,88 \mathrm{kPa}$

Critério de ruptura adotado: Van der Veen

$q_{p}=12938,63 \mathrm{kPa}$ 
Hierarquia dos Solos

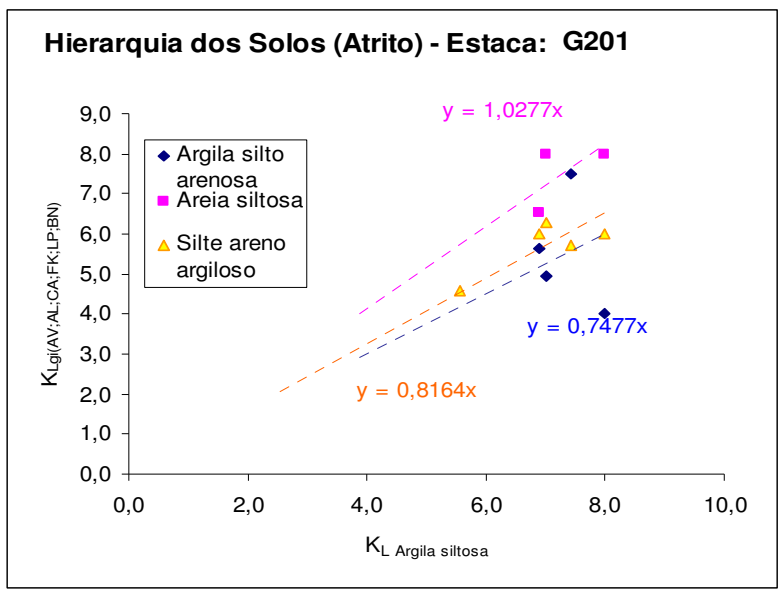

Hierarquia dos Solos (Ponta) - Estaca: G201

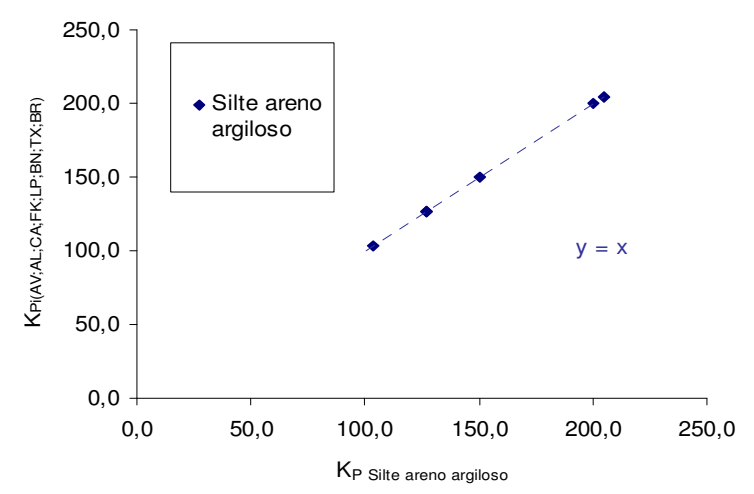

Correção dos coeficientes empíricos

Método Mediado

\begin{tabular}{|c|c|c|c|c|c|c|}
\hline Solo & $\mathbf{k}_{\mathrm{tD}}$ & $\mathrm{k}_{\mathrm{tEL}}$ & $k_{t s}(\%)$ & $\mathrm{k}_{\mathrm{te}}(\mathrm{kPa})$ & $\mathbf{k}_{\mathrm{tEP}}(\mathrm{kPa})$ & $\mathrm{k}_{\mathrm{tc}}$ \\
\hline Argila silto arenosa & 1,00 & 0,290 & 3,92 & 311,42 & \#N/D & \#N/D \\
\hline Areia siltosa & 1,00 & 0,290 & 2,44 & 687,73 & $\# \mathrm{~N} / \mathrm{D}$ & $\# \mathrm{~N} / \mathrm{D}$ \\
\hline Areia argilo siltosa & 1,00 & 0,290 & 3,06 & 533,98 & $\# \mathrm{~N} / \mathrm{D}$ & $\# N / D$ \\
\hline Silte areno argiloso & 1,00 & 0,290 & 3,13 & 426,31 & 0,61 & 1,00 \\
\hline
\end{tabular}

Originais

\begin{tabular}{|c|c|c|c|c|c|c|}
\hline Solo & $\mathbf{k}_{\mathrm{tD}}$ & $\mathbf{k}_{\mathrm{tEL}}$ & $\mathbf{k}_{\mathrm{ts}}(\%)$ & $\mathrm{k}_{\mathrm{te}}(\mathrm{kPa})$ & $k_{\text {tEP }}(\mathrm{kPa})$ & $\mathbf{k}_{\mathrm{tc}}$ \\
\hline Argila silto arenosa & 1,00 & 0,439 & 3,92 & 320,00 & 0,474 & - \\
\hline Areia siltosa & 1,00 & 0,439 & 2,44 & 670,00 & 0,474 & - \\
\hline Areia argilo siltosa & 1,00 & 0,439 & 3,06 & 533,33 & 0,474 & - \\
\hline Silte areno argiloso & 1,00 & 0,439 & 3,13 & 426,67 & 0,474 & - \\
\hline
\end{tabular}

\section{Método Expedito}

Atrito
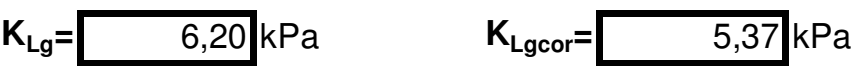

Ponta

Solo

$\mathrm{K}_{\mathrm{Pg}(\mathrm{i})}(\mathrm{kPa})$

Silte areno argiloso 539,11

Silte areno argiloso 539,11

0 
Estaca: G201

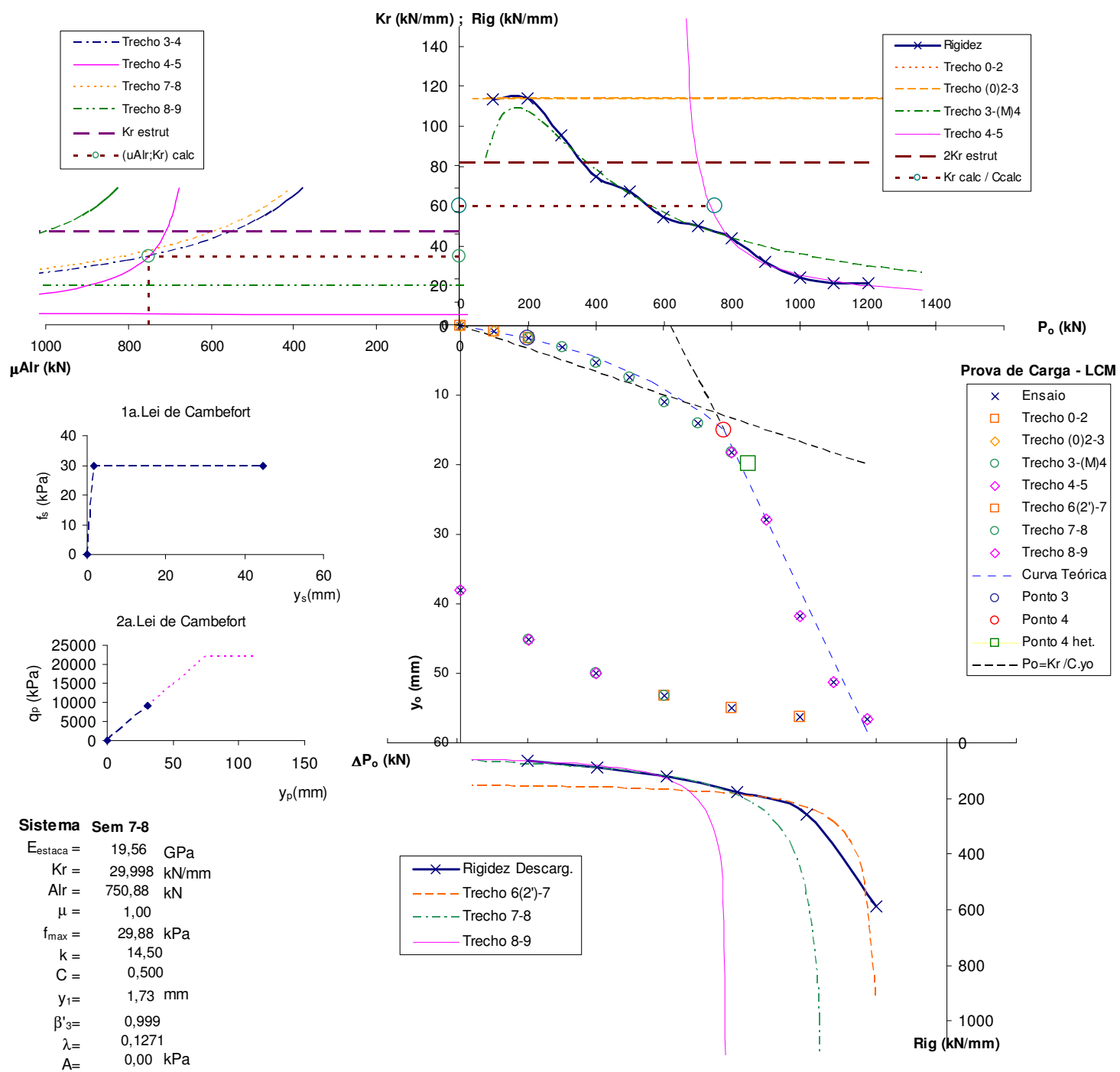




\section{APLICAÇÃO DA METODOLOGIA SEMIEMPÍRICA UNIFICADA}

ESTACA: G603

Local: São Paulo

Tipo: Raiz
Dimensões:

$\mathrm{D}=$

$\mathrm{L}=$

$\mathrm{L}_{2}=$

Embutimento:

Estratigrafia: Fuste

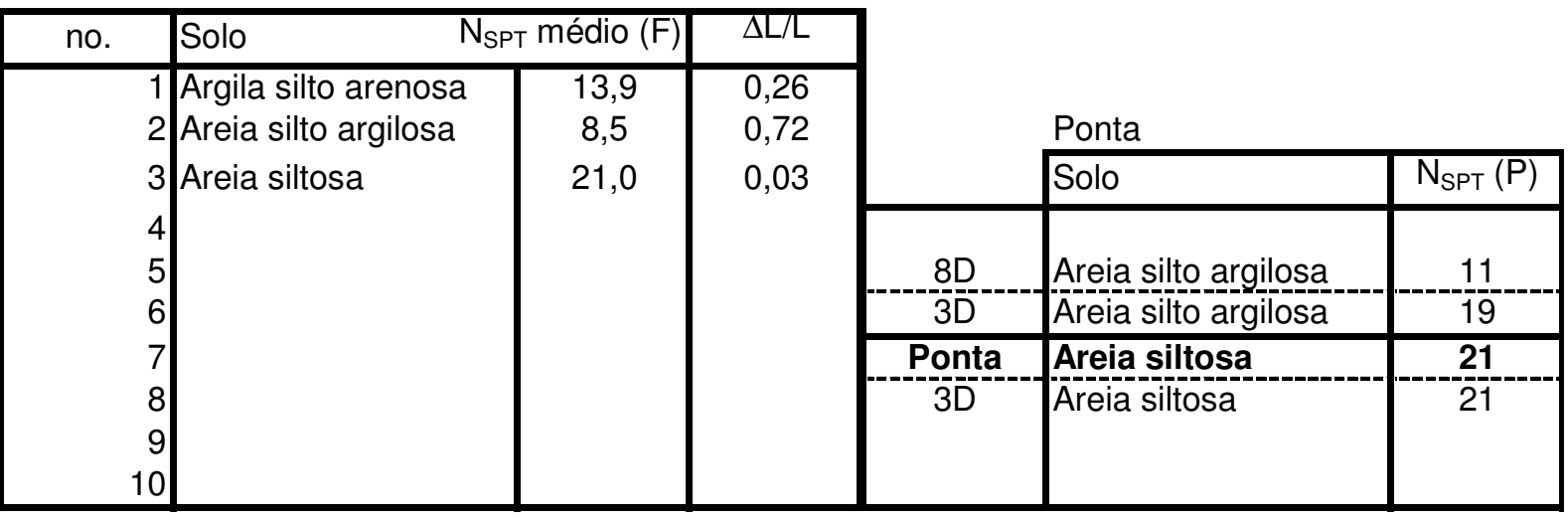

$260 \mathrm{~mm}$

$19,73 \mathrm{~m}$

$0 \mathrm{~m}$

Ponta

Estimativas x Critérios de Ruptura

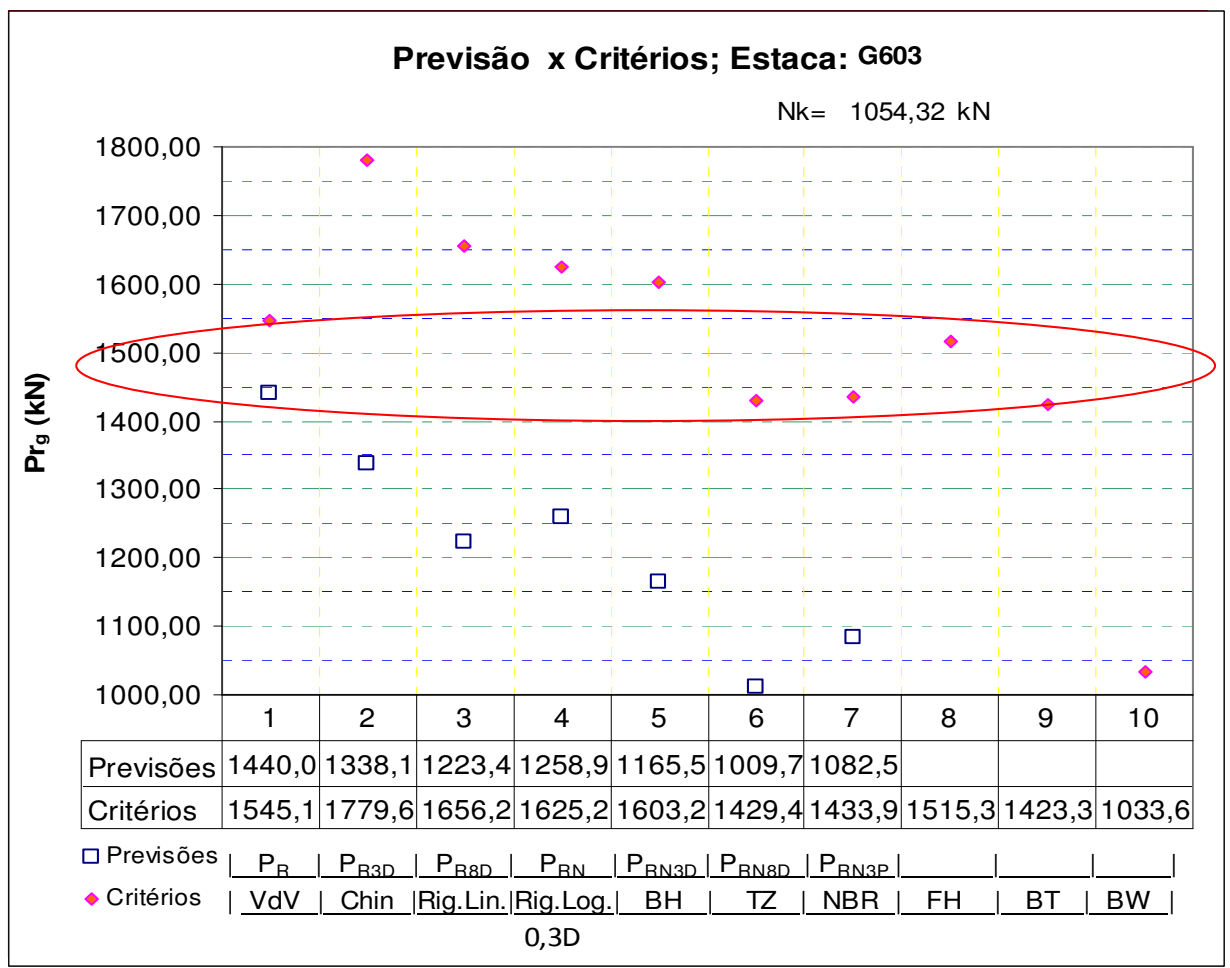

Transferência de carga: Sistema Sem 7-8

$f_{\max }=\quad 84,25 \mathrm{kPa}$

Critério de ruptura adotado: Van der Veen

$\mathrm{q}_{\mathrm{p}}=3530,56 \mathrm{kPa}$ 
Hierarquia dos Solos

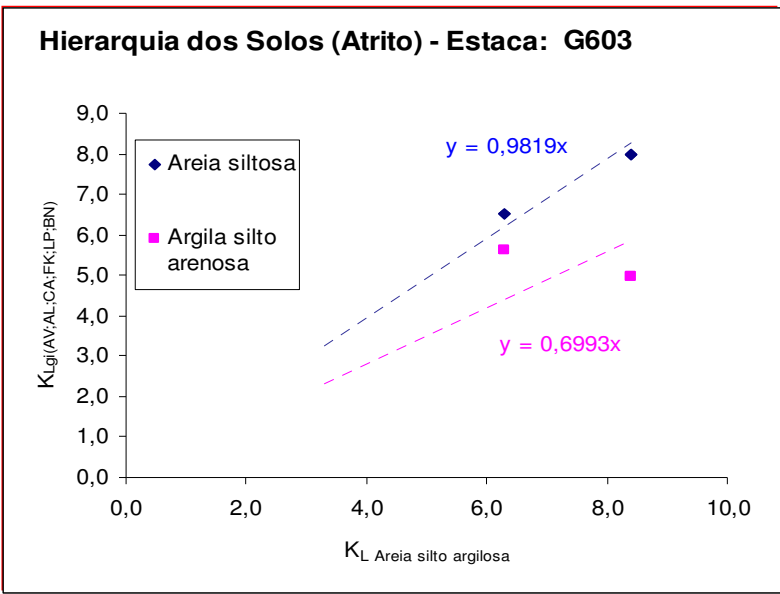

Hierarquia dos Solos (Ponta) - Estaca: G603

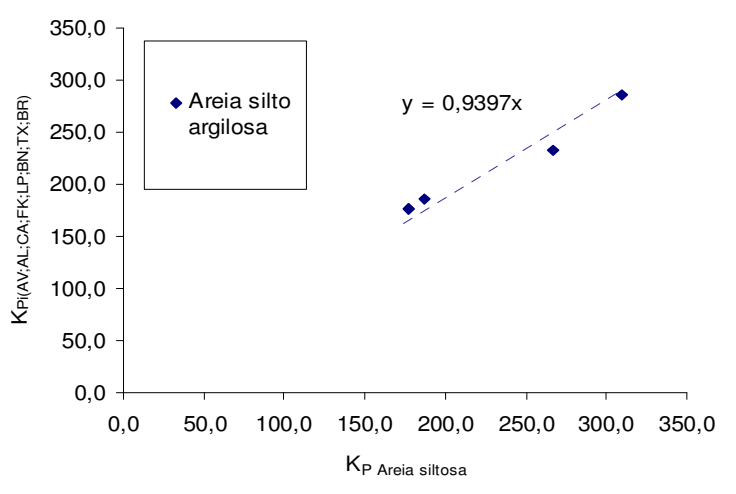

Correção dos coeficientes empíricos

Método Mediado

\begin{tabular}{|c|c|c|c|c|c|c|}
\hline Solo & $\mathbf{k}_{\mathrm{tD}}$ & $\mathbf{k}_{\mathrm{tEL}}$ & $\mathbf{k}_{\mathrm{ts}}(\%)$ & $\mathrm{k}_{\mathrm{te}}(\mathrm{kPa})$ & $\mathrm{k}_{\mathrm{tEP}}(\mathrm{kPa})$ & $\mathrm{k}_{\mathrm{tC}}$ \\
\hline Argila silto arenosa & 1,00 & $\overline{0,543}$ & 3,92 & 301,62 & $\# \mathrm{~N} / \mathrm{D}$ & $\# \mathrm{~N} / \mathrm{D}$ \\
\hline Areia silto argilosa & 1,00 & 0,543 & 2,62 & 645,90 & $\# \mathrm{~N} / \mathrm{D}$ & \#N/D \\
\hline Areia siltosa & 1,00 & 0,543 & 2,44 & 680,48 & 0,25 & 1,00 \\
\hline
\end{tabular}

Originais

\begin{tabular}{|c|c|c|c|c|c|c|}
\hline Solo & $\mathbf{k}_{\mathrm{tD}}$ & $\mathbf{k}_{\mathrm{tEL}}$ & $\mathbf{k}_{\mathrm{ts}}(\%)$ & $\overline{k_{\text {te }}(\mathrm{kPa})}$ & $\mathrm{k}_{\mathrm{tEP}}(\mathrm{kPa})$ & $\mathbf{k}_{\mathrm{tc}}$ \\
\hline Argila silto arenosa & 1,00 & $\overline{0,439}$ & 3,92 & 320,00 & 0,474 & - \\
\hline Areia silto argilosa & 1,00 & 0,439 & 2,62 & 620,00 & 0,474 & - \\
\hline Areia siltosa & 1,00 & 0,439 & 2,44 & 670,00 & 0,474 & - \\
\hline
\end{tabular}

\section{Método Expedito}

Atrito
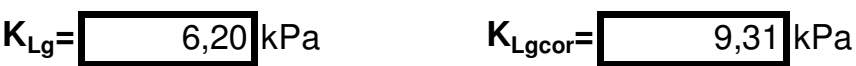

Ponta

\begin{tabular}{|c|r|} 
Solo & $\mathbf{K}_{\mathbf{P g}(\mathbf{i})}(\mathbf{k P a})$ \\
\hline Areia silto argilosa & 557,46 \\
0 & 0,00 \\
0 & 0,00 \\
\hline
\end{tabular}




\section{Estaca: G603}

\begin{tabular}{|c|}
\hline$-\cdots-$ Trecho 3-4 \\
\hline — Trecho 4-5 \\
\hline …... Trecho 7-8 \\
\hline -... - Trecho 8-9 \\
\hline $\begin{array}{l}- \text { - Kr estrut } \\
- \text { - - - - (uAlr;Kr) calc }\end{array}$ \\
\hline
\end{tabular}
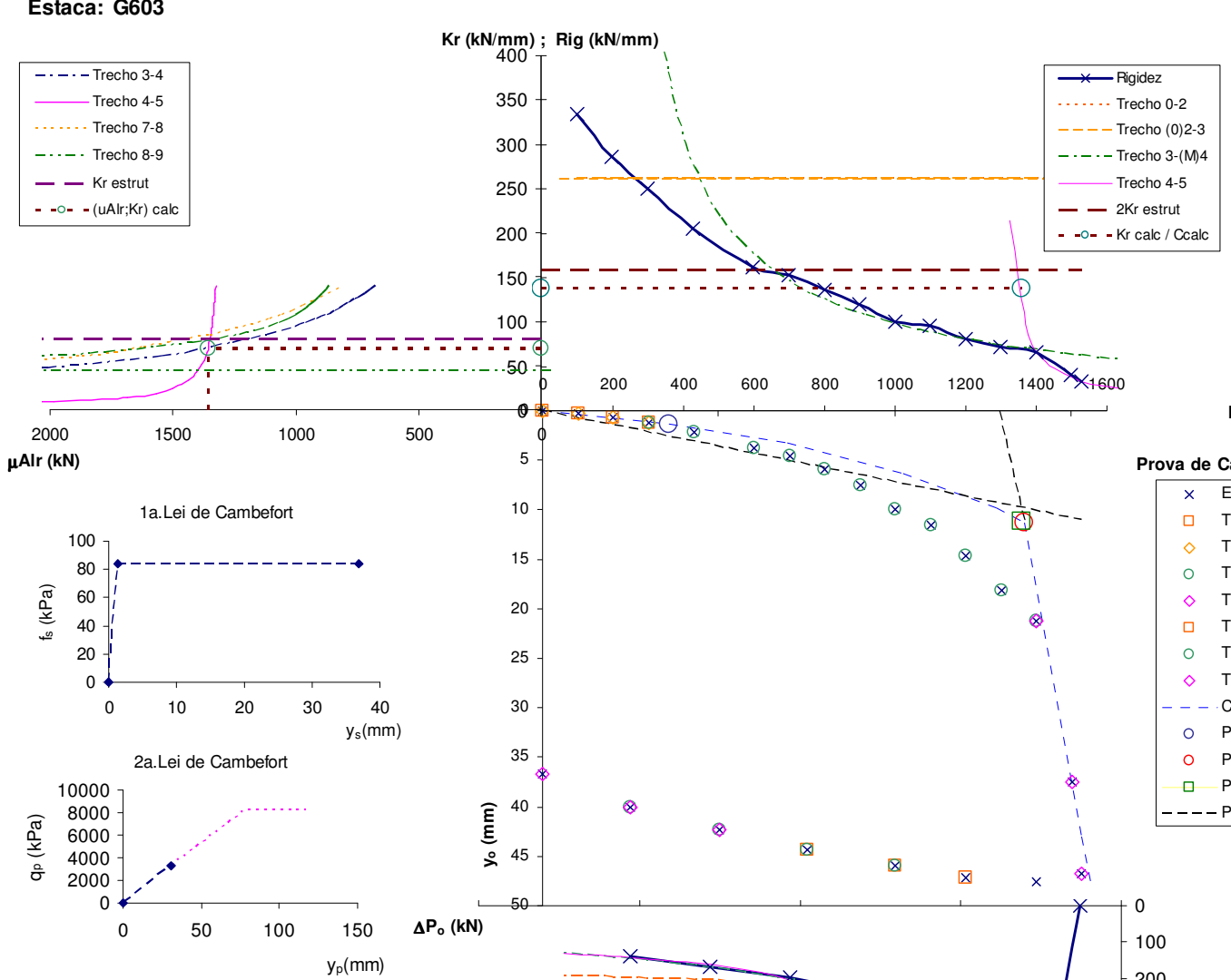

Sistema Sem 7-8

$\begin{aligned} \mathrm{E}_{\text {estaca }}= & 25,67 \mathrm{GPa} \\ \mathrm{Kr}= & 69,090 \mathrm{kN} / \mathrm{mm} \\ \mathrm{Alr}= & 1357,69 \mathrm{kN} \\ \mu= & 1,00 \\ \mathrm{f}_{\max }= & 84,25 \mathrm{kPa} \\ \mathrm{k}= & 14,45 \\ \mathrm{C}= & 0,500 \\ \mathrm{y}_{1}= & 1,36 \mathrm{~mm} \\ \beta_{3}^{\prime}= & 0,999 \\ \lambda= & 0,0214 \\ \mathrm{~A}= & 0,00 \mathrm{kPa}\end{aligned}$

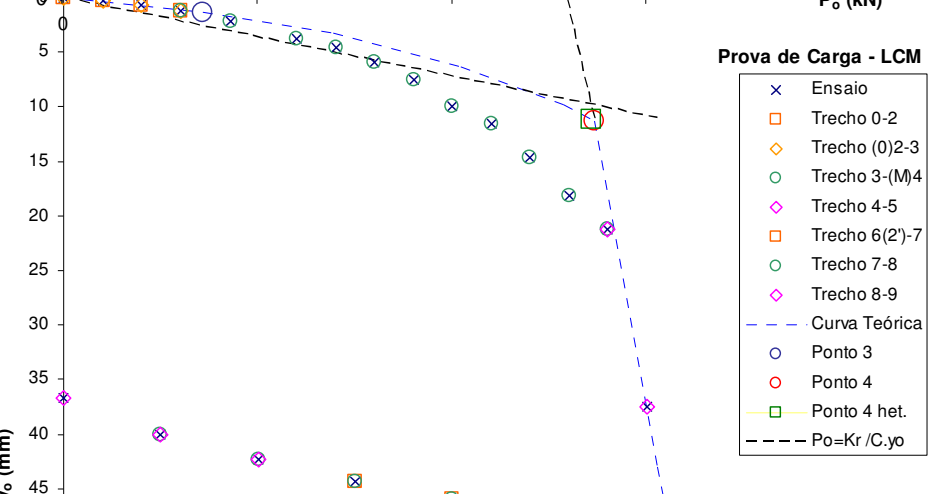

$\mathrm{A}=0,00 \mathrm{kPa}$

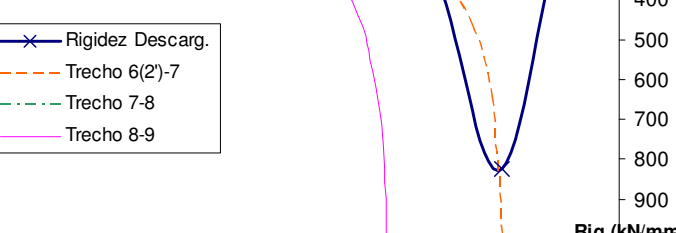




\section{APLICAÇÃO DA METODOLOGIA SEMIEMPÍRICA UNIFICADA}

ESTACA: Barrete

Local: São Paulo

Tipo: Esc. com lama
Dimensões:

$\mathrm{H}=\quad 400 \mathrm{~mm}$

$\mathrm{L}=\quad 7,0 \mathrm{~m}$

Estratigrafia: Fuste

Embutimento:

$\mathrm{L}_{2}=$

$3,2 \mathrm{~m}$

8D

\begin{tabular}{|c|c|c|c|c|c|c|}
\hline no. & Solo & édio $(F)$ & $\Delta \mathrm{L} / \mathrm{L}$ & & & \\
\hline & $\begin{array}{l}\text { Silte argilo arenoso } \\
\text { Areia argilo siltosa }\end{array}$ & $\begin{array}{l}24,3 \\
31,0\end{array}$ & $\begin{array}{l}0,76 \\
0,21\end{array}$ & & \multicolumn{2}{|l|}{ Ponta } \\
\hline \multirow{6}{*}{$\begin{array}{r} \\
8 \\
\\
10\end{array}$} & \multirow[t]{6}{*}{ Silte arenoso } & \multirow[t]{6}{*}{39,1} & \multirow[t]{6}{*}{0,03} & & Solo & $\mathrm{N}_{\mathrm{SPT}}(\mathrm{P})$ \\
\hline & & & & $8 \mathrm{D}$ & Silte arenoso & 40 \\
\hline & & & & $3 \mathrm{D}$ & S̈ilte arenoso & 50 \\
\hline & & & & Ponta & Silte arenoso & 45 \\
\hline & & & & $3 \mathrm{D}$ & Silte arenoso & 35 \\
\hline & & & & & & \\
\hline
\end{tabular}

Estimativas x Critérios de Ruptura

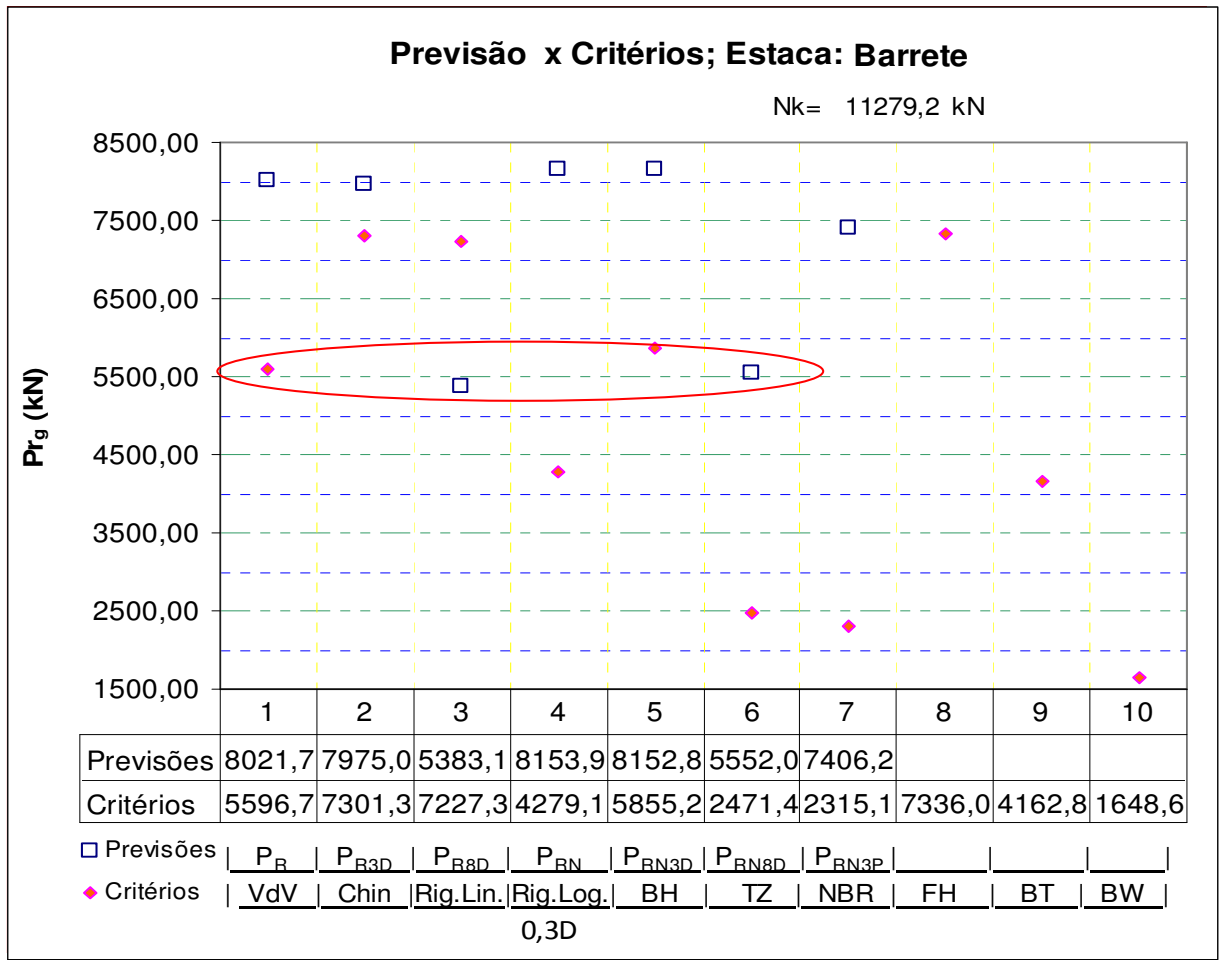

Transferência de carga: Sistema DRM-C

$f_{\max }=\quad 50,62 \mathrm{kPa}$

Critério de ruptura adotado: Van der Veen

$\mathrm{q}_{\mathrm{p}}=6278,64 \mathrm{kPa}$ 
Hierarquia dos Solos

Hierarquia dos Solos (Atrito) - Estaca: Barrete

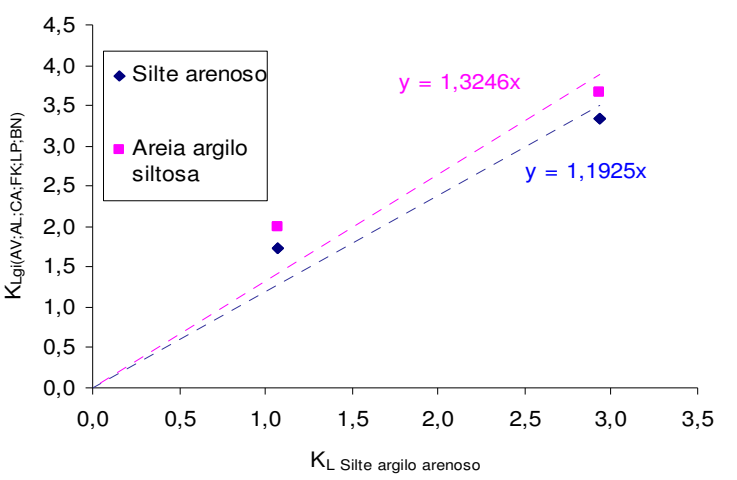

Hierarquia dos Solos (Ponta) - Estaca: Barrete

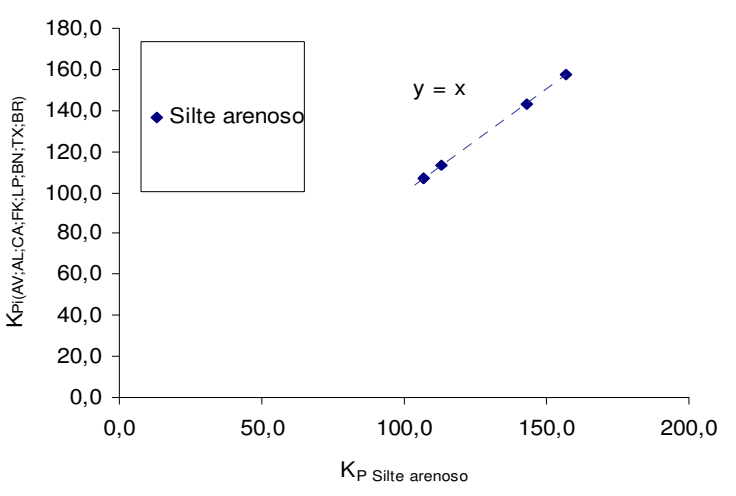

Correção dos coeficientes empíricos

Método Mediado

\begin{tabular}{|c|c|c|c|c|c|c|}
\hline Solo & $\mathbf{k}_{\mathrm{tD}}$ & $\mathbf{k}_{\mathrm{tEL}}$ & $\mathbf{k}_{\mathrm{ts}}(\%)$ & $\mathrm{k}_{\mathrm{te}}(\mathrm{kPa})$ & $\mathrm{k}_{\mathrm{tEP}}(\mathrm{kPa})$ & $\mathbf{k}_{\mathrm{tC}}$ \\
\hline Silte argilo arenoso & 1,00 & 0,153 & 3,04 & 381,62 & \#N/D & \#N/D \\
\hline Areia argilo siltosa & 1,00 & 0,153 & 3,06 & 503,27 & \#N/D & \#N/D \\
\hline Silte arenoso & 1,00 & 0,153 & 2,87 & 481,87 & 0,17 & 1,00 \\
\hline
\end{tabular}

Originais

\begin{tabular}{|c|c|c|c|c|c|c|}
\hline Solo & $\mathbf{k}_{\mathrm{tD}}$ & $\mathbf{k}_{\mathrm{tEL}}$ & $\mathbf{k}_{\mathrm{ts}}(\%)$ & $\mathrm{k}_{\mathrm{te}}(\mathrm{kPa})$ & $\mathrm{k}_{\mathrm{tEP}}(\mathrm{kPa})$ & $\overline{\mathbf{k}_{\mathrm{tC}}}$ \\
\hline Silte argilo arenoso & 1,00 & 0,209 & 3,04 & 343,33 & 0,355 & - \\
\hline Areia argilo siltosa & 1,00 & 0,209 & 3,06 & 533,33 & 0,355 & - \\
\hline Silte arenoso & 1,00 & 0,209 & 2,87 & 510,00 & 0,355 & - \\
\hline
\end{tabular}

\section{Método Expedito}

Atrito
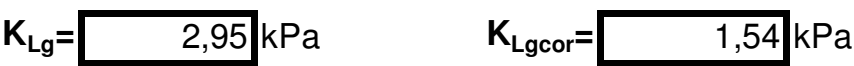

Ponta

Solo $\quad \mathrm{K}_{\mathrm{Pg}(\mathrm{i})}(\mathrm{kPa})$

\begin{tabular}{|c|r|}
\hline Silte arenoso & 376,72 \\
0 & 0,00 \\
0 & 0,00 \\
\hline
\end{tabular}


Estaca: Barrete

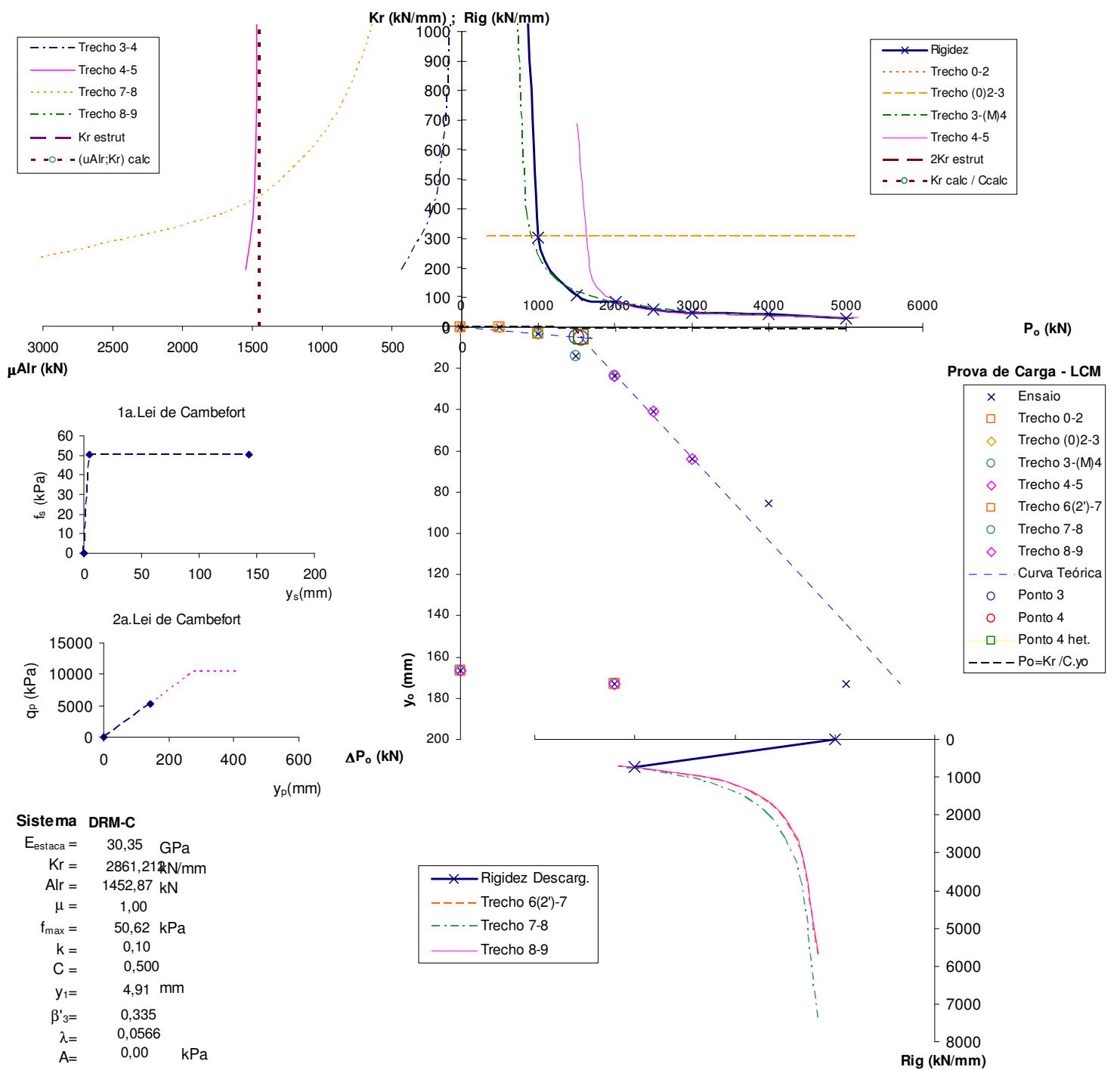




\section{APLICAÇÃO DA METODOLOGIA SEMIEMPÍRICA UNIFICADA}

ESTACA: PC19

Dimensões:

$\mathrm{D}=\quad 350 \mathrm{~mm}$

Local: Recife-Pe

Tipo: Pré-moldada cravada

$L=\quad 11,2 \mathrm{~m}$

Estratigrafia: Fuste

Embutimento:

$\mathrm{L}_{2}=$

$0 \mathrm{~m}$

Ponta

\begin{tabular}{|c|c|c|c|c|c|c|}
\hline no. & Solo & $\mathrm{N}_{\mathrm{SPT}}$ médio $(\mathrm{F})$ & $\Delta \mathrm{L} / \mathrm{L}$ & & \multirow{2}{*}{\multicolumn{2}{|c|}{ Ponta }} \\
\hline & \begin{tabular}{|l} 
Areia \\
Argila
\end{tabular} & \begin{tabular}{l|l}
5,8 \\
4,0
\end{tabular} & $\begin{array}{l}0,27 \\
0,13\end{array}$ & & & \\
\hline \multirow{6}{*}{$\begin{array}{r}4 \\
5 \\
6 \\
7 \\
8 \\
9 \\
10\end{array}$} & \multirow[t]{6}{*}{ Argila siltosa } & \multirow[t]{6}{*}{3,0} & \multirow[t]{6}{*}{0,60} & & Solo & $\mathrm{N}_{\mathrm{SPT}}(\mathrm{P})$ \\
\hline & & & & $8 \mathrm{D}$ & Argila siltosa & 3 \\
\hline & & & & $3 \mathrm{D}$ & Ärgila siltosa & 3 \\
\hline & & & & Ponta & Argila siltosa & 3 \\
\hline & & & & $3 D^{-}$ & Argila siltosa & 3 \\
\hline & & & & & & \\
\hline
\end{tabular}

Estimativas x Critérios de Ruptura

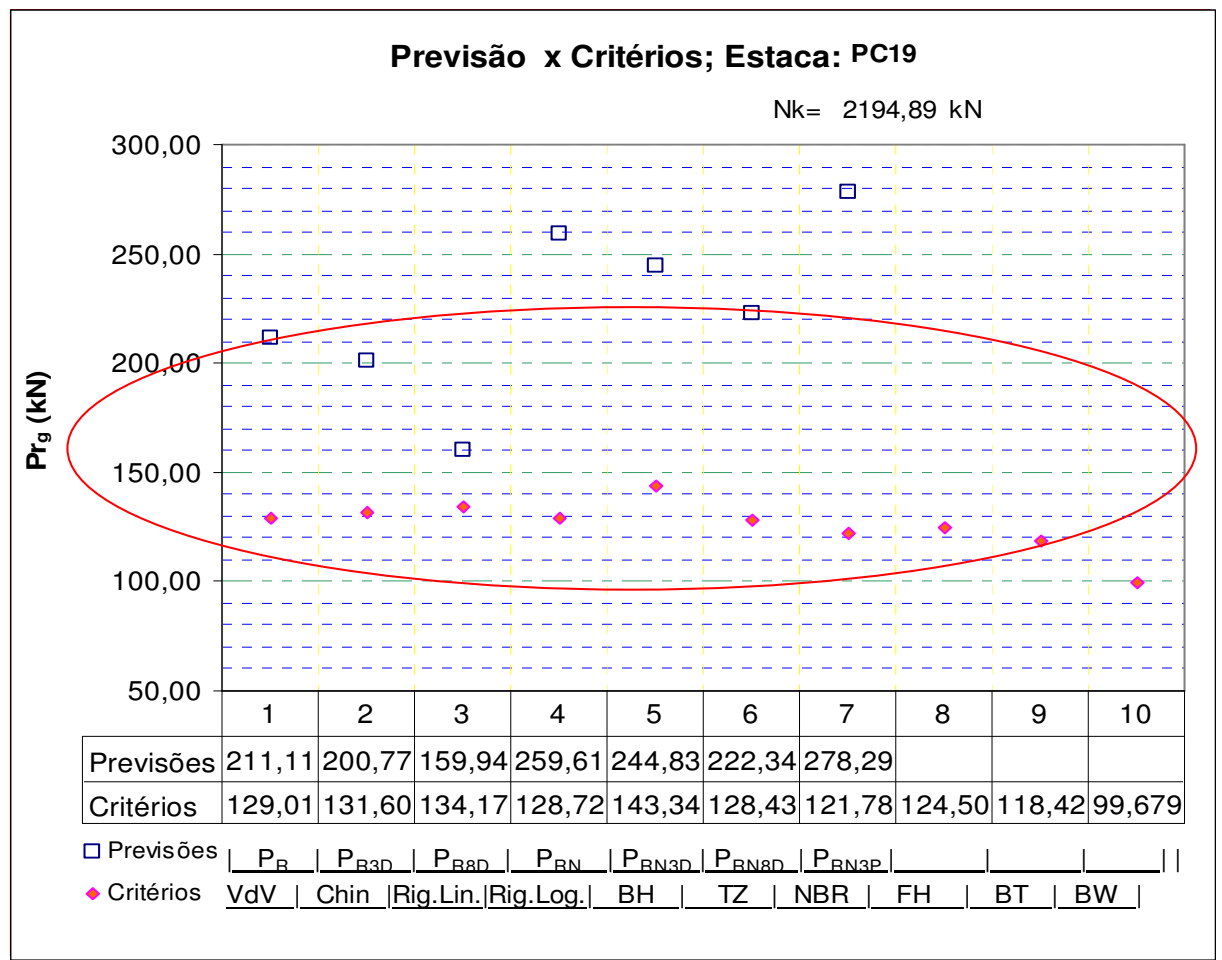

Transferência de carga: Sistema DRM-C

$f_{\max }=\quad 4,80 \mathrm{kPa}$

Critério de ruptura adotado: Van der Veen

$\mathrm{q}_{\mathrm{p}}=\quad 726,21 \mathrm{kPa}$ 
Hierarquia dos Solos

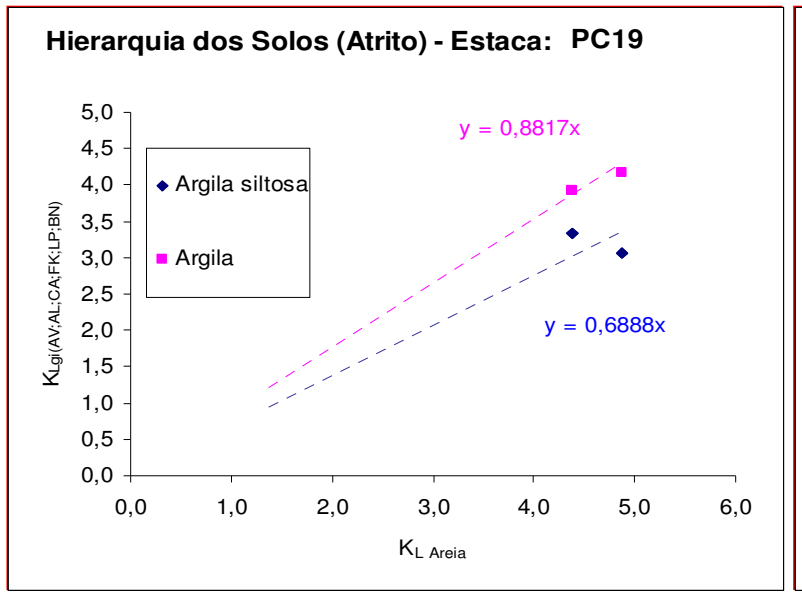

Hierarquia dos Solos (Ponta) - Estaca: PC19

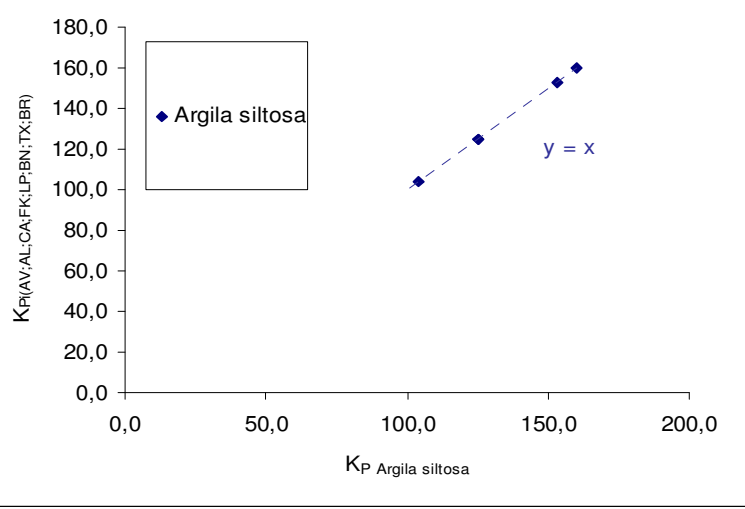

Correção dos coeficientes empíricos

Método Mediado

\begin{tabular}{|c|c|c|c|c|c|c|}
\hline Solo & $\mathrm{k}_{\mathrm{tD}}$ & $\overline{\mathbf{k}_{\mathrm{tEL}}}$ & $\mathrm{k}_{\mathrm{ts}}(\%)$ & $\mathrm{k}_{\mathrm{te}}(\mathrm{kPa})$ & $\mathrm{k}_{\mathrm{tEP}}(\mathrm{kPa})$ & $k_{t c}$ \\
\hline Areia & 1,00 & 0,094 & 1,90 & 762,95 & $\# \mathrm{~N} / \mathrm{D}$ & \#N/D \\
\hline Argila & 1,00 & 0,094 & 5,41 & 184,75 & $\# \mathrm{~N} / \mathrm{D}$ & $\# \mathrm{~N} / \mathrm{D}$ \\
\hline Argila siltosa & 1,00 & 0,094 & 4,29 & 298,30 & 0,81 & 1,00 \\
\hline
\end{tabular}

Originais

\begin{tabular}{|c|c|c|c|c|c|c|}
\hline Solo & $k_{t D}$ & $k_{\text {tEL }}$ & $\mathbf{k}_{\mathrm{ts}}(\%)$ & $\mathrm{k}_{\mathrm{te}}(\mathrm{kPa})$ & $\mathrm{k}_{\mathrm{tEP}}(\mathrm{kPa})$ & $\mathbf{k}_{\mathrm{tc}}$ \\
\hline Areia & 1,00 & 0,286 & 1,90 & 776,67 & 0,571 & - \\
\hline Argila & 1,00 & 0,286 & 5,41 & 233,33 & 0,571 & - \\
\hline Argila siltosa & 1,00 & 0,286 & 4,29 & 243,33 & 0,571 & - \\
\hline
\end{tabular}

\section{Método Expedito}

Atrito

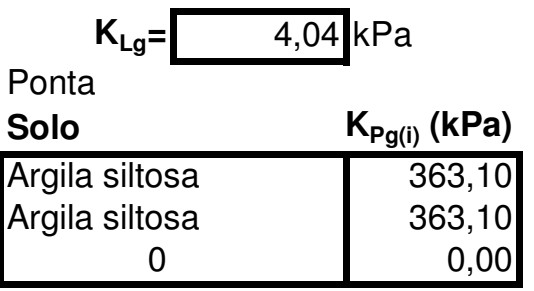


Estaca: PC19

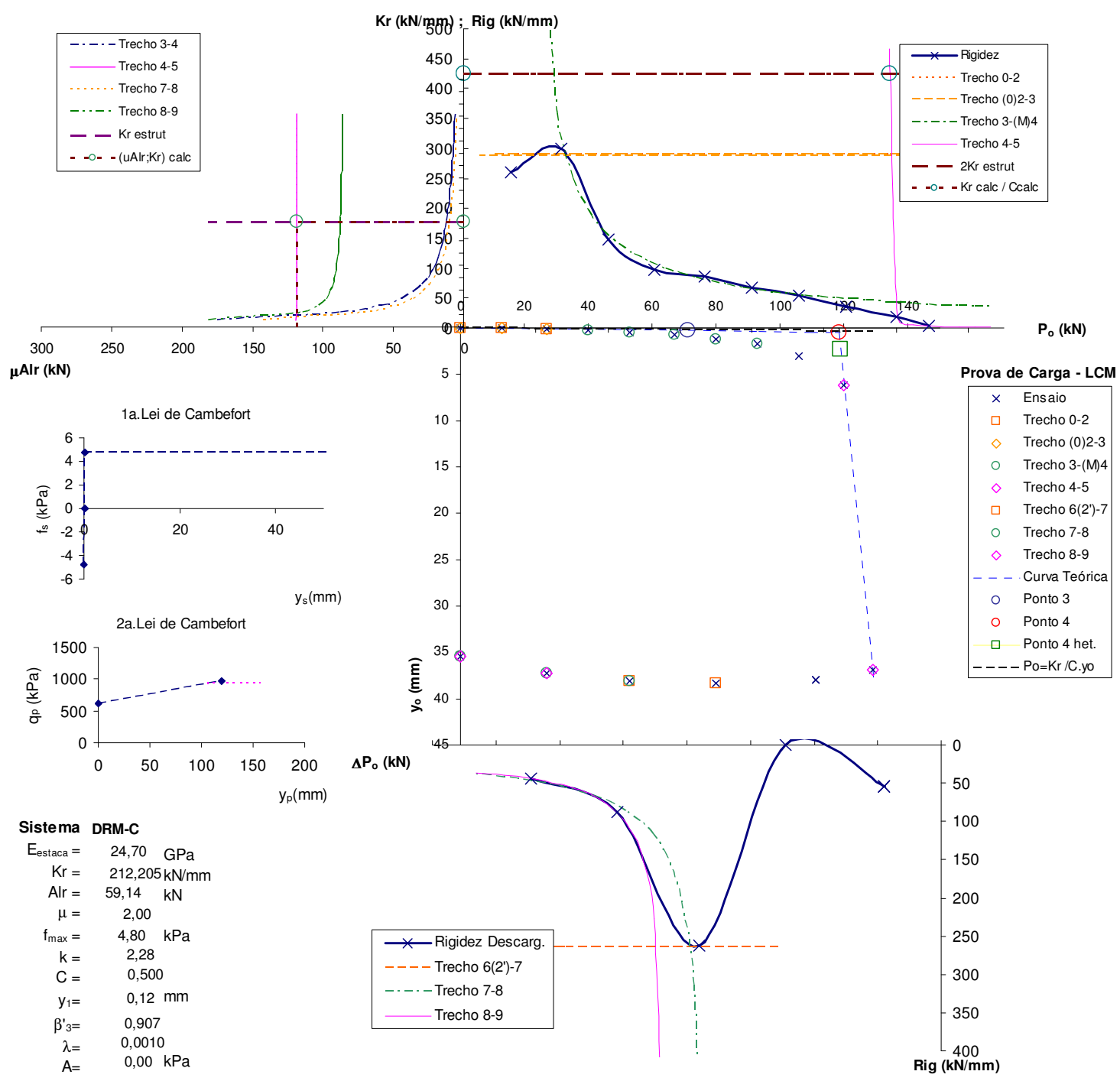




\section{APLICAÇÃO DA METODOLOGIA SEMIEMPÍRICA UNIFICADA}

ESTACA: CON-3

Local: Ilha Solteira

Tipo: Escavada

Estratigrafia: Fuste
Dimensões:

$\mathrm{D}=$

$\mathrm{L}=\quad 10 \mathrm{~m}$

Embutimento:

$\mathrm{L}_{2}=$

$0 \mathrm{~m}$

Ponta

\begin{tabular}{|c|c|c|c|c|c|c|}
\hline no. & Solo & $\mathrm{N}_{\mathrm{SPT}}$ médio $(\mathrm{F})$ & $\Delta \mathrm{L} / \mathrm{L}$ & & \multirow{2}{*}{\multicolumn{2}{|c|}{ Ponta }} \\
\hline & \multirow{7}{*}{\begin{tabular}{l|l} 
& Areia argilosa \\
3 &
\end{tabular}} & \multirow[t]{7}{*}{5,2} & \multirow[t]{7}{*}{1,00} & & & \\
\hline 3 & & & & & Solo & $\overline{N_{S P T}(P)}$ \\
\hline 5 & & & & $8 \mathrm{D}$ & Areia argilosa & 6 \\
\hline 6 & & & & $3 \mathrm{D}$ & Áreia argilosa & 9 \\
\hline 7 & & & & Ponta & Areia argilosa & $\overline{9}$ \\
\hline 8 & & & & $3 \mathrm{D}$ & Äreia argilosa & 9 \\
\hline $\begin{array}{r}9 \\
10\end{array}$ & & & & & & \\
\hline
\end{tabular}

Estimativas x Critérios de Ruptura

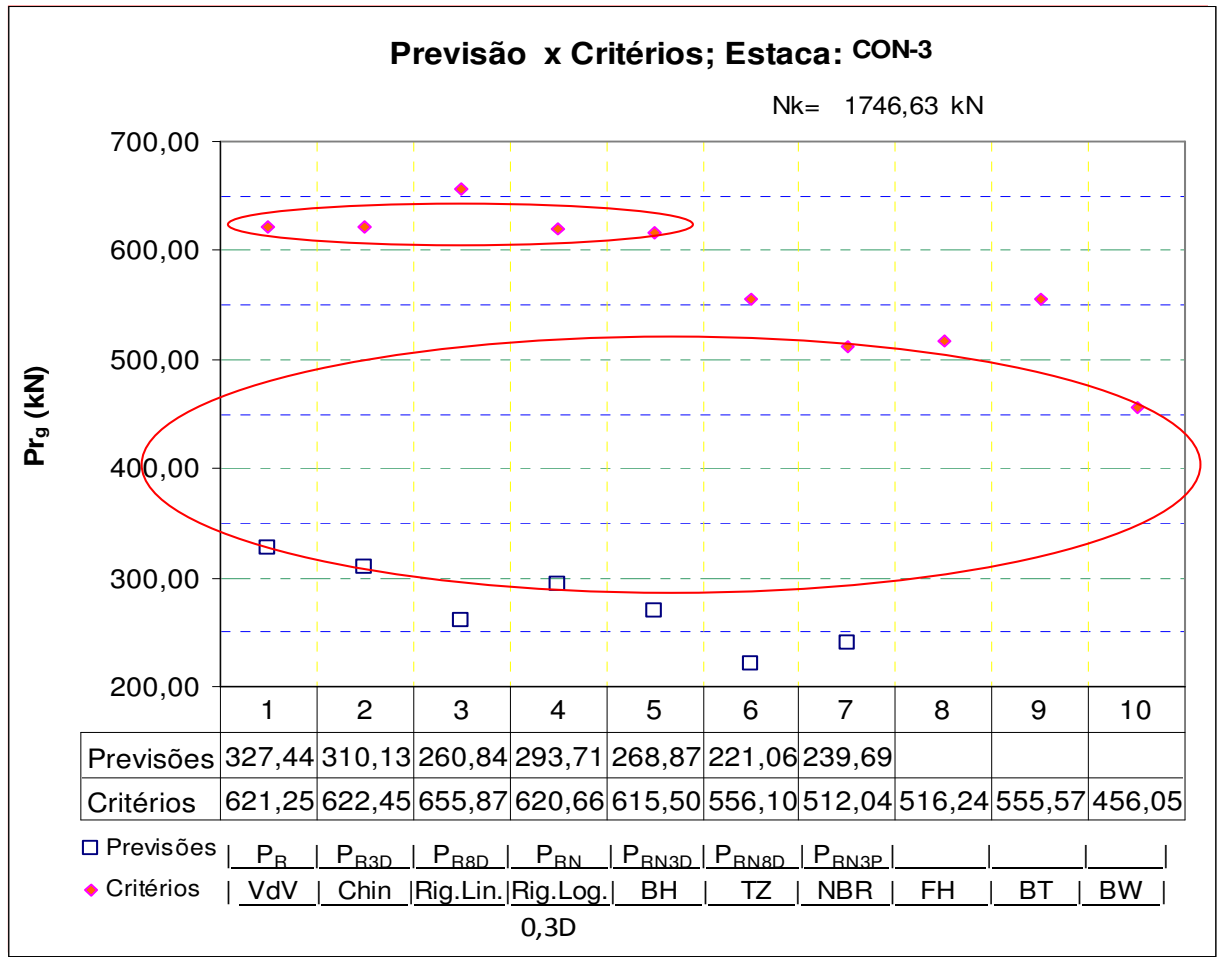

Transferência de carga: Sistema Sem 7-8

$f_{\max }=\quad 42,44 \mathrm{kPa}$

Critério de ruptura adotado: Van der Veen

$q_{p}=2419,48 \mathrm{kPa}$ 
Hierarquia dos Solos

Hierarquia dos Solos (Atrito) - Estaca: CON-3

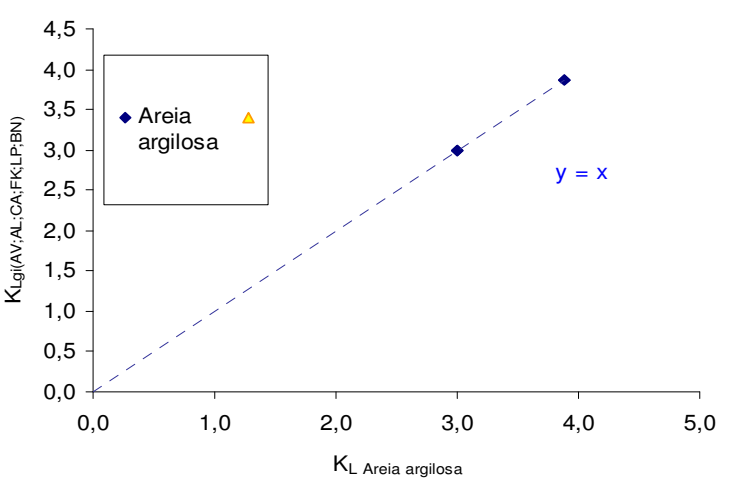

Hierarquia dos Solos (Ponta) - Estaca: CON-3

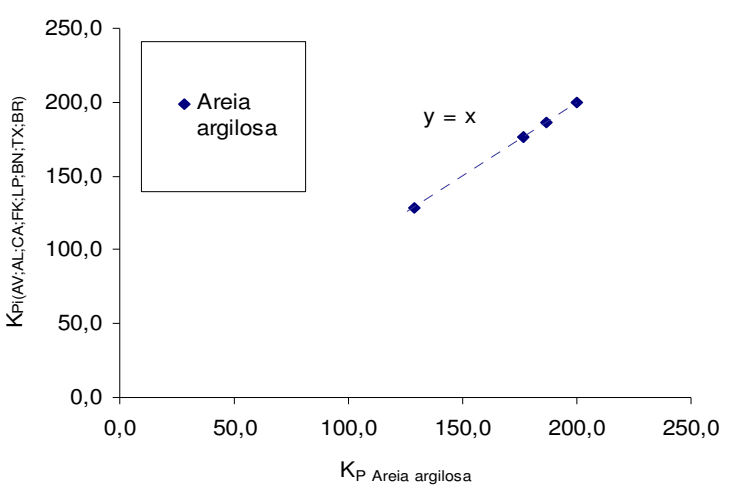

Correção dos coeficientes empíricos

Método Mediado

\begin{tabular}{|c|c|c|c|c|c|c|}
\hline Solo & $\mathbf{k}_{\mathrm{tD}}$ & $\mathbf{k}_{\mathrm{tEL}}$ & $\mathbf{k}_{\mathrm{ts}}(\%)$ & $\mathrm{k}_{\mathrm{te}}(\mathrm{kPa})$ & $\mathrm{k}_{\mathrm{tEP}}(\mathrm{kPa})$ & $\mathbf{k}_{\mathrm{tc}}$ \\
\hline Areia argilosa & 1,00 & 0,470 & 3,12 & 556,67 & 0,48 & 1,00 \\
\hline
\end{tabular}

Originais

\begin{tabular}{|c|c|c|c|c|c|c|}
\hline Solo & $\mathbf{k}_{\mathrm{tD}}$ & $\mathbf{k}_{\mathrm{tEL}}$ & $\mathbf{k}_{\mathrm{ts}}(\%)$ & $\mathrm{k}_{\mathrm{te}}(\mathrm{kPa})$ & $\mathrm{k}_{\mathrm{tEP}}(\mathrm{kPa})$ & $\mathbf{k}_{\mathrm{tc}}$ \\
\hline Areia argilosa & 1,00 & 0,199 & 3,12 & 556,67 & 0,365 & - \\
\hline
\end{tabular}

Método Expedito

Atrito
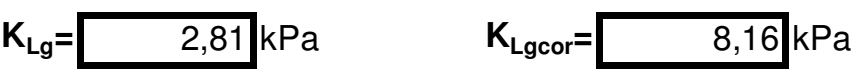

Ponta

Solo $\quad \mathrm{K}_{\mathrm{Pg}(\mathrm{i})}(\mathrm{kPa})$

\begin{tabular}{|c|r|}
\hline Areia argilosa & 806,49 \\
0 & 0,00 \\
0 & 0,00 \\
\hline
\end{tabular}


Estaca: CON-3

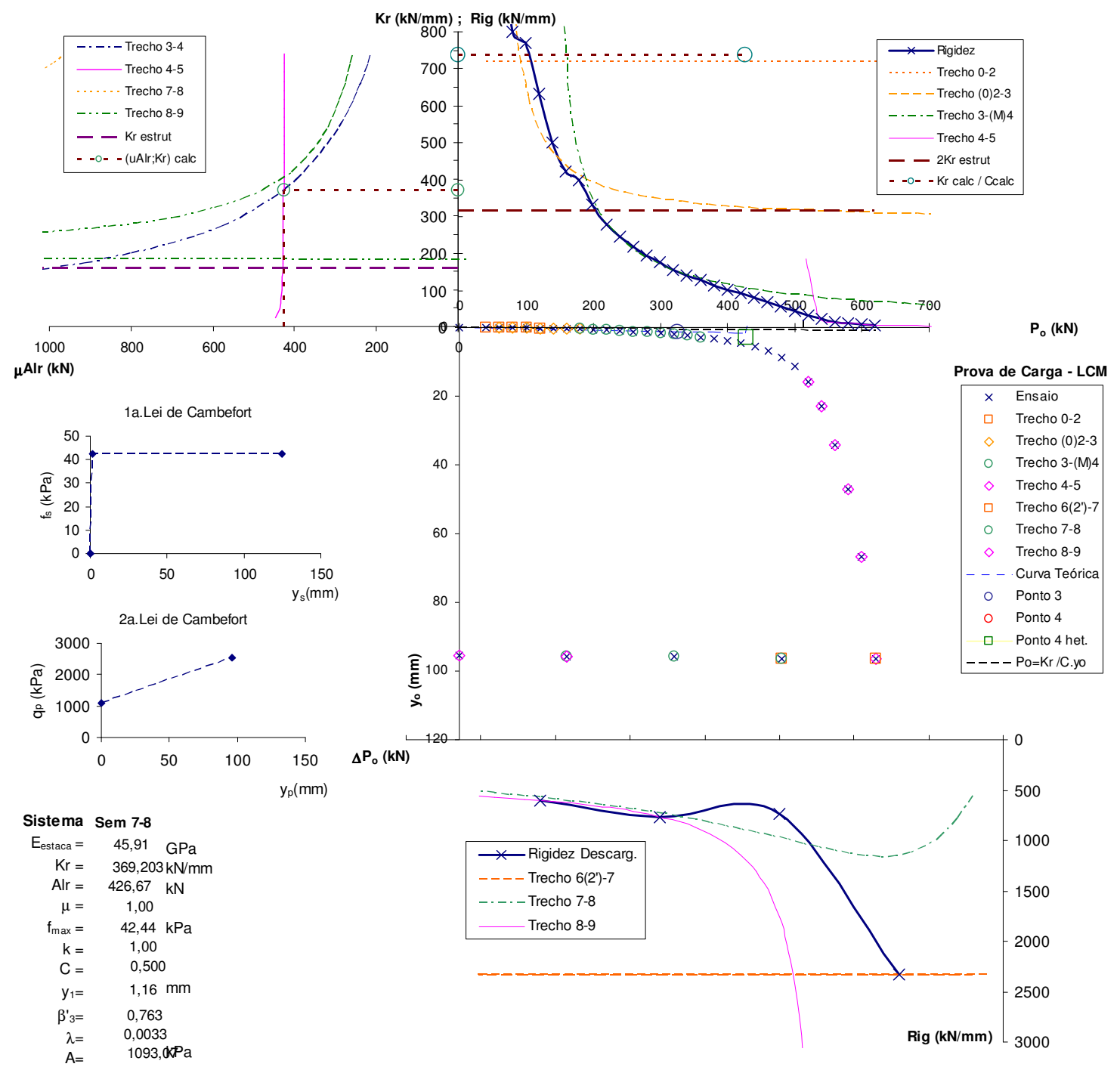




\section{APLICAÇÃO DA METODOLOGIA SEMIEMPÍRICA UNIFICADA}

ESTACA: ESC 3

Local: Campinas

Tipo: Escavada
Dimensões:

$\mathrm{D}=$

$\mathrm{L}=$

$\mathrm{L}_{2}=$

Embutimento:
$400 \mathrm{~mm}$

$11,5 \mathrm{~m}$

Estratigrafia: Fuste

\begin{tabular}{|c|c|c|c|c|c|c|}
\hline no. & Solo & $\mathrm{N}_{\mathrm{SPT}}$ médio $(\mathrm{F})$ & $\Delta \mathrm{L} / \mathrm{L}$ & & \multirow{2}{*}{\multicolumn{2}{|c|}{ Ponta }} \\
\hline & \multirow{7}{*}{$\begin{array}{l}\text { Argila silto arenosa } \\
\text { Areia argilo siltosa } \\
\text { Silte argilo arenoso }\end{array}$} & $\begin{array}{l}4,0 \\
5,0\end{array}$ & $\begin{array}{l}0,48 \\
0,04\end{array}$ & & & \\
\hline 3 & & 7,3 & 0,48 & & Solo & $\mathrm{N}_{\mathrm{SPT}}(\mathrm{P})$ \\
\hline 5 & & & & $8 \mathrm{D}$ & Silte argilo arenoso & 7,3 \\
\hline$\epsilon$ & & & & $3 \mathrm{D}$ & Šite argilo arenoso & 7,3 \\
\hline 7 & & & & Ponta & Silte argilo arenoso & 7,3 \\
\hline 8 & & & & $3 \mathrm{D}$ & Silte argilo arenoso & 7,3 \\
\hline 10 & & & & & & \\
\hline
\end{tabular}

$0 \mathrm{~m}$

Ponta

Estimativas x Critérios de Ruptura

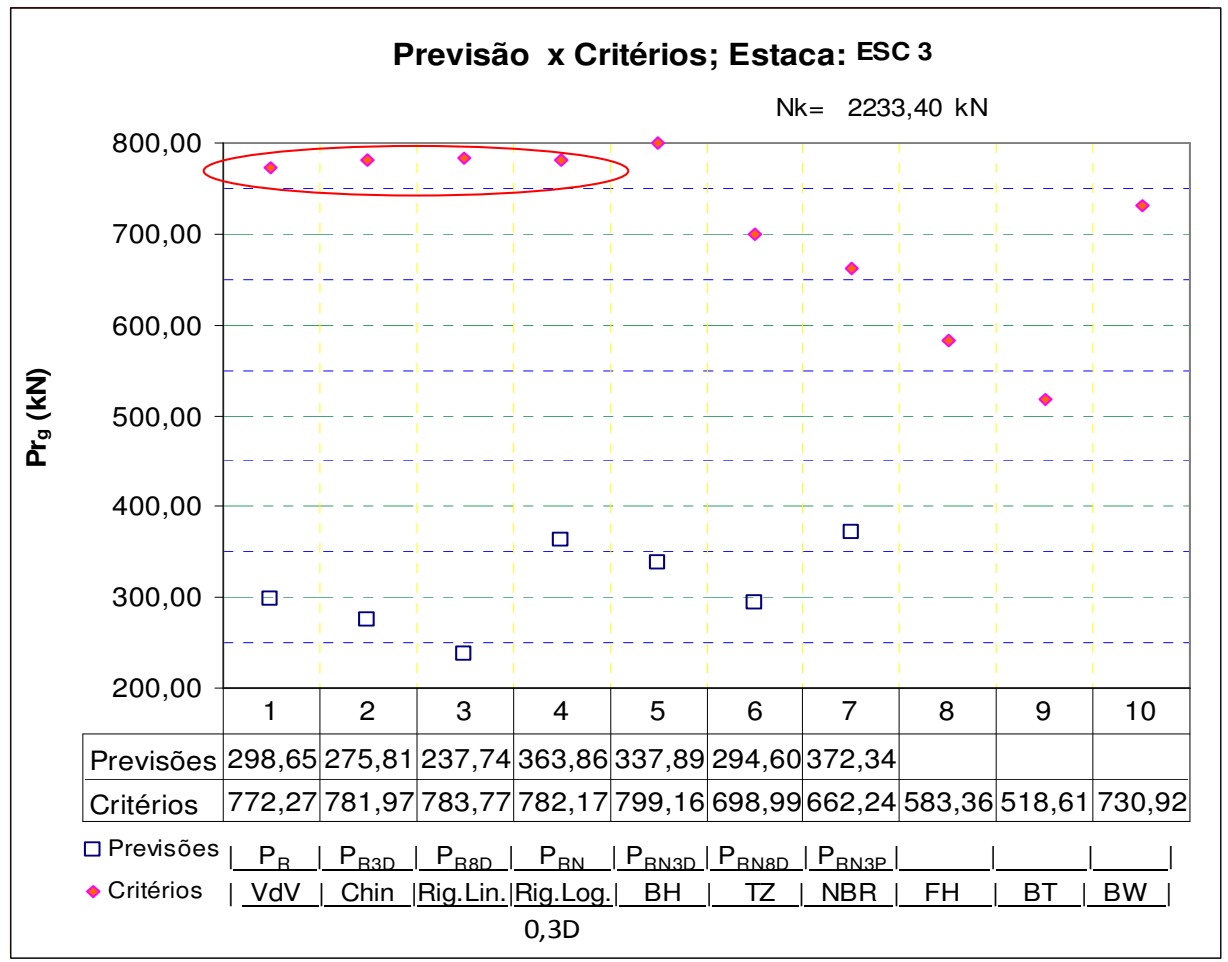

Transferência de carga: Sistema Sem 7-8

$$
f_{\max }=\quad 45,57 \mathrm{kPa}
$$

Critério de ruptura adotado: Van der Veen

$\mathrm{q}_{\mathrm{p}}=\quad 905,26 \mathrm{kPa}$ 
Hierarquia dos Solos

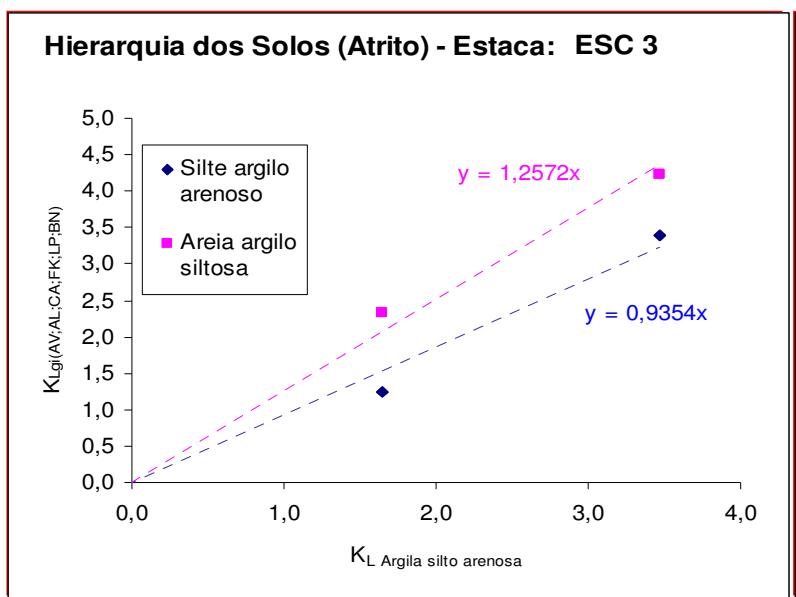

Hierarquia dos Solos (Ponta) - Estaca: ESC 3

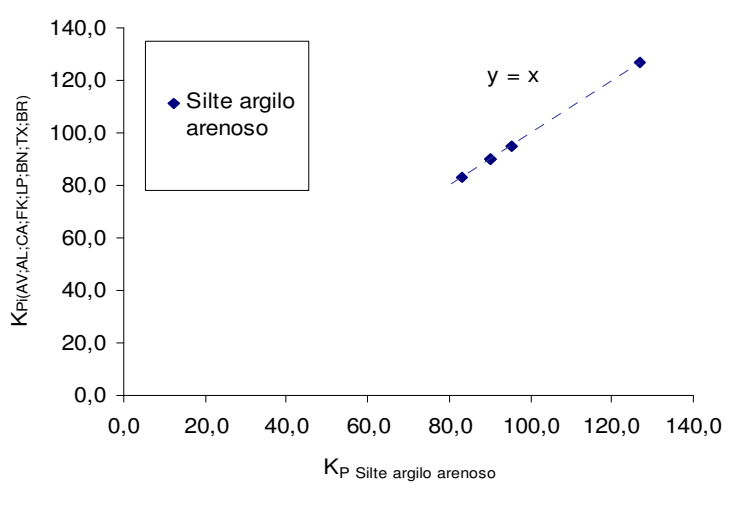

Correção dos coeficientes empíricos

Método Mediado

\begin{tabular}{|c|c|c|c|c|c|c|}
\hline Solo & $\mathbf{k}_{\mathrm{tD}}$ & $k_{t E L}$ & $\mathbf{k}_{\mathrm{ts}}(\%)$ & $\mathrm{k}_{\mathrm{te}}(\mathrm{kPa})$ & $\mathrm{k}_{\mathrm{tEP}}(\mathrm{kPa})$ & $\mathrm{k}_{\mathrm{tC}}$ \\
\hline Argila silto arenosa & 1,00 & 0,687 & 3,92 & 310,70 & $\# \mathrm{~N} / \mathrm{D}$ & $\# \mathrm{~N} / \mathrm{D}$ \\
\hline Areia argilo siltosa & 1,00 & 0,687 & 3,06 & 500,81 & $\# \mathrm{~N} / \mathrm{D}$ & \#N/D \\
\hline Silte argilo arenoso & 1,00 & 0,687 & 3,04 & 374,25 & 0,33 & 1,00 \\
\hline
\end{tabular}

Originais

\begin{tabular}{|c|c|c|c|c|c|c|}
\hline Solo & $\mathbf{k}_{\mathrm{tD}}$ & $\mathbf{k}_{\mathrm{tEL}}$ & $\mathbf{k}_{\mathrm{ts}}(\%)$ & $\mathrm{k}_{\mathrm{te}}(\mathrm{kPa})$ & $k_{\text {tEP }}(\mathrm{kPa})$ & $\mathbf{k}_{\mathrm{tc}}$ \\
\hline Argila silto arenosa & 1,00 & 0,199 & 3,92 & 320,00 & 0,365 & - \\
\hline Areia argilo siltosa & 1,00 & 0,199 & 3,06 & 533,33 & 0,365 & - \\
\hline Silte argilo arenoso & 1,00 & 0,199 & 3,04 & 343,33 & 0,365 & - \\
\hline
\end{tabular}

\section{Método Expedito}

Atrito
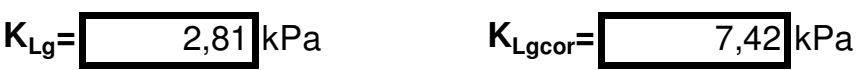

Ponta

Solo $\quad \mathrm{K}_{\mathrm{Pg}(\mathrm{i})}(\mathrm{kPa})$

\begin{tabular}{|l|r|}
\hline Silte argilo arenoso & 372,02 \\
\hline
\end{tabular}

\begin{tabular}{l|l}
0 & 0,00 \\
\hline
\end{tabular}

\begin{tabular}{l|l}
0 & 0,00 \\
\hline
\end{tabular} 
Estaca: ESC 3

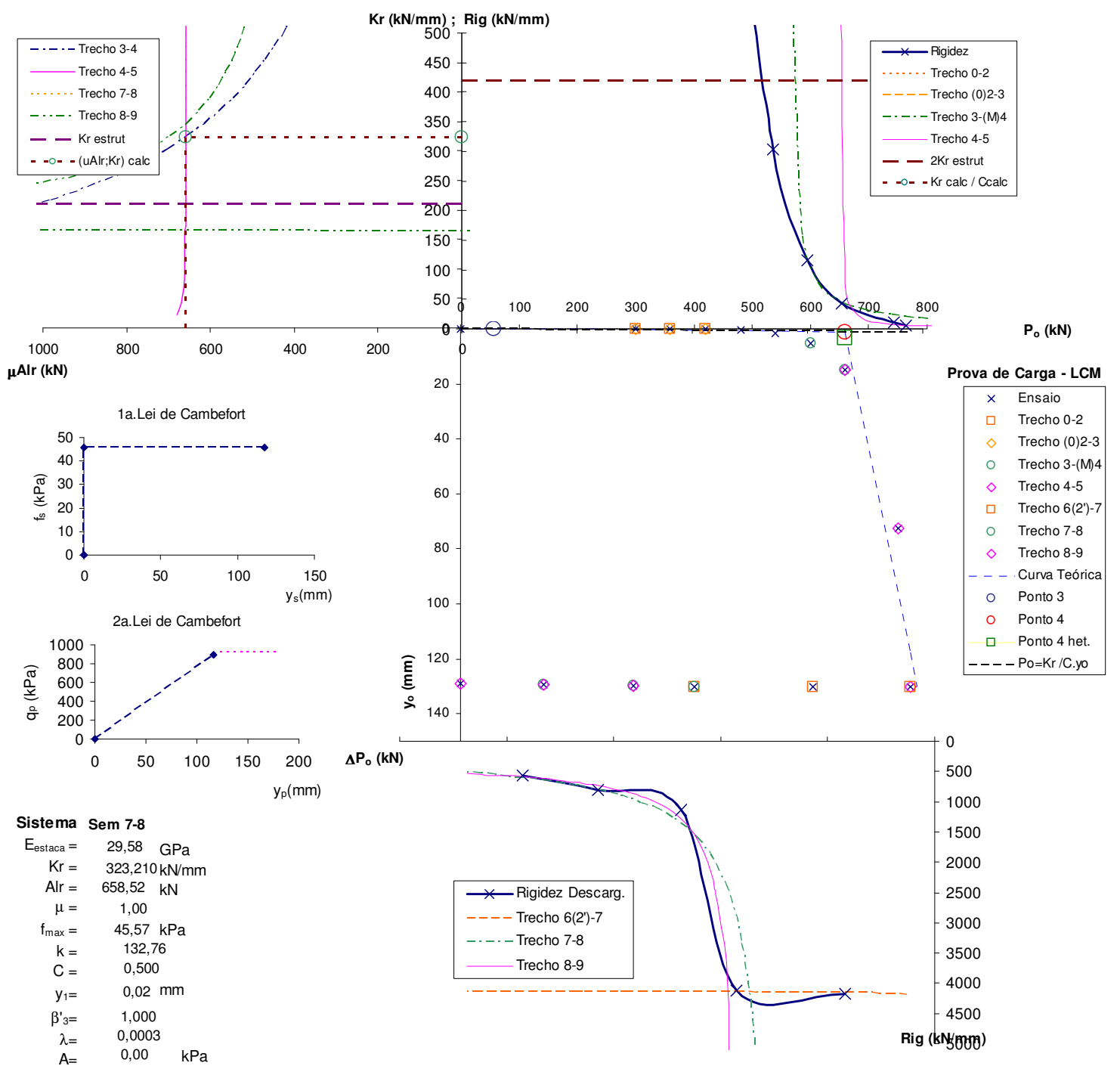




\section{APLICAÇÃO DA METODOLOGIA SEMIEMPÍRICA UNIFICADA}

ESTACA: ESC 1

Local: Campinas

Tipo: Escavada

Estratigrafia: Fuste
Dimensões:

$\mathrm{D}=$

$\mathrm{L}=$

$\mathrm{L}_{2}=$

Embutimento:
$450 \mathrm{~mm}$

$11,5 \mathrm{~m}$

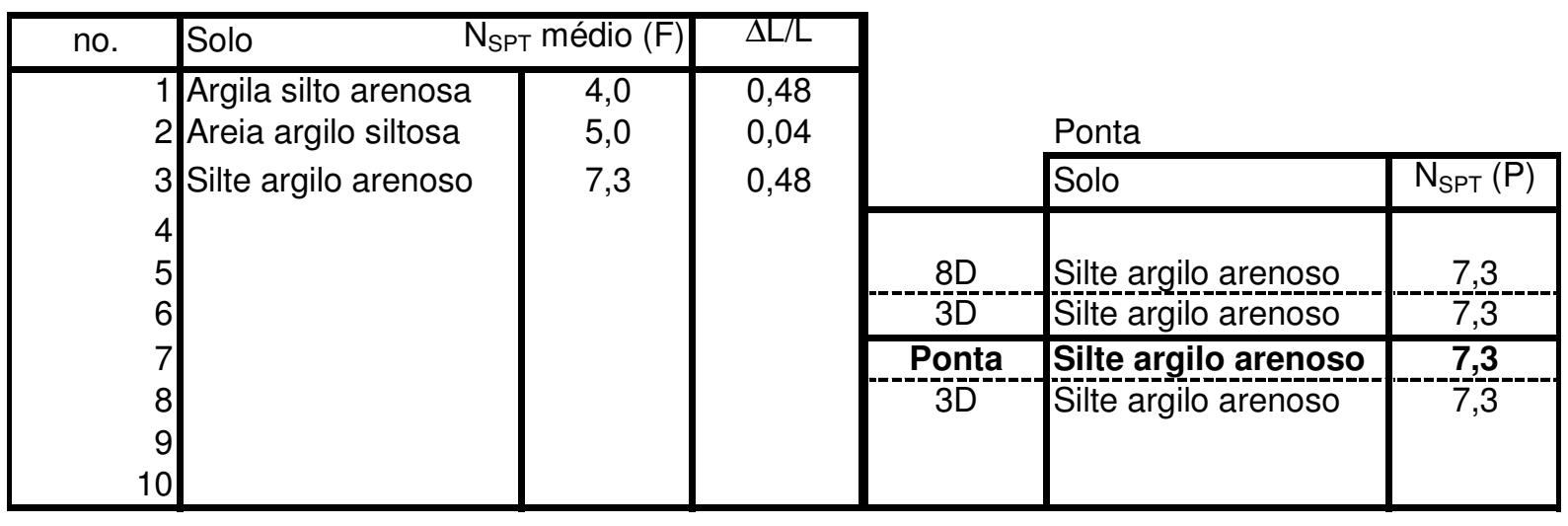

Estimativas x Critérios de Ruptura

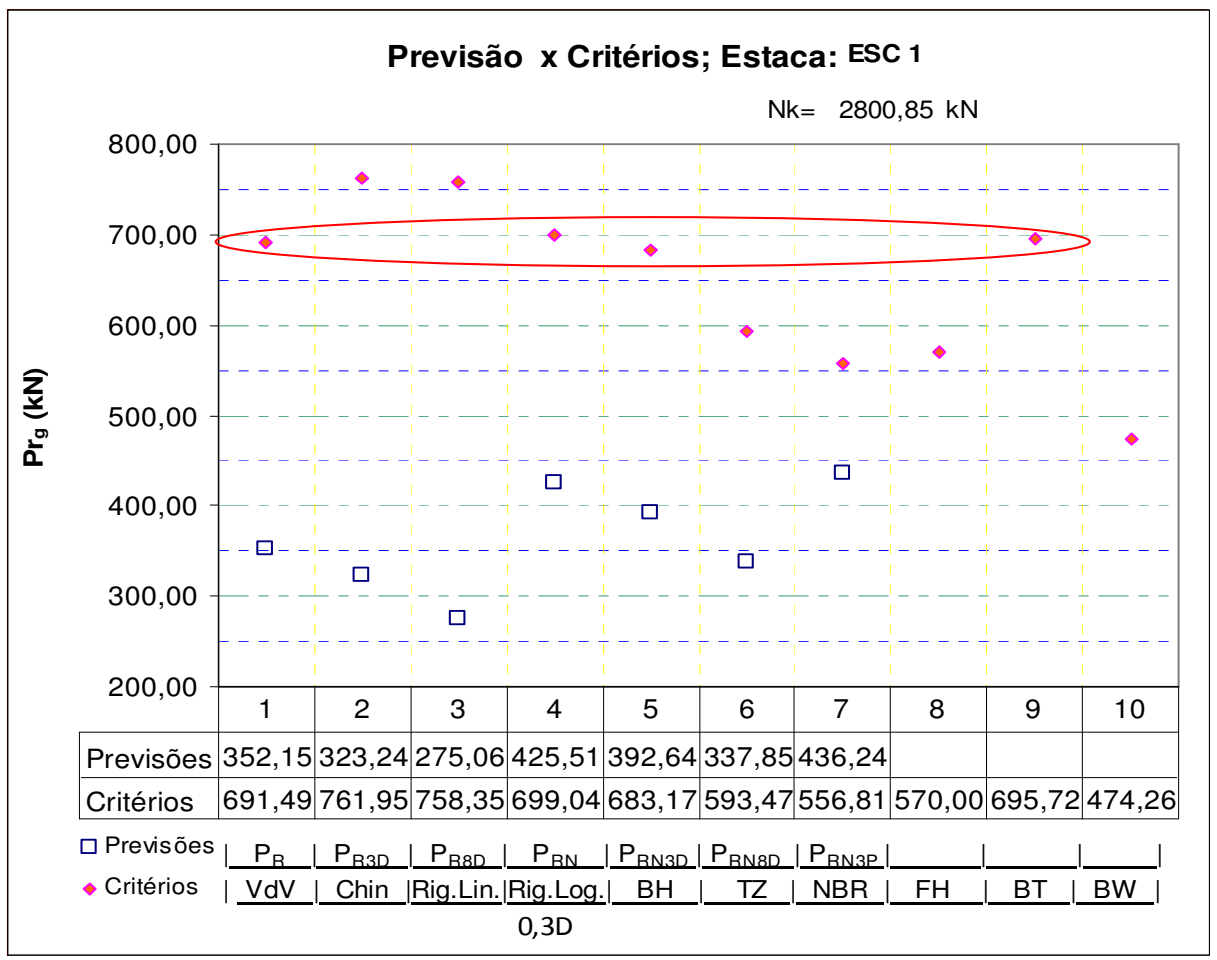

Transferência de carga: Sistema Sem 7-8

$$
f_{\max }=\quad 39,45 \mathrm{kPa}
$$

Critério de ruptura adotado: Van der Veen

$$
\mathrm{q}_{\mathrm{p}}=\quad 315,27 \mathrm{kPa}
$$


Hierarquia dos Solos

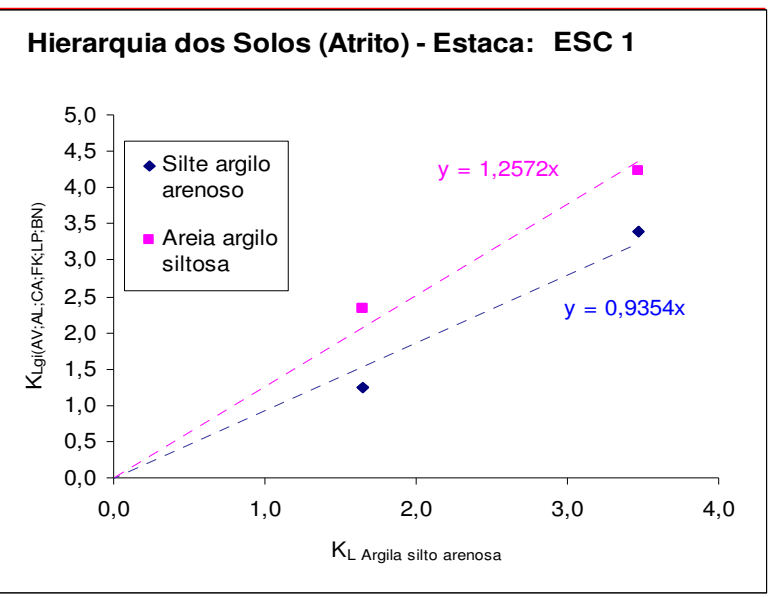

Hierarquia dos Solos (Ponta) - Estaca: ESC 1

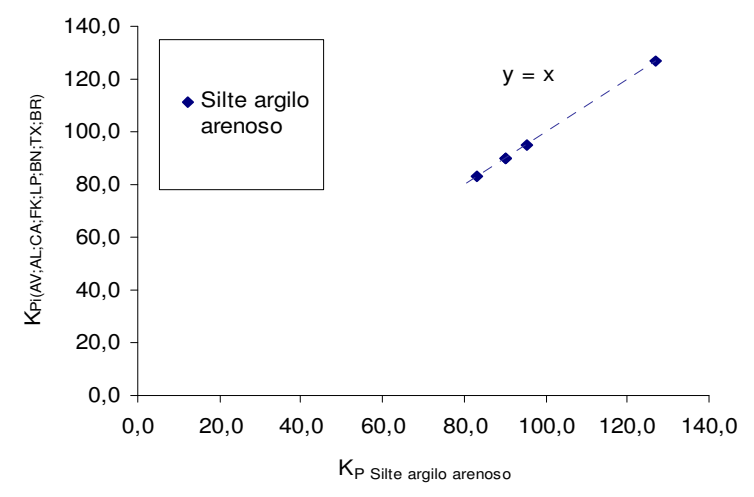

Correção dos coeficientes empíricos

Método Mediado

\begin{tabular}{|c|c|c|c|c|c|c|}
\hline Solo & $\mathbf{k}_{\mathrm{tD}}$ & $\mathbf{k}_{\mathrm{tEL}}$ & $\mathbf{k}_{\mathrm{ts}}(\%)$ & $\mathrm{k}_{\mathrm{te}}(\mathrm{kPa})$ & $\mathrm{k}_{\mathrm{tEP}}(\mathrm{kPa})$ & $\mathrm{k}_{\mathrm{tC}}$ \\
\hline Argila silto arenosa & 1,00 & 0,594 & 3,92 & 310,70 & $\# \mathrm{~N} / \mathrm{D}$ & $\# \mathrm{~N} / \mathrm{D}$ \\
\hline Areia argilo siltosa & 1,00 & 0,594 & 3,06 & 500,81 & $\# \mathrm{~N} / \mathrm{D}$ & \#N/D \\
\hline Silte argilo arenoso & 1,00 & 0,594 & 3,04 & 374,25 & 0,12 & 1,00 \\
\hline
\end{tabular}

Originais

\begin{tabular}{|c|c|c|c|c|c|c|}
\hline Solo & $\mathbf{k}_{\mathrm{tD}}$ & $\mathbf{k}_{\mathrm{tEL}}$ & $\overline{\mathrm{k}_{\mathrm{ts}}(\%)}$ & $\mathrm{k}_{\mathrm{te}}(\mathrm{kPa})$ & $\mathrm{k}_{\mathrm{tEP}}(\mathrm{kPa})$ & $\overline{\mathrm{k}_{\mathrm{tc}}}$ \\
\hline Argila silto arenosa & 1,00 & 0,199 & 3,92 & 320,00 & 0,365 & - \\
\hline Areia argilo siltosa & 1,00 & 0,199 & 3,06 & 533,33 & 0,365 & - \\
\hline Silte argilo arenoso & 1,00 & 0,199 & 3,04 & 343,33 & 0,365 & - \\
\hline
\end{tabular}

\section{Método Expedito}

Atrito
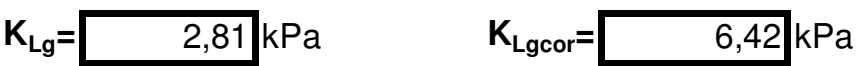

Ponta

Solo $\quad \mathrm{K}_{\mathrm{Pg}(\mathrm{i})}(\mathrm{kPa})$

\begin{tabular}{|l|r|}
\hline Silte argilo arenoso & 129,56 \\
\hline
\end{tabular}

\begin{tabular}{l|l}
0 & 0,00 \\
\hline & 0,00 \\
\hline
\end{tabular}

\begin{tabular}{l|l}
0 & 0,00 \\
\hline
\end{tabular} 
Estaca: ESC 1

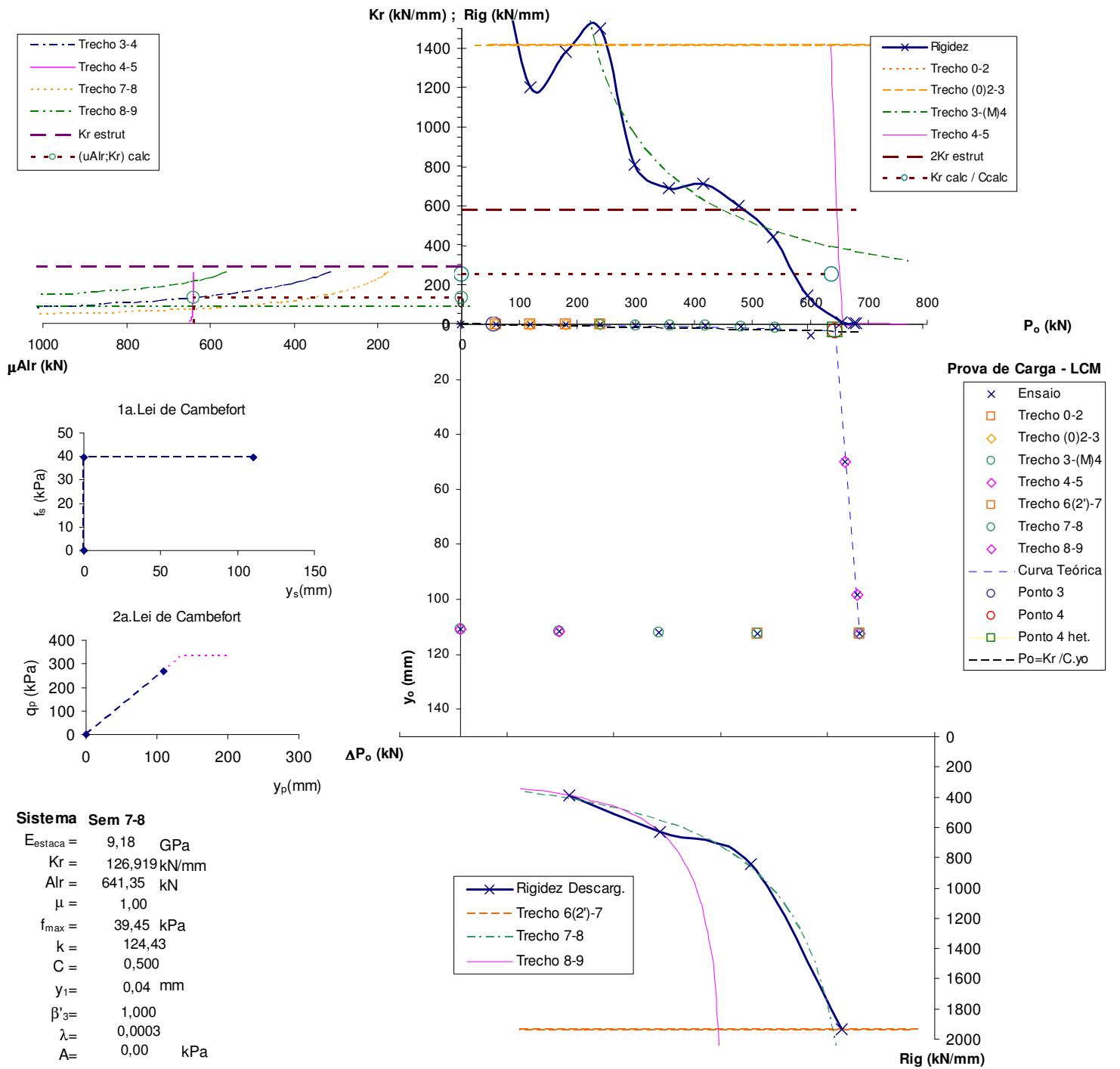




\section{APLICAÇÃO DA METODOLOGIA SEMIEMPÍRICA UNIFICADA}

ESTACA: PC $25 \quad$ Dimensões: $\quad \mathrm{D}=\quad 330 \mathrm{~mm}$

Local: Santo André

Tipo: Pré-moldada cravada

$L=11,6 \mathrm{~m}$

Estratigrafia: Fuste $\quad$ Embutimento: $\quad \mathrm{L}_{2}=\quad 0 \mathrm{~m} \quad$ Ponta

\begin{tabular}{|c|c|c|c|c|c|c|}
\hline no. & Solo & $\mathrm{N}_{\mathrm{SPT}}$ médio $(\mathrm{F})$ & $\Delta \mathrm{L} / \mathrm{L}$ & & \multirow{2}{*}{\multicolumn{2}{|c|}{ Ponta }} \\
\hline \multirow{7}{*}{$\begin{array}{r}1 \\
2 \\
3 \\
4 \\
5 \\
6 \\
7 \\
8 \\
9 \\
10\end{array}$} & \multirow[t]{7}{*}{$\begin{array}{l}\text { Argila arenosa } \\
\text { Argila }\end{array}$} & \multirow[t]{7}{*}{$\begin{array}{l}7,2 \\
9,8\end{array}$} & \multirow[t]{7}{*}{$\begin{array}{l}0,32 \\
0,68\end{array}$} & & & \\
\hline & & & & & Solo & $\mathrm{N}_{\mathrm{SPT}}(\mathrm{P})$ \\
\hline & & & & $8 \mathrm{D}$ & Argila & 16 \\
\hline & & & & $3 \mathrm{D}$ & Ärgila & 12 \\
\hline & & & & Ponta & Argila & $\overline{12}$ \\
\hline & & & & $3 \mathrm{D}$ & Argila & 11 \\
\hline & & & & & & \\
\hline
\end{tabular}

Estimativas x Critérios de Ruptura

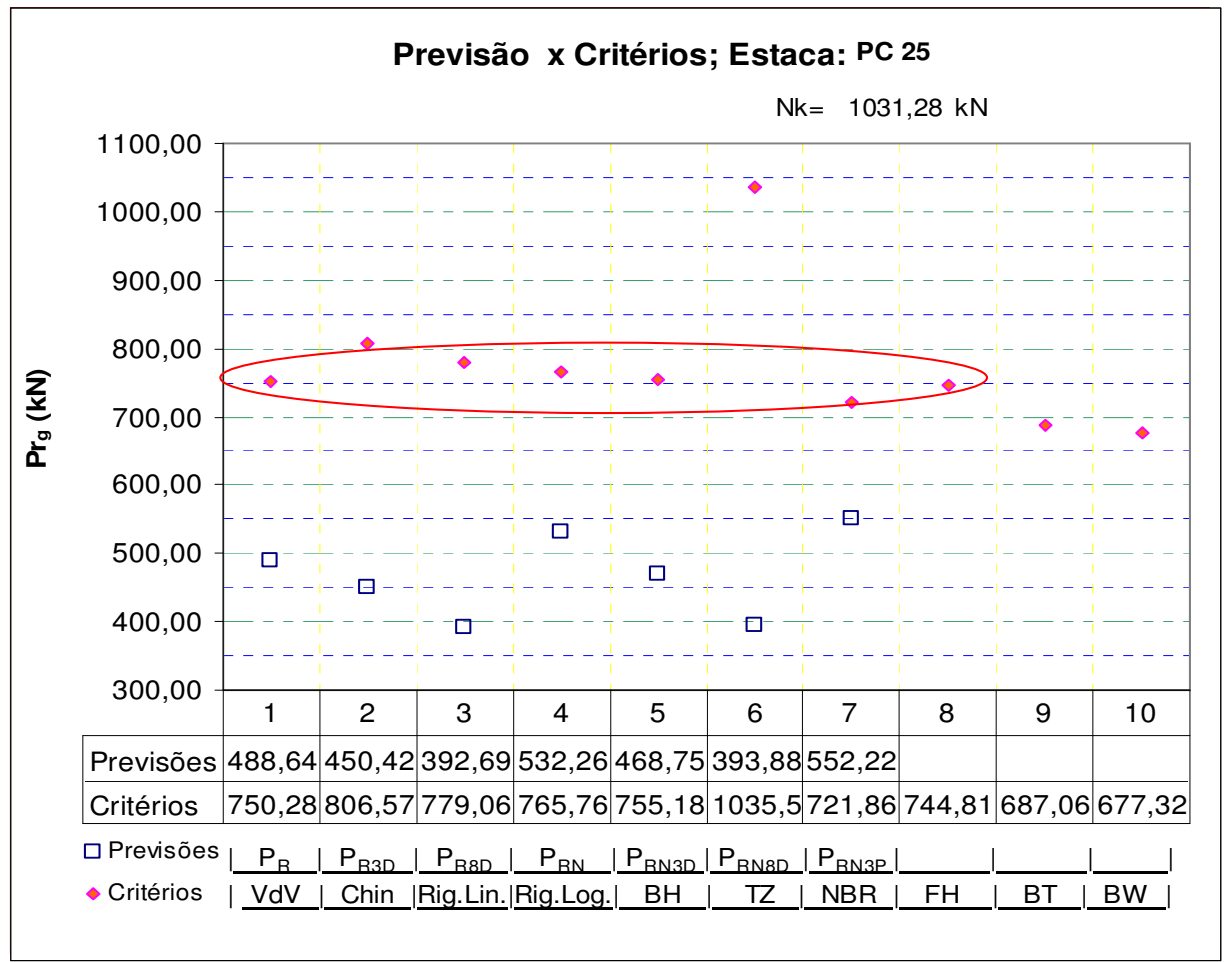

Transferência de carga: Sistema DRM-C $\quad f_{\max }=\quad 20,39 \mathrm{kPa}$ 
Hierarquia dos Solos

Hierarquia dos Solos (Atrito) - Estaca: PC 25

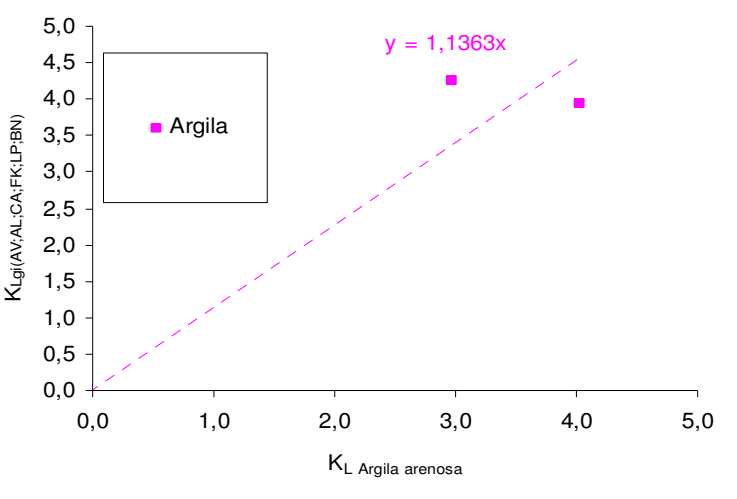

Hierarquia dos Solos (Ponta) - Estaca: PC 25

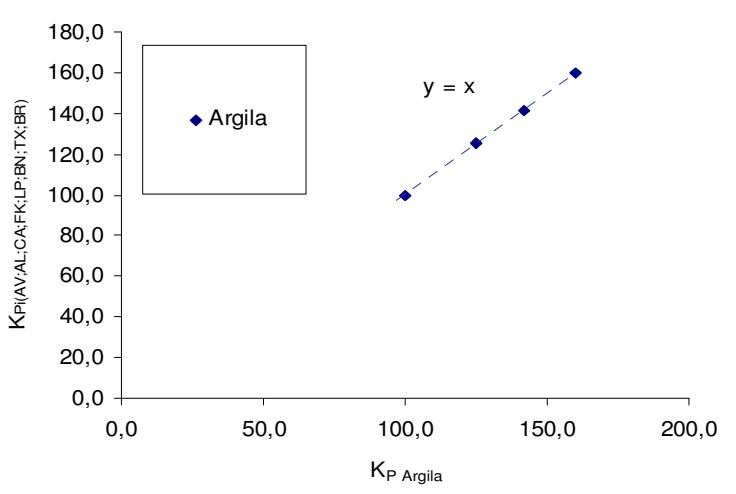

Correção dos coeficientes empíricos

Método Mediado

\begin{tabular}{|c|c|c|c|c|c|c|}
\hline Solo & $\mathbf{k}_{\mathrm{tD}}$ & $k_{t E L}$ & $\mathbf{k}_{\mathrm{ts}}(\%)$ & $\mathrm{k}_{\mathrm{te}}(\mathrm{kPa})$ & $\mathrm{k}_{\mathrm{tEP}}(\mathrm{kPa})$ & $\mathrm{k}_{\mathrm{tC}}$ \\
\hline Argila arenosa & 1,00 & 0,168 & 3,27 & 377,34 & $\# \mathrm{~N} / \mathrm{D}$ & $\# \mathrm{~N} / \mathrm{D}$ \\
\hline Argila & 1,00 & 0,168 & 5,41 & 258,68 & 1,94 & 1,00 \\
\hline
\end{tabular}

Originais

\begin{tabular}{|c|c|c|c|c|c|c|}
\hline Solo & $\mathbf{k}_{\mathrm{tD}}$ & $\mathbf{k}_{\mathrm{tEL}}$ & $\mathbf{k}_{\mathrm{ts}}(\%)$ & $\mathrm{k}_{\mathrm{te}}(\mathrm{kPa})$ & $\mathrm{k}_{\mathrm{tEP}}(\mathrm{kPa})$ & $\mathbf{k}_{\mathrm{tc}}$ \\
\hline Argila arenosa & 1,00 & 0,286 & 3,27 & 423,33 & 0,571 & - \\
\hline Argila & 1,00 & 0,286 & 5,41 & 233,33 & 0,571 & - \\
\hline
\end{tabular}

\section{Método Expedito}

Atrito
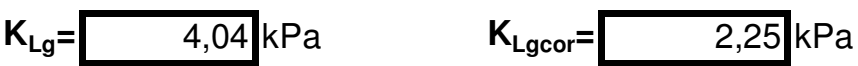

Ponta

\begin{tabular}{|c|c|}
\hline Solo & $\mathrm{K}_{\mathrm{Pg}(\mathrm{i})}(\mathrm{kPa})$ \\
\hline Argila & 1505,42 \\
\hline 0 & 0,00 \\
\hline 0 & 0,00 \\
\hline
\end{tabular}


Estaca: PC 25

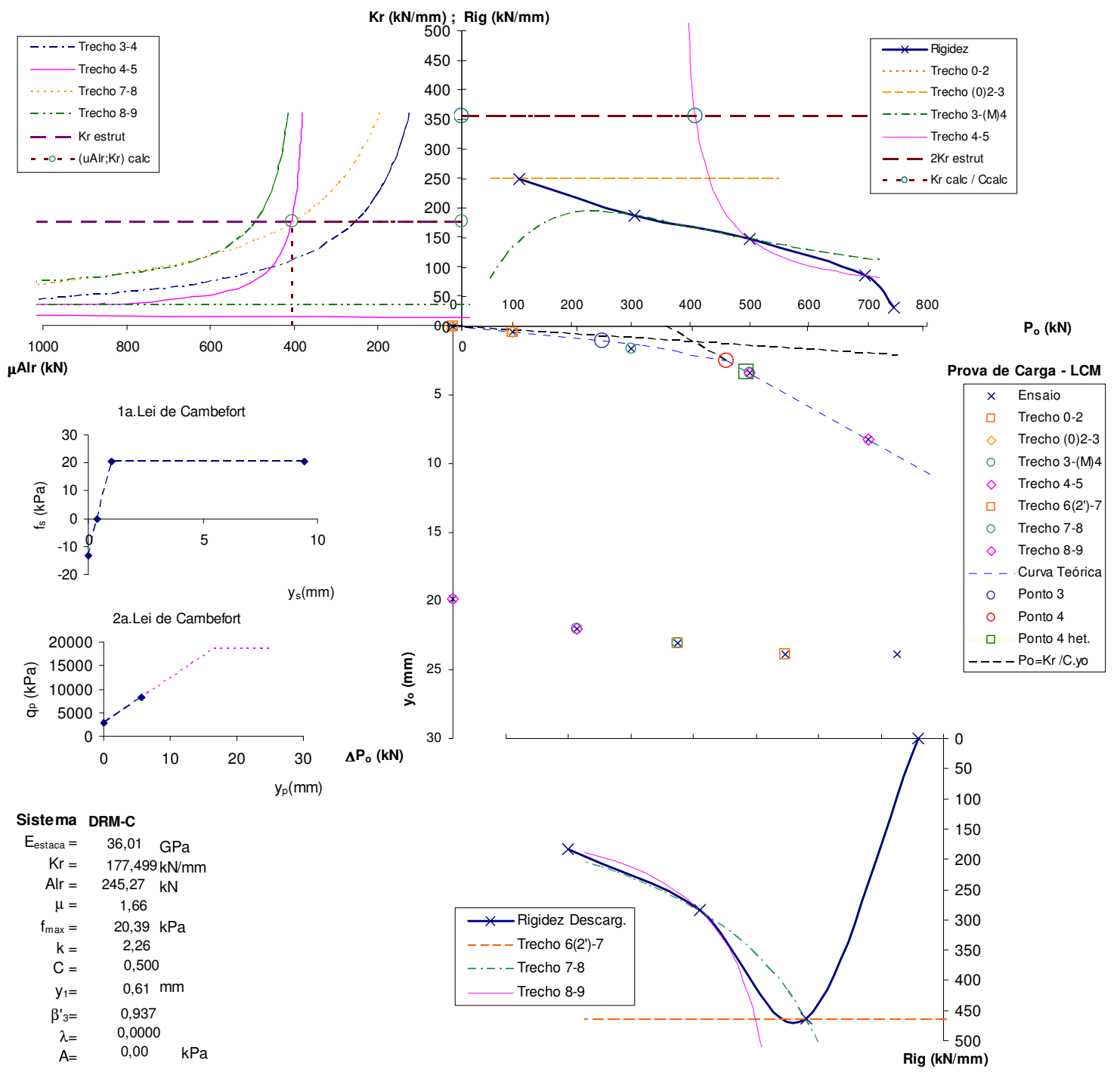




\section{BIBLIOGRAFIA}

ALBIERO, J.H. O emprego de fórmulas empíricas na previsão da carga última de Estacas. 1990. 253p. Tese (Livre-Docência) - Escola de Engenharia de São Carlos, Universidade de São Paulo, São Carlos, 1990.

ALBUQUeRQUE, P.J.R., MASSAD, F., CARVALHO, D., FERREIRA, M. A. M. Comportamento à compressão de estacas escavadas, hélice contínua e hélice tipo ômega, em solo residual de diabásio. Campinas: UNICAMP/EPUSP/FAPESP/CNPq/ABMS/FUNDESP, 2001. 198 p.

ALLEDI, C.T.D.B.; POLIDO, U.F. Capacidade de carga de estacas hélice-contínua: previsão por métodos semi-empíricos versus provas de carga. In: SEMINÁRIO DE ENGENHARIA DE FUNDAÇÕES ESPECIAIS E GEOTECNIA, 6, 2008, São Paulo. Anais... SEFE VI. São Paulo: ABEF, 2008. p. 249-262.

ALLEDI, C.T.D.B.; POLIDO, U.F.; ALBUQUERQUE, P.J.R. Provas de carga em estacas hélice-contínua monitoradas em solos sedimentares. In: CONGRESSO BRASILEIRO DE MECÂNICA DOS SOLOS E ENGENHARIA GEOTÉCNICA, 13, 2006, Curitiba. Anais... COBRAMSEG XIII. Curitiba: ABMS, 2006. v. 2. p. 10671072.

ALONSO, U.R. Correlações entre Resultados de Ensaios de Penetração Estática e Dinâmica para a cidade de São Paulo. Revista Solos e Rochas, São Paulo, v. 3, n. 3, p. 19-25, dez. 1980.

Estimativa da Curva Carga-Recalque de Estacas a partir dos Resultados de Sondagens à Percussão. Revista Solos e Rochas, São Paulo, v. 4, p. 19-32, 1981.

Estimativa da Transferência de Carga de Estacas Escavadas a partir do SPT. Revista Solos e Rochas, São Paulo, v. 4, p. 21-27, 1983.

Dimensionamento de Fundações Profundas. São Paulo: Edgard Blücher, 1991. p. 1-9.

Reavaliação do dimensionamento estrutural de estacas raiz face à exigência do ensaio MB-3472 da ABNT. Revista Solos e Rochas, São Paulo, v. 16, n. 1, p. 41-44, 1993.

Correlações entre o atrito lateral medido e com o torque e o SPT. Revista Solos e Rochas, São Paulo, v. 17, n. 3, dez. 1994.

Estacas hélice contínua com monitoramento eletrônico - previsão da capacidade de carga através do ensaio SPT-T. In: SEMINÁRIO DE ENGENHARIA DE FUNDAÇÕES ESPECIAIS, 3, 1996, São Paulo. Anais... SEFE III. São Paulo: ABEF/ABMS, 1996. v. 2. p. 141-151.

Estimativa da adesão em estacas a partir do atrito lateral medido com torque no ensaio SPT-T. Revista Solos e Rochas, São Paulo, v. 20, n. 1, p. 47-59, 1997. 
ALONSO, U.R. Previsão e controle das fundações. São Paulo: Editora Edgar Blücher, 2ª reimpressão., 1998. p. 62-69.

Projeto e desempenho das fundações (retrospectiva da experiência brasileira). In: SEMINÁRIO DE ENGENHARIA DE FUNDAÇÕES ESPECIAIS, 5, 2004, São Paulo. Anais... SEFE V. São Paulo: ABEF/ABMS, 2004, v. 2, p. 1-34.

A experiência brasileira no projeto de fundações. In: SEMINÁRIO DE ENGENHARIA DE FUNDAÇÕES ESPECIAIS, 6, 2008, São Paulo. Anais... SEFE VI. São Paulo: ABEF/ABMS, 2008. v. 1. p. 1-34.

ASSOCIAÇÃO BRASILEIRA DE NORMAS TÉCNICAS. NBR 6122: Projeto e execução de fundações. Rio de Janeiro. 1996. 33 p.

2006.8 p.

NBR 12131: Estacas-Provas de Carga-Método de ensaio. Rio de Janeiro.

NBR 13208: Estacas-ensaio de carregamento dinâmico. Rio de Janeiro. 2006. 12 p.

AMANN, K.A.P. Avaliação crítica dos métodos semi-empíricos de estimativa da carga de ruptura, aplicados a estacas raiz. 2000. 230p. Dissertação (Mestrado) Escola Politécnica da Universidade de São Paulo, São Paulo, 2000.

Avaliação crítica de métodos semi-empíricos aplicados a estacas hélicecontínua e ômega. In: SEMINÁRIO DE ENGENHARIA DE FUNDAÇÕES ESPECIAIS, 5, 2004, São Paulo. Anais... SEFE V. São Paulo: ABEF/ABMS, 2004. v. 2. p. 308-318.

Discussão de conceito e validação da hierarquia dos solos a partir das análises dos métodos semi-empíricos para previsão da capacidade de carga de estacas. In: CONGRESSO BRASILEIRO DE MECÂNICA DOS SOLOS E ENGENHARIA GEOTÉCNICA, 13, 2006, Curitiba. Anais... COBRAMSEG XIII. Curitiba: ABMS, 2006. p. 811-816.

Análise matemática e paramétrica dos métodos de interpretação da curva carga recalque de estacas. In: CONGRESSO NACIONAL DE GEOTECNIA, 11, 2008, Coimbra. Anais... XI GEO. Coimbra: SPG, 2008. v. 4. p. 75-82. CD-ROM.

Simulação parametrizada de provas de carga utilizando as leis de Cambefort modificadas por Massad (1992, 1993). In: CONGRESSO BRASILEIRO DE MECÂNICA DOS SOLOS E ENGENHARIA GEOTÉNICA, 14, 2008, Búzios. Anais... COBRAMSEG XIV. Rio de Janeiro: ABMS, 2008. p. 869-876.

Comparação analítica de métodos de transferência de carga para interpretação de provas de carga de estacas. In: SEMINÁRIO DE ENGENHARIA DE FUNDAÇÕ̃ES ESPECIAIS, 6, 2008, São Paulo. Anais... SEFE VIII. São Paulo: ABEF/ABMS, 2008. v. 1. p. 397-412. 
AMANN, K.A.P; MASSAD, F. Estacas raiz: avaliação crítica e proposta de melhoria dos métodos semi-empíricos de estimativa da carga de ruptura. In: SEMINÁRIO DE ENGENHARIA DE FUNDAÇÕES ESPECIAIS, 4, 2000, São Paulo. Anais... SEFE IV. São Paulo: ABEF/ABMS, 2000. v. 1. p. 273-279.

AMANN, K.A.P; MASSAD, F. Avaliação da "hierarquia dos solos" e generalização dos métodos semi-empíricos de estimativa da carga de ruptura de estacas. In: CONGRESSO BRASILEIRO DE MECÂNICA DOS SOLOS E ENGENHARIA DE FUNDAÇÕES, 12, 2002, São Paulo. Anais... COBRAMSEF XIV. São Paulo: ABMS, 2002, v. 3, p. 1321-1332.

ANTUNES, W.R., CABRAL, D.A. Capacidade de carga de estacas hélice contínua. In: SEMINÁRIO DE ENGENHARIA DE FUNDAÇÕES ESPECIAIS, 3, 1996, São Paulo. Anais... SEFE III. São Paulo: ABEF/ABMS, 1996. v. 2. p. 105-110.

AOKI, N. Considerações sobre Projeto e Execução de Fundações Profundas. In: SEMINÁRIO DE FUNDAÇÕES DA SOCIEDADE MINEIRA DE ENGENHEIROS, 1979, Belo Horizonte. Anais... p. 1-32.

Sobre a origem do método Aoki-Velloso. [entrevista pessoal]. São Carlos, Escola de Engenharia de São Carlos da Universidade de São Paulo. Entrevista concedida em 20 de março de 2007.

. Dogma do fator de segurança. In: SEMINÁRIO DE ENGENHARIA DE FUNDAÇÕ̃E ESPECIAIS, SEFE VI, 2008, São Paulo. Anais... São Paulo: ABEF/ABMS v.1 p. 9-42.

AOKI, N. ; ALONSO, U.R. Provas de Carga em Estacas de Concreto Armado Centrifugado. In: CONGRESSO BRASILEIRO DE MECÂNICA DOS SOLOS E ENGENHARIA DE FUNDAÇÕES, 8, 1986, Porto Alegre. Anais... COBRAMSEG VIII. Porto Alegre: ABMS, 1986, v. 6, p. 287-295.

AOKI, N. ; LOPES, F.R. An approximate method to estimate the bearing capacity of piles. In: CONGRESSO PANAMERICANO DE MECÂNICA DOS SOLOS E ENGENHARIA DE FUNDAÇÕES, 5, 1986, Porto Alegre. Anais... Buenos Aires, 1975, p. 367-376.

AOKI, N. ; VELLOSO, D. A. Estimating Stresses and Settlements due to Deep Foundations by the Theory of Elasticity. In: CONGRESSO PANAMERICANO DE MECÂNICA DOS SOLOS E ENGENHARIA DE FUNDAÇÕES, 5, 1986, Porto Alegre. Anais... Buenos Aires, 1975, p. 377-386.

AZEVEDO Jr., N. ; NIYAMA, S. Determinação do Módulo de Elasticidade de Estacas de Concreto. In: CONGRESSO BRASILEIRO DE MECÂNICA DOS SOLOS E ENGENHARIA GEOTÉCNICA, 9, 1990, Salvador. Anais... COBRAMSEG IX. Salvador: ABMS, 1990. v. 2. p. 519-522. 
BAGUELIN, F. ; VENON, J.P. Influence de la Compressibilité des Pieux sur la Mobilisation des Efforts Résistants. In: Le Comportement des Sols Avant la Rupture. Bulletin de Liaison des Laboratories des Ponts et Chaussées, n. Spécial, p. 308-322, Mai. 1971.

BRASFOND FUNDAÇÕES ESPECIAIS S.A. Estacas Raiz. Catálogo. 1991. 38 p.

BURIN, S.M. Estimativa da carga de ruptura de estacas a partir de resultados de provas de carga. 1989. 149 p. Dissertação (Mestrado) - Escola Politécnica da Universidade de São Paulo, São Paulo, 1989.

CABRAL, D.A. O uso da estaca raiz como fundação de obras normais. In: CONGRESSO BRASILEIRO DE MECÂNICA DOS SOLOS E ENGENHARIA DE FUNDAÇÕES, 8, 1986, Porto Alegre. Anais... COBRAMSEF VIII. Porto Alegre: ABMS, 1986. v. 6. p. 71-82.

CABRAL, D.A.; ANTUNES, W.R.; FERREIRA, M. (2000). Apresentação não formal.

CABRAL, D.A.; FEITOSA, G.O.; GOTLIEB, M. Um caso de reformulação de fundações com emprego de estacas raiz. In: SEMINÁRIO DE ENGENHARIA DE FUNDAÇÕES ESPECIAIS, 2, 1991, São Paulo. Anais... SEFE I. São Paulo: ABEF/ABMS, 1991, v. 1, p. 58-68.

CAMBEFORT, M. Essai sur le comportement en terrain homogène des pieux isolés et des groupes de pieux. Annales - L'INSTITUTE DU BATIMENT ET DES TRAVAUX PUBLIC, $\mathrm{n}$. 204, p. 1478-1518, Dec. 1964.

CARVALHO, et.al. Concurso para previsão do comportamento de estacas raiz. São Paulo: ABEF/ABMS/CTIC, 2004. 184 p.

CHIN, F. K. Estimation of the Ultimate Load of Piles not Carried to Failure. In: SOUTHEAST ASIAN CONFERENCE ON SOIL ENGINEERING, 2, 1970, Singapore. Proc... 1970, p. 81-92.

CINTRA, J.C.; AOKI, N. Carga admissível em fundações profundas. São Carlos: EESC/USP, 1 ed. 1999. 21 p.

CORREAA, R.S. Previsão da carga de ruptura de estacas raiz a partir de sondagens de simples reconhecimento. 1988. 131p. Dissertação (Mestrado) Escola Politécnica da Universidade de São Paulo, São Paulo, 1988.

COYLE, H.M. ; REESE, L.C. Load transfer for axially loaded piles in clay. Journal of the Soil Mechanics and Foundation Division - ASCE, v. 92, n. SM2, p. 1-26, Mar. 1966.

CRAIG, R.F. Mecânica dos solos. Rio de Janeiro: Livros Técnicos e Científicos, 7ª̣ . ed, 2007. p. 254-261.

DANZIGER, B. R. ; VELLOSO, D. A. Correlações entre SPT e os resultados dos ensaios de penetração contínua. In: CONGRESSO BRASILEIRO DE MECÂNICA 
DOS SOLOS E ENGENHARIA DE FUNDAÇÕES, 8, 1986, Porto Alegre. Anais... COBRAMSEF VIII. Porto Alegre: ABMS, 1986, v. 6, p. 103-113.

DAVISSON, M.T. High Capacity Piles. In: Proceedings, Lecture Series, Innovation in Foundation Construction. Illinois: American Society of Civil Engineers - ASCE, 1972. $52 \mathrm{p}$.

DÉCOURT, L. Predicted and measured behavior of non displacements piles in residual soils. In: DEEP FOUDATIONS ON BORED AND AUGER PILES, 2, 1993, Ghent. Proc... BAP II, p. 369-376.

Discussão da Nota Técnica "Reavaliação dos métodos de capacidade de carga à tração de estacas tipo raiz" de Urbano Rodriguez Alonso - Revista Solos e Rochas, vol. 18, no. 1, Abril de 1995, pp. 45-49. Revista Solos e Rochas, São Paulo, v. 18, n. 3, p. 173175, dez. 1995.

DÉCOURT, L. Análise e Projeto de Fundações Profundas - Estacas. In: Fundações: teoria e prática. 1 ed. São Paulo-SP: ABMS/ABEF/Pini, 1996. p. 265301.

. Sobre a origem do método Décourt-Quaresma. [entrevista pessoal]. São Paulo, Sede da Luciano Décourt Engenheiros Consultores. Entrevista concedida em 12 de abril de 2007.

A. Ruptura de fundações avaliada com base no conceito de rigidez. In: SEMINÁRIO DE ENGENHARIA DE FUNDAÇÕES ESPECIAIS, 3, 1996, São Paulo. Anais... SEFE III. São Paulo: ABEF/ABMS, 1996, p. 215-254.

Provas de carga em estacas podem dizer muito mais do têm dito. In: SEMINÁRIO DE ENGENHARIA DE FUNDAÇÕES ESPECIAIS, 6, 2008, São Paulo. Anais... SEFE VI. São Paulo: ABEF/ABMS, 2008, p. 221-245.

DÉCOURT, L. \& NIYAMA, S. Predicted and measured behavior of displacement piles in residual soils. In: INTERNATIONAL CONFERENCE ON SOIL MECHANICS AND FOUNDATION ENGINEERING, 13, 1994, New Delhi. Proc... ICSMFE XIII, v. 1 p. 143-146.

DÉCOURT, L. ; QUARESMA, A.R. Como calcular (rapidamente) a capacidade de carga limite de uma estaca. Revista Construção, São Paulo, n. 1800, ago. 1982. Separata.

DÉCOURT, L. ; QUARESMA FILHO, A. Practical apliccations of the Standard Penetration Test complemented by the Torque measurements, SPT-T; present estage and future trends. In: INTERNATIONAL CONFERENCE ON SOIL MECHANICS AND FOUNDATION ENGINEERING, 13, 1994, New Delhi. Proc... v. 2 p. 447-486.

DE GENNARO, V.; FRANK, R. Elasto-plastic analysis of the interface behavior between granular media and structure. In: Computer and Geotechnics. : Elsevier, 2002. Eletronic edition. 
FELLENIUS, B.H. Test Loading of Piles and New Proof. Journal of the Soil Mechanics and Foundation Division - ASCE, v. 101, n. GT9, p. 855-869, Sep. 1975.

FELLENIUS, B.H. The analysis of results from routine pile load tests. Ground Engineering, p. 19-31, Sep. 1980.

Limit states design for deep foundations. In: INTERNATIONAL CONFERENCE ON DESIGN AND CONSTRUCTION OF DEEP FOUNDATIONS, 1994, Orlando. Proc... FHWA. v. 2 p. 415-426.

What capacity value to choose from the results a static loading test. Fulcrum. Deep Foundation Institute, p. 19-22, Winter 2001.

Basics of Foundation Design. USA: eletronic edition, 2006. 275 p. Disponível em: <http://www.fellenius.net>. Acesso em set. 2006.

FLEMING, W. G.L.. A new method for single piles settlement prediction and analysis. Géotechnique, v. 42, n. 3, p. 411-425. 1982.

FLEMING, W.G.L.; WELTMAN, A.J.; RANDOLPH, M.F. ; ELSON, W.K. Piling engineering. London: E\&FN Spon, 2ª . ed, 1992. p. 92-331.

FONSECA, A.V.; SANTOS, J.A.; ESTEVES,E.C.; MASSAD, F. Analysis of piles in residual soil from granite considering residual loads. Soils and Rocks. v. 30: ABMS/ABGE/SPG, n. 1, p. 63-80. jan-apr. 2007.

FRANK, R. Calcul des fondations superficielles et profundes. Paris: Presses de l'École Nationale des Ponts et Chaussées, 1999. 141 p.

GOTLIEB, M.; PENNA, A. S. D.; ROMAN JR., R. ; RODRIGUES, L.H.B. Um método simples para a avaliação da tensão admissível no topo de estacas tipo hélicecontínua. In: SEMINÁRIO DE ENGENHARIA DE FUNDAÇÕES ESPECIAIS, 4, 2000, São Paulo. Anais... SEFE IV. São Paulo: ABEF/ABMS, 2000, v. 1, p. 312-319.

HACHICH, W. ; NADER, J. J. Correlações entre Parâmetros: Análise Crítica. In: " Solos da Cidade de São Paulo. São Paulo: ABMS, 1993. p. 181-192.

HALDAR, S. ; BABU, G.L.S. Load resistance factor design of axially loaded pile based on load test results. Journal of Geotechnical and Geoenvoironmental Engineering - ASCE, p. 1106-1117, Aug. 2008.

KAREZ, M. B. ; ROCHA, E. A. C. Estacas tipo hélice-contínua previsão da capacidade de carga. In: SEMINÁRIO DE ENGENHARIA DE FUNDAÇÕES ESPECIAIS, 4, 2000, São Paulo. Anais... SEFE IV. São Paulo: ABEF/ABMS, 2000, v. 1, p. $274-278$.

LAZO, G. Previsão do Comportamento de Estacas Pré-moldadas na região da Grande São Paulo, Brasil, por meio de Modelos Matemáticos. 1996. 222p. Tese (Doutorado) - Escola Politécnica da Universidade de São Paulo, São Paulo, 1996. 
LIZZI, F. The design of large diameter cast-in-place bored piles using a 'pilot' pile and congruence equations. Ground Engineering. v. 14, n. 4, p. 24-33. May. 1981.

MARQUES, J.A.F.; MASSAD, F. Provas de carga instrumentadas em estacas escavadas com bulbos, executadas na região praieira de Maceió, Alagoas. Revista Solos e Rochas, São Paulo, v. 27, n. 3, p. 243-260, 2004.

MARZIONNA, J.D. O projeto geotécnico de fundações e a norma brasileira NBR6122- Projeto e execução de fundações. In: SEMINÁRIO DE ENGENHARIA DE FUNDAÇÕES ESPECIAIS - SEFE VI, 2008, São Paulo. Anais... São Paulo: ABEF/ABMS, v. 1, p. 43-57.

MASSAD, F. Notes on the interpretation of failure load from routine pile load tests. Revista Solos e Rochas, São Paulo, v. 9, n. 1, p. 33-36, 1986.

Análise da transferência de carga de duas estacas instrumentadas, quando submetidas à compressão axial. In: SEMINÁRIO DE ENGENHARIA DE FUNDAÇÕES ESPECIAIS, 2, 1991, São Paulo. Anais... SEFE II. São Paulo: ABEF/ABMS, 1991, v. 1, p. 235-244.

MASSAD, F. Comportamento de estacas escavadas de elevadas compressibilidades. In: SEMINÁRIO DE ENGENHARIA DE FUNDAÇÕES ESPECIAIS, 2, 1991, São Paulo. Anais... SEFE II. São Paulo: ABEF/ABMS, 1991, v. 1 , p. 245-254.

. Estacas escavadas em compressão axial: comportamento e parâmetros visando a estimativa dos recalques. In: SEMINÁRIO DE ENGENHARIA DE FUNDAÇÕES ESPECIAIS, 2, 1991, São Paulo. Anais... SEFE II. São Paulo: ABEF/ABMS, 1991, v. 1, p. 255-264.

Sobre a interpretação de Provas de Carga em Estacas considerando as Cargas Residuais na Ponta e a Reversão do Atrito Lateral. Parte I: Solos Relativamente Homogêneos. Revista Solos e Rochas, São Paulo, v. 15, n. 2, p. 103-115, 1992.

Sobre a interpretação de Provas de Carga em Estacas considerando as Cargas Residuais na Ponta e a Reversão do Atrito Lateral. Parte II: Estaca Embutida em Camada mais Resistente. Revista Solos e Rochas, São Paulo, v. 16, n. 2, p. 93-112, 1993.

Considerações sobre a forma da curva carga recalque de estacas solicitadas axialmente. São Carlos: Escola de Engenharia de São Carlos da Universidade de São Paulo, Publicação 045/94. 1994. 35 p.

- Limites das extrapolações em provas de carga verticais interrompidas prematuramente. In: CONGRESSO BRASILEIRO DE MECÂNICA DOS SOLOS E ENGENHARIA DE FUNDAÇÕES, 10, 1994, Foz do Iguaçu. Anais... COBRAMSEF X. Curitiba: ABMS, 1994, v. 1, p. 93-112. 
MASSAD, F. Sobre algumas representações da curva carga-recalque de estacas solicitadas axialmente. In: CONGRESSO BRASILEIRO DE MECÂNICA DOS SOLOS E ENGENHARIA DE FUNDAÇÕES, 10, 1994, Foz do Iguaçu. Anais... COBRAMSEF X. Foz do Iguaçu: ABMS, 1994, v. 1, p. 287-294.

MASSAD, F. The analysis of piles considering soil stiffness and residual stresses. In: PANAMERICAN CONFERENCE OF SOIL MECHANICS AND FOUNDATION ENGINEERING, 10, 1995, Guadalajara. Proc... v. 2, p. 1199-1210.

. Novo método para a interpretação de provas de carga cíclicas, estáticas ou dinâmicas, em estacas verticais. In: CONGRESSO BRASILEIRO DE MECÂNICA DOS SOLOS E ENGENHARIA GEOTÉCNICA, 12, 2002, São Paulo. Anais... COBRAMSEG XII. São Paulo: ABMS, 2002, v. 3, p. 1627-1638.

Fundamentação matemática do método da rigidez de Décourt e definição de seu campo de aplicação. In: SEMINÁRIO DE ENGENHARIA DE FUNDAÇÕES ESPECIAIS, 6, 2008, São Paulo. Anais... SEFE VIII. São Paulo: ABEF/ABMS, 2008, v. 1, p. 117-131.

MASSAD, F.; LAZO, G. Método gráfico para interpretar a curva carga-recalque de provas de carga verticais em estacas rígidas e curtas. In: CONGRESSO BRASILEIRO DE MECÂNICA DOS SOLOS E ENGENHARIA GEOTÉCNICA, 11, 1998, Brasília. Anais... COBRAMSEG XI. Brasília: ABMS, 1998, v. 3, p. 1407-1414.

MASSAD, F.; MARQUES, J.A.F. Provas de carga instrumentadas em estacas escavadas com bulbos, executadas na região praieira de Maceió, Alagoas. Revista Solos e Rochas, São Paulo, v. 27, n. 3, p. 243-260, dez. 2004.

MELO, B. Análise de provas de carga à compressão à luz do conceito de rigidez. 2009. 219p. Dissertação (Mestrado) - Faculdade de Engenharia Civil, Arquitetura e Urbanismo da Universidade Estadual de Campinas, São Paulo, 2009.

MELLO, V.F.B. Fundações e elementos estruturais enterrados. São Paulo: EPUSP, 1975. Apostila de apoio às aulas

MONTEIRO, P.F.F. A estaca ômegafranki - capacidade de carga. In: SEMINÁRIO DE ENGENHARIA DE FUNDAÇŌES ESPECIAIS, 4, 2000, São Paulo. Anais... SEFE IV. São Paulo: ABEF/ABMS, 2000, v. 2, p. 356-369.

MYLONAKIS, G. Winkler modulus for axially loaded piles. Géotechnique, Paris, v. 51, n. 5, p. 455-461, 2001.

NIELSEN NETO, H. Filosofia básica. São Paulo: Atual, 3ª . ed, 1991. 311 p.

NIYAMA, S.; AOKI, N.; CHAMECKI,P.R. Verificação do Desempenho - Provas de Carga Estáticas. In: Fundações: teoria e prática. 1 ed. São Paulo-SP: ABMS/ABEF/Pini, 1996. p. 726-739. 
POULOS, H.G. ; DAVIS, E.H. Pile Foundation Analysis and Design. New York: John Wiley and Sons, 1980. 397 p. (Series in Geotechnical Engineering)

QUARESMA, A.R. ; DÉCOURT, L. ; QUARESMA Fo., A.R. ; ALMEIDA, M.S.S. ; DANZIGER, F. Investigações geotécnicas. In: Fundações: teoria e prática. 1‥ ed. São Paulo: ABMS/ABEF/Pini, 1996. p. 119-162.

RANDOLPH, M.F. Design methods for pile groups and piled rafts. In: INTERNATIONAL CONFERENCE ON SOIL MECHANICS AND FOUNDATION ENGINEERING, 13, 1994, New Delhi. Proc... v. 5 p. 61-82.

RANDOLPH, M.F. ; WROTH, C.P. Analysis of Deformation Vertically Loaded Piles. Journal of the Soil Mechanics and Foundation Division - ASCE, v. 104, n. GT12, p. 1465-1488, Dec. 1978.

RANZINI, S.M.T. SPT-F. Revista Solos e Rocha, São Paulo, v. 11, p. 29-30, dez. 1978.

ROCHA, R. ; YASSUDA, A.J. ; MASSAD, E. Provas de Carga em Estaca tipo Raiz Instrumentada. In: SEMINÁRIO DE ENGENHARIA DE FUNDAÇÕES ESPECIAIS, 1, 1985, São Paulo. Anais... SEFE I. São Paulo: ABEF/ABMS, 1985, v. 1, p. 179-193.

SCHMERTMANN, J.H. Static of SPT. Journal of the Soil Mechanics and Foundation Division - ASCE, v. 105, n. GT15, 655 p. May. 1979.

SCHNAID, F. Ensaios de campo: e suas aplicações à engenharia de fundações. 1a․ ed. São Paulo: Oficina de Textos, 2000.

SOUZA, A. Estaca Piloto Instrumentada: uma ferramenta para o estudo da capacidade de carga de estacas, quando submetidas a esforços axiais de compressão. 2001. 296 p. Tese (Doutorado) - Escola Politécnica da Universidade de São Paulo, São Paulo, 2001.

TEIXEIRA, A. H. Sondagens, metodologia, erros mais comuns. novas normas de execução. In: SIMPÓSIO DA ASSOCIAÇÃO BRASILEIRA DE MECÂNICA DOS SOLOS, 1, 1977, Recife. Anais... ABMS, 1977, p. 41-61.

TEIXEIRA, A. H. Um Aperfeiçoamento das Sondagens de Simples Reconhecimento à Percussão. In: Solos do Estado de São Paulo. São Paulo: ABMS, 1993. p. 7593.

- Uma retrospectiva e as tendências da engenharia de fundações no Brasil. In: SEMINÁRIO DE ENGENHARIA DE FUNDAÇÕES ESPECIAIS, 4, 2000, São Paulo. Anais... SEFE IV. São Paulo: ABEF/ABMS, 2000, v. 1, p. 1-22.

TITI, H. H. e ABU-FARSAKH, M. Y. Assesment of direct cone penetration test methods for predicting the ultimate capacity of friction driven piles. Journal of the Soil Mechanics and Foundation Division - ASCE, p. 935-944. Sep. 2004. 
VARGAS, M. Fundações de edifícios. São Paulo: Grêmio Politécnico, 1979. p. 9091.

VEEN, C. V. Design The Bearing Capacity of Piles. In: INTERNATIONAL CONFERENCE ON SOIL MECHANICS AND FOUNDATION ENGINEERING, 3, 1953, Amsterdam. Proc... v. 2 p. 84-90.

VELLOSO, D. A.; ALONSO, U.R. Previsão, Controle e Desempenho de Fundações. In: Previsão de Desempenho x Comportamento Real. São Paulo: ABMS/NRSP, 2000. p. 95-139.

VELLOSO, D. ; LOPES, F.R. Concepção de obras de fundações. In: Fundações: teoria e prática. 1a. ed. São Paulo: ABMS/ABEF/Pini, 1996. p. 211-226.

Fundações. Rio de Janeiro: COPPE-UFRJ, 2002. v.2, 472p.

Fundações. São Paulo: Oficina de Textos, 2004. v. 1, 226 p.

VÉSIC, A. S. A Study of Bearing Capacity of Deep Foundations. Atlanta: Georgia Institute of Technologie, 1967. (Final report, proj. B-189).

. Load Transfer in Pile-soil Systems. Durham: Duke University, 1970. 60 p. (Soil Mechanics Series, n. 23).

Principles of Pile Foundations Design. Durham: Duke University, 1975. 60 p. (Soil Mechanics Series, n. 38).

Design On the Significance of Residual Loads for Load response of Piles. In: INTERNATIONAL CONFERENCE ON SOIL MECHANICS AND FOUNDATION ENGINEERING, 10, 1977, Stockholm. Proc... v. 3 p. 373-379.

YANG, Q.J. Determination of load capacity of a pile - an alternative. In: CONGRESSO BRASILEIRO DE MECÂNICA DOS SOLOS E ENGENHARIA DE FUNDAÇÕES, 10, 1994, Foz do Iguaçu. Anais... COBRAMSEF X. Foz do Iguaçu: ABMS, 1994, v. 1, p. 159-166.

ZHU, H.; CHANG, M.F. Load transfer curves along bored piles considering modulus degradation. Journal of the Soil Mechanics and Foundation Division - ASCE, p. 764-773. Sep. 2002. 